CREOLE LANGUAGE LIBRARY

\title{
Language and Slavery
}

A social and linguistic history of the Suriname creoles

\section{Jacques Arends}


Language and Slavery 


\section{Creole Language Library (CLL)}

ISSN 0920-9026

A book series presenting descriptive and theoretical studies designed to add significantly to the data available on pidgin and creole languages. All CLL publications are anonymously and internationally refereed.

For an overview of all books published in this series, please see http://benjamins.com/catalog/cll

\section{Editors}

Miriam Meyerhoff

Victoria University of Wellington

\section{Editorial Advisory Board}

Marlyse Baptista

Ann Arbor, USA

George L. Huttar

Dallas, USA

Silvia Kouwenberg

Kingston, Jamaica

Susanne Michaelis

Leipzig, Germany

Salikoko S. Mufwene

Chicago, USA

Pieter Muysken

Nijmegen, The Netherlands
Umberto Ansaldo

The University of Hong Kong

Peter Mühlhäusler

Adelaide, Australia

Shobha Satyanath

Delhi, India

John Victor Singler

New York, USA

Norval Smith

Amsterdam, The Netherlands

Sarah G. Thomason

Ann Arbor, USA

Tonjes Veenstra

Berlin, Germany

\section{Volume 52}

Language and Slavery. A social and linguistic history of the Suriname creoles by Jacques Arends 


\section{Language and Slavery}

A social and linguistic history

of the Suriname creoles

Jacques Arends

John Benjamins Publishing Company

Amsterdam / Philadelphia 
The paper used in this publication meets the minimum requirements of the American National Standard for Information Sciences - Permanence of Paper for Printed Library Materials, ANSI Z39.48-1984.

DOI $10.1075 / \mathrm{cll} .52$

Cataloging-in-Publication Data available from Library of Congress: LCCN 2017001385 (PRINT) / 2017020733 (E-BOOK)

ISBN 978902725276 O (нB)

ISBN 9789027265807 (Е-BOOK)

An electronic version of this book is freely available, thanks to the support of libraries working with Knowledge Unlatched. KU is a collaborative initiative designed to make high quality books Open Access for the public good. The Open Access isbn for this book is 9789027265807.

(C) 2017 - John Benjamins B.V.

This e-book is licensed under a Creative Commons CC BY-NC-ND 4.o license. To view a copy of this license, visit https://creativecommons.org/licenses/by-nc-nd/4.o/. For any use beyond this license, please contact the publisher.

John Benjamins Publishing Company · https://benjamins.com 


\section{Table of contents}

List of tables and figures

IX

List of oral texts

XIII

List of written texts

XV

Introduction to this edition

XIX

Series editor's preface

XXI

Trotji (Sranan: Preface)

XXIII

Outline of the book

XXVII

CHAPTER 1

\section{Introduction}

1.1 Suriname, a creole society 1

1.2 The creole languages of Suriname 6

1.3 A note on the reliability of early texts $\mathbf{2 6}$

1.4 Diachronic studies of the Suriname creoles: The state of the art 27

1.5 Creole genesis 32

CHAPTER 2

The 'prehistory' of the Suriname creoles

2.1 Early contacts between European and non-European languages (1450-1600) 36

2.2 Early settlements in and around Suriname (1600-1650) 43

2.3 The formative years: $1651-1690 \quad 54$

2.3.1 The English period (1651-1667) 56

2.3.1.1 The colonization by the English 56

2.3.1.2 The Sephardic Jews 63

2.3.2 The first years of Suriname as a Dutch colony (1667-1690) $\quad 71$

2.3.2.1 The transition period (1667-1680) $\quad 71$

2.3.2.2 The English exodus (1667-1680) 77

2.3.2.3 The Indian war (1678-1686) 86

2.3.2.4 Early marronage: The formation of the Saramaka Maroons and their language $\mathbf{8 9}$ 
CHAPTER 3

Social and demographic factors in creole formation

3.1 Introduction 101

3.2 Social stratification and network relations 102
3.2.1 Social stratification 104
3.2.2 External networks 114
3.2.3 Conclusion 121

3.3 Demographic factors $\mathbf{1 2 2}$

\subsubsection{Introduction $\mathbf{1 2 2}$}

3.3.2 Factors related to immigration $\mathbf{1 2 3}$

3.3.2.1 Africans 124

3.3.2.2 Origins 124

3.3.2.3 Age and sex distribution 138

3.3.2.4 Europeans 141

3.3.3 Factors related to population $\quad \mathbf{1 4 2}$

3.3.3.1 Africans and Europeans $\mathbf{1 4 3}$

3.3.3.2 The rate of nativization among the Blacks 151

3.3.3.3 The creole-to-bozal ratio among slave children on the plantations 154

3.3.3.4 The creole-to-bozal ratio among Maroons 158

3.4 Summary and conclusion $\mathbf{1 6 0}$

\section{CHAPTER 4}

Meta-linguistic evidence: Variation, attitudes and linguistic repertoires in the pre-Emancipation era

\subsection{Introduction 163}

4.2 Variation in early Sranan 163

4.2.1 Ethnicity: nengre tongo and bakra tongo 166

4.2.2 Geography: The Creole of the plantations and the Paramaribo Creole $\mathbf{1 7 3}$

4.2.3 Ownership: Differences between the language of English, Jewish, and other plantations $\mathbf{1 7 9}$

4.2.3.1 The Creole of the 'old English plantations' $\quad 180$

4.2.3.2 Djutongo: The Creole of the Jewish plantations $\mathbf{1 8 2}$

4.2.3.3 The Creole as spoken on other plantations $\quad 188$

4.2.4 Religion: 'church Sranan', the creole variety used

by the Moravian missionaries $\mathbf{1 8 8}$

4.2.5 Place of birth: Native and non-native Sranan 192

4.2.6 Some additional observations 195

4.2.7 Summary and conclusion $\quad 198$ 
4.3 Language choice and attitudes 200

4.3.1 Attitudes towards Sranan 201

4.3.2 Linguistic repertoires 209

4.3.2.1 Sranan 210

4.3.2.2 European languages $\mathbf{2 1 4}$

4.3.2.3 The use of African languages and Arabic 223

4.3.2.4 Some miscellaneous observations $\quad \mathbf{2 2 8}$

4.4 Appendices 231

4.4.1 Lexical items labeled bakratongo in Schumann's (1783)

Sranan dictionary $\quad \mathbf{2 3 1}$

4.4.2 Lexical items labeled dju tongo in Schumann's (1783)

Sranan dictionary $\mathbf{2 3 4}$

CHAPTER 5

Early developments (1667-c1800)

5.1 Sranan 237

5.1.1 Miscellaneous early sources (1667-1763) 237

5.1.2 Herlein (1718) and Nepveu (1770) 243

5.1.3 Van Dyk (c1765) 255

5.1.4 Comparing Herlein, Nepveu, and Van Dyk 257

5.1.4.1 A second look at Herlein's Sranan 257

5.1.4.2 Van Dyk 260

5.1.5 Stedman 269

5.2 Saramaccan 274

5.3 The other Suriname creoles 275

5.4 Introducing early texts $\mathbf{2 7 5}$

CHAPTER 6

Oral texts

6.1 Songs 277

6.2 Odos 305

6.3 Anansi stories 310

CHAPTER 7

Written texts

7.1 Secular texts 316

7.2 Religious texts $\mathbf{4 1 0}$

References

Index 



\section{List of tables and figures}

Figure 1.1 The numerical distribution of ethnic groups in present-day Suriname

2

Table 1.1 Major events in the history of Suriname (1499-1975) 3

Figure 1.2 Genealogical tree of the Suriname creoles

8

Figure 1.3 The Suriname creoles grouped according to their major lexifier language(s)

Table 1.2 Nomenclature, geographical distribution, and numbers of speakers of the Suriname languages

Table 1.3 Published editions of early Sranan and Saramaccan texts

Table 1.4 Contents of the digitalized corpus of early Sranan and Saramaccan texts

Table 1.5 A survey of diachronic studies on Sranan and Saramaccan (1982-2002)

Table 2.1 Lexical correspondences between baragouin and Sranan

Table 2.2 Toponymical conventions with regard to the 'Greater Guyana' region

Table 2.3 Survey of the earliest settlements in Suriname and adjacent areas (1530-1650)

Table 2.4 Documented figures of European immigration into Suriname (1651-1653)

Table 2.5 Documented figures of the European population of Suriname (1651-1667)

Table 2.6 The immigration of Sephardic Jews into Suriname (1651-1667)

Table 2.7 Numbers of plantations in Suriname River and Commewijne Rivers areas (1667/1686)

Table 2.8 Place of departure of slave ships arriving in Suriname between 1667 and 1674

Table 2.9 The English exodus according to Voorhoeve \& Lichtveld (1975:2) 77

Table 2.10 Population figures for the European population of Suriname (1666-1684) according to Voorhoeve \& Lichtveld (1975:3)

Table 2.11 Emigration from 1668 to 1680

Figure 2.1 The genealogy of an unwarranted claim: The construction of the Machado Theory with respect to the inception of Saramaccan 
Table 3.1 Annual wages for white plantation personnel: Early 18th century 106 Table 3.2 Social stratification of free plantation population: 18 th century 107

Table 3.3 Social stratification of enslaved plantation population: 18th-century

108

Table 3.4 African origins in the overall Dutch slave trade (1658-1674)

Table 3.5 Place of departure of slaves imported into Suriname (1652-1803)

Figure 3.1 Place of departure of slaves imported into Suriname (1652-1803) 128

Table 3.6 Maximum radius of slave recruitment areas

Table 3.7 Percentage of children (3-15 yrs) in a sample of Suriname imports and in a sample of the overall Dutch trade (1680-1803)

Table 3.8 Projected percentages and numbers of children (3-15 yrs) among slaves imported to Suriname (1680-1803)

Table 3.9 Percentages of children among slaves imported to Suriname (1684-1803)

Table 3.10 Numbers of Maroons (1678-1863)

Table 3.11 Numbers of manumitted slaves (1783-1830)

Table 3.12 Growth of black and white population in Suriname (1651-1862)

Table 3.13 Composition of the population on 12/31/1684

Table 3.14 Development of black-to-white ratio (1652-1830)

Table 3.15 National origins of whites married in Paramaribo between 1687 and 1700. Source: Van der Linde (1966:58)

Table 3.16 Regional origins of whites of Dutch descent married in Paramaribo between 1687 and 1700

Table 3.17 Ratio of slave import per decade to slave population present at beginning of decade (1651-1799)

Figure 3.2 Ratio of slave import per decade to slave population present at beginning of decade (1651-1799)

Table 3.18 Percentages of locally-born slaves on sugar plantation Roosenburg

Table 3.19 Age distribution among the black and white population (1684-1830)

Table 3.20 Estimated numbers of permanent run-away slaves (1702-1749)

Table 4.1 Non-Dutch derived bakra tongo words, with their equivalents in nengre tongo (Schumann 1783)

Table 4.2 Dutch derived bakra tongo words, with their English- and non-English-derived equivalents in nengre tongo (Schumann 1783)

Table 4.3 Words labeled bakra tongo in Schumann's 1783 Sranan dictionary which are unlabeled in Schumann's 1778 Saramaccan dictionary

Table 4.4 English-derived words in Herlein (1718) later replaced by Dutch-derived words 
Table 4.5 Names for the days of the week in Van Dyk (c1765) and Weygandt (1798)

Table 4.6 English-based words containing a diphthong in Herlein (1718) which have a monophthong in post-1718 sources 181

Table 4.7 Examples of semantic extensions of Sranan words used by Moravian missionaries to denote Christian concepts 191

Table 5.1 Question words in Herlein 1718 and Nepveu 1770 254

Table 5.2 Question words in 18th-century Sranan 263

Table 5.3 The nominal copula in 18th-century Sranan 264

Table 5.4 The development of clefting in Sranan (1718-1798)

Table 5.5 The expression of comparison in Van Dyk (c1765) and Schumann (1783) 266

Table 5.6 The development of serialization in Sranan (1750-now) 267

Table 7.1 Sranan translations of texts concerning Emancipation 373

Table 7.2 Sources for Dutch and Sranan versions of texts concerning Emancipation 



\section{List of oral texts}

$\begin{array}{lll}\text { 1. A farewell song (c1775) } & \mathbf{2 7 8}\end{array}$

2. Celebrating the Ndyuka Peace Treaty (c1760) 279

3. A black Odysseus (c1800) 279

4. A children's song (c1800?) $\quad \mathbf{2 8 0}$

5. Praise for Governor Friderici (c1800) $\quad \mathbf{2 8 1}$

6. Mocking a corrupt public servant (c1815) $\quad \mathbf{2 8 2}$

7. Making fun of the Governor's eating habits (c1825) $\quad \mathbf{2 8 3}$

8. $\quad$ Prince Hendrik visits Suriname (1835) 283

9. A sceptic view of love (pre-1850) $\quad \mathbf{2 8 3}$

10. Love is war (pre-1850) $\quad \mathbf{2 8 3}$

11. Putting a curse on someone (pre-1850) $\quad \mathbf{2 8 3}$

12. Teasing a girl who's in love (pre-1850) $\quad \mathbf{2 8 4}$

13. The end of a love affair (pre-1850) $\quad \mathbf{2 8 4}$

14. Changing lovers (pre-1850) $\quad \mathbf{2 8 4}$

15. A rowing song (pre-1850) $\quad \mathbf{2 8 4}$

16. Another rowing song (pre-1850) $\quad 285$

17. A susa song (pre-1850) $\quad \mathbf{2 8 6}$

18. Another susa song (pre-1850) $\mathbf{2 8 6}$

19. Love and money (pre-1850) $\quad \mathbf{2 8 6}$

20. Love and colour (pre-1850) $\quad \mathbf{2 8 7}$

21. A songe dance song (Ndyuka) $\quad \mathbf{2 8 7}$

22. 'Basya, lash out!' (1854) $\quad 288$

22a. Wishing the master a Happy New Year 290

22b. A work song $\quad 291$

23. 'Puttin' on ole massa' (1862) 293

24. Slaves get punished, freemen do not (pre-1863) 294

25. Celebrating Emancipation (1863) 295

26. Poking fun at the nouveaux riches (c1870) 296

27. Mock-praise for Governor Van Sypesteyn (c1880) 296

28. A children's song (pre-1884) $\quad 297$

29. Pride in the face of oppression (19th century?) 297

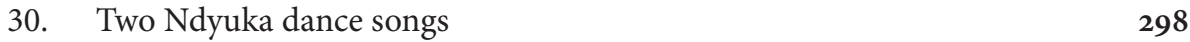


30a. A baboon song $\quad 298$

30b. The white-toothed Black $\quad 298$

31. A lobi singi (c1900) 299

32. An unfaithful husband (c1900) 299

33. Nobody knows you when you're down and out (c 1900) 300

34. A children's song (c1900) 302

35. A lullaby (c1900) 302

36. A comical song (c1900) 302

37. A satirical rowing song (1900) 303

38. The tongue of the gods $\quad 304$

39. The national anthem of Suriname (1959) 304

$\begin{array}{ll}\text { 40. Sranan odos } & 307\end{array}$

41. A folk-tale in Sranan $\quad 311$

42. A folk-tale in Saramaccan $\quad 312$ 


\section{List of written texts}

1. George Warren's Impartial description (1667) 316

2. Aphra Behn's Oroonoko (1688) 317

3. Hermann (1689) 317

4. Maria Sybilla Merian’s Studienbuch (1699) 317

5. The voice of the slaves (I) (1702-1711) 318

5a. Words (1702-1711) 319

5b. Sentences (1707) 319

6. Herlein's (1718) Dialogues 321

7. The voice of the Maroons (I) (1728/1733) 324

8. The voice of the slaves (II) (1745-1762) 324

9. The voice of the Maroons (II) (1757-1759) 326

10. The Saramaka Peace Treaty in Sranan (1762) 327

10a. The text of the treaty 329

11. The voice of the Maroons (III) (1762) 338

12. The voice of the slaves (III) (1763-1767) 338

13. Van Dyk (c1765) 339

13a. The burial scene from Van Dyk's reading drama 340

13b. Dialogue no 2 from Van Dyk's language primer 342

14. Fermin (1769) 343

15. Nepveu (1770) 343

15a. Nepveu's corrections toHerlein 1718 (1770) 344

15b. Nepveu's additions to Herlein 1718 (1770) 344

16. Hartsinck (1770) 348

17. Schumann (1778) and (1783) 349

17a. Sample lemmas from Schumann's Saramaccan dictionary 351

18. Anon. [Schumann] (c1780) 352

18a. The verbal system of Early Saramaccan 353

19. Schouten (1783) 354

20. Stedman (1790) 356

21. Weygandt (1798) 358

22. Riemer (1801) 360

23. Bolingbroke (1807) 361

23a. A dialogue between a newly arrived bakra and a free mulatto girl (1829) 361 
24. Benoit (1830) 363

25. Anon. (c1836) 363

26. Them belly full (but we hungry) (1835) 367

27. Winkels (1840) 367

28. Greeting the master (c1840) 369

29. Focke (1855) 369

29a. Sample lemmas from Focke's (1855) Sranan dictionary 370

30. Wullschlägel (1854) and (1856) 370

30a. Wullschlägel (1854) on logophoric pronouns 371

30b. Sample lemma from Wullschlägel's Sranan dictionary 371

31. Documents concerning Emancipation (1862-1873) 372

31a. The Emancipation Act (1862) 373

31b. The placard announcing Emancipation (1862) 382

31c. The placard announcing amnesty for runaway slaves (1862) 384

31d. The placard announcing the rights and obligations of emancipated slaves $(4 / 16 / 1863)$

31e. The placard announcing an addendum to the rights and obligations of emancipated slaves (1863)

31f. The placard announcing the end of 'State supervision' (6/14/1873)

32. Blacks talking back

33. Ndyuka-Trio Pidgin: Crevaux (1883)

34. A Sranan grammar in Sranan: Helstone (1903)

404

35. Ndyuka-Trio Pidgin: De Goeje (1908)

36. Saying 'hello' in Ndyuka: De Goeje (1908)

37. Koenders (1946)

38. Skipio (1768): Asking for help with a sore foot

39. Schumann (1779) and Anon. (1803): 'Oh Head so full of bruises' in Saramaccan and Sranan

40. Christian Grego and Johannes Alabi (1790-1791):

The Saramaka Maroon Letters

41. The Lord's Prayer in Saramaccan and Sranan $(1779,1801,1829,1884)$

41a. Late-18th-century Saramaccan version I: Schumann (1779)

41b. Late-18th-century Saramaccan version II: Riemer (1801)

41c Early 19th-century Sranan version: Anon. (1829)

41d. Late 19th-century Sranan version: Bonaparte (1884)

42. The Acts of the Apostles in Saramaccan and Sranan (1805 [1793], 1829)

42a. Acts 1:1-10 in Saramaccan: Wietz (1805[1793])

42b. Acts 1:1-10 in Sranan: Anon. (1829) 
43. The Apostles' Creed in Sranan: A Catholic and a Moravian translation (1822, c1830) 422

43a. The Catholic version (1822) 423

43b. The Moravian version (c1830)

44. Jonas Adam: A Sranan letter written by a slave (1835) 424

45. 'Little white man talking sweet': W. Boekhoudt's sermon in Sranan (1846)

46. A papal bull in Sranan (1878) 425

47. 'The writing in the sky': Visions from Johannes King's Skrekibuku (1882-1888)

48. Food for christian souls: The Makzien foe Kristen-soema zieli (1902) 428

49. An indigenous syllabic script for Ndyuka: Afaka (1917) 430 431 



\section{Introduction to this edition}

The author of this book passed away before he could finish it, on August 16, 2005. Jacques Arends considered the manuscript to be the culmination point of his long-standing research on Suriname creolization. He had told friends and colleagues that he was about to complete the work. It was for the sake of Jacques Arends' scholarly labour and for language science that some of them, supported by his wife Melanie, felt that the manuscript deserved serious publication.

It was a book-to-be, though. Jacques bequeathed us both soft and hard concepts of (partial) chapters, outlines, lists of references and sources, proposals, and even a preface - the author's own preface following this one. Clearly, the texts were part of a master plan, but the plan was not fully transparent to outsiders and the texts were pre-final.

It took eleven years for the book to appear in print. There are quite a few reasons but very few excuses why it took so long. Two chapters mentioned in the author's draft book-proposals we could not trace back. A chapter dubbed Syntax was mentioned there but could not be identified. Presumably, Jacques Arends planned to rely on previous work of his, but we could not decide which work he had intended. It occurred to us, however, that the chapter would not add new aspects to the book's main line of argument, and that the merit of the book would not depend on such a chapter either. Therefore, we decided not to 'invent' that chapter. In addition, the intended final chapter Conclusions was not in the materials available to us. Again, we decided not to try and reconstruct the author's intentions in this respect.

All other concept chapters were handled very conservatively. No major changes of any kind have been implemented. Mainly, we have tried to resolve 'weak spots' - some of which Jacques had indicated himself - and factual gaps (notably in the references). In doing so, we have not chosen a philologists' point of view; rather, we went for scholarly integrity and relevance, while not interfering unnecessarily with stylistic matters. In this spirit, we also refrained from adding maps and illustrations to the text. Although Jacques compiled many of these, it was beyond our competence to decide which material he had intended to use and in which way. Therefore, this edition is less illuminated than the author had envisaged.

The book is - above all - meant to be an original and important contribution to the study of creolization. Notwithstanding the delay, we trust that it will turn 
out to be just that, and that it will consolidate Jacques Arends' reputation as an eminent researcher. This book is yet another testimony of the the author's scholarship and perseverance We hope that his sons Jasper, Michiel and Tom will also find inspiration from his impressive legacy.

The manuscript was initially evaluated by Eithne Carlin, Norval Smith, Saskia de Haan and Crit Cremers. They also decided on the outline of the present edition. Subsequently, Saskia de Haan conscientiously and thoroughly edited the manuscript. Eithne Carlin wrote an addendum to the original preface. Adrienne Bruyn provided essential advice and support with respect to the references and the index. Crit Cremers is responsible for the final draft.

We are indebted to Miriam Meyerhoff as an Editor of the Creole Language Library and to Kees Vaes representing John Benjamins Publishing Company for their willingness, patience and advice in finally publishing Jacques Arends' opus magnum.

Crit Cremers

May 2017 


\section{Series editor's preface}

When John Singler decided to stand down as a co-editor of the Creole Language Library in the early $00 \mathrm{~s}$, he approached me to see if I would be willing to replace him. We both understood that this would be contingent on whether the other editor of CLL at the time, Jacques Arends, and I believed we could work well together.

I knew Jacques by sight from meetings of the Society of Pidgin and Creole Linguistics but primarily I knew his work. His textbook (in the CLL series) was the text in the course on pidgins and creoles that I took as a $\mathrm{PhD}$ student at the University of Pennsylvania. I was also deeply sympathetic to the arguments he made about the gradual development of creoles based on his careful demographic and corpus-based research. I liked that he was willing to recognise when others' research raised problems or issues for his theory.

Jacques and I met and chatted about the Creole Language Library at the next conference we both attended in Amsterdam in 2004. I learnt then that he combined a steely professional rigour with an affectionate view of life. I came away from the meeting reassured and looking forward to the prospect of working with and learning from him as his co-editor in the series. It was not to be.

When I agreed to work with Jacques on the series, I agreed to give it at least six years. This year, it has been more than a decade. As I prepare to hand on the role of editing the Creole Language Library this year, I am terribly happy to see this volume go to press. This is the second volume we have had the pleasure of publishing in the Creole Language Library that celebrates Jacques Arends' profound scholarly contribution to the field of creolistics (see also CLL 34, 2009).

It speaks volumes for Jacques Arends that his colleagues have been moved to secure his invaluable intellectual legacy for future researchers in the field. Many of the people involved in editing this volume have done so at considerable effort over and above their other work and their busy lives. It is truly a labour of love, for a man who knew quite a lot about that emotion.

Miriam Meyerhoff August 2016 



\section{Trotji (Sranan: Preface)}

This book is being published on the premise that it is possible for a white, European linguist in the 21st century to write the history of a group of languages whose formation is so deeply entwined with the strange and cruel history of the people who created these languages some three hundred years ago. From a purely scientific point of view, of course, this should pose no problem whatsoever. The histories of many languages have been written before, although most often from a purely linguistic point of view, that is without taking the external history into account. In fact, the building of modern Western linguistics rests on the foundation of the historical linguistics of the 19th century which dealt almost exclusively with languages' internal history, the structural changes they underwent through time without taking into account the historical context in which these changes took place. In such cases the color of the scholar's skin or the 'strangeness' of the historical context or the time-depth involved did not play any role at all.

In the case discussed in this book, however, these things do play a role. The extraordinary nature of the history of the Blacks in Suriname made it impossible for this author, at least - to write the history of the Suriname Creoles in purely linguistic terms, as just one more study in diachronic linguistics. This is not to say that this could not be done, or that there would be anything wrong doing it. In fact, because of the underdeveloped state of the historiography of Suriname it would be a whole lot easier. The author of any such study would have been spared the many instances where the historical record is either incomplete or contradictory or simply wrong. On the other hand, I am certain that in such an approach many phenomena would have received an incorrect explanation or no explanation at all. This is especially so because the formation of the Suriname Creoles (and of Creoles in general) is first and foremost a process of language contact, more in particular one where the coming into contact of the speakers of a number of different languages leads to the emergence of one or more new languages. Once this is recognized, it becomes clear that to write this history of the Suriname Creoles in a responsible way the historical context must taken into account, if only to determine on independent grounds which languages exactly were involved in the contact situation.

Apart from the identification of the languages involved in the contact situation, there are other reasons why it is wise or even necessary to take the historical 
context into account in the study of Creole genesis and development. As has been amply demonstrated in recent studies in contact linguistics (Thomason \& Kaufman 1988; Thomason 2001), the question of what will happen in a contact situation is ultimately dependent on social rather than purely linguistic factors. This does not mean that an exhaustive knowledge - if at all possible - of the historical context will yield a solution to each and every linguistic problem connected with Creole formation. But it does enable us to at least avoid the kind of erroneous explanations that are sometimes proposed simply because the historical context is not taken into account at all. To give just one example, if it can be shown on demographic grounds that children were not present in sufficient numbers to create a Creole and subsequently enforce it onto the rest of the community, any theory of Creole genesis which accords a crucial role to L1 acquisition should be abandoned.

As far as the historical context of creolization is concerned, this book even goes one step further in that it attempts to tell the history of the Suriname Creoles as an integral part of Suriname's history per se. In other words, rather than reverting to historical factors whenever this seems necessary, this book attempts to treat the history of these languages as part and parcel of the history of Suriname. I use the word 'attempt' on purpose here, not out of some kind of modesty, because the present state of the historiography of Suriname does not allow a fully historical treatment of the topic. Although the situation is improving (Van Stipriaan, Oostindie, Beeldsnijder, Van der Meiden), there are simply too many gaps in the historical literature, e.g. with regard to demographics (Van der Meiden 1987: 14). Compare e.g. the fact that the most recent general history of Suriname, based on primary sources, dates from 1861 (Wolbers 1861)! This means that in many cases one has to rely on partial studies, often done by amateur historians ( $c f$. Van der Meiden 1987:57, 64, 68; the history of Suriname is an amateur history). Apart from sheer lack of professionalism, another problem is that even if historical studies are based on original documents, there is the problem that these do not necessarily tell the truth (Van der Meiden 1987: 9, 42,77). Colonialism was part of the big political game among the major European powers of the time (England, France, The Netherlands), and often, there were reasons to hide the truth.

Since this book is based on work done during the past twenty years, many people have been involved in its gestation in one way or another. While I thank all of them wholeheartedly, I will mention only a few names in particular. Pieter Seuren put me on the track of Creoles by suggesting the development of Sranan syntax as a topic for my dissertation and Jan Voorhoeve supervised it. Pieter Muysken cordially accepted me as a post-doctoral researcher at the University of Amsterdam's Department of Linguistics and continuously asked me about 'the progress of my book' when I didn't even know I was writing one. My colleagues at the department, especially my fellow creolists, even more especially my fellow 
Surinamists: Liliane Adamson, Margot van den Berg, Adrienne Bruyn, Norval Smith, and Tonjes Veenstra. Adrienne and Norval provide an almost continuous soundboard. Peter Bakker also deserves a special word of thanks for noting and sometimes even sending me obscure but highly relevant old references. During the actual writing of the book, my participation in the Transatlantic Sprachbund Research Project provided much inspiration. For advice and support, I am indebted to Sue Ang, Marlyse Baptista, Ruud Beldsnijder, Hans den Besten, Eithne Carlin, Silvia Kouwenberg, André Kramp, Herman Wekker and many students at the University of Amsterdam. Hein Eersel checked my interpretation and translation of the Sranan sentences which form the corpus for the analysis in Chapter 6 . Frank Byrne checked the English of my translation of Van Dyk (c1765). Finally, the book would not have been written without the support of my family.

Rather than dedicating this book to anyone in particular, I prefer to dedicate it to this mysterious force which I believe is behind the wonder of creolization and for which I have no better name than 'the Creole spirit', the power that is ultimately - through the Creole speakers - responsible for the creation of not just Creole languages but of Creole cultures as well. It is a power that unites what has been divided, recreates what has been destroyed, heals what has been broken. It is a power which - in a sense - is present in all of life, not just in creolization but in the continuous creation and recreation of the world and which is usually taken for granted, unless, as in creolization, it is present with a force that cannot be denied. May the Creole spirit continue to renew our world and our lives.

Jacques Arends

May 2005

[Editor's addendum. From notes left by the author and linked to this preface, one can infer that Jacques Arends intended to gratefully acknowledge various types of support from the following institutions:

the Netherlands Organization for Scientific Research NWO the Dutch Academy of Sciences KNAW and its Institute for Advanced Studies NIAS the University of Amsterdam and its research institutes IFOTT and ACLC the Archives of the Moravian Church.] 



\section{Outline of the book}

The Surinamese creole languages enjoy the notable status of being the bestdocumented creoles in the earlier stages of their development, albeit that the initial written documentation of the two main languages, Sranantongo (henceforth Sranan) and Saramaccan, was mainly by the hand of non-native speakers. For this reason much scholarship exists on the diachrony of these two languages while synchronic variation at any given period of time is lacking for precisely the same reason. This book aims to shed new light on and address the various questions that have arisen regarding the genesis and development of these Surinamese languages.

The contribution of the present book is to give an in-depth synthesis of previous scholarship on not only the linguistic history of the Surinamese creole languages, but also to re-visit the sociohistorical developments pertinent to the formation and growth of these languages. Much previous scholarship has not only been based on erroneous historical-demographic evidence but also the period before colonization by the English in 1651 has been largely ignored even though there is sufficient historical evidence of European settlements before that date and no convincing evidence of an absence of African slaves. Given that Captain Marshall attempted settlement in Suriname in 1630 it is likely that he took African slaves with him since slaves were already present in Barbados from the mid-1620s. This bone of contention among creolists and historians alike is dealt with here giving strong evidence for including the period 1630-1651 in an analysis of the developments ensuing in Suriname in the colonial period. This book also includes in its deliberations areas beyond the borders of Suriname, namely Brazil and the Greater Guyana area showing how the 150 years prior to settlement in Suriname were forerunners of developments in Suriname.

This book starts with an overview of the history of Suriname as a creole society within the larger historical context, including the previously ignored early settlements, and leads up to a concise overview of the most relevant theories, hypotheses and questions in creole studies, one of which remains creole genesis.

Chapter 2 starts out with the claim that the formation of the Surinamese creoles may go further back than the generally accepted mid-seventeenth century, to a period prior to colonization. This the author refers to as the 'pre-history' of the Surinamese creoles. He walks us through the early settlements, the English period, 
the arrival of Sephardic Jews, and the early years of Dutch colonization leading up to the English exodus, the turbulent years of transition from English to Dutch rule which resulted in the Amerindian war (1678-1686) and early marronage which led to the formation of the Saramaka Maroons and their language. Given the historical relationship between Sranan and Saramaccan, any hypothesized dating of the formation of Saramaccan has direct repercussions for the reconstruction of creole genesis in Suriname. Thus the author scrutinizes the empirical evidence used notably by Richard Price $(1976,1983,1990)$ to form his claims for the earliest date of 1690 as the formation of the Saramaka Maroons - and by extension their language - rather than the 1640s during Captain Marshall's second settlement, which is corroborated by Saramaccan oral traditions.

Chapter 3 seeks to address an issue that is generally ignored by creolists, namely the social and demographic factors that played a role in the formation of the creole languages. Besides offering a wealth of detailed demographics, the author shows that internal social stratification favored linguistic differentiation, whereas an external social network favored linguistic homogenization. In Chapter 4 the author zooms in on language variation and linguistic repertoires in the preEmancipation era, giving an all-encompassing sociolinguistic overview of the early colony, showing how ethnicity, language attitude, religion and location (urban versus plantation) had an effect on by whom and how Sranan was spoken.

Chapter 5 then discusses the linguistic data gleaned from texts from the pre1800 period, namely some miscellaneous texts (1667-1763) and those of Herlein (1718), Nepveu (1770), Van Dyk (c1765) and Stedman (1790). Some of these texts, which include court transcriptions and dialogues, constitute the earliest written sources for Sranan, better known as Suriname Plantation Creole. The author also looks in detail at some features of Herlein's Sranan texts that are indicative of a pre-creole stage of that language.

Chapters 6 and 7 offer the reader a wealth of dated and annotated textual data, including both oral and written texts, carefully chosen to represent different genres and stages of the Surinamese creole languages, Sranan, Ndyuka, and Saramaccan. The oral texts in Chapter 6 include mainly songs but also odos 'proverb-like sayings' and some examples of Anansi tori 'folktales'. Chapter 7 comprises written texts that belong to the oldest specimens known for the Surinamese creoles. Those texts discussed earlier in Chapter 5 are given here in full, with complete biographical data of the authors where possible. The written texts in Chapter 7 constitute two different types of textual data, namely secular texts and religious texts. The 'texts' include lists of single words found embedded in published work, for example, words used in Aphra Behn's 1688 novel Oroonoko, or the royal slave, as well as full dialogues (Herlein 1718) and full transcriptions of, for example, the Saramaka 
Peace Treaty in Sranan (1762) and the Saramaka Maroon Letters. With the aim to facilitate future researchers on the creole languages of Suriname, the author has kept the transcriptions of these texts true to the original so that they can be used without bias. It was the author's wish that research, linguistic and otherwise, on the creole languages in Suriname will continue.

Eithne Carlin

March 2016 



\section{CHAPTER 1}

\section{Introduction}

Before embarking on the main topic, which is about the social and linguistic history of the Creoles of Suriname, we will give a brief introduction to the country, its history and geography, and its linguistic situation (For an up-to-date survey of many aspects of 20th-century Suriname, see Hoefte \& Meel 2001). We will present brief sketches of the three 'main' Creoles - Sranan, Saramaccan, and Ndyuka; each of these will also be illustrated by short texts. We will also say a few words about the field of Creole Studies, since at many points in this book we refer to current issues in that branch of linguistics. More specifically, we will be concerned with Creole formation - the genesis and early development of Creole languages - a topic that has led to much controversy over the past few decades. While much of this controversy has been largely theoretical, the specific aim of our study is to present historicalevidence in an attempt to establish the empirical validity of these theories and, where insufficient, to provide an empirical basis for alternative hypotheses.

\subsection{Suriname, a creole society}

The Republic of Suriname is an independent state of some $164,000 \mathrm{~km}^{2}$ (roughly the size of Ireland), located in the north-eastern part of South America between $2^{\circ}$ and $6^{\circ}$ north latitude and $54^{\circ}$ and $58^{\circ}$ west longitude, between the Atlantic Ocean to the north, Guyana to the west, the French overseas département of Guyane to the east, and Brazil to the south. It is largely covered with rain forest, except for the coastal plain, which is part savannah, part swamp. The climate is tropical, with two rainy seasons, one from September until early February (pikin alenten 'small rainy season') and one from late April until mid-August (bigi alenten 'big rainy season'). The country is intersected by a number of large rivers, many of them running from south to north, as well as many smaller rivers and creeks. Since the country's surface descends in a terrace-like manner from the interior to the coast, the navigability of the larger rivers, especially upstream, is diminished by the presence of sulas 'rapids', where large rocks make it difficult or even impossible for boats to pass through (boats have to be carried overland at these locations). This was especially important in pre-aviation times since rivers formed virtually the only channel of transportation through the rainforest. 
The population of Suriname consists of approximately 435,000 inhabitants, some 220,000 of whom live in the capital, Paramaribo (De Bruijne 2001:27,32). Another 300,000 people of Surinamese descent (i.e. nearly half of the total number!) reside in the Netherlands (Adamson 2001:293). Many of these continue to speak Sranan, usually in addition to another Surinamese language, such as Sarnami or Surinamese Javanese, and (Surinamese) Dutch. As a result of frequent transatlantic travel and the maintenance of other types of contact, the two communities may be described as forming a so-called 'trans-nation'. The phenomenon of 'trans-nationality' is of linguistic importance because of the fact that the two communities may, in a sense, be seen as forming one speech community. However, since the phenomenon of 'trans-nationality', at least on this scale, is a very recent development, its linguistic relevance is largely restricted to the present-day situation.

The population consists of the following groups:

$\begin{array}{lc}\text { Ethnic group } & \text { Percentage } \\ \text { Hindustanis } & 35 \% \\ \text { Creoles }^{1} & 33 \% \\ \text { Javanese } & 16 \% \\ \text { Maroons } & 11 \% \\ \text { Amerindians } & 3 \% \\ \text { Chinese } & 2 \%\end{array}$

Figure 1.1 The numerical distribution of ethnic groups in present-day Suriname

The original inhabitants, mainly Caribs and Arawaks, were quickly surpassed numerically by the Europeans (English, Dutch, Sephardic Jews, and others) and the laborers they brought with them from overseas, first from Africa, and later, after the abolition of the slave trade, from Asia. Asians were first brought to Suriname as indentured laborers in the period between 1853 and 1930. As a result Suriname is now a multi-ethnic, multicultural, and multilingual society where over fifteen different languages are spoken (see Carlin \& Arends 2002). While the Creoles and Chinese live mainly in Paramaribo, the other groups are also significantly present in rural areas, both along the coast (Hindustanis, Javanese, Amerindians) and in the interior (Maroons, Amerindians). In recent years, the (re) discovery of

1. In present-day Suriname, the word 'Creole', when used to refer to people (rather than language), means 'non-Maroon Surinamese of (partial) African descent'. Throughout this book, the distinction between 'creoles' in the sense of languages and 'Creoles' in the sense of persons will be indicated by using lower case ' $c$ ' for the former and uppercase ' $C$ ' for the latter (except in cases where 'Creole' occurs as part of the name of a language, as in 'Eastern Maroon Creole'). 
gold in Suriname has attracted a large number of Brazilians (estimates vary from 20,000 to 40,000), many of whom spend time in Paramaribo. As a result, Brazilian Portuguese has become a language with a significant presence there (Carlin 2001).

As far as the history of Suriname is concerned, it does not seem appropriate to include a full summary at this point as historical issues run as a continuous thread through this book. On the other hand, it is useful to have an overview of the most important events especially as some of these are frequently referred to in the book. For this reason, we have provided the historical timeline below, a sort of 'mini historical calendar', largely based on the 'classic' historical literature on Suriname, by writers such as Wolbers (1861), Van Lier (1977), Helman (1982), and Buddingh' (1995). The table lists the major historical events of the last 500 years that are relevant to the history of the Surinamese creoles.

Table 1.1 Major events in the history of Suriname (1499-1975)

1499 'Discovery' of 'Guiana' (the area between the Orinoco and Amazon Rivers) by Alonso de Ojeda

$1607 \quad$ First recorded (Dutch) settlement on the Corantijn River

1613 First recorded (Dutch) trading post on the Suriname River

1621 Foundation of the 'first' West India Company

1625-50 Several settlements in Suriname by English, French, and Dutch

1651 Colonization by some forty English settlers from Barbados under Francis Willoughby

1651-53 Arrival of several hundred English settlers from Barbados

1650s/1660s Start of sugar cultivation. First recorded shipments of African slaves to Suriname 1662 'Willoughbyland' (the coastal area between the Coppename and Marowijne Rivers) granted to Willoughby (and one Lawrence Hyde) by Charles II

1665 Departure of some 200 English settlers. Death of Willoughby

1665-67 Major epidemic. Arrival of some 200 Sephardic Jews from Brazil, Italy, and Amsterdam

Feb 1667 Suriname captured by Captain Abraham Crijnssen from the Dutch province of Zeeland

31/7/1667 Treaty of Breda: Suriname officially ceded to the Dutch

Oct 1667 Suriname recaptured for the English by Henry Willoughby

Early 1668 Willoughby urges English settlers to leave and destroys many plantations

30/4/1668 Suriname factually ceded to the Dutch

1660s-1670s First recorded Maroon groups (Para and Coppename Rivers)

1675 Foundation of the 'second' West India Company (after bankruptcy in 1674)

1668-1680 Some 600 English settlers leave with some 1,500 slaves for Antigua and Jamaica

1678-1686 Amerindian War

1682 Ownership of Suriname transferred from Province of Zeeland to West India Company 
Table 1.1 (continued)

\begin{tabular}{|c|c|}
\hline 1683 & $\begin{array}{l}\text { Ownership of Suriname transferred from West India Company to Societeit van } \\
\text { Suriname }^{2}\end{array}$ \\
\hline $1683 / 84 / 86$ & Peace Treaties with Indians and Coppename Maroons \\
\hline $1683-88$ & Van Sommelsdyk governor of Suriname \\
\hline 1685 & $\begin{array}{l}\text { Huguenots start emigrating to Suriname after revocation of the Nantes Edict by } \\
\text { Louis XIV }\end{array}$ \\
\hline 1686 & $\begin{array}{l}\text { Members of the Labadists' sect set up (unsuccessful) plantation on the Suriname } \\
\text { River }\end{array}$ \\
\hline $1699-1700$ & $\begin{array}{l}\text { Maria Sibylla Merian visits Suriname to work on her Metamorphosis Insectorum } \\
\text { Surinamensium }\end{array}$ \\
\hline c1707-c1715 & J.D. Herlein lives in Suriname \\
\hline 1712 & $\begin{array}{l}\text { An undetermined number of slaves join the Maroons as a result of Cassard's } \\
\text { attack on Suriname }\end{array}$ \\
\hline 1718 & Publication of Herlein's Beschrijvinge, containing the first printed text in Sranan \\
\hline 1724 & Start of coffee cultivation \\
\hline 1735 & Arrival of first Moravian Brethren in Suriname \\
\hline 1749 & Christian Ludwig Schumann born in Pilgerhut (Berbice) \\
\hline 1757 & $\begin{array}{l}\text { Several hundreds of slaves join the Ndyuka Maroons as a result of the Tempati } \\
\text { rebellion }\end{array}$ \\
\hline 1760 & Peace Treaty with the Ndyuka Maroons \\
\hline 1762 & Peace Treaty with the Saramaka Maroons \\
\hline 1765 & $\begin{array}{l}\text { Start of the Moravian mission among the Saramaka Maroons. Publication of } \\
\text { Pieter van Dyk's Onderwijzinge, the first Sranan primer (approximate date) }\end{array}$ \\
\hline 1767 & Peace Treaty with the Matawai Maroons. \\
\hline $1763-65$ & Jan Nepveu writes his 'Annotations' to Herlein 1718 \\
\hline $1768-79$ & Jan Nepveu (interim) governor of Suriname \\
\hline $1768-77$ & First Boni Maroon War \\
\hline 1770 & $\begin{array}{l}\text { Founding of a corps of (free) black soldiers (the Negervrijkorps) to fight the Boni } \\
\text { Maroons }\end{array}$ \\
\hline 1771 & First Saramaka Maroon (Johannes Alabi) baptized by the Moravian Brethren \\
\hline 1772 & $\begin{array}{l}\text { Founding of a second corps of (enslaved) black soldiers (the Zwarte Jagers or } \\
\text { Redi Musu), to fight the Boni Maroons }\end{array}$ \\
\hline $1773-77$ & $\begin{array}{l}\text { Captain John Gabriel Stedman serves in the colonial army fighting the Boni } \\
\text { Maroons }\end{array}$ \\
\hline
\end{tabular}

2. The shares were equally divided over the city of Amsterdam, the West India Company, and Cornelis van Sommelsdyk.

3. Van der Meiden (1987:78) corrects the generally accepted idea that the number of Maroons increased considerably as a result of Cassard's attack. While the idea goes back to Herlein's (1718: 93) claim that 'more than 700 or many more got lost in the bushes', Van der Meiden notes that 'it is not mentioned in contemporary sources'. 
Table 1.1 (continued)

c1770 Plantation Suriname at its maximum, with a population of some 60,000 Blacks and some 600 plantations

1776 First black slave baptized by Moravian Brethren

$1773 \quad$ Economic decline sets in

1777-78 C. L. Schumann does missionary work among the Saramaka Maroons

1778 C.L. Schumann's completes his Saramaccanisches Wörterbuch, the first Saramaccan dictionary

1780s Moravians start missionary work on plantation Fairfield

1790-91 First recorded texts written in Creole by Surinamese Blacks (Christian Grego, Johannes Alabi)

1783 C.L. Schumann's completes his Deutsch-Neger-Englisches Wörterbuch, the first Sranan dictionary

1789-93 Second Boni Maroon War. The Boni cross the Marowijne River to live in French Guiana

1791 Dissolution of the West India Company

1795 Dissolution of the Societeit van Suriname. Suriname directly under Dutch government

$1796 \quad$ Publication of Stedman's Narrative

1798 Publication of Weygandt's Leerwijze, the second oldest Sranan primer

1799-1802 Suriname a British Protectorate

1802-1804 Suriname under Dutch rule again

1804-16 British interregnum in Suriname

1808 Official abolition of the slave trade. Illegal trade continues until 1830

c1830 Start of 'amelioration policy', directed at improving living conditions among the slaves

1829 Publication of Da njoe testament, the first printed Bible translation in Sranan

1830 Publication of William Greenfield's Defence of the Negro-English version of the New Testament.

Beginning of Moravian mission among plantation slaves on a wider scale (approximate date)

$1838 \quad$ First Hindustani contract laborers in Suriname

1844 Moravian missionaries permitted to teach slave children how to read

1852 Publication of first issue of Makzien vo Kristen-soema zieli, Moravian religious magazine entirely in Sranan (continued until 1932)

$1853 \quad$ First Chinese contract laborers in Suriname

1854 Publication of the anonymous Kurzgefasste Neger-Englische Grammatik, the first printed Sranan grammar

1855 Publication of Focke's Neger-Engelsch woordenboek, the first printed Sranan dictionary

1856 Publication of Wullschlägel's Deutsch-Negerenglisches Wörterbuch, a GermanSranan dictionary. Moravian missionaries permitted to teach slave children how to write

1860s-1890s Johannes King, the first black Surinamese author, writes his diaries and other works 
Table 1.1 (continued)

\begin{tabular}{ll}
\hline $1 / 7 / 1863$ & Emancipation \\
$1863-73$ & Period of 'apprenticeship': ex-slaves supervised by colonial authorities \\
1876 & Introduction of compulsory education for 6-12 year olds in Suriname; although \\
& $\begin{array}{l}\text { Dutch is designated as the language of instruction, the Moravians continue } \\
\text { using Sranan for some time }\end{array}$ \\
1891 & Official ban on the use of Sranan as a medium of instruction \\
1894 & First Javanese contract laborers in Suriname \\
1903 & Publication of Helstone's Spraakkunst, the first Sranan grammar written in Sranan \\
1917 & End of Hindustani immigration \\
1939 & End of Javanese immigration \\
$1946-56$ & Publication by 'Papa' Koenders of Foetoeboi, emancipatory journal written in \\
& Sranan \\
c1950 & Foundation of Wi Eygi Sani, emancipatory Surinamese cultural organization \\
1954 & Suriname becomes an autonomous part of the Kingdom of the Netherlands \\
1957 & Publication of Trefossa's Trotji, first book of poetry in Sranan \\
1969 & Publication of Edgar Cairo's Temekoe, the first literary story in Sranan \\
1970 s & Many Surinamese immigrate to the Netherlands during pre-Independence years \\
1975 & Independence
\end{tabular}

Now that the main geographical and historical features have been sketched, it is perhaps time to make acquaintance with what this book is about - the creole languages of Suriname.

\subsection{The creole languages of Suriname}

Before going into the creole languages themselves, a few words need to be said about the other languages of Suriname, if only because they have left their traces in the creoles. First of all, there are several Native American languages, such as Lokono, Kari'na, Trio, Akuriyo, and Wayana, of which the first belongs to the Arawakan family while the others are Cariban languages. Then there are the Asian languages spoken by the contract laborers who were brought to Suriname in the 19th and early 20th centuries: Hakka, Sarnami, and Javanese. Hakka (or: Kejia) is a Chinese language spoken in the Pearl River Delta, the place where many Chinese immigrants originally came from. Sarnami (or: Sarnami Hindustani) is a koiné, based on Bhojpuri and several other varieties of Hindi that are spoken in the United Provinces in India, where most Indian immigrants came from. Surinamese Javanese (or: Yampanesi) is the variety of Javanese that was introduced by the immigrants from this Indonesian island. As is to be expected, all three Asian languages have developed into specifically Surinamese varieties, each 
with its own characteristics. Finally, Dutch - the (only) official language in the country - is widely known as a second or third language, especially in its particular Surinamese variety called Surinaams Nederlands (Surinamese Dutch). ${ }^{4}$ (For a summary of the current language situation, see Carlin 2001.) Since Sranan is used as the major lingua franca for communication between the different ethnic groups, it is widely known as a second or third language.

Before we go on to introduce the Surinamese creole languages, it is important to point out that in most cases we are dealing with oral languages, languages that have or had until recently no or only a marginal written tradition. This is especially relevant as most of the diachronic work reported later in this book is based on the analysis of written sources. As far as the creole languages are concerned, the only ones written down before the 19th century were Sranan and Saramaccan. And even in these cases, $99 \%$ of the remaining documents were composed by non-native speakers. Apart from the ten Saramaccan letters written around 1800, and the score of Sranan letters from the early 19th century, in both cases probably heavily influenced, or even directly dictated, by European missionaries (see Chapter 3), the first true native writing in any of the Suriname creoles was by Johannes King in the second half of the 19th century. The explanation for this is that until well into the 19th century slaves were simply not allowed to acquire any literacy skills. It is not surprising, therefore, that it was not slaves but Maroons, such as Grego, Alabi and King, who became the first native authors.

But the restriction on learning to read and write was not the only reason why the plantation and Maroon societies were thoroughly oral. Many, although not all, of the Africans who were brought to Suriname came from intrinsically oral cultures. There are two things we have to keep in mind throughout this book. Firstly, many creole textual sources on which this study is based were produced by writers who were not native speakers. Secondly, these writers chose genres such as dictionaries, grammars and Bible translations, which were completely alien to the cultural context of the creole language they were using as a medium. Apart from the scattered sentences attributed to native speakers in early documents such as Court Records and a few other sources, the first authentic textual material which may be said to be truly representative of not only native but also culturally appropriate Sranan (or any other Surinamese creole) is probably the collection of odos (proverbs) published by Teenstra in 1837. Later, other sources, such as Wullschlägel's (1856) collection of odos, become available, but it was not until the invention of the phonograph that samples of oral literature begin to be recorded and published, as for example in Herskovits \& Herskovits (1936).

4. Not to be confused with Surinaams, the Dutch name for Sranan. 
Unfortunate as this may be, there is no way of overcoming this problem. Anyone who wants to study the early stages of creolization in Suriname will have to make use of the non-optimal sources mentioned above. All one can do is be aware of the drawbacks and take them into account in one's interpretations and analyses as best as one can.

Having discussed this, we can now go on to introduce the topic of this book, the creole languages of Suriname. On the basis of a number of linguistic (especially phonological and lexical) criteria as well as their mutual (un)intelligibility, the Suriname creoles can be divided into three groups: Sranan, Western Maroon Creole (WMC, with two varieties: Saramaccan, Matawai), and EAstern MAroon Creole (EMC, with four varieties: Ndyuka, Paramaccan, Aluku, and Kwinti ${ }^{5}$ ). There are good reasons, however, to assume that they are all derived from the same 'proto language', which, following Migge (1998), we will refer to as Suriname Plantation Creole (SPC). The historical relationships between the creoles will be discussed more fully later in this book. They are provisionally represented as a genealogical tree, in Figure 1.2 below.

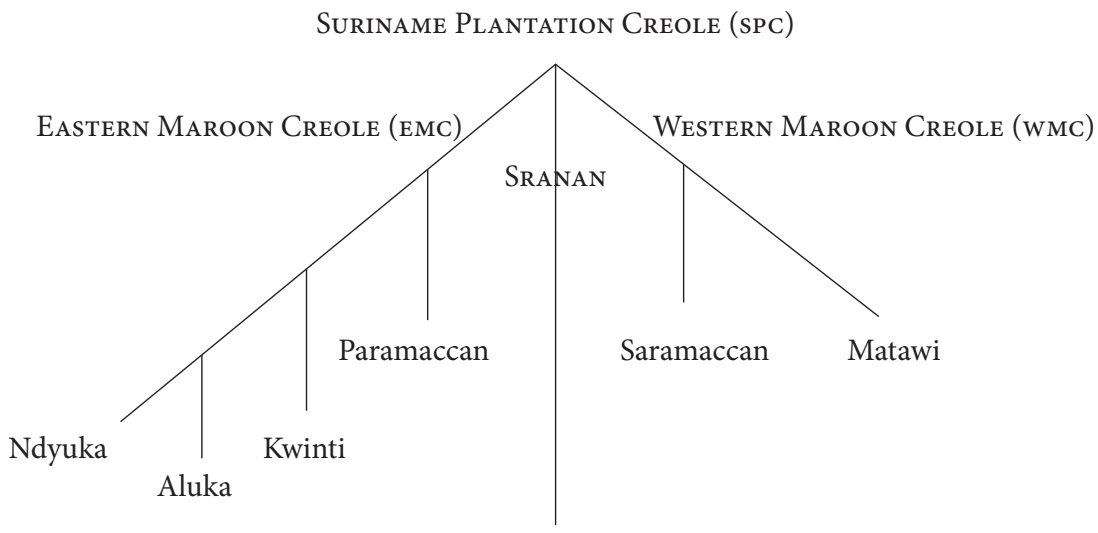

Sranan

Figure 1.2 Genealogical tree of the Suriname creoles

5. In the case of Kwinti, which is spoken in Central Suriname, the name 'Eastern Maroon Creole' should, of course, not be taken literally. 
The figure above represents the seven creole languages that are still currently in use, but there is also another creole that is sometimes mentioned in historical sources. It is called Djutongo, literally 'language of the Jews', which refers to the fact that it was the language used on plantations owned by Sephardic Jews whose primary language was Portuguese. While only a dozen or so lexical items are known from this language (see Smith 1987, 1999; Ladhams 1999), it is clear that it must have been a mainly Portuguese-lexicon creole, which may have been a precursor of Saramaccan. If this is indeed the case, the place for Djutongo in the tree given above would have to be at a separate node, in between WMC and the split between Saramaccan and Matawai.

Another way of representing the relationships between the Suriname creoles is by grouping them on the basis of their main lexifier language(s), i.e. the language(s) that provided the basis of their lexicons. This yields the following picture:

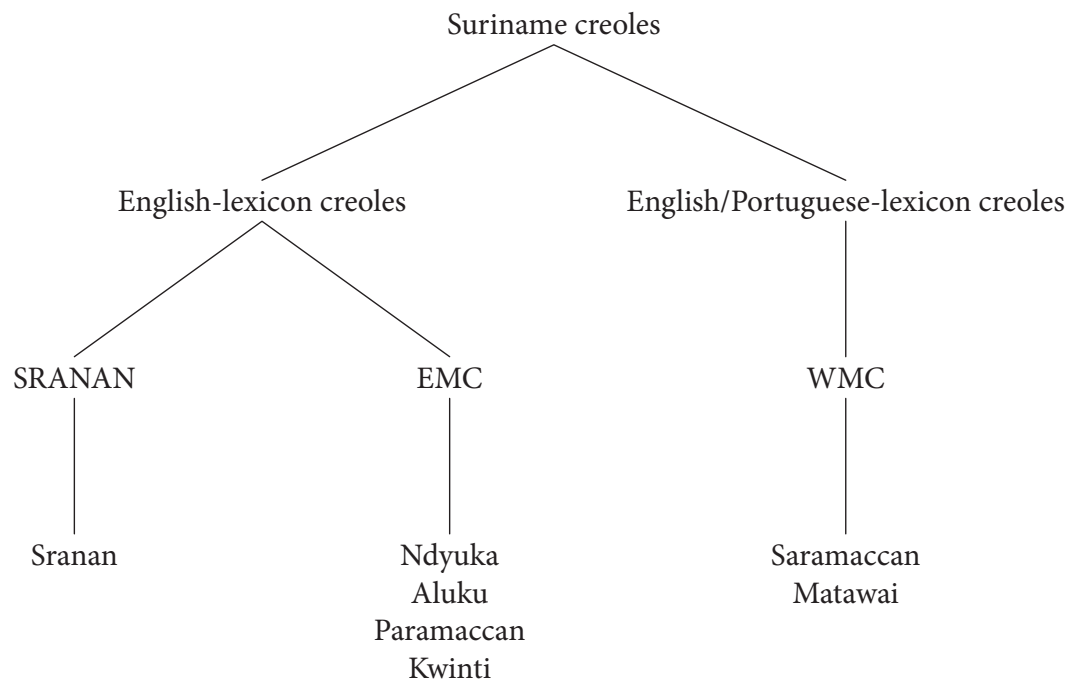

Figure 1.3 The Suriname creoles grouped according to their major lexifier language(s)

The following convention will be used throughout this book to refer to groups of creoles as opposed to individual creole languages: small caps will be used for groups of creoles (Eastern Maroon Creole, Western Maroon Creole), while lower case (Ndyuka, Aluku, etc) will be used for individual languages. A survey of the Suriname creoles is given in Table 1.2 below (numbers of speakers are estimates, adapted from Grimes 1996; the numbers include speakers living in the Netherlands): 
Table 1.2 Nomenclature, geographical distribution, and numbers of speakers of the Suriname languages

\begin{tabular}{|c|c|c|c|c|}
\hline $\begin{array}{l}\text { Language } \\
\text { group }\end{array}$ & Language(s) & Alternative name(s) & $\begin{array}{l}\text { Geographical } \\
\text { distribution }\end{array}$ & $\begin{array}{l}\text { Number } \\
\text { of speakers }\end{array}$ \\
\hline SRANAN & Sranan (Sranang) & $\begin{array}{l}\text { Sranan Tongo, } \\
\text { Surinaams, Nengre } \\
\text { (Tongo), Taki Taki }\end{array}$ & $\begin{array}{l}\text { Paramaribo and } \\
\text { coastal area }\end{array}$ & 400,000 (incl. L2) \\
\hline $\begin{array}{l}\text { EASTERN } \\
\text { MAROON }\end{array}$ & $\begin{array}{l}\text { Ndyuka (Ndjuka, } \\
\text { Djuka, Djoeka) }\end{array}$ & $\begin{array}{l}\text { Okanisi, Auka, } \\
\text { Aukaans }\end{array}$ & $\begin{array}{l}\text { Cottica, Marowijne, } \\
\text { Tapanahony Rivers }\end{array}$ & 20,000 \\
\hline \multirow[t]{3}{*}{ Creole } & Aluku (Aloekoe) & Boni & $\begin{array}{l}\text { French Guyana } \\
\text { border, French } \\
\text { Guyana }\end{array}$ & 2,500 \\
\hline & Paramaccan & Paramakaans & Marowijne River & 2,500 \\
\hline & Kwinti & & Coppename River & 500 \\
\hline $\begin{array}{l}\text { WESTERN } \\
\text { MAROON }\end{array}$ & Saramaccan & $\begin{array}{l}\text { Saamáka, } \\
\text { Saramakaans }\end{array}$ & Suriname River & 25,000 \\
\hline Creole & Matawai & $\begin{array}{l}\text { Matuari (Matoewari, } \\
\text { Matawari) }\end{array}$ & Saramacca River & 2,000 \\
\hline
\end{tabular}

As can be seen from this table, the total number of speakers of the six Maroon creoles added together, (i.e. excluding Sranan) is well below figures proposed as being critical for a language to survive in the 21st century. According to this criterion, all the Surinamese Maroon creoles are in danger of extinction within the next hundred years. While this may certainly be true for the smaller creoles - Kwinti, Aluku, Paramaccan and Matawai - it is important to realize that other factors than the number of speakers alone play a role in determining the vitality of a language. One of these is the extent to which a language is related to the identity and self-esteem of the group. In the case of the Maroon groups, their existence as culturally autonomous communities is intimately linked to the language they speak. The history of their formation as independent sub-societies within plantation society is completely intertwined with the development of their own creole language. In terms of this factor, there seems to be hope for the survival of these languages. However, they are under increasing pressure from other, 'bigger' languages, such as Sranan, and Dutch, through education, media, and migration. Moreover, they receive no support from the government whatsoever. There is good reason, therefore, to be concerned about the future of these languages.

The three creole groups: Sranan, West Maroon and East Maroon, will now be discussed in turn. We will not discuss each and every member of the latter groups separately but restrict ourselves to a discussion of the main representatives of the three groups, namely Sranan, Saramaccan and Ndyuka. 
Sranan. ${ }^{6}$ The name Sranan is short for Sranan Tongo, literally 'language of Suriname.' It is an English-lexicon creole language that has been used in Suriname since the late 17th century. In the past it has also been referred to as Negro-English, Nengre 'Negro (language)', or, in a rather derogatory manner, Taki-Taki 'chatter'. It is spoken by some 400,000 people in Suriname, French Guiana, and the Netherlands, either as a first or as a second language. It is the native language of most Surinamese people of African descent, while it serves as an interethnic lingua franca between the other ethnic groups, which include Amerindians, Hindustanis, Javanese and Chinese. Although it does not have any official status - the only official language in Suriname is Dutch - it is being used more and more in formal contexts, such as education, the media, politics, and public information. Apart from that, flowering literature in Sranan is flourishing, especially poetry ( $c f$. Van Kempen 1995).

The reason why an English-lexicon creole is spoken in a country that has been a Dutch colony throughout most of its existence is purely historical. Before it became a Dutch possession in 1667, Suriname had been an English colony for seventeen years, and it is generally assumed that the foundations of the Sranan lexicon stem from that period. However, although many English had left the colony by 1680 , this did not put a definitive stop to the presence of the English in Suriname. Many more speakers of English remained in Suriname than has usually been assumed. This means that the window of opportunity for the establishment of an English-lexicon creole remained open for a longer time than the thirty-year period between 1651 and 1680 .

Apart from the English element, the Sranan lexicon reveals several other influences as well. First, a number of Portuguese-derived words have been incorporated into the language due to the fact that many of the planters in the early period were Portuguese-speaking Jews. Second, many of the words for local flora and fauna, originate from the Amerindian languages, mainly Arawak and Carib. Third, a fair number of words have been adopted from some of the African languages spoken by the slaves, especially Gbe (a cluster of Kwa languages, spoken in Ghana, Togo and Benin), Akan (another Kwa language cluster, spoken in Ghana, Togo, and Ivory Coast), and Kikongo (a Bantu language cluster, spoken in Gabon, Congo, the Democratic Republic of Congo (former Zaire), and Angola). Finally, since Dutch rule, a large number of Dutch words have been borrowed, a process that continues to the present day.

Sranan is somewhat unusual among creoles in general in that the early stages of its development are relatively well documented. Many written documents from

6. This section is largely based on Arends (2005). 
the early 18th century as well as later - either in printed or manuscript form - are still available. This is largely due to the work of the Moravian Brethren, a German missionary organization that was very active in Suriname. They produced a large number of religious texts in Sranan as well as a number of invaluable descriptive works such as dictionaries and grammars. In addition, members of the colonial elite produced a number of language primers and dictionaries in printed form. Because of these early documents, linguists have been able to carry out detailed diachronic research on Sranan, especially on the development of its phonology and syntax (cf. Arends 2002b). In Chapter 6, several early Sranan texts have been reproduced.

Like many other creoles, Sranan is the product of a process of language contact involving a number of different languages from different language families. Historical research has shown that although the early, say pre-1740, African population was made up of many different ethnolinguistic groups, the majority belonged to one of three main language clusters: Gbe, Kikongo, or Akan (Arends 1995a). This means that the major African linguistic input in the formation of Sranan (and the other Suriname Creoles as well) came from these languages. The predominant role of Gbe, Kikongo and Akan is confirmed by the fact that the great majority of the African elements in the Sranan lexicon can be traced to these three languages. This is further supported by evidence from other research domains of language such as phonology, lexical semantics, and morphosyntax (cf. Smith 1987; Huttar 1985; Migge 1998).

It is important to realize that, although Suriname was a Dutch colony from 1667 onwards, the Dutch were never a majority of the European population made up of Germans, Portuguese, French, Scandinavians, among others. In fact, from the late 17 th to the early 19 th century, it was the Portuguese Jews who were numerically the most important group of Europeans. Dutch did not become a majority language among Suriname's Europeans until well into the 19 th century. The absence of a dominant European language may be partly responsible for the fact that Sranan was widely used by Europeans, not only in their contacts with Blacks but also with Europeans speaking other languages and even among themselves.

Below, the major features of each of the linguistic subsystems will be briefly discussed (largely based on Bruyn 2002; see also Adamson \& Smith 1995) followed by a few remarks on the 'verbal arts,' an important activity in traditionally oral languages such as Sranan.

Lexicon. About three quarters of the basic vocabulary (words for crosslinguistically (near) universal concepts such as 'sun', 'mother', 'eat') is derived from English, while most of the remainder is from Dutch. The non-basic vocabulary is mainly derived from Dutch, although some words can be traced to other sources, such 
as Portuguese, Amerindian languages (Lokono, Kari'na), and African languages (Gbe, Kikongo, Akan). Some examples are katibo 'slave' (< Portuguese cativo), kruyara 'dug out canoe' (< Lokono kojarha), awara 'palm species' (< Kari'na awa:ra), agama 'lizard species' (< Gbe a:gáma), pinda 'peanut' (< Kikongo mpinda), and gongosa 'gossip' (< Akan konkonsa).

As to grammatical words, although most of these were not adopted from English into Sranan directly, many grammatical functions are expressed through words derived from English. English-derived content words from the Sranan lexicon were grammaticalized to fulfill functional roles. For example, the English definite article: 'the' was not adopted in Sranan but two definite articles: $a$ (singular, from the demonstrative dati 'that') and: den (plural, from the personal pronoun den 'they') emerged in its place. Similarly, while the English indefinite article 'a' was not retained in Sranan, the numeral wan 'one' took on the role of an indefinite article. Moreover, some words that are clearly derived from English changed in meaning. For example, anu (< 'hand'), means both 'hand' and 'arm,' and futu ( $<$ 'foot') means both 'foot' and 'leg.' Semantic shifts such as these can be related to features of African languages such as Gbe that have only one word for what in English is expressed by either 'hand' or 'arm' or by either 'foot' or 'leg'. African influences are also responsible for the existence of a special category of words known as ideophones whose function is to intensify or specify the meaning of another word with which they occur in a fixed combination. For example, the ideophone fáán, used to intensify the meaning of the adjective weti 'white,' is probably from Gbe. An example is a weti so fáán 'he is so very white' (lit.: he white so IDEOPHONE). Phonology. In its phonology, Sranan shows a clear tendency towards an open syllable structure, which leads to the addition of paragogic vowels to English-derived words ending in a consonant; so 'wood' becomes $u d u$ and 'walk' becomes waka. Word-final nasals are velarized, an allophonic process which is not reflected in the spelling, for example $<$ Sranan $>$, which is pronounced [Sranang]. ${ }^{7}$

Morphology. There are four morphological processes in Sranan: conversion, compounding, suffixation, and reduplication. Conversion (also known as multifunctionality or zero-derivation) refers to the derivation of a word, e.g. a verb, from another word, such as a noun, without any overt change in form. For example, from the adjective $e b i$ 'heavy' both a noun $e b i$ 'weight' and a verb $e b i$ 'to weigh' have been derived. Compounding is quite common in Sranan, especially when both elements are nouns, as in man-pikin 'son' (lit.: 'man child') and uman-pikin 'daughter' (lit.: 'woman child'). One of the few cases of inflection is the use of the noun man 'man' as an agentive suffix as in siki-man 'sick person' (lit.: 'sick man')

7. Contrary to what is sometimes assumed, word stress is on the second syllable. 
and bere-man 'pregnant woman' (lit.: 'belly man'). That, in the latter two cases, man is used as an affix rather than as a noun appears from the fact that it is not restricted to male persons, as in the case of bere-man. Finally, reduplication, the creation of a new word by (partially) doubling an already existing word, is quite common. It can be used to create new words belonging to a different category than the base word, as appears from sisibi 'broom' (< sibi 'to sweep').

Syntax. Sranan is a strict SVO language with a strong tendency towards an isolating morphology. The latter appears from the fact that tense $(\mathrm{T})$, mood $(\mathrm{M})$ and aspect (A), as in many creoles, are expressed through independent particles, which are preposed to the verb, rather than through inflection. The TMA system is too complex to be discussed in detail here but it is vital to recognize that the distinction between stative verbs (e.g. 'love') and non-stative verbs (e.g. 'eat') is of paramount importance for the functioning of the system. For example, a bare stative verb indicates present while a bare non-stative verb indicates the past tense. For a non-stative verb to indicate the present tense, it has to be preceded by the particle $e$. Compare the following examples: mi lobi fisi 'I love fish;' mi nyan fisi 'I ate fish;' mi e nyan fisi 'I'm eating fish.' While the distinction between stative and non-stative verbs also plays a role in the use of the particle ben, other factors, such as discourse structure, come into play here as well (for detailed discussion, see Winford 2000, 2006). Like many other creoles, Sranan has two copula forms: de, for location, possession, and existence, and $a$, for nominal predication (although $d e$ is sometimes used here as well). Adjectival predicates are treated on a par with verbal predicates, i.e. they normally follow the subject without an overt copula being inserted in between, as in yu futu bigi 'your feet are big' (lit.: 'your feet big'). To express intensity or contrast, both verbal and adjectival predicates may be clefted, with a copy of the predicate left behind, as in na bigi yu futu bigi 'your feet are really big' (lit. 'is big your feet big'). Finally, a syntactic phenomenon seen in many creoles is the serial verb construction, where one subject is connected with two or more main verbs which together form one semantic unit, as in Rudy ben tyari den buku kon na ini a oso 'Rudy has brought the books into the house' (lit.: 'Rudy has carried the books come at in the house'). In this sentence, the meaning of what is expressed by the preposition 'to' in English, is expressed by the verb kon 'come,' which forms a series with the verb tyari 'carry.' Sranan has a wide variety of different types of serial verb constructions, for the expression of direction, location, instrumental, dative, benefactive, causative, comparative, completion, and complementation (see Sebba 1987). Since both predicate clefting and serial verbs are common features of many West African languages, it seems justified to interpret the occurrence of these constructions in Sranan as retentions from the African languages spoken by the slaves (cf. McWhorter 1992; Migge 1998). 
Verbal arts. The domain of language use known as the 'verbal arts' includes such activities as story telling and the performance of song and drama. Probably the best-known genre is the so-called Anansi tori, named after the trickster-spider Anansi, but including other types of folk-tales as well. Although the canonical context for telling Anansi tori is at funeral wakes, they may be told on other occasions as well. Both the content and the performative structure of these tales have their roots in West Africa. The basic pattern is the call-and-response structure known from many African-American oral genres (for example, gospel songs), with the story-teller being interrupted by members of the audience punctuating the story with remarks, songs or even entire 'sub-stories' of their own. The importance of songs, as an emotional outlet for the slaves, is apparent in early sources, where reference is made to a social activity known as pree 'play' in which dance and song play an important role. Various kinds of drama, that have their origins in the plantation period, were also important and these continue to be performed to the present day (for splendid collections of Sranan oral literature, see Herskovits \& Herskovits 1936 and Voorhoeve \& Lichtveld 1975). Finally, the tradition of verbal dueling, known from many African and African-American cultures (cf. 'playing the dozens' in the United States) and called fatu in Suriname, is still being practiced today (Adamson 2001).

Sranan text (story from De Drie 1985, adapted from Bruyn 2002)

Basya, granbasya, kari ala den basya a aksi den a taki basya great-basya call all the.PL basya 3sG ask 3PL 3sG say The Basya [overseer], the Chief Basya, called all the basyas together and asked them:

'We baya, un no weri anga na katibo dan?' well listen 1/2PL NEG weary with the.sG slavery then 'Now listen, aren't you fed up with being slaves?'

Den taki 'Ya basya.

3PL say yes basya

They answered 'Yes Basya.

Un wroko nomo, un n' e kisi pikin sukru 1/2PL work only 1/2PL NEG ASP get little sugar We only work, we don't even get some sugar

$f u$ un dringi wan pikin fayawatra te manten, for 1/2PL drink a little hot-water tea morning so we could drink some hot drink in the morning, 
soso malasi granmasra e gi unu.

just molasses great-master ASP give $1 / 2 \mathrm{PL}$

just molasses, that's what Granmasra [the plantation owner] gives us.

Un wroko so tranga, te un wani nyan wan fèrs sani, $1 / 2 \mathrm{PL}$ work so hard when $1 / 2 \mathrm{PL}$ want eat a fresh thing

We work so hard, but if we want to eat something fresh

na unsrefi mu go tapu kriki, ponsu kriki.

it-is $1 / 2$ PL-self must go close creek fish creek

we must close off the creek ourselves, and catch fish [with poisonous branch-

es] from the creek.

Dan toku den teki ala den buba fisi

then still 3PL take all the.PL scale fish

But then they take all the scaled fish

dan de gi un de nengrefisi.

then 3PL give 1/2PL the.PL negro-fish

and they give us the nengrefisi [unscaled fish].

$\mathrm{Na}$ dati wi abi fu nyan wan pikin tonton.'

it-is that 1PL have for eat a little tonton

In that way we have a little tonton [dish] to eat.'

Den taki 'We basya fa yu de vanplan $f u$ du dan?'

$3 \mathrm{PL}$ say well basya how 2SG COP intend for do then

They said, 'Well Basya, what are you intending to do then?'

A taki 'We mi de van plan

3sG say well 1 sG cop intending

He said, 'Well, I'm having this plan

$f u$ un ala slafu $f u$ a pernasi $f u$ un

for $1 / 2 \mathrm{PL}$ all slave of the.sG plantation of $1 / 2 \mathrm{PL}$

for us, for all the slaves of our plantation

taki anga den mansrafu un lowe go a busi.

that with the.PL man-slave $1 / 2 \mathrm{PL}$ run away go LOC forest

that together with the slaves, we escape into the forest.

Libi a pernasi. Libi granmasra anga en pernasi.

leave the.SG plantation leave great-master with 3sG plantation

Leave the plantation. Leave Granmasra and his plantation.

Un sa de tevrede dan?' 'Ya basya'.

$1 / 2 \mathrm{PL}$ FUT COP content then yes basya

Would you be content then?' 'Yes, Basya'. 
'Di suma habi wan pikin sowtu, dan a mu kibrikibri. when somebody have a little salt then 3sG must hide-hide 'If somebody has some salt, then he must hide it very securely / in different places.

Un mu e go a busi,

1/2PL must ASP go LOC forest

We have to go into the forest,

un mu diki boto meki un kan abi boto.

1/2PL must dig boat make 1/2PL can have boat we have to dig out boats so that we can make use of boats.

Bika te anga a sroyti fua yari un mu wroko, because until with the.sG closing of the.sG year $1 / 2 \mathrm{PL}$ must work gi skin, give body

Because until the end of the year, we must work, make an effort, meki granmasra anga driktoro no habi denki a un tapu.' make great-master with manager NEG have thought LOC 1/2PL top so that Granmasra and the manager won't get suspicious about us.'

Saramaccan. Saramaccan is the creole language spoken by the Saramaka ${ }^{8}$ people, who live along the Suriname River in central Surinam. The name 'Saramaka' derives from the fact that the first settlements of these people were located along the Saramacca River, in central Suriname. While the Saramaka later moved on to the Suriname River, the Matawai, who split off from the Saramaka during the peace negotiations of the 1760s, stayed in the Saramacca River area. The around 25,000 Saramaccans living today are the descendants of African slaves who, in the 17th and 18th centuries, escaped from the plantations to create their own communities in the Suriname rain forest. These run-away slaves and their descendants are often referred to as 'Maroons', a word derived from Spanish cimarron, meaning 'stray animal'. The creole languages spoken by Maroon communities may be referred to as 'Maroon creoles', to distinguish them from (former) 'plantation creoles', such as Sranan. While there are only very few Maroon Creoles in the rest of the world

8. I will distinguish the Saramaccan language from the people who speak it by using 'Saramaccan' as a glottonym and 'Saramaka' as an ethnonym. The same procedure will be followed with regard to 'Paramaccan' vs. 'Paramaka. In the case of 'Boni/Aluku' I will use 'Aluku' as a glottonym and 'Boni' as an ethnonym. For reasons to be explained later, I will use 'Ndyuka' to refer to both language and people, referring explicitly to either the language or the ethnic group as necessary. The same procedure will be followed for 'Kwinti' and 'Matawai'. 
(Palenquero in Colombia, Angolar in São Tomé), Suriname has two: apart from Western Maroon Creole, Eastern Maroon Creole (to be discussed below) also belongs in this category.

The main reason for distinguishing Maroon creoles as a separate category is the fact that, due to their relative isolation from outside influence, they are assumed to be more 'radical' than (former) plantation creoles, which have retained more intense contact with their lexifier (or other European) language(s). The term 'radicality' refers to the typological distance between a creole and its lexifier language. Although until now very little comparative research regarding the degree of radicality of different creoles has been done, it seems clear that the typological distance between, say, Saramaccan and its (main) lexifier, English, is larger than that between, say, Cape Verdean Creole and Portuguese. Therefore, Maroon creoles like Saramaccan are assumed to be structurally closer to the creoles as they were when first formed (some 300 years ago) than (former) plantation creoles like Sranan. Among the Maroon creoles, Saramaccan has acquired a somewhat special status, in that it is sometimes considered to be the most radical creole. Whether this is justified or not, it is certainly true that Saramaccan provides an excellent, perhaps unique, opportunity for creolists to gain a better understanding of the process of creolization.

While there are still significant gaps in the history of the Saramaka people and their language, the following is known. The origins of the Saramaka people and their language ultimately go back to the period before 1700, when slaves escaped from the plantations at a time when the plantation creole was being formed. However, this does not mean, as is often assumed, that the formation of the Saramaka people was largely completed by the early 18th century. Assuming that most of the runaway slaves had been on the plantations for some time before making their escape, they took at least some knowledge of the evolving plantation creole with them. This explains the structural similarities between Saramaccan and Sranan, both of which descend from the Suriname Plantation Creole (SPC) ( $c f$. Figure 1.2 above).

In spite of their structural similarities, there are also a number of important differences between the two languages. One of these is the proportion of Portuguesederived words, which is much larger in Saramaccan than it is in Sranan. In the former, one third of the basic vocabulary is derived from Portuguese, while this proportion is much smaller in Sranan. The remainder of the basic vocabulary is largely derived from English, while there are also a few basic vocabulary items taken from West African languages. The presence of Portuguese-based words is explained by the fact that many of the first Saramaka came from plantations on the Upper Suriname River (Wong 1938:299; Price 1976, 1983) which were owned by Sephardic Jews who spoke Portuguese. Although the presence of many Portuguese-derived words could lead one to view Saramaccan as a creole with two 
lexifier languages - English and Portuguese - the fact that most function words are from English suggests that the Portuguese element was added later. For this reason Saramaccan is generally categorized as an English-lexicon creole, albeit one with a strong Portuguese element.

A second difference between Saramaccan and Sranan is the fact that the former has a higher percentage of words derived from African languages. This is probably due to the fact that the Saramaka were much less open to influences from outside than the people who spoke Sranan. Although nothing is known about the specific African origins of the individual runaway slaves who formed the 'founder population' ( $c f$. Mufwene 2001) of the Saramaka people, we do have reliable information about the origins of the African slaves in general who were brought to Suriname in the 1675-1700 period (Arends 1995a:243). In this period, roughly half of all Suriname slaves came from an area where Bantu languages, such as Kikongo, were spoken, while the other half came from an area where Kwa languages, such as Gbe and Akan, were spoken. The connection between ethnolinguistic origin of the Suriname slaves and traces of Kikongo, Gbe and Akan found in the Suriname creoles is further highlighted by the fact that Saramaccan exhibits some rather marked phonological features, such as lexical tone and nasal and complex stops, which are characteristic of one or more of these three African language clusterss (see below).

As is the case for its sister language Sranan, the early stages of Saramaccan are well documented. In the case of Saramaccan, however, the early documentation is limited to a very short period, roughly $1780-1820$. This has to do with the fact that the Moravian Brethren, to whom we owe these early writings, more or less abandoned their missionary activities among the Saramaka in the early 19th century. Their writings, which together number well over 2,000 manuscript pages, consist mainly of religious texts, such as Bible translations, although some linguistic descriptive works, such as dictionaries, are included as well (see Arends 1995b for further information). Unfortunately, however, only a few of these documents have been made available for linguistic research (Arends \& Perl 1995).

Many of the major structural features of Saramaccan are also found in Sranan. We will now present and give examples of some features that differ between the two languages. (This section draws heavily on Bruyn 2002; see also Bakker, Smith \& Veenstra 1995.)

Lexicon. Some examples of Portuguese-derived basic vocabulary items are búka (< boca) 'mouth' and dá (< dar)'give'. In both cases, the equivalent word in Sranan is derived from English: mofo (< mouth) 'mouth' and gi (<give) 'give'. Some examples of African-derived words are katangá 'cramp' from Kikongo nkatangá, and aze 'magic' from Gbe àze. 
Phonology. Like many other languages in the world - but especially in West and Central West Africa - Saramaccan uses lexical tone. This means that syllables can have a high tone, a low tone, or an unspecified tone, which is either subject to tone-sandhi (assimilation) or realized as low. As a result, words that are otherwise completely identical can convey meanings that are entirely different by means of tonal pattern alone. An example is the pair ná nà, with the first having a high tone where the second has a low tone. Despite this (seemingly) small difference, the meaning of the two words is completely opposite: ná means 'be', while nà means 'be not'. Another feature of some African languages is the presence of nasal stops, such as $/ \mathrm{mb} /$ and $/ \mathrm{nd} /$, and complex stops, such as $/ \mathrm{kp} /$ and $/ \mathrm{gb} /$. These are also found in Saramaccan in words such as mbéti 'meat, animal' and kpéfa 'baby hood'. 9

Morphology. Apart from other functions, reduplication is used in Saramaccan - in contrast to Sranan and Ndyuka - to derive adjectives from verbs, e.g. nákináki 'beaten', derived from náki 'beat'. These reduplicated forms are used both attributively, as in dí nákináki miíi 'the beaten child', and predicatively, as in dí mií dè nákináki 'the child has been beaten (is in a beaten state)'. Saramaccan also differs from Sranan in that the agentive suffix -ma (cf.-man in Sranan) may follow an entire verb phrase, which may itself even contain a subordinate clause. This may result in quite complex agentive nouns, such as seti-u-kanda-ma 'precentor' (lit.: 'start-to-sing-agentive.suffix').

Syntax. Although at first sight Saramaccan seems to be very similar to Sranan in terms of syntax, it may be expected that more subtle differences will emerge once more comparative studies of the two languages are made. One difference although lexical rather than syntactic - worth mentioning here has to do with the Tense-Mood-Aspect system, namely the selection of the forms for the expression of tense and aspect: while Sranan uses ben and $e$ (probably from Eng. 'been' and 'there'), Saramaccan has selected $b i$ and $t a$ (perhaps from Portuguese vir 'turn' and estar ' $\mathrm{be}^{\text {' }}{ }^{10}$ ). Another difference dates from earlier stages of the two languages: while 18th-century Sranan used the verb taki 'say' to introduce object clauses of speech act verbs, such as 'ask', and mental state verbs, such as 'think', early Saramaccan used the complementizer $v a$.

Verbal arts. While the literature on the 'verbal arts' in Saramaccan often treats it together with Sranan (Herskovits \& Herskovits 1936; Voorhoeve \& Lichtveld 1975), there is one work (Price \& Price 1991) that is entirely devoted to Saramaccan.

9. Note that $/ \mathrm{mb} /$ etc. refers to phonemes, not combinations of phonemes. In other words, a word like mbéti 'meat, animal' consists of four phonemes, not five.

10. An alternative etymology of $t a$ is English 'stand'. 
Unfortunately, however, with the exception of a small fragment, their integral transcription of two story-telling sessions contains only the English translation, not the Saramaccan original.

Saramaccan text (folk-tale from Rountree and Glock 1982, adapted from Bruyn 2002)

[There is water hidden under a rock. All the birds are invited to break the rock, but none of them succeeds. Then the woodpecker shows up.]

Hen totómbotí táa we a ó-dú lúku tu then woodpecker say well 3sG IRR-do look too Then the woodpecker said that he would try too.

'Gaamá mi ó-gó náki lúku.' granman, 1SG IRR-go hit look

'Chief, I am going to try to hit it.'

Hen déé ótowan táki táa:

then the.PL other say saying

Then the others said:

'Ku ún-búka, $i$ lánga bákahédi $k u$ dí gaán taku fi-i de!?' with Q-beak 2sG long back-head with the big ugliness of-2sG there 'With what beak, you long back-of-the-head, with your great ugliness?'

'Úm-fá a dú ufố i sá boóko घ!n?'

Q-manner 3sG do before 2sG can break 3sG

'How are you going to break it?'

'U túu we...lúku dí bígi de! ku mi, wokó.'

$1 \mathrm{PL}$ all FOC look the.sG big(ness)there with 1sG black curassow

'All of us [have tried] ... look how big I, the curassow, am.'

Gbaniní táa: 'We lúku mi. Ún totómbotí?'

hawk say well look 1 sG Q woodpecker

The hawk said: 'Well, look at me [how big I am]. Which woodpecker [is going to try such a thing]?'

Hen totómbotí wáka te kó dóu. then woodpecker walk till come arrive Then the woodpecker went out there.

Hen a tjökố dí sitónu kookookoo.

then 3sG stab the.sG rock IDEO

Then he pecked at the rock: peck peck peck!

Hen a wáka gó seeká taámpu.

then 3sg walk go arrange stand

Then he went away and got himself ready. 
[The woodpecker finally succeeds in breaking the rock, and thus provides water for all the birds. However, since that time the woodpecker has not been able to stop pecking at things.]

Hen a táa án sá disá soní u náki mốön. then 3sg say 3sG-NEG can leave thing for knock more After that, he said that he can't stop knocking anymore.

Ndyuka. The language is named 'Ndyuka' after the name of the Djuka Creek (a tributary of the Marowijne River where part of the Ndyuka people settled in the eighteenth century after fleeing from the plantations. The alternative names Auka, Aukaans, Okanisi are derived from the name of a plantation (Auka) along the Suriname River, which was used as a topographical point of reference by the colonial authorities when dealing with the Ndyuka Maroons. The slaves involved in the Tempati Rebellion of 1757, who later joined the Ndyukas, were referred to as the 'vrije bosnegers van achter Auka' (the free Bush Negroes from behind Auka) (Hoogbergen 1990:82), 'behind Auka' referring to the Tempati River area where the rebellion took place (see map). Although the name 'Auka/Okanisi' is preferred by the speakers themselves for their language (as well as their ethnic group), we will use 'Ndyuka' in this book, as it has become the generally used designation among creolists.

Although it may be true that the origins of the Ndyuka Maroons ultimately go back to escaped slaves in the time of the attacks by the French under Cassard in 1712, this does not mean, as is often assumed (cf. Smith 2002), that this Maroon group was fully formed at the time. Van der Meiden (1987:78) refutes the generally accepted idea that the number of Maroons increased considerably as a result of Cassard's attack. This idea goes back to Herlein's (1718:93) claim that 'more than 700 or many more got lost in the bushes', but Van der Meiden notes that this 'is not mentioned in contemporary sources'. This leads Van der Meiden (p. 77) to conclude that, although 'in the historiographical literature a strong increase in marronage is mentioned as the most important result [of Cassard's attack, JA], this is probably an exaggeration'. In addition, as noted by the same author (p. 73), at the time of Cassard's attack no slaves had been brought to Suriname for over two years, something which is confirmed by the information given in Chapter 4 . Knowing that runaways were mainly newly-arrived slaves, the possibility of largescale marronage in 1712 is diminished even more. This means that the generally accepted scenario of the formation of the Ndyuka and of their language has to be thoroughly revised, in that the formation of Ndyuka extended until the late 18th century rather than being more or less complete by 1712. A major impetus to the establishment of the Ndyuka as a separate Maroon group was provided by the Tempati rebellion of 1757 when so many runaways joined the existing group that it doubled in size, from ca. 300 to ca. 600 people (Van den Bouwhuijsen et al. 1988). 
This scenario is adhered to by one of the experts on Suriname Maroon history, Wim Hoogbergen, who claims that in the 1730s the Ndyuka group was still in the process of being formed: 'Around 1730, groups of runaways started to form tribes in at least four different places in Surinam [...] The area southeast of the Commewijne River was inhabited by groups of Maroons who can be considered the antecedents of the Ndjuka tribe' (Hoogbergen 1990: 73). Although by that time the formation of Ndyuka as a separate creole was already on its way, it can be assumed that the relatively large number of newcomers joining around 1757 had a substantial influence on its further development.

The proportion of Portuguese-derived words in Ndyuka (between 5\% and $10 \%$; see Huttar 1989) is higher than it is in Sranan (below 5\%) but much lower than in Saramaccan (over 35\%). This is related to the fact that the founders of the Ndyuka Maroons largely came from plantations in the Commewijne and Cottica River areas, where there were more speakers of Portuguese than in and around Paramaribo but less than in the Suriname River area, the Saramakas' region of origin. More importantly, however, part of the first Ndyukas came from the Suriname River, an area with many plantations owned by Sephardic Jews (Wong 1938: 299). This explains the occurrence of Sephardic-related Ndyuka clan names such as $\mathrm{La}$ Parra, Castillie, and Djoe (a Dutch influenced spelling of 'Dju' i.e. 'Jew') (Wong 1938: 311). It should also be remembered that Ndyuka was formed several decades later than Saramaccan, at a time when the Suriname Plantation Creole, on which it is based, was already developing into Sranan. As a descendent of the 18th-century Suriname Plantation Creole and having developed in relative isolation Ndyuka has preserved several features of Early Sranan which have been lost in Modern Sranan. An example of this is the occurrence of an epenthetic vowel in a word like sígisi 'six' where Early Sranan had sikisi but Modern Sranan has siksi.

The genetic relationships between the different member languages of the EAStern MARoon Creole group are not entirely clear. Not only is very little known of the history of the Kwinti, but with the exception of Ndyuka, these languages have hardly been studied at all. In fact, there are virtually no early language data available for any of the EAstern MAroon Creoles and so it is very difficult to reconstruct the genealogy of this group. It is important to realize, however, that the similarities between Aluku and Paramaccan on the one hand and Ndyuka on the other cannot be explained by these being divergences from early Ndyuka (as is the case for Matawai with regard to Saramaccan). The Boni and Paramaka groups were not formed until about 1770 and $1800,{ }^{11}$ respectively (Hoogbergen 1992). A more likely explanation is that the founders of the Boni and Paramaka

11. Wong (1938:300) places the formative period of the Paramaka ethnic group even later, namely in the second half of the 19th century. 
groups largely came from the same plantation areas as the Ndyuka and there was always a great deal of contact between these groups. Schaafsma (1967:257) notes that after the end of the second Boni Maroon War in 1793 the Boni were placed 'under the supervision of the Ndyuka', while Wong (1938:306) writes that the Boni were 'slaves of the Ndyuka' until as late as 1860. In the case of Kwinti, however, such contact cannot be adduced since they always lived completely apart from the Ndyuka, Boni, and Paramaka. Although on purely linguistic grounds the Kwinti language belongs to the EAstern Maroon Creoles, the historical reasons for this have not yet been traced.

Before discussing some of the structural properties of Ndyuka, it may be useful to note that, although Ndyuka has received less scholarly attention than Sranan or Saramaccan, it is the only Surinamese creole for which an elaborate and reliable reference grammar is available, Huttar \& Huttar (1994). On the other hand, the Ndyuka verbal arts have not received much scholarly attention until now and are therefore not included in the sketch presented below.

Phonology. Being a Maroon creole, Ndyuka may be expected to be a little more 'radical' than Sranan, and likewise, because of its later formation, perhaps somewhat less radical than Saramaccan. Several features point in this direction. Like Saramaccan, Ndyuka tends to avoid certain consonant clusters, which are permitted in Sranan, e.g. sitonu vs ston 'stone'. Another difference with Sranan is that, while in the latter English intervocalic liquids generally appear as $/ r /$, as in bere < Eng. 'belly', in Ndyuka they disappear between identical vowels, as in bée (in other cases they become /1/). Ndyuka also resembles Saramaccan in being a tone language, with three tones: high, low, and unspecified, the latter of which is either subject to tone-sandhi or realized as low. As in Saramaccan, in words derived from European languages the high tone corresponds to the main stress in the source word. Tone may distinguish otherwise similar words, for example búku 'book' vs. bukú 'mould'. Another African feature shared with Saramaccan is the occurrence of nasal stops, such as $/ \mathrm{mb} /$, and of complex stops, such as $/ \mathrm{kp} /$. While both of these are alien to European languages they do occur in the Gbe languages that were spoken by many of those who were brought to Suriname in the early colonial period. One special feature of Ndyuka is that it has its own (syllabic) script, which was developed by a Ndyuka, named Afaka, in the 1920s, but this is not widely used (see Dubelaar, Pakosie \& Hoogbergen 1999) for further information).

Lexicon. Some words are derived from Amerindian and African languages, such as manáli cassava sifter' < Lokono manarhi; pingo 'white-lipped peccary' < Kari'na piii go; nzaú 'elephant' < Kikongo nzawu; and gá 'arrow' < Ewe ga. 
Morphology. Multifunctionality is quite common, for example the same word may function both as a verb $(\mathrm{V})$ and as a noun $(\mathrm{N})$, even when this was not the case in the source word, as in boó 'breathe, blow' (V), 'breath' $(\mathrm{N})<$ Eng. 'blow' $(\mathrm{V})$. Reduplication of nouns may be used to express variety or separateness, as in kulukulú 'in different groups' (cf. kulú 'group'). The Head-Modifier order in a compound such as watáa-mófu (lit.: water-mouth) 'saliva', which is unexpected in view of Ndyuka's general word order pattern, may be a consequence of the calquing of a model in some African language(s). Particularly productive are word-forms containing items such as those expressing 'person', 'thing', 'time', 'place', or 'manner', for example, líbi-sama (lit.: live-person) 'human being'. Because the last part in forms such as these tend to lose their independent status they may be difficult to distinguish from derivation.

Syntax. One Ndyuka feature shared with both Sranan and Saramaccan is the use of a complex locative prepositional phrase - not attested in any other creole - with the following structure: na - NP - LOCATIVE ELEMENT. Compare for example the phrase a den deé uwí tápu 'on the dry leaves' (lit.: at the dry leaves top), where the locative element (tapu < Eng. 'top') can itself also be a noun, meaning 'top'. Although the construction resembles a juxtaposed possessive construction, the locative element does not appear as a noun: the meaning of the prepositional phrase is 'on the dry leaves' rather than 'on the top of the dry leaves.' There is substantial evidence that the construction is modelled on a similar pattern in the Gbe languages (Bruyn 1995a, 1996; Migge 1999).

Ndyuka text (story from Huttar and Huttar 1994, adapted from Bruyn 2002)

Ne wán déi, somen sama be de a sitaáti then one day many person ANT COP LOC street Then one day there were many people in the street

e súku wági fu gó a ósu.

CNT look for cart for go LOC house

looking for buses to go home.

Ne mi de a íni mi wínkii e séli lóti. then 1sG COP LOC inside 1sG store CNT sell roti And I was in my store selling rotis.

Ne mi yée te a ípi sama e báli a then 1sG hear until the.sG crowd person CNT call LOC dóosé fu a wínkii outside for the.sG store Then I heard lots of people yelling outside the store. 


\section{Biká wan sani be e pasá a dóosé. because a thing ANT CNT pass LOC outside Because something had been happening outside.}

Ne mi lón gó lúku. Mi sí fó sikóutu e wípi den. then 1 SG run go look 1 sG see four police CNT whip 3PL Then I ran to look. I saw four policemen whipping them.

\subsection{A note on the reliability of early texts}

The relative under-representation of native speaker texts in the corpus constitutes a problem that deserves special attention. Of the Sranan sources used for this book, less than half (Schumann, Cesaari, Focke, King, Albitrouw, Kraag, Helstone, Herskovits \& Herskovits, Koenders, and Bruma) were produced by, or with the help of, native speakers. If we look at the amount of data provided by these 'native' sources the picture is even worse since they often contain fewer data than 'non-native' sources. Unfortunately, the problem cannot be easily remedied. For example, a meticulous investigation of the Sranan material in the State Archives at Utrecht (the largest collection available) did not yield a single native-written source pre-dating the middle of the 19th century, - when there was a sudden outburst of writing, starting with work by Johannes King. Some years ago, however, the author discovered a number of letters and other documentary writings in Sranan dating from the early 19th century that appear to have been written by native speakers ( $c f$. Arends 1995b). Although this material has been transcribed, it has as yet not been analyzed. Therefore, unfortunately, it could not be incorporated in this study. As far as Saramaccan is concerned, we are in a somewhat better position since one of the two sources we have used (the Maroon letters) was written by native speakers.

The fact that our data had to be 'enriched' with non-native sources is not as bad as it seems, since some, especially those of Moravian origin, are of high quality. The Moravian Brethren have a reputation as knowledgeable and accurate observers of language, although a certain normative and Europeanizing influence cannot be denied. This tendency, however, is largely confined to orthography, phonetics and lexicon, and affects syntax to a much lesser degree (Voorhoeve 1971). In this context not only Schumann's dictionaries but also the translations of Acts, the Grammatik and Wullschlägel's dictionary should be highly valued as reliable sources for earlier stages of Sranan and Saramaccan.

For background information on the authors of the texts, see Chapter 7. 


\subsection{Diachronic studies of the Suriname creoles: The state of the art ${ }^{12}$}

As mentioned earlier, the Suriname creoles - especially Sranan and Saramaccan are rather special in that they are exceptionally well documented in the earlier stages of their development. This explains why their diachrony has been investigated in much more detail than any other creole. The historical interest in the Suriname creoles goes back to Hugo Schuchardt, who - in his well-known Die Sprache der Saramakkaneger in Surinam (1914) - published several early sources in Saramaccan, the most important of which was Schumann's (1778) manuscript Saramaccan-German dictionary. In his introduction to that volume, Schuchardt also included an elaborate discussion of some early sources in Saramaccan's sister language - Sranan, such as Van Dyk (ca. 1765) and Weygandt (1798). The historical study of the Suriname creoles was continued by Jan Voorhoeve ( $c f$. Lichtveld \& Voorhoeve 1980 [1958]; Voorhoeve 1961; Voorhoeve \& Donicie 1963; Voorhoeve \& Lichtveld 1975), who laid the foundations for the diachronic investigations of Sranan and Saramaccan by scholars such as Kramp (1983), Smith (1987a), Arends (1989), Plag (1993), and Bruyn (1995a). ${ }^{13}$

Let us briefly summarize what the historical investigation of Sranan and Saramaccan has resulted in thus far. Firstly, a number of new editions of early printed and manuscript texts have been made available. These are listed in Table 1.3.

One of the most recent additions to the body of early Sranan sources is an edited version of the original Sranan manuscript version of the Saramaka Peace Treaty of 1762 by Hoogbergen \& Polimé (2000). However, this item (edited by two anthropologists) is not included in our list as the transcription contains a disturbing number of errors. An improved transcription, based on the original manuscript (stored in the State Archive in The Hague), is included in Chapter 6 of this book.

12. This section is largely based on Arends (2002a).

13. During the last two decades, the historical approach in creole linguistics has been extended to English-lexicon creoles, such as those of Guyana (Rickford 1987), Jamaica (Lalla \& D'Costa 1990), Trinidad (Winer 1993), Barbados (Rickford \& Handler 1994; Fields 1995), and St Kitts (Baker \& Bruyn1999), to French-lexicon creoles, such as those of the Indian Ocean (Chaudenson 1981), Louisiana (Neumann-Holzschuh 1987), and the Lesser Antilles (G. Hazaël-Massieux 1996) as well as to Negerhollands (e.g. Van Rossem \& Van der Voort 1996). 
Table 1.3 Published editions of early Sranan and Saramaccan texts

\begin{tabular}{lll}
\hline & Text & Edition(s) \\
\hline Sranan & Court Records (1667-1767) & Van den Berg (2000) \\
& Herlein (1718) & $\begin{array}{l}\text { Schuchardt (1914); Voorhoeve \& Lichtveld } \\
(1975) ; \text { Arends \& Perl (1995) }\end{array}$ \\
& Van Dyk (ca 1765) & Arends \& Perl (1995); Lichtveld \& Voorhoeve \\
& & $(1980)$ \\
& Nepveu (1765) & Voorhoeve \& Lichtveld (1975) \\
& Nepveu (1770) & Arends \& Perl (1995) \\
Schumann (1783) & Kramp (1983) \\
Schumann (1778) & Schuchardt (1914) \\
& Riemer (ca 1780) & Arends \& Perl (1995) \\
& Wietz (1793) & Schuchardt (1914) \\
Alabi \& Grego (1790-1818) & Arends \& Perl (1995) \\
\hline
\end{tabular}

Secondly, creolists at the University of Amsterdam ${ }^{14}$ (Lilian Adamson, Jacques Arends, Adrienne Bruyn, and assistants) are compiling a digitalized corpus of early Sranan and Saramaccan texts. This corpus contains not only well-known Sranan sources such as Van Dyk (ca. 1765) and Schumann (1783), but also lesser-known manuscripts such as Schumann's (1781) Gospel Harmony. Apart from these and other Sranan sources, most of the early Saramaccan manuscripts stored in the Moravian Archives in Paramaribo, Herrnhut, and Utrecht (over 2000 pages; see Arends 1995b), will also be part of the corpus. On completion, its total size is estimated to be some 500,000 words. Parts of it have already been used for diachronic research ( $c f$. Bruyn 1995a; Arends 1998). One of the advantages of the digitalization of texts, of course, is that it enables the use of search procedures allowing the (semi) automatic extraction of data for (quantitative) analysis. It may be useful to list the sources that have been included so far (situation as of $1 / 1 / 02){ }^{15}$

14. [Editor's note. The Suriname Creole Archive (SUCA) is presently a joint project of Radboud University Nijmegen, University of Amsterdam and the Max Planck Institute Nijmegen for digitally collecting, cataloguing and preserving historical texts in Sranan and Saramaccan for research.]

15. Note that in some cases these transcriptions still have to be collated with the original before they may be considered definitive. 
Table 1.4 Contents of the digitalized corpus of early Sranan and Saramaccan texts

\begin{tabular}{ll}
\hline Sranan & Saramaccan \\
\hline Court Records (1667-1767) & Schumann (1779) \\
Herlein (1718) & Randt (1779) \\
Saramaka Peace Treaty (1762) & Anonymous (1789-1806) \\
Van Dyk ca. (1765) & Alabi \& Grego (1790-1818) \\
Nepveu (1770) & Wietz (ca. 1792) \\
Schumann (1781) & Wietz (1793) \\
Schumann (1783) & Wietz (ca 1795) \\
Stedman (1790/1796) & \\
Weygandt (1798) & \\
Anonymous (ca. 1825) & \\
Focke (1855) & \\
\hline
\end{tabular}

Thirdly, the availability of early textual material in Sranan and Saramaccan has led to a number of diachronic studies on these languages being produced by creolists over the last two decades. A selected list of publications from this period is presented in Table 1.5. ${ }^{16}$

Table 1.5 A survey of diachronic studies on Sranan and Saramaccan (1982-2002)

\begin{tabular}{|c|c|c|c|}
\hline \multirow[t]{9}{*}{ Sranan } & \multicolumn{2}{|l|}{ phonology } & $\begin{array}{l}\text { Smith (1987a); Smith (2003); Plag \& } \\
\text { Uffmann (2000); Alber \& Plag (2001) }\end{array}$ \\
\hline & \multirow[t]{7}{*}{ morphosyntax } & miscellaneous & Voorhoeve \& Kramp (1982), Kramp (1983) \\
\hline & & $\begin{array}{l}\text { copula, comparative, } \\
\text { clefting }\end{array}$ & Arends $(1986,1987,1989)$ \\
\hline & & question words & Bruyn (1993a) \\
\hline & & $\begin{array}{l}\text { sentential } \\
\text { complementation }\end{array}$ & Plag $(1993,1995)$ \\
\hline & & $\begin{array}{l}\text { determiner system } \\
\text { and relativization }\end{array}$ & Bruyn (1995a, 1995b, 1997) \\
\hline & & complex prepositions & Bruyn (1995a, 1996) \\
\hline & & compounds & $\begin{array}{l}\text { Alber \& Plag (2001), Braun (2001), Braun } \\
\text { \& Plag (2003), Van den Berg (2003) }\end{array}$ \\
\hline & lexicon & & Koefoed \& Tarenskeen (1996) \\
\hline \multirow[t]{5}{*}{ Saramaccan } & phonology & & Smith (1987a), Aceto (1996) \\
\hline & morphosyntax & focus marking & Smith (1996) \\
\hline & & complementation & Byrne (1987), Arends (1998) \\
\hline & & negation & McWhorter (1996) \\
\hline & $\begin{array}{l}\text { lexicon (incl. } \\
\text { Djutongo) }\end{array}$ & & Smith (1987a, 1999), Aceto (1997) \\
\hline
\end{tabular}

16. Publications in which the diachronic/historical aspect is only of cursory importance have been excluded from this list. 
As can be seen from this table, relatively little diachronic work has been done on lexical issues. This is especially surprising in view of the fact that excellent early lexicographic sources are available, such as Schumann $(1778,1783)$, Focke (1855), and Wullschlägel (1856). This makes the diachronic study of the Sranan and Saramaccan lexicons both an opportune and potentially fruitful area of research. Another striking feature is the recent upsurge of interest in compounding in early Sranan. Hopefully, this marks the beginning of a more sustained attention to diachronic morphology in this and other creoles.

Fourthly, a number of extralinguistic (i.e. sociohistorical and demographic) aspects of the formation of the Suriname creoles have been investigated (Arends 1995a, 1999; 2001; Ladhams 1999; Smith 1999). The primary motivation for this line of research was the need to identify, on independent (i.e. non-linguistic) grounds, the languages that were present during the formation of these creoles. While early sociohistorical and demographic work (e.g. Price 1976) was rather sketchy, more recently (Arends 1995a) it has become more detailed and precise on account of the major advances in the historiography of slavery (especially Postma 1990).

Although we will not provide an exhaustive review of the diachronic studies listed in Table 1.5, we will signal some of the more noteworthy trends. In many of these works, substantial evidence has been adduced to demonstrate the influence of particular West African languages in the structure and lexicon of the Suriname creoles. What is more, certain languages are mentioned again and again as being most influential in this regard, namely Gbe, Akan, and Kikongo. As will be shown in Chapter 4, these are precisely the languages that were numerically by far the most important during the period in which the Suriname creoles were formed. It should be noted, however, that other researchers (e.g. Smith 1987; Byrne 1988) have applied diachronic findings to support the argument for the role of universals in creole genesis.

As far as theoretical aspects of creole genesis are concerned, different studies have yielded different results. While Smith's (1987) detailed investigation of phonological developments has been taken to support an abrupt scenario of creole formation, as espoused in Bickerton's Bioprogram Theory (cf. Bickerton 1981, 1984, 1988), Arends' work on syntactic developments has been interpreted as supporting a gradualist model of creolization (Arends 1986, 1989, 1993a). And while Plag's $(1993,1995)$ diachronic study of complementation has lent further support to the gradual view, the results of Bruyn's (1995a) investigation of relativization and determiners is less clear-cut with regard to the rate at which creolization takes place. In addition, Bruyn's work has adduced evidence for the role of grammaticalization (although not necessarily in its traditional form) in the formation of creoles. However, the single most important conclusion that can be drawn when reviewing this body of work is that there is a growing tendency to approach the historical 
investigation of creolization in a thoroughly empirical way by using large corpora of older texts, but at the same time applying relevant findings from historical linguistics, contact linguistics, and linguistic theory.

This brief survey shows that, although important information is still missing, the time is ripe for the synthesis we are presenting in this book of data that has been collected up to now, in order to get a better understanding of the genesis and development of the Suriname creoles. There are several reasons why this is so. First of all, these creoles have occupied a prominent place in discussions about creole genesis over the last few decades. As these discussions have been largely theoretical, with little regard for diachronic evidence, it is time that the historical side of the story is told. Secondly, and perhaps even more importantly, the people of Suriname are in need of a book that provides them with a history of their native language. As is commonly known, creole languages are still stigmatized and, because of indoctrination by the former colonizing power, even native speakers themselves sometimes regard their own language with disdain, claiming that it has no grammar, that it is not a real language, et cetera. Hopefully, this book will help to eradicate these misconceptions and contribute to a better appreciation of these languages, on the part of native speakers and others alike.

As this book aims to be a synthetic work, it is clear that it could not have been written without the work of other Surinamists, especially those mentioned in Table 1.5 above. At the same time, although aiming at synthesis, the book clearly bears the stamp of its author, e.g. in its emphasis on the (relatively) gradual nature of Suriname creole formation, the role of language contact, and the importance of external historical circumstances. Since this latter feature makes this work somewhat different from the usual case study in linguistic change, a few words have to be said about the special character of this book.

In a way, this is not one but two books because it is made up of two intertwined threads of history: one purely linguistic, the other more broadly historical. The first discusses the development of the Suriname creoles, i.e. their formation as language systems and their development through time. Since only a small part of these languages' structural systems can be taken into account in this book, the different domains of language are not dealt with equally. So, while syntax is treated in depth, other areas such as phonology, morphology, and lexicon are only discussed summarily. This linguistic thread is closely intertwined with a historical thread: the history of colonial Suriname and its people, which is crucial to a proper understanding of the linguistic history. However, since many aspects of the history of Suriname are still unclear, we are inevitably confronted with gaps, which means that the fabric of this book is still very much unfinished in terms of both threads. It is hoped that by doing this we will be able to provide the foundations of a truly integral history of the creole languages of Suriname. 


\subsection{Creole genesis}

Although the focus of this book is clearly more empirical than theoretical, the fact that it is about the formation of the Suriname creoles makes it inevitable that, at times, we must engage in theoretical discussions about creole genesis. Therefore, we should say a few words about the most relevant theories and hypotheses in this field, although this will not be a complete overview. (For a more detailed approach, see Chapters 8-11 in Arends, Muysken \& Smith 1995).

The central question that needs to be addressed by any theory of creole genesis can be formulated as follows: 'How can the emergence of a new language out of the contact between other pre-existing languages be explained'? One could say that any theory aiming to provide an answer to this question should take into account at least three dimensions of the process of creole genesis. Adopting the terminology of Aristotle's dramatic unities, these dimensions could be formulated as those of Time: When did it happen?, Place: Where did it happen? and Action: How did it happen? Each of these will now be discussed in more detail.

Time. With regard to the dimension of Time at least the following questions seem to be relevant:

When? Apart from establishing the time frame itself, purely in terms of chronolo$\mathrm{gy}$, it is also important to understand the historical context in which creolization took place. Although strong opinions have been put forward about the time frame within which specific creoles were supposedly formed, these opinions are often based on little or even erroneous historical evidence. It is one of the specific aims of this book to provide a better empirical basis for establishing the time of formation for each of the major creoles of Suriname. In addition, we will also show the effect of certain aspects of the historical context - social, cultural, political, economic, religious, military, geographic - on creole genesis.

How fast? The question of the rate at which creolization takes place involves a number of important issues, such as the respective roles of children and adults in creolization particularly in terms of first and second language acquisition. Although the idea of single generation creolization was quite popular in the 1980s ( $c f$. Bickerton 1981), most creolists nowadays accept that creole formation is a gradual process (Chaudenson 1979; Arends 1986, 1989; Singler 1986) that spans several generations. This book will produce both diachronic-linguistic and historical-demographic evidence to demonstrate the gradual nature of creole formation. ${ }^{17}$

17. The term 'gradual' is somewhat misleading, since the construction of a system as complex as a natural language within the space of less than a hundred years is, of course, actually very fast. 
In what sequence? The traditional idea that every creole is preceded by a pidgin stage (Hall 1966) is no longer universally accepted, not only because a pidgin stage has not been identified for most creoles but also because the boundaries between pidgin and creole are blurred (e.g. Baker 1995). Although some evidence has been found to support a pidgin stage for the Suriname creoles (see Chapter 3), it is not sufficiently convincing to allow us to posit a pidgin-to-creole scenario. Another, perhaps more interesting, aspect of sequentiality, and one which has received far less attention, is the question of the order in which the construction of a creole takes place. Since creolization is a very complex process that unfolds over time, some parts of the system are bound to be in place before others. Apart from the issue of chronological order, this poses the questions of why some things come before others and how they build on each other. This issue will be dealt with in several places elsewhere in this book).

Place. With regard to the issue of where creolization took place, the following parameters are relevant:

Rural vs. urban environment? Rural environments - plantations, mines, Maroon communities - are relatively independent and isolated whereas urban environments - especially port towns - are far more dependent on and in touch with the outside world.

Slavery vs. marronage? Although there have been investigations as to whether Maroon communities were isolated in comparison to plantations, the question of whether these different environments had linguistic consequences has hardly been asked. Although this book will not provide any definitive answers in this regard, the fact that it deals with Sranan and Saramaccan, one a plantation creole and the other a Maroon creole, may help to shed some light on the issue.

Endogeneous vs. exogeneous environment? 'Endogeneous' and 'exogeneous' refer to whether or not the formation of a creole took place in the natural habitat of the substrate languages ${ }^{18}$ ( $c f$. Chaudenson 1992). For example, the creole of GuineaBissau, formed in an environment where the substrate languages continued to be spoken, is an endogeneous creole while the Suriname creoles, cut off from contact with West and West Central Africa, are exogeneous. Although the Suriname creoles belong to the group of exogeneous creoles in that their formation took place outside of Africa, this does not mean that substrate interference is not possible. The frequently made claim that slaves were forced to abandon their native languages because of the linguistic diversity assumed to obtain in most colonies

18. The 'substrate languages' are the African languages originally spoken by the slaves, while the 'superstrate language' is the language of the colonial power. In the case of Suriname, the situation is a little more complex as the original superstrate, English, was replaced by Dutch and, for part of the colony, Portuguese. 
is unsubstantiated. At the same time, there is substantial evidence that African languages remained in use into the 19th century.

Action. Whereas the dimensions of Time and Place have received relatively little attention until now, the question as to which processes are responsible for the outcome of creole formation has been widely discussed. Many proposals have been made regarding the question as to what is, or what are the central mechanism(s) in creolization. The most influential of these are listed here by the name of what is assumed to be the central process followed by the names of their proponents:

- Substrate influence (Alleyne 1980; Boretzky 1983)

- Superstrate influence (Chaudenson 1992)

- Universal Grammar / L1 acquisition (Bickerton 1981)

- Relexification / L2 acquisition (Lefebvre 1998)

- Semantic Transparency (Naro 1978; Seuren \& Wekker 1986)

While all of these, in one way or another, have been presented as theories of creole genesis, it is striking to find that they are concerned with the product of creolization rather than with the process itself. The underlying assumption seems to be that the genesis of creole languages may be explained by a theory that accounts for (certain aspects of) their structure. Although some of the other proposals that have been made, such as Baker's (2000) constructivist theory, are more sensitive to the process aspect of creole formation, we cannot escape the conclusion that, after several decades of research into creole genesis, a true theory of creole formation does not exist. Although this book does not provide such a theory either, it explicitly aims to contribute to the empirical foundations of such a theory, one that is, moreover, historically realistic. This entails a number of things. First of all, of course, the theory must agree with the historical facts. Obvious as it may seem, this is not a common feature in theories of genesis. Secondly, creole formation is conceptualized here as a thoroughly historical process, a process that unfolds over time. One aspect of such a historical view is to see creole formation as an incremental process, a process in which each following stage builds on the previous one ( $c f$. the issue of sequentiality discussed above). This may be helpful in 'deconstructing' what, until now, is often viewed as a monolithic process into its component parts (Arends 2002a). Thirdly, in the historical approach, creole formation is seen as a process of language contact and language change. This means that the theory should be in agreement with what is known from the study of language change and language contact in other areas besides creoles. What this book does is to look at creole formation from a historical angle in the hope that this will increase our understanding of creolization both as a linguistic and as a historical process. 


\section{The 'prehistory' of the Suriname creoles}

In this chapter we will discuss the 'prehistory' of the Suriname creoles, not in the sense of the time prior to the first written attestations (ca 1690 in the case of the Suriname creoles), but to refer to the period before the colonization by the English in 1651 . We use the term 'prehistory' to stress the fact that, although this period is usually entirely neglected by creolists, it may be of crucial importance for the formation of the Suriname creoles. Although the year 1651 is widely taken to be the starting date of the colonization of Suriname, this does not mean there were no European settlements before that. To the contrary, as we will show below, a substantial number of settlements had existed prior to the arrival of the English in 1651. This is important because the year 1651, on the basis of the alleged starting date of colonization, has been widely accepted as the terminus a quo of creole formation in Suriname (cf. Voorhoeve 1975; Bickerton 1981; Smith 1987). The presence of substantial numbers of English and other Europeans, perhaps accompanied by African and/or Amerindian slaves, in the first half of the seventeenth century suggests that the formation of the Suriname creoles may well go back to before 1651. Since in the relevant period, Suriname was part of a larger area known as 'Guyana' (the coastal area between the Orinoco and Amazon Rivers), it would be rather artificial to restrict our survey of early settlements to the borders of the present-day republic of that name. Therefore, we will include the parts of 'Guyana' to the east (French Guiana) and to the west (Guyana) of Suriname in our discussion.

Since Creolization does not take place in isolation every single time it occurs, the formation of the Suriname creoles may in fact go back in time even further than the first half of the seventeenth century. Although little is known about the communicative practices that were in use between Europeans and 'others' in the earlier stages of European expansion, there is some reason to suspect that these earlier practices, whether in the form of a pidgin or a creole or something else, may have left some traces in the creoles of Suriname. It is for that reason that we will begin this chapter by giving a brief survey of the history of the European colonial expansion from its beginning (around 1430) until the moment the actual settlement of Suriname began (around 1600), focusing on its linguistically most relevant features. 


\subsection{Early contacts between European and non-European languages (1450-1600)}

Although the history of the creole languages of Suriname does not go back more than three or four hundred years, that does not mean it can easily be traced. In fact, the story of the formation of these languages is extremely complex. To a large extent this is due to the complexity of the socio-historical context in which these languages arose and developed. Like many other creole languages, the Suriname creoles are a result of the contacts between cultures and languages that was a by-product of European colonialism. These contacts go back to the early 15th century, when the Portuguese began their exploration of the Atlantic area, bringing European languages into contact with languages spoken along the coast of Africa. Although, due to lack of documents, it is not clear whether any pidgins or creoles emerged from these early encounters between Africans and Europeans, it seems justifiable to say that the seeds of the 'colonial' pidgins and creoles (the pidgins and creoles that arose in the context of European colonialism) that arose later, both in Africa and elsewhere, were planted then and there.

While this book is about the genesis and development of the creoles of Suriname, in particular Sranan and Saramaccan, it may be useful to go back in time a little, to the period before they came into existence. Rather than having emerged in isolation the formation of these languages is probably related - in ways not entirely clear - to interethnic communication patterns that were in use at the time, going back to the beginning of the European expansion in the early 15th century. Seen from this perspective, the history of the Suriname creoles does not begin in 1651 or 1600, but even earlier. Although an exact date cannot be given, one could take the year 1530, when the first attempts at settlement in the Guyana area were made, as a point of reference.

On a more global scale, there may even be a link between the Suriname creoles and the communication patterns that had come into use in the context of the European expansion in other parts of the world, especially West Africa. When the English and the Dutch began to participate in colonial activities in the late 16th century, the Portuguese had already been doing this for more than 150 years. And although the latter did not manage to get more than one foot in the door to the New World, their only American colony, Brazil, served as a model for the rest of 'Plantation America'. It was the first New World colony to develop the form of plantation agriculture involving slave labor which turned out to be an important motor for the development of creole languages. Although the question whether this led to the formation of a creole in Brazil itself has not been solved, the important thing is to realize that by the time the formation of the colonial creoles began, whether in Suriname or elsewhere, a tradition of interethnic communication had 
already existed for more than 150 years, not only in the Atlantic region but in the Indian Ocean as well.

However, since it is the Atlantic region which formed the context for the formation of the Suriname creoles, we will focus on that area. Although Suriname is located on the western shore of the Atlantic, the eastern Atlantic is also relevant to the prehistory of its creole languages. Apart from the fact that some slaves may have picked up some Portuguese in West Africa, the Europeans who arrived there around 1600 adopted for their communication with Africans the Portuguesebased lingua franca that had been used there for many decades. Although many historical sources refer to the type of Portuguese used between Europeans and Africans as "corrupted Portuguese" (see e.g. Arends 1999), this does not necessarily mean that a pidgin or creole language was involved. In fact, the direct evidence in terms of textual documentation - is too scant (but $c f$. Naro 1978; Perl 1990; Ladhams 2006) to allow such a conclusion. At the same time, the virtual absence of textual evidence for the existence of a West African Portuguese Pidgin/Creole does not entail that it did not exist. It may simply have gone unnoticed or the relevant documents may not have been discovered. We do know, however, that early on in their exploration of Africa, the Portuguese developed a practice of capturing Africans who were taken to Portugal to be trained as interpreters (Hein 1993). For some time, the use of interpreters may have preempted the need for a "medium of inter-ethnic communication" (Baker 1990) between Africans and Europeans and this may have delayed the development of a pidgin or creole in West Africa.

Nevertheless, the few records that have survived clearly show that some form of restructured Portuguese had begun to be used in contacts between Portuguese and Africans at least as early as the late 17th century. This appears from both linguistic and meta-linguistic evidence, some of which will be presented here. An informative source in this regard is Jean Barbot's (1732) travel account, based on two trips to West Africa made in 1678 and $1679 .{ }^{1}$ Referring to several places along the West African coast, Barbot makes a number of interesting observations regarding the language used between Europeans and Africans, such as the following: "Some of the Blacks here speak a little Portuguese, or Lingua Franca", ${ }^{2}$ and: "For many of the coast Blacks speak a little English or Dutch, and for the most part speak to us in a sort of Lingua Franca, or broken Portuguese and French" (Barbot 1732: 136, 249). A similar observation is made by La Courbe, who traveled to West Africa in 1685:

1. A new edition of Barbot's account, with very informative introduction and annotations, can be found in Hair et al. (1992).

2. The question of how the terms Lingua Franca and langue franque in this and other quotations should be interpreted, will not be discussed here (but see Arends 1999). 
Il y a parmi eux de certains negres et mulastres ${ }^{3}$ qui se disent Portugais, parcequ'ils sont issus de quelques Portugais qui y ont habité autrefois; ces gens la, outre la langue du pays, parlent encore un certain jargon qui n'a que tres peu de ressemblance a la langue portugaise, et qu'on nomme lange [sic] créole, comme dans la mer Méditerranée la langue franque.

(La Courbe 1688, published in Cultru 1913:192)

(Among them there are certain Blacks and Mulattoes who call themselves Portuguese because they are descended from some Portuguese who used to live here; apart from the local language these people speak a certain jargon which has only very little resemblance to Portuguese and which is called creole language like in the Mediterranean the 'langue franque').

Finally, Labat (1730, quoted in Silva Neto 1957: 133), referring to the Slave Coast and Loango areas, writes:

La langue portugaise corrompue s'y est conservée jusqu'à présent, produit un jargon ou langue franque que presque tout le peuple entend, parle de sorte que ceux qui sçavent le portugais, n'ont pas besoin d'interprète.

(Labat 1730, vol 1:287-88)

(The corrupted Portuguese language has persisted there up till now [and has?] produced a jargon or 'langue franque' which almost everybody understands, and which is spoken in such a way that those who know Portuguese do not need an interpreter).

The fact that some form of restructured Portuguese was in use among Africans made it useful for interpreters to be acquainted with it, which becomes evident from the following observation by Barbot: "[...] the interpreter, who understood a little Lingua Franca or broken Portuguese...” (Barbot 1732: 129).

While there is a fairly substantial body of texts containing indirect reflections of early West African Portuguese Pidgin (WAPP), such as theatre plays containing lingua de preto (lit. 'language of the Blacks', i.e. Portuguese as (supposedly) spoken by Africans), there is only very little direct evidence of what this "corrupted Portuguese" may have looked like. Here are some of the few examples we have:

(1) star mi Mingo
Cop my friend
"you are my friend"

(Von der Groeben 1694, quoted in Jones 1985:33)

(2) Jan-Commé sta atra forte

(Müller 1676:95, quoted in Kropp God cop behind strong

Dakubu 1997: 145)

"there is a heavy thunder"(lit. "God is strong inside (the sky)")

3. It is clear from La Courbe's description of these people (see Foltys 1988:63) that he is referring to the descendants of Portuguese lançados and African women, who formed an intermediate group between Africans and Europeans both linguistically and culturally. 
(3) agora mi sta sabi (Portuense 1696, quoted in Do Couto 1994:37) now I cop good "now I feel good"

(4) pretto diabol sta adentro black devil cop inside (Müller 1676: 193, in Creolist Archives "tere's a black devil inside"

Text Collection)

(5) Nao me chegua a ela poque sa Ramera e meu Pai, me votar a a tonco, se sabe que me fale co ela mais que mi non quero chegar a ela, porque sa Kamera.

(De Naxera 1672:238; Slave Coast; John Ladhams, pers. comm.; diacritics omitted)

"I didn't go near her because she's a prostitute and my father would send me to prison if he knew that I talked to her but I didn't go near her because she's a prostitute"

Whether or not a Portuguese-lexicon creole came into existence during the first 100-150 years of Portuguese exploration of West Africa, it is certain that later on several Portuguese-based creoles emerged in places where the Portuguese presence was of a more permanent nature, such as the upper part of West Africa (Cape Verde, Senegal, Guinea Bissau), and the Gulf of Guinea islands (São Tomé, Fernando Poo, Annobon). An important reason why these Portuguese creoles are of interest for the history of the Suriname creoles is that the latter, while being primarily English-based, contain a substantial amount of Portuguese-derived lexicon. This is related to the fact that the planter population in Suriname not only included English and Dutch but a number of other nationalities as well, among whom Portuguese-speaking Jews were especially important (see Chapter 3). A significant part of these Jewish planters had come to Suriname from Pernambuco, a region in north-east Brazil, which was a Dutch colony from 1630 to 1654 . Although there is no evidence for the transmission of a creole from Portuguese West Africa to Suriname (e.g. via Brazil), the fact remains that there are a number of striking phonological parallels between the Suriname creoles and the Gulf of Guinea creoles (Smith 1987). This issue will be discussed in more detail in Chapter 3.

Around the same time, say, between 1500 and 1650, on the other side of the ocean, in the Caribbean area, contacts between European and Amerindian languages led to the emergence of a jargon, or rudimentary pidgin called baragouin. Although most of the few sources that exist on this jargon refer to it as being lexically based on French, there is some evidence to suggest that it may go back to an earlier, Spanish-based variety. It would not be at all surprising in view of the fact that the Spanish were present in this part of the world long before the French. Samples of this baragouin can be found in several contemporary French sources, such as Bouton (1640), Du Tertre (1654-1671), and Labat (1722). Some of these sources also present some meta-linguistic information. For example, Bouton (1640, 
quoted in G. Hazaël-Massieux 1996: 87) says the following: '[...] ils [the Caribs, JA] ont un certain baragouin meslé de francois, espagnol, anglois et flament [...]' (They speak a certain jargon, which is a mixture of French, Spanish, English, and Dutch). A similar characterization, but with the omission of English, is given by Du Puis (quoted in G. Hazaël-Massieux 1996: 87): 'Ils ont composé eux-mêmes une sorte de langue, dans laquelle il se rencontre de l'Espagnol, du Francois, \& du Flamand...'(They have composed some sort of language themselves, in which one finds Spanish, French, and Dutch). Finally, Breton (1666, ch. 2, p. 55, quoted in G. Hazaël-Massieux 1996:90) leaves out both English and Dutch, but specifically mentions Carib: 'Ils ont un baragoüin ou langage corrompu [...] qui est espagnol-francois-caraïbe peslé-meslé par ensemble’ (They speak a jargon or corrupted language, which is Spanish-French-Carib mixed together).

While the references to English and Dutch remain somewhat obscure - none of the samples given below seems to contain any element derived from these languages -, the mention of Spanish and French by all three authors offers no problem of explanation. Since the Spanish were present in the Caribbean since 1492, it comes as no surprise that traces of their language should be found in the contact language used by the Amerindians when communicating with other Europeans, such as the French. The presence of the French element is due, of course, to the fact that these French sources represent the variety of baragouin as it was used between Amerindians and French. Some examples are presented below:

(6) magnane navire de France

(Bouton 1640: 107, quoted in tomorrow ship from France

Prudent 1993: 108) "a big ship will arrive tomorrow from France"

(7) mouche bourrache (Bouton 1640:111, quoted in Prudent 1993:108) much drunk "quite drunk"

(8) mouche manigat, mon compère much strong my friend

(Bouton 1640: 117, quoted in "it is very strong, my friend"

(9) Mouche comme este much like this "more than this"

(10) Jacques, France mucho faché, l'y matté Caraïbes oh Jacques France much bad he kill Carib

(Du Tertre 1654), quoted in G. Hazaël-Massieux 1996: 88) "oh Jacques, the French are very angry; they killed the Caribs" 
(11) Bonjour, Compère, toy tenir tafia? hello friend you have taffeta "hello friend, do you have taffeta?"

(12) Tenir mouche have much "there is a lot of it"
(Labat 1722, vol 2:289, quoted in G. Hazaël-Massieux 1994: 806 = 1996:90)

(Labat 1722, vol. 2, ch. 5, p. 262, quoted in G. Hazaël-Massieux 1996: 90)

Apart from these phrases and sentences, there is one word - pik(e)nine - which drew comments from two other early authors, De Rochefort (1658) and Breton 1665). De Rochefort (1658, quoted in G. Hazaël-Massieux 1996:68) notes that the baragouin word for 'weak, trivial' is pikenine. The same word - in the spelling piknine - is mentioned as a baragouin word (without its meaning) by Breton (1666: 14, quoted in G. Hazaël-Massieux 1996: 90). As is well-known, the word pequenino 'small, child' is found in many pidgins and creoles across the globe, including the Suriname creoles, where it is attested for the first time in 1688, as pickaninny. This suggests that rather than taking this word directly from Portuguese or Spanish, the Suriname creoles may have adopted this word via baragouin.

While the Suriname creoles show very few traces of influence from French (despite the presence of French-speaking planters), the influence from Portuguese, and to some extent Spanish, is very clear. Although the Iberian lexical element in the Suriname creoles is usually related to the presence of Sephardic planters in Suriname, that does not mean other routes of transmission are excluded. It may be useful, therefore, to take a look at the Iberian-derived words of baragouin. The list below presents those words occurring in examples (6) to (12) that seem to have their origin in Spanish or Portuguese or both: ${ }^{4}$

(13) Spanish- (and/or Portuguese) derived words in baragouin magnane < Sp. mañana (Ptg. manhã, amanhã) "morning, tomorrow" mouche < Sp. mucho (Ptg. muito) "much"

bourrache $<$ Sp. borracho "drunk"

manigat < Sp. magno (Ptg. magno) "big"; magnitud (Ptg. magnitude) "bigness" este < Sp. este (Ptg. este) "this"

matté < Sp. matar (Ptg. matar) "kill"

tenir < Sp. tener (Ptg. ter) "have"

tafia $<$ Sp. tafetán (Ptg. tafetá) "taffeta"

pik(e)nine < Sp. pequeño (Ptg. pequenino) "little (child)"

compère < Fr. compère, ultimately < Sp. compadre (Ptg. compadre) "friend"

4. It should be noted that Spanish and Portuguese were much less divergent 300 years ago than they are now, to the extent that they should, perhaps, be seen as varieties of one language.

5. The latter derivation is suggested by Prudent (1993: 144). 
Although it would be rash to posit a historical link between baragouin and the Suriname creoles on the basis of a few lexical correspondences, it still worthwhile to note that they have some words in common. Taking Sranan as a representative of the Suriname creoles, we find the following correspondences:

Table 2.1 Lexical correspondences between baragouin and Sranan

\begin{tabular}{ll}
\hline Baragouin & Sranan \\
\hline magnane 'morning, tomorrow' & maman- (in mamanten 'morning', lit. 'morning-time'6) \\
mouche 'much' & - musi (in tumusi 'very', lit. 'too much') \\
pik(e)nine 'little (child)' & pikin 'small, child' (earlier: pickanninny (Behn 1688)) \\
compère 'friend' & kompe 'friend' \\
\hline
\end{tabular}

Whatever the source of these Sranan words may be, the fact that they belong to the lexicons of both baragouin and Sranan suggests that they may have been part of some common-core, Romance-derived vocabulary that was in use in the larger Caribbean area (i.e. including coastal parts of the mainland) around the middle of the 17th century. It should also be remembered in this connection, that in the period of creolization there were occasional contacts between Suriname and Spanish 'Guyana', i.e. the coastal area of present-day Venezuela (e.g. Schaafsma 1966).

Another, more speculative, route by which a common Romance-derived lexicon could have been transmitted to the Caribbean would be to posit a diffusion of the Romance-based Lingua Franca from the Mediterranean, perhaps via West Africa, to the New World. This is not as far-fetched as it may seem, especially as far as the role of West Africa is concerned. One indication is provided by the references to the use of 'Lingua Franca' in Barbot's observations on inter-ethnic communication in West Africa, quoted above. The same author, however, also includes Lingua Franca among the languages which he recommends for anyone planning to travel to 'Guinea and the American islands' (Barbot, in Hair, Jones \& Law 1992: 7; emphasis mine, JA). That Lingua Franca was a useful language in the Caribbean appears also from a remark by the French Jesuit Biet, who reports a brief conversation in Lingua Franca, used as a kind of secret code, between himself and an Irishman on the island of Barbuda in 1652. Some even go so far as to claim that the Lingua Franca was spoken by the sixteenth-century buccaneers of Tortuga (an island off the coast of Haiti) and that this formed the basis for the Caribbean creoles (Steger 1973). While these authors present no evidence for their case, there is some, scant evidence that Lingua Franca was not unknown among sailors on the Atlantic (cf. Arends 1999). As to the role of buccaneers and privateers in linguistic

6. As noted by Schuchardt (1914: 86), English 'morning-time' may have played a role in this formation too. 
diffusion across the Atlantic, it may be relevant to know that the Lingua Franca was also widely used by corsairs in the Mediterranean area. Although it cannot be excluded that European pirates operating in the Mediterranean were also present in the West Atlantic, serving as a channel for the transmission of the Lingua Franca, much more research is needed before this can be substantiated.

The Iberian element in the Suriname creoles, however, is not the only feature to suggest a historical link with creolization elsewhere in the Atlantic. The presence of a number of lexical and structural parallels between the Caribbean English-lexicon creoles (CECs), including those of Suriname, on the one hand, and African English-lexicon creoles, such as Krio, on the other, has led scholars such as Hancock (1986), Smith (1987a) and McWhorter (1997) to suggest that the origin of the CECs should be located not in the Caribbean but in West Africa. Although there seems to be no doubt about the existence of a historical relationship per se, other evidence has been brought forward to suggest that its direction is precisely the other way around (Devonish 2001; Huber 1999). According to the latter view, the parallels between Krio and the CECs are a result of the migration of speakers of English-lexicon creoles from the New World to Sierra Leone around 1800. While this issue is too complex to be discussed here, let us just say that these parallels form another reason to take a broad view in examining the formative history of the Suriname creoles and not to restrict ourselves to Suriname per se. In the next section, however, we will focus on Suriname, in particular its early settlement history.

\subsection{Early settlements in and around Suriname (1600-1650)}

And hereafter within few yeeres, wee shall returne thence great plenty of Sugers. Robert Harcourt, A voyage of discouerie to Giuana, 1613

Although, as noted above, the year 1651 has come to be perceived as the terminus a quo of creolization in Suriname, a substantial number of settlements had been in existence before. Since it cannot be excluded that the formation of the Suriname creoles ultimately goes back to these early settlements, it is necessary to take a close look at their history. While most of the pre-1651 attempts at settlement in Suriname were unsuccessful in the sense that they were abandoned by all or part of the settlers after some time, that does not mean there was no continuity whatsoever between them. Although most of the historians who have dealt with this matter have concluded that these pre-1651 settlements were temporary (e.g. Schilder 1973), this is not what the historical documents tell us. When the latest reference in the historical record to the existence of a particular settlement is from 
year $y$, that does not allow concluding that this settlement ceased to exist that year. Still, based on the fact that the, last time Marshall's first settlement was allegedly reported was in 1634 (De Vries 1655), Schilder concluded that it only lasted until that year. Similar misinterpretations have been made by other historians with regard to other settlements. Another source of possible misinterpretation is of a more philological nature. The verb "to cut off", which is used a number of times in historical documents with regard to several settlements, as in the phrase 'cut off by the natives', does not necessarily mean that all settlers were killed. According to the Oxford English Dictionary, "cut off in 17th-century English may also mean "to remove" or "to bring to an end suddenly or abruptly". Although it is certainly true that in some cases, some settlers were killed by the Indians, this does not mean that in every case where this phrase is used there was not a single survivor among them. Yet, that is precisely how these references have usually been interpreted. Finally, there is a potential source of continuity which has been completely overlooked by historians, namely the fact that apart from Europeans these early settlements may have involved others as well, such as Amerindian and/or African slaves. If this was indeed the case, some of these non-Europeans may have stayed behind when their European masters abandoned their settlement. As far as linguistic continuity is concerned, i.e. the transmission of some form of contact language, the role of non-Europeans, especially Africans, would be especially important.

Although the early records that have been investigated do not seem to contain any explicit references to the presence of African slaves in the early settlements, that does not necessarily mean none were there. According to Rens (1953: 13, 16n5), the fact that 'the plantation settlement, in its initial stages, had no need for slave labour [...] does not mean that there were no Negro slaves to be found in Guiana during the first few decades of the seventeenth century. ${ }^{7}$ Although the only slaves mentioned in the context of the early settlements are Amerindians, it cannot be excluded that Africans were involved as well. Speaking about Marshall's first (1630) settlement (number 15 in Table 2.3 below), Schaafsma (1966:339) claims that 'he [Marshall, JA] probably brought the first African slaves with him.' This is not at all an unlikely claim in view of the fact that Marshall's group came from Barbados, where slaves were present from the late 1620s onward. Further, some of the early settlements were devoted to the cultivation of sugar, (Schilder 1973: 19), a crop known to promote the use of slave labour. ${ }^{8}$ Another piece of evidence comes from

7. With regard to the 1626 French settlement and the 1643 English settlement (see Table 2.5 below), Rens (1953:13-14) notes that probably no slaves were involved.

8. Although Schilder's remark is somewhat vague (there is evidence 'that by the middle of the seventeenth century there were several Dutch sugar plantations on the Marowijne and Commewijne rivers'), it seems clear he refers to settlements dating back to the pre-1651 period. 
Saramaka oral history: According to Hoeree (1983:58-69, 105-29), the Matjáu, the oldest clan of the Saramaka Maroons, trace their origins to slaves who escaped from Captain Marshall's settlement in the 1630s (A different view, however, is presented in Price 1983a). The relevance of whether or not Africans were present in Suriname before 1650, of course, is that if they were some form of pidgin or creole may have started to develop prior to the arrival of the English in 1651, which may then have been transmitted to post-1650 slaves.

However, for transmission to be possible, we would have to show that there was some sort of continuity not only from one pre-1650 settlement to another but also between one or more of these and the 1651 colonization by the English under Willoughby. While it is very difficult, or even impossible, to prove continuity on the basis of historical documents, it is important to realize, as was noted above, that these same documents do not allow us to conclude that there was no continuity either. In one of the most in-depth study of Suriname's early settlement history, Schaafsma (1966:339) states explicitly that 'in 1640 he [Marshall, JA] returns with part of his compatriots to Barbados' [emphasis mine]. If Schaafsma's earlier claim that Marshall brought slaves with him in 1630 is true, this would mean not only that Marshall's first settlement continued to exist after 1640 but also that both Europeans and Africans remained there. A second argument in favor of continuity is the fact that the 'town' of Thorarica, which was founded along the Suriname River by Marshall in the 1630s, was adopted as 'capital' by Willoughby in the 1650s. This suggests that Thorarica had continued to function in some way through the 1640s; otherwise it would not have survived in the Suriname rain forest. Thirdly, speaking about Marshall's second settlement (number 23 in Table 2.3 below), Schaafsma (1966:339) claims that in 1645 Marshall leaves 'with the larger part of his compatriots' [emphasis mine]. Finally, speaking about Willoughby's arrival in 1651, Schaafsma (1966:340) claims that 'there he [Willoughby, JA] finds Dutchmen along the Commewijne and Jews along the Upper-Suriname as well as the English who had stayed behind in 1645'. The idea of continuity between pre- and post-1650 settlements receives further support form another expert on Suriname's early settlement history, Schilder (1973: 19), who writes:

The exact fate of all these trading posts and settlements after Lord Willoughby arrived in Guyana [i.e. Suriname, JA] is unknown, but it is likely that they were incorporated in Willoughby Land [the part of Suriname roughly between the Coppename and Sinnamary Rivers colonized by the English in the 1650s and $60 \mathrm{~s}, \mathrm{JA}]$, and thus came under British rule.

A more general consideration with regard to the issue of continuity has to do with the size of the early settlements. While some of these were rather small, at least two of the early settlements in Suriname were surprisingly large enterprises. 
Of those settlements for which information about their size is available, the two French settlements of 1626-1629 and 1639-1642 (numbers 14 and 20 in able 3, respectively) both involved more than 500 persons, while Marshall's second settlement involved some 1,000. In order to appreciate these figures, it is sufficient to realize that the English settlement under Willoughby did not reach similar figures until the mid-1650s, i.e. five years after the beginning of colonization in 1651 (Arends 1995a:259).

Since the issue of continuity between pre- and post- 1650 settlement is of crucial importance for the reconstruction of creole formation, we will go into Suriname's early settlement history in some detail. It should be remembered, however, that as far as the amount and reliability of information is concerned, in the words of Rens (1953: 13), '[t]he first few decades of the 17th century are the 'dark age' in the history of Guiana.' On the other hand, a couple of important studies have appeared since the publication of Rens's book in 1953, most notably Schaafsma (1966) and Schilder (1973). The most important source of information, however, is of course the original historical documents from the relevant period. The most important of these is probably Major John Scott's manuscript Description of Guiana (Sloane mss 3662) written around $1667 .{ }^{9}$ Scott, who knew the local circumstances from his own observation, is widely recognized as a very reliable source of information (Edmundson 1901:640-2; Oudschans Dentz 1918: 174; Schilder 1973:21). ${ }^{10}$ In his manuscript he lists no less than 14 settlements that existed between 1530 and 1650 in the area covering present-day Suriname, Guyana and Guyane. Scott's account will be supplemented here by information from a number of additional sources, such as Wolbers (1853), Rens $(1953,1982)$, Hira (1982) and, especially, Schaafsma (1966), Schilder (1973) and Essed (1984).

Essed's work, published in Suriname and - perhaps because of that - little known, is one of the most detailed treatments of Suriname's early history, especially with regard to marronage but also the Indian War of 1678-1684. Schilder (1973) is a thorough historical-geographical study, based on a detailed investigation of early maps of Suriname. As noted by Schilder, several of these early settlements were engaged in the cultivation of tobacco as well as sugar, the latter of which was to become the motor of Suriname's growth as a plantation colony after 1651. Schaafsma's article is the first part of a two-part study (Schaafsma 1966, 1967) of the military history of Suriname, published - somewhat surprisingly - in the

9. Scott's manuscript was published in Harlow (1925:132-148) as well as in Oudschans Dentz (1918: 176-187). In this book, we refer to Harlow's edition.

10. Pace Williamson (1923:150), where political motives concerning disputed borders between Suriname and former British Guiana may have played a role. 
Jaarboek van de Koninklijke Landmacht ('The yearbook of the Dutch army'), an annual publication devoted mostly to 'household affairs' concerning the Dutch military forces. It is perhaps because of this particular forum for publication that the author did not include any references whatsoever in his article. In spite of that, however, there can be no doubt that it is based on a serious and detailed study of the original documents. Although Schaafsma's work is not referred to very often in the historiography of Suriname, the first part belongs - together with Rens (1953, 1982) and Schilder (1973) - to the very best that has been written about the early period of the colony, including its settlement history. It is for this reason that this work, in spite of the absence of bibliographical and archival references, is used as an important source of information in this chapter.

Before discussing the early settlement history, it may be useful to insert a brief excursion on the topography and toponymy of the part of South America referred to in contemporary works as 'Guyana' or 'Guiana'. In early texts as well as in modern works dealing with the pre-20th-century situation, the toponym 'Guyana' (or its spelling variants 'Guiana', 'Guayana') refers to the entire coastal region between the Orinoco and Amazon Rivers, including not only Suriname's neighbor states to the east and west, Guyana (i.e. former British Guyana) and Guyane (i.e. the overseas French department of French Guiana, also sometimes referred to as 'Cayenne'11), but also the parts of present-day Venezuela and Brazil bordering on Guyana and Guyane, respectively. This area is also sometimes referred to as 'Greater Guyana' or the 'Wild Coast (of Guyana)'. Although older sources sometimes refer to Suriname as 'Dutch Guyana' (sometimes with inclusion of the former Dutch colonies of Berbice, Demerara, Essequibo and Pomeroon), in this book we will always use 'Suriname' to refer to the part of 'Guyana' located between the Corantijn and Marowijne rivers. It should be noted, however, that in the plantation period, the inhabited area was restricted to the strip of land between the Marowijne and the Coppename Rivers, extending only some 50 miles into the interior. In the earliest colonization period (1600-1700), it was even more restricted: settlements and plantations were largely restricted to (the lower parts of) the Suriname, Commewijne, and to some extent Saramacca, Rivers. See Table 2.2 below for a summary of this information.

11. In order to avoid confusion, the name 'Cayenne' will only be used here to refer to the former French colony of that name, also known as 'Isle de Cayenne.' 
Table 2.2 Toponymical conventions with regard to the 'Greater Guyana' region

\begin{tabular}{|c|c|}
\hline Toponym & Geographical area \\
\hline Guyana & $\begin{array}{l}\text { The coastal area of Guyana, esp. the colonized areas (Berbice, Demerara, } \\
\text { Essequibo and Pomeroon) }\end{array}$ \\
\hline Suriname & $\begin{array}{l}\text { The coastal area of Suriname, esp. the colonized areas on the Suriname } \\
\text { and Commewijne Rivers }\end{array}$ \\
\hline Guyane & $\begin{array}{l}\text { The coastal area of French Guiana, especially the colonized area around } \\
\text { the town of Cayenne }\end{array}$ \\
\hline Berbice & The colonized area on the Berbice River \\
\hline Demerara & The colonized area on the Demerara River \\
\hline Essequibo & The colonized area on the Essequibo River \\
\hline Pomeroon & The colonized area on the Pomeroon River \\
\hline Dutch Guyana & $\begin{array}{l}\text { Suriname, plus - when referring to the pre-1800 situation - Berbice, } \\
\text { Demerara, Essequibo, Pomeroon }\end{array}$ \\
\hline Greater Guyana & $\begin{array}{l}\text { Guyana, Suriname, Guyane (sometimes including the neighboring areas } \\
\text { of Venezuela and Brazil }\end{array}$ \\
\hline
\end{tabular}

Before the first known settlements in Suriname in the early 1600s, there were a few attempts at settlement in the Greater Guyana area. The first of these, undertaken by the Spanish on the Pomeroon River, took place as early as 1530. Other early settlements were attempted by the Spanish, English and French in the Guyane area, in 1568, 1604, 1607, 1609 and 1613, respectively. Although the first attempt at settlement in Suriname mentioned by Scott dates from 1625, Schilder (1973: 14), drawing on unspecified Spanish archival documents, mentions the existence in 1613-1614 of a Dutch settlement along the Corantijn River, consisting of 'more than fifty Dutchmen with their families'. The fact that according to De Laet (1625, quoted in Schilder 1973: 14), these settlers 'kept some folk [there]' suggests that there may have been Amerindian or perhaps even African slaves involved. Apart from settling in this region, the Dutch also seem to have been involved in trade there, as appears from a Dutch notarial act from 1617 which refers to the existence of the 'village of Parmurbo' on the Suriname River in 1613 (Schilder 1973: 14).

As to the settlements that we will discuss here in relation to the colonization of Suriname, we will not restrict ourselves to Suriname per se, but we will also take into account the directly neighboring regions, i.e. Guyana and Guyane, as these may have been relevant in terms of contact with Suriname. The first settlement in the Suriname/Guyana/Guyane area that is mentioned by Scott (number 9 in Table 2.3) took place in Guyane in 1615, involving 280 Zealanders but lasting less than one year (Harlow 1925:13912). Dutch attempts at settlement were more successful in Guyana, where flourishing colonies were established, in 1616 and

12. For Scott's manuscript, reference will be made throughout to Harlow's 1925 edition. 
1624, respectively, along the Essequibo and Berbice Rivers (number 10). Turning to Suriname, there was an attempt in 1625 by the French along the Marowijne River (number 12), which apparently did not last very long. Another French party, from La Rochelle, consisting of 534 men and some women and children, had a settlement along the Saramacca River from 1626 until 1629 (number 14). This was succeeded by a settlement which is not mentioned by Scott, namely the first of the two settlements led by the English Captain Marshall, who established himself with 60 English colonists some 75 kilometres up the Suriname River in 1630 (number 15; from now on, this settlement will be referred to as 'Marshall I'). While it is certain that they were still there in October 1634, when they were found by David de Vries (Rens 1953: 17n13; Schilder 1973: 19), Schaafsma (1966:39) claims they stayed until 1640, and even then not all of them left. Although it is assumed by several authors (Schilder 1973: 19, Wolbers 1853:32) that Marshall's first attempt failed, the only basis for this assumption seems to be the fact that the latest reference to 'Marshall I' in the contemporary literature is from 1634. David de Vries also encountered a second settlement along the Suriname River, consisting of some 15 Englishmen, who were growing tobacco (Rens 1953:17n13). Captain Marshall is found in Suriname again in 1643, leading a substantial settlement along the Suriname, Saramacca and Corantijn Rivers of '300 Famillies of English Imployed by the Earle of Warwick, \& c' (Harlow 1925: 141). (This settlement will be referred to here as "Marshall II"). According to Scott, they 'lived peaceably vntill the yeare 1645 at which time they espoused the Quarrell of ye French and were cut of by the natives' (Harlow 1925: 141).

As indicated earlier, it is not at all impossible that there was some sort of continuity between Marshall I and Marshall II. Apart from the explicit claim made by Schaafsma (1966) that not all English left Marshall I in 1640, it is also important to know that in the intervening years between Marshal I and Marshall II there were several other settlements in the same area. Schilder (1973:19) refers to the existence of a settlement on the Suriname River in the years between 1635 and 1637, mentioned in an archival document. A French settlement was found to exist along the Saramacca River, founded in 1639 by 370 French men, who were supplemented by 'many Famillies' (Harlow 1925: 141) in 1640 when it spread out to the Suriname and Corantijn Rivers. The relationship of this French settlement (number 20) to the one dating from 1640, mentioned by Hira (1982:32) and Wolbers (1853:32) (number 22), remains unclear. As to the possibility of continuity between Marshall's second settlement and Willoughby's colony, this has been discussed above. Apart from the fact that whatever remained of Marshall II was incorporated into Willoughby Land, it is also important to know that there were several other settlements in the same area in the years between 1645 and 1651. According to Schaafsma (1966:339), Portuguese Jews coming from Pernambuco 
settled in eastern Suriname in 1646. In 1649 an unknown number of French were found to be living along the Saramacca River. Rens (1953: 15), based on Oxenbridge (c1667), refers to a one-family settlement along a branch of the Suriname River 'two years before the English Plantation', i.e. in 1649.

The importance of these settlements in the 1634-1643 and the 1645-1651 periods is, of course, that they may have acted as intermediaries in the continuation of communicative practices between Marshall I and Marshall II and between the latter and Willoughby's settlement. If a pidgin or creole had started to develop in one of Marshall's settlements, this could have been transmitted to the 'new', permanent colony established by Willoughby in 1651 . This means that the traditional idea that the formation of Sranan, or rather its precursor, Suriname Plantation Creole, must have been completed in the 1651-1680 time-span cannot be maintained. In the next chapter we will show that a similar argument can be made with regard to the alleged terminus ad quem, 1680.

Table 2.3 Survey of the earliest settlements in Suriname and adjacent areas (1530-1650)

\begin{tabular}{|c|c|c|c|c|c|c|}
\hline \# & Year(s) & Location $^{13}$ & $\begin{array}{l}\text { Number } \\
\text { of people } \\
\text { involved }\end{array}$ & Nationality & Remarks & Source \\
\hline 1 & 1530 & Pomeroon R. & 300 men & Spanish & $\begin{array}{l}\text { 'drave thence by } \\
\text { the Indians the } \\
\text { same yeare' }\end{array}$ & ST (HL $\left.138^{14}\right)$ \\
\hline 2 & $1568-1573$ & Cayenne R. & c $400^{15}$ & Spanish & $\begin{array}{l}\text { 'expelled by the } \\
\text { Careebs and } \\
\text { Paracoates' }\end{array}$ & ST (HL 138) \\
\hline 3 & $1604-1606$ & Oyapock R. & 70 men & English & $\begin{array}{l}\text { soon largely } \\
\text { abandoned, as a } \\
\text { result of disease }^{16}\end{array}$ & HL lxviii-lxix \\
\hline 4 & $1607-1609$ & Oyapock R. & 400 men & French & $\begin{array}{l}\text { 'all cut off Anno } \\
1609 \text { except a few } \\
\text { Marriners" }\end{array}$ & ST (HL 138) \\
\hline
\end{tabular}

13. It should be noted that designations such as 'Suriname R., Berbice R.' etc refer to the Suriname, Berbice etc Rivers (plus adjacent areas, where the plantations were located), not to the larger areas known as 'Suriname', 'Berbice' etc.

14. The number refers to the relevant page number(s); for abbreviations, see bottom of this table.

15. This figure is based on Scott's "one hundred \& 26 Families “(Scott c1667, in Harlow 1925: 138).

16. A Spanish document from 1612 reports the existence of a settlement consisting of 80 English and 'Flemish' (i.e. Dutch) men on the Oyapock in that year, probably a continuation of the 1604-06 settlement (Harlow 1925: 138n1). 
Table 2.3 (continued)

\begin{tabular}{|c|c|c|c|c|c|c|}
\hline$\#$ & Year(s) & Location & $\begin{array}{l}\text { Number } \\
\text { of people } \\
\text { involved }\end{array}$ & Nationality & Remarks & Source \\
\hline 5 & $1609-1613$ & Oyapock R. & c 25 men & English & & $\begin{array}{l}\text { HC (HR 7-8, } \\
115-6)\end{array}$ \\
\hline 6 & 1613 & Cayenne R. & c $500^{17}$ & French & $\begin{array}{l}\text { 'In few months } \\
\text { many destroyed.. } \\
\text { forct to quitt' }\end{array}$ & ST (HL 139) \\
\hline 7 & $1613-?$ & Suriname R. & $1-5^{18}$ & Dutch & a trading post ${ }^{19}$ & $\begin{array}{l}1617 \text { Dutch } \\
\text { notary record } \\
\text { (SI 14) }\end{array}$ \\
\hline 8 & $1613-14$ & Corantijn R. & $100-200^{20}$ & Dutch $^{21}$ & $\begin{array}{l}\text { settlement } \\
\text { completely } \\
\text { destroyed by the } \\
\text { Spanish }\end{array}$ & $\begin{array}{l}1613-1614 \\
\text { Spanish records } \\
\text { (SI 14) }\end{array}$ \\
\hline 9 & 1615 & Cayenne R. & 280 & $\begin{array}{l}\text { Dutch } \\
\text { (Zealand) }\end{array}$ & $\begin{array}{l}\text { 'Forced to quit... } \\
\text { the same yeare' }\end{array}$ & ST (HL 139) \\
\hline \multirow[t]{2}{*}{10} & $1616-$ & Essequibo R. & $?^{22}$ & Dutch & $\begin{array}{l}\text { this became } \\
\text { a permanent } \\
\text { settlement }\end{array}$ & $\begin{array}{l}\text { ST }(H L \\
139-40)\end{array}$ \\
\hline & & Berbice R. & $?^{23}$ & $\begin{array}{l}\text { Dutch } \\
\text { (Zealand) }\end{array}$ & $\begin{array}{l}\text { this became } \\
\text { a permanent } \\
\text { settlement }\end{array}$ & ST (HL 140) \\
\hline 11 & $1624-1625$ & Oyopock R & $?^{24}$ & Dutch $^{25}$ & $\begin{array}{l}\text { all settlers left in } \\
1625\end{array}$ & $\begin{array}{l}\text { unidentified ms. } \\
\text { journal (SI 16) }\end{array}$ \\
\hline
\end{tabular}

17. This figure is based on Scott's $>160$ Families(Scott c1667, in Harlow 1925: 139).

18. Probably a one-man business, according to Schaafsma (1966:338).

19. This is Schilder's inference, based on the fact that the notarial document refers to 't dorp Parmurbo 'the village Parmurbo', located on the Suriname River. However, Parmurbo could just as well have been an Indian village.

20. 'More than fifty Dutchmen with their families' (unspecified Spanish archival records, in Schilder 1973: 14).

21. Both Schilder (1973) and Schaafsma (1966:338) note that Spanish records are not very reliable in their determination of national identities.

22. Since this was a flourishing colony (Scott c1667, in Harlow 1925: 140), the number of settlers was probably not very small.

23. See preceding note.

24. 'a handful of men' (Schilder 1973: 16).

25. The company consisted - partly or entirely - of exiled Waloons (Schilder 1973: 15). 
Table 2.3 (continued)

\begin{tabular}{|c|c|c|c|c|c|c|}
\hline \# & Year(s) & Location & $\begin{array}{l}\text { Number } \\
\text { of people } \\
\text { involved }\end{array}$ & Nationality & Remarks & Source \\
\hline 12 & $1625-?^{26}$ & Marowijne R. & $?^{27}$ & French & $\begin{array}{l}\text { 'without all dout } \\
\text { destroyed by the } \\
\text { Natives' }\end{array}$ & ST (HL 141) \\
\hline 13 & $?-1626$ & Commewijne R. & & English & & ES 3 \\
\hline 14 & $1626-29$ & Saramacca R. & c $550^{28}$ & French & $\begin{array}{l}\text { 'Those few that } \\
\text { were left went to } \\
\text { St. Christopher's' }\end{array}$ & ST (HL 141) \\
\hline 15 & $1630-?^{29}$ & Suriname R. & $60^{30}$ & English & $\begin{array}{l}\text { coming from } \\
\text { Barbados } \\
\text { (Schaafsma } \\
\text { 1966:339) } \\
\text { ('Marshall I') }\end{array}$ & DV (SI 19) \\
\hline 16 & $1634-?$ & Suriname R. & c 15 & English & $\begin{array}{l}\text { a tobacco } \\
\text { 'plantation' }\end{array}$ & $\mathrm{DV}$ (RE 17n13) \\
\hline 17 & 1634 & Cayenne R. & 30 & Dutch & $\begin{array}{l}\text { a tobacco } \\
\text { 'plantation' }\end{array}$ & DV 1655 (SI 19) \\
\hline 18 & 1634 & Commewijne R. & $?$ & $?$ & 'plantation' & DV(SA 339) \\
\hline 19 & $1635-37 ?$ & $\begin{array}{l}\text { Oyapock R., } \\
\text { Cayenne R., } \\
\text { Suriname R., } \\
\text { Saramacca R. }\end{array}$ & $?$ & Dutch & $\begin{array}{l}\text { reference to seven } \\
\text { Dutch settlements } \\
\text { on the Wild Coast } \\
\text { in } 1635 \text { and } 1637^{32}\end{array}$ & $\begin{array}{l}\text { Archival record } \\
\text { (SI 19; 35n64) }\end{array}$ \\
\hline
\end{tabular}

26. This settlement had already disappeared by the time the next ship arrived (Scott c1667, in Harlow 1925: 141).

27. 'a ship and a Barque' (Scott c1667, in Harlow 1925: 141).

28. '534 men some Women and Children' (Scott c1667, in Harlow 1925: 141).

29. Although Schilder (1973:19) and Rens (1953:17n13) claim this settlement ended in 1634, it lasted at least until 1637 according to Lorimer (1989:113n6) or even until 1640, according to Schaafsma (1966:339).

30. Note that this number only includes whites, not the slaves who, according to Schaafsma (1966:339), were probably also involved in this settlement.

31. Lorimer's claim (1989: 112) that they came from Brazil does not seem very likely.

32. The reference also includes Berbice and Essequibo (which colonies had been existence since 1616 and 1624, respectively), plus an unknown settlement; the reference to Saramacca ('Serrano') is doubtful. 
Table 2.3 (continued)

\begin{tabular}{|c|c|c|c|c|c|c|}
\hline \# & Year(s) & Location & $\begin{array}{l}\text { Number } \\
\text { of people } \\
\text { involved }\end{array}$ & Nationality & Remarks & Source \\
\hline 20 & $1639-42$ & Saramacca R. & $500-1000^{33}$ & French $^{34}$ & $\begin{array}{l}\text { 'were all cut of in } \\
\text { one Day' }\end{array}$ & ST (HL 141) \\
\hline 21 & $1639-42$ & Suriname R. & $?$ & $\begin{array}{l}\text { Dutch, Jews } \\
\text { (<Italy) }\end{array}$ & & SA 339 \\
\hline 22 & $1640-42^{35}$ & Suriname R. & 65 & French $^{36}$ & $\begin{array}{l}\text { destroyed by } \\
\text { disease and } \\
\text { Indian attacks }\end{array}$ & $\begin{array}{l}\text { HI } 32 ; \\
\text { WO } 32^{37}\end{array}$ \\
\hline 23 & $1643-45$ & $\begin{array}{l}\text { Suriname R. } \\
\text { Saramacca R. } \\
\text { Corantijn R. }\end{array}$ & $\mathrm{c} 1000^{38}$ & English & < Marshall Isl. & ST (HL 141) \\
\hline 24 & 1646 & $\begin{array}{l}\text { Eastern } \\
\text { Suriname }\end{array}$ & $?$ & Jews ${ }^{39}$ & & SA 339 \\
\hline 25 & $1648-?$ & Suriname R. & $c 5^{40}$ & & & $\begin{array}{l}\text { OX (RE 15, } \\
\text { 19n31) }\end{array}$ \\
\hline 26 & 1649 & Saramacca R. & $?$ & French & $\begin{array}{l}\text { 'were the greatest } \\
\text { part cut of' }\end{array}$ & ST (HL 142) \\
\hline 27 & 1650 & $\begin{array}{l}\text { Pomeroon R. } \\
\text { Wacopon R. } \\
\text { Moroca R. }\end{array}$ & $?^{41}$ & $\begin{array}{l}\text { Dutch } \\
\text { Dutch/ } \\
\text { Jews }^{42}\end{array}$ & $\begin{array}{l}\text { this became } \\
\text { a flourishing } \\
\text { settleme }\end{array}$ & ST (HL 142) \\
\hline
\end{tabular}

Abbreviations:

DV $=$ De Vries 1655, ES $=$ Essed 1984, HC $=$ Harcourt 1613, HI $=$ Hira 1983, HL = Harlow 1925,

OX = Oxenbridge c1667, RE = Rens 1953, SA = Schaafsma 1966, SI = Schilder 1973, ST = Scott c1667

33. '370 men', supplemented the year after with 'many Famillies' (Scott c1667, in Harlow 1925: 141).

34. According to Schaafsma (1966:339), the Suriname River settlement involved Dutch settlers as well as Jews who had come from Italy via Holland.

35. The end date of 1642 is provided by Schaafsma (1966:339).

36. Fleeing from Cayenne, according to Schaafsma (1966:339).

37. No original, contemporary documents are mentioned by either Hira or Wolbers.

38. This figure is based on the ' 300 Famillies of English Imployed by the Earle of Warwick', mentioned by Scott (Harlow 1925: 141).

39. Sephardic Jews coming from the Dutch colony of Pernambuco (North-East Brazil).

40. 'one Jacob Enosh... with his family' (Rens 1953:15).

41. This colony was 'setled by the Zealanders' in 1650, but 'ye yeare following a great Collonie of Dutch, and Jewes, draue of from Brazil, by the Portugaize setled there' (Scott c1667, in Harlow 1925: 141-142).

42. These included both Sephardic Jews and Dutch from the Dutch colony of Pernambuco. 


\subsection{The formative years: $1651-1690$}

Now that we have some idea of the situation in Suriname in the fifty years preceding the arrival of the English coming from Barbados in 1651, we will continue by discussing the first decades of the period of actual colonization. Although the dividing line between the pre- and post-1651 periods may not be as sharp as has been assumed traditionally, the fact is that 1651 and the immediately following years mark a number of important differences with the preceding period. While we have shown in Chapter 2 that there may well have been some degree of continuity between several of the pre-1651 settlements, it is not until the colonization by Willoughby that we can speak of a truly continuous development of Suriname as a colony. This appears among other things from the fact that within a dozen years after Willoughby's arrival, the colony is granted to him (and one Lawrence Hyde) by Charles II as 'Willoughby Land', the coastal strip of land between the Coppename River (in West Suriname) and the Sinnamary River (in Guyane). This was undoubtedly related to the fact that from the very beginning Willoughby had invested large sums of money in the colony in a determined effort to make it into a successful enterprise. In all likelihood, Willoughby was aided in his ambition by the fact that a number of settlements was already present in the area where he set up his colony, namely the upper Suriname and Commewijne Rivers.

Another important factor in the colony's success is the fact that Suriname was colonized from Barbados by people who already had some experience in the world of plantation agriculture and slavery. Apart from the direct linguistic consequences this may have had, namely that an emerging pidgin or Creole may have been imported form Barbados, this type of 'secondary' colonization (cf. Chaudenson 1992) also has certain social effects that may have an indirect bearing on the language situation. One of these is that the preparatory stage of robinsonnade (Chauenson 1992), during which the first settlers, just like Robinson Crusoe, have to take care of the most basic requirements in order to survive, may be considerably shortened. The fact that Willoughby's settlers came from Barbados, where large-scale plantation agriculture including the cultivation of sugar by African slaves, had been introduced sometime before their departure, explains why it was possible for them to set up sugar plantations within a matter of years after their arrival. Although undoubtedly these plantations were not of the same size as those set up in the 18th century, it still suggests that the [period during which Suriname was a société d'habitation 'homestead society' was relatively short, passing relatively quickly into the stage of a société de plantation ${ }^{43}$ 'plantation society' (cf. Williamson 1923,

43. For these terms, see Chaudenson (1992). 
especially p. 154). ${ }^{44}$ The social-linguistic correlate of this is that while on largescale plantations there was little contact between the Europeans and the majority of the Africans, allowing little access to the European language, on the much smaller homesteads Europeans and Africans worked more or less side by side, providing a much better opportunity for language acquisition. This, in turn, suggests that the restructuring of English in Suriname not only began relatively soon but also that it was relatively drastic, when compared to other creole speaking areas.

Although the development of Suriname as a plantation colony during the English period took place rather quickly (the 'establishment phase ${ }^{45}$ ': 1651-1665), the whole process had to start more or less all over again after it had been taken by the Dutch in 1667 . While an epidemic disease had already done much damage in the preceding years, the fact that many old settlers and slaves left during the transition period (1667-1680), taking their equipment an expertise with them, weakened the colony considerably. This was enhanced by the fact that the Dutch who had little expertise in plantation agriculture to begin with were not very successful in attracting new settlers from Europe. A war with the Amerindians (1678-1686) and problems caused by the first bands of Maroons did the rest. As a result of all that, the colony had to be built up anew during the 1680s and did not reach its previous state of development until around 1690 (this could be called Suriname's 're-establishment phase': 1665-1690). It is only in the late 1680s that Suriname enters a new phase of development (the 'expansion phase': 1690-1770), characterized by an enormous expansion of the number of plantations as well as of slaves. This phase, finally, is followed by a 'consolidation phase' (1770-1870) during which the colony remains more or less at the level of economic development it had reached by the end of the expansion phase. While the 1651-1690 period forms one phase in terms of socio-economic development, the discussion in this chapter is divided over two main sections, one dealing with English period (1651-1667), the other with the first decades after take-over by the Dutch (1667-1690). Since several of the themes to be discussed do not lend themselves to a strictly chronological treatment, the subdivision within these sections is largely thematic. Sections 2.3.1.1 and 2.3.1.2 deal with the role of the English and of the Sephardic Jewish planters, respectively. Sections 2.3.2.1 to 2.3.2.4 deal with the transition period (1667-1680), the English 'exodus', the Indian War (1678-1686), and the beginning of marronage, respectively.

44. Williamson (1923) is based on a large number of contemporary sources, including Scott (c1667), Byam (1662, 1665, 1665-67), Sanford (1662), Warren (1667) and Oxenbridge (c1667), as well as several installments of the Calendar of State Papers.

45. The terms 'establishment phase', 'expansion phase' and 'consolidation phase' are taken from Bickerton (1988). 


\subsubsection{The English period (1651-1667)}

Because of the important and rather special role played by the Sephardic Jewish planters both in the development of Suriname as a colony and in the formation of its creoles, a separate section is devoted to them. We will begin, however, by discussing the period of colonization by the English.

\subsubsection{The colonization by the English}

It appears from a number of facts that the colonization by the English was a serious undertaking from the very beginning. For example, the group dispatched from Barbados in 1651 by Francis Willoughby was led by one Anthony Rowse, 'a Gentleman [...] of Long Experience in ye West Indies' (Scott c1667, in Harlow 1925 : 142). Second, by 1661 , Willoughby had spent no less than 20,000 pounds 'on his infant colony' (Cundall 1919: 145). For a first-hand account of his commitment to the colony, let us listen to what Willoughby himself has to say about this in a protest he wrote to Cromwell, by whom he had been imprisoned in the mid-1650s:

The Lord Willoughby of Parham did in the yeare 1650 sett forth one Ship and a small vessell in which twenty persons were transported and furnished to make discovery of the Maine of Guiana. Vpon the retorne of which Shipp accordinge to aduice hee did fitt a Frygott of twenty guns with two other Vessells to attend vpon that Service, and in them did send 100 men with all maner of provisions to make a Settlement vpon the Riuer of Serranam. After wich hee did at severall tymes and vpon seuerall Vessells send Men, prouisions, armes, and Amunition.

And in further prosecution thereof did in the year 1652 take a voyage thither himselfe in person and with him caryed an adition of strength soe that hee left well setled there 300 persons all English well fortifyed and furnished with Canon, Armes, amunition, and other necessaryes all which was done at his sole proper Coast and Charges to the expence of many thowsand pownds. That since his retorne, though his right and interest hath been contested and disturbed, yet his piety to his settellment of soe many poore English men hath been such That hee hath notwithstandinge sent thither from hence at his own charge one ship ladeinge of all provisions and necessaryes for their releife and settlement in supporting them. [Willoughby c1656, 'Reasons offered by the Lord Willoughbie why hee ought not to be confined in his settlement vpon Serranam,' Egerton mss 2,395 f.280-280b; reprinted in Harlow 1925: 180-181].

This document clearly suggests that as far as financial investments are concerned the early colonization of Suriname was very much Willoughby's personal enterprise. Apart from that, other interesting bits of information, e.g. regarding the time of arrival of the first settlers, their ethnic affiliation, and the number of immigrants, can be gleaned from this document as well. The fact that, according to Willoughby, '300 persons all English' were present upon his departure in 1652, 
combined with what we know about the numbers of immigrants in 1651 and 1652, suggests that at least one hundred immigrants arrived earlier that year. Although Willoughby's reference to 'soe many poore English men' does not necessarily imply the presence of indentured servants, it seems to be safe to assume that at least some of them were servants or at least poor, small farmers. On the basis of this and other information, the following table can be drawn up with regard to the arrival of 'English' (i.e. English, Irish, Scottish) immigrants into Suriname during the early years of Suriname as an English colony. Unfortunately, no immigration figures for the remainder of the English period have been found.

Table 2.4 Documented figures of European immigration into Suriname (1651-1653)

\begin{tabular}{lll}
\hline Date & Number, nationality and origin & Source \\
\hline 1651 & 20 'English' persons from Barbados & Willoughby (c1656, in Harlow 1925: 180-181) \\
& $\begin{array}{l}20 \text { persons }^{46} \\
100 \text { 'English' men from Barbados }\end{array}$ W7 & Willoughby (1651, in Schilder 1973: 23) \\
& $\begin{array}{l}\text { 1651-1653 (c1656, in Harlow 1925: 181) } \\
\text { several hundred 'English' men from } \\
\text { Barbados }^{48}\end{array}$ & Willoughby (c1656, in Harlow 1925: 181) \\
\hline
\end{tabular}

It seems safe to assume that in these early years, the word 'persons' refers to 'men' only. This is reinforced by the fact that Willoughby himself in the passage quoted above uses both terms to refer to the same group of people. With regard to the number of immigrants, the information in Table 2.4 can be supplemented with additional information, such as that provided by Renatus Enys, who writes that around 1662 in two months' time nine ships had brought immigrants (Cundall 1919: 146); unfortunately, their number is not mentioned.

The immigration figures given in Table 2.4 dovetail rather nicely with the population figures provided in a number of historical documents, such as Willoughby (1651, c1656), Biet (1664), and assorted documents collected in the Calendar of State Papers. In contrast to the immigration figures, these population figures cover almost the entire 1651-1667 period. The figures for the years 1661-1665 confirm Williamson's claim that the heyday of English Suriname was during this period:

46. This is based on a letter written by Francis Willoughby (9/8/1651, quoted in Schilder 1973:23), referring to the presence of 'forty persons' in Suriname (it is not clear whether they stayed or not) and mentioning that he was 'sending hence a hundred men to take possession.'

47. It is not clear whether this figure includes the fifty settlers 'sent [...] from Barbados towards the close of 1651,' mentioned by Williamson (1923:155), referring to the Calendar of State Papers (1574-1660:373).

48. According to Schaafsma (1966:340), there were also Jews among the colonists brought by Willoughby. 
'All accounts agree that in 1665 the colony reached its maximum development' (Williamson 1923: 164; see also p. 160). Its downfall set in with an epidemic which began in April or May 1665. As noted by Byam, '[...] a little before his Excyes departure [Willoughby left Suriname May 9, 1665, JA], a Sickness began at our Toun of Toorarica, \& spred itself in ye Plantacons adioyning \& swept many away' (Byam 1667, in Harlow 1925: 199). (A similar observation is made by Scott (c1667, in Harlow 1925: 144). According to Byam (1665-1667, quoted in Williamson 1923: 164), the epidemic diminished the number of 'men capable of bearing arms from 1500 in 1665 to 500 in 1666.' The same author, writing in early 1667 (Byam 1667, in Harlow 1925:221), states that in February 1667, after the invasion by the Dutch, there were about 500 men in the 'Companyes', i.e. the civil militias. ${ }^{49}$ This means that the total number of Europeans, including women, children and elderly people, must have been considerably larger. It also suggests that Byam's figure of 500 'men capable of bearing arms' present in 1666 only refers to the number of men in the civil militias rather than the overall population. The idea that the effects of the epidemic were less devastating than has sometimes been assumed is confirmed by Byam (1667, in Harlow 1925: 212), when he states in February 1667 that ' [...] through ye late heavy Visitacon of sickness, one 4th part of our ablest men are swept away [...]'.

Assuming that Byam's figure of one fourth refers to the total number of victims among the European population as a whole during the entire epidemic, we may infer that out of a total of at least 2,200 Europeans who were present in 1666, there were at least between 1,000 and 2,000 (including Jews, indentured servants, women, children ${ }^{50}$ ) left in 1667 . Taking the average of 1,500 and estimating the number of Jews in 1666 at some 300, we arrive at a figure of at least 1,200 English in 1666. This is in stark contrast with the figure of 820 given for 1668 by Voorhoeve \& Lichtveld (1975:3), which formed the basis for their claim that after the end of the English exodus there were less than forty English left. As we will see later, this revision has important consequences for the reconstruction of creole formation in Suriname. The figures discussed above, supplemented with additional information regarding status and nationality, are summarized in the following table.

49. Schaafsma (1966:344), referring to the same month, calculates the 'nominal' size of the militias at some 700 men, of whom 300 were 'fit for battle. This is a further indication that the number of men 'capable of bearing arms' should not be equated with the total number of men in the militias, let alone with the total European population.

50. It has been established that during this period white servants included not only men but women and children as well (Smith 1947: 166-168). Beckles (2000:229) shows that in 1678 in the three islands of St Kitts, Nevis and Montserrat, children constituted almost one third of the entire Scots and Irish population (including non-servants), the proportion of women to men being well over 1:3. 
Table 2.5 Documented figures of the European population of Suriname (1651-1667)

\begin{tabular}{|c|c|c|}
\hline Date & European population & Source \\
\hline Aug 1651 & 40 persons & Letter Willoughby 9/8/1651 (in Schilder 1973:23) \\
\hline Feb 1652 & 150 'pioneers' & Cal St Pap ${ }^{51}$ (1574-1660:373, in Williamson 1923: 163) \\
\hline 1652 & 300 English & Willoughby (c1656, in Harlow 1925:180-181) \\
\hline Jan 1654 & 350 'Englishmen’ & Biet $(1664: 267$, in Rens 1953:78) \\
\hline 1661 & 1,000 inhabitants $^{52}$ & Cal St Pap (1661-8, no 83, in Williamson 1923:163) \\
\hline Nov 1663 & $\begin{array}{l}2,000-2,500 \\
\text { inhabitants }^{53}\end{array}$ & $\begin{array}{l}\text { Cal St Pap. (1661-8, no 577, in Williamson 1923:164); } \\
\text { Biet (1664: 267, in Rens 1953:79) }\end{array}$ \\
\hline 1665 & $\begin{array}{l}1,500 \text { men 'capable of } \\
\text { bearing arms' }\end{array}$ & Byam (1665-67, ff.27, 37, in Williamson 1923: 164) \\
\hline 1666 & $\begin{array}{l}500 \text { men 'capable of } \\
\text { bearing arms' }\end{array}$ & Byam (1665-67, ff.27, 37, in Williamson 1923: 164) \\
\hline July 1666 & $\begin{array}{l}<700 \text { men in the } \\
\text { 'Companyes' }\end{array}$ & Byam (1667, in Harlow 1925:221) \\
\hline Feb 1667 & $\begin{array}{l}\text { ca } 500 \text { men in the } \\
\text { 'Companyes' }\end{array}$ & Byam (1667, in Harlow 1925:221) \\
\hline
\end{tabular}

Note that the numbers for the European populations are not uniform, in some cases referring only to 'men capable of bearing arms', in others to all persons, of all sexes and ages.

As to the location of the early English colony, this was largely restricted to the Suriname River, with a concentration between the fort located at what is now Paramaribo and the town of Torarica, about 50 miles upstream. As regards the origins of the first English settlers, i.e. those who arrived in late 1651 and early 1652 (totaling about 150 persons) came from Barbados, although some of them had been resident on other Caribbean islands before, such as St Kitts, Nevis and Montserrat (Rens 1953: 14). This is an important fact as St Kitts, the first Caribbean island to be colonized by the English, in 1624, may have been a center of diffusion of restructured English throughout the Caribbean, including Barbados (see Baker \& Bruyn 1999). Therefore, the roots of the Suriname creoles, as far as the English element is concerned, may have to be sought not only in Barbados but in St Kitts and other Caribbean islands as well. Apart from English settlers, other nationalities were represented in Suriname during the English period as well. While there are several references in the contemporary literature to the presence of Dutch

51. Cal St Pap $=$ Calendar of State Papers.

52. Cf. Williamson (1923: 163): 'Presumably this refers to Europeans, although we cannot be sure that it does not include negroes [...]'

53. Although no distinction as to ethnicity is made here, we follow Rens' (1953: 79-81) argumentation that the figure of 4,000 mentioned by Biet (1664) includes some 1,500-2,000 Africans. 
planters (e.g. Warren 1667:927), the most important non-English colonists were the Sephardic Jews who arrived towards the end of the English period, in the years 1665 to 1667 (see Section 2.3.1.2).

In spite of the presence of other nationalities, however, the English clearly formed the majority of Suriname's European population throughout the 16511667 period. The preponderance of English speakers is reflected in the proportion of English-derived basic vocabulary in Sranan, which has been calculated at some 75\% for Sranan and some 50\% for Saramaccan (Smith 1987: 145-146). This does not mean, however, that all persons designated as 'English' in the contemporary literature were in fact speakers of English. Apart from the fact that the English spoken in Suriname was in all likelihood a collection of different regional and social varieties of that language, it is also important to know that Suriname's 'English' population included a group of indentured servants' (or 'indentured laborers'), who came to work under contract for a fixed number of years (usually five). One piece of evidence for the presence of indentured servants in Suriname comes from Willoughby (c1656), who, referring to 1652, writes that he 'dispos[ed] his servants there [i.e. in Suriname, JA]'. Another is provided by Byam (1667, in Harlow 1925:213), who, writing about the Dutch take-over in 1667, refers to 'our Christian servants' (in contrast to Amerindian and/or African slaves). More indirect evidence canbe gleaned from Willoughby's prospectus, dating from around 1655 and designed to draw potential settlers to the colony, where he explicitly invites persons not able to pay for transport to be 'at his alone charge transported, serving ther but foure yeers' (Harlow 1925: 175). Elsewhere in the same document, Willoughby offers 'poore familyes' to 'furnish them [...] with servants, English or Negroes' (Harlow 1925: 176-7). The presence of indentured servants, or at least poor farmers, is made all the more likely by the fact that precisely during this period small farmers were being ousted from Barbados. According to Beckles (1990:27), in the same period some 3,000 small farmers and servants left Barbados for other Caribbean islands and the mainland.

Unfortunately, no information is available with regard to the number or the regional origins of indentured servants in Suriname (cf. Rens 1953:75-77). However, from what is known about the origins of indentured laborers in other 17th-century English colonies (Smith 1947; Le Page 1960: 87; Rickford 1986:254; Beckles 2000:229) we may infer that, apart from English citizens, Scots and, especially, Irish were well represented among them. More importantly, the origins of white servants in Barbados at the time of the colonization of Suriname are known to some extent. According to an archival document (Egerton manuscript no 2395, f. 625), quoted in Smith (1947:332), there were 8,000 servants in Barbados in 1652, 'mainly Scots and Irish.' Since most of the servants brought by Willoughby 
probably came from Barbados, ${ }^{54}$ this means that most indentured laborers in Suriname were also Irish or Scots. To the extent that other islands, especially St Kitts, Nevis and Montserrat, also provided input to Suriname (Rens 1953), it may be important to note that in these three islands too the Irish were well represented among indentured servants (Smith 1947: 172; Beckles 2000:220). Figures for these three islands show that in 1678 the proportion of Irish to Scots (including all inhabitants, not just servants) was more than 25: 1 (Beckles 2000:220). Another source of indentured servants may have been provided by the English colonization of Ireland, coinciding in time with the colonization of Suriname, as a result of which many Irish were sent as servants to the West Indies, including perhaps Suriname (Smith 1947: 164). Since indentured labor from Scotland remained relatively small until 1707 (Le Page 1960:87), the conclusion seems to be warranted that indentured labor in Suriname consisted primarily of Irish, with English and Scots being only of secondary importance. This conclusion is supported by Bridenbaugh \& Bridenbaugh (1972: 17, quoted in Rickford 1986:251), who conclude that 'in the English West Indies in 1650, the Irish settlers constituted more than half of the entire population and outnumbered even the English'.

As far as the languages spoken by the indentured servants are concerned, it is important to realize that the Irish spoke Irish. As convincingly shown by Rickford (1986:252-3), 'in British colonies of the 17th century, it was probably true for Irish servants, as for African slaves, that most knew little or no English when they came.' As to the language of the English servants, regional, especially Southwestern, dialects were probably spoken by them (Rickford 1986:252). The existence of indentured labor, especially during English rule, is important from a linguistic point of view because, due to the fact that at that time the colony was still (partly) in its homestead phase, these servants were in relatively close contact with the slaves (Rens 1953:76-77; Le Page 1960:85). However, to the extent that these servants did not speak English, both groups, servants and slaves, found themselves in the same situation, namely that of having to learn English as a second language. The possibility that this may have led to some Irish influence in the emerging Suriname Creoles has, to my knowledge, never been investigated.

As far as the non-European population in this period is concerned, it is known that both Amerindians and Africans were used as slaves on the plantations in the early stages of colonization. While a number of scholars have suggested that the English brought African slaves with them from Barbados, Rens

54. Theidea that Barbados provided many of the white servants for Suriname receives some additional support from the fact that their numbers in Barbados fell sharply during the English period in Suriname: from 8,000 in 1652 to some 2,200 in 1680 (Smith 1947:332). 
(1953:30n8), basing himself on archival documents, remarks: 'The wording of the documents supplying data on the first few hundred settlers do [sic] not give the impression of accompanying slaves.' Although in recent years much new evidence has been discovered about the origins of the Africans who were brought to Suriname from 1675 onwards (Postma 1990; Arends 1995a), the pre-1675 years are still largely shrouded in darkness, at least as far as documentary evidence is concerned. Nevertheless, since both the English and the Dutch were involved in the slave trade to Suriname between 1651 and 1675, it is possible to make some inferences with regard to Suriname on the basis of what is known about this trade in general (Postma 1990; Le Page 1960). This shows that the major recruitment area of slaves for both the Dutch and the English in this period was formed by the Slave Coast, a region where varieties of Gbe were the most frequently spoken languages. As to the Amerindian slaves during the English period, it may be assumed that since the Caribs had friendly relations with the English the slaves belonged mainly to the Arawak or other non-Carib groups (Buve 1962, 1966). As will be shown in Section 2.3.2.3, this changed after the peace treaty of 1684, where it was stipulated that neither Caribs nor Arawak (nor Warrau) were allowed to be enslaved by the Dutch.

A final topic to be discussed in this section concerns the question which crops were grown on the English plantations, especially the question if and from what moment on sugar was being produced. This is important since, as explained earlier, the cultivation of sugar requires a type of plantation and social organization which may have important consequences for social interaction. Due to its special character, the production of sugar requires a quasi-industrial approach to agriculture, which involves technical skills, a factory-like operation and a large labor force. The linguistic relevance of this is that the opportunities for contacts between Africans and Europeans, and therefore for the acquisition of English as a second language, were probably much more restricted on sugar plantations than on the smaller plantations where crops such as coffee and tobacco were grown. This suggests not only that the restructuring of English began relatively early in Suriname but also that it was probably more drastic than in other colonies, which went through a homestead phase that was considerably longer.

While there are some references to the cultivation of sugar as well as tobacco in the pre-1651 period, we may assume that this did not involve the kind of large-scale agriculture known from later years. As regards the English period, it is known that the same products, tobacco and sugar, were also among the major crops. As for the introduction of sugar, Rens (1953: 78), based on Biet's (1664) eye-witness account, concludes that its cultivation had not yet begun by 1654 , when tobacco was still the main crop (Van der Meiden 1987: 18, also based on Biet 1664). This situation changed quickly, as appears from a number of historical documents. Williamson 
(1923: 162) refers to a letter from 15 August 1662 saying that seven ships have just completed loading sugar, which is of better quality and higher price than that of Barbados. The letter also says that one planter has erected a windmill [to power the cylinders that are used to crush the cane, JA], with others following the example. A manuscript account by Renatus Enys from the same time (around 1663, quoted in Cundall 1919:46) refers to sugar as being 'the chiefest commodity' in Suriname. In his eye-witness account, Warren (1667:927) writes that as early as the mid-1660s there were 'forty or fifty sugar-works, yielding no small profit to their owners...'

On the same page, he mentions sugar, along with specklewood, cotton and tobacco as 'the commodities', and says that 'of sugar very considerable quantities are made', making it clear that sugar was the main product. His description of the situation of the slaves (p. 928) also fits the characteristics of a plantation society more than those of a homestead society: Heavy punishments, poor nourishment and housing, heavy labor, marronage and suicide are among the features mentioned by Warren.

\subsubsection{The Sephardic Jews ${ }^{55}$}

A small but economically important section of the European population of Suriname were the Sephardic Jews, some hundred-and-fifty of whom arrived in Suriname between 1665 and 1667, some coming from Pernambuco (a former Dutch colony in North East Brazil), some from Essequibo, and some from Europe (Livorno, Amsterdam) (Arends 1999: 199). Since their 'ultimate' place of origin was the Iberian Peninsula, their main languages were Portuguese and Spanish. Being experienced colonists, they were of crucial importance for the continuation of the colony, especially after its take-over by the Dutch in 1667. They established their plantations mainly along the upper Suriname and Commewina Rivers, forming a community of their own, with their newly founded town of Joden Savanne ('Jews' Savannah'), as its center. Although it has often been assumed that the Jews who came from Brazil brought slaves with them (Goodman 1987; Smith 1987), there is no historical evidence to support this. As shown by Arends (1999) and Ladhams (1999) on the basis of historical documents, it is in fact quite unlikely, not only because the means of transportation necessary for such an operation were not available when the Portuguese forced the Jews to leave Brazil, in 1654, but also because they did not own that many slaves to begin with. Also, it should not be forgotten that a substantial part of the early Jewish immigrants in Suriname did not come from Brazil but from Europe, which makes it extremely unlikely that they brought any slaves with them.

55. This section is based on Arends (1999). 
The linguistic relevance of the presence of Portuguese-speaking Jews lies in the fact that the lexicon of the Suriname Creoles, especially Saramaccan, contains a significant Portuguese element. As far as basic vocabulary is concerned, this has been calculated at some 4\% for Sranan and a substantial 35\% for Saramaccan (Smith 1987: 145-146). If our argument that no slaves from Pernambuco were brought to Suriname is correct (see below), this means that the Portuguese lexical element in the Suriname Creoles does not derive from a Brazilian Portuguese creole but rather from the variety of Portuguese spoken by the Sephardic Jews. Although Jews have also been mentioned as being present in Suriname before the immigration 'wave' of 1665-1667 or even before the arrival of the English in 1651 , this can only have involved very small numbers. Also, it is not clear that these early Jews were speakers of Portuguese, although Schaafsma (1966:339) says that Portuguese Jews from Pernambuco 'are supposed to have settled in eastern Suriname' in 1646. But even if this is true, it is not clear that they brought any slaves with them. In view of the linguistic implications of what has come to be known as the 'Pernambuco connection' ( $c f$. Ladhams 1999), we will deal with this issue in some detail.

According to Goodman (1987:375) 'in 1664-1665, a group of approximately 200 [Jews, JA], accompanied by some slaves,${ }^{56}$ arrived [in Suriname, JA] from Cayenne..., adding that apart from Brazilian refugees this group included a number of Spanish-speaking and Portuguese-speaking Jews from Livorno (Italy). A few pages later (p. 379) he goes even further, claiming with regard to these Jewish planters that 'they evidently brought slaves with them from Cayenne who spoke Creole Portuguese...' Apart from a reference to Voorhoeve (1970) to support the figure of 200 Jews, Goodman adduces no concrete evidence whatsoever to support his claims with regard to the importation of slaves from Cayenne ${ }^{57}$ and the language they spoke. Nevertheless, Goodman is followed by Smith (1987a: 115) who writes that 'the Portuguese element in Saramaccan derives from a Portuguese creole spoken in Brazil and brought to Suriname along with the slaves of the Portuguese Jews who came to Surinam in 1665.' In the same vein, Aceto (1997:221) refers to Goodman's claim that 'Portuguese-speaking Jews moved to Suriname ... bringing slaves from Brazil to the new plantations' as providing 'strong support...for the high percentage of PD [Portuguese-derived, JA] lexical items in Saramaccan'.

As noted above, the only source referred to by Goodman to support his claims regarding the origin of the Jewish planters in Suriname and their slaves is Voorhoeve (1970). It is important, therefore, to take a close look at Voorhoeve's

56. Italics here, as in the following quotations in this section, are mine.

57. Here 'Cayenne' refers to 'Cayenne Island', the 'island around the settlement of Cayenne'. 
article. The crucial sentence in it runs as follows: 'In that same year [1665, JA], about 200 Portuguese Jewish planters, perhaps with their own slaves, settled in Surinam (coming possibly from Cayenne)' (Voorhoeve 1970:55). Although Voorhoeve refers to the arrival in Suriname of slaves from Cayenne as a mere possibility, both Goodman and in his footsteps Smith and Aceto simply state as facts that the Sephardic Jews came to Suriname from Brazil and brought a number of slaves with them. Goodman and Smith even go further in assuming that these slaves upon their arrival in Suriname spoke a Portuguese Creole, which formed the basis of the Portuguese element in the Suriname creoles. Let us see how these claims hold against the historical facts.

Since the assumption of a Brazil connection rests entirely on Voorhoeve's statement quoted above, it seems useful to inspect the source on which it, in turn, is based, namely a little-known article by Rens published in 1954 in a Surinamese journal called Vox Guyanae. (It was republished, with some slight modifications, in Cohen (1982); references will be to the 1982 version). Quite surprisingly, none of the authors mentioned above, except Smith, ${ }^{58}$ refer to Rens's article, even though it is explicitly mentioned in Voorhoeve's article on which their claims are based. Rens' article, unlike the works mentioned above, is based on a detailed investigation of historical documents as well as a number of publications which in their turn are based on archival research. On page 36 of his article, Rens summarizes his main findings regarding the early immigration of Jews into Suriname. Supplemented with observations elsewhere in his paper these findings may be summarized as follows: ${ }^{59}$

(14) Rens estimates the number of Jews that came to Suriname before 1665 at a maximum of 30. Although a few of these may have come from Dutch Brazil, most of them came from a variety of places such as Barbados, Jamaica, Martinique, St-Christophe (French St. Kitts), the 'Dutch colonies' [probably Curaçao, JA], and England. Also, these early Jewish settlers in Suriname were merchants rather than planters.

(15) Rens estimates the number of Jews that came to Suriname from Cayenne in 1665 at a maximum of 100 . Some of these may have been residents of Dutch Brazil before coming to Cayenne.

58. Although Rens (1954) is referred to in the introductory chapter of Smith's dissertation, it is completely ignored in the paragraph dealing with the origin of the Portuguese element in Saramaccan (pp. 116-125), where Goodman's scenario is adopted.

59. It should be stressed that all numbers mentioned by Rens are maximums that were inferred by him from available sources rather than exact figures provided by them. As a result, actual figures were in all likelihood lower than the estimates made by Rens. 
(16) Although not supported by any direct documentary evidence, Rens finds it reasonable to suppose that after the English attack on the Dutch colonies of Pomeroon and Essequibo in 1666, a number of Jews left these colonies for Surinam. The number of this group is estimated by Rens at a maximum of 50 .

Rens's conclusions may be supplemented with the following information, gathered from various sources dealing with this issue. First, since at least some of the places mentioned under (1) besides Brazil were among the destinations of Jews leaving Brazil between 1645 and 1654 (Klein 1986:49), this early pre-1665 Jewish contingent in Suriname may have included a few extra 'ex-Brazilians.' Second, there were 'ex-Brazilians' among the Jews who came to Pomeroon/Essequibo from Europe in 1658 (Arbell 1995:346-348, 352-54; Israel 1995: 105; Marcus 1970: 147; Netscher 1888: 73; Oppenheim 1907: 103, 122). ${ }^{60}$ Furthermore, some of the Pomeroon/ Essequibo settlers who had come from Cayenne in 1664-1665 may also have been former residents of Dutch Brazil. However, since the coming of Jews from the Pomeroon/Essequibo area in Suriname is hypothetical to begin with, the relevance of their origin is only marginal at best. ${ }^{61}$ Finally, it should be noted that Rens's list of pre-1668 Jewish immigrants does not include the second group from Cayenne numbering around 50 persons - which, according to Jennings (1995:24), came to Suriname in 1667 (see below).

With regard to Rens's findings and the way they were interpreted by others, two things are especially important. First, regarding the number of Jews arriving in Suriname in the 1660s, the figure of two hundred mentioned by Rens (p. 36), refers to the maximum total of those present in 1667, not to the number arriving in 1665 (from Cayenne), as inferred by Voorhoeve. In fact, on the very same page (p. 36) the number of Jews arriving in 1665 is given by Rens as at most one hundred, i.e. half the number claimed by Voorhoeve. Second, although slaves are mentioned by Rens in connection with the Jews from Cayenne (p. 33-34), this is done only in passing, without making any reference to archival documents and not carrying any implication that these slaves came ultimately from Brazil. Nevertheless, Goodman and Smith, basing their claims indirectly on Rens (1982) (via Voorhoeve 1970), state as a fact that in 1665 two hundred Jews came to Suriname from Cayenne, bringing slaves with them who spoke a Portuguese creole they had supposedly acquired in Brazil.

6o. Marcus (1970: 1412, note 8) refers to Scott (1667, published in Harlow 1925: 141-142), which says that 'Jewish refugees from Brazil settled in the Pomeroon area of western Guiana as early as 1651 ', but he adds that this is unsubstantiated.

61. Note, however, that Rodway (1912:71-72), quoted in Arbell (1995:358), claims that 'a few of the ruined Jews from Pomeroon came [to Surinam, JA]' 
Some additional evidence against a Brazilian origin of the Surinamese Jewish planters can be derived from a comparison of the names of Jewish planters in Dutch Brazil and in Suriname. Not a single one out of the six Sephardic plantation owners in Pernambuco in 1639 whose names are mentioned in Böhm (1992:73-74) is among the thirteen Jewish planters in Suriname in 1668 whose names are given in Oudschans Dentz (1927: 14) and Rens (1982:41). Although two of these early Jewish settlers in Suriname (Isaac Pereira and Arão da Silva) may have been residents of Dutch Brazil before coming to Suriname (Mello 1989:390,443), they did not occupy themselves with plantation agriculture there and are therefore unlikely to have possessed large numbers of slaves.

Rather than in Brazil the origin of at least part of the Surinamese Jewish planters should be sought in Livorno, as was noted by Goodman in the passage quoted above. In 1659 David Nassy, a former resident of Dutch Brazil, obtained permission from the West India Company for a group of 152 Jews from Livorno ${ }^{62}$ to establish a settlement in Cayenne. Arriving there in 1660, they were initially not admitted by the Dutch governor Langendijk. In the following year, however, they returned and were permitted to settle on 'Cayenne Island'. From the fact that the Livorno Jews initially had trouble being allowed into Cayenne, Rens (1982:33) concludes that there were no Jews among the 30 to 35 people who were already there when the party from Livorno arrived (Bloom 1931). This leads Rens to conclude that 'this group of 152 people from Leghorn [=Livorno, JA] sent hither [to Cayenne, JA] by David Nassy was the first and only large body of Jews to settle in the island of Cayenne' (Rens 1982:33).

Jennings (1995:22-23), however, drawing on Du Tertre (1667) and Artur (1770), says that a group of Dutch and Jewish refugees from Brazil - most likely without bringing any slaves - settled in Cayenne Island in 1654, the former around the town of Cayenne and the latter at Rémire. At least some of these must have stayed there until the arrival of the Livorno group in 1661: a French archival document refers to the presence of 15 to 20 Jewish families in 'Hermière' (Rémire) in 1660. The difference between Rens's and Jennings's conclusions may be due to the fact that Jennings includes both the area around the town of Cayenne and the Rémire area, while Rens seems to refer only to the former. Assuming that these 15 to 20 Jewish families counted $75-100$ persons and that representative numbers of both this group and the Livorno group were among the Jews who left for Suriname in 1665 , we may tentatively conclude that roughly one third of the Jews coming to

62. During this period Livorno was one of the two major Sephardic communities in the world, the other being Amsterdam (Israel 1992:391). 
Suriname from Cayenne in 1665 were from Brazil and two thirds from Livorno. ${ }^{63}$ As to the other early contingents of Jewish immigrants in Suriname, these may have included some 'ex-Brazilians', but in all of these cases they were outnumbered by Jews from Europe, especially Livorno, ${ }^{64}$ who had no prior New World experience. The above findings with respect to the origins of the Sephardic Jews who came to Suriname in the 1651-1667 period are summarized in Table 2.6. ${ }^{65}$

Table 2.6 The immigration of Sephardic Jews into Suriname (1651-1667)

\begin{tabular}{llllll}
\hline $\begin{array}{l}\text { Year of } \\
\text { immigration }\end{array}$ & $\begin{array}{l}\text { Place of } \\
\text { departure }\end{array}$ & Number & Jews origin & Number & Slaves origin \\
\hline $1651-1665$ & Caribbean & & Holland/Brazil & -66 & - \\
& England & $<30$ & Holland & - & - \\
& Brazil & & Holland & - & - \\
1665 & Cayenne & $<100$ & Livorno/Brazil/Holland & very few & Africa \\
1666 & Pomeroon/ & $<50(?)$ & Livorno/Brazil/Holland & $? 67$ & [Africa] \\
& Essequibo & & & & \\
\hline \multirow{2}{*}{1667} & Cayenne & $c 50$ & Livorno/Brazil/Holland & - & - \\
\hline
\end{tabular}

As noted above, Rens (1982) does not refer to any slaves being brought to Suriname from Brazil. ${ }^{68}$ In fact, there are several reasons why it would be unlikely for the Jews leaving Brazil to have taken many slaves with them. First of all, during the first three years of the Portuguese rebellion against the Dutch in Pernambuco (which lasted from 1645 to 1654) most of the plantations had been destroyed (Israel 1995: 102). Also, the siege of Pernambuco's main town, Recife, meant years of

63. Note that 'Livorno' occurs as the name of a sugar plantation on the left bank of the Suriname River, not far from Paramaribo (Lilian Adamson, p.c.).

64. The population of Pomeroon/Essequibo also included a significant proportion of Jews from Livorno who, like their coreligionists in Cayenne, had been brought there under the aegis of David Nassy (Oppenheim 1909:57). Marcus (1970:147) notes that the charter issued by the Zealanders to the Jews of Pomeroon/Essequibo in 1657 'may well have been influenced by $L a$ Livornina, Livorno's liberal charter of 1593.

65. Although there are some references to the presence of small numbers of Jews prior to 1664, due to conflicting opinions and lack of concrete data these have not been included in this table.

66. '-' means: no slaves mentioned.

67. '?' means: unspecified number of slaves mentioned.

68. Although in an earlier work Rens (1953:25) suggests that "the Jewish refugees from Cayenne and the Pomeroon (were) accompanied by their slaves", this is not supported by any evidence. Moreover, note that also here there is no implication whatsoever to suggest that these slaves derived from Brazil. 
famine for its inhabitants (Wiznitzer 1960). It is very unlikely that under these circumstances the Jews who stayed in Recife until 1654 continued to possess many slaves. ${ }^{69}$ Second, there was a shortage of ships to take away the inhabitants of Pernambuco after it was reconquered by the Portuguese, making it very unlikely that slaves were taken aboard (Wiznitzer 1954: 83, 1960: 124ff). Third, not a single group of Portuguese planters came to Suriname from Brazil directly ( $c f$. Rens 1982:30), using indirect routes instead, either via Europe (Amsterdam, London, La Rochelle) or the Caribbean (Cayenne, Pomeroon/Essequibo). It is very unlikely for slaves to have been brought from Brazil to Suriname through such indirect and often lengthy routes. Fourth, Sephardic Jews in Dutch Brazil never owned many slaves to begin with. As shown by Wiznitzer (1956: 195, 1960:69) and Böhm (1992: 73), only 6 percent of the 166 sugar plantations present in Dutch Brazil in 1639 were owned by Jews. ${ }^{70}$

With respect to the Jews who came to Suriname from Cayenne in 1665, Jennings' (1995) study of the demographics of 1660s Cayenne provides some evidence that they brought very few slaves with them. Jennings (p. 23) notes that in 1660 the first group of slaves ever to arrive from Africa in Cayenne (120 persons) were sold to the Jews at Rémire. He also argues (p. 29) that these were the only slaves to enter Cayenne between 1660 and 1665, i.e. the period covering the arrival of the Livorno group in 1660 and the departure of part of them in 1665. After the French take-over of Cayenne in 1664, 80 of these slaves and their offspring stayed behind with 60 Jews. Taking into account the usual decrease among slave populations of sugar plantations, this leaves only a small number of slaves who could have been taken along by the Jewish planters who left Cayenne for Suriname

69. This is confirmed by quantitative data regarding numbers of slaves in this period: there were no more than 2671 slaves in Dutch Brazil in 1645 (Wiznitzer (1960: 129), but $c f$. Ladhams (1996:7), who, referring to Mello (1985), suggests that this figure may be too low), while only 1550 were imported during the nine years of the war (1646-1654) (Van den Boogaart \& Emmer 1979:369, Table 14.5). The extent of marronnage during this period in this part of Brazil (Van Kanten 1992; $c f$. also Ladhams $i b$.) suggests that many slaves used the chaos of the war to escape to the interior.

70. This is in striking contrast to the two thirds of all plantations in Dutch Brazil claimed by Wätjen 1921 to be owned by Jews, a figure which was accepted uncritically by many scholars afterwards. The Sephardic Jews in Dutch Brazil were mainly involved in trade and commerce rather than plantation agriculture (Bloom 1934:62; 1937: 133). This does not mean, of course, that they could not have established plantations later on, in Cayenne or Surinam, but if they did, these were not worked by slaves brought from Brazil. That the Jews in Dutch Brazil were not heavily engaged in plantation agriculture emerges also from the fact that in the years 1637, 1640 and 1643 on average no more than $17 \%$ of the slaves imported into that colony were acquired by Jews (Böhm 1992: 76, note 176), most of whom were probably resold (Bloom 1969: 133). 
around this time. The remaining Jews, numbering around 50, were brought from Cayenne to Suriname by the English in September 1667 but their slaves had to stay behind (Jennings 1995:24). This leads to the inescapable conclusion not only that very few slaves came to Suriname from Cayenne in 1665, but also that those who did, had not come to Cayenne from Brazil. As to the other contingents of Jews that came to Suriname, it is only the (hypothetical) group from Pomeroon/Essequibo that might have brought some slaves with them, although many of them probably had escaped to the bush during the English attack (cf. Netscher 1888: 77). Also, since slaves were imported into Pomeroon/Essequibo directly from Africa (Arbell 1995: 346, 353), only few of these would have come from Brazil. As to the two remaining groups, it is very unlikely that they brought any slaves, either because they were merchants rather than planters (the pre-1665 group) or because they were not allowed to take any slaves with them (the 1667 group from Cayenne).

However, this does not exhaust all possible routes by which slaves from Brazil could have been brought to Suriname. There is one other possibility - at least in theory - which has to do with the very first group of African slaves who were brought to Cayenne in 1652. Jennings (1995:21), referring to Biet (1664), says that in September or October 1652 the French colonists in Cayenne captured an English pirate ship carrying 14 black slaves, 'the first people of African origin in Cayenne,' all deriving from the same plantation in Pernambuco and speaking 'Portuguese, or a language with a Portuguese lexical base'. This is based on a passage in Biet (1664: 124), where it is said that one of these slaves 'crossed himself saying in Portuguese al nombre de Dios. ${ }^{{ }^{71}}$ A year later (December 1653) the survivors of these colonists (around 130 people, Jennings p.c. 1/2/96) left Cayenne, while 'the fate of the 14 slaves is not known' (Jennings 1995: 22). In Jennings' opinion (p.c. 14/2/96), it is not very likely that these slaves were taken along by the French, primarily because there was a shortage of boats. However, if they were, there is a chance that they ended up in Suriname, because the French, on their way to Martinique, stopped in Suriname for two weeks (Jennings p.c. 1/2/96). During this stay some of these slaves may have been sold to the English. Even if this were the case, however, it does not seem very likely that this small group could have played a very important role in the linguistic situation of that time, since there were already two hundred or more slaves present (Arends 1995a:259).

We may conclude, therefore, that only a minority of the Sephardic Jews coming to Suriname in the 1660s came from Pernambuco and that those who did brought at most a very small number of slaves with them. This does not exclude, of course,

71. Note, however, that, as correctly noted by Jennings, the orthography points in the direction of Spanish rather than Portuguese. 
that there may have been 'ex-Brazilians' among the Jews who came to Suriname later on, e.g. from Barbados, which was an important center of 'ex-Brazilian' Jews (Wiznitzer 1960: 175; Klein 1986: 48), or from Europe (Böhm 1992: 135; Ladhams 1996: 13). But even if this was the case, the chances that they brought Brazilian slaves with them are extremely low. This implies that, as far as the historical evidence goes, the origin of the Portuguese element in the Suriname creoles should not be sought in Brazil (but see Smith 1999 for a different view).

\subsubsection{The first years of Suriname as a Dutch colony (1667-1690)}

Like many other colonies in the Caribbean, Suriname did not remain in the same European hands for a very long time. In the context of the second Anglo-Dutch war (1664-1667), the Dutch sent out a fleet to try and conquer several English colonies, including Suriname. Although this was a successful enterprise at the beginning, in that the colony was indeed taken over, it turned out not to be without problems in the longer run. First, the English colonial powers did everything they could to do as much harm to the colony as possible, primarily by trying to persuade the English planters to leave with their slaves and equipment, especially their sugar-mills (that were disassembled) (Section 2.3.2.2). As if that was not enough, the Amerindians took the opportunity to wage a war (1678-1686) on the new invaders, which brought the colony on the verge of collapse (Section 2.3.2.3). In this war they were aided by the Maroons who were quickly growing in numbers during this period. Although marronage did already occur during the English period, or even earlier, it is during the late 1670s and early 1680s that it begins to be a serious problem. Since the history of early marronage is of crucial importance for the reconstruction of the formation of the Maroon Creoles, especially Saramaccan, we will go into that in some detail (Section 2.3.2.4). We will begin, however, with a more general discussion of what may be called the 'transition period', i.e. the period between 1667, when the colony became formally Dutch, and 1680, when most of the English had left.

\subsubsection{The transition period (1667-1680)}

On February 15, 1667 - during the second Anglo-Dutch war (1664-1667) - a fleet of seven ships appeared on the Suriname River and the colony, which had been seriously weakened in the preceding years as a result of the epidemic referred to above, was taken in a matter of days. Although tradition has it that Suriname was taken by 'the Dutch', it should be borne in mind that it was the Province of Zeeland, rather than the United Provinces as a whole, which was responsible for 
the attack. ${ }^{72}$ The colony fell under the jurisdiction of Zeeland from 1667 until 1683 , when it was transferred to the Societeit van Suriname ('Society of Suriname') under a charter granting equal participation to the West India Company (WIC), the city of Amsterdam, and the Van Sommelsdyk family. For various reasons, one of them being the 'Indian War' (1678-1686) to be discussed in some detail below, the new possessors were not very successful in their role as colonists during the first ten or fifteen years. The strength of the United Provinces as a colonial power lay primarily in the areas of commerce, transportation and finance rather than tropical agriculture. Throughout its existence as a plantation colony, Suriname had problems in attracting colonists from the Netherlands. For example, although attempts were made to continue the system of indentured labor under Dutch rule, it was never really successful and it was quickly abandoned (Buddingh' 1995:51-52). As a result of the lack of interest among the Dutch to settle in Suriname, they did not become a majority among the European population until well into the 19th century (Arends 1995a).

Other groups beside the Dutch were French Huguenots and Sephardic (later also Ashkenazic) Jews, both of them groups that had sought refuge in the Netherlands after having been expelled from France and Portugal, respectively. ${ }^{73}$ The Sephardic Jews have played an especially important role, both in the development of the colony and in the formation of the Creoles spoken there, particularly Saramaccan. From the 1670s until the second half of the 18th century, they formed no less than one third of the entire European population (Arends 1995a). This demographic fact is of utmost importance for the history of the Suriname creoles as the Sephardic Jews continued speaking Portuguese (and to some extent Spanish) until far into the 18th century (Arends 1999). Their position as linguistic role models was strengthened by the fact that most of them were involved in plantation agriculture in this period which put them in close contact with slaves.

The relatively large number of 'foreigners' (i.e. non-Dutch) among Suriname's European population becomes less surprising when seen in the light of how the population of the Netherlands was composed at the time. In the period between

72. Whether this has influenced the development of the Suriname Creoles - in the form of specifically 'Zeelandish' dialectal features - is a matter which, to my knowledge, has not been examined as yet. Suffice it to say here that comparison with Zeelandish features in Negerhollands (Van Rossem \& Van der Voort 1996:20-1) suggests that items such as yu, 'you sg., nu 'now', and $k e$ 'want' in early Sranan and early Saramaccan might perhaps be ascribed to a similar influence from the dialect of Zeeland.

73. Note that Van Sommelsdyk, governor of Suriname from 1683 to 1688, was related to Huguenots through his marriage to the daughter of Alexandre du Puy de St. André Montbrun, a well-known French Protestant at the time. 
1650 and 1750 some 6 to 9 percent of the population of the Netherlands was from abroad, while the percentage for Amsterdam during the same period was as high as 20 to 40. (Lucassen \& Penninx 1994:28). Since there was a strong economic link between the city of Amsterdam and Suriname, especially after the establishment of the Societiet van Suriname in 1683, it is not surprising to find the international composition of the one being reflected in the other. Apart from people who went to Suriname with the purpose of settling there, another group of colonists were the soldiers and sailors who stayed in Suriname after their contracts had expired. Since foreigners, especially Germans, were well represented in these professions at the time (Lucassen \& Penninx 1994:49,52), this further explains the strong presence of foreigners in Suriname.

The problems encountered by the Dutch in continuing the prosperity of the colony were enhanced by the fact that many English planters left Suriname together with many of the slaves they had purchased before 1667. Although some of them preferred to stay, they were urged by the English colonial administration to leave Suriname once it had been officially ceded to the Dutch under the Treaty of Breda (July 31, 1667). In an attempt to ruin the colony as much as possible, sugar mills were disassembled and taken away or simply demolished (see e.g. Harlow 1925). Even before Dutch take-over, some 200 English had already left the colony in 1665 . As will be shown in the next section, between 1665 and 1680 some 830 English and some 1,550 slaves left Suriname, heading for Barbados and Jamaica.

While the Dutch were struggling to keep the colony going, the Amerindians, sensing an opportunity to get rid of the new colonizing power, started attacking them fiercely. The Indian War (1678-1686) which brought Suriname to the verge of collapse. The situation only improved in 1686, when a peace treaty was concluded with the Amerindians by Van Sommelsdyk, who had become governor of Suriname after his family had taken a share of one third in the Societeit van Suriname in 1683. In Van Sommelsdyk's wake, a party belonging to a religious sect called the 'Labadists', led by two of his sisters, came to Suriname in their pursuit of religious freedom. After the revocation of the Edict of Nantes by Louis XIV in 1685, which effectively ended a period of religious tolerance in France, they were followed by a number of French Huguenots, many of whom tried to build up a new life in Suriname. Their presence is reflected in a number of French plantation names, such as La Providence and Mon Plaisir. Although it is hard to assess to what extent French was a spoken language in Suriname, the presence of Frenchspeaking Huguenots adds to the picture of Suriname as not only a multi-ethnic but also a multilingual society, both in terms of African and of European languages. ${ }^{74}$

74. As late as 1759 a 'notification' was published prohibiting the use of French in addresses in correspondence to the Netherlands (De Smidt 1973, vol 1:655). 
Although Amerindian slave labor was still used in this period, the majority of slaves were brought from Africa. While the total number of African slaves present at the arrival of Van Sommelsdyk in 1683 may be estimated at two thousand at most (Buve 1962:29n19; cf. Arends 1995a:259, 263-4), at least five times that number were imported in the following eight years (almost three times the amount that had been imported in the preceding eight years; see Arends 1995a:263-4). In terms of demographic upheaval, the second half of the 1680-1690 decade is by far the most dramatic in Suriname's entire history: within the space of five years, the black population more than quintupled through new arrivals from Africa (Arends 1995a:264).

The great majority of these new slaves must have ended up on plantations along the Commewijne and Cottica Rivers: precisely during these years, these areas show an enormous expansion, while the 'old' plantation area along the Suriname and Para Rivers show a strong decrease (Buve 1962: 43, based on a comparison of old maps; see also Van Renselaar 1966). As appears from Table 2.7 below, in terms of numbers of plantations the importance of these two areas practically reversed in the twenty years between 1667 and 1686. According to Van der Meiden (1987:55), these new plantations were mostly owned by Christian planters whereas most Jewish planters stayed in the Suriname River area.

Table 2.7 Numbers of plantations in Suriname River and Commewijne Rivers areas $(1667 / 1686)$

\begin{tabular}{|c|c|c|c|c|c|c|}
\hline & \multicolumn{3}{|c|}{ Suriname River area } & \multicolumn{3}{|c|}{ Commewijne River area } \\
\hline & Suriname R. & Para R. & Total & Commewijne R. & Cottica R. & Total \\
\hline 1667 & 103 & 29 & 132 & 38 & 5 & 43 \\
\hline 1686 & 39 & - & 39 & 75 & 34 & 109 \\
\hline
\end{tabular}

As far as sugar plantations in particular are concerned, Cundall (1919) writes that in 1674 there were still seventeen in the Suriname River area and three in the Commewijne River area. Compared to the forty sugar plantations mentioned by Warren (1667), this would mean that the number of sugar plantations would have been reduced by $50 \%$ in the first seven years after Dutch take-over.

According to Buve (1962:43), this geographical shift already began around 1680 , because the Commewijne River area was pacified several years earlier than the Suriname River area, which did not become safe until the Peace Treaty of 1686. Another reason for the shift towards the Commewijne River may have been that the Dutch, who were experienced in polder technology, were able to cultivate land in this lower river area, which had been impossible for the English. Finally, since the Dutch, in contrast to the English, did not have good relations with the Carib 
Indians, it may have been difficult for them to operate plantations further into the interior, such as the Upper Suriname River area.

A culturally and linguistically important question with regard to the slaves working these plantations is where in Africa they came from. Unfortunately, the origins of the slaves imported into Suriname during the pre-1675 period are largely undocumented. Since most slaves during these years (including the English period) were brought by Dutch slavers (Price 1976: 13), we may infer the origins of the Suriname slaves by extrapolating from the general Dutch slave trade during this period (taking into account a certain margin of error, of course). While there is no information predating 1658, data collected by Postma (1990: 112) for the 1658-1674 period show that the Slave Coast and Loango areas were the prime suppliers of slaves during this period. As will be shown later, this is very similar to what we know about the origin of the Suriname slaves during the 1675-1725 period.

There is one exception to the lack of documentation on slaves brought to Suriname before 1675. Unpublished research by the Austrian historian Franz Binder shows that for a brief period in the early 1670s, the area around Calabar (Nigeria) - also known as the Bight of Biafra - was a supplier of slaves for Suriname (see Table 2.8; Johannes Postma, pers. comm.). It should be noted, however, that these data are very incomplete: the years 1651-1666 are not covered at all, the shipments listed for the years 1667-1674 do not necessarily cover all shipments that took place, and, finally, for those shipments that are listed the data are incomplete as well, especially with regard to the numbers of slaves involved. Since, more specifically, no numbers are given for any of the Calabary shipments, we cannot draw any positive conclusions regarding the number of 'Calabary slaves' brought to Suriname. In addition to Binder's data, there is one other piece of information regarding the importation of slaves before 1675: Schaafsma (1966:346) writes that in April 1667, shortly after Dutch take-over, an English ship, unaware of the change in power, brought 270 slaves, all of whom were sold in Suriname.

Much more detailed information is available for the post-1675 period. Restricting ourselves to the period under discussion, some 12,000 Africans were transported to Suriname between 1675 and 1690. Their origins were more or less equally distributed over the 'Slave Coast' (the coastal areas of Togo, Benin and Eastern Ghana) and 'Loango' (the coastal areas of Zaire, Congo and Northern Angola) (Arends 1995a:245,278). We may conclude, therefore, that the major languages spoken in these two areas, namely the Gbe (Slave Coast) and the Kikongo (Loango) language clusters, are the ones that were best represented among the Africans who came to Suriname in the second half of the 17th century. This historical finding is supported by the fact that it is precisely these languages that have left a strong imprint on the Suriname creoles, as appears from a large number of 
Table 2.8 Place of departure of slave ships arriving in Suriname between 1667 and $1674^{75}$

\begin{tabular}{llll}
\hline Year & Ship & Origin & Number of slaves \\
\hline 1667 & $?$ & $?$ & $270^{76}$ \\
1667 & Maria & Calabary & $?$ \\
1668 & Zeven Gebroeders & Arguin & 198 \\
1669 & $?$ & $?$ & 160 \\
1671 & St. Jan & Calabary & $?$ \\
1671 & Maria & Calabary & $?$ \\
1672 & Poelwijk & Calabary & $?$ \\
1674 & $?$ & Ardra & $?$ \\
1674 & Goude Poort & Loango & $?$ \\
1674 & $?$ & Calabary & $?$ \\
\hline
\end{tabular}

linguistic studies such as Daeleman (1972), Huttar (1981, 1985), Smith (1987a), Bruyn (1995a), Migge (1998) and Winford (1998).

While the history of early marronage will be dealt with separately in Section 2.3.2.4, in connection with the formation of Saramaccan, let us say a few words here about early marronage in general. Although the year 1690 is often seen as the beginning of large-scale marronage in Suriname ( $c f$. Price 1983a), it is an established fact that slaves have been escaping from their plantations since the beginning of slavery. Marronage increased during the Indian War $\left(1678-1686^{77}\right)$, when Suriname was in a state of chaos (Price 1976:23-24; Buve 1962, 1966). In late 1679 , governor Heinsius estimated that as a result of the war, already some seven to eight hundred slaves had run away or been kidnapped by the Indians (Buve 1962:24). Given that marronage in Suriname goes back as early as the beginning of the English period, ${ }^{78}$ we may estimate the total number of Maroons around 1680 at well above 1,000. In addition to this, the fact that part of the 1684 peace treaty with the Indians was devoted to a group called the Coppename Nengre shows that marronage was a well-known phenomenon in pre-1690 Suriname. ${ }^{79}$

75. Johannes Postma, p.c., May 7, 1995, based on unpublished data collected by Franz Binder, unless noted otherwise.

76. Schaafsma (1966:346)

77. According to Schaafsma (1966:351), troubles with the Maroons occurred for the first time in 1678 .

78. According to Schaafsma (1966:340), the first mention of marronage, referring to the area between the Suriname, Coppename and Para rivers, dates from 1655.

79. Note that, according to Van der Meiden (1987:113), there is no archival evidence for this treaty. 
Although this group has left no creole language (see Smith 2002), this does not mean it never existed. If it did, this language could perhaps be the missing link in the transmission of language from Marshall's settlements to the English/Dutch plantation colony. However, without supporting evidence, such a scenario must necessarily remain speculative.

\subsubsection{The English exodus (1667-1680)}

One particularly important consequence of the take-over by the Dutch was the departure of a large number of English colonists with their families and part of their slaves ${ }^{80}$ in the years between 1667 and 1680 . This event has come to be known as 'the English Exodus' and it is generally - but erroneously - been assumed that there were virtually no English settlers left after 1680. This assumption is based on only one source, namely Voorhoeve \& Lichtveld's (1975:2) claim that in 1680 'only 39 Englishmen' ${ }^{81}$ were left in Suriname. Since the assumption that there were virtually no English speakers left in Suriname after 1680 has far-reaching linguistic implications, it is important to take a closer look at how Voorhoeve \& Lichtveld might have arrived at this figure. As to the number of English who left during the exodus, these authors present the following figures: (Voorhoeve \& Lichtveld 1975:2)

Table 2.9 The English exodus according to Voorhoeve \& Lichtveld (1975:2)

\begin{tabular}{ll}
\hline Year & Number of English emigrants \\
\hline 1667 & 67 \\
1671 & $? 82$ \\
1675 & 250 \\
1680 & 102 \\
\hline
\end{tabular}

Although no exact number of English emigrants is given for 1671 by Voorhoeve \& Lichtveld (1975), more specific information can be found in an unpublished note written by Voorhoeve in 1961, summarizing his findings from archival documents related to the 1667-1681 period and stored in the State Archives in Middelburg

8o. The English were only allowed to take slaves they had acquired before February 1667.

81. Incidentally, in their table (p. 3) a number of 38 is given. Since it is the number of 39 that has been repeatedly quoted in the literature, we will use that number here.

82. The total number of people (white and black) who left this year is known to be 517 . According to Rens (1953: 85), approximately half of these must have been English (but $c f$. note 111). In Rens (1954:38) an original document is quoted, referring to ' 105 families and the whole number of 517 persons'. 
(Province of Zeeland, The Netherlands). In this note, which apparently formed the basis for Voorhoeve \& Lichtveld's (1975) discussion of the exodus, Voorhoeve (1961:2) mentions a figure of 98 English who were willing to leave in 1671. Rens (1954:38), however, has argued that of the total of 518 emigrants in 1671 approximately half must have been English. If we depart from this figure of 250 emigrants in 1671, we arrive at a total number of emigrants of 619 for the entire exodus. That means that in order to arrive at the figure of 39 Englishmen left in 1680, Voorhoeve and Lichtveld must have departed from a figure of 658 English inhabitants in 1667. ${ }^{83}$ As we have show above (Section 2.3.1.1), this cannot possibly be correct: a figure of at least 1,200 English inhabitants in 1667 is much more likely. If this is true, the number of remaining Englishmen in 1680 would be at least 500 rather than the mere 39 claimed by Voorhoeve.

In order to get a clear picture of the size of the English population after the departure of the last group of English in 1680, we have to take into account several demographic factors. Apart from the size of the English population in 1667 and the number of emigrants in the 1667-1680 period, it is also important to know whether any English may have entered the colony during the period of the exodus. Unfortunately, no figures whatsoever are known with regard to European immigration into Suriname during these years. Although it is unlikely that substantial numbers of English colonists came to Suriname during this period, it cannot be excluded that some English émigrés returned after some time, especially since they were not very willing to leave in the first place and their presence was very much desired by the Dutch (see below). Secondly, and this also seems to have been completely overlooked by Voorhoeve and Lichtveld, one has to incorporate the factor of natural population increase during the $1667-1680$ period. In other words, while the English population decreased as a result of emigration, this decrease was compensated to some extent by new births. That there was a substantial birth rate among the English in Suriname at this time appears from several contemporary documents, such as Oxenbridge (c1667). Renatus Enys, a colonist who lived in Suriname at the time, wrote in November 1663 that ' $[. .$.$] the women { }^{84}$ are very prolifical and have lusty children' (Calendar of State Papers 1661-1668, quoted in Buve 1962:13). Although we do not have any hard figures regarding the natural population growth during the exodus, it is an important demographic factor that cannot be simply ignored in establishing the effects of emigration.

83. Ignoring natural increase among the English population in the $1667-1680$ period; this issue will be discussed below.

84. It is clear from the context that Enys is referring to white women here. That there was a substantial number of women among the English population is supported by the fact that of the 224 emigrants whose sex is mentioned in Cundall (1919:164-6) 43\% was female. 
Now that we have mentioned some of the potential pitfalls one has to avoid in doing these seemingly simple demographic calculations, we may take a closer look at how Voorhoeve and Lichtveld arrived at their calculations. Let us begin by looking at the figures they provide for the European population at different moments during the 1666-1684 period. These figures are important because, in the absence of any direct argumentation, they must have formed the basis for their conclusion that only 39 Englishmen were left in 1680. These figures are presented in the following table.

Table 2.10 Population figures for the European population of Suriname (1666-1684) according to Voorhoeve \& Lichtveld (1975:3)

\begin{tabular}{llcl}
\hline Date & Europeans & English & Non-English \\
\hline 1666 & 2200 & 2000 & 200 \\
1668 & 1070 & $820^{85}$ & 250 \\
1671 & 800 & 500 & 300 \\
1675 & $550^{86}$ & 200 & $350^{87}$ \\
1679 & 460 & 60 & 400 \\
1680 & 438 & 38 & 400 \\
1684 & 730 & 30 & 700 \\
\hline
\end{tabular}

85. This figure seems to be far too low: Schaafsma (1966:344) claims that in February 1667 the civil militia consisted of some 700 men. This means that the total European population at that time must have been at least around 2,000 (including women and children; $c f$. also the figure given by Voorhoeve for 1666, namely 2,200). In other words there were at least 1,750 English present in 1667. There is no reason whatsoever to assume that the population dropped to 1,070 in a year's time: the worst phase of the epidemic was over and only 67 English left in January 1668 (see Table 2.9).

86. In March 1674, the Council of Trade and Plantations estimates the number of 'English and their negroes' (Cundall 1919:158) at 700. However, in November 1674, governor Lynch of Jamaica says that the number of English early that year was 'not above 40' (Cundall 1919: 159), 'the ill climate and ill usage having killed the rest'. Also in 1674, Sir Joseph Williamson, basing himself on an eye-witness, writes in his note-book that 'the English have 1,200 negroes on Surinam, and may be themselves about $300^{\prime}$ (160).

87. The distribution given by Voorhoeve and Lichtveld would seem to be in agreement with Cundall (1919: 158), who claims, based on the writings of the Deputy Governor of Barnados, that 'there were about 200 English and 300 Dutch' in Suriname in August 1673. Writing a month later, Pieter Versterre, the Governor of Suriname, said that 'the population had fallen to about 200 men only, of whom 50 or 60 were sick' and that 'most planters' negroes have nought to eat but the greens they pick in the fields' (Cundall 1919: 158?). Finally, a report from June 1675 claims that 'at Surinam' (the river or the entire colony? JA) 'there were but 130 Dutch inhabitants besides the garrison, who, with the merchants in the town, consisted of about 140 more' (Cundall 1919: 161). 
Although Voorhoeve and Lichtveld (1975:2) refer to 'historical documents, both English and Dutch, and old maps (see Rens 1953 and 1954, Voorhoeve 1964, Renselaar 1966)' as a basis for these figures, they do not provide any rationale for the specific figures they present, for example with regard to the subdivision of the European population into 'English' and 'Non-English'. ${ }^{88}$ It is significant in this respect that Buve $(1962: 16,19)$, also based on Voorhoeve's (1961) unpublished note, does not make such a subdivision. As mentioned above, there are good reasons to cast doubt on at least some of these figures. For example, the figure of 820 English in 1668 is presumably based on a misinterpretation of the figures mentioned by Byam (1665-1667, c1667) regarding the results of the 1665-1667 epidemic. As shown in Section 2.3.1.1, a figure of some 1,200 English (including women and children) in early 1667 is much more likely. As shown below, the total number of English who left Suriname between 1667 and 1680 can be calculated at some 630. Taking all this into account, the total number of English who remained in Suriname after the departure of the last group in 1680 would have to be estimated at some 500 at the very least. It should be realized that among those 'English' who stayed behind there may have been a fair number of indentured servants. This is important as for most of them English was a second language which they had only started to acquire during their indenture. Nevertheless, the fact remains that English, in one form or another, remained present in Suriname after 1680 to a much larger extent than has been assumed.

Apart from these purely numerical considerations, there are other reasons for assuming that more Englishmen stayed in Suriname than has been previously assumed. First of all, it is known from historical documents that many English planters defected to the Dutch in 1667 (Byam 1667, in Harlow 1925:209-10, 213-4). Van der Meiden $(1987: 21,23)$ notes that they had not been very enthusiastic to defend the colony against the Dutch, who did everything they could to prevent them from leaving the colony. The reason the Dutch were so eager to have the English colonists stay was they were experienced in plantation agriculture, especially the production of sugar. Note the following remark from a 1674 document, quoted in Cundall (1919: 160): 'All the artificers are English, carpenters, smiths, \&c. The Dutch have not the skill of making sugar, but hire the very raggedest English, \&c'. Several measures were taken to make it attractive for the English to stay, such as the incorporation of three Englishmen in the governing body in 1669 (Buve

88. Note that none of the references mentioned by V\&L in this connection - Rens $(1953,1954)$, Voorhoeve (1964b), Renselaar (1966) - contains any evidence regarding the number of English staying behind in 1680 . 
1962: 19). Also, the capitulation agreement made between Crijnssen and Byam in March 1667 stipulated ' $t$ ] hat all lawes, acts and declarations shall bee published in the Dutch and English tongues, because that the inhabitants doe not understand the Dutch language and that the inhabitants shall be governed by the Netherland lawe' (De Smidt 1973, vol 1:5). Finally, the agreement reduced the initial levy of 500,000 pounds of sugar to 100,000 and the only possessions to be confiscated were those belonging to absentee owners.

Secondly, some of the English who left Suriname after 1667 may have returned after some time. While we have no data to support this, we do have some evidence that new colonists came to Suriname during the period of the exodus or shortly after. Governor Lynch of Jamaica, in a letter of January 1672, says that Christopher Rendar ${ }^{89}$ has gone to Suriname where he has bought a plantation (Cundall 1919: 157).${ }^{90}$ Furthermore, 100 English soldiers brought by Henry Willoughby in October 1667 in his attempt to re-conquer the colony stayed behind when he returned to Barbados in January 1668 (Schaafsma 1966:348). Although their fate is unknown, it does not seem unlikely that they would be absorbed in Suriname's plantation society, for example as white overseers. Finally, an additional agreement made between the Dutch commander, De Rama, and the former English governor, Byam, stated that any English who came to Suriname from Pomeroon and Essequibo were allowed to stay in Suriname (Schaafsma 1666:347). ${ }^{91}$

The claim that after 1680 there was still a considerable number of English speaking persons present in Suriname, is supported by several historical sources. For example, Hartsinck (1770:647) writes that 'de Plantagiën meestendeels door Directeurs, en wel veele Engelschen, geregeerd werden' ['the plantations are for the greatest part directed by managers, many of whom are English'; emphasis mine, JA]. The historian Van der Meiden (1987: 14), an expert in Suriname-related archival documents, claims that until 'the years between 1690 and 1700 there was an

89. In September 1673, Rendar is mentioned by Pieter Versterre, Suriname's Governor, as one of the English still present, but 'very sick... with little hope of life'(Cundall 1919: 158). In 1674, in Banister's letter referred to below, he is reported dead (Cundall 1919: 155).

90. Also note that according to Rens (1982:45n43), 168 of the 412 slaves taken to Antigua in 1668 were probably returned to Suriname after protests by the Dutch that these belonged to absentee owners and should, according to the 1667 agreement, not have been removed.

91. This agreement also included Dutch captured by the English in Guyane and Berbice not long before. The arrival of Dutch planters former Berbice in Suriname may account for the presence of the Berbice Dutch word mira 'ant' in Sranan (cf. Smith 1983). 
important English element' among Suriname's European population. ${ }^{92}$ Elsewhere, Van der Meiden (1987:29) states that 'the English element in the colony did not disappear abruptly but only gradually.' And, finally, Schilder (1973:25), on the basis of relevant original documents, says that

[t]he surrender of Willoughby Land, or Suriname as it now became, did not however mean that the British settlers were expelled. The plantations of absentee landlords living in England were confiscated, but the resident owners were given the option of selling their holdings or swearing allegiance to the States of Zeeland: if they did the latter they were permitted to remain in the colony.

(Schilder 1973:25)

Finally, there is some, slight, linguistic evidence to support the idea that speakers of English remained present after 1680. Adriaan van Berkel (1695, quoted in Smith 1984), who lived in Suriname as a plantation overseer from 1680 to 1689, mentions the following English or English-derived words being used in Suriname in the 1680s: jawes 'yaws', muskyta 'mosquito', potatoes id., speckle-wood id, swampen 'swamps', tortoises id. IT should be admitted, however, that these words could already have been borrowed from English during the transition period.

Turning now to the actual exodus, this has been dealt with in quite some detail by a number of authors, such as Rens (1953: 84-5n35), Voorhoeve \& Lichtveld (1975:2), Bilby (1983:60) and Arends (1995a: 236-8). However, with the exception of Bilby, none of these authors made use of the single most important and informative study on this topic, namely Cundall (1919). Since Cundall's study, in contrast to all others, is entirely based on archival evidence it will be taken as the basis for our discussion. Before discussing the emigration figures for the 1667-1680 period, it should be noted that two years before the Dutch take-over, in May 1665, some 200 colonists ${ }^{93}$ had already left Suriname. ${ }^{94}$ 'His Eccy Francis Lord Willoughby of Parham, our Genll \& one of our Lords Proprietors was then here, and sayled hence ye 9 th of this month [May 1665, JA]) wth whom, \& in other Ships wch imediately went after, at least 200 of our men went off.'

92. This is also supported by the presence of English names among planters after 1680. Van der Meiden $(1987: 62,113,114,118,126)$ mentions the following English names among plantation owners: Cliffort (1696), Greenwood, Neale (1731), Hope (1750).

93. Byam c1667 (Harlow 1925: 199) refers to "200 of our men".

94. It is not clear whether Barbados was the final destination of this party. This is doubtful in view of the shortage of land on the island at this time. 
The first post-1667 departure mentioned by Cundall (1919: $\left.147^{95}\right)$ refers to William Byam, former Governor of Suriname, who at an unspecified moment is said 'with some of the settlers' to have gone to Antigua (where Byam became governor). This concurs with Henry Willoughby's (Francis Willoughby's nephew) remark from July 1668 that '[...] many from Surinam were settling at Antigua' (Cundall 1919: 149). Although this group first went to Barbados (cf. Arends 1995a: 236, based on Rens 1953: 84n35), it becomes clear from Rens (1982:37) that after arriving at Barbados in February 1668 the group went on to Antigua. The second 'wave' of emigration occurs in 1671, when on 28 February two ships, the Johanna and the America, leave Suriname for Jamaica, where they arrive midMarch. 'There came 105 families, numbering in all 517 persons [...] the two ships were so filled that they had scarce room to lodge in' (Cundall 1919: 152). The third and largest 'wave' takes place some four years later, when in August 1675 three ships, the Henry and Sarah (300 tons), the America (494 tons), and the Hercules (484 tons), accompanied by the frigate Hunter as convoy, leave for Jamaica, where they arrive between mid August and early September ((Cundall 1919: 161-162). The Jamaican Governor, Lord Vaughn, writes: 'About ten days ago since arrived three of his Majesty's hired ships with 1,100 or 1,200 whites, blacks and Indians that the Commissioners had removed from Surinam' (Cundall 1919: 163). Vaughn also refers to 'a poor man that came from Surinam in his own sloop', who arrived around that same time Cundall 1919: 164). The fourth and final 'wave' takes place in February 1680 and, like the first group, has Antigua as its destiny, as appears from a letter by the Governor of Nevis, Sir William Stapleton, stating that 'the Deptford ketch had returned from Surinam with 102 persons, blacks and whites, who were now in Antigua' (Cundall 1919: 171). Although the ethnic distribution among this group is not given, it may be inferred from Buve (1962:28-9n17) that at least 50 of these were slaves. Finally, Stapleton's letter adds that 'the Dutch Governor would not permit any more to come without orders from the States [General, JA]' (Cundall 1919: 171). That this was indeed the end of the English exodus is confirmed by several historical documents. ${ }^{96}$ The figures discussed in this paragraph are summarized in the following table.

95. In what follows, reference is to Cundall (1919) unless specified otherwise.

96. It should be noted that the English were not the only ones to leave the colony after 1667. According to Buve (1962:27n9,29n18), twenty Jewish families left the colony during the 16671680 period, ten in 1667 (totaling 322 persons, including slaves), and ten in 1677. 
Table 2.11 Emigration from 1668 to 1680

\begin{tabular}{|c|c|c|c|c|c|}
\hline \multirow[t]{2}{*}{ Date } & \multicolumn{3}{|c|}{ Number of emigrants } & \multirow[t]{2}{*}{ Destination } & \multirow[t]{2}{*}{ Source } \\
\hline & Total & Whites & Slaves $^{97}$ & & \\
\hline Jan 1668 & $479^{98}$ & $67^{99}$ & $412^{100}$ & Antigua $^{101}$ & $\begin{array}{l}\text { Letters H. Willoughby, Cal } \\
\text { St Pap 1661-1668, Nos 1759, } \\
\text { 1812, in Buve 1962:26n7, Rens } \\
\text { 1982: } 37\end{array}$ \\
\hline $28 / 2 / 1671$ & 517 & $?^{102}$ & $?^{103}$ & Jamaica & $\begin{array}{l}\text { Cal St Pap 1669-1674, No } 734 \text {, } \\
\text { in Rens 1953: } 84 \text { n35; unspecified } \\
\text { source, in Cundall 1919: } 152\end{array}$ \\
\hline Aug 1675 & 1231 & 250 & $981^{104}$ & Jamaica & $\begin{array}{l}\text { Documentary evidence, }{ }^{105} \text { in } \\
\text { Cundall 1919: } 164-6\end{array}$ \\
\hline
\end{tabular}

97. In principle, this category includes both African and Amerindian slaves, although the latter are only mentioned in one case (see note referring to 1675).

98. Buve (1962:26n7), however, refers to a list - also included in Cal St Pap - containing much smaller numbers

99. Cf. Van der Meiden (1987:135n49), who says that the basis for the figure of 67 Whites is unclear, Rens's reference to the Calendar of State Papers being unjustified (without saying why, unfortunately).

100. According to Rens (1982:45n43), 168 of these were probably returned to Suriname after protests by the Dutch that these belonged to absentee owners and should, according to the 1667 agreement, not have been removed.

101. Via Barbados.

102. Rens (1953: 85n35), based on documentary evidence that about half of the settlers had to be left behind in 1671 and that in 1675 (evidently prior to the 1675 exodus), according to one source there were still 120 English families, according to another 300 Englishmen in Suriname, estimates that the figure of 517 consisted of roughly 250 Englishmen and 250 slaves. However, as shown above, these estimates of the number of English present in Suriname in 1671 are probably too low. According to Voorhoeve (1961:3): ca 151 Englishmen; according to Buve (1962:27n9, based on Voorhoeve 1961): 98 Englishmen; according to Rens (1953:84n35): 105 families. This suggests that the number of English was higher and that of slaves lower than suggested by Rens.

103. See preceding note.

104. Including, at least, 31 Amerindian slaves (documentary evidence, in Cundall 1919: 166).

105. 'A List of His Majesty's subjects and slaves transported from Surinam to Jamaica', in an unspecified volume of Cal St Pap (Cundall 1919: 164). This list contains all the names of the English settlers (men, women and children), as well as the number of slaves belonging to each family. Since this information is more reliable than that adduced by Buve (1962:19,27n9), we will disregard the latter. 
Table 2.11 (continued)

\begin{tabular}{|c|c|c|c|c|c|}
\hline \multirow[t]{2}{*}{ Date } & \multicolumn{3}{|c|}{ Number of emigrants } & \multirow[t]{2}{*}{ Destination } & \multirow[t]{2}{*}{ Source } \\
\hline & Total & Whites & Slaves & & \\
\hline Aug 1675 & $1^{106}$ & 1 & - & Jamaica & $\begin{array}{l}\text { Letter by Governor Vaughn of } \\
\text { Jamaica, in Cundall 1919: } 171\end{array}$ \\
\hline Jan 1680 & 102 & $?^{107}$ & $?$ & & $\begin{array}{l}\text { Letter of } 7 / 2 / 1680 \text { by Sir } \\
\text { William Stapleton, governor of } \\
\text { Nevis, in Cundall 1919: } 171\end{array}$ \\
\hline Total & 2329 & c600 & $\mathrm{c} 1550^{108}$ & & \\
\hline
\end{tabular}

The 1675 group of emigrants has been documented exceptionally well: A document entitled 'A List of His Majesty's subjects and slaves transported from Surinam to Jamaica' (unidentified volume of the Calendar of State Papers, quoted in Cundall 1919: 164-166) contains a listing of all Englishmen, their wives and children and the numbers of servants and slaves, including the names and sex of most of the Whites as well as the names of some of the Blacks. ${ }^{109}$ From this list it can be calculated that the 1675 group included 250 Englishmen, 950 African slaves, and 31 Indian slaves. Of the 224 Englishmen whose sex is mentioned, 131 (57\%) were male, and 99 (43\%) were female.

If we want to calculate the total number of emigrants during this period, we should take into account that apart from the ones listed in official documents, there may have been a certain number who left the colony without permission. In fact it is known that in 1679 , when it was very difficult to obtain permission to leave, some planters left Suriname 'illegally' with some 30 to 40 slaves (Buve 1962:31). Assuming that this type of 'illegal emigration' was not common during the pre-1679 years and taking into account the slaves who were probably returned to Suriname in 1668 , the total number of emigrants in the $1667-1680$ period amounts to some 2,200 , of whom approximately 650 whites and approximately

106. '... a poor man that came from Surinam in his own sloop...' (Letter Vaughn, in Cundall 1919: 164).

107. Although the respective numbers of whites and slaves in this party are unknown, it is clear that both groups were represented (letter of 7/2/1680 by Sir William Stapleton, governor of Nevis, in Cundall 1919:171). However, we know that at least 50 slaves and one English woman were involved (Buve 1962:28-9n17).

108. This figure is based on the fact that the total of $c 1,700$ should be diminished with the 168 who were returned to Suriname according to Rens (1982).

109. The latter are, unfortunately, not given by Cundall (1919). 
1,550 slaves (including at least 31 Indian slaves ${ }^{110}$ ). Combining the figure of 650 emigrants with the figure of 1,200 English inhabitants present in 1667, this leads to the conclusion that at least 500 'English' (including an unknown number of, mostly Irish, indentured servants) were left in Suriname in $1680 .{ }^{111}$ This means that, contrary to what is often assumed, the 'window of opportunity' for an Englishbased creole to develop in Suriname was by no means closed by 1680 . Combined with the evidence presented in Section 2.2. regarding the presence of English prior to 1651 , this means that the formative period of the Suriname Plantation Creole was much longer than the mere 30 years allowed in traditional accounts.

\subsubsection{The Indian war (1678-1686)}

As noted above, the transition from English to Dutch rule was not a very smooth one because many of the experienced English planters left while the Dutch were not ready yet to take it into their own hands. The latter also made a strategic mistake by seeking an alliance with the Arawak Indians, the enemies of the Carib Indians, who had been the allies of the English. Seeing how weak the military situation of the Dutch was, the Caribs took the opportunity to start a guerilla war against them, which lasted from 1678 to 1686. In this war they were soon joined by runaway slaves who had escaped in significant numbers during the 1670s. Rather than presenting a full account of this episode, we will concentrate on the - direct or indirect - consequences of the Indian War for the language situation in Suriname, specifically with regard to the formation of the Creole languages. ${ }^{112}$

While the Caribs in the eastern and western parts of the colony (the Marowijne River and Corantijn River areas, respectively) were pacified rather quickly (in 1680), the peace treaty with the Caribs in central Suriname (the Suriname, Saramacca and Coppename River areas) was not made until $1684 .{ }^{113}$ As a result of this, the plantation area shifted from the Suriname River to the Commewijne and Cottica Rivers (see Table 2.7 above). While during English rule plantations had been concentrated along the Suriname and Para Rivers, the situation had been completely reversed by the time the Indian War was over. This geographical

110. It may be suspected that the total number of Indian slaves was not very high as the Dutch would not allow them to be taken by the English (Buve 1962:20).

111. Probably more, since natural population growth during the period of the exodus is not taken into account in the calculation of this figure.

112. The following account is based on Buve (1962:21-46), Buve (1965), Hira (1982:38-47) and Essed (1984: 10-221).

113. Since final peace was not reached until 1686, we take $1678-1686$ as the duration of the Indian War. 
shift is especially important as it coincided with the emigration of many English planters and their slaves. Although a substantial number of English stayed behind after 1680, many of the new plantations in the Commewijne and Cottica area must have belonged to planters who had arrived after 1667. In addition to that, most of the plantations that still existed in the Suriname River in the 1680s area must have been owned by Sephardic planters. The latter had mostly settled along the Upper Suriname River, around Jews' Savannah, upon their arrival in the mid-1660s and many of them stayed there until their plantation grounds became depleted during the 18th century. ${ }^{114}$ The linguistic relevance of this is that while the 'old' Jewish planters in the Suriname River area spoke Portuguese (and Spanish), the 'new' planters in the Commewijne/Cottica area spoke a variety of languages, including (dialects of) Dutch, English, French and German. ${ }^{115}$ This strongly suggests that as a result of the Indian War, Suriname's plantation area was linguistically split into two sub-areas, a homogeneous one where Portuguese, and a heterogeneous one where a variety of languages were spoken by the ruling class. The linguistic implications of this for the reconstruction of creole genesis in Suriname, e.g. with respect to the differential role of Portuguese in Saramaccan on the one hand and Sranan and Ndyuka on the other, will be discussed elsewhere.

Another important consequence of the Indian War was the impetus it gave to marronage among slaves. While at first the Caribs tended to regard the slaves as enemies, this situation changed when many slaves ran away to join them in their fight against the Whites. In 1679, Governor Heinsius estimated that by that time already some 700 to 800 slaves had escaped as a result of the Indian War (Voorhoeve 1961:4). In early 1680, another 60 to 70 slaves from Jewish plantations escaped (Voorhoeve 1961:4). The role of the Maroons in the war became so important that by 1680 they formed the actual nucleus of the resistance (Buve 1966:24). While much remains unclear with regard to the fate of these early Maroons, it seems certain that at least some of them mixed with Caribs living in the Coppename region. Rather than continuing to speak their own (creole?) language, they adopted the language of the Caribs, Kari'na. In the contemporary literature, the Coppename Maroons are referred to as the 'Vrije negers van Coppename' ('Free Blacks of Coppename'); in Sranan they are known as Coppename Nenge 'Coppename Blacks'. The mixed Carib-Maroon group is known as Muraato ( $<$ Ptg. mulato, with the specific meaning of 'of mixed Amerindian-African descent') or Kabugru (< Ptg. caboclo, with the same meaning as Muraato).

114. As early as May 1668 six out of nine plantations in the 'division' of Torarica were owned by Sephardic Jews (Oudschans Dentz 1927: 13-14).

115. Since some of the plantations in this area were owned by Jews, Portuguese should also be included in this list. 
As to the origin of the Coppename Nenge, Smith (2002) dates them to the 1660s, adopting De Beet \& Sterman's (1980:6) assumption that they are related to the Maroons led by Jermes, who were already there in the English period (Hartsinck 1770: 755). This, however, is not supported by any documentary evidence. ${ }^{116}$ Pending evidence to the contrary, we will assume that the Coppename Nenge are the Maroons who escaped around the time of the Indian War, i.e. during the late 1670 s and early 1680 s. Whatever may be the case, the linguistically important fact here is that the relatively high number of pre-1690 Maroons casts serious doubt on the widely adopted scenario that the formation of the Maroon creoles post-dates the year 1690 . This complex issue, which has far-reaching implications for the reconstruction of creole formation in Suriname, is discussed in more detail in Section 2.3.2.4 below.

A third, linguistically less important, consequence of the Indian War was that according to the 1684 treaty Caribs and Arawaks (and Warraus) could no longer be enslaved. As the demand for 'red slaves' continued, these groups, especially the Caribs, started capturing members of other Amerindian groups outside of Suriname, especially to the North, selling them in Suriname as slaves. The use of these Amerindian slaves, especially for domestic tasks, continued until well into the second half of the 18th century. But since it is unknown which languages were spoken by these post-Treaty Amerindian slaves, it is difficult to assess their influence on the emerging creole languages. However, the fact that Amerindian influence in the Suriname creoles is not very strong to begin with suggests that the influence of these post-Treaty Amerindian languages has only been minimal at best.

In spite of the great damage that was caused by the Indian War, Suriname's recovery was remarkably quick once peace had been made in 1686 . This was largely due to the new governor, Van Sommelsdyk, who arrived in the colony in late 1683. He had a personal stake in its success as the Van Sommelsdyk family had a one-third share in the ownership of Suriname through the Societeit van Suriname, which had been established earlier that year. In the five years of his governorship Van Sommelsdyk was able to rebuild the colony to a size it had never had before. In the ten years between 1680 and 1690, almost 10,000 Africans were brought to Suriname and the black population increased from ca 1,500 in 1680 to ca 6,000 in $1690 .{ }^{117}$ The proportion of the number of Blacks who entered Suriname during this

116. Note, however, that Wong's (1938:299) archive based research similarly claims that Jermes's group mixed with Indians in the Coppename region to form the basis of the Kaboegers. Wong adds that, although Jermes's group should be considered as predecessors of the Saramaka, they never were part of them.

117. To understand the figure of 6,500 Blacks in 1690, despite the immigration of 10,000 during the preceding decade, one has to realize that the mortality rate among slaves was abnormally high. 
decade to the number of Blacks present at its start was more than 6.5:1 (Arends 1995a: 264). As to the exact number of plantations, for various reasons this is more difficult to establish. Still, it is without doubt that their number increased during the 1680s. Based on a cartographic analysis of early maps such as the 'Mogge map' from 1671 and the 'Labadist map' from 1686 (see Koeman 1973), Wekker (1991:75) shows that the number of plantations grew from 107 in $1671^{118}$ to 141 in 1686 . De Wit's map from 1688, not consulted by Wekker, presents some 150 plantations. The increase in the number of slaves as well in the number of plantations indicates that by 1690, after 20 years of decline, the 're-establishment' phase of Suriname was completed and that it was ready to enter a new phase, which turned out to be one of enormous expansion.

\subsubsection{Early marronage: The formation of the Saramaka Maroons and their language}

Although the formation of the Suriname Maroon creoles, in particular Saramaccan, has been a major focus of research in creole genesis, very little is known with any certainty about the formative history of the group that created this language. Nevertheless, a number of claims have been made about the genesis of and the historical relationship between the Suriname creoles, in particular Saramaccan and Sranan, based on the assumption that the formation of the Saramaka group - and, by extension, the Saramaccan language - did not begin until the 1670s (McWhorter 1997: 12), the 1680s (Bickerton 1984: 178, 1994:33; Byrne 1987:28), or even the 1690s (Bruyn 1995a: 12; Smith 1987: 117; Veenstra 1996:5). The latter two scholars claim in addition that the formation of Saramaccan was essentially completed around 1712 (Smith 1999; Veenstra 1996:5; cf. also Goodman 1987:376), leaving us with a formative phase of one generation only: 1690-1712. Without exception, all these authors base these assumptions, either directly or indirectly, on the work of anthropologist and Saramaka history expert, Richard Price (1976, 1983, 1990). Because of the historical relationship between Saramaccan and Sranan, the hypothesized formative period of Saramaccan has immediate implications for the reconstruction of creole genesis in Suriname. It is of some importance, therefore, to subject Price's claims about the formation of the Saramaka group to a serious examination, both with regard to the alleged terminus a quo (1690) and the alleged terminus ad quem (1712). These crucial events in Saramaka history will now be dealt with in turn.

The terminus a quo. Price's claim with regard to the year 1690 as the actual start of the Saramaka maroon group is based on the alleged congruence of two

118. According to an archival document referred to by Voorhoeve (1961:2) in 1671 there were 52 large plantations, each with its own sugar mill, as well as a large number of smaller plantations. 
pieces of information. The first of these consists of two fragments of oral history about the origin of the Saramaka group as presented by Otjútju, one of Price's Saramaka informants:

Oral history: Otjútju, p.c. 1978, in Price (1983a)

a. 'They had called a council meeting, those great men. To go to battle. They didn't go for any other reason! They went and stood watch, patiently, until they saw him [the white man]. Then they killed him. And then they set fire to the plantation.' (Otjútju p.c. (1978), quoted in Price (1983a:52))

b. 'From there [i.e. Matjáu Creek, JA; which is also known as Marshall's Creek or Marechal's Creek, JA], Ayako returned for a second time to their old plantation to liberate people. Lanu again prepared him. There had been a great council meeting in the forest. You see, the white man who had whipped Lanu didn't own just one plantation. They decided to burn a different one of his plantations from the place where he had whipped Lanu because they would find more tools there. This was the Cassewinica plantation, which had many slaves. They knew all about this plantation from slavery times. So they attacked. It was at night. They killed the head of the plantation, a white man. They took all the things, everything they needed. And then they sacked the plantation, burned the houses, and ran.'

(Otjútju p.c. (1978) in Price (1983a:52-53))

The second piece of evidence consists of a reference in Nassy (1788) to a group escape in 1690 from a plantation owned by one Immanuel Machado:

\section{Contemporary history: Nassy (1788)}

'A l'exception de la fuite de 2 ou 3 esclaves, ce qui arrivoit souvent aux Plantations en général, il y eut dans l'année 1690, une révolte sur une Plantation située dans la crique de Cassewine, derriere la savane, appartenant à un Juif nommé Imanuël Machado, ou apres avoir tué leur maiîre, ils s'énfuirent, emportant tout ce qu'il y avoit, avec eux ...' (Nassy 1788: 76) [Apart from the fact that two or three slaves would run away, which generally happened often on the plantations, there was in 1690 a rebellion on a plantation along the Cassewine Creek, behind the savannah, owned by a Jew named Immanuel Machado. Having killed their master, they ran away, taking everything with them that was there.] [Translation here and elsewhere is mine unless noted otherwise, JA]

It is important to note that the identification of the two events mentioned in these quotations, the 1690 escape from the Machado plantation (Nassy) and the plantation raid launched from Matjáu Creek (Otjútju), is an inference made by Price, not an established historical fact. Price's inference is based among other things on 
the fact that the name of the allegedly oldest Saramaka clan, the Matjáu, and the name Machado are 'pronounced almost identically in Portuguese/Saramaccan' (Price 1983a: 52). Additional support for this is provided by Smith (1987a: 117), who notes that the Saramaccan word matjáu 'axe' is without any doubt derived from the Portuguese word machado 'axe'119 However, neither Suriname's written history nor Saramaka oral history provides a single indication to suggests that these two events are the same. This is acknowledged by Price (p. 52), when he says, referring to Saramaka folk etymologies of the name Matjáu, that none implies any knowledge of such a planter [i.e. Immanuel Machado, JA].' With regard to Nassy's book, Price admits that it is the only written source in Suriname's entire historiography to refer to the Machado escape, adding that his 'search of the [...] 1689-90 documents in the Algemeen Rijksarchief uncovered no further information' (p. 51). In fact, the name Machado does not occur on a map from 1686, which is the only map from the relevant period that lists the names of all plantation owners of that time and which is regarded as highly reliable in an historical-cartographic study by Loor (1973:37,59). To make matters even worse, Price himself questions Otjútju's reliability as a Saramaka oral historian, admitting that Otjútju's version of Saramaka history is sometimes 'consciously distorted' (19) and that 'his [i.e Otjútju's, JA] information sometimes turned out upon examination to be spurious' (p. 36). In spite of all that, Price felt entitled to make 'a positive identification' (p. 52) between the events referred to by Nassy and by Otjútju. What is more, without presenting any real evidence - apart from the fact that from Nassy's wording it may be inferred that apparently more than two or three slaves were involved - as to the size of the escaping group, Price refers to the Machado escape as 'the great raid from Matjáu Creek' and 'this large collective escape' [p. 51; emphasis mine, JA].

Summarizing the evidence, what we have is a single written reference to the 1690 Machado escape and a single oral reference to an undated raid on an unidentified plantation launched from Matjáu Creek. As to the reason why this rather meager evidence led Price to identify the formation of the Matjáu clan (and, it being the oldest clan, of the entire Saramaka group) with the 1690 Machado escape, he provides us with something of a clue when he says that this finding represented the 'very earliest link between the Saramaka vision of their own past and the documentary record' he found and that it was 'one of (his) greatest satisfactions as a scholar of Saramaka history, and a small way of repaying (his) Matjáu hosts' (p. 51). Needless to say, considerations such as these, as important as they may be

119. It should also be noted that in the late 17 th century the name Machado may have been pronounced [Masjadu] rather than [Matsjadu] (Kenneth Brown, p.c., November 2001), which makes the link between planter and clan less strong than assumed by Price and Smith. 
from a personal point of view, should not be allowed to enter into the evaluation of empirical evidence.

As long as what is presented as a conjecture is interpreted as such, there is really nothing wrong with it. However, when it is interpreted as an established fact and starts to lead a life of its own, something is wrong. Note that neither Otjútju nor Nassy refer to a mass escape. All Otjútju says, based on oral history referring to events taking place some 300 years ago, is that the plantation he is talking about 'had many slaves' (p. 51) and that 'they took all things, everything they needed' (p. 52). As far as Nassy is concerned, although he mentions the Machado escape in a context where it is contrasted with the more usual small-group escape which involved only two or three slaves, implying that he is talking about a bigger escape here, he does not provide any information regarding the size of the escaping group, saying only that 'the slaves ran away.' (1788: 76). Nevertheless, several creolists, such as Smith (1987a:117) and Veenstra (1996:5), have claimed, on the basis of Price's conjectures, that the inception of the Saramaka began with the 1690 escape and that the formation of Saramaccan, therefore, cannot have begun before that year. This scenario, which will be referred to as the 'Machado theory', will be contrasted with an alternative scenario, the 'Marshall theory', which locates the formation of the Saramaka group several decades earlier, in the 1640s. Before that, however, some further problems with regard to the Machado theory will be discussed.

Apart from the fact that the Machado theory has been seriously misinterpreted by creolists, there are other problems with it as well, especially of a toponymical nature. In his book, Price (1983a:51), without any further explanation, interprets Nassy's (1788) Cassewine as Cassewinica. The latter is a creek located between the Suriname and Commewijne Rivers some 20 miles north-east of Jews Savannah, the Jewish settlement along the Suriname River. Although this creek is referred to as Cassewinica (or variant spellings) on maps from 1671, 1686 and 1718 (Koeman 1973, Plates 8,9 and 11), there is one map, from 1737 (Koeman 1973, Plate 13), where it is given two alternative names: Caswinica and Cassewine. Although this speaks in favor of Price's interpretation, there is at least one other possibility, namely that Nassy's (1788) Cassewine refers to the Coesewijne River, which was known in earlier times as Cossowine or Coesowine River ( $c f$. Janssen, Ten Hove and Van der Aa 1993: 148). This river is located between the Saramacca and Coppename Rivers in western-central Suriname. Although the Coesewijne River could hardly have been the 'home' of run-away slaves in 1690, simply because there were no plantations there at the time, this may have been different in the 1630s and 1640s, during the time of Marshall's settlements. This is important because this is precisely the period of origin for the Saramaka according to an alternative theory which will be discussed further below. 
Another, but related toponymical problem has to do with Price's interpretation of Nassy's phrase 'derriere la savane' (lit. 'behind the savannah') as 'behind Jews Savannah' (Price 1983a: 51), instead of the more neutral 'behind the savannah'. This interpretation seems to be motivated by Price's wish to bring Nassy's story in line with Otjútju's. Note that the word 'savane' in the Nassy quotation is spelled with lower case 's' while the proper name 'Savane' (meaning 'Jews Savannah') is consistently spelled with capital 'S' ( $c f$. Nassy 1788, part I: 22, 84, 148, 149, 160; part II: $39,49,50,52,54,55)$. This suggests that what Nassy referred to by the word 'savane' was the savannah area, not Jews Savannah. On this interpretation, the phrase 'derriere la savane' simply means 'behind the savannah'. This interpretation is consistent with both interpretations of Cassewine (either as Cassewinica or as Coesewijne), since both areas were known as savannah areas (Encyclopedie 1977, s.v. savannen).

The Coesewijne interpretation receives further support from Hartsinck (1770), who relates the origin of the Saramaka group to pre-1690 escapes in the area between the Suriname and Coppename Rivers, an area which includes the Coesewijne River:

(19) Contemporary history: Hartsinck (1770)

'De Saramecaansche Negers Marons zyn oorspronkelyk van de ten tyde der Engelsche Weggeloopene Neger-Slaaven, en hebben, langs de Rivieren van Suriname, Sarameca en Copename, boven in de Boschachtige Landstreeken zich nedergezet, en aldaar een soort van Gemeenebest opgerecht: eenigen derzelven hadden reeds moed genoeg toen de Engelschen nog in de bezitting van deeze Colonie waren, van zich in Para te verschansen, onder een Opperhoofd Jermes genaamd, zynde een Cormantyn-Neger; van daar de bygelegene Plantagien ontrustende. Vervolgens zyn zy versterkt door die geenen welke by de Landing van Cassard (in 1712) in het Bosch gevlucht zyn, en zich by dezelven gevoegd hebben; en eindelyk, van tyd tot tyd, door nieuwe Wegloopers van onze Plantagien, vooral van de Jooden: waar door zy nog een gebrooke Portugeesch onder hun Neger-Engelsche Taal voegen.' (Hartsinck 1770:755-56) ['The Saramaka maroons are descended from the slaves who ran away during the English period; they have settled upstream along the Suriname, Saramacca, and Coppename Rivers in the wooded areas and have established a kind of commonwealth; some of them had the courage, when the English were still in possession of the colony, to hide in the Para region under a chief named Jermes, a Cormantin slave, from where they disturbed nearby plantations. Subsequently, they were expanded with those who fled into the woods during Cassard's invasion (in 1712) and joined them. And finally, from time to time by new groups of runaways from our plantations, especially those owned by Jews, as a result of which their Negro-English is mixed with a broken Portuguese.'] 
The fact that Hartsinck mentions the Suriname, Saramacca and Coppename Rivers suggests that he may not refer to marronage during the 'official' English colonization (1651-1667), but to escapes in earlier period, namely during Captain Marshall's second settlement in the mid-1640s.

It is interesting to note that in an earlier work (Price 1976), before he had espoused the Machado theory, Price still endorsed the idea of an early (1640s) origin of the Saramaka, going back to escapes from Captain Marshall's settlement:

(20) Modern history: Price (1976)

'...it is possible that... the only non-Indian inhabitants of the colony [in 1651, JA] were maroons who had escaped from the short-lived settlement of Captain Marshall in the 1630s and 1640s, or from those of the French during the same period ... The supporting evidence on this point is admittedly unclear ... but were it in fact to have been the case it would mesh nicely with Saramaka oral accounts of their own earliest history...'

(Price 1976:23)

Even in Price (1983a) it is acknowledged that the beginning of the Matjáu clan goes back to pre-1690 escapes:

(21) Modern history: Price (1983a)

'the Matjáus conceive of their collective identity as having originated in a tiny band of escaped slaves who lived for some time just outside the bounds of the cultivated plantation area, on the creek now called by them Matjáu Creek.'

(Price 1983a: 52)

In Price's 1976 scenario, this 'tiny band of escaped slaves' was supplemented by others who ran away during the 1651-1690 period, when there was a continuous stream of slaves fleeing the plantations (Price 1976:23-24), especially during the war between the Indians and the colonial government, when the colony was in complete chaos and many slaves took the opportunity to escape. As noted above, in 1679 the number of Maroons was estimated by Governor Heinsius at some 700 to 800 . Since Heinsius' estimate refers to the beginning of the Indian War, it is reasonable to assume that the total number of slaves who had ran away during the war was higher by the time it ended in 1686. Although a part of them probably returned to their plantations after some time (see below), we may still assume that the total number of Maroons increased by some 500 between the late1670s and the mid-1680s. Whether these Maroons all became Saramaka or not, at least part of them will have joined Maroon groups that were already present from the 1650s onwards or even earlier. This obviously preempts the need to posit a 1690 'mass escape' in order to explain the inception of the Saramaka.

This alternative scenario, linking the origin of the Saramaka group to escapes from Captain Marshall's settlement in the 1640s, will be referred to as the 'Marshall theory'. This theory is based on Saramaka oral history, collected by the 
Belgian anthropologist Hoeree (1983). According to Hoeree (1983: 59), the Matjáu relate their name explicitly to that of Captain Marshall, making no connection whatsoever with the name Machado. What is more, Hoeree's main informant, Papreki, explicitly links the origin of the Matjáu clan to a group escape from Marshall's Creek (an alternative name of the Matjáu Creek):

Oral history: Papreki p.c., early 1980s, in Hoeree (1983)

a. '...de naam 'Marshall' (wordt) telkens weer opnieuw als verklaringsgrond voor de naam 'Matjáu' aangehaald.'(Hoeree 1983:59) [...the name 'Marshall' is adduced time and again as an explanation for the name 'Matjáu'.]

b. 'Marshall was de meester der slaven. Hij had plantages aan de (huidige) Marshallskreek (nu genoemd Matjáu kiiki)...De overige Matjáu-slaven... slaagden er toen in een 'kuutu'...ter beleggen, waarop ze besloten in groep te vluchten...Toen de andere weglopersgroepen arriveerden, waren de Matjáu reeds talrijk.'(Papreki in Hoeree 1983: 105) [Marshall was the slave master. He owned plantations along Marshall's Creek (now called Matjáu kiiki)...The other Matjáu slaves were able to have a 'kuutu' [consultation, JA], where they decided to escape in a group...When the other runaway groups arrived, there were already a large number of Matjáus.]

This scenario is supported by a high quality contemporary source, namely Schumann's (1778) manuscript dictionary of Saramaccan (compiled with the help of native speaker informants), where the clan name Matjaru (i.e. modern Matjáu) is explicitly linked to the Matjaru Creek (i.e. modern Matjáu Creek), also known as Marshall's Creek:

Contemporary lexicography: Schumann (1778)

'Matjáru-ningre ein Teil der saramakkischen Neger, die an einem Arm der Suriname zwischen dieser und der Saramakka oberhalb uns wohnen...Den Namen haben sie daher weil die Plantage ihres ehemaligen Herrn dem sie entlaufen sind, an der Kriek Matjaru lag' (Schumann 1778: 87) ${ }^{120}$ [Matjáruningre part of the Saramaka negroes living upstream along a branch of the Suriname Riverbetween this river and the Saramacca River ... The name derives from the fact that the plantation of their former master, from whom they ran away, was located along the Matjaru creek.]

Although it has been argued (Norval Smith, personal communication) that a derivation of matjáu from Marshall is problematic because of the different stress

120. The importance of the counter evidence provided by Schumann is recognized by Price, when he says that 'Matjáu 'folk etymologies' began to be recorded more than two hundred years ago (Schumann 1770 [a typographical error for Schumann 1778, JA], s.v. "Matjaru"), but none implies any knowledge of such a planter [i.e. Machado, JA]' (Price 1983:52). 
patterns of these two words, this objection disappears when it is realized that Marshall's Creek was formerly known as Marechals Creek (Janssen, Ten Hove and Van der Aa 1993:150), with stress on the final syllable in Marechal.

While little is known about Captain Marshall's first settlement of the 1630s along the Suriname River, his second, larger settlement along the Suriname, Saramacca and Corantijn Rivers in the mid 1640s has been documented in Major Scott's (c1667) Description of Guyana. The possibility that there were African slaves involved in Marshall's second settlement should certainly be kept open. There is no reason, therefore, to exclude on principled grounds the possibility that the Matjáu clan, and by extension the Saramaka Maroons as a whole, goes back to escapes from Marshall's settlement in the 1640s. This means that, as far as the empirical evidence is concerned, the two theories, Price's Machado Theory and Hoeree's Marshall Theory, should be valued equally. At this juncture, none of them can be definitively proved or disproved.

The reasoning, first followed by Price and accepted and expanded by a number of creolists, in favor of the Machado Theory seems to consist of a number of steps that are represented in Figure 2.1.

As to the reason why Price's scenario has been widely adopted by creolists while Hoeree's has gone completely unnoticed, the fact that the latter was proposed in an unpublished dissertation, written in Dutch by an unknown author, may be part of the explanation. ${ }^{121}$ Whatever may be the case, it seems clear that the question of the inception of Saramaccan has by no means been settled definitively. As will appear from the next section, this is also the case with regard to its completion.

The terminus ad quem. Just as we have shown to be the case with regard to the inception of the Saramaccan language, a similarly unwarranted assumption, again based on the work of Richard Price, has been adopted by a number of creolists (Bickerton 1994: 7; Smith 1999; Veenstra 1996:5) with regard to the end of its formative period. Price (1976), referring to the invasion of Suriname by the French captain Cassard in 1712, claims that:

(24) Modern history: Price (1976)

a. '...the last significant influx into this tribal population [i.e. the Saramaka, JA] came from slaves who escaped during the 1712 invasion of Cassard...'

(Price 1976: 30)

121. It should be noted that the absence of any reference to Hoeree (1983) in Price (1983a) may be explained by the fact that both publications appeared in the same year. This excuse is not valid, however, for Price's later publications, especially Price (1990), where the Machado theory is maintained unchanged (including the re-writing of Nassy's (1788) Cassewine as Cassewinica). In fact, Hoeree (1983) is not referred to at all in Price (1990), nor, as far as I know, in any of Price's other works. 
A. Oral evidence (Otjútju 1978): The first large Saramaka escape takes place at some unspecified (but 'early') date, when runaway slaves attack a large Cassewinica plantation, kill the owner and take everything they need.
B. Written evidence (Nassy 1788): In 1690 there was a larger-than-usual rebellion on a Cassewina plantation, owned by one Machado. The rebels kill Machado and run away, taking everything with them.
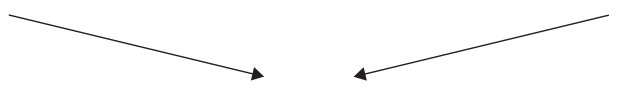

C. Price’s inferences (Price 1983a)

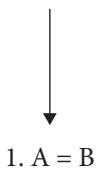

2. A/B is a large, collective escape

3. A/B forms the beginning of the Saramaka people, i.e. 1690

D. Creolists' inference (Bickerton 1984, Byrne 1987, Smith 1987, Bruyn 1995a, Veenstra 1996, McWhorter 1997):

4. Because of 3, the formation of Saramaccan as a separate language begins in 1690

E. Creolists' inference:

5. Because of 4, any similarities between Saramaccan and Sranan must date from before 1690

Figure 2.1 The genealogy of an unwarranted claim: The construction of the Machado Theory with respect to the inception of Saramaccan

This claim is based on

b. '...the fragmentary but enormously valuable genealogical information gathered by missionaries who lived and worked with them [i.e. the Saramaka, JA] on the Upper Suriname River and the Saramacca River in the 1760 s, 1770s, and 1780s, together with more recent oral data that can be correlated with it.'

(Price 1976:30)

Unfortunately, Price does not present a single piece of evidence, neither from his oral data nor from the missionaries' written documents to substantiate his claim 
that influx into the Saramaka group effectively ended in 1712. Instead, he notes casually that he 'leav[es] the documentation as well as the geographical details for another publication' (p. 30). This manuscript, entitled 'Toward an AfricanAmerican history: Saramaka society in the eighteenth century' which was still in preparation at the time of the publication of his 1976 book. Because of its theme, there can be little doubt that this manuscript was finally published as Price (1983). In this book, Price says the following about the 1712 escape:

(25) Modern history: Price (1983)

'Because the evidence is at once fragmentary and enormously complex, I merely summarize here, not citing sources, asking the reader to refer at this point to the map on p. 57 and its legend.'

(Price 1983a:56)

Unfortunately, neither the map in question nor its legend provides any additional evidence for Price's claims. As to the single piece of oral evidence that he adduces to support his claim (Price 1983a, p. 56: fragment number 15, dating from 1888 and quoted in an undated, unpublished manuscript), Price feels entitled to infer that it 'apparently refers...to the...invasion of...Cassard in 1712' (p. 56), even though in the fragment itself no mention whatsoever is made of Cassard nor any other Frenchmen, referring to "the invasion of the "English" instead.

The original source for the idea that the 1712 runaways formed a mass escape, an idea which has been adopted all through Suriname's historiography from Hartsinck (1770: 756) to Hoogbergen (1992:39), is Herlein (1718):

(26) Contemporary history: Herlein (1718)

'In de laatste onderneming der Franschen, hebben de Zurinamers ook grote schade geleden aan haar Slaven, want buiten de gene die ze mee namen, zijn 'er over de zeven hondert of veel meer, in de Bosschen, wegt geraakt.' (Herlein 1718: 93) [During the latest enterprise by the French, the Surinamese suffered great damage among their slaves, because apart from those they took with them more than seven hundred or many more were lost in the bushes.]

Although it is certainly true that the planters sent many of their slaves to the bushes during Cassard's attack, there is no evidence for the claim that 'seven hundred or many more' stayed away permanently. Apart from the fact that part of the runaways returned to their plantations after some time (Hoogbergen 1990:71), Herlein's claim is not supported by a single reference in any contemporary source (Van der Meiden 1987: 78). And even if it were true, that would still not mean that the 1712 escape formed 'the last significant influx' into the Saramaka group, as claimed by Price. Maroon groups, including the Saramaka, were continuously being supplemented by new arrivals, a process which continued even until after 
the conclusion of the peace treaties in the 1760s, which stipulated that the Maroons should return post-treaty run-away slaves to their owners.

Summarizing, there is no historical basis for the claim that the formative period of the Saramaka or their language ended by 1712 . To the extent that the formation of a creole language is embedded in the formation of its speech community, there is reason to assume that the formative period of Saramaccan extended well into the 18th century. While the potential value of historical evidence for determining the formative period of creole languages is evident, the discussion above shows that creolists should be extremely careful in adopting and interpreting historians' claims for linguistic purposes. It seems clear that the true story of the formation of Saramaccan as well as other creoles will not be uncovered until creolists cease to put blind faith in secondary sources and begin studying the primary (i.e. archival and other documentary) sources themselves.

\subsection{Conclusion}

Taking a bird's eye perspective on the entire 1651-1690 period and trying to establish its linguistic relevance, we can identify a number of events that seem especially important. On the one hand we have shown that the social-demographic continuity between the English period and the Dutch period was much stronger than is usually assumed. In its turn, this promoted continuity at the level of language in the sense that whatever contact language was developing at the time could be transmitted across the transition from English to Dutch rule. At the same time, several other events may have acted as a brake on linguistic development. The departure of a large number of English, together with a large number of their slaves, the Indian War, the rise of marronage, and the generally poor state of the colony during the first fifteen years after Dutch take-over, all contributed to disrupting the social-demographic continuity to such an extent that the colony had to be re-established. Undoubtedly, this had a negative effect on continuity in linguistic terms. Taken together, these facts may explain why an English-lexicon creole could survive after the switch in colonial power, while at the same time it was hampered in the rate of development it would otherwise have had. As we will see in the following chapters, this scenario is supported by other linguistic as well as extra-linguistic evidence. 



\section{CHAPTER 3}

\section{Social and demographic factors in creole formation}

\subsection{Introduction}

Now that the previous chapter has given us an idea of the larger historical context in which the Suriname creoles were formed, we will now zoom in on two aspects of that history that are of special importance, namely the social and demographic factors that played a role in their formation. Even though many creolists now agree that 'Creole' is a sociohistorical rather than a linguistic category ( $c f$. Mufwene 1986a, 2001), that does not mean they devote a lot of attention to studying the sociohistorical context of creolization. Apart from a few exceptions - most notably Chaudenson - the early social history of most creoles is still largely ignored by most creolists. Issues such as the social stratification within the black and white populations of the plantations or the social networks in which they participated as well as their relevance for creole formation have still hardly been touched upon. While sociohistorical evidence may still be scarce for a number of creoles, for Suriname enough information has become available in recent years to tackle these issues.

With regard to demographic questions, the situation is a little better. Le Page (1960) was the first to demonstrate the importance of incorporating historicaldemographic research in the study of creole formation, using historical evidence to gain insights into the ethnolinguistic origins of the slaves brought to Jamaica. Even though some of his results are put in doubt by more recent research ( $c f$. Arends 2008), Le Page was the first to give an empirical, historical basis to the study of substrate influence in creole languages. Some twenty years later, Baker (1982a) made crucial use of demographic data to refute Chaudenson's 'Bourbonnais' theory about the origin of Mauritian creole. While that debate still continues, Baker's study convincingly showed the importance of the demographics of inter-island migration for creole formation. More recently, scholars such as Singler (1990) and Arends (1995a) used demographic evidence to argue against Bioprogram Theory, showing that, based on the composition of the black population in Jamaica and Suriname, creolization was best seen as a matter of second as well as first language acquisition. Although the publication of Eltis et al.'s monumental (1999) CD-Rom 
has made available a vast array of historical-demographic data for many Atlantic creoles, as yet this data source has not been made much use of by creolists. For Suriname most relevant data have already been available since 1990, with the appearance of Postma's (1990) landmark study, which has been the major source for the second part of this chapter. Postma's findings replaced those of Price (1976) (based on Postma 1970), which had been creolists' major source of information on Suriname's demographic history until then.

The remainder of this chapter consists of three sections. Section 3.2 is about social issues, in particular the social stratification of the plantation populations and the external network relations in which both slaves and Maroons were engaged. In Section 3.3, a number of demographic factors are discussed, such as the ethnolinguistic origins of the slaves, the ratios of blacks to whites, bozals to creoles, children to adults, coloureds to blacks, and free to enslaved. In Section 3.4, I will summarize these findings and discuss their implications for the formation of the Suriname creoles.

\subsection{Social stratification and network relations ${ }^{1}$}

Before going on to the actual discussion, some preliminary remarks may be in order regarding the relevance of sociohistorical evidence for creole formation. First of all, as will be shown below, this evidence may serve to correct certain assumptions about the plantation system which are widely held among creolists, even though they are seldom based on actual historical evidence. One of these assumptions is the stereotypical view of plantations as extremely isolated, strictly bi-stratal micro-societies, which we have shown to be incorrect for the case of Suriname (Arends 2001). Referring to 19th rather than 18th-century Suriname (which is the focus of this section), Lamur (1985:52-3) writes that 'the pluriformity of the slaves' social life differed fundamentally from the image of uniformity that emerges from the current literature." As far as contacts with the outside world are concerned, a similar 'isolationist' view is often held with regard to Maroon communities. Based on the evidence presented here, this view also needs correction.

Second, while it is not possible at this moment to make any direct links between social structure on the one hand and linguistic structure on the other, it is still useful to get as precise a picture as possible of the social context in which creole formation took place. For instance, the existence of social contacts between slaves from different plantations, between slaves and Maroons, and between Maroons

1. This section is based on Arends (2001). 
and the outside world is directly relevant to the question to what extent language contact played a role in creolization. Similarly, information on the social stratification of the slave community may allow us to identify more precisely groups of speakers who played an important role in this process. The evidence presented below suggests that the black overseers may have formed such a group. Finally, the role of internal social networks, both within plantations' black populations and in Maroon societies, will also be discussed.

While, as noted above, important progress has been made in the investigation of sociohistorical factors in creole genesis at the macro level, especially with regard to demographics (apart from the references given above, e.g. Parkvall 2000; Singler 1990, 1993a, 1995), remarkably little attention has been devoted to sociohistorical factors at the micro level, more particularly the social structure of plantation communities. $^{2}$ One of the reasons for this is the (alleged) scarcity of relevant sociohistorical information that is available. Although for a long time this kind of information has been rather scarce for Suriname as well (cf. Oostindie 1987), the situation has improved significantly since the last two decades. Well-known works from the late 1940s and early 1950s, such as Van Lier (1977 [1949]) and Rens (1953), have been followed up by a number of highly informative studies, such as Lamur (1987), Oostindie (1989), G. Brana-Shute (1990), Van Stipriaan (1993), Muyrers (1993), Beeldsnijder (1994) and Everaert (1999).

Apart from these studies, which are devoted specifically to (aspects of) the history of Suriname's plantation society at the micro level, several other works have appeared, such as Beeldsnijder (1991), R. Brana-Shute (1989), Hoefte (1996), Lamur (1985, 1990), McLeod-Ferrier (1993) and Dragtenstein (2002, 2004), which touch upon it only marginally, but still contain interesting information on this topic. The fact that both the latter studies and those mentioned before are largely based on primary evidence (i.e. archival documents) adds significantly to their reliability. This is important because contemporary historical works, which have determined the image of plantation life for the past few centuries, often have a tendency to neglect or distort aspects of the world of the slaves, if they provide any original information at all rather than simply plagiarizing their predecessors. In fact, I have tried to avoid relying on tertiary historical sourcesas much as possible, i.e. works which are themselves based on secondary sources rather than original archival research. Due to the state of progress in Surinamese historiography, however, it has not always been possible to exclude such tertiary sources. It may also be important to note that, while some of these works (e.g. Oostindie 1989; Muyrers 1993) are in-depth case-studies, based on data for only one or two plantations, other studies

2. A notable exception, apart from Chaudenson's work mentioned above, is Singler's work (1993b, 1993c) on the French Caribbean. 
(especially Van Stipriaan 1993, Beeldsnijder 1994) are based on data for a representative selection of plantations, thereby providing a more generally valid view. ${ }^{3}$

This section contains a detailed discussion of two aspects of the social structure of the plantation system: (1) the internal social stratification of the plantation community and (2) the external relations (i.e. contacts outside the plantation) maintained by the slaves. Since the focus is on social life at the plantation - the primary locus of creole formation - and because the social history of Paramaribo has hardly been investigated as yet (R. Brana-Shute 1990:121), the urban setting will only be touched upon in passing. Although they are not without possible linguistic relevance, intra-plantation contacts will not be considered explicitly, simply because the type of evidence that would be needed to assess that relevance is largely lacking. If the fact that slaves had a much more elaborate social life than is often assumed - dance and music festivities, such as the balyar party, the pree, the banya, and the $d u$ ( $c f$. Chapter 7), religious events (winti), story-telling sessions etc - did have an impact on their language, it is entirely unclear what that impact was. The same is probably true with regard to the Maroons.

As far as the Maroons are concerned, most of the information that is available deals with their contacts with slaves, especially relating to the preparation of escapes. Since such information is discussed below in connection with slaves, it would be a mere duplication to treat it separately with regard to Maroons. Evidence regarding other external contacts of Maroons, however, will be discussed separately.

The discussion will be restricted to the expansion and stabilization phases (i.e. the post-establishment phase) in the development of Suriname's plantation society, i.e. roughly the $1690-1770$ period. The reason not to include the equally (or even more) important pre-1690 years in this study is the fact that, apart from Rens (1953), hardly any historical evidence for this period is available.

\subsubsection{Social stratification}

Until quite recently, the typical image of the New World plantation based on slave labour was that of a strictly bi-stratal mini-society in which the two ethnic groups involved - blacks and whites - formed two 'blocks' that were both

3. Van Stipriaan (1993) is based on archival documents concerning some 200 plantations in the $1750-1863$ period, i.e. almost $30 \%$ of the total number of Suriname's plantations throughout its existence as a plantation colony. Beeldsnijder (1994) is based on archival documents for 18 plantations, providing data about 2,062 slaves ( $12 \%$ of the total slave population) in the 1730-1750 period. In both cases, the archival documentation consists primarily of plantation inventories (i.e. valuation reports); these data are supplemented by letters, legal records and other archival documents. 
internally homogeneous and externally strictly separated from each other. Modern historical research, however, has shown that the situation was much less extreme than is suggested by this picture. The technical complexity of the plantation as an agro-industrial unit brought along a division of labour which inevitably led to a differentiation in occupations and concomitant social stratification. The production and processing of tropical crops, especially sugar, was such that it required the labour of highly specialized technicians, especially sugar boilers, in order to be executed professionally. Once the cane had been cut, it had to be processed within twenty-four hours in order to prevent it from going bad. The juice that was pressed from the cane had to undergo a number of operations during all of which keeping the right temperature was essential. Apart from sugar, a number of by-products were made from the juice, such as molasses and 'dram', the production of which required their own special skills (for further information, see, e.g. Mintz 1987). Although the processing of other crops, such as cocoa and tobacco, was less complex, these too required special skills. As in the case of sugar, all these specialized tasks were performed by blacks.

Apart from these highly specialized tasks involved in the production and processing of plantation crops, there were a number of other skilled professions that, although they were often carried out by whites, were sometimes practiced by blacks, such as those of carpenter, cooper, mason and blacksmith. In addition to that there were a number of tasks pertaining to providing and preparing food for the whites, such as hunting, fishing, gardening and cooking, and the care for the planter and his house. The latter category of domestic slaves included maids, servants, washerwomen etc. The total number of slaves involved in tasks such as these was so high that, added to those groups who were not fit to work (children, elderly, sick), on average less than $50 \%$ of a plantation's black population actually worked in the fields (Van Stipriaan 1993, Beeldsnijder 1994). This is in stark contrast to the stereotypical image of the plantation as a place where most slaves are involved in field labour. The division of labour that was a result of this led to a social differentiation among the black population, especially between so-called 'elite slaves' (especially the skilled workers, the domestic slaves, and, of course, the black overseer) on the one hand and field slaves on the other. This differentiation was enhanced by the fact that locally-born and mulattos were clearly preferred for the elite jobs.

The fact that on average the slaves would be $90-95 \%$ of a plantation's total population indicates that the group of free persons - who did not necessarily consist only of whites since some skilled jobs could also be performed by free blacks - was usually very small. The total number of whites on an average plantation (50-100 slaves) would be well below five, often no more than two or three (unless the owner's family lived on the plantation, which - except on Jewish-owned plantations - was 
the exception rather than the rule). While some owners lived on their plantations, others preferred to live in Paramaribo or even in the Netherlands, leaving the daily operation of their estate to a directeur, a plantation manager. When from the late 18th century onwards many plantations came into the hands of banks and other investment companies in the Netherlands, local responsibility was delegated to so-called administrateurs 'agents', who would also more often live in Paramaribo than on the plantation. Since on an average plantation skilled workers would often be hired rather than being employed on a permanent basis, apart from the directeur and a bookkeeper - if present - the only other permanent white resident(s) would be the one or two white overseer(s). This function, which belonged to the lowest in plantation society and which in many ways was below that of the black overseer, was often performed by former soldiers or sailors. This hierarchy within the white population was already in place in the early 18th century, as appears from the average annual wages mentioned by Herlein (1718: 84-87), who presents the following figures (in Surinamese guilders):

Table 3.1 Annual wages for white plantation personnel: Early 18th century

\begin{tabular}{ll}
\hline Professional category & Average annual wage \\
\hline Manager & $700-1500$ \\
Mill-maker/Carpenter & $250-300$ \\
Bookkeeper & $200-250$ \\
Cooper & 200 \\
Surgeon & $150-200$ \\
White overseer & $80-100$ \\
\hline
\end{tabular}

This clearly shows that division of labour - contra Lamur's (1985) suggestion that this was unknown in Plantation Suriname until the 19th century - was in place as early as the beginning of the 18th century (cf. also Oostindie 1989:449-451; Beeldsnijder 1994, ch. 6).

Looking at the 18th century as a whole and basing ourselves on works which are themselves based on primary evidence such as archival documents (Lamur (1987), Oostindie (1989), Van Stipriaan (1993), Beeldsnijder (1994)), we arrive at the picture in Table 3.2, which presents the social stratification of a plantation's free population. Here not only annual wages but other variables, especially ethnic group and average number per plantation, are included as well. As can be seen from this table, division of labour correlates to a large extent with annual wage. It should be stressed, however, that the picture represented in this table is a schematic one, showing tendencies rather than absolute truths. 
Table 3.2 Social stratification of free plantation population: 18th century

\begin{tabular}{llll}
\hline $\begin{array}{l}\text { Professional } \\
\text { category }\end{array}$ & $\begin{array}{l}\text { Social/ethnic } \\
\text { group }\end{array}$ & $\begin{array}{l}\text { Average annual } \\
\text { wage (guilders) }\end{array}$ & $\begin{array}{l}\text { Average number per } \\
\text { plantation (50-100 slaves) }\end{array}$ \\
\hline Owner & Whites & n.a. & $0 / 1$ \\
Administrator & Whites & n.a. & $0 / 1$ \\
Manager & Whites & $700-1500$ & 1 \\
Skilled worker & Whites, free Blacks, & $200-800$ & $0 / 1$ \\
Bookkeeper & Wree Mulattoes & & \\
White overseer & Whites & 250 & $0 / 1$ \\
\hline
\end{tabular}

Several aspects of this table require some explanation:

- Temporary personnel, such as barbers/surgeons, who visited plantations only occasionally, and certain specialized artisans, who were hired for limited periods of time, are not included in the table.

- The identification of social/ethnic groups from which people were selected for particular tasks does not exclude the possibility that in some cases people from other groups performed these tasks. Thus, in the literature mention is made sometimes of mulatto or even black 'white' overseers, managers, and even plantation owners, but this seems to have been rare, especially at the beginning of the 18th century. According to Lamur (1987:43), black and mulatto skilled workers became a more frequent phenomenon in the course of the 18th century.

- Annual wages were not given for plantation owners and administrators, since they derived their income directly from the profits of their plantation(s).

- Within the category of skilled workers, wages varied from 200 guilders for coopers to 800 for carpenters (Beeldsnijder 1994:92). According to the same author (p. 89), usually one (non-captive) carpenter resided permanently on sugar plantations in the $1730-1750$ period.

- The bookkeeper's task was often performed on the side by one of the other white personnel (Beeldsnijder 1994: 93).

- The low position of the white overseer (blankofficier) in the plantation's hierarchy also appears from regulations for plantation personnel (dating from 1686 and 1725), discussed in Beeldsnijder (1994: 90).

- In the course of the 18th century, especially from the 1750s onwards, after going bankrupt many plantations fell into the hands of overseas owners, such as banks and other financers. According to Beeldsnijder (1994: 63), more than $70 \%$ of the plantations was owned by absentee planters from 1770 onwards. Similarly, Oostindie (1993:34 n90) estimates the percentage of absentee 
owners at $70-80 \%$ in the $1780-1830$ period. Although Beeldsnijder claims that large-scale absenteeism may have begun much earlier, according to Van Stipriaan (1993:293) around 1750 only 20 to $25 \%$ of the plantation owners were living outside Suriname. This phenomenon is known as 'absenteeism' (Van Lier 1977), i.e. the situation whereby the actual Europe-based owner of a plantation was represented in Suriname by an administrateur (agent), who resided in Paramaribo rather than on the plantation itself. The actual day-today management of the plantation was in the hands of a directeur (plantation manager).

- During the expansion and stabilization phases, with the important exception of the Jewish-owned plantations, white women and children were rarely present on plantations. Beeldsnijder (1994:41) has calculated, on the basis of head tax payments, that at least half of the planters coming to Suriname were unmarried. Jewish planters, however, often lived on their plantations with their families (p. 247). White plantation personnel, especially white overseers, were mostly recruited among unmarried former soldiers and sailors.

- Needless to say, perhaps, all of the above professions were restricted to males.

Taking the same sources that we used for Table 3.2 (Lamur (1987), Oostindie (1989), Van Stipriaan (1993), Beeldsnijder (1994)), we arrive at the following picture of the social stratification among the captive population, given in Table 3.3. Since, for obvious reasons, this hierarchy could not be based on annual wages, it is based on estimated market values. Apart from market value, other variables, especially social/ethnic group and percentage of the overall enslaved population, are included too. Again, it should be stressed that the picture represented in this table is a schematic one, showing tendencies rather than absolute truths.

Table 3.3 Social stratification of enslaved plantation population: 18th-century

\begin{tabular}{lllc}
\hline $\begin{array}{l}\text { professional } \\
\text { category }\end{array}$ & Socails/ethnic group & $\begin{array}{l}\text { Estimated market } \\
\text { value (guilders) }\end{array}$ & $\begin{array}{l}\text { Approximnate } \\
\text { percentage of enslaved } \\
\text { population }\end{array}$ \\
\hline $\begin{array}{l}\text { Black overseer } \\
\text { Skilled slave }\end{array}$ & $\begin{array}{l}\text { Creoles/Africans } \\
\text { black/mulatto Creoles, } \\
\text { Africans }\end{array}$ & $500-800$ & $2 \%$ \\
Domestic slave & $\begin{array}{l}\text { black/mulatto Creoles, } \\
\text { Africans }\end{array}$ & $10 \%-500$ & $4 \%$ \\
Unskilled slave, field & Africans, black Creoles & $300-500$ & $25-60 \%$ \\
slave & all groups & $<100$ & $20-40 \%$ \\
Unproductive slave & & & \\
\hline
\end{tabular}


Again, some additional information is in order:

- The terms 'Creoles' and 'Africans' refer to locally-born and African-born slaves respectively. While Creoles were generally preferred for skilled labour and for domestic tasks (Oostindie 1989: 114-115; Beeldsnijder 1994: 124-5, 139, 149), this was apparently not the case to the same extent for the position of black overseer (basya). Even though the number of locally-born male slaves exceeded the number of basya positions by far, less than half of these were occupied by Creoles (p. 124, 154). ${ }^{4}$ However, although African-born slaves were frequently selected as basyas, this should not obscure the fact that in general 'salt water slaves' were looked down upon by Creoles. Oostindie (1989:115) notes that only those who had been brought to Suriname at a young age had any chance of becoming a skilled labourer.

- In Suriname, as in other colonies, slaves newly arrived from Africa were subjected to a process of 'seasoning', whereby an older slave would acquaint them with plantation life, including the creole language, before they were made to work the fields. Cf. Stedman (1988:528): ' ...under the Care of Other Old Negro Slaves, they Soon become verry Fat \& Sleek, learn the Language of the Colony, $\&^{c}, \ldots$, and Anon. (ca.1740: ${ }^{5} 77$ ): 'If they are females, the manager should have these new slaves married right-away, and if they are males, he should put them in the house of some old slaves, but he should see to it that thay are not suppressed too much for it is customary for such a new slave to serve in an old slave's household and act as a servant, until he understands the language and the work, or until, if he has a woman of his own, he has his own household'.

- Within the category of skilled slaves there was a sub-hierarchy, with carpenters (in a wide sense, i.e. including sawyers and coopers) at the top. And even within this subcategory, a further hierarchy obtained with carpenters (in a narrow sense) at the top, followed by coopers, sawyers and apprentices (Oostindie 1989: 105). Other craftsmen which are sometimes mentioned are blacksmiths, coppersmiths and bricklayers (Oostindie 1989: 105-10). As mentioned earlier, another type of skilled labour that was highly valued because it required great technical skill was that of sugar boiler.

- The number of Mulattoes mentioned in the plantation inventories studied by Beeldsnijder (1994: 125) is surprisingly low, namely 1.5\% of the slave

4. This observation is based on a sample of 89 basyas.

5. Based on information in the text itself, this work was written sometime between 1730 and 1748. I was made aware of the existence of this text by the late Dr Ruud Beeldsnijder, for which I am very grateful. 
population. This may be due to the fact that not only those who were manumitted by their white fathers but also those who were sent to Paramaribo to learn a trade (p. 139) were not included in the inventories. Mulattoes were preferred over Blacks for skilled labour (Oostindie 1989: 115). Within the category of coloured slaves, there was a finely-grained sub-hierarchy depending on the proportion of white ancestry, with its accompanying terminology. In increasing order of 'whiteness' (using the terms that were common in colonial Suriname): karboeger (1/8), sambo (1/4), mulatto (1/2), quadroon (3/4), mesties (7/8), casties (15/16), and poesties (31/32) (Stedman 1988:399, bottom part of Plate 54). The fact that the terminology is more fine-grained at the white end of the scale is indicative of the importance that was attached to light skin colour.

- The category of domestic slaves (in a wide sense, i.e. including not only those who worked in or near the big house but also those whose work was in some way related to the household) was a very diverse one. While some of the domestic tasks were largely restricted to women, others would usually only be performed by men (Oostindie 1989: 109-10,116). The former include midwife, orderly, maid, washerwoman, seamstress, cook, and nanny (creole mama). Typically male domestic tasks were that of dresneger (black medical expert), watchman (over cattle, the provision grounds, sluices), cattle-herder, and gardener. Apart from the first, these were often performed by elderly or invalid male slaves, just as the creole mama was usually an elderly female slave. Finally, slaves were sometimes sent out to hunt and fish, in order to supplement the food supply for the planter's house.

- The category of unproductive slaves includes persons who were unable to work, either due to age or some physical or mental defect. Slave children started to perform light duties around the age of ten to twelve; around the age of eighteen they were considered to be fully grown workers (p. 180). As noted by Beeldsnijder (p. 116), the average life expectancy of a mid-18th-century Caribbean slave who had survived his first year in the colony was 30 years.

- Some of these positions, e.g. those of basya and skilled slave, could be occupied by one and the same person. Also, slaves could be promoted or demoted from one position to another. According to Beeldsnijder (1994: 16), switching between different tasks was the rule rather than the exception on Surinamese plantations. This means that the hierarchy was less fixed than may be suggested in Table 3.3.

- There is some evidence that the categories of black overseers, skilled slaves and domestic slaves formed a kind of 'elite' within the enslaved population. Beeldsnijder (1994: 157) has found some evidence in legal records to support this. This suggests that the stratification within the slave population was primarily a dichotomous one: elite slaves versus all the other slaves. 
In what follows, one category within the enslaved population, the black overseer, will be discussed in some more detail. Before doing that, however, I will say a few words about the issue of social stratification within the early Maroon communities. Although little direct historical evidence is available on the social structure of these communities, it is still possible to say a few things about this issue. It is clear that by the time of the 1760s peace treaties, but perhaps even long before that, the administrative system with a granman as a chief of the whole 'tribe' and a kabiten 'captain' for every village was already in place ( $c f$. the text of the Saramaka Peace Treaty in Chapter 7, where the names of the captains are mentioned at the end). A more differentiated system - with a Groot-Opperhoofd 'great chief' (i.e. granman), a Majoor 'major', Hoofd-Kapiteins 'head captains', and Kleine Kapiteins 'little captains' - existed at least as early as the 1820s (Van Eyck 1830:265). It is quite likely that the domain of religion also led to social differentiation early on, with religious functionaries, such as the obiaman, enjoying high prestige in the community. It is unclear, however, what the linguistic correlates (if any) of this social differentiation may have been.

Going back to the plantations, an important fact about the plantations' residence patterns is that white personnel were by far the least continuous segment of the population. Suriname's 18th-century white population is characterized by Beeldsnijder (1994:45) as "a white pioneer community consisting of many single men, who had no intention to stay permanently". Towards the end of the stabilization phase (around 1770), the average duration of a manager's residence on a plantation was 5.5 years, while that of a white overseer was as short as 1.1 years (Van Stipriaan 1993:284-285). In contrast, slaves usually spent large parts of their lives on one and the same plantation. The absence of continuity among white personnel, especially among white overseers, undoubtedly contributed to a situation where the position of the black overseer in the hierarchy, in spite of his colour and his status as a slave, in some respects equaled that of his white counterpart, the blankofficier. Other factors also contributed to this state of affairs. Many of a basya's daily activities, such as allocating tasks, supervising work, and executing punishments, made him into an intermediary between manager and slaves. Combined with his knowledge of black culture, this gave the basya a degree of power among the slaves which sometimes may have surpassed that of the white overseer. At the same time, however, the basya's role as a buffer between masters and slaves may have had unfavorable consequences for his hierarchical position as well (Van Deursen 1975:217; Oostindie 1989: 165).

In addition to this, there are some indications that the black overseer not only performed the role of priest in Afro-Surinamese religion but that he played a central role in subversive activities, such as rebellions and escapes, as well (Van der Meiden 1987: 111; Lamur 1990: 112-113; Van Stipriaan 1993:282; Beeldsnijder 
1994: 155). Although Beeldsnijder (1994:157) is not certain that the basya occupied a socially privileged place within the slave community, he adds that in at least one legal document basyas are referred to as 'chiefs' among the slaves. The same author (p. 232) mentions a case of a rebellion in 1750 where five out of sixteen conspirators were black overseers. The convergence of the roles of basya and priest on Surinamese plantations has been noted by Lamur (1985:26), who quotes a Moravian missionary’s report referring to “...den ersten Bastian welcher zugleich der erste prister ist...” [the highest ranking basya who is also the highest ranking priest]. Documents referring to a religious conflict between missionaries and slaves that took place on the plantation Vossenburg around 1850 show that it was especially basyas who were involved in this. Lamur (1990:112-113) concludes from this that the basyas "were looked upon by the fellow slaves as functionaries responsible for maintaining the slaves' religious system." Although the evidence is still rather sketchy, it suggests that black overseers were central figures among the plantations' black populations.

The question is, of course, whether the basyas' seemingly pivotal role on the plantation had any linguistic consequences, and if yes, what these consequences were. Unfortunately, at this stage it is only possible to speculate. One possible avenue through which this question could be pursued is the social networks approach developed by Leslie and James Milroy (L. Milroy 1980). Due to his intermediary position, in between the white and black segments of the population, the basya probably had weaker (though not fewer) network ties within the black community than other slaves had. At the same time, his contacts with the few Whites on the plantation were stronger and more frequent than those of most other slaves (except perhaps the domestic slaves who worked in the planter's house). Also, his verbal interactions with white personnel must have involved a more extended vocabulary, including technical terminology relating to the production of crops such as sugar or coffee. The idea that this vocabulary was Sranan (rather than Dutch) is supported by references to the importance of managers and artisans knowing Sranan, which can be found in 18th-century plantation manuals such as Van Dyk (ca. 1765) (see also Beeldsnijder 1994: 86).

From the perspective of the social network model of language variation and change (J. Milroy 1992), this combination of features adds to the basya's potential role as a linguistic innovator. At the same time his prestige as a political and religious leader contributes to his position as a linguistic role model, especially for the African-born slaves, who formed a majority among the black population until the end of the 18th century (Price 1976: 12; cf. also Section 3 of this chapter). The question, of course, is whether it is justified to apply this model, which was designed for 'normal' language change, to the process of creole formation. A major difference between the two is that in the latter case we are dealing with 
the creation of a linguistic system rather than changes within an already existing language. Nevertheless, it would be interesting to know whether black overseers, many of whom were African-born, were selected from specific ethnolinguistic groups, since in that case the languages spoken by those groups may have played a disproportionately large role in the formation of Sranan.

Unfortunately, no evidence on this matter is available with regard to Suriname. All we have are occasional remarks in contemporary works regarding personality traits of different ethnic groups, the reliability of which is difficult to assess. What is needed is the kind of primary evidence on ethnic affiliation of basyas that is sometimes found in plantation inventories or similar archival documents. Some evidence of this kind is available for another colony, namely Cayenne (French Guiana). Singler (1993b: 206-207), based on detailed archival documents from 1690 concerning a sugar plantation in this colony, states that among the African ethnolinguistic groups present on the plantation (including Atlantic, Mande, Akan, Gbe, Yoruba, and Bantu) the Gbe and Akan groups received the highest rankings in terms of productivity. Typically, it was a 'Juda' (an African transported from Ouidah on the Slave Coast, i.e. probably a Gbe-speaker) who served as a black overseer at this plantation.

Similarly, Alleyne (1971: 176), referring to "certain psychological and cultural traits possessed by the Coromanti [Akan, JA]," states that "they certainly seem to have been everywhere leaders of slave revolts," but unfortunately he does not mention any sources to substantiate this claim. Alleyne's claim is in line with the general impression gathered from the literature regarding Suriname to the extent that the Akan were favored among planters, while Loango slaves were considered second choice (Beeldsnijder 1994: 108, 122-123). This is supported by the fact that the average price for a Loango slave was some $20 \%$ below that for other slaves (p. 110). Although much more historical research is needed to substantiate the idea that speakers of particular Kwa languages were preferred as overseers, if such a preference were found, it would be in line with the general impression that the influence of Kwa languages on Sranan and other Suriname creoles is stronger than that of Bantu languages.

As far as the urban context is concerned, a development with major social consequences was manumission, i.e. the freeing of slaves on an individual basis, which in Suriname did not begin on a significant scale until well into the 18th century (Brana-Shute $1985^{6}$ ). Since manumission was largely restricted to Paramaribo, its implications were especially important for the urban context. The most important of these implications was the emergence of a new class of free blacks and free

6. The remainder of this paragraph is largely based on Brana-Shute (1985: 74-83), one of the very few studies of the social development of Paramaribo in the 18th century. 
coloureds, the latter of which were more numerous since they were more often manumitted than blacks. As a result of this, the proportion of free blacks/coloureds to the overall free population rose from around $22 \%$ in 1738 to some $60 \%$ in 1811 (p. 99). Since manumitted slaves were concentrated in Paramaribo, their proportion to the overall free population there must have been even higher. This means that Paramaribo had not only become very much a black town but also one in which there were far more free blacks than there were free whites. This, combined with the fact that increasing numbers of free blacks were themselves owners of slaves, had a strong impact on the 'plantation ideal' of a completely dichotomous white-black society, as a result of which Paramaribo became a completely different type of society from that of the plantations. In this new context, the free blacks/ coloureds, who lived in much closer proximity to whites than did the slaves on the plantations, contributed significantly to the creation of a new urban creole culture.

The emergence of this new group coincided with the growth of Paramaribo from 'a spare, squalid settlement huddled around a fort to a primate capital city that dictates to the rest of the country' (74). While social institutions such as churches (Reformed, Lutheran, Moravian) and synagogues (one for Sephardic and Ashkenazic Jews each) had been present from the late 17th and early 18th centuries onwards, it was only during the second half of the latter that new phenomena such as theatres (one for Christians and Jews each), gentlemen's clubs (again one for Christians and one for Jews) and Freemason lodges (which have continued to play an important role in Paramaribo's social life until today) were introduced, along with a school for coloureds. In this same period the first newspapers started to appear.

\subsubsection{External networks}

Before we turn to the issue of the external contacts maintained by plantation slaves as well as by Maroons, it should be emphasized again that during the post-establishment phase on average less than half of a plantation's black workforce actually worked in the fields (Beeldsnijder 1994: 160,276; see also Table 3.3 above). This means that the stereotypical view of the plantation as a place where the bulk of the slaves belonged to the anonymous labour force working the fields and having hardly any contact at all with anybody except fellow-slaves is incorrect. Due to the technical complexity of sugar cane processing, which required a considerable portion of the slave population to work at the sugar mill rather than in the field, this seems to be especially true for sugar plantations (Klein 1986:61-62). The significance of this fact becomes clear when it is realized that a significant part of the formative period of Sranan took place in the context of sugar production; coffee, the other major crop, was not introduced until the second quarter of the 18th century (Van Stipriaan 1993). 
The primary source for information on external network relations is Muyrers (1993), which is entirely devoted to this subject. Much of Muyrers' data is based on primary evidence regarding only one plantation (Catharina Sophia), which was owned by the colonial government and which therefore may have been a kind of 'model' plantation. In addition to this, her data refer to the mid-19th rather than the 18th century, which is the focus of this chapter. Nevertheless, Muyrers claims, based on data from secondary 18th- and 19th-century sources, that her data may be considered representative for other plantations from the same and earlier periods. ${ }^{7}$ This is confirmed by other studies, such as Keller (1982), R. Brana-Shute (1989), Oostindie (1989, 1993), Van Stipriaan (1993), and, especially, Beeldsnijder (1994), which show that virtually all types of external contacts mentioned by Muyrers for the mid-19th century were common a hundred years earlier. (Studies such as Fleischmann (1984), on the French Caribbean, and Speedy (1995), on Louisiana, show that the existence of relatively frequent external contacts among slaves was by no means limited to Suriname.)

The types of contact listed by Muyrers (p. 99-108) are subdivided here into four categories according to the context in which these contacts took place: work, trade, leisure, and resistance. The list is supplemented with two additional types of contact which are not mentioned by Muyrers. (If no particular source is mentioned in this list, the reference is Muyrers 1993; in cases where a source is mentioned, it is often complementary to Muyrers 1993.)

Contexts enabling external contacts for slaves:

Work:

- Transport of persons, products, necessities, and correspondence by boat to and from Paramaribo, enabling communication with slaves on other boats, on other plantations, and in Paramaribo. Blacks used for this work were mostly skilled slaves, either from Paramaribo or from the plantation. Communication with other Blacks often took place through - sometimes secret - songs ( $c f$. the rowing songs discussed in Chapter 7).

- Hiring of slaves from other plantations or from Paramaribo.

7. Apart from archival documents about Catharina Sophia, Muyrers' database includes some fifteen contemporary secondary sources. According to Muyrers, during the 18th century the number and intensity of contacts may have been less than in the 19th century, because sanctions were more severe and the solidarity among slaves from the same plantation was weaker, which enhanced the chance of being betrayed when leaving the plantation without the owner's consent. To some extent, however, this may have been counterbalanced by the fact that in the 18th century ethnolinguistic identity and the relationship between sipis (slaves who had been transported on the same ship) were more important factors of solidarity than living on the same plantation. 
- Hiring of skilled workers or contractors from Paramaribo to supervise certain jobs done by local skilled slaves on the plantation (Oostindie 1989: 73, 94-95, 116).

- Apprenticeship with a craftsman in Paramaribo (Beeldsnijder 1994; Oostindie 1989: 114).

- Taking part in the so-called commando service, the compulsory service to the colonial government comprising such tasks as digging out creeks, building fortifications, ${ }^{8}$ and taking part in military patrols against Maroons. Around the middle of the 18th century, military tasks began to become more professionalized and slaves were used less to perform them (Beeldsnijder 1994: 78, 83). In the 1770s, two regiments of free black soldiers were founded, whose special task it was to bring back runaway slaves and to fight newly formed Maroon tribes such as the Boni.

- Temporary or permanent transfer of whole workforces from one plantation to another (see also Beeldsnijder 1994:219).

- Banishment of slaves to other plantations as a means of punishment.

- Working at a plantation's provision grounds, which were often located behind the plantation itself (i.e. several miles away from the planter's house), enabling contact both with slaves from other plantations and with Maroons and runaway slaves.

- In the period following the 1760 s peace treaties, Maroons would occasionally be hired to work on plantations; it seems, however, that this practice lasted only a few years (Wolbers 1861:285note§).

- Hunting and fishing by slaves, to supply both their masters and themselves with food.

- Temporary residence of ailing and pregnant slaves in Paramaribo. This did not happen frequently until the last quarter of the 18th century.

Trade:

- Trading at the marketplace in Paramaribo. Note that trading at the market in Paramaribo is mentioned as early as Herlein (1718:95).

- Trading on the plantations with Maroons, free Indians, and Whites. According to Beeldsnijder (1994: 87,224), both free Indians and Europeans (soldiers, sailors, and smugglers) came to the plantations in order to trade with slaves. Although trading with Maroons was not officially permitted until the 1760s peace treaties, this seems to have happened quite frequently. A fact which has been neglected up to now is that, due to the intensive trade between North

8. The total number of slaves that planters were officially required to deliver in order to work at the fort in Paramaribo was 300, but this number was never reached by far (Beeldsnijder 1994: 81). 
America and Suriname, North Americans were very well represented among sailors visiting the colony. While ships from North America, especially New England, had already been coming (illicitly) to Suriname in the last quarter of the 17th century (Van der Meiden 1987:55,71) or even before (Postma 1998: 114), their presence increased considerably during the 18 th century. This had to do with the fact that they were the main suppliers of horses, needed for the operation of the sugar mills. The average number of North American ships, with an average crew of around ten, visiting Suriname annually rose from 25 in 1710 to almost 90 in 1790 (Postma 2003:295; see also p. 300). As noted by Postma (1998: 129), this had a 'significant social impact on the Surinam settlement.' Since American ships remained an average of eighty days in Paramaribo, 'there were always many...American sailors and officers at Paramaribo.' Dutch ships involved in the bilateral trade between Suriname and The Netherlands, with crews averaging from twenty to thirty, even stayed an average of 194 days (Postma 2003:310). As a result, 'Paramaribo's population must have been increased by several hundred temporary residents on a continuous basis' (Postma 1998: 129-30). In a later article, Postma notes:

With such lengthy layovers by dozens of Dutch and North American ships, the many visiting sailors and officers must have made quite an impact on the isolated town of Paramaribo.

(Postma 2003: 311)

The presence of North Americans in Suriname is especially interesting since many of them must have spoken English, the main lexifier language of the Suriname creoles, which had became less prominent in Suriname with the departure of part of the English in the 1670s. The potential linguistic relevance of the North Americans' presence in Suriname is enhanced by the fact that they frequently visited sugar plantations in order to buy molasses on the spot (Pares 1956:20, 106-107). While communication with these Americans was in all likelihood largely conducted by the plantation manager or other whites, we cannot exclude that occasionally blacks were involved in these contacts as well.

\section{Leisure:}

- Visits of manumitted slaves from Paramaribo. Some plantations had special buildings where former slaves, who had been manumitted and were living in Paramaribo, could stay when they were on a visit (Beeldsnijder 1994: 127, 304 n27).

- Religious gatherings, such as funerals, winti prees (religious sessions), and visits to shared sanctuaries, outside the plantation. While no figures are available for winti prees held on plantations, contemporary Moravian diaries show that 18th-century Saramaccan prees would be attended by up to 500 visitors (Price 
\& Price 1980: 169). Hoogbergen (1990:70) notes that slaves owned dugout canoes, which increased their mobility significantly. Lamur (1990: 107), writing about the plantation Vossenburg in the late 1840s, says that "the cult of the slaves at Vossenburg was apparently so important that the place of worship in the bush where the icon of the Supreme God was located was also attended by slaves from the nearby plantations..." Another altar "was located at a distance of one hour walking from the center of the plantation."

- Secular festivities, such as the annual distribution of food and goods around New Year, at which slaves from neighboring plantations would be invited, baljar (i.e. dance) parties, and musical performances by so-called $d u$ societies. A painting by Dirk Valkenburg from 1707 presents iconographic evidence that baljar parties were known at least as early as the beginning of the 18thcentury (see also Beeldsnijder 1994: 131). From the late 18th century onwards both free Blacks/Mulattoes and slaves participated in $d u$ societies, which were devoted to composing and performing song, dance and music (Voorhoeve \& Lichtveld 1975: 16). Festivities where slaves from different plantations were present are mentioned from 1765 onwards (Muyrers 1993: 105).

- Inter-plantation communication through talking drums, tutus (wooden horns) or bèntas (finger pianos), used to announce a death or a rebellion or to warn a nearby Maroon community of an approaching military patrol.

- Sexual relationships between slaves from different plantations. Such relationships are reported as early as the beginning of the 18th century ( $c f$. the very earliest Sranan sentences discussed in Chapter 6; $c f$. also Herlein 1718: 97; Muyrers 1993: 103-104).

\section{Resistance:}

- Maroons' and runaways' temporary residence on plantations, either secretly or openly. Maroons did not always hide (e.g. in slaves' barracks) when visiting plantations; according to Lamur (1985: 11), they were sometimes present quite openly.

- Maroons' visits to their former plantations. This seems to have happened especially with female Maroons who had been abducted from their plantation by force.

- Contacts between slaves in Paramaribo and Maroons living in villages in the surrounding area (Dragtenstein 2004:23, 40,42).

- Consultations between slaves and Maroons preceding rebellions, escapes, and plantation raids. ${ }^{9}$

9. An example of this can be found in Van den Bouwhuijsen et al's (1988) analysis of the 1750s Tempati rebellion. As stated by Hoogbergen (1990:76), "rebellion was often the result of collaboration between the slaves who had run away before and the ones who had stayed behind. After the 
- Slaves' temporary residence in Maroon communities (petit marronnage). As observed by Hoogbergen (1990: 84, 93), "even after the peace settlement [in the 1760s, JA] slaves continued to flee from the Surinamese plantations, while the Maroons themselves avoided the extradition of new fugitives as much as possible...It often happened that the fugitives were only delivered after several years of pressure from the colonial authorities."

- Contacts between black members of military expeditions against Maroon groups and Maroons (Dragtenstein 2002: 124, 126, 127).

Not mentioned by Muyrers are two additional types of contact: those that happened through imprisonment and those that were the result of foreign residence. As to the first, since the number of crimes committed by slaves was relatively low and since the great majority of those slaves who were tried in court received the death penalty (Beeldsnijder 1994:249), the number of former prisoners among plantation slaves cannot have been very high. As to foreign residence, both slaves, accompanying white families, and free Mulattoes sometimes stayed in Europe temporarily, although the latter only in very small numbers. In the 50 -odd years between 1729 and 1781 some 750 Blacks from Suriname (only a few percent of the total black population) visited the Netherlands, where they usually stayed for only a short time (Oostindie 1990:232). Sometimes, however, their residence lasted longer, as in the case of Elisabeth Samson, a wealthy, free black woman, who lived in Holland for some three and a half years, after which she returned to Suriname (McLeod-Ferrier 1993:46-7). Lenders (1996) mentions the case of Scipio, a baptized Saramaka Maroon, who by the end of the 18th century accompanied a Moravian missionary on his trip to Holland (paying his own fare). Since European residence generally did not last very long and involved only small numbers of people, its linguistic impact cannot have been very strong. Generally speaking, however, we may conclude that slaves in 18th- and 19th-century Suriname had quite a number of opportunities for establishing and maintaining contacts with people outside their plantation, not only with other slaves, but with Amerindians, Maroons, free Mulattoes, and Whites as well.

As far as the Maroons are concerned, the historical record shows that contacts among different Maroon bands and villages were always rather frequent. In the early stages of formation of each Maroon group, life was nomadic or semisedentary and groups were on the move almost continuously. Although the parts of the Suriname rain forest where Maroons lived form an enormous area, especially compared to the small number of people involved (around 5,000 in the mid

revolt on the plantation of Palmeneribo on the Suriname River in 1758, it appeared that the slaves had been in contact with small groups of Maroons who had been staying near the plantation for seven months without the white people ever aware of it." See also Beeldsnijder (1994:214,221). 
18th century), it is remarkable how well their internal communication was organized. An important reason for this, of course, was the fact that a well-organized warning system (using horns, drums, or conch shells) was vital in order to defend themselves against military expeditions. Another factor that promoted inter-village contacts is extra-village marriage and its accompanying 'conjugal residence' system whereby partners would spend significant periods of time in their spouse's village (Price 1975). Finally, the fact that the descendants of the earliest generations of runaways formed clearly distinguishable Maroon groups (e.g. the Saramaka), with their own cultural characteristics, as early as the mid-18th century, shows that different villages must have maintained frequent contacts from very early on. As to contacts between different Maroon groups, e.g. the Saramaka and the Ndyuka, much is still unknown, but it is clear that inter-group contacts existed, e.g., in the context of the preparations of the peace treaties. Another possibility for external contact was formed by the fact that a person who was accused of a murder for which there was not sufficient evidence would sometimes be banned to one of the other Maroon groups (Van Eyck 1830:268).

As far as external contacts (i.e. contacts with Amerindians, whites and enslaved and free blacks) are concerned, there were a number of opportunities for contact in addition to the contacts between Maroons and slaves mentioned above under the categories of Trade and Resistance. Contacts between Maroons and Amerindians, e.g., trade relations between the Ndyuka and the Trio, seem to go back to the period of the peace treaties. These contacts were sufficiently intensive to result in the creation of a new contact language, Ndyuka-Trio Pidgin (Huttar \& Velantie 1997; cf. Chapter 7 for a sample text). Contacts between the Saramaka and Amerindians, which also primarily involved trade, e.g., in hunting dogs which were trained by the latter, probably go back to the same period. Linguistic traces of these contacts can be seen in the borrowings from Carib, Arawak, and Trio which are still part of the Ndyuka and Saramaka lexicons (although some of these may go back to an earlier period, when Amerindians were employd as slaves on the plantations; $c f$. Chapter 1).

Apart from their confrontations with members of the military expeditions sent out against them, not much is known about contacts with whites in the pre-treaties (i.e. pre-1760) period (some of the verbal exchanges that happened during such confrontations are reported in Chapter 7). It seems clear, however, that opportunities for contacts outside the Maroon community increased when peace was established in the 1760s. As part of the treaties, for example, an exchange of persons took place between Maroons on the one hand and the colonial government on the other. The former sent some of their youth as hostages to Paramaribo while the latter installed a representative posthouder 'postholder' among the Maroons ( $c f$. the text of the Saramaka Peace Treaty in Chapter 7). Another important post-treaty development, at least among the Saramaka, was the arrival of the Moravian missionaries, 
who began their missionary work in 1765 , continuing on a regular basis until the 1820s. This had a clear influence on the Saramaka or at least on some of their converts, as appears from the letters written by Grego and Alabi (cf. Chapter 7).

In the following decades, Saramaka external contacts increased further, to the extent that '...by the middle of the nineteenth century, Saramaka men from the Upper [Suriname, JA] River had established a fairly stable pattern of brief yearly trading trips to the coast.' (Price 1975:65). After the abolition of slavery (1863), Saramaka and Ndyuka men became heavily involved in two types of labour which involved frequent contacts with the outside world, logging and river transportation (Price 1975; Thoden van Velzen 2003). They floated their logs in rafts along the rivers to the sawmills that were located in the coastal area, often staying there for long periods of time. A more important opportunity for contact was offered by the gold rush that happened in the southern border area between Suriname and Guyane in the 1880-1940 period and which brought along a great demand for river transportation. Thoden van Velzen (2003: 23), for example, notes that in 1907 there were some 10,000-12,000 (!) gold diggers in the Mana River basin (Guyane) alone (i.e. roughly the same number as Suriname's total Maroon population at the time). As expert river pilots, completely used to dealing with the dangerous sulas 'rapids' in the Surinamese rivers, Saramaka and Ndyuka men virtually monopolized river transportation during this period. For Saramakas, this often led to long-term residences away from their homes: 'The preferred pattern throughout this time [i.e roughly 1880-1940, JA] was to spend two or three years in French Guiana followed by a similar period in Saramaka, but even in the nineteenth century, many men stayed 10 or 20 years or even longer at one stretch, and some simply never returned' (Price 1975:66).

To conclude, this brief discussion has shown that, far from being the completely isolated communities located in the interior of the Suriname rain forest, Maroon groups had fairly frequent contacts with the outside world, from quite early on in their existence. Although it is difficult to assess the linguistic implications of these contacts, it is clear that the Maroon creoles did not emerge in virtually complete isolation, as has often been assumed. This is shown, among other things, by the fact that as early as the 19th century Sranan was widely spoken as a second language among the Saramaka, especially by men ( $c f$. Chapter 4$)$.

\subsubsection{Conclusion}

With respect to the social factors discussed in this paper, two forces can be discerned whose linguistic consequences were more or less opposed: an internal social stratification favoring linguistic differentiation, and an external social network 
system favoring homogenization. Early social stratification provides indirect support for the hypothesis, first formulated by Baker (1982b), that creole continua may have arisen quite early on in the formation of creole languages. In a socially stratified population, different groups of Blacks had differential access to the language spoken by the Whites as well as differential motivation to learn it. As a result, a spectrum of varieties may have developed from quite early on. At the same time, early external contacts contributed to the homogenization of creole varieties spoken on different plantations. As a result, one, more or less homogeneous, creole developed rather than a number of different creole 'dialects,' one for each plantation ( $c f$. Speedy 1995: 103). Apart from these rather general inferences, it does not seem possible at this moment to make any direct links between this type of sociohistorical evidence and purely linguistic developments. Nevertheless, I think that any historically realistic theory of creole formation should take into account the kind of extralinguistic evidence presented here.

\subsection{Demographic factors ${ }^{10}$}

Sugar... has been one of the massive demographic forces in world history.

S. Mintz (1959:49)

\subsubsection{Introduction}

As stated in the introduction to this chapter, demographic issues are of major importance for creole formation - both those related to the (forced) immigration of slaves through time and to the slave population at any given moment. ${ }^{11}$ The most important issue related to immigration is the question of the ethnolinguistic origins of the slaves. Another factor, which has a less immediately obvious linguistic relevance, is the sex and age distribution within the groups of Africans brought to Suriname. These issues will be discussed in Section 3.3.2. The most important issues related to population are the proportions between blacks ${ }^{12}$ and whites and

10. This section is based on Arends (1995a).

11. Although emigration is also relevant, of course, this will not be discussed separately since hardly any information is available on out-migration from Suriname, with the exception of the 'English exodus', which is treated in detail in Chapter 2.

12. I use the term 'blacks' to refer both to people of African as well as people of mixed AfricanEuropean descent. Only when it is necessary to do so will I use terms such as 'people of colour' or, more frequently, 'mulattos' to refer to people of mixed descent. As to the latter, it should be noted that, in contrast to its original meaning - a person of half African, half European descent - I use 'mulatto' to refer to any person of African-European descent, not just those who 
between black children and black adults and the rate of nativization among the blacks. These issues are the topic of Section 3.3.3.1 and 3.3.3.2. Some additional issues, such as the role of the founder population and the black-to-coloured and free-to-enslaved ratios will be discussed in Section 3.3.3.3 and 3.3.3.4.

\subsubsection{Factors related to immigration}

The immigrants to Suriname fall into two large groups, blacks and whites. While little is known about the exact composition of the latter, quite a lot of information is available on the former. Until recently, the main problem with regard to African influence, at least in the case of the Atlantic creoles, was the fact that the linguistic origins of slaves brought to the New World were not known in enough detail and with enough certainty to allow the identification of relevant substrate languages. This led to a serious methodological problem, in that the range of potentially relevant substrate languages was not sufficiently constrained for parallels between these languages and particular creoles to be of any real significance. While this section does not pretend to completely resolve that problem, it does contribute significantly to a refinement of our knowledge about the African linguistic input into Suriname. It also contributes to the discussion of the respective roles of the locally-born and African-born blacks in the process of creolization by looking at the sex and age distribution among African imports. For this purpose I made a detailed investigation, on the basis of Postma's definitive study of the Dutch participation in the Atlantic slave trade (1990), ${ }^{13}$ of the demographic composition of the African immigrant groups that were brought to Suriname between 1675 and $1803 .{ }^{14}$

are $50 \%$ African and $50 \%$ European. Terms such as mestizo, quadroon, etc, indicating finer degrees of mixture, will only be used when necessary for the discussion. Also, in accordance with historical reality, such terms as 'import' and 'importation', even though in themselves degrading when used to refer to human beings, will sometimes be used here to refer to the forced migration of Africans to Suriname.

13. In what follows, 'Postma' (without year of publication) will always refer to Postma (1990). Readers wondering why I do not refer to Eltis et al.'s (1999) more recent CD-Rom should realize that as far as the trade to Suriname is concerned Eltis et al. is entirely based on Postma's (1990) data.

14. This is the period covered by Postma's own data. Both the pre-1675 and the post-1803 periods have been studied by other scholars: Binder (unpublished data) and Chander (1988). Part of Binder's data are summarized in Postma (Table 2.2, p. 35); additional data were later made available to me by Postma through personal communication. Chander (1988) is left out of the discussion here, since the post-1803 period is relatively unimportant for the purpose of this book. 


\subsubsection{Africans}

In this section some quantitative aspects of the immigration of Africans into Suriname will be discussed, both with respect to their ethnolinguistic origins and with respect to their age and sex distribution. Most of what will be said here is based on Postma's detailed study (1990) of the Dutch Atlantic slave trade. It should be noted that, although the subject of Postma's book is the Dutch slave trade in general rather than their trade to Suriname, his work is highly useful for the purposes of this chapter, since the Dutch trade accounted for practically all of the import to Suriname throughout the slavery period, both during the monopoly of the West India Company (WIC) (i.e. until 1738) and during the free trade period (i.e. from 1739 onwards) (Postma 1990: 180, 201-205, 211). Through meticulous archival research Postma was able to obtain data on the numbers of slaves and on the place and year of their embarkation and disembarkation for 581 ships landing some 200,000 slaves in Suriname in the $1675-1803$ period. ${ }^{15}$ For most of these shipments the documents provide information on all of these variables; in a minority of cases information is limited to part of them. For 51 shipments additional information regarding age and sex of the slave cohorts is given. It should be noted that in by far the majority of cases the quantitative information is precise, i.e. specific figures are mentioned in the archival documents. The fact that slaves were economically highly valued merchandise, ensures that, purely as a matter of good book-keeping, their numbers were recorded accurately, which enhances the reliability of these figures considerably. Where exact figures are lacking, they are compensated by Postma's educated estimates, based on his calculations of average slave cargoes and average mortality rates during the middle passage. It seems safe to say, therefore, that the figures given below present a historically realistic picture of the demographics of the African immigration into Suriname.

\subsubsection{Origins}

Little is known with absolute certainty about the origins of slaves imported into Suriname before 1675, i.e. those brought from Barbados in the 1650s or acquired later by the English. (As to the possibility of the Sephardic Jews bringing slaves with them from Pernambuco, this was shown to be highly unlikely: $c f$. Chapter 2).

15. Postma's (2003) recalculations of the Dutch slave trade, based on several important publications which appeared since 1990, did not lead to significant adjustments for the trade to Suriname, especially not for the early period which is most important from a linguistic point of view. The total number of slaves imported into Suriname between 1668 and 1803 is now calculated at almost 185,000 (Postma 2003, Table 11.5). This is only slightly higher than the figure of around 182,000 I arrived at on the basis of Postma (1990). Although Postma (2003) does not talk about ethnolinguistic origins, pending evidence to the contrary I assume his reassessment does not have serious consequences for his earlier findings. 
Although we may suspect that the first English settlers brought some slaves with them, when they started their colonizing efforts in Suriname in 1651, their numbers were probably quite low. After all, one of the reasons for the colonization of Suriname was the overpopulation of whites, not blacks in Barbados; in fact, there even was a shortage of slaves in Barbados at the time (Voorhoeve \& Lichtveld 1975:2). After the beginning of the sugar boom in the 1650s, there simply was not enough land to provide a living for the more than 30,000 whites, mostly ex-indentured servants and small tenants, who lived on the island (Beckles 1990; Van der Linde 1966:44). At the time of the colonization of Suriname, there were about 8,000 servants in Barbados, mainly Scots and Irish (Smith 1947:332). The white population of other islands from which colonists came to Suriname, such as St Kitts, Montserrat and Nevis, also contained a considerable proportion of servants at that time (Smith 1947: 172). This explains the predominance among the first settlers in Suriname of former indentured servants, who did not have the money to buy more than one or two slaves (Rens 1953:58).

As to the slaves that the English did bring from Barbados, most of these had been purchased there from Dutch slavers, since 'up to 1663, the slave trade to Barbados was practically a Dutch monopoly' (Curtin 1969, quoted in Price 1976: 13; cf. also Beckles 1990:32). This means that, to get an idea of the African origins of these slaves we can take the figures for the overall Dutch trade in the pre-1675 period. Unfortunately, the earliest figures available go back no further than 1658. The percentages for the Dutch trade in the 1658-1674 period are as follows (Postma 1990: Table 5.2):

Table 3.4 African origins in the overall Dutch slave trade (1658-1674)

\begin{tabular}{lr}
\hline Windward Coast & $4.3 \%$ \\
Gold Coast & $10.4 \%$ \\
Slave Coast & $28.0 \%$ \\
Loango & $13.9 \%$ \\
Unknown origin & $43.4 \%$ \\
\hline
\end{tabular}

Apart from the much higher percentage of unknown origins, and the somewhat higher proportion of Gold Coast slaves, these figures are comparable to the ones provided for Suriname for the 1675-1720 period in Table 3.5 below. Assuming that the Dutch trade to the English in Barbados was a reflection of the overall trade, we may conclude that the origins of the slaves brought from Barbados are roughly identical to the origins of the ones imported during the first fifty years under Dutch rule ( $c f$. also Beckles 1990:32-3).

As to the slaves bought by the English after their arrival in Suriname, these were also largely imported by Dutch slavers (Price 1976: 13). Although Postma 
does not provide any pre-1675 Suriname-specific figures, we are not left in the dark completely in this regard. This is due to unpublished research by Franz Binder, discussed in Chapter 2, which has unearthed evidence about 9 shipments between 1667 and 1675. Although the information is much scarcer than for post- 1675 shipments with regard to a number of variables, place of origin is given in most cases: remarkably at least 5 out of these 9 came from 'Calabary', i.e. the Bight of Biafra, a region which provided hardly any slaves to Suriname in the post-1675 period (except two shipments in the 1680s; see below). Interestingly, recent research has shown that this area was also the main supplier for Barbados in the 1660s (Morgan 1997: 126). As shown in Appendix II, another 844 Bight of Biafra slaves were brought to Suriname in 1685 and 1686 . This is linguistically relevant as the languages spoken in the Bight of Biafra area belong to other language groups (e.g. Cross River languages, such as Ibibio) than those spoken in the areas that became the major suppliers later on. Their role may be especially important as speakers of these languages belonged to the earliest slave cohorts who arrived in Suriname.

To the extent that any slaves were brought to Suriname from Pernambuco (but see Chapter 2), these had also been acquired from Dutch slavers (Postma, pp. 1922). Based on the Dutch import to Brazil in the relevant period (Postma 1990: Table 1.1), we can say that the geographical origins of these slaves were largely identical to those of the Suriname imports in the decades following Dutch take-over.

Archival documents are much richer for the post-1675 period. Appendices 1 and 2 in Postma (1990:308-48) list all 1209 Dutch shipments between 1675 and 1803 for which archival records were found. For a quarter of these (310, i.e. 25.6\%) the New World destination was not recorded. This does not mean, however, that a proportionate part of these 'unknown destiny ships' arrived in Suriname. On the contrary, Postma (Tables 8.2 and 9.2, pp. 186,212) estimates that in the entire 1668-1803 period a total of only 6,490 slaves arrived in Suriname from ships without verified destination (2,140 between 1668 and 1734 and 4,350 between 1735 and 1803). Also, according to Postma, the importation by Dutch interlopers or foreign ships in the 1668-1734 period 'can hardly have been significant enough to alter the overall picture' (p. 187-8), and the same goes for unrecorded shipments in the 1732-1803 period (p. 212). Therefore, Postma's data on the origin, destination, and numbers of slaves, brought to Suriname by the Dutch between 1651 and 1803, can be regarded as an accurate and reliable representation of the historical facts.

Of the 899 ships for which the New World destination was recorded, 556 (61.8\%) delivered their cargoes in Suriname, with another 25 listed with a mixed Suriname-Guiana destination. It may be important to stress that Table 3.5 below is based on historically accountable facts rather than estimates and projections. 


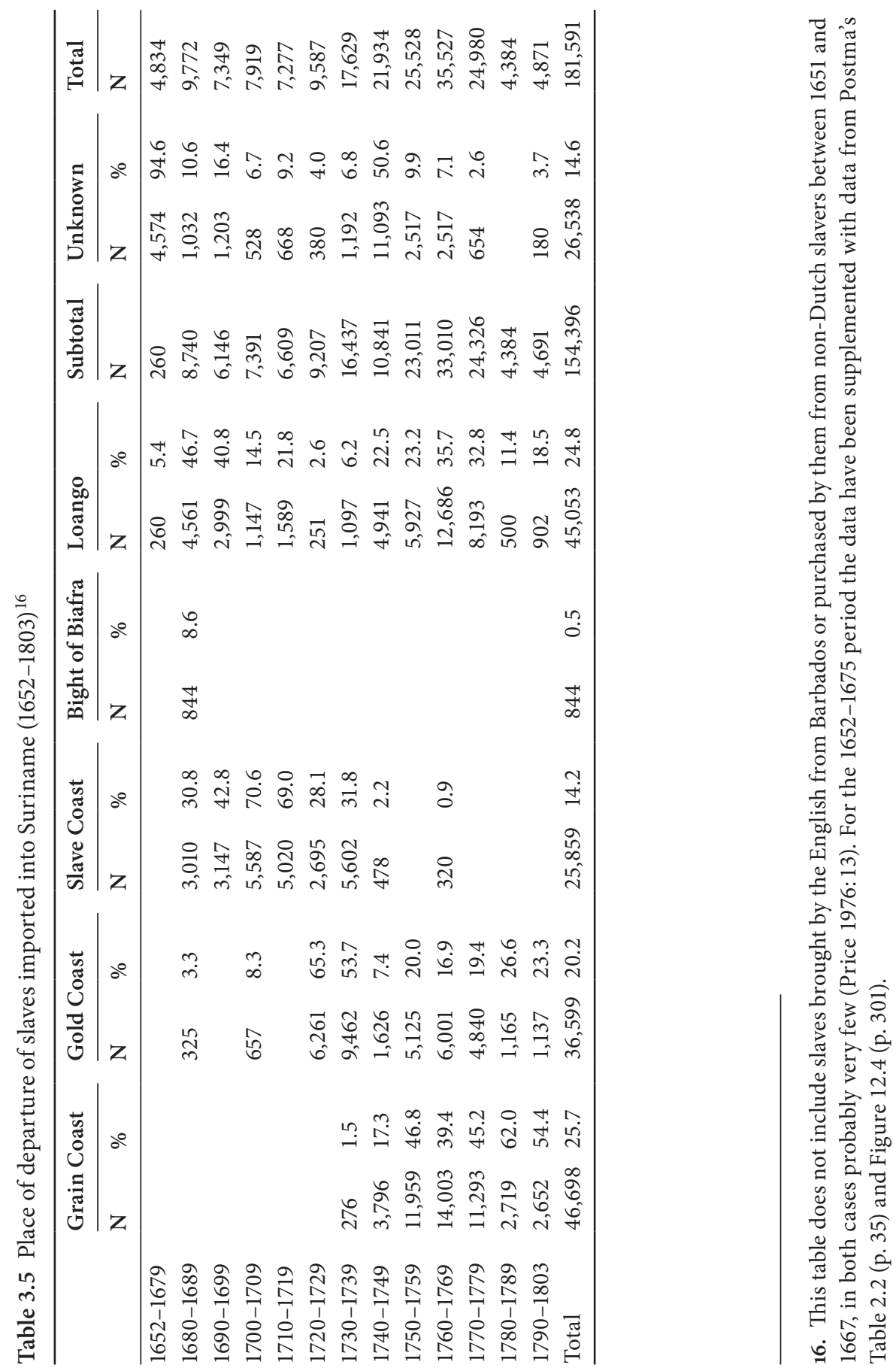


Since Table 3.5 may be difficult to interpret, the same information is represented graphically in the following figure.

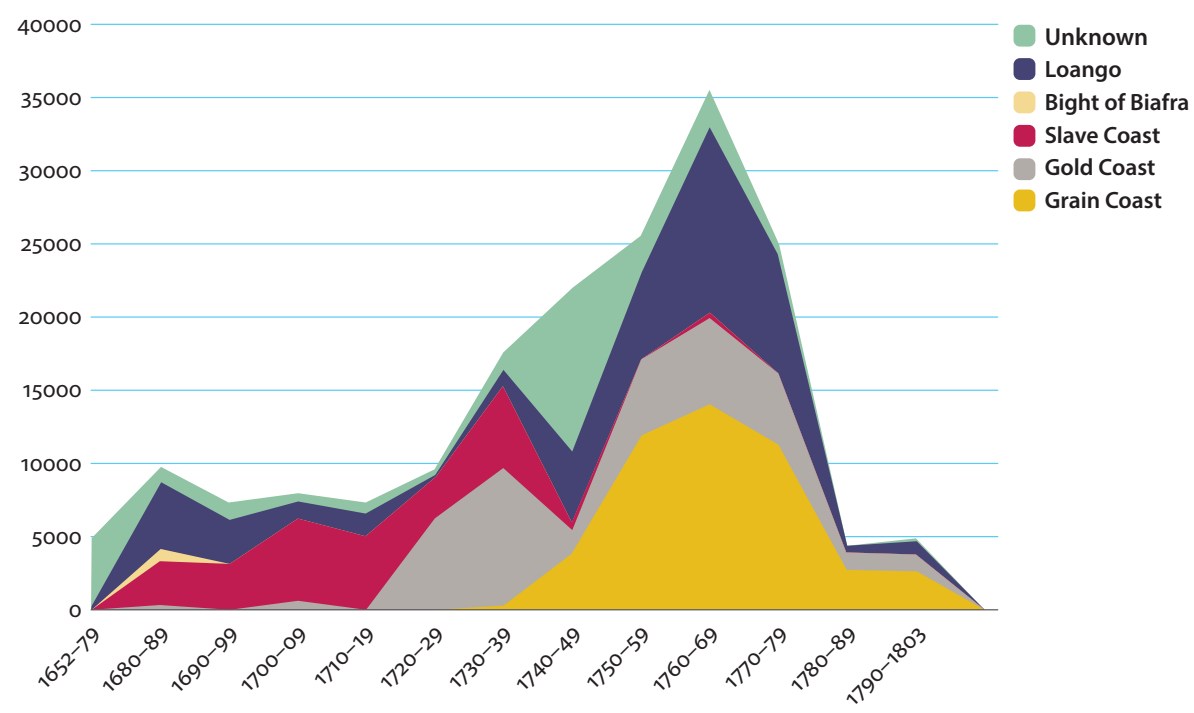

Figure 3.1 Place of departure of slaves imported into Suriname (1652-1803)

Before discussing some of the details of Table 3.5 and Figure 3.1, let me first explain the meanings of the geographical terms used here, especially as they are not always identical to how they are used in other works. They correspond roughly to modern geographical terms as follows (Postma 1990:57-60; 122-123; for more detailed topographical information, see the excellent maps in Fage 1978).

Grain Coast. Although the term 'Grain Coast' (also known as 'Pepper Coast' or 'Malagueta Coast') refers to the entire region ${ }^{17}$ stretching from Sierra Leone to western Ghana, as far as the Dutch slave trade is concerned it was almost exclusively restricted to Liberia and, especially, Ivory Coast.

Gold Coast. This term refers to central and eastern Ghana up to Accra.

Slave Coast. This includes eastern Togo, Benin, and western Nigeria.

Bight of Biafra. This refers to the Niger Delta region and eastern Nigeria.

Loango. This term (derived from the name of a Dutch trading post north of the Congo River) refers to the area stretching from southern Cameroon down to Cabinda, with an emphasis on the area including Cabinda (just north of the Congo River), the coastal regions of the two Congos, and southern Gabon. Note that in contrast to Postma's hyphenated term 'Loango-Angola', 'Loango' in this

17. Needless to say, I am referring to the coastal regions of the countries mentioned in this paragraph; the question as to how far inland recruitment of slaves stretched is discussed in some detail below. 
book does not include Angola, although, of course, slaves from Angola may have been shipped from the Loango area.

A few remarks about the category 'Grain Coast' as used in Table 3.5 and Figure 3.1 are in order here. As noted above, Table 3.5 and Figure 3.1 are based on Appendices 1 and 2 in Postma (1990). In these Appendices, Postma uses the undifferentiated category of 'Guinea Coast' for the post-1738 period, when the WIC had lost its monopoly on the slave trade. In this period, the free traders were mainly active in the Upper Guinea area, where they worked from ships rather than from castles or forts. Since this makes it impossible to identify exactly the places of embarkation for their ships, Postma used the undifferentiated category of 'Guinea Coast'. At the same time, however, we know that these free traders purchased most of their slaves in the Liberia/Ivory Coast region, going on to the Gold Coast only in case they had not succeeded in acquiring a full cargo of slaves. Since on average, 70\% of these cargoes were acquired in the Liberia/Ivory Coast region (see below), I allocated $70 \%$ of all 'Guinea Coast' shipments to the Grain Coast category and the remaining 30\% to the Gold Coast. Although for the linguistic questions I am dealing with here the post-1738 period is less crucial than earlier periods, it may still be useful to motivate this decision a little bit more elaborately by quoting Postma at some length here, especially since such a large proportion of the overall African immigration to Suriname is involved.

Occasionally, slaves were purchased in the Senegambia region, but as a rule the acquisition of slaves commenced on the coasts of present-day Sierra Leone and Liberia. Cape Mesurado, where Monrovia was subsequently built, was the most frequent starting point of slave acquisition. The average free-trade slave cargo, according to this sample [i.e. Postma's Table 5.8, JA], was nearly 70 percent complete before the Gold Coast was reached, making the Windward Coast (the approximate equivalent of today's Liberia and Ivory Coast) one of the principal slaving areas for the Dutch. All export regions taken together, the Dutch free traders may well have obtained 40 percent of their slaves from the Windward Coast. Cape Lahou in particular and the Ivory Coast in general clearly emerged as the most prolific supplier of slaves in this region.

(Postma 1990: 122-123)

About the ships for which the Gold Coast is recorded as their place of departure Postma says the following:

The ships designated as having boarded their slaves at Elmina [the most important Dutch fort on the Gold Coast, JA] did not necessarily obtain all their slaves on the Gold Coast; usually it meant that Elmina was their last port of call in Africa. In 1744 the WIC director at Elmina reported that most of the free traders purchased their slaves on the Windward coast, sailing on to Elmina only when their cargo was still deficient.

(Postma 1990: 120-121) 
Although Postma's remark is confined to Elmina, we may infer from his earlier quotation as well as from remarks made elsewhere in his book that it also applies to the other Gold Coast forts and trading posts. The validity of the 70/30 allocation is supported by the fact that it results in an overall percentage of Grain Coast slaves in the post- 1738 period of $39.6 \%$, which is completely in agreement with Postma's estimate of $40 \%$ mentioned above.

It should be stressed that, while all toponyms used above refer only to the coastal strips of the areas involved, from where slaves were shipped, this does not imply that the origins of the slaves purchased by the Dutch were necessarily limited to these areas. Although the question of the exact regional origins of the African slaves is a notoriously difficult one, recent historical research has made it possible to identify these regions with more precision than before. On the basis of extensive demographic research, Manning (1990) has made educated estimates of the maximum distances of different supply areas from the coast as well as how these changed through time. Postma (1990) relates the location of supply areas to internal political developments in Africa. Since the issue is of paramount importance from a linguistic point of view, it will be dealt with in some detail here.

However, before going into Postma's and Manning's findings regarding the slavers' radius of action, it will be useful to discuss the numerical and geographical distribution of the relevant languages in the relevant periods. ${ }^{18}$ As far as the Guinea Coast (the area stretching from Senegambia to the Bight of Biafra) is concerned, Hair (1967) has shown, on the basis of detailed historical research, that there has been little change over the past 300 to 500 years:

If we...compare the ethnolinguistic inventory of today with that of the period before 1700 , we find a striking continuity...the ethnolinguistic units of the Guinea coast have remained very much the same for three, four or five centuries.

(Hair 1967:247)

As to the numerical distribution of these languages, unfortunately no historical data are available. In order to get some idea of the relative numbers of speakers in the relevant period, we have to rely, with all due caution, of course, on extrapolations from present-day figures. (But note that what we are interested in is proportions rather than absolute numbers.)

18. The term 'language' is a simplification since in the case of Akan, Gbe and Kikongo we are dealing with clusters of languages (or language varieties) rather than separate languages, some of which are mutually intelligible while others are not. The numerically most important among them are Ewe and Fon (Gbe), Kikongo (Kikongo), and Twi (Akan). 
What is important for the African substrate with regard to Suriname, is the fact that the areas from which slaves were recruited are linguistically much less diverse than West Africa as a whole. The most important language clusters spoken in these areas, Gbe (Kwa) and Kikongo (Bantu), have relatively many speakers and are distributed over relatively large areas. The total number of speakers of Gbe and Kikongo may be estimated at 7 million - 4 million Gbe, 3 million Kikongo (if Kikongo in a wider sense is included the total figure becomes around 11 million) (source: <www.ethnologue.com $>$ ). These two language clusters, which together constitute less than $0.5 \%$ of all Niger-Congo languages, are spoken by some $5 \%$ of all Niger-Congo speakers. Extrapolating these figures to 17th and 18th-century Africa, we may conclude that Suriname's major pre-1720 recruitment areas were exceptionally homogeneous from a linguistic point of view, especially when seen in the light of the high degree of linguistic diversity which is the norm in West and West-Central Africa.

The Suriname case provides decisive evidence against the idea that the linguistic heterogeneity among the slaves was too strong to allow a significant influence from any African language or language cluster. This notion of profound linguistic heterogeneity among slave populations in Caribbean colonies, is based on the fact that West and West Central Africa belong to the linguistically most diverse regions of the world, coupled with the assumption that planters adhered to a linguistic divide-and-rule strategy ensuring that slaves from different language background were mingled on plantations in order to prevent them from planning rebellions or any other kind of insubordinate activity. It is becoming more and more clear, however, that, despite the frequent mention of the divide-and-rule strategy in the contemporary literature, it constituted a desideratum on the part of the planters rather than an actual practice. (For that reason it would be better to refer to it as the 'mixing myth'.) In fact, in some colonies the supply of slaves was so scarce that planters did not have any choice as to the ethnolinguistic background of the slaves they bought to work their plantations.

Recent research on the Atlantic slave trade shows that the linguistic diversity of West and West Central Africa was not equally reflected among the Africans who were taken to the New World. The claim that slaves brought to the Caribbean formed relatively homogeneous groups is supported by Eltis et al.'s (1999) data base, which leads historians to conclude that 'the distribution of peoples from West Africa in the Americas was far from random' (Eltis \& Richardson 1997:8). In other words, rather than drawing slaves from all over coastal West and West Central Africa, specific regions in the New World recruited their slaves from specific regions in Africa. Since this finding is of major importance for theories of creole genesis, the passage where it is articulated most clearly is quoted here in full: 
$[\mathrm{O}] \mathrm{n}$ the issue of transatlantic links, the picture of African coerced migrants arriving mainly in a mix of peoples - often on the same vessel - needs revising. Like the free migrant and indentured servant trades, systematic geographic patterns existed. Scholars should now turn to exploring what these mean both for Africa and for African influences in the shaping of the New World.

(Eltis 2001:41)

Although this observation in itself is not new (cf. Curtin 1969), its importance lies in the fact that it is based on a data set covering some 27,000 transatlantic voyages (two thirds of the estimated total) concerning all major slave trading nations (Eltis et al. 1999).

The importance of ethnic homogeneity cannot be easily overestimated as it has been demonstrated convincingly that the degree of homogeneity of the substrate plays an important role in determining the extent of substrate influence (Singler 1988; Smith, Robertson \& Williamson 1987). The importance of linguistic homogeneity is further enhanced by the fact that, contrary to the stereotype of linguistic mixing on the part of the planters, plantation populations were relatively homogeneous. An important piece of evidence is provided in Anon. (ca.1740), a manual for plantation managers written by an experienced planter. He writes:

Usually the slaves prefer to marry women from their own nations [i.e. ethnic groups, JA], and in such cases arguments, jealousy, or family problems will not occur easily. In my opinion, the reason for that is, among other things, that the man knows how to treat his wife and the woman knows how to treat her husband according to the customs of their nation. If, however, a man and a woman of different nations get together, there will always be differences between them. Therefore, when buying slaves one should be very careful in coupling them to slaves of a different nation and one should see whether there is a man or a woman on the plantation who needs one.

(Anon. ca. 1740:60-1)

Speaking about the early history of Sranan, Focke confirms this practice of promoting rather than discouraging ethnolinguistic homogeneity among the slaves:

Whenever possible, the Africans, who, belonging to different peoples, spoke different languages, were allocated upon their arrival, to their fellow countrymen among the slaves to be taken care of and seasoned. An important part of their task was to teach the local language, i.e. the Negro-English thus knocked together, to these 'green blacks'.

(Focke 1855: viii)

Ethnolinguistic homogeneity was valued so highly that even Maroon groups were occasionally organized along ethnic lines, a relic of which can still be found today in the names of a Saramaka clan, called Lángu (Loango), and a Saramaka village, called Pápa (i.e. Popo) (Hoogbergen 1992:284-285, 294). 
As far as the Loango area is concerned, there is some evidence that Kikongo speaking slaves were well represented among the slaves purchased in this area, since 'the decline of the once powerful Kongo state to the southwest [of the Dutch trading area around Loango seems to have contributed to the steady supply of slaves after the middle of the sixteenth century' (Postma 1990: 101). With regard to the Slave Coast area Postma (p. 99) says that up to around 1730

...located about fifty miles from the coast [north of Ouidah, JA], Dahomey had long been one of the weaker brother states in the Aja system. ${ }^{19}$ They had often been the object of slave raids from their more powerful neighbours...

(Postma 1990:99)

This suggests that among Slave Coast slaves, it was primarily Dahomeyans, i.e. Gbe speakers who arrived in Suriname. Finally, in the Gold Coast area at the beginning of the 18th century the Asante kingdom came to power, first in the western and interior parts of the region, later also in the eastern part. At the same time, the Fante took over power in the coastal area (Postma, p. 94). This suggests that Gold Coast slaves brought to Suriname were mostly non-Asantes and non-Fantes. Linguistically speaking, this means that, as far as the Akan (Kwa) language cluster is concerned, Akuapem Twi and Abron rather than Asante or Fante were imported into Suriname. Interestingly, the three languages mentioned here (Kikongo, Gbe and Twi) are precisely those that have survived as ritual languages in Suriname (Smith 1987: 88).

Postma's remarks above are supported by Manning's (1990) observations. These are summarized below:

Table 3.6 Maximum radius of slave recruitment areas (Source: Manning 1990:62-70)

\begin{tabular}{lll}
\hline & Before $\mathbf{1 7 0 0}$ & After $\mathbf{1 7 0 0}$ \\
\hline Grain Coast & $<200 \mathrm{~km}$ & $<200 \mathrm{~km}$ \\
Gold Coast & ca $100 \mathrm{~km}$ & ca $300 \mathrm{~km}$ \\
Slave Coast & $<200 \mathrm{~km}$ & $<200 \mathrm{~km}$ \\
Loango & ca $300 \mathrm{~km}$ & $300-600 \mathrm{~km}$ \\
\hline
\end{tabular}

As can be seen from Table 3.6, supply areas stretched into the interior for more than 200 kilometers only in the Gold Coast and Loango areas. If we concentrate on the periods and areas relevant to Suriname, we see that both in the Slave Coast and in the Grain Coast area slaves were brought from no further than 200 kilometers from the coast. With regard to the Slave Coast, which was of major importance

19. The Aja king ruled over other monarchs in the Slave Coast area during this period. 
for the period of creole formation in Suriname, Manning is quite specific about the language area where slaves came from:

In addition, according to recorded ethnic designations of slaves exported from the region [i.e. the Slave Coast area, JA], the overwhelming majority of these slaves were from the Aja (or Gbe-speaking) peoples of the coastal fringe in the period up to the late eighteenth century.

(Manning 1990:67, italics mine, JA)

For the Grain Coast, which did not become a supply area for Suriname until after 1740 , this means that slaves from these areas were speakers of languages belonging to such groups as Kru, (southern) Mande and (southern) Atlantic, rather than languages spoken in the interior. Since the Dutch Grain Coast trade was concentrated in the Cape Lahu area, speakers of western Kwa languages will also have been present among the slaves.

About the Gold Coast area, which did not become important for Suriname until after 1720, Manning (p. 65) says that after 1700, the supply area shifted from the core to the periphery of the Akan-speaking region. After 1750, when there was a rise in the number of Suriname slaves from the Gold Coast, it shifted to the north and northwest of the Asante empire, which by then had become much expanded (p. 135). This means that Suriname slaves from this region were more likely to be speakers of Akuapem Twi and Gã (in the 1720-1740 period) and Anyi-Baule and Abron (in the 1750-1780 period) than Asante and Fante.

Loango was the only supply area that had a large hinterland from the beginning, which was expanded even more in the course of the eighteenth century. Although the first (pre-1720) wave of Loango slaves entering Suriname, which consisted largely of Kikongo speakers, already may have contained speakers of non-coastal languages, the second (post-1740) wave, which was brought from as far inland as the Ubangi River valley and the northern hinterland of Angola, must have contained speakers of other Bantu languages, especially Kimbundu.

Finally, in the Bight of Biafra area Ibibio rather than Igbo speakers were purchased (p. 69). Although this area only provided slaves for two short periods of time - 1667-1674 and 1685-1686 - this is important because these slaves arrived at such an early stage. The five shipments in the 1667-1674 period are especially relevant since they formed more than half of the shipments recorded for that period. In addition to that, this period, which formed the transition of Suriname from an English to a Dutch colony, was a crucial one in the formation of the Suriname creoles.

The combined evidence provided by Postma and Manning strongly suggests that the range of major substrate languages can be narrowed down to two clusters, Gbe and Kikongo, with a somewhat more diverse group of western Kwa languages (Akuapem Twi, Abron, Gã, Anyi-Baule) playing a secondary role. These findings, 
based on modern quantitative research, are supported by what earlier sources have had to say about the ethnolinguistic origins of Surinamese slaves based on the alleged 'characteristics' of different ethnic groups. As noted by Price 1976:15-16), the lists of African 'nations' compiled in such works

are problematical, however, not only because they provide no quantification but also because the major ones... all postdate 1770 , leaving us with little systematic information from the Suriname side of the Atlantic about which 'types' of slaves were imported (and in what ways) during the whole first century of the colony's history, when local Afro-American institutions, languages and other cultural systems were being forged.

(Price 1976: 15-16)

This problem is remedied to some extent by the fact that recently an important pre-1770 source (Anon. ca.1740, first discussed in Beeldsnijder 1994) has come to light which presents some relevant information on this issue. Writing about the origins of the slaves, the author, a Surinamese planter, says that 'the slaves are of many diverse nations...the best known nations are Cormantins, Papas, Fidas, Loangos, Congos etc.' (Anon. ca.1740:56).

Another problem with regard to these early sources is formed by the fact that it is often very difficult to determine exactly which ethnic groups are referred by the names used in them. This is so for a variety of reasons, e.g. because these names are represented in idiosyncratic spellings or because they are the names used by other groups rather than the groups itself or because they are no longer in use. Wooding (1981) has made a detailed study of the names mentioned in the four sources mentioned by Price - Hartsinck 1770, Stedman 1796 [1790], Teenstra 1835, and Hostmann 1850. Taking into account several older sources too, such as Dapper (1668) and Bosman (1704), as well as the internal military and political developments in 18th-century West Africa, Wooding (1981:26) reaches the following conclusion:

On the basis of the identified tribes, it appears that the Afrosurinamese population comes mainly from four West African linguistic groups: Mandingo, FanteAkan, Ewe-Fon and Western Bantu.

(Wooding 1981:26)

Although Wooding's identification of the major ethnolinguistic groups is not completely identical to mine ( $c f$. especially his reference to Mandingo), this can be explained by the fact that Wooding's study was published before Postma (1990) had become available. Taking into account Postma's findings, however, it becomes clear that the early authors support the identification of the major ethnolinguistic groups made on the basis of modern quantitative research. This is further supported by the fact that it is precisely the groups from the regions identified as the major recruitment areas in my study - Gold Coast (Akan), Slave Coast (Gbe), and 
Loango (West Bantu) - which are shown by Wooding to have made the largest contribution to the formation of the Surinamese religious system known as winti (Wooding 1981:289).

In terms of identifying the major ethnolinguistic groups as such, the picture presented in Table 3.5 and Figure 3.1 by and large confirms the calculations made by Price (1976: 13), which were based on Postma's (1970) earlier, much less complete, study (which does not present any Suriname-specific figures). However, with regard to the distribution of these groups through time there are some marked differences (for full details, see Arends 1995a, Table 1.4). One of these is the fact that the proportion of Gold Coast slaves in the 1726-1735 period was twice as high as calculated by Price. Also, the proportion of Loango slaves was higher in the 1651-1700 period and lower in the 1701-1735 period than calculated by Price.

One example may serve to illustrate the linguistic relevance of these adjustments. The fact that the immigration of Loango slaves between 1650 and 1750 was largely concentrated in the first half of that period, rather than being equally divided over this entire period, as assumed by Price, may explain why the Bantu contribution to the lexicon of the Suriname creoles is much greater than would be expected on the basis of Price's figures ( $c f$. Huttar 1985: 64).

Bantu-speaking slaves simply were present in Suriname in a greater proportion in the early period than assumed until now and for that reason exerted a stronger substrate influence.

The most important conclusion to be drawn from Table 3.6 and Figure 3.1 is the fact that both the quantity and the regional origins of slaves were subject to considerable fluctuations. If we divide the entire 1652-1803 period into four subperiods (1652-1690; 1690-1720; 1720-1740; 1740-1803), the overall pattern can be summarized as follows. In the first period African immigration is roughly equally divided between Slave Coast and Loango. In the second period Slave Coast slaves form roughly two thirds and Loango slaves one third of the imported Africans. The third period witnesses a sudden rise of Gold Coast imports, taking up two thirds of all immigration, while the Slave Coast segment decreases to one third and the Loango segment almost disappears. Finally, the last period is dominated by the Grain Coast trade, taking up almost half of the immigration, while the Loango and Gold Coast segments each take up roughly one quarter and the Slave Coast segment disappears. Quantitatively speaking, the Suriname import of slaves doubled in each successive period (if the last two decades of the 1740-1803 period, when the Suriname trade dropped drastically, are left out of account): it increased from an annual average of below 400 in the first period, via 750 and 1350 in the second and third periods to 2650 in the final period. 
These findings about the slave trade to Suriname amply demonstrate that we should not rely on overall figures to inform us about the relevance of potential substrates: both the timing and the compactness of substrate language input have to be taken into account. Thus, the influence from Grain Coast languages is much smaller than would be expected from the sheer numbers of their speakers, simply because they arrived so late on the linguistic scene. In the same vein, the influence from Slave Coast and Loango languages (Gbe, Kikongo) is disproportionately strong, simply because their speakers arrived early and almost to the exclusion of speakers of other languages.

Linguistic evidence for the influence of these two language clusters on the Suriname creoles has been adduced for almost every level of the language system: lexicon (e.g. Daeleman 1972; Huttar 1985), phonology (e.g. Smith 1987), morphology (e.g. Braun 2005), syntax (e.g. Bruyn 1995a; Migge 1998), and (lexical) semantics (Huttar 1975). Generally speaking, the influence of Bantu appears to be largely lexical, while that of Gbe ranges over all linguistic subsystems. It is not clear to what extent this might be related to structural differences between the two language clusters, in particular the fact that Gbe has a rather isolating morphology while that of Kikongo is more of the agglutinating type: is a language with 'little morphology' more likely to leave structural traces in a language contact situation than a language with 'more morphology'? Of course, the question is put far too crudely here, but it certainly warrants further investigation, all the more so as the structural influence of Bantu languages is surprisingly small in many WestAtlantic creoles, not just those of Suriname (in spite of the fact that West-Central Africa was by far the largest supplier of slaves to the New World (Eltis 2001: Table II)). At the same time, however, one should not forget that the possible substrate influence of Bantu languages has received far less attention on the part of creolists than the languages of West-Africa, especially Kwa.

The fact that the two languages for which substrate influence has been demonstrated most convincingly, i.e. Kikongo and Gbe, are those which were spoken by the two ethnic groups which dominated slave immigration in Suriname during the first seventy years, suggests that substrate influence played its part predominantly during the first two or three generations of slaves. We have to be cautious, however, since substantial (especially lexical) influence of Twi, a language which was practically absent in Suriname until the 1720s, has also been demonstrated. Nevertheless, it seems safe to say that the primary candidate languages to subject to further investigation with regard to structural influence in the Suriname creoles are Gbe and Kikongo. 


\subsubsection{Age and sex distribution}

Another demographic variable that is important for the reconstruction of creole formation in Suriname is the age composition of the slave cohorts that entered the colony. Especially the question whether or not these cohorts contained significant proportions of children is important, since, if this turns out to be the case, these African-born children formed part of the non-adult segment of the black population in Suriname. In other words, it is not necessarily the case that the entire group, or even a majority, of black children present at some point in time in Suriname consisted of children who were born there. Although it has sometimes been assumed that there were hardly any children among the imported slaves (Bickerton 1992; but $c f$. Arends 1994), this was certainly not the case for Suriname:

The number of children and youths [3-15 years, JA] transported from Africa by Dutch slavers remained fairly steady until the free-trade period [i.e. 1735, JA], when their numbers increased. In the Brazil trade [1637-1645, JA] 13 percent were counted as youths, and these percentages remained about the same for the remainder of the WIC trade [until 1735, JA], although individual human cargoes might vary considerably. During the first decades of the free trade the number of young slaves increased to 20 percent and it reached a peak during the 1770 s, when about a quarter of the slaves were below the age of fifteen. This does not take into consideration the very young children and infants who remained with their mothers. There are only sporadic references to these little ones, and a meaningful statistical assessment of them is therefore out of the question.

$($ Postma 1990:231) 20

The issue, of course, is not without importance, because the proportion of locally-born slave children is an essential element in determining the role of first language acquisition in creolization. Evidently, in order to arrive at reliable estimates of the number of locally-born slave children, we have to take into account the fact that part of the non-adult slave population was born in Africa. Although no information on the place of birth of Suriname's black population at different points in time is available, there is an indirect way to estimate the proportion of African-born children among the entire non-adult black population (see

20. Because so little is known with certainty about the presence of infants among slave cargoes, and because their chances of survival were probably not too good, both during middle passage and after arrival in Suriname, in what follows the assumption is made that no children at all below the age of three were imported into Suriname. Note, however, that among the few Suriname-destined slavers for which data on children below the age of three are available, there is one (the Rusthof) that reports the presence of approximately 100 infants on board (Postma 1990: 231). It should be kept in mind, therefore, that the estimates of the numbers of Africanborn children that will be presented below are on the conservative side. 
Section 3.3.3.2 below). For this we make use of the fact that for Suriname we have relatively reliable figures for the age distribution both among the imports from Africa and among the black population, at specific points in time. The archival documents with respect to immigration, on which Postma's calculations are based, contain information about the age composition for $13.6 \%$ of all Dutch slavers and for $10.3 \%$ of all Suriname-destined Dutch slavers. Table 3.7, which is based on Postma's Tables 10.1 and 10.2, shows that between 1680 and 1803 the proportion of children (3-15 years) among the Suriname slave imports varied between 13.8 and 23.3 percent: ${ }^{21}$

Table 3.7 Percentage of children (3-15 yrs) in a sample of Suriname imports and in a sample of the overall Dutch trade (1680-1803)

\begin{tabular}{lll}
\hline & Overall Dutch trade & Suriname imports \\
\hline $1680-1749$ & $11-12 \%$ & $13.8 \%$ \\
$1750-1759$ & $19 \%$ & $17.9 \%$ \\
$1760-1779$ & $24-25 \%$ & $23.3 \%$ \\
$1780-1803$ & $21 \%$ & $22.7 \%$ \\
\hline
\end{tabular}

A comparison of the Suriname figures with those for the overall Dutch trade shows a close correspondence between the two. The fact that with regard to the age distribution of the imported slave cargoes the Suriname sample corresponds so closely to the overall Dutch sample, both in the percentages of children imported and in the distribution of these percentages over time, clearly enhances the reliability of these figures. Further, the fact that there are no reasons to assume ${ }^{22}$ that the presence of children was limited to the sample of the cargoes for which data on age composition have been found, allows us to project the sample data onto the entire Suriname import without distorting historical reality too much. The results of this projection are shown below:

21. Note that these figures are considerably higher than those given in Postma's earlier work (1970: 104,179-81), where it is stated that hardly any children were purchased by the Dutch before 1700 , whereas their proportion grew to $7.5 \%$ between 1700 and 1735 and to $21.5 \%$ between 1735 and 1803.

22. Although Postma does not confirm the representativeness of the sample explicitly, I assume that if there were any reasons to suppose that the sample was not representative, he would have mentioned them. Compare also the fact that, while almost all ships transported both men and women, data on sex distribution have been preserved for only 172 cargoes on a total number of 1,209 shipments. It may be assumed, therefore, that children were on board of most ships for which no age data were recorded. 
Table 3.8 Projected percentages and numbers of children (3-15 yrs) among slaves imported to Suriname (1680-1803)

\begin{tabular}{llr}
\hline & \multicolumn{2}{l}{ Children $(3-15$ yrs $)$} \\
\cline { 2 - 3 } & $\%$ & $\mathrm{~N}$ \\
\hline $1680-1729^{23}$ & 15.2 & 6,555 \\
$1730-1759$ & 15.2 & 10,298 \\
$1760-1779$ & 23.4 & 13,956 \\
$1780-1803$ & 22.7 & 2,263 \\
Total & 18.3 & 33,072 \\
\hline
\end{tabular}

The findings presented in Table 3.8, combined with information on the age composition of the black population at specific points in time discussed further below, allow us to estimate the proportions between African-born and locally-born black children in Suriname at specific points in time. This will be done in Section 3.3.3.2 below.

The proportion of children among slave cohorts differed according to place of departure. The percentages of children are as follows:

Table 3.9 Percentages of children among slaves imported to Suriname (1684-1803)

\begin{tabular}{ll}
\hline Grain Coast $^{24}$ & $20.8 \%$ \\
Gold Coast & $15.4 \%$ \\
Slave Coast & $10.0 \%$ \\
Loango & $23.2 \%$ \\
Unknown & $14.8 \%$ \\
\hline
\end{tabular}

The differences between the recruitment areas have to do with the fact that the overall percentage of children among slave cargoes increased between the end of the 17th and the end of the 18th century (cf. Table 3.7 above). Therefore, the percentage of children from the Slave Coast, a region that was important in the beginning of slave importation, is lower than that of children from e.g. the Grain Coast which did not begin to supply slaves until later.

23. Note that the periodizations given in Tables 7 and 8 are not identical.

24. With regard to post-1740 undifferentiated Guinea Coast ships and post-1740 Gold Cost ships, the same procedure was followed as for Table 3.5, i.e. $70 \%$ of these cargoes were allocated to the Grain Coast and 30\% to the Gold Coast category. For explanation see the remarks accompanying Table 3.5 . 
Finally, I will say a few words about the sex distribution among Africans brought to Suriname. The ratio of males to females among African imports was roughly 6 to 4 . This means that the Dutch, in contrast to most other slave trading nations, almost succeeded in arriving at the 2-to-1 sex ratio among their slave cargoes which was considered 'ideal'. The low proportion of women among Suriname imports may well be one of the causes for the relatively low percentage of black children that were present in Suriname during the first one hundred years (see Section 3.3.3.2).

\subsubsection{Europeans}

In contrast to the immigration of blacks, very little is known about the immigration of whites. The information that is available is largely limited to estimates of the numbers of the different groups of immigrants; information on other variables, such as sex and age, is usually lacking. Since the pre-1667 immigration of English and Sephardic Jews was already discussed in Section 2.3, it will only be summarized here. At least four to five hundred English must have come to Suriname in that period, coming not only from Barbados but from St Kitts, Nevis and Montserrat as well (Rens 1953:14). As to their ultimate origin, many of them appear to have derived from the south of England, in particular the area around London (Smith 1987). While it is not clear how many of these immigrants were indentured labourers, there can be no doubt that a fair number of them belonged to that category. Since by far most indentured labourers in that period were Irish, this must also have been the case for Suriname. This means that at least part of them were native speakers of Gaelic, not English. In other words, for them, just as for the African slaves, interethnic communication on the plantations involved the use of English as a second, not a first, language. This is especially relevant in view of the fact that these servants, who were the group closest to the African slaves in terms of social distance, played an important role in the formation of Sranan.

The number of Sephardic Jews who came to Suriname in the 1665-1667 period is estimated at some 200 at most. Part of them came from Pernambuco while others came directly from Europe; ultimately they all derived from the Iberian Peninsula, of course, with Portuguese and Spanish as their primary languages. In the last quarter of the 17th century they were complemented by Ashkenazic Jews coming from or via Amsterdam but ultimately deriving from Eastern and Central Europe. Although no information about their language(s) is available, it is reasonable to assume that Yiddish and German would have been part of their linguistic repertoire. This is relevant since there has been a continuous presence of German, especially Low-German, in Suriname from early on (see below). 
As regards immigration in the post-1667 period, information is largely restricted to those who were involved in military activities, i.e. sailors and soldiers. Of the 735 men in the fleet that took Suriname in February 1667, only 125 stayed behind upon its departure in April of that year. Suriname's 'reconquest' in 1668 brought another 450 men in 1668; it is not clear how many of them stayed behind. Other groups of soldiers who came to Suriname in 1680 (152 men) and 1683 (611 men) only stayed for a limited period of time (Schaafsma 1966). Generally speaking, however, soldiers tended not to return to Europe, as noted by Postma on the basis of archival evidence (Postma 2003:320). In spite of the limited duration of their residence, these groups may still have played a linguistically relevant role because they formed a significant part - between a quarter and a third - of the overall European population of the colony. In addition to that, some sailors and soldiers stayed in Suriname after the expiration of their contract, of them, trying to make a living in the colony, for example, as a white overseer. As to the origin of these sailors and soldiers, it is important to know that in this period Dutch ships as well as Dutch armies contained large numbers of foreigners (around 50\%), a majority of whom were from areas where Low-German was spoken (Van der Sijs 2004: 50). Since 17th-century Low-German was more or less mutually understandable with Dutch, one might surmise that this had some influence on the Dutch spoken in Suriname, e.g. in the form of koinéization. Whether such influence can still be detected in modern Surinamese Dutch is unclear.

Another group among the Dutch immigrants about whom we have a little information are the people who were brought to Suriname as servanten (comparable to the indentured labourers in the English colonies). Between 1685 and 1691, a group of 177 Dutch orphans was brought to Suriname, but this experiment was never repeated (Van der Linde 1966:56). Forced labour was also used to some extent, but it seems that generally speaking Dutch attempts to use indentured labour were unsuccessful (Van der Linde 1966: 52ff, 82).

\subsubsection{Factors related to population}

While the previous section dealt with immigration, we will now turn our attention to the demographics of the population of Suriname at different points in time. It is important to discuss these topics separately because, although the two are obviously related, they may certainly not be equated. For example, the ethnic composition of the African population at a certain point in time $t$ is by no means necessarily identical to that of the immigration during a certain period $p$ preceding $t$, if only because there was already an African population present at the beginning of $p$. At the same time, distinguishing the two systematically is somewhat artificial because 
they are so closely related, for example in cases where we do have immigration data but no population data. In those cases, we will have to use the former to fill in gaps regarding the latter. I will begin by discussing developments in the ethnic composition of the overall population in terms of African versus European descent. Then, what little evidence is available about the national and regional origins of the European population will be presented. Finally, the rate of nativization of the black population, i.e. the rate at which the proportion between the locally-born and the African-born changed in favor of the former, will be discussed.

\subsubsection{Africans and Europeans}

Apart from enlarging enormously our knowledge of the African immigration into Suriname, Postma (1990) has also added substantially to what we know about the development of Suriname's population, both of its black and white segments. Postma's data, covering the years 1684-1754, are nicely supplemented by Van Stipriaan (1993), who presents figures for the 1752-1862 period. Taken together they cover the entire period of slavery except the first quarter of a century (16511684). While most figures predating Postma (1990) are based on estimates and extrapolations rather than hard data, these two authors have based their calculations on archival documents, especially those concerning the payment of so-called 'head taxes', ${ }^{25}$ which were 'paid on an annual basis by the free citizens for members of their families, their servants, and their slaves' (Postma, p. 185). Apart from census figures, which are very rare, head tax payment figures from the most specific data about population growth available. Unfortunately, they are not entirely unproblematic. First, new settlers were exempt from these taxes for their first ten years in the colony (Postma, p. 185). Second, these taxes were sometimes evaded by underreporting, i.e. reporting lower numbers of slaves than were actually present (Van Stipriaan, p. 311n). Postma has estimated the deviation due to the former factor at maximally $10 \%$. As to underreporting, Van Stipriaan has calculated the following multiplication factors for three different years: 1.1 (1752), 1.41 (1774), and 1.76 (1795). These figures are based on a comparison of head tax payment figures with a sample of plantation inventories providing full data on numbers of slaves.

It should be noted that, while Van Stipriaan included these multiplication factors in his calculations, Postma did not do so with regard to the $10 \%$ deviation percentage. Since multiplication factors for other years are not available, I have chosen to present the figures from both authors in Table 3.10 as they are given by them. In order to make the figures presented by these two authors fully

25. In Van Stipriaan's case only the figures for 1752, 1774 and 1795 are based on head tax data. The remaining figures are based on a diversity of sources, mainly archival documents. 
comparable, Postma's figures should be adjusted by adding $10 \%$ and by applying a multiplication factor, which, extrapolating from Van Stipriaan's calculations, may be estimated at somewhere between 1.0 and 1.1.

The information provided by Postma and Van Stipriaan was supplemented with data from other sources, especially for the initial period, but these are based on estimates rather than head tax payments. Since the initial period is least documented, figures are given for as many years and from as many sources as could be found, in order to counterbalance potentially deviant estimates. A result of this is that some discrepancies appear, most notably between the figures for the white population in 1666 given by Williamson (1923) and by Voorhoeve \& Lichtveld (1975) (500 versus 2,200). Apparently, the latter did not include the large number of deaths caused by the 1665 epidemic (see Chapter 2) in their calculations until 1668. Nevertheless, on the whole the figures for the initial period are sufficiently consistent to be considered reasonably reliable.

Table 3.12 below presents the ethnic composition (in terms of European versus African descent) of Suriname's population between 1651 and 1862. With regard to the category of blacks, we should note that this does not include Maroons. Although it is notoriously difficult to estimate their number, it is still useful to list the most reliable estimates found in the literature:

Table 3.10 Numbers of Maroons (1678-1863)

\begin{tabular}{lcl}
\hline Year & Number & Source \\
\hline 1678 & $350-400$ & Price (1976: 23) \\
1679 & $700-800$ & Price (1976:23-4) \\
1702 & 1,000 & Hoogbergen (1992:39) \\
1738 & 6,000 & Brana-Shute (1985:90n41) \\
1749 & 3,000 & Van der Meiden (1987: 109) \\
1786 & 7,000 & Encyclopaedie (1977: 87) \\
c1800 & 6,200 & Wolbers (1861:538-9) \\
1863 & 8,000 & Encyclopaedie (1977: 87) \\
\hline
\end{tabular}

The numbers of blacks mentioned in the historical sources (which form the basis for the column 'blacks' in Table 3.12) probably also do not include manumitted slaves. These were present from around 1700 onwards but their exact number before the last quarter of the 18th century is very difficult to assess (Beeldsnijder 1991:7). In any case, their numbers did not exceed a few percent of the entire black population until the end of the 18th century, when their number started to grow rapidly, as can be seen in Table 3.11 .

To the extent that the figures for blacks are based on head tax data, these may also include Amerindian slaves. However, although Amerindians were kept as 
Table 3.11 Numbers of manumitted slaves (1783-1830)

\begin{tabular}{lcl}
\hline Year & Number & Source \\
\hline 1783 & 598 & Beeldsnijder (1991:25) \\
1787 & 650 & Hoogbergen (1992:58) \\
1791 & 1,760 & Hoogbergen (1992:58) \\
1812 & 3,075 & Van Lier (1977:71) \\
1830 & 5,041 & Van Lier (1977:71) \\
\hline
\end{tabular}

slaves until well into the 19th century (Brana-Shute 1989), their numbers always remained very low, so even if they are included in the category of blacks, this cannot have made a big difference. Based on tax data, Van der Meiden (1987:54), for example, gives a number of 134 Amerindian slaves for 1684. Oudschans Dentz (1949: 13), however, claims there were no less than 500 Amerindian slaves in 1671 (in addition to the 2,500 black slaves), a figure that carries some weight as it is based on a historical document (a letter written by the colonists to the States of Zeeland (Encyclopaedie 1914-1917:613)). Pending evidence to the contrary, I assume the number of 'slaves' or 'blacks' given in historical sources to refer only to black slaves.

Table 3.12 Growth of black and white population in Suriname (1651-1862)

\begin{tabular}{|c|c|c|c|c|}
\hline & Blacks & Whites $^{27}$ & Direct source & Ultimate source \\
\hline 1652 & 200 & $150-200$ & Williamson 1923: 163 & Calendar of State Papers \\
\hline $1653 / 1654^{28}$ & $?$ & 350 & $\begin{array}{l}\text { Van der Meiden 1987: 18; } \\
\text { Rens 1953: } 78\end{array}$ & Biet 1664 \\
\hline 1661 & 2,000 & 1,000 & $\begin{array}{l}\text { Williamson 1923: 163; Van } \\
\text { der Meiden 1987: } 20\end{array}$ & Calendar of State Papers \\
\hline 1663 & $\begin{array}{l}1,500- \\
2,000\end{array}$ & $\begin{array}{l}2,000- \\
2,500^{29}\end{array}$ & $\begin{array}{l}\text { Williamson: 164; Rens: 79; } \\
\text { Van der Meiden 1987: } 20\end{array}$ & Calendar of State Papers \\
\hline
\end{tabular}

(continued)

26. Note that the figure of 598 manumitted slaves given for 1738 (instead of 1783) by Van Lier (1977:71) and Hoogbergen (1992:58) goes back to a printing error in Van Hogendorp (1801) as convincingly demonstrated by Beeldsnijder (1991:25-26).

27. It is unclear whether soldiers are included in this category. Soldiers formed a fluctuating, but at times considerable part of the white population. For example, in 1675 the regiment formed one fourth of the entire European population and a hundred years later, in 1773, the 500 soldiers who came to Suriname to suppress the revolt of the Boni maroons likewise formed approximately one fourth of the entire white population.

28. Van der Meiden (1987: 18) takes the date of Biet's visit to Suriname to be January 1653, while Rens (1953:78) assumes it to be January 1654.

29. This number is based on the fact that the total population for this year is given as ca 4,000 , combined with Rens' estimate of the number of slaves as 1,500-2,000. 
Table 3.12 (continued)

\begin{tabular}{|c|c|c|c|c|}
\hline & Blacks & Whites & Direct source & Ultimate source \\
\hline 1665 & 3,000 & $1,500^{30}$ & Williamson 1923: 164 & Calendar of State Papers \\
\hline 1666 & 2,400 & $500^{31}$ & $\begin{array}{l}\text { Voorhoeve \& Lichtveld 1975:3; } \\
\text { Williamson 1923: } 164\end{array}$ & $\begin{array}{l}\text { historical documents \& old } \\
\text { maps; Byam 1665-667 }\end{array}$ \\
\hline $1667^{33}$ & 2,000 & $?$ & Rens 1953 & ?? \\
\hline 1668 & 1,850 & 1,070 & Voorhoeve \& Lichtveld 1975: 3 & $\begin{array}{l}\text { historical documents \& old } \\
\text { maps }\end{array}$ \\
\hline 1671 & 2,500 & 800 & Voorhoeve \& Lichtveld 1975: 3 & hist. documents \& old maps \\
\hline 1673 & 3,000 & $?$ & Rens 1953: 80 & various historical sources \\
\hline 1675 & 1,800 & $550-600^{34}$ & $\begin{array}{l}\text { Voorhoeve \& Lichtveld 1975:3; } \\
\text { Mulert 1917: 404-6 }\end{array}$ & letter by Governor Versterre \\
\hline 1679 & 1,000 & 460 & Voorhoeve \& Lichtveld 1975:3 & hist. documents \& old maps' \\
\hline 1684 & $3,326^{35}$ & $652^{36}$ & Postma 1990: 185 & head tax data \\
\hline
\end{tabular}

30. Note that this only refers to 'men capable of wearing arms' (Williamson,1923: 164). The epithet 'capable of wearing arms' is added frequently, but by no means always, when numbers of whites are mentioned in early sources. This raises the question whether the other figures presented in the column 'Whites' in Table 3.12 only refer to weerbare mannen 'able-bodied men' (as they are called in Dutch sources) or to all whites (including women, children and elderly). Due to lack of information, this problem, which is especially relevant to the 1651-1680 period (for which no head tax data are available), cannot be solved here. At the same time, it should be realized that the numbers of white women and children in this period cannot have been very high.

31. The sudden drop from 1,500 to 500 whites was the result of a major epidemic (Williamson 1923: 164).

32. Rather than mentioning specific historical sources, Voorhoeve \& Lichtveld (1975:2) say their figures are based on 'historical documents, both English and Dutch, and...old maps', referring to several 20th-century publications, such as Rens (1953; 1954 [=1982]) and Van Renselaar (1966). Although these works make extensive use of historical works and old maps, these are not specifically mentioned under 'Ultimate source', since it is not exactly clear what their relationship is to the figures presented by Voorhoeve \& Lichtveld.

33. This date refers to early 1667, before the take-over by the Dutch late February that year.

34. Approximately half of these were English. According to Mulert (1927), the composition of the white population in 1675 was as follows: 120 English 'families' (either a single or a couple with or without children), 80 of whom were bound to leave the colony later that year; 57 Portuguese Jewish men; and 247 Dutch men, 119 of whom were soldiers. The number of children is not mentioned.

35. This figure differs from that presented by Van der Meiden (1987:54). For a decomposition of the latter into adult males and females, and children, see Table 2.8.

36. This figure is supported by a letter by Governor Van Sommelsdyk, who mentions 1,200 whites in 1684, including the ca. 600 soldiers who had arrived with him the year before. This figure differs from that presented by Van der Meiden (1987:54). For a decomposition of the latter into adult males and females, and children, see Table 2.8. 
Table 3.12 (continued)

\begin{tabular}{|c|c|c|c|c|}
\hline & Blacks & Whites & Direct source & Ultimate source \\
\hline 1694 & $?^{37}$ & $?$ & Oudschans Dentz 1949: 18 & 'census data'38 \\
\hline 1695 & 4,618 & 379 & Postma 1990: 185 & head tax data \\
\hline 1700 & 8,926 & 745 & Postma 1990: 185 & head tax data \\
\hline 1705 & 9,763 & 733 & Postma 1990: 185 & head tax data \\
\hline 1710 & 12,109 & 845 & Postma 1990: 185 & head tax data \\
\hline 1715 & 11,664 & 838 & Postma 1990: 185 & head tax data \\
\hline 1720 & 13,604 & 933 & Postma 1990: 185 & head tax data \\
\hline 1725 & 14,327 & 947 & Postma 1990: 185 & head tax data \\
\hline 1730 & 18,190 & 1,085 & Postma 1990: 185 & head tax data \\
\hline 1735 & 22,196 & 1,266 & Postma 1990: 185 & head tax data \\
\hline 1744 & 25,135 & 1,217 & Postma 1990: 185 & head tax data \\
\hline 1749 & c30,000 & $\mathrm{c} 1,500$ & Van der Meiden 1987: $14^{39}$ & $\begin{array}{l}\text { estimate by planter S. du Plessis } \\
\text { in Recueil } 1752 \text { (vol.1:271) }\end{array}$ \\
\hline 1752 & 37,835 & $?$ & Van Stipriaan 1993: 311 & head tax data \\
\hline 1754 & 33,423 & 1,441 & Postma 1990: 185 & head tax data \\
\hline 1774 & 59,923 & $?$ & Van Stipriaan 1993:311 & head tax data \\
\hline 1783 & 51,096 & 2,133 & Beeldsnijder 1991:25-6 & $\begin{array}{l}\text { Van Hogendorp } 1801 \text { (based } \\
\text { on head tax data) }\end{array}$ \\
\hline 1787 & 57,650 & 5,356 & Oudschans Dentz 1949:32 & 'census data' \\
\hline 1791 & $?^{40}$ & $?$ & Oudschans Dentz 1949: 33 & 'census data' \\
\hline 1795 & 48,155 & $?$ & Van Stipriaan 1993: 311 & head tax data \\
\hline 1812 & 50,725 & 2,124 & Wolbers 1861: 565 & census data ${ }^{41}$ \\
\hline 1836 & 46,879 & $?$ & Van Stipriaan 1993: 311 & head tax data \\
\hline 1854 & 38,545 & $?$ & Van Stipriaan 1993: 311 & head tax data \\
\hline 1862 & 36,484 & $?$ & Van Stipriaan 1993: 311 & head tax data \\
\hline
\end{tabular}

37. Oudschans Dentz does not distinguish between blacks and whites but only gives an overall number, 6,423, which he claims is based on 'the first census in Suriname'.

38. I use scare quotes here since Oudschans Dentz does not provide any information as to which 'census' he is referring to here ( $c f$. also his figures for 1787 and 1791). The census taken by the English in 1812 is generally recognized to be the first serious census to have taken place in Suriname.

39. According to Van der Meiden (1987: 108), minors are not included in these figures.

40. Oudschans Dentz does not distinguish between blacks and whites but only gives an overall number, 58,120 , which he claims is based on a 'census'.

41. This is the first professional census taken in Suriname; according to Wolbers (1861:565), it was performed 'with utmost care'. 
Table 3.13 Composition of the population on $12 / 31 / 1684 .{ }^{42}$ Source: Van der Meiden (1987:54)

\begin{tabular}{lcccc}
\hline & Male $>\mathbf{1 2}$ & Female $>\mathbf{1 2}$ & M+F $<\mathbf{1 2}$ & Total \\
\hline Christians & 362 & 127 & & \\
Jews & 105 & 58 & & 742 \\
Christians + Jews & $467^{43}$ & 185 & 90 & 3,844 \\
African slaves & 1,842 & 1,384 & 618 & 134 \\
Amerindian slaves & 39 & 67 & 28 & \\
\hline
\end{tabular}

When compared to the earlier figures given by Price (1976: Fig.1, Table 1, pp. 8/10), some strong discrepancies appear: from 1710 onwards Price's figures for the black population are (much) too high. The reason for this is that Price, referring to Van Lier (1971), calculated his figures by extrapolating from an incorrect figure for 1738, which ultimately goes back to Van Hogendorp (1801:327). As was convincingly shown by Beeldsnijder (1991:25-6), '1738' in Van Hogendorp's work must be a typographical error for ' 1783 '. In other words, the number of blacks given by Van Hogendorp $(51,694)$ for 1738 was not reached until almost fifty years later, in 1783.

The consequences of this typographical error are considerable, since it affects virtually all other estimates made by Price. From a linguistic point of view, the most important among these are those relating to birth and death rates, since these immediately affect his estimates of the number of locally-born slaves present at different points in time. It was these figures on which my earlier contention (Arends 1989, 1993a) was based that there were not enough locally-born children on the plantations to enable a bioprogram-like formation of Sranan. As will be shown in more detail in Section 3.3.3.2 below, the new data provided by Postma (1990) demand an adjustment of these figures.

What is especially interesting about these population figures from the perspective of language acquisition is the development of the black-to-white ratio, since this may tell us something about the access Africans had to Europeans as speakers of the 'target language'. A rough calculation of the development of that ratio, based on Table 3.10, is represented in Table 3.14.

Between the beginning of slave importation in the middle of the 17th century and the end of the 18th century, the black-to-white ratio shows a continuous increase, from 1:1 in 1651 to almost 25:1 in 1783. After 1783 the ratio remains more

42. This figure does not include the ca 300 soldiers who had come with Van Sommelsdyk in 1683.

43. Based on taxes, therefore reliable according to Van der Meiden. 
Table 3.14 Development of black-to-white ratio (1652-1830)

\begin{tabular}{lr}
\hline 1652 & $1: 1$ \\
1661 & $2: 1$ \\
1671 & $3: 1$ \\
1684 & $5: 1$ \\
1700 & $12: 1$ \\
1744 & $20: 1$ \\
1783 & $24: 1$ \\
1830 & $18: 1$ \\
\hline
\end{tabular}

or less constant, until 1830, when it drops to $18: 1$. The dramatic increase of the proportion of blacks to whites between 1651 and 1783 is a result of the increase of the black population, which was not due to natural growth, but to large-scale importation, coupled with an extremely slow growth of the white population during this period. As Table 3.11 shows, blacks' access to white language models deteriorated rapidly from the very beginning of colonization in 1651 . The proportion of blacks to whites increased dramatically during the 1670 s and, especially, the 1680 s, due to the expansion of the colony, in particular the number of sugar plantations. Blacks' access to native speakers of English was reduced even further by the fact that in this same period a significant part of the English and their 'old' (pre-1667) slaves left the colony. Whatever the role of the non-English colonists as language models may have been, it is clear that that role was quickly diminished by the increase of the black-to-white ratio after 1680 .

As to the origins of the white population, only very little truly quantitative information is available. More frequent are general remarks concerning the overall composition of the white population in terms of European descent. For example, Wolbers (1861: 171-3), referring to the mid-18th century, writes that 'the white population of Suriname consisted of a mixture of several European nations', including Dutch, French, Germans, and Sephardic and Ashkenazic Jews. That this was already so at the beginning of the 18th century (and probably before) appears from Van der Meiden (1987: 74), who bases his claim on archival documents. As regards the quantitative information we do have, it is important to present whatever information is available. Table 3.15, based on the Register der getrouwde persoonen aan Paramaribo ('Record of persons married in Paramaribo') for the years 1687-1700, included in the Generael Kercke Boeck ('General Church Book') presents the national origins of these people: 
Table 3.15 National origins of whites married in Paramaribo between 1687 and 1700 . Source: Van der Linde (1966:58)

\begin{tabular}{lccc}
\hline National origin & Men & Women & Total \\
\hline Netherlands & 50 & 73 & 123 \\
France & 27 & 10 & 37 \\
Germany & 21 & 5 & 26 \\
Sweden & 3 & 1 & 4 \\
Denmark & 2 & - & 2 \\
England & 2 & 2 & 4 \\
West India and Brazil & 1 & 4 & 5 \\
North America (New York) & 1 & - & 1 \\
East India (Batavia) & 1 & - & 1 \\
Total & 108 & 95 & 203 \\
\hline
\end{tabular}

Clearly, this table is not fully representative. Apart from the fact that it is only based on marriage records, it is also restricted both spatially (it only relates to Paramaribo) and temporally (it only covers the $1687-1700$ period). In addition to that, it does not include Portuguese Jews, since most of them lived - and married - in their own enclave, Jews' Savannah. In 1684, i.e. only three years prior to the period covered in Table 3.15, Jews formed approximately one third of the total white population (Rens 1953:79), a situation which continued throughout the next century. By the end of the 18th century, when many Jewish planters had left their plantations and moved to the city, Jews formed more than half of the white population of Paramaribo (excluding soldiers) (Cohen 1991: 80). From a linguistic point of view, it is important to know that at this time most Sephardic Jews still spoke Portuguese as well as Spanish (Cohen 1991: 113).

Despite its incompleteness, Table 2.10 confirms the picture that we find in the historical literature, namely that white 17 th-century Suriname was an extremely diverse and multilingual society. Dutch was by no means the only or even the major European language used by whites: throughout the 17th and 18th centuries: the Dutch were never a majority among the white population and Portuguese and French were widely used. Van Stipriaan (1993:32) notes that in 1737 no less than half of all plantations was in the possession of non-Dutch owners: French $\left(25 \%{ }^{44}\right)$, Portuguese (18\%), and English/German (7\%). Although the exact linguistic consequences of this heterogeneity cannot be easily determined, it seems clear that it favored the use of Sranan as a lingua franca among whites (see Chapter 4 for further information).

44. The high figure for French owners in 1737 may serve to explain a remark made by Anon. (c1740: 80-1), who, talking about 'Negro-English', says that 'on plantations that used to be owned by French many French words are used'. 
As to the regional origins of the people of Dutch descent, these are presented in the table below.

Table 3.16 Regional origins of whites of Dutch descent married in Paramaribo between 1687 and 1700

\begin{tabular}{lccc}
\hline Regional origin & Men & Women & Total \\
\hline Holland & 25 & 42 & 67 \\
Zeeland & 12 & 18 & 30 \\
Utrecht & 1 & 3 & 4 \\
Gelderland & 2 & 2 & 4 \\
Overijssel & 4 & 3 & 7 \\
Friesland & - & 1 & 1 \\
Brabant & 1 & 3 & 4 \\
Drente & 1 & - & 1 \\
'The Southern Provinces'45 & 4 & 1 & 5 \\
Total & 50 & 73 & 123 \\
\hline
\end{tabular}

Table 3.16 shows that half of the people of Dutch descent came from the province of Holland (roughly the area between Amsterdam, The Hague, Rotterdam and Utrecht), while Zeeland accounted for another sixth. Apart from other factors, this may be related to the fact that as a colony Suriname was very much connected to these two provinces, first to Zeeland (1667-1683), then, after the establishment of the Societeit van Suriname in 1683, to the city of Amsterdam. Although this bias in the regional origins of Dutch inhabitants of Suriname may have had an impact on the formation of Sranan (as well as, of course, Surinamese Dutch), at this moment too little is known to go into this matter any further.

\subsubsection{The rate of nativization among the Blacks}

Although, as noted above, the earlier estimates made by Price (1976:12) on the basis of Postma (1970), can no longer be maintained, it still holds true that the nativization of the black population of Suriname was an extremely slow affair. Van Stipriaan (1993:341) has calculated, on the basis of sample figures gathered from archival documents, the proportion of African-born slaves to the whole enslaved population as $71 \%$ in the third quarter and $52 \%$ in the fourth quarter of the 18 th century. In other words, more than one hundred years after the first Africans arrived in Suriname, two out of every three slaves living in Suriname had been born in Africa, not in Suriname.

45. This refers to what is now the Dutch province of Limburg and the Dutch-speaking part of Belgium. 
The high degree of Africanness of the slave population throughout the 18th century also becomes evident from data on the 'rate of replacement', i.e. the ratio of the number of slaves imported in a certain period to the number present at the beginning of that period. As shown in Table 3.17 and Figure 3.2, until 1700 the black population, the vast majority of whom had been born in Africa themselves, was continuously being supplemented and outnumbered by new arrivals from Africa. Although this tendency lessened somewhat in the 18th century, until 1750 the black population, more than two thirds of whom were African-born themselves, continued to be supplemented and replaced by huge numbers of new arrivals. In other words, during the entire formation period of Sranan the 'African connection' remained extremely strong, keeping the channel for cultural and linguistic input from Africa wide open.

Note that for one particular decade the immigration-to-population ratio is especially high, indeed astronomical, namely the 1680-1699 decade, when almost 10,000 new slaves were imported while at the beginning of that decade there were only some 1,500 blacks present in the entire colony. In terms of demographic development, the impact of such a change cannot be easily overestimated. To appreciate this, just try to imagine that eight or nine out of every ten people in your society are recent immigrants. In terms of language acquisition this implies that bozals' access to seasoned slaves as target language models became progressively more difficult, to the point of being almost non-existent, during these years.

Table 3.17 Ratio of slave import per decade to slave population present at beginning of decade (1651-1799)

\begin{tabular}{llll}
\hline & $\begin{array}{l}\text { Number of blacks } \\
\text { present in Suriname at } \\
\text { beginning of decade }\end{array}$ & $\begin{array}{l}\text { Number of immigrated } \\
\text { blacks per decade }\end{array}$ & $\begin{array}{l}\text { Proportion of } \\
\text { immigration to } \\
\text { population }\end{array}$ \\
\hline $1651-59$ & - & 200 & n.a. \\
$1660-69$ & 2,000 & 2,800 & $1.4: 1$ \\
$1670-79$ & 2,000 & 3,500 & $1.8: 1$ \\
$1680-89$ & 1,500 & 9,850 & $6.6: 1$ \\
$1690-99$ & 6,000 & 7,345 & $1.2: 1$ \\
$1700-09$ & 8,926 & 7,773 & $0.9: 1$ \\
\hline
\end{tabular}

46. For those years $(1660,1670,1680,1690,1760,1770,1780,1790)$ for which no exact figures are available, we have to work with estimates. These estimates are based on the figures for the surrounding years in Table 3.12 and the annual import figures in Postma's Table 2.2 (p. 35). As a result of this, the replacement rates for these years are less exact than those for other years.

47. Figures for the period 1651-1679 are estimates based on Postma's Table 2.2 (p. 35) and my Table 3.4. 


\begin{tabular}{llll}
\hline & $\begin{array}{l}\text { Number of blacks } \\
\text { present in Suriname at } \\
\text { beginning of decade }\end{array}$ & $\begin{array}{l}\text { Number of immigrated } \\
\text { blacks per decade }\end{array}$ & $\begin{array}{l}\text { Proportion of } \\
\text { immigration to } \\
\text { population }\end{array}$ \\
\hline $1710-19$ & 12,109 & 7,617 & $0.6: 1$ \\
$1720-29$ & 13,604 & 10,538 & $0.8: 1$ \\
$1730-39$ & 18,190 & 18,603 & $1: 1$ \\
$1740-49$ & 23,666 & 22,734 & $1: 1$ \\
$1750-59$ & 29,818 & 26,412 & $0.9: 1$ \\
$1760-69$ & 45,000 & 34,443 & $0.8: 1$ \\
$1770-79$ & 55,000 & 25,206 & $0.5: 1$ \\
$1780-89$ & 50,000 & 4,690 & $0.1: 1$ \\
$1790-99$ & 50,000 & 3,943 & $0.1: 1$ \\
\hline
\end{tabular}

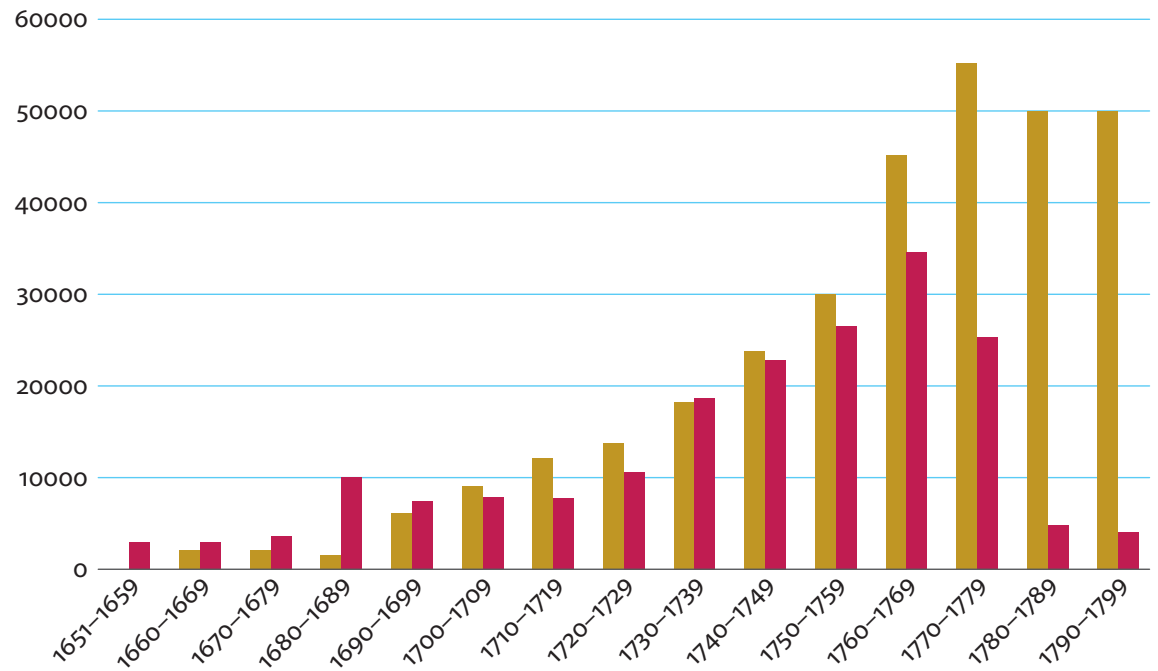

Population at start of decade Immigration during decade

Figure 3.2 Ratio of slave import per decade to slave population present at beginning of decade (1651-1799)

The slow speed of nativization of black Suriname also becomes evident from Oostindie's and Van Stipriaan's (1993: ch. 10) work in this area. Oostindie (1989, p. 99) presents the following figures for the sugar plantation Roosenburg: 
Table 3.18 Percentages of locally-born slaves on sugar plantation Roosenburg

\begin{tabular}{ll}
\hline 1733 & 27.3 \\
1762 & 37.1 \\
1768 & 49.2 \\
1811 & 58.8 \\
\hline
\end{tabular}

Things were not better on the other plantation studied in detail by Oostindie, Mon Bijou - a coffee plantation: here, as late as 1811 , only $56 \%$ of all slaves were locally born. The most striking results of Van Stipriaan's research, based on a large number of archival documents covering some 200 plantations, are the following: Death rates exceeded birth rates right until emancipation; in other words, Suriname's black population experienced a negative natural population growth during the entire slavery period (Table 3.15, p. 318; cf. also Oostindie 1989, Table 1, p. 132). As late as the end of the 18th century the mortality rate was 40.7 per 1,000 (Table 3.16, p. 323), while the birth rate remained below 20 per 1,000 in the same period (Table 52, p. 332). This means that without continuous massive importation from Africa, Suriname's black population would have been doomed to extinction. As late as 1835 , the average age at death for all those plantation slaves who survived past the age of ten, was 37 years, while it was below 30 for the entire black population. It is especially the combination of an extremely high death rate and a low birth rate which caused the nativization of the black population to proceed at a very slow pace. This means that there was a continuous and massive influx of speakers of African languages into Suriname for more than one hundred years after the onset of colonization. The most important linguistic implication of this, of course, is that African languages were in a position to leave their traces in the emerging creoles throughout the entire period during which they were formed.

\subsubsection{The creole-to-bozal ratio among slave children on the plantations} Another important linguistic issue related to the rate of nativization of the black population is the question to what extent the formation of the Suriname creoles was a matter of second rather than first language acquisition. In this connection it is important to have an idea of the proportion between African-born and locally-born children, both among slaves and among Maroons. I will first discuss this issue with regard to the plantations, Unfortunately, no archival data about the place of birth of the black population are available. However, it is possible to estimate the proportion of African-born and locally-born children in an indirect way. This can be done by combining data on the age distribution among the black population at specific points in time (see Table 3.19 below) with data on the age distribution among the 
African imports (see Table 3.8 above). It should be noted that although the figures in Table 3.19 are not corrected for tax exemption nor for underreporting, this is not really a problem here since what we are interested in here is the proportion of children on the overall population rather than absolute numbers.

Table 3.19 Age distribution among the black and white population (1684-1830)

\begin{tabular}{|c|c|c|c|c|c|c|c|}
\hline & \multicolumn{3}{|l|}{ Blacks } & \multicolumn{3}{|l|}{ Whites } & \multirow[t]{2}{*}{ Source } \\
\hline & $>12$ (n) & $<12$ (n) & $<12(\%)^{48}$ & $>12$ (n) & $<12$ (n) & $<12(\%)$ & \\
\hline $1684^{49}$ & 3,226 & 618 & 16.1 & 652 & 90 & 12.1 & $\begin{array}{l}\text { Van der Meiden (1987: } \\
\text { 54) (head tax data) }\end{array}$ \\
\hline 1702 & 7,353 & 1,193 & 14.0 & $?$ & $?$ & $?$ & $\begin{array}{l}\text { Hoogbergen (1992: } \\
\text { 304n53) (head tax } \\
\text { data) }\end{array}$ \\
\hline 1705 & 8,433 & 1,330 & 13.6 & 601 & 132 & 18.0 & $\begin{array}{l}\text { Postma (1990: } \\
\text { Table 8.1) (head tax } \\
\text { data) }\end{array}$ \\
\hline 1710 & 10,372 & 1,737 & 14.3 & 672 & 173 & 20.5 & id. \\
\hline 1715 & 9,702 & 1,962 & 16.8 & 671 & 167 & 19.9 & id. \\
\hline 1720 & 11,347 & 2,257 & 16.6 & 767 & 166 & 17.8 & id. \\
\hline 1725 & 11,945 & 2,382 & 16.6 & 785 & 162 & 17.1 & id. \\
\hline 1730 & 15,391 & 2,799 & 15.4 & 909 & 176 & 16.2 & id. \\
\hline 1735 & 18,799 & 3,397 & 15.3 & 1,038 & 228 & 18.0 & id. \\
\hline 1744 & 20,707 & 4,428 & 17.6 & 1,028 & 189 & 15.5 & id. \\
\hline 1754 & 27,533 & 5,890 & 17.6 & 1,275 & 166 & 11.7 & id. \\
\hline 1830 & 32,350 & 16,434 & 33.7 & $?$ & $?$ & $?$ & $\begin{array}{l}\text { Oomens (1986: 156) } \\
\text { (based on Teenstra } \\
1835,1842)\end{array}$ \\
\hline
\end{tabular}

48. Unfortunately, my earlier Table 2.6 in Arends (1995a) contains a serious mistake: the figures given there, both for black and white children, represent the percentages of children below twelve as a proportion of the number of persons above twelve rather than as a proportion of the entire population. Mea culpa. The good news - at least from my point of view - is that the correct percentages, which are considerably lower than those given in Arends (1995a), strengthen my argument that the percentage of black children was abnormally low.

49. The figures given here for 1684, based on head tax data summarized by Van der Meiden (1987:54), replace those given in Arends (1995a). These earlier - strikingly deviant - figures were based on head tax data as summarized by Van der Linde (1966:50). Since Van der Meiden's figures are much more in line with those given for other years, I prefer those over Van der Linde's. I have no explanation as to why the figures presented by these two authors differ so widely (but $c f$. note 38 in Arends 1995a). 
The low percentages for black children are confirmed by the figures given by Oostindie (1989), who, in his in-depth study of the sugar plantation Roosenburg, notes that the percentage of black children below 15 was as low as $11 \%$ in 1720 , only rising to around $25 \%$ in the $1760-1800$ period, and to $41 \%$ in 1852 (Oostindie 1989: 76). These percentages are very low when compared to the figures presented by Singler (1995: Table 5) for Martinique and Haiti: an average of around 15\% during the first 65 years in Suriname's existence against 25\% and 30\% for comparable periods in Haiti and Martinique, respectively. This is undoubtedly related to the fact that the percentages of children as well as women in the trade to Suriname were lower than those in the French trade (see below).

On the basis of Table 3.8 and Table 3.19 the proportion of African-born to locally-born slave children can now be estimated as follows. (The calculation will only be demonstrated for one year, 1702, but the principle works the same for other years.) The number of black children (0-12 years) present in the colony in 1702 is 1,193. Since Amerindian slave children are also included in this number, we have to adjust it slightly, say to 1,100 . Projecting the Suriname sample figures for the age distribution among African immigrants (Table 3.8) on the entire Suriname import reveals that between 1693 and 1701 approximately 1,200 African children (3-25 years) were imported. (The 1693-1701 period is the period during which children were imported who were potentially still below the age of thirteen in 1702.) Since almost all children in the 12-15 age span that were imported prior to 1702 were past the age of twelve in 1702, we have to subtract approximately one quarter from the total of 1,200 (assuming even distribution of imported children over the 3-15 age $\operatorname{span}^{50}$ ). This leaves us with a group of approximately 900 children between the ages of three and twelve that arrived in the nine years preceding 1702 .

Before we continue, it should be noted that, due to the absence of accurate mortality figures for this period, it is impossible to calculate the exact proportion of African-born to Suriname-born black children. The earliest reliable mortality rates available are from the middle of the nineteenth century: at that time almost $40 \%$ of all black children (by then all Suriname-born) died before the age of five. The mortality rate for children between the ages of five and ten was much lower, i.e. 3-4\%. (Van Stipriaan 1993: Table 3.19, p. 330). Apparently, the age of five was critical for survival in Suriname. Note that this percentage obtained at a time when for more than fifty years planters had been making serious efforts to improve the living conditions for their slaves - especially since the late 1820s, when the policy of

50. Since it is known that generally-speaking slave traders had a strong preference for adolescents and young adults, my assumption of even distribution across the 3-15 age span is probably not correct. However, since no age-specific figures are available, I am forced to make this assumption. Later on I will apply a correction factor to account for this bias. 
so-called lotsverbetering (lit. 'improvement in one's fate', i.e. amelioration policy) was initiated. Therefore it would be reasonable to assume that in the 18th century a higher mortality rate, say $50 \%$, among black children obtained (note that this is a very conservative estimate). Departing from this mortality figure we can estimate the number of African-born children in 1702 as follows.

If, as we may assume in the absence of evidence to the contrary, the 900 imported children were evenly divided over the 3-12 age span, then some 300 of them were below the age of six upon arrival in Suriname. If $50 \%$ of these died (assuming that African children were subject to the same critical age as locally-born children ${ }^{51}$ ), then some 150 of them were still alive in 1702 . Of the remaining 750 , some of those who arrived while past the age of five will have died before 1702 . Since mortality at this age was relatively low, let us put this number at 50 . Then, we have to subtract from the remaining 700 children all those who had passed the age of twelve by 1702. Again assuming even distribution of the imported children over the age span, we can estimate the proportion of these at approximately $50 \%$, i.e. 350 children. This leaves us with a total of 350 African-born children on a total of 1,100 black children. In other words, approximately one out of every three black children present in Suriname in 1702 had been born in Africa. This does not necessarily mean that this proportion obtained throughout Suriname, since the situation on the plantations was different from that in Paramaribo. Since locally-born children were preferred as domestic slaves in the city while new imports were immediately sent to the plantations, the ratio of locally-born to African-born children on the plantations must have been lower than 2-to-1. However, as noted above, my assumption of even distribution across the 3-12 age span among imports is probably not correct. If we let these two factors cancel each other out, we arrive at a proportion of locally-born to African-born children on the plantations as 2-to-1.

It is not surprising that applying the same method to later years $(1730,1754)$ yields higher creole-to-bozal ratios among children (in the range of 5-to-1), simply because, however slowly, the process of nativization of the black population still continued. Still, the conclusion to be drawn from these figures is that, as far as the role of children in creole formation is concerned, this was clearly not a matter of

51. This, of course, is open to doubt: it is possible that the critical age for survival should be stated in terms of years since arrival rather than birth. In that case, the African children surviving past the age of five should be estimated at a lower number. In addition, differential mortality rates between African-born and locally-born children may have played a role as well. But note that, although in general (i.e. across the Caribbean) mortality rates for African-born seem to have been higher than for locally-born, Van Stipriaan (1993:325) suggests that Suriname may have been an exception to that rule. For the purpose of this chapter I assume critical age and mortality rates to be equal for African-born and locally-born children. 
first language acquisition only. Every African child between ages three and twelve arrived in Suriname with knowledge of one or more West African language(s). Since all black children on the plantations, whether they had been born in Africa or Suriname, (as well as, if present, the white children, for that matter) were taken care of by a creole mama, ${ }^{52}$ they grew up in close contact with each other. This means that there were ample opportunities for Suriname-born and African-born children to influence each other in their language acquisition processes, although in exactly what ways is impossible to say.

\subsubsection{The creole-to-bozal ratio among Maroons}

Although no historical documents are known that contain figures on the proportion between the African-born and locally-born segments of the Saramaka population in the 18th century, there is sufficient information available on the basis of which this proportion can be estimated. Due to limitations in the data, these calculations are subject to two restrictions: first, they can be made for two years only, 1702 and 1749; second, they apply to the entire Maroon population, which from ca. 1730 onwards includes not only the Saramaka but the Ndyuka as well, whose formation began around that time (Hoogbergen 1990: 73). Since by 1749 the proportion of locally-born among the latter most likely was lower than it was among the Saramaka (due to the fact that their formation began almost 50 years after the Saramaka), the incorporation of the Ndyuka in these calculations has a negative effect on my calculation of the proportion of locally-born. In other words, the proportion of locally-born among the Saramaka was probably higher than appears from the calculations below.

As noted by Hoogbergen (1990:71), '[b]ased on information received from the plantations, the authorities in the districts - the so-called burgher-kapiteins - held a record of all '-awayaway' or 'returned' slaves. ${ }^{53}$ On the basis of these records, Hoogbergen estimates the number of runaways per year at $0.5 \%$ of the entire Surinamese black population in that year. However, only one third of these (i.e. $0.17 \%$ ) stayed away from the plantations permanently. The fact that reliable figures (based on head tax records ${ }^{54}$ ) of the black population for the 1702-1749 period are available (see Table 3.10 above), makes it possible to calculate the numbers of permanent runaways in this period by projecting the $0.17 \%$ figure on these figures:

52. The name refers to the fact that most of these children were 'creoles', i.e. born in Suriname.

53. Burgher-kapitein (lit. 'civilian captain') was the highest rank in a burgher militia (lit. 'civil militia').

54. Due to underreporting, these figures should be raised by approximately $10 \%$ (Arends 1995a: 257-58). 
Table 3.20 Estimated numbers of permanent run-away slaves (1702-1749)

\begin{tabular}{llc}
\hline & $\begin{array}{l}\text { Number of blacks } \\
\text { at beginning of period }\end{array}$ & $\begin{array}{l}\text { Estimated number of permanent } \\
\text { run-away slaves per period }\end{array}$ \\
\hline $1702-09$ & $9,345^{55}$ & 127 \\
$1710-19$ & 12,109 & 214 \\
$1720-29$ & 13,604 & 265 \\
$1730-39$ & 18,190 & 361 \\
$1740-49$ & $23,666^{56}$ & 402 \\
Total & & 1,369 \\
\hline
\end{tabular}

Addition of $10 \%$ (because of underreporting) yields a total number of around 1,500 permanent runaways for the entire 1702-1749 period.

A reliable estimate of the proportion of locally-born among the Maroon population in 1749 is possible if, in addition to the 'immigration' figures in Table 3.17, we have at our disposal population figures for the 1702-1749 period. These figures are provided by Hoogbergen, a leading scholar in Suriname Maroon history, who estimates the number of Maroons present in Suriname in 1702 and 1749 at 1,0001500 and 6,000, respectively (Hoogbergen 1990:73,75). Since the same author, in a later publication (Hoogbergen 1992:39), gives 1,000 as the number of Maroons in 1702 , I will proceed from that figure. ${ }^{57}$ By combining population figures and immigration figures, the number of locally-born Maroons in 1749 may be estimated at some 4,500 , i.e. $3 / 4$ of the Maroon population. ${ }^{58}$ This figure is in agreement

55. Since no figure is available for the year 1702, I have taken the mean of the figures for 1700 and 1705.

56. Since no figure is available for the year 1740, I have taken the mean of the figures for 1735 and 1744 .

57. Van der Meiden (1987: 109), referring to a letter written by Governor Mauricius in 1750, estimates the total number of Maroons around this time at 3,000 ( $c f$. Table 2.5 above). The difference may be explained by the fact that some Maroon areas (especially the Eastern and North Eastern regions, where new Maroon tribes such as the Ndyuka had started to form recently) are included in Hoogbergen's calculation (p. 75) but not in Van der Meiden's (p. 109).

58. This figure is calculated as follows. The difference between the Maroon population in 1749 $(6,000)$ and in $1702(1,000)$ is 5,000. Subtraction from this figure of the 1,500 newcomers who joined the Maroon groups in this period yields 3,500. However, part of these newcomers were not alive anymore in 1749, say one third, i.e. 500. Part of the original population of 1,000, almost all of whom were African-born (Price 1976:32), was not alive anymore in 1749 either, say half, i.e. 500. Therefore, we have to raise the number of 3,500 locally-born with an extra 1,000, yielding 4,500 locally-born. This means that roughly three quarter $(4,500$ out of 6,000$)$ of the Maroon population in 1749 had been born in Suriname. 
with Price's (1976:34) estimate that around 1770, i.e. 20 years later, 'about $99 \%$ of the Saramaka population would have been Suriname-born.'

Comparing these figures with those for the plantations shows an enormous difference.

On the basis of Van Stipriaan's (1993:341) calculations, based on plantation records for a sample of 5,555 slaves, the percentage of locally-born slaves in 1749 can be estimated at a maximum of $25 \% .{ }^{59}$ This means that by 1750 the nativization among Maroons had progressed at least three times as far as it had among slaves. The fact that the nativization rates of the two populations among whom two creoles emerged - Saramaccan and Sranan - differ so markedly, shows that the formative processes that produced them differed in certain respects, in particular the fact that first language acquisition played a bigger role and second language acquisition a smaller role in the case of Saramaccan than of Sranan.

\subsection{Summary and conclusion}

Before I go on to summarize the major findings of this section, there is one additional conclusion that can be drawn. Relating the figures and estimates presented above to what is the most reliable information regarding the numbers of plantations in Suriname (Wekker $1991^{60}$ ), we can calculate the average black population per plantation at different points in time. Starting with an average of around ten slaves per plantation in the 1660s, the number rose to around twenty in the 1670 s. Once the expansion phase was well on its way, it jumped to around seventy at the turn of the 18th century, leveling out at 45-60 in the first half of the 18th century. While the average adult black population went up and down throughout this period, the non-adult population remained more or less constant. On average there were between seven and ten black children per plantation, two of whom had been born in Africa. This means that even as late as 1750 for every locally-born

59. Since the proportion of locally-born slaves was $29 \%$ for the $1750-1769$ period and $48 \%$ for the 1780-1809 period, an estimate of $25 \%$ for 1749 seems realistic. The $25 \%$ estimate is supported by the fact that Beeldsnijder (1994: 125), based on plantation inventories for a sample of 2,062 slaves, calculates the proportion of locally-born slaves in the $1730-1750$ period at $16.2 \%$, a figure which, due to inaccuracies in plantation inventories, was probably higher in reality.

6o. Wekker's (1991) figures, based on extensive historical-cartographic research, are the most reliable to date. I adjusted Wekker's figures downward somewhat to correct for the timber estates that are included in his category of 'plantation'. Timber estates were very different from plantations in many respects which are linguistically relevant: only males worked there, there were no children, and the slaves enjoyed a much greater degree of independence. 
child acquiring the creole as a first language there were around ten African-born adults - for whom learning the creole was a matter of second language acquisition. Clearly, the formation of Sranan was no less a matter of second as it was of first language acquisition.

Summarizing the main results of this section, it is clear that, with the exception of the early but poorly documented shipments from the Bight of Biafra, almost all slaves that were imported into Suriname during the first 75 years of its existence were shipped from the Slave Coast and from the Loango area. Gold Coast and Grain Coast slaves did not arrive until after the foundations of the Suriname creole languages had been laid. This means that the primary candidates for substrate influence are Kikongo and Gbe. Secondary influence may have been exerted by Kwa languages from the Gold Coast area, such as Twi. Other languages, such as those belonging to the Kru, Mande and Atlantic branches of Niger-Congo, were not represented in Suriname during the formative period of the Suriname creoles. Therefore, the West African substrate in Suriname may be characterized as relatively homogeneous.

It was also shown that the rate of nativization of the slave population was extremely slow: more than one hundred years after colonization still more than $70 \%$ of that population was African-born. During the first fifty years of colonization the entire population was outnumbered by new arrivals from Africa every three to five years; during the next fifty years this happened almost every ten years. While there was little vertical (generational) continuity within the black population itself, due to high death rates and low birth rates, there was an enormous amount of horizontal continuity in terms of an ongoing stream of cultural and linguistic input from Africa, which lasted until the last quarter of the 18th century. This means that creole formation in Suriname was to a large degree a matter of second rather than first language acquisition. Since the substrate was relatively homogeneous, this also means that there was ample opportunity for the substrate languages to leave their imprint on the emerging creoles. 



\section{Meta-linguistic evidence}

\section{Variation, attitudes and linguistic repertoires in the pre-Emancipation era}

\subsection{Introduction}

In the historical study of Creoles little attention has been devoted to synchronic variation in the early stages of these languages. This can be explained, of course, by the fact that for most of these languages the early stages have hardly been studied at all, so the issue of variation did not arise in the first place. It seems, however, that for some Creoles, such as Sranan, enough data are available to allow at least an exploratory investigation of this issue. ${ }^{1}$ The primary sources to contain such data are the manuscript and printed dictionaries that were compiled by the Moravian missionaries in the 18th and 19th centuries, such as Schumann $(1778,1783)$ and Wullschlägel (1856). While the majority of our data are concerned with lexical issues, there are a few places where observations are made regarding other aspects of variation, such as pronunciation.

Another topic on which these as well as several other sources provide relevant information has to do with language attitudes and use: what do our sources say about the views different groups of speakers held about Sranan and about who used it, and when and where? It turns out that, in spite of the overwhelmingly negative attitude towards it, Sranan was widely spoken by Europeans, especially women, a finding that may have important implications for the reconstruction of its history.

\subsection{Variation in early Sranan}

The investigation of early variation, apart from being worthwhile in itself, is relevant to a number of issues. First of all, since almost all of our information on the early stages of the Suriname Creoles - as well as most other Creole languages - is derived from European sources, such as dictionaries, grammatical descriptions

1. Although Saramaccan will be referred to frequently in the discussion, this will mostly be in terms of what Saramaccan sources tell us about variation in Early Sranan. Variation in Early Saramaccan is not sufficiently documented to enable us to discuss it in any detail. 
and Bible translations, the question arises whether these documents provide us with a representative image of the language as it was actually spoken, especially by the blacks. Some creolists (e.g. Bickerton 1988:281) have even gone so far as to claim that early documents are so unreliable as to make them unfit as sources of hard linguistic evidence. While this is clearly an exaggeration, it is true that we cannot simply take the information presented in early sources for granted. A study of variation in early Sranan may help us shed some light on this issue.

Second, with our greatly increased insight into the historical development of the Suriname Creoles, especially Sranan and Saramaccan (e.g. Arends 1989, Smith 1987, Bruyn 1995a, Plag 1993, Migge 2003, Van den Bergto appear, Braun 2005), information concerning variation in the early stages may contribute to acquiring a more precise understanding of the diachronic development of these languages.

Third, an empirical confirmation of the existence of early variation would provide independent support for the hypothesis, first expressed by Alleyne (1971: 170), that the Caribbean Creoles 'show considerable variation from the beginning rather than early and rapid crystallization'. Any evidence we would be able to find for variation in Early Sranan could be taken to support the argument for an early origin of the Creole continuum (cf. Alleyne 1980:198). By extension, it would also support the claim that creolization is a gradual rather than an instantaneous process (cf. Arends 1986, 1989, 1993a).

These issues, however, will not be dealt with in any detail in this chapter, since its main purpose is simply to present a survey of the types of variation found in the early sources. First, I will present a list of the dimensions along which variation occurred in Early Sranan; ${ }^{2}$ then, these dimensions of variation will be discussed and illustrated in some more detail; and, finally, I will briefly consider the implications of my findings for the issues mentioned above.

Based on meta-linguistic remarks found in a number of 18th and 19th century sources, the following dimensions of variation may be distinguished: ${ }^{3}$ ethnicity (African vs. European), geography (plantation vs. Paramaribo), ownership (whether speakers fell under the authority of the English, the Portuguese or the Dutch),

2. The period referred to by the word 'Early' in this label stretches roughly until 1850. It should be noted, however, that due to lack of information we can say very little about the presence of variation during the first one hundred years or so in the existence of Sranan.

3. My primary sources were Schumann's (1783) and Wullschlägel's (1856) Sranan dictionaries, both written within the 'Moravian linguistic tradition', which is characterized by a conscientious and insightful treatment of the Surinamese creole languages. Departing from their observations, additional sources were consulted. It should be stressed, however, that this chapter is not based on a systematic investigation of all relevant sources; it is, rather, intended as an exploratory survey of what meta-linguistic information about variation can be gleaned from these early sources. 
religion (the special variety of Sranan developed by the Moravian missionaries), and, finally, place of birth (whether speakers were born in Suriname or in Africa). The dimensions of variation discussed here are the following:

\section{Ethnicity}

The distinction here is between bakra tongo lit. 'white man's language', i.e. 'white Sranan, 'Sranan as spoken by whites', on the one hand, and nengre tongo lit. 'black man's language', i.e. 'black Sranan', 'Sranan as spoken by Blacks', on the other. ${ }^{4}$ Whereas the former would be more influenced by the European language(s) spoken by bakras (Europeans), the latter would be more influenced by the African languages spoken by the (ancestors of the) blacks.

\section{Geographical location}

Our source clearly indicates that there were differences between 'urban Sranan', the language of the capital (Paramaribo), on the one hand, and 'rural Sranan', the language as it was spoken on the plantations, on the other.

\section{Ownership}

This label refers to the fact that since different plantations were owned by speakers of different languages - mainly English, Portuguese, or Dutch, the Creoles spoken on these plantations differed as well. In the contemporary literature a distinction is made between the language of the 'new' (post-1667, i.e. non-English-owned) plantations vs. the language of the 'old' (pre-1667, i.e. - formerly - English owned) plantations. Similarly, a separate variety called Djutongo (lit. 'Jews' language') is occasionally mentioned in the early sources. This label refers to the lexically Portuguese-influenced Creole once used on the Portuguese-owned plantations along the Upper Suriname River, which may well have been the predecessor of Saramaccan.

\section{Religion}

Because the Moravian Brethren, ${ }^{5}$ who made extensive use of Sranan in their missionary activities, needed new vocabulary to refer to Christian concepts, a separate register of Sranan called 'church Creole' or 'pulpit language' emerged. Apart from exhibiting lexical idiosyncrasies, this register is also characterized by certain phonetic features such as spelling pronunciation.

4. In referring to these two varieties I will use the modern spellings (bakra tongo, nengre tongo), except, of course, in quotations from older sources using a different spelling.

5. The Moravian Brethren began their missionary work in Suriname in 1735 among the Indians, expanding it to the Saramaka Maroons in 1765, and finally to the plantation slaves in late 1820s. They are known for their linguistic abilities, both in description (grammars, dictionaries) and translation (mostly biblical). 


\section{Place of birth}

The fact that some blacks acquired Sranan as a first language (i.e. those who were either born in the colony or during the 'middle passage' or shortly before departure from Africa) while for others (i.e. those who entered Suriname as speakers of some African language(s)) it was a second language, led to differences between 'native Sranan' and 'non-native Sranan'. Although the same situation may have existed for whites, lack of documentary evidence does not allow us to go into that any further. Lack of evidence also precludes any discussion of Saramaccan in terms of differences between native and non-native varieties, although such differences must have existed as long as new runaways were accepted into the community (i.e. until the early 19th century).

Although age is not distinguished as a separate category here, a few remarks may be found in the contemporary literature concerning this variable (Stedman 1790: 516; Wullschlägel 1856: vii-viii). The remarks made by these authors relate to the preservation by older speakers of English-derived words for concepts for which younger speakers use Dutch-derived words. Since the replacement of certain English-derived words by Dutch-derived words will be shown to be primarily a feature of urban Sranan, these remarks will be discussed in the section on geographical variation. Apart from the references to the dimensions of variation listed above, a few remarks can be found in the early sources concerning types of variation which cannot be related to any of these categories. These are briefly discussed in Section 4.2.6.

\subsubsection{Ethnicity: nengre tongo and bakra tongo}

Under the entry bakkra, Schumann's Sranan dictionary (1783) clearly indicates that the Sranan spoken by Europeans was sufficiently different from the Blacks' variety to warrant a separate name: ${ }^{6}$

a jeri Bakkra, 'he understands the Negro language', because, when the blacks say Bakkra-tongo, they mean by that the Negro English language as the European whites here speak it: the Dutch and the German language are both called Duitstongo. $^{7}$ (source: Schumann) ${ }^{8}$

(Schumann 1783, s.v. bakkra)

6. All translations are mine, unless indicated otherwise.

7. The use of the term 'Duits-tongo' for both German and Dutch can be explained by the fact that in earlier stages of Dutch the word 'duits' was sometimes used to refer to both languages.

8. Since in compiling his Sranan and Saramaccan dictionaries, Schumann used one or more informant(s), whom he sometimes quotes more or less verbatim, quotations from these dictionaries are followed by an indication of their actual source, i.e. either 'source: Schumann' or 'source: 
In all, there are thirty-six words in Schumann's dictionary which are labeled ' bakra tongo'. As would be expected, most of these words are of Dutch derivation, since quite some time before Schumann's compiled his dictionary English as the language of the ruling class had been replaced by Dutch. ${ }^{9}$ There are, however, some exceptions, i.e.words identified by Schumann as bakra tongo, which are not taken from Dutch. These words are either derived from English (arede, fesi, pili/piri, sibi) or from Portuguese (adjossi). The nengre tongo (Blacks' Sranan) counterparts of these non-Dutch-derived bakra tongo words, as given by Schumann, are of diverse origin: either English, Portuguese, or, in one case (dorro, 'sieve') even Dutch).

Table 4.1 Non-Dutch derived bakra tongo words, with their equivalents in nengre tongo (Schumann 1783)

\begin{tabular}{|c|c|c|}
\hline Meaning & nakra tongo & nengre tongo \\
\hline already & arede (< En. 'already') & kaba $(<$ Pt. 'acabar', i.e. 'finish') \\
\hline goodbye & adjossi (< Pt. 'adeus', i.e. 'goodbye') & kroboi $\left(<\right.$ En. 'goodbye'? $\left.{ }^{10}\right)$ \\
\hline go towards s.o. & fesi $(<$ En. 'face') & $\underline{\text { miti }}(<$ En. 'meet') \\
\hline pull s.o.s leg & pili/piri (< En. 'peel') & $?^{11}$ \\
\hline sieve & $\underline{\text { sibi }}(<$ En. 'sieve') & $\underline{\text { dorro }}(<$ Du. 'door', i.e. 'through') \\
\hline
\end{tabular}

The great majority of bakra tongo words, however, as mentioned above, are derived from Dutch. In most cases, the nengre tongo equivalents of these Dutch-derived bakra tongo items are taken from English, such as lossi, 'roast', biggi, 'big', redi/ledi, 'red'/'yellow', and NT biggi futtu, 'thigh' < En. 'big + foot' (BT boutu< Du. 'bout' i.e. 'leg, quarter'). ${ }^{12}$ In a few cases the nengre tongo counterpart of Dutch-derived

Schumann's informant'. Commentary by Schumann himself is always in German in the original manuscript (with occasional usage of Latin grammatical terminology), never in Sranan. This would have been odd anyway, since the primary purpose of the dictionary was to facilitate the acquisition of Sranan by his fellow Brethren (most of whom were speakers of German). Cf. the following remark from Schumann's diary referring to his Saramaccan dictionary: 'I checked and improved it thoroughly together with our Johannes'. (Stähelin p. 347, quoted in Kramp 1983:9). As noted by Price (1990), this Johannes could only be Johannes Alabi.

9. However, other European languages, such as German, Portuguese and French, were also used (cf. Section 4.3.2 below). Contrary to what is usually assumed, English remained in use as well, albeit on a relatively small scale (cf., e.g. Stedman 1790; see Section 4.3.3.2 below).

10. This is the derivation proposed by Schuchardt (1914:xxv); an African origin has also been claimed for this item.

11. Schumann does not provide the nengre tongo equivalent with the intended meaning.

12. Although the constituent words are derived from English, the expression as such, of course, is either an innovation or a substrate calquing. 
bakra tongo items has a different, i.e. non-English, origin. It may be Portuguese, as in the case of kaba 'and', or African, as in the case of jorka 'picture.' ${ }^{13}$ This information is summarized in the table below:

Table 4.2 Dutch derived bakra tongo words, with their Englishand non-English-derived equivalents in nengre tongo (Schumann 1783)

\begin{tabular}{|c|c|c|}
\hline Meaning & bakra tongo & nengre tongo \\
\hline and & en (< Du. 'en') & $\underline{k a b a}(<\text { Pt. 'acabar', i.e. 'finish') })^{14}$ \\
\hline roast & bakka (< Du. 'bakken') & lossi $(<$ En. 'roast') \\
\hline fat & deki (< Du. 'dik', i.e. 'fat') & biggi (< En. 'big') \\
\hline picture & $\begin{array}{l}\text { printje (<Du. 'prentje', i.e. 'small } \\
\text { picture') }\end{array}$ & $\begin{array}{l}\text { jorka }(<\text { unknown African } \\
\text { language })\end{array}$ \\
\hline yellow & geel (< Du. 'geel', i.e. 'yellow') & $\underline{\text { redi/ledi }}$ (< En. 'red') \\
\hline shelter from rain & $?$ & kibri areen $(<$ En. 'cover + rain') \\
\hline thigh & boutu (< Du. 'bout', i.e. 'leg, quarter'15) & biggi futtu $(<$ En. 'big + foot') \\
\hline
\end{tabular}

In one case, the etymon for the bakra tongo and nengre tongo equivalents is the same (En. 'devil'), but the latter has it in a partially reduplicated form (didübri), while the former does not (dübri). Finally, there is one item in Schumann's dictionary which is relevant here, namely the word kibri, which occurs in the sentence mi go kibri areen (s.v. kibri), 'I'm going to take shelter from the rain', where the informant adds that this is how "we blacks usually say it", without, however, providing any further information about bakra tongo usage. Summarizing, the examples given here indicate that the most salient feature of the variety known as bakra tongo in the late 18th century is the use of Dutch-derived words where blacks would use English-derived words instead.

As mentioned at the beginning of this chapter, another major Sranan dictionary besides Schumann's - Wullschlägel's (1856) German-Sranan dictionary - was also consulted for information on variation in Early Sranan. In the preface to this work, the author talks about

[t]his (language) [i.e. Sranan, JA], which (is) usually called Ningre-tongo 'Negro language' by the blacks themselves, or simply Ningre 'Negro', but often also Bakra 'European' (presumably as opposed to their original African languages)...

(Wullschlägel 1856:vi)

13. The African origin of this word is suggested by Echteld (1961:50), but, unfortunately, no specific source language is mentioned.

14. An alternative word for 'and' in nengre tongo is derived from English: nanga (< En. 'along').

15. Note that Du. 'bout' refers only to animals, not humans. 
This remark is made more explicit by a note under the entry Sprache, 'language' in the same dictionary, where it is said that ningre-tongo is the word for the language of the blacks, but that "African [italics mine, JA] blacks call the language spoken here [i.e. in Suriname, JA] bakra as well". This strongly suggests that the word bakra as used in Wullschlägel's dictionary is not synonymous with the word bakra tongo as used in Schumann's. According to Wullschlägel, the term bakra was sometimes used by African-born blacks to refer not specifically to the European variety of Sranan, but to the entire spectrum of this language, apparently in opposition to their native African languages. In fact, the word bakra tongo does not occur at all in Wullschlägel's dictionary. ${ }^{16}$

This suggests that by the time Wullschlägel published his dictionary - some seventy-five years after Schumann compiled his - the distinction between bakra tongo and nengre tongo, as a consequence of the substitution and addition of many Dutch-derived words in both varieties, had become blurred. Further evidence for this may be found in the following. In his dictionary, Wullschlägel uses the labels ' $h$ ' (for 'holländisch', i.e. Dutch) and 'a' (for 'alt, veraltet', i.e. archaic) to mark words recently borrowed from Dutch and words going back to the English period, respectively:

In the present dictionary those words [recently borrowed from Dutch, JA], which may be quite common among Paramaribo blacks, but unknown among the blacks at the plantation, are marked $\mathbf{h}$ (for 'holländisch', i.e. Dutch)...Those originally English words, however, that have gradually fallen out of use, but that are still understood by many elderly blacks, are marked a (for 'alt, veraltet', i.e. obsolete).

(Wullschlägel 1856: vii-viii)

Now, the fact that many of the Dutch equivalents for English-derived words (known only to elderly blacks) are not marked by Wullschlägel to indicate that they were restricted to a specific variety such as urban Sranan or 'church Sranan', indicates that these Dutch words were fully accepted, not only in Paramaribo, but on the plantations as well. This shows that by the middle of the 19th century a new lexical stratum taken from Dutch had been added to the Sranan lexicon in both its nengre tongo and its bakra tongo varieties.

The idea that the distinction between bakra tongo and nengre tongo was dying out by the middle of the 19th century is receives further support from the fact that none of the lexical items labeled 'bakra tongo' by Schumann is given the label

16. Based on an automatic search $(1 / 25 / 05)$ of the electronic version of the dictionary available at $<$ www.sil.org $>$. 
' $h$ ' by Wullschlägel. ${ }^{17}$ This means that these words were not restricted to urban Sranan but had been integrated into the plantation variety as well. Some of these items, however, are given by Wullschlägel in a form different from Schumann's, the difference consisting in most cases either in the addition or replacement of a paragogic vowel (in the latter case, the vowel being replaced is usually <e>). Examples are geeli for geel, 'yellow', joeroe for üre and hüre, 'hour, rent', kapoe for kappe, 'cut', morsoe for morse, 'dirty', and sneiri for sneier, 'tailor'. Apparently, these Dutch-derived words were being adapted to the phonology of the great majority of words in the Sranan lexicon, as a result of which they ceased to function as markers of bakra tongo.

This does not mean, however, that the older English layer of the Sranan lexicon was replaced completely by these new words taken from Dutch. The fact that in Wullschlägel's dictionary almost half of the bakra tongo words have a nengre tongo synonym, without the latter being marked 'archaic', suggests that this is not the case. Rather, these new Dutch words served to create doublets for a number of English-derived words which still remained in use, perhaps mostly on the more distant plantations. At the same time, many other Dutch-derived words, which are absent from Schumann's dictionary, are marked by Wullschlägel as being typical of urban Sranan. This shows that proportion of Dutch vocabulary - the variable that used to mark the difference between bakra trongo and nengre tongo - was beginning to serve as a marker of the difference between urban Sranan and plantation Sranan. This may be related to the fact that towards the end of the 18th century 'urban Sranan' came to be identified less and less with 'white Sranan'. In this period, as a result of the significant growth of the black population, mainly due to the influx of manumitted blacks, Paramaribo had become very much a black town (R. Brana-Shute 1989; Hoefte 1996): in 1787, out of a total population of around 15,000 people, blacks numbered over 12,000 (Cohen 1991: 80). In addition, the fact that the urban black population, which consisted of manumitted blacks, mulattoes, domestic slaves, and skilled slaves, had a higher prestige than the plantation slaves undoubtedly contributed to making the urban variety the socially higher valued one.

One, perhaps, puzzling finding is that several of the words labeled bakra tongo in Schumann's Sranan dictionary (adjossi, aréde, bakka, beginn, dondro, dübri), are

17. Five of the thirty-six items labeled bakra tongo by Schumann do not occur in Wullschlägel's dictionary. These words are (the equivalent given by Wullschlägel is given in parentheses): arede $(k a b a)$, dübri (didiebri), kalfe (no equivalent), pili/piri - in the specialized meaning of 'to pull someone's leg' - (kori), and winiboom (droifiboom). Note that in two cases the equivalent given by Wullschlägel ( $k a b a$, didiebri) is identical to the word labeled nengre tongo by Schumann. (Based on an automatic search (1/25/05) of the electronic version of Wullschlägel's dictionary available at <www.sil.org $>$ ). 
included without any qualifying remark in that same author's (1778) Saramaccan dictionary. Although the absence of any qualification seems to suggest that these, non-Portuguese-derived, words were ordinary words in Saramaccan, this is made less likely by the fact that most of these (all except adjossi)have synonyms in the Saramaccan dictionary; see Table 4.3.

Table 4.3 Words labeled bakra tongo in Schumann's 1783 Sranan dictionary which are unlabeled in Schumann's 1778 Saramaccan dictionary

\begin{tabular}{llll}
\hline Meaning & $\begin{array}{l}\text { Item labeled bakra } \\
\text { tongo in Schumann } \\
\mathbf{1 7 8 3} \text { (Sranan) }\end{array}$ & $\begin{array}{l}\text { Unlabeled item in } \\
\text { Schumann 1778 } \\
\text { (Saramaccan) }\end{array}$ & $\begin{array}{l}\text { Synonym in } \\
\text { Schumann 1778 } \\
\text { (Saramaccan) }\end{array}$ \\
\hline Already & aréde & arêre & kaba \\
Bake & bakka & bakka & jassa \\
Begin & beginn & begìnn & setti \\
Devil & dübri & dübri & diabo \\
Goodbye & adjossi & adjossi & krubòi ${ }^{18}$ \\
Thunder & dondro & dondro & liba \\
\hline
\end{tabular}

Since most of these synonyms (kaba, jassà, liba and diabo,) are derived from Portuguese, it is reasonable to suppose that they are part of a deeper layer of the Saramaccan lexicon. This hypothesis is strengthened by the fact that in at least one case - jassa-Schumann explicitly says that this is the more frequent variant. Also, apart from the words labeled bakra tongo in the Sranan dictionary, Schumann's Saramaccan dictionary contains several words which are obviously of Dutch derivation but which do not occur in his Sranan dictionary. An example of these is the word dagga 'day' ( $<$ Du. 'dag'), for which Sranan has the English-derived deh. ${ }^{19}$ All this suggests that the non-Portuguese derived words listed in Table 4.3 had a status in Saramaccan similar to that held by bakra tongo items in Sranan, even though it is very unlikely that a separate bakra tongo-like variety existed in the case of Saramaccan (because the latter was hardly spoken by any whites). This is further supported by the fact that two of the six synonyms given in Schumann's Saramaccan dictionary (kaba, krùboi) are words that are labeled nengre tongo in his Sranan dictionary.

18. While no exact synonym for adjossi is given in Schumann 1778, a word with a related meaning does occur, namely krubòi. The meaning of this word (which in Sranan, according to Schumann's dictionary, is 'goodbye), is given as 'you'll be finished, I won't see you anymore'.

19. The only occurrences of $d e(h)$ found in Schumann's Saramaccan dictionary are as part of a word, as in dehbrokko 'daybreak' and tidè 'today', never as an independent word. 
At first sight, the occurrence in Schumann's Saramaccan dictionary of words labeled bakra tongo as well as of words of clearly Dutch origin (even when they are not labeled bakra tongo, such as dagga) in the same author's Sranan dictionary may seem a bit surprising, since one would expect the language of the Maroons, due to their relative isolation from whites, to be largely inaccessible for bakra words. Only a minority of these words (bakka, dagga) is of undoubtedly Dutch origin, and these have non-Dutch-derived homonyms. Of the others, one is derived from Portuguese (adjossi), while the remainder is either of English (arêre, dübri) or of undecided or mixed English/Dutch derivation (beginn, dondro). The presence of the Portuguese-derived word hardly needs any explanation at all: it is part of the well-established Portuguese component of the Saramaccan lexicon, which was already present in the early stages in the formation of this language (cf. Smith 1987).

The presence of the Dutch- and English-derived words, however, cannot be so easily explained. The fact that the words that have both a bakra tongo and a nengre tongo variant in both Sranan and Saramaccan largely overlap may point to a common origin of the two languages. This would mean that these shared nengre tongo and bakra tongo doublets were already part of the lexicon of the 17th-century plantation Creole from which both Sranan and Saramaccan descended. The early presence of a number of bakra tongo/nengre tongo doublets in both Sranan and Saramaccan suggests that the bakra tongo items did not function as markers of a special European variety, since in that case they would not have been incorporated into Saramaccan in the first place. In this scenario, then, bakra tongo as an ethnic variety of Sranan may have emerged only sometime during the 18th century, after Saramaccan split off from Sranan. Its existence as a separate variety did not last longer than around 150 years at most, since, as argued above, it had clearly begun to recede by the middle of the 19th century.

The 'rise and fall' of the bakra tongo variety of Sranan could be interpreted as a function of the changes in the social distance between the black and white portions of Suriname's population between the middle of the 17th and the middle of the 19th century. In the beginning the distance between Europeans and Africans was relatively small since many of the whites were (former) indentured laborers, who worked their small-scale plantations side-by-side with one or two slaves (Rens 1953). This situation changed drastically when the plantation economy began to expand and huge numbers of slaves began to be imported, especially between 1740 and 1780, but with a prelude in the 1680s (Arends 1995a). This led to a deepening of the social dichotomy between blacks and whites, which continued until emancipation came in sight in the 1850s, although an intermediate group of people of African origin - manumitted slaves, free coloreds, domestic slaves, and skilled slaves - had begun to establish itself in Paramaribo from around 1800 onwards (R. Brana-Shute 1989; Hoefte 1996). 
Although, in principle, the presence of bakra tongo items in the Saramaccan lexicon might also be explained as a result of borrowing from Sranan, this is less likely. It is certainly true that some Saramaka had more or less regular contacts with other blacks, both on plantations and in Paramaribo, especially after the signing of the Peace Treaty in 1762, as well as, to a much lesser extent, with whites ( $c f$. Price 1990). Also, run-away slaves continued to join the Saramaka communityuntil well after the signing of the Peace Treaty, which means that bakra tongo items from Sranan could have been introduced into Saramaccan through this channel. The fact, however, that during this period the bakra tongo variety of Sranan was first and foremost a variety spoken by whites, whereas Saramaka culture is characterized by its distance from the world of the whites, renders this possibility unlikely.

Summarizing, what evidence we have for variation according to ethnicity shows that with the decrease in geographical and cultural distance and the increase in communication between the black and white portions of the population, the distinction between nengre tongo and bakra tongo became blurred in the course of the 19th century. At the same time, however, the variable that used to mark ethnic variation - the amount of Dutch-derived vocabulary - became a marker of geographical and social variation, namely between high-status urban Sranan and low-status rural Sranan. These varieties are the topic of the next section.

\subsubsection{Geography: The Creole of the plantations and the Paramaribo Creole}

At several places in his Sranan dictionary, Schumann refers to differences between the language of the capital, Paramaribo, and that spoken on the plantations. ${ }^{20}$ For instance, the entry for the word brens 'brain', reads as follows:

\footnotetext{
20. Although Schumann's Saramaccan (1778) dictionary seems to contain some evidence to the contrary, this may be easily explained. Under the entry fotto, 'fort, town' (i.e. Paramaribo), he says the following: "fotto-tongo the Negro-English language as it is spoken in Paramaribo and on most plantations in this country (on some plantations the blacks have their own particular language" [italics mine, JA] (Schumann 1778, s.v. fotto). While this seems to suggest that there was little or no difference between the Sranan spoken in Paramaribo and the language on the majority of the plantations, one should realize that this remark was written at a time when Schumann was not yet well acquainted with Sranan. Between his arrival in Suriname in late August 1776 and the beginning of his residence among the Saramaka in May 1777, Schumann had spent at most three or four months in Paramaribo, which gave him little opportunity to really get to know the language ( $c f$. Stähelin 1913-1919, III (1), who says that Schumann spent five to six months at the Indian mission post Saron during this period). Also, the fact that what Schumann wants to emphasize here is the difference between Djutongo on the one hand and all the other varieties on the other, may explain why he subsumed the latter into one category, fotto tongo. The remarks in the 1783 Sranan dictionary that do indicate urban-rural variation may have been inspired by the - apparently very insightful - informant(s) Schumann used.
} 
brens, the brain, tumtum va heddi (English 'brains') (source: Schumann);

that is truly English (da reti English tongo); we do not have this word, and the Paramaribo blacks do not understand it at all; it is known on the old English plantations; we do not say otherwise than: tumtum va heddi [lit. 'porridge of the head', JA] (source: Schumann's informant ${ }^{21}$ ).

(Schumann 1783, s.v. brens)

Apart from suggesting variation between urban and rural Sranan as such, this remark also seems to imply variation between 'the old English plantations' (i.e. the plantations established during the English period) and the other plantations; this issue is discussed in some detail in Section 2.3. Another example of variation along the geographical axis can be found under the entry kákka, 'rooster', where in a discussion of the sentence 'the rooster crowed', Schumann's informant says:

On the plantations they say kakka kreh [lit. 'the rooster cried', ${ }^{22} \mathrm{JA}$ ]; in town they will rather say kakka bari [lit. 'the rooster screamed', JA] (source: Schumann's informant).

(Schumann 1783, s.v. kákka)

One final piece of information concerning geographical variation to be found in Schumann's dictionary, this time at the lexical-semantic level, is a remark under the entry jeje 'ghost', 'ancestor', saying that on certain plantations, e.g. along the Upper Cottica, jeje or djeje in addition may also mean 'family, kinfolk'.

Some more evidence for geographical variation is provided by Captain John Stedman, who stayed in Suriname from 1773 until 1777, and who through his romance with Johanna - a slave - was in close contact with the black population. After presenting a short sample of 'this mixt speech' (i.e. Sranan), Stedman writes:

In this Sample may be Perceived many Corrupt English Words, Which however begin to Wear out near the Capital Town [i.e. Paramaribo, JA], but are Retain'd Near the Distant Plantations - At the Estate Goet Accoord, ${ }^{23}$ I have heard an Old Negro Woman Say, we lobee fo lebee togeddere [lit. 'we love to live together', JA],

21. The commentary part of this entry (marked 'source: Schumann's informant') is a translation of the Sranan original, which should not be ascribed to the lexicographer, C. L. Schumann, but to his informant. Many of the other remarks about urban-rural variation made in the dictionary similarly may have to be ascribed to Schumann's informant(s), rather than to Schumann himself.

22. In my translation, I use the present tense, following Schumann's own translations elsewhere in the same entry, even though the present tense marker de is not present.

23. In the 1796 version of Stedman's Narrative the phrase 'in Cottica' is added to the name of the plantation, i.e. the same geographical location as the one referred to by Schumann under the entry jeje. The 1737 map of Suriname by Lavaux, exhibited at the Rijks Museum in Amsterdam, locates an estate of the same name not on the Cottica River, but on one of its tributaries, the Commewina River, i.e. in the same general area. Since the Cottica region is one of the areas where the English established plantations in the pre-Dutch period, the variety illustrated in the 
by Which she Meant we Love to live together - At Paramaribo to Express the Same they tell you, we Do looko for tanna ${ }^{24}$ Macandera [lit. 'we Asp look to be with each other', JA].

(Stedman 1790:516)

This remark clearly points to variation between town language and plantation language, although the example given, intended to illustrate the loss of 'Corrupt English Words' in the urban variety, is not quite to the point. In the second sentence, taken from the urban variety, the obviously English-derived words lobee $(<$ En. 'love'), lebee ( $<$ En. 'live'), and togeddere $(<$ En. 'together') used in the plantation variety have been replaced by looko ( $<$ En. 'look'), tanna ( $<$ En. 'stand'), and macandera, $(<$ Du. 'mekander', 'malkander'). The first two of these, however, are derived from English, just like the words they replaced. In addition, the phrase libi togedere 'live together', ${ }^{25}$ next to tann tegedere 'be with one another', is given without any further qualification as to geographical variation by Schumann 1783 (s.v. tegédere). There is even considerable reason to doubt the correctness of lobee and lebee as examples of archaic usage since these words are perfectly normal in Modern Sranan (in the spellings lobi and libi, respectively).

The third example, however, is completely justified since the word tegedere has indeed been replaced by makandra in Modern Sranan Apart from these three words, there is an additional difference between the two sentences discussed by Stedman: in the second sentence the form do was added. This is one of only two cases I have found of this word, ${ }^{26}$ but it is reported by Donicie. (1954:61) to occur in modern Sranan as an aspect marker in a few fixed expressions (as a variant of (d)e). Summarizing, the difference between the Paramaribo and the plantation variants of this sentence consists in the replacement of an English-derived word by a Dutch-derived word and the insertion of an aspect marker in the former.

Some additional evidence dating from a much earlier period but also showing that the English-derived words in Sranan are older than those taken from Dutch, is provided by the two-page 'Herlein fragment' (Herlein 1718), which contains three examples of English words which were later replaced by Dutch words. In each case, the form used by Herlein is given first, followed by the form by which it was replaced later:

quotation from Stedman might be representative of variation along the 'European domination dimension', rather than along the geographical dimension.

24. $\operatorname{tanna}=\tan n a$, i.e. 'be with'.

25. Even the expression in which this occurs in Schumann is almost identical to that used by Stedman: Indjin no lobbi va libi tegedere 'Indians don't like to live together'.

26. It occurs in the sentence me do go (Stedman 1796:362). However, the original manuscript version (Stedman 1790:516) has de. 
Table 4.4 English-derived words in Herlein (1718) later replaced by Dutch-derived words

\begin{tabular}{lll}
\hline Meaning & Word in Herlein (1718) & Post-1718 word \\
\hline Pretty & hansom/hansum/hantsum $(<$ En. 'handsome') & moy $(<$ Du. 'mooi') \\
Window & windels $(<$ En. 'windows') & fensre $(<$ Du. 'venster') \\
Very & belle (in belle wel $)(<$ En. 'very') & heri $(<$ Du. 'heel') \\
\hline
\end{tabular}

Another source which hints at the existence of two geographical varieties of Sranan is Weygandt's (1798) Leerwyze, one of the first printed descriptions of the language. In its preface, the author says that "... some words and phrases ${ }^{27}$ in the Negro-English language are expressed differently along the various rivers and in Paramaribo" (Weygandt 1798:2). Although Weygandt follows this up with the remark that these differences are not very significant, this may have been motivated by a wish not to scare away potential buyers of the book. Weygandt's statement that what he presents is the language as it is spoken in Paramaribo combined with his claim that it is his aim to enable foreigners to speak with the slaves, strongly suggests that the Sranan presented in his book is the urban variety of Sranan as spoken by blacks. This makes for an interesting difference with another, contemporaneous, language manual - Van Dyk's undated Onderwijzinge (c1765) - which, as I have argued in Chapter 3, represents the rural variety of Sranan. ${ }^{28}$

One of the differences between Van Dyk and Weygandt, perceptively noted by Schuchardt (1914: xxiii), has to do with the names for the days of the week. While the naming system in both sources seems to related to that of Portuguese, Weygandt differs from Van Dyk in using Portuguese-like names for only three days (Tuesday, Wednesday, Thursday) while Van Dyk uses them in six. (Monday through Saturday). Cf. the next table, where bold is used to mark the differences between Weygandt and Van Dyk.

The fact that the naming system presented by Weygandt is the one that is still used today strongly suggests that Van Dyk's system represents an older, more archaic variety. If this is true, it would be entirely in accordance with the claim made above that what Van Dyk presents is the plantation variety while Weygandt's Sranan is the variety spoken in Paramaribo.

27. Although the Dutch word used by Weygandt - spreekwijzen, lit. 'ways of speaking' - in 18th-century Dutch grammatical usage may refer both to sayings and to dialects (Cefas van Rossem, p.c.), the latter meaning is less likely in this context since spreekwijzen is used in conjunction with woorden, 'words'.

28. The same observation was already made by Schuchardt (1914: xxiii), but $c f$. Voorhoeve \& Donicie (1963) for a diametrically opposed view. 
Table 4.5 Names for the days of the week in Van Dyk (c1765) and Weygandt (1798)

\begin{tabular}{lllll}
\hline English & Portuguese & Dutch & Van Dyk & Weygandt \\
\hline Sunday & Domingo & zondag & & Zondé $(<$ En.) \\
Monday & Segunda-feira & maandag & Wan de Worké $(<\mathrm{Pt})$. & Moendee $(<\mathrm{En})$. \\
Tuesday & Terça-feira & dinsdag & & Toe de Worké $(<\mathrm{Pt})$. \\
Wednesday & Quarta-feira & woensdag & & Tri de Worké $(<\mathrm{Pt})$. \\
Thursday & Quinta-feira & donderdag & & Fo de Worké $(<\mathrm{Pt})$. \\
Friday & Sexta-feira & vrijdag & Vyfi de Worké $(<\mathrm{Pt})$. & Fryda $(<$ En./Du. $)$ \\
Saturday & Sabado & zaterdag & Zikkisi de Worké $(<\mathrm{Pt})$. & Satra $(<$ En./Du. $)$ \\
\hline
\end{tabular}

As to the question why Weygandt's day-naming system shows fewer traces of Portuguese influence than Van Dyk's, we can only answer this in tentative and rather general terms. From the late 18th century onwards, when many Portuguese planters left their plantations moving to Paramaribo (e.g. Goodman 1987:380), the Portuguese element in Sranan became less and less important ( $c f$. Wullschlägel's remark quoted above). Related to this is the fact that while Djutongo - the Portuguese-based Creole spoken on Jewish plantations - was still spoken at the time when Van Dyk wrote his booklet, it was becoming obsolete by the turn of the century, when Weygandt wrote his. Although it is impossible to be certain as long as we have no further information on Djutongo, the relatively strong Portuguese stamp on Van Dyk's naming system as opposed to Weygandt's may be a reflection of that fact. (For a discussion of other differences between Weygandt and Van Dyk - more likely to reflect diachronic change rather than synchronic variation see Chapter $5 .^{29}$ )

To conclude this section, I will briefly discuss two pieces of evidence showing that variation between urban and rural Sranan persisted well into the 19th century. A phonological difference between plantation and urban varieties is mentioned by Focke in the Introduction to his Neger-Engelsch woordenboek (1855), when he says that

many blacks, especially plantation slaves [italics mine, JA], insert a vowel between some consonant clusters, and say siton (for ston) ('stone'), sikropoe (for skropoe) ('shell'), soetoeloe (for stoeloe) ('chair'), soepoen (for spoen) ('spoon'), sineki (for sneki) ('snake'), sipiti (for spiti) ('spit'), konopo (for knopo), ('button').

(Focke 1855: xii)

29. Although the difference in time-depth between Van Dyk and Weygandt - no more than roughly three decades - may seem too small from a historical-linguistic point of view to allow for substantial diachronic change, this is not necessarily so in the case of 'young' languages such as creoles. Cf. e.g. Arends (1989), which contains ample evidence of drastic changes in the Sranan copula system which occurred within the time span from 1800 to 1850. 
Focke adds, however, that this pronunciation is not in general use. The fact that most of these words do not have the inserted vowel in modern Sranan $-c f$., e.g. ston, stulu, sneki - shows that this form of vowel epenthesis has been lost. It does, however, still occur in modern Ndyuka, as appears from words like sitón, sutúu (with lost intervocalic liquid), supún, and sineki (De Groot 1984). Apparently, Ndyuka, which emerged as an off-shoot of plantation Sranan around the middle of the 18th century, preserved a feature which was (marginally) present in that variety but which has disappeared from it since.

The second piece of evidence is provided by Wullschlägel's (1856) dictionary where, as noted in the previous section, words that were recently borrowed from Dutch are marked with ' $h$ ' (for 'holländisch', i.e. Dutch) while words that were taken from English in an earlier period are marked with 'a' (for 'alt, veraltet', i.e. obsolete). The remark from Wullschlägel's Introduction where these labels are explained, strongly suggests that a difference in the proportion of Dutch vocabulary to English vocabulary correlated with a distinction between urban Sranan and plantation Sranan:

In the present dictionary those words [recently borrowed from Dutch, JA], which may be quite common among Paramaribo blacks, but unknown among the blacks on the plantation, are marked $\mathbf{h}$ (for 'holländisch', i.e. Dutch)...Those originally English words, however, that have gradually fallen out of use, but that are still understood by many elderly blacks, are marked a (for 'alt, veraltet', i.e. obsolete).

(Wullschlägel 1856: vii-viii)

This shows that the distinction between these two varieties was still alive around the middle of the 19th century.

A small-scale investigation of the words marked 'archaic' under the letter A in Wullschlägel's dictionary yielded some interesting additional results (the reader is reminded that this is a German-Sranan, not a Sranan-German dictionary). First of all, it showed that in the middle of the 19th century not only English words were becoming obsolete, but African words as well, such as mapokro ' witchcraft' and gongosa' betray'. This is not surprising, in view of the fact that Wullschlägel's dictionary was compiled more than two hundred years after the inception of Sranan. Second, in the case of English-derived words it was not always the word itself that was becoming obsolete but rather the pronunciations of a word. Examples are worko, 'work', findi, 'find', and bendi, 'bend', which were being replaced by wroko, finni, and beni, respectively. This phonological development should be seen as part of the ongoing creolization of Sranan in the sense that in the course of time, the pronunciation began to follow its own rules more and more, thereby departing more and more from the English etymon. Third, it seems that not only English words were replaced but also phrases composed of English words: of all the entries 
under the letter A there is only one word which is marked as obsolete. This is the word $\min$ in potti min, lit. 'put mind', i.e. 'pay attention', for which the non-archaic expression is potti jesi, lit. 'put ears'; but note that even here the word being replaced is part of a phrase rather than an independent word. In all the other cases we are dealing with phrases or expressions consisting of English-derived words. Examples are dresi-watra, 'dress + water', i.e. 'medicine', libi dati, 'leave + that', i.e. 'apart from that', and komoto na dati, id., which were being replaced by items taken from Dutch, such as 'dranki' for the former and 'buiten-dien' for the latter two. The English-derived words themselves (dresi, watra etc), however, of which these expressions are composed, were not obsolete at all. In fact, they are still in use at present. What this means is not so clear, especially as long as it has not been established that the letter $\mathrm{A}$ is representative for the entire dictionary in this respect.

As to the emergence of a distinct urban variety of Sranan in the 18th century, it seems clear that this must be related to the growth of Paramaribo during this period. From a village with at most a few hundred inhabitants in the late 17th century, it developed into a thriving town with well over fifteen thousand people by the end of the 18th century (e.g. Cohen 1991:78, 80; Van Lier 1977: 110). The intrusion of Dutch lexical items must have taken place through the Dutch-speaking part of the relatively small, multilingual white segment of the city's population, which (excluding soldiers) counted some 2,000 people in 1787 (Cohen 1991: 80).

Summarizing, and judging from the limited evidence available, differences between urban Sranan and rural Sranan, just as that between nengre tongo and bakra tongo, were mainly concentrated in the lexicon, with some evidence of phonological, lexical-semantic and idiomatic variation. Lexical variation consisted of the use of English words in plantation language, where the urban variety would use either a different English word or a Dutch word or a periphrastic construction. Finally, there is some evidence that plantations in the Cottica area used a variety that had a particularly strong English lexical element.

4.2.3 Ownership: Differences between the language of English, Jewish, and other plantations

This section is divided into two parts: in Section 4.2.3.1 a difference between (formerly) English-owned and non-English-owned plantations will be briefly discussed. Then the somewhat mysterious Djutongo, which was spoken on the Portuguese-owned plantations along the Upper Suriname River, will be dealt with more extensively in Section 4.2.3.2. Finally, some scattered remarks concerning special features of the Creole spoken on other (e.g. French-owned) plantations will be discussed in Section 4.2.3.3. 


\subsubsection{The Creole of the 'old English plantations'}

There is some evidence in Schumann's Sranan dictionary that there was a difference between the language of the 'old English' plantations and that spoken on the other plantations. The phrase 'old English plantations' refers to plantations that were established during the English period (1651-1667), whether or not their owners were English-speaking at the time Schumann wrote his dictionary. ${ }^{30} \mathrm{~A}$ crucial difference with the other plantations, of course, is that on the English plantations there was only one superstrate - English - while on the other plantations other languages, such as Portuguese and Dutch, came into play as well. The relevant entry from Schumann, which was quoted above in Section 4.2.2, is repeated here for convenience:

brens, the brain, tumtum va heddi (English 'brains') (source: Schumann);

that is truly English (da reti English tongo); we do not have this word, and the Paramaribo blacks do not understand it at all; it is known on the old English plantations; we do not say anything else than: tumtum va heddi [lit. 'porridge of the head', JA] (source: Schumann's informant). (Schumann 1783, s.v. brens)

While this is the only straightforward piece of evidence showing a difference between the Creole of the English plantation and that spoken on other plantations, Stedman's remark, quoted in Section 4.2.2 above, about characteristics of the language used on some 'distant plantations', such as the use of tegeddere instead of makandra, might also be interpreted as being illustrative of a variety spoken on 'old English plantations' in particular. This is so because the plantation in question, called Goet Accord, was located in an area where many plantations were established during the English period. If this is correct, it means that, apart from the word brens mentioned by Schumann, the word tegedere was also characteristic of the 'old English plantation language'.

The fact, however, that these are the only references to idiosyncratic features of this variety, suggests that these may not have been very numerous. Perhaps they were not even enough to speak of a distinct variety, at least not by the time these authors wrote - the late 18th century. This does not mean, of course, that a distinct 'English plantation' variety of Sranan could not have existed before, say until around 1700, when there was still a significant number of English-speaking people in the colony (see Chapter 3.2.2). If it did, it would not be too far-fetched to assume that this earlier variety was closer to English than the varieties used in later stages.

30. It should be borne in mind, though, that contrary to what is widely held, English planters were still present in Suriname by the end of the 18th century (cf. Chapter 3.2.2). 
Some indirect evidence for the existence of an acrolectal form of Sranan among the blacks is provided by two contemporary sources. One is a remark by Reeps, who spent about six months in Suriname in 1693-94, and who wrote that 'that language [i.e. English, JA] is spoken mostly by the slaves there' (Van Alphen 1963:370). The other is a remark by Herlein, who stayed in Suriname for several years between 1695 and 1705, saying that 'they [i.e. the slaves, JA] have mostly learned their language [i.e. English, JA]' (Herlein 1718: 121). Although such remarks, made by linguistically uninformed observers, should perhaps not be taken at face value, they may still give an indication of the language situation as it was around the end of the 17th century.

In addition, there is some direct linguistic evidence, indicating that the variety of Sranan spoken around 1700 was not only lexically but also phonologically closer to English than later varieties. This appears from the Sranan fragment in Herlein (1718), which contains three English-derived words that, judging from the spelling at least, have a diphthong where later sources have a monophthong. Cf. the table below:

Table 4.6 English-based words containing a diphthong in Herlein (1718) which have a monophthong in post-1718 sources

\begin{tabular}{llll}
\hline Meaning & Etymon & $\mathbf{1 7 1 8}$ (Herlein) & Post-1718 $^{31}$ \\
\hline Below & below & bie laeu & bilo \\
Go & go & gaeu & go \\
Hello & howdy & oudy & odi \\
\hline
\end{tabular}

It would be important to obtain more information about this early variety of Sranan, since this could throw some light on the very earliest stages of Sranan, about which hardly any documentary evidence is available (except in the form of court records discussed in Van den Berg (2000) and Van den Berg \& Arends 2004). In particular, it would be interesting to find out whether it is true that this early variety was closer to English, something which would be in accordance with the socio-historical and demographic facts discussed above and in the next chapter. More generally, it would enable us to find out to what extent a kind of interlanguage continuum, with an English-like variety at one extreme and a pidgin-like variety at the other, existed at the time when Sranan was being formed.

31. Note that the spellings in this column do not represent the (different) spellings used in these sources. What is important, though, is that all these sources use a spelling representing a monophthong rather than a diphthong. 


\subsubsection{Djutongo: The Creole of the Jewish plantations}

Although there are several indirect pieces of evidence showing that a separate Portuguese-based variety - called Djutongo, lit. 'Jews' language' - was used on the Jewish plantations, ${ }^{32}$ the earliest reference to the existence of an Iberian-lexicon Creole in Suriname is the following passage from an anonymous description of Suriname, written around 1740 by someone who must have worked as a planter in Suriname for a considerable stretch of time: ${ }^{33}$

The language one [i.e. a plantation manager, JA] should speak with the slaves is called Negro-English. However, on plantations where the owners used to be French, many French words occur. In the same vein, on the plantations of the Portuguese Jews many Spanish and Portuguese expressions can be found and often the slaves understand nothing but Spanish or Portuguese.

(Anon. ca 1740: $80-1^{34}$ )

Apart from the reference to the French-influenced Creole spoken on French-owned plantations (see Section 4.2.3.3), two things are remarkable here. First, there is the fact that not just Portuguese but both Portuguese and Spanish are mentioned. This concurs with other evidence which shows that both Iberian languages were used by Sephardic planters, even though Spanish left far fewer remaining traces in the Suriname Creoles than Portuguese. Second, in the remark at the end claiming that on the plantations of the Portuguese Jews 'often the slaves understand nothing but Spanish or Portuguese' the references to these languages most likely should be understood as referring to 'Spanish- or Portuguese-lexicon Creole'. In any case, the wording is so strong as to suggest that this Iberian-lexicon Creole at that time was completely distinct from Sranan.

The earliest reference to what appears to be a specifically Portuguese-lexicon Creole is found in a 1751 document discussed by De Beet \& Price (1982: 74), where the wife of a Jewish planter says that she did not understand a Maroon who had attacked their plantation because 'as far as I could understand he spoke Portuguese'. The next reference to a specifically Portuguese-lexicon Creole comes from a letter by the Moravian Brother Stoll. It was written in 1767 at the Saramaka mission post Sentea, where at the time of writing Stoll had been resident for one and a half year:

32. $C f$. archival documents dating from 1739 which show that slaves from Jewish plantations appearing in court sometimes needed the assistance of an interpreter (Beeldsnijder 1994: 132).

33. This appears from the fact that the entire manuscript is full of details testifying to the author's knowledge of plantation life.

34. This approximate date is based on the fact that the work was written between 1739 at the earliest and 1748 at the latest ( $c f$. items 43,161, and 568 in the text of this work; source: Beeldsnijder 1994). 
The language of the blacks in Paramaribo is somewhat different from the language of the blacks on the plantations. They [i.e. the latter, JA] have many broken Portuguese words. They can describe many things in three or four different ways. And then again they have words that can have between six and eight different meanings.

(Stähelin 1913-19, III(1): 75-76)

Although Stoll does not indicate clearly what he means by the phrase 'the blacks on the plantations', Price (1976:37) assumes that this refers to the Jewish plantations along the Upper Suriname river, and that therefore the language referred to is Djutongo. This assumption is probably based on geographical grounds, i.e. the fact that Sentea, Stoll's mission post, was located on the Upper Suriname River (see also Price 1990: 143). ${ }^{35}$ Price's assumption is supported by the fact that if Stoll knew anything about plantation language, this most likely related to the plantations he knew from his own experience, i.e. those along the Suriname River. These were probably the only plantations Stoll knew anything about because in his days most plantations were still forbidden territory for the Moravian missionaries. Further support for Price's assumption may be derived from the following remarks under the entry fotto, 'fort, town' (i.e. Paramaribo) in Schumann's (1778) Saramaccan dictionary:

fotto-tongo the Negro-English language as it is spoken in Paramaribo and on most plantations in this country (on some plantations the blacks have their own particular language) [italics mine, JA] (source: Schumann / Schumann's informant).

(Schumann 1778, s.v. fotto)

It is not far-fetched to assume that the remark in parentheses refers to Djutongo. ${ }^{36}$ The fact that Schumann's missionary post - Bambey - was located on the Upper Suriname River, just like Stoll's post Sentea, suggests that he refers to the same region as did Stoll. Schumann's wording in the original - 'ihre ganz eigene Sprache', i.e. lit. 'their very own language' [italics mine, JA] - seems so strong as to refer to a substantially different variety. According to Stoll, this variety was characterized by a fair amount of Portuguese vocabulary.

35. The distance between Sentea and the most southern Jewish plantations, however, must have been at least some 200 kilometers. This means that the only contact Stoll and other Moravian missionaries, had with these plantations, occurred during the occasional visits they paid to some plantations on their way between Paramaribo and Sentea (Price 1990).

36. Although it is theoretically possible that this refers to an African language rather than Sranan, this is not very likely. First, the reference is in the singular, whereas it is not very probable that Schumann would refer to one particular African language. Second, Schumann was enough of a linguist to distinguish between a Suriname creole and an African language (in his Sranan dictionary there are several references to African languages that were still spoken in Suriname during his residence). It is equally unlikely to refer to Portuguese, since Schumann, who knew a fair amount of Latin, would probably not have confounded Portuguese with Portuguese Creole. 
Another piece of evidence is provided by Hartsinck (1770: 812). When describing a group of blacks characterized by a specific physical defect and referred to as Touvingas (lit. 'two fingers'), Hartsinck writes that 'they mostly speak NegroPortuguese'. Although it is not clear where exactly these people had their residence, Hartsinck says explicitly (p. 811) that they were acquainted with the Saramaka villages along the Upper Suriname River. If the Touvingas' Negro-Portuguese may be equated with Djutongo, this would again speak in favor of an Upper Suriname River location of that language. However, a 1762 document discussed in De Beet \& Price (1982:131) says that at that time Saramaka Maroons and Touvingas did not yet understand each other well since it was only three years before that the groups first came into contact.

A quotation from Schumann's (1783) Sranan dictionary is also relevant in this connection. Under the entry bringi, 'give birth', it says:

in Paramaribo it [i.e. the word bringi, JA] is not used that much; it's Djutongo: but many ${ }^{37}$ plantations use it (source: Schumann's informant).

(Schumann 1783, s.v. bringi)

This suggests that at least some Djutongo words were also in use on other, non-Portuguese-owned plantations. This may be related to the fact that in the last quarter of the 18th century, when Suriname's economy collapsed, many Jewish planters abandoned their plantations and moved to Paramaribo (e.g. Goodman 1987:380). Their slaves were probably sold or transferred to other plantations in order to pay their masters' debts. In both cases they were being dispersed over a range of other, mostly non-Jewish, plantations. In this process their language, apart from isolated lexical items, began to dieout. This might explain Wullschlägel's (1856: vi) remark that the 'Negro-Portuguese language', that had been used on the Jewish plantations, had more or less disappeared by the middle of the 19th century. ${ }^{38}$

In view of its importance and because it has played a role in a recent debate on the origin of the Portuguese element in the Suriname Creoles ( $c f$. Ladhams 1999; Smith 1999), it may be worthwhile to quote the passage from which the above remark is taken in full: ${ }^{39}$

37. The word nuffe (<En. 'enough'), when used as a quantifier in Schumann's Sranan dictionary, often means 'many' rather than 'enough'.

38. The word djoe-tongo does occur, however, in Wullschlägel's dictionary (s.v. Jüdisch, i.e. 'Jewish') in the phrase na djoe-tongo, 'in Jewish [language, JA]'. It is absent from Focke's contemporaneous (1855) dictionary.

39. Because of the importance of this passage, I provide my own translation, which, in order to stay as close to the original as possible, is a rather literal one (cf. Smith 1987: 121-2 for a slightly different translation). 
The first settlers of Suriname were partly English, partly Portuguese-speaking Jews who had immigrated from Brazil and the island at Cayenne [i.e. the coastal area of French Guyana where the city of Cayenne, the capital of French Guyana is now located, JA]. Both spoke their own language to their numerous Negro slaves; these, however, were only imperfectly understood and spoken by the Negroes, who had originally belonged to various African tribes, each of which spoke its own dialect. Thus, from the beginning two new distinct 'language stocks' (Sprachstämme) developed, Negro-English and Negro-Portuguese. No matter how sharply distinguished these may have been in the beginning, in the course of time they supplemented each other mutually, sharing many words and phrases. The latter language, originally a corrupted Portuguese, was spoken on the numerous plantations that belonged to Jewish owners; now it has nearly disappeared from the colony, together with the prosperity of those who brought it here. It is only spoken by one Maroon tribe, that of the so-called Saramaka on the Upper Suriname River. They derive mostly from the plantations mentioned above and at the time of the conclusion of the Peace Treaty in $1760^{40}$ they inhabited the forests along the Upper Saramaka River, deep in the interior, but now they have their houses on the Upper Suriname River. These Saramaka, however, among whom we have had a mission for nearly one hundred years, - at least those among them who are in contact with the actual colony - learn and understand Negro-English, besides their own dju tongo 'Jews' language'.

(Wullschlägel 1856: vi)

That Djutongo had not disappeared completely by the middle of the 18th century, appears from Focke (1855), who, writing in the same period, says of at least one word - foegà, 'be too much' -that it is used "by the blacks owned by Portuguese Jews [italics mine, JA]” (Focke 1855, s.v. foegà). ${ }^{41}$

Some seemingly contradictory evidence, which was adduced by Voorhoeve (1973: 140) to suggest that Djutongo was not a separate variety but rather an alternative name for Saramaccan, can be found under the entry Dju, 'Jew', in Schumann's Sranan dictionary: ${ }^{42}$

Djutongo is how the blacks here [i.e. in Paramaribo, JA] call the Negro language that is mixed with Portuguese (source: Schumann).

Saramaccan negroes use Djutongo (source: Schumann's informant).

(Schumann 1783, s.v. Dju)

40. The treaty with the Saramaka was concluded in 1762, not 1760 (which is when the treaty with another Maroon group, the Ndyuka, was signed).

41. If Djutongo was indeed dying out during this period, then its demise roughly co-occurred with the disappearance of Portuguese, which remained in active use in Suriname at least as late as the beginning of the 19th century. But a temporal coincidence, of course, does not necessarily imply a causal relationship.

42. Cf. also Wullschlägel (1856: vi), who refers to the language of the Saramaka as 'Djoe-tongo;' it seems clear, however, that here the word Djutongo is used as a synonym for Saramaccan. 
Price (1976:37), however, disagrees with Voorhoeve, arguing that the remark made by Schumann's informant may only imply that the Saramaka also know Djutongo in addition to Saramaccan). The interpretation of the Sranan sentence translated above as 'Saramaccan Negroes use Djutongo' - Saramakka-Ningre habi Djutongo crucially depends on the meaning of the word habi. The meaning implicitly attached to this word by Price ('have as one of their languages') is quite plausible: habi is used with a similar meaning under the entry bringi, quoted above. ${ }^{43}$ Also, if the meaning intended by Schumann's informant was 'Djutongo is the language of the Saramaka', then why would he not have said so explicitly - e.g. Djutongo da tongo va Saramakka-Ningre? ${ }^{44}$

This interpretation is strengthened by the following remark, found under the entry krijà in Schumann's Sranan dictionary:

krijà, 'breed, raise' (approximately the same as kweki) (source: Schumann)

'krijà' is Djutongo; but still we [i.e. the blacks in Paramaribo, JA] use it rather frequently. Saramaccan negroes say 'kilja' (source: Schumann's informant).

(Schumann 1783, s.v. krijà)

If Saramaccan were identical to Djutongo, then why would Saramaccan have a different variant of the word for 'breed, raise' than Djutongo? The same argument applies to the Djutongo word panja, which has no counterpart in Schumann's Saramaccan dictionary, but which, as Schuchardt (1914:94) notes, has the form paaja in 18th century Saramaccan: again two different forms for Djutongo and Saramaccan. In this connection it also may be significant to note that under the entry Saramakka in Schumann's Saramaccan dictionary, where the Saramaccan language is discussed, the word Djutongo does not appear at all:

They [the Saramaka, JA] have their own language, which is not the same as Negro English (source: Schumann).

(Schumann 1778, s.v. Saramakka)

If Djutongo were identical to Saramaccan, then this would surely have been the place to mention that, quod non. What is more, the word Djutongo does not occur at all in Schumann's Saramaccan dictionary, ${ }^{45}$ which would seem rather strange

43. In the MS version of Schumann's Saramaccan dictionary in the Unitäts-Archiv in Herrnhut (Germany) the word habi was corrected by the author for the word taki, which was crossed out. This suggests that Schumann himself was aware that the phrasing with taki, i.e. 'Saramaccans speak Djutongo' was too strong.

44. The same argument was brought forward by Goodman (1987:379) in a much broader discussion of the Portuguese element in the Atlantic creoles.

45. The two occurrences in Schuchardt's edition were both added by the editor. 
if it were simply an alternative name for Saramaccan, especially since Schumann was a linguistically sensitive and sophisticated lexicographer.

Finally, as Smith (1987: 126) correctly observes, of the nineteen words labeled Djutongo in Schumann's Sranan dictionary, only twelve appear in the same author's Saramaccan dictionary. These words are: adjabre, bae, bassia, bikà, buija/ bulja, fikka, fruta, glua/grua, kilja, mai, pai (three of them with a (slightly) different meaning from the one it has in the Sranan dictionary). The absence of the other words (bringi, bruija, frement $u$, panja, plattiri/plattérin, tanga, and faija tanga) would seem strange if 'dju tongo' and 'Saramaccan' referred to the same language, especially since Schumann based his Saramaccan dictionary on conscientious consultations with a very knowledgeable informant. ${ }^{46}$

The fact that references to Djutongo in the early sources are so scarce may be due to the fact that Djutongo was not known as a separate variety to the majority of the whites (who, at the same time, clearly recognized Saramaccan as a separate language ${ }^{47}$ ) rather than to Djutongo and Saramaccan being one and the same language. This is supported by the fact that the addition 'this is Djutongo' in almost all entries in Schumann's Sranan dictionary, as far as can be inferred from the wording, ${ }^{48}$ was provided not by Schumann himself but by his informant, which suggests that Djutongo was a term used primarily by blacks rather than whites. ${ }^{49}$

Summarizing, the evidence in favor of the idea that the label 'dju tongo' refers to a separate, Portuguese-influenced variety, spoken in the 18 th century on a number of Upper Suriname River plantations and possibly related to, but not identical with Saramaccan, is much stronger than that brought forward by Voorhoeve to

46. Schumann's Saramaccan informant has been unambiguously identified by Price (1990) as (Johannes) Alabi, one of the first baptized Saramaccans, and later granman, 'chief', of the Saramaccan tribe.

47. That Sranan and Saramaccan had clearly developed into two different, mutually unintelligible languages by the last quarter of the 18th century, emerges from missionary reports stating the problems Moravians, who already knew Sranan, had in mastering Saramaccan (Price 1990). Compare also Schumann's (1778) remark under the entry Saramakka, quoted above, which is repeated here for convenience: "They [i.e. the Saramaccans, JA] have their own language, which is different from Negro English".

48. The criterion is whether information is given in German (and/or Latin) or in Sranan (see above).

49. This is also suggested by Schumann's (1783) wording under the entry Dju, which was quoted before and which is repeated here for convenience: 'Djutongo is how the blacks here call the Negro language that is mixed with Portuguese' [italics mine, JA]. Perhaps the term was also unknown to the Saramaccans themselves, since, as mentioned earlier, it does not occur in Schumann's Saramaccan dictionary (although the term djù, 'Jew', does). 
claim that Djutongo is the same as Saramaccan. The important question, of course, is what implications the existence of Djutongo has for our understanding of the genesis and early development of the Suriname Creoles. Until more linguistic or meta-linguistic information about this 'mysterious' language comes available, this general question cannot be answered (but see Ladhams 1999 and Smith 1999 for more information).

As far as the available evidence indicates, both varieties discussed here, i.e. 'old English plantation language' and Djutongo, are mainly characterized by lexical differences from the other varieties. In the case of Djutongo, however, there is some evidence that it differed not only in terms of the words being used, but also in certain lexical-semantic aspects (some Djutongo words have a different meaning in Saramaccan, see Smith 1987: 126-127) as well as in pronunciation ( $c f$. the remark under the entry krijà, quoted above).

\subsubsection{The Creole as spoken on other plantations}

[Editor's Note. Evidently, this section is unfinished. The reference may be relevant.]

One reference:

The language one (i.e. a plantation manager, JA) should speak with the slaves is called Negro-English. However, on plantations where the owners used to be French, many French words occur.

(Anon. ca 1740:80-81)

4.2.4 Religion: 'church Sranan', the creole variety used by the Moravian missionaries

The label 'church Sranan' refers to the variety of Sranan used by the Moravian Brethren, which is characterized not only by certain phonetic features, especially spelling pronunciation, but also by lexical innovations used to denote Christian concepts. While they began their missionary work among blacks in Suriname in 1765, for more than 60 years their activities were largely restricted to Saramaka territory. This was because until 1828, when circumstances forced them to change their policy, most owners, fearing that christianization would lead to rebellion, refused to allow missionary activities among their slaves. ${ }^{50}$ In the course of time, this special variety, which at first was only used by the Moravian Brethren themselves, became a prestige variety imitated by others. In both functions it is still used to the present day (for information on its use in the mid-20th century, see Voorhoeve 1971).

50. But $c f$. Stähelin 1913-1919 (Pt I), who says that services were already held in 1736 by the Moravian missionaries on a plantation in the Para region. 
The major distinguishing characteristics of church Sranan, as pointed out by Voorhoeve (1971:310-313), have to do with pronunciation. The most salient phonological characteristics are: the frequency of word-final nasal consonants (as opposed to nasalization of the preceding vowel, e.g. [ben] instead of [be ]), the presence of - in Voorhoeve's words - 'strange vowels' (such as certain diphthongs, all derived from Dutch, that are not used in 'ordinary Sranan', e.g. mooi instead of $m o i$ ), and the absence of vowel elision, e.g. tanapu instead of tnapu. All these are the result of a literal pronunciation of the etymological spelling used by the Moravians in their writings - mainly Bible translations and religious tracts. Apart from this, there is some specialized vocabulary for Christian concepts (mostly borrowed from Dutch or German; see below), there are some archaic words, and in the written variety only - sometimes the preposition $n a$ is used instead of the serial verb $g i .^{51}$

In some cases the specifically 'church Creole' character of such features can be traced back to the past. For example, in the Preface to his 1856 dictionary Wullschlägel refers to the coinage of new words to denote Christian concepts:

The fact that not only the vernacular, but also the - if you may call it that spiritual or pulpit language, which was built little by little by the missionaries and which is well understood by the blacks, has been taken into account, will be considered useful by those for whom the book was primarily written - the neophyte missionaries of the Moravian Community. (Wullschlägel 1856: iv)

In the Introduction to the same work Wullschlägel writes:

Many Dutch words, which up to then [i.e. until the Moravian missionaries started their large-scale missionary work among the slaves, i.e. 1828, JA] were completely alien to the blacks, were introduced into the language by us missionaries while translating the Psalms and the New Testament, and they are now fairly generally understood, at least by the blacks educated in our schools.

(Wullschlägel 1856:vii-viii)

Examples of Moravian lexical innovations are not hard to find. A quick search through the first three chapters of the 1829 Sranan translation of Acts (Anon. 1829) yielded the following: Gadokondre (lit. 'God's country') for 'the Kingdom of God', hopo bakka ('get up again') for 'resurrection', kibrisanni ('hidden things') for 'visions', gran avoo ('great forefather') for 'patriarch', draai en libi ('turn one's life') for 'convert', tron baka ('turn back') for 'be remorseful', and santa liebi ('holy life') for 'piety'.

51. Note that the latter feature may also be an archaism, not specifically characteristic for church Sranan: Schumann's (1783) dictionary - which, in spite of the fact that the author was a Moravian missionary, mostly presents vernacular Sranan rather than church Sranan - contains a number of cases where dative/benefactive na is used instead of Modern Sranan gi. 
Lexical differences, however, are not the only characteristics of church Sranan mentioned by Wullschlägel. With regard to pronunciation, he says that

some words, whose etymology the blacks, of course, do not know, are pronounced incorrectly. In cases where such an incorrect pronunciation, or rather distortion, of words is not in general use, or at least should not be imitated, it is added within parentheses, because one should be familiar with it. Thus j'repi for helpi $i^{52}$ ('help'); fristeri for feliciteri ('congratulate'); piesiroetoe for absolutoe ('absolute'), etc.

(Wullschlägel 1856: viii)

Needless to say, the 'correct', i.e. etymological, pronunciation was the one used by the Moravians, whereas the 'incorrect', i.e. creolized pronunciation was the one used by the blacks. Similar remarks concerning 'correct' pronunciation can be found in Schumann's (1783) Sranan dictionary under the entries lei, 'lie' and lai, 'load', where it is said that the pronunciation of both words should be clearly kept apart by lowering and lengthening the vowel in the latter as compared to the former. This shows that one of the features mentioned by Voorhoeve as being characteristic for 20th century church Sranan - the use of Dutch-derived 'strange' diphthongs such as the long /ai/ - was already present more than two hundred years ago.

A third area, apart from vocabulary and pronunciation, in which church Sranan shows some differences from ordinary Sranan is lexical semantics. An example is given by Schumann under the entry pikkado:

pikkado, sin: for the blacks this word refers only to some of the worst sins, such as adultery, murder, poisoning. But we[i.e. the Moravian Brethren, JA] use this word in a general sense, referring to all kinds of sins (source: Schumann).

(Schumann 1783, s.v. pikkado)

An obvious reason for this difference would seem to be a difference in Weltanschauung between the missionaries andthe blacks, i.e. the fact that all kinds of behavior that were considered to be sins by the Moravian missionaries simply did not fall into this category from the Blacks' point of view. This semantic extension, however, was apparently unsuccessful, since the 1829 translation of Acts, referred to above, does not use pikkado, but Dutch-derived zondoe (<'zonde', i.e. 'sin') instead. Some examples of Moravian neologisms for Christian terminology found in Schumann's dictionary are presented in the next table.

52. Significantly, the use of helpi as opposed to yepi is mentioned by Voorhoeve (1971:312) as one of the 'church creole' features. 
Table 4.7 Examples of semantic extensions of Sranan words used by Moravian missionaries to denote Christian concepts

\begin{tabular}{lll}
\hline Word & Original meaning & Extended meaning \\
\hline $\begin{array}{l}\text { helpiman } \\
\text { jeje }\end{array}$ & midwife & Savior \\
vo bunne hatti & forefather & ghost/spirit ${ }^{53}$ \\
from a good heart & $\begin{array}{l}\text { an expression used to refer to the special nature of } \\
\text { the gift of heavenly goods, such as grace }\end{array}$ \\
wasi & wash & baptism
\end{tabular}

These examples from 18th and 19th-century sources show that the history of 'church Creole' goes back to the late 18th century, when the Moravian missionaries started to work among the black people of Suriname.

I have not been able to establish to what extent 'church Creole' - apart from its use in certain formal, non-religious settings mentioned above - may have influenced the vernacular, although it is hard to imagine that the blacks educated in Moravian schools would have been totally immune to such influence. This is especially true for the period when Sranan was the only language of instruction used in those schools, i.e. at least until 1876, when Dutch was officially declared the language of instruction, but even after that, since Sranan continued to be widely used in education. On the other hand, this influence may have been largely restricted to written language, and even there may have been confined to Christian terminology.

Since many of the earlier Sranan sources are of Moravian origin, a more important matter is the question to what extent these sources can be taken be reliable reflections of the 'real' (i.e. vernacular) Creole and whether they can be reliably used as data for historical-linguistic research. Although this question can certainly

53. As in santa jeje 'Holy Ghost'. As appears from Schumann's comment quoted below, this semantic extension was explicitly modeled on Saramaccan jeje, which already had 'ghost' as one of its meanings. Schumann's comment under jeje gives some insight into the practice of 'semantic engineering' used by the Moravian Brethren:

Among the Paramaribo blacks this word [i.e. jeje, JA] actually did not have this meaning [i.e. 'ghost', JA], at least not clearly (it did however among the Saramaccans); among the Paramaribo blacks it meant 'an ancient man' and 'ancestor' of a big family, with children's children into the fourth and fifth generation; on some plantations (for instance on the Upper Cottica) jeje or djeje also means 'family', 'kinfolk' ... But this meaning included a certain superstitious concept in that they took such an ancestor as a ghost or a semi-god, rather than a human being. Therefore it was not difficult for these blacks to capture the true meaning of jeje, namely 'ghost' (and to abandon the old, incorrect one); and now it has become so generally accepted that we can use it without any objection. 
not be definitively resolved on the basis of the rather limited data discussed in this section, I would like to maintain that - based on my overall experience with this material, and pending evidence to the contrary - these sources provide adequate data bases for diachronic research. A possible exception will have to be made with regard to phonological issues since in this area significant differences between church Sranan and ordinary Sranan may be found.

\subsubsection{Place of birth: Native and non-native Sranan}

Since large numbers of new, African-born slaves continued to be brought to Suriname throughout the 18th and into the 19th centuries, Sranan functioned both as a first language and as a second language. This raises the question as to what differences may have existed between these two varieties. That these differences must have existed until quite late appears, e.g. from an archival document from 1823 stating that sometimes it takes African (i.e. bozal) slaves years to master Sranan (Everaert 1999: 125). Cf. also Klinkers' (1997:35) reference to two slaves who after some years in Suriname were reported in 1823 still not to be able to express themselves well in Sranan.

Unfortunately, the concrete evidence for differences between native and non-native Sranan is very scant. Also, it seems to be largely limited to pronunciation, as in the first two quotations below. Under the entry kriólo in Schumann's Sranan dictionary the informant is quoted as follows:

if you want to hear nengre tongo, you must listen to how the Creoles [i.e. locally-born blacks, JA] pronounce it (Schumann's informant).

(Schumann 1783, s.v. kriólo ${ }^{54}$ )

Since the word taki, translated here as 'pronounce', may also have the more general meaning of 'speak', at face value it is not entirely clear whether this remark refers to general differences or more specifically to phonetic differences between the two varieties. However, since precisely the same combination of words - taki krin is used by Wullschlägel (s.v. Aussprache, 'pronunciation') with regard to quality of pronunciation, it seems safe to assume that the remark made by Schumann's informant similarly refers to pronunciation, and not to general features of Sranan as spoken by native speakers.

54. The exact wording in Sranan reads: ju wanni kissi Ningre tongo krîn, ju musse harki na kriolo, hufa dem takki, lit. 'if you want to catch black Sranan clear/pure, you must listen to the Creoles, how they speak/pronounce it'. The word kriolo refers to those speakers who had been born in Suriname. 
Focke, writing some 70 years later, unambiguously refers to pronunciation when he writes that "[1]ater[i.e. after the initial formative stage of Sranan, JA], the locally-born Negroes (Creoles) made the pronunciation more uniform and pure...". Although the concept of 'purity' in itself is not entirely unambiguous, the fact that Focke also refers to 'uniformity' ${ }^{55}$ here seems sufficient to conclude that what he intends to say is that the pronunciation of locally-born is more regular than that of African-born. If this is correct, this would be in line with a view of creolization as a process in which koineization qua gradual reduction of inter-dialectal differences is one of the constituent elements (cf. Siegel 1997).

The third remark discussed here is less informative than the preceding two in that it refers to a very specific - rather than a more general - difference in the pronunciation between native and non-native speakers of Sranan. Under the entry passumà, pánsuma'get stuck, stay small, not grow', Schumann's dictionary says:

pánsuma and passumà are the same: Salt Water Negroes [ i.e. 'bozals', JA] say pansumà [sic, JA], because that's a Loango ${ }^{56}$ word; but we Creoles [ italics mine, $\mathrm{JA}]$ have made it shorter ${ }^{57}$ we say passumà (Schumann's informant).

(Schumann 1783, s.v. passumà, pánsuma)

This remark unequivocally refers to a phonological difference: the pre-consonantal nasal in the 'Loango word' is deleted in the pronunciation of the locally-born speakers. ${ }^{58}$ Apparently, slaves originating from Loango had difficulty learning Sranan, as claimed by Teenstra (1835, vol. 2: 180): 'They [i.e. 'Loango Negroes', JA] learn the Negro-English language only wit the greatest difficulty'. That Loangos distinguished themselves linguistically from other slaves is also supported by archival documents that refer to specifically Loango words for certain plants, as well as word like Loango dron, Loango banya and Loango tetei (referring to a specific type of drum, banya, and rope, respectively (cf. Beeldsnijder 1994:297n11; $c f$. also Schumann 1783).

Two points emerge from these observations, both of which are important even though they are not very surprising in themselves. Their importance is due to the

55. The Dutch original has 'gelijkheid', which, in this context, means 'sameness'.

56. The word 'Loango' refers to the slave recruitment area around the mouth of the Zaire River, where West-Bantu languages were spoken.

57. My translation in this case differs substantially from Kramp's (1983:342), who translates this sentence as: 'but we creoles became their offspring. This rendering is not only strange in this context, but it is also not warranted on linguistic grounds.

58. Although the acute accent in pánsuma might be taken to indicate stress, I find it more likely to be due to a writing error or a transcription error. Compare, e.g. Focke's dictionary, which gives both pansoemà and passoemà. 
fact that they provide historical evidence with regard to two issues - nativization and substrate influence - for which truly historical - i.e. documentary - evidence is rarely available. The first point, evidenced by all three quotations, is that there were indeed differences between native Sranan and non-native Sranan. That both a native and a non-native variety of Sranan existed up to Schumann's time is supported by the historical-demographic evidence brought forward in Chapter 5, which shows that even as late as the end of the 18th century the majority of those who spoke Sranan were non-native speakers. ${ }^{59}$ The second point - referred to in the third quotation and, again, not very surprising in itself - is that the pronunciation of Sranan by non-native speakers was influenced by their native language. This observation is supported, of course, by a wealth of contemporary research showing that the phonology of Sranan bears clear traces of the African languages that were involved in its formation (cf., e.g. Smith 1987; Alber \& Plag 2001; Plag \& Uffmann 2000).

An additional point to emerge from the first quotation is that by the late 18th century something of a 'consensus norm' (cf. Milroy 1992) had started to develop in the Sranan speech community with respect to what did and what did not count as 'proper' ${ }^{60}$ Sranan. Another observation that is relevant here is the remark under the entry bassia 'bend' in Schumann (1783), where Schumann's informant says that, although the Djutongo word bassia is used by Creoles speaking Sranan, 'buku is better'. This means that, although at that time a majority of those who spoke Sranan were second language speakers, at least some speakers had developed a clear judgment about the status and/or value of the different varieties of the language. In other words, it seems that Sranan as a whole was becoming established in terms of the awareness in the community of its existence as a separate entity, even though on a structural level the language was still not fully stabilized. Although a further exploration of the differences between native and non-native Sranan and their effect on the emerging Creole would be of paramount importance for a better understanding of the process of creolization, lack of data precludes any such investigation at this moment.

59. Incidentally, the second remark ('we Creoles') indicates that at least one of Schumann's informants belonged to the category of native speakers. This information is important in terms of how to evaluate the data provided by this informant in the rest of the dictionary.

6o. The sentence in Sranan (ju wanni kissi Ningre tongo krîn, ju musse harki na kriolo, hufa dem takki) literally means: 'if you want to catch nengre tongo clear (or: pure), you must listen to the Creoles, how they speak'. The intended meaning of krîn ('pure' or 'clear') is of crucial importance here. 


\subsubsection{Some additional observations}

Apart from the five categories of variation discussed above, a few remarks can be found in the sources about cases of variation which do not seem to be related to any of these parameters. As with the categories discussed above, most of these examples concern pronunciation. Before discussing these, however, there is one other issue that needs to be mentioned here. In the early stages two developmental varieties of Sranan may have existed side by side, one more pidgin-like, the other more creole-like.

A second remark concerns the use of secret languages, which are discussed here under the rubric of variation, even though we cannot be sure that all secret codes mentioned in the sources are actually variants of one of the creole languages. This is the case for what seems to be a secret whistling language, mentioned by Herlein (1718):

On Sundays the slaves in the town of Paramaribo [italics in original, JA] take a walk along the Waterkant [the bank of the Suriname River in Paramaribo, JA], or they go to the savannah in order to 'baljar', which is a kind of dancing, called thus by them; however, this is prohibited because they were having too much communication among each other, disclosing things they wanted each other to know by singing, sometimes even by whistling with the mouth.

(Herlein 1718:95-6)

Unfortunately, nothing more is known about this whistling code since, as far as I know, it is not mentioned by any other author. Still, Herlein's remark is worth quoting here as it shows that secret ways of communicating were used by slaves as early as the turn of the 18 th century, both by whistling and by singing. Both types of secret communication are known from other places, both from slave societies and from other cultures. The use of whistling as a code is known, for example, from the Canary Islands, where a code called Silbero is still in use here and there. The use of singing to convey in-group messages in the presence of the out-group has been well established for Suriname, witness, for example, some of the songs, such as Miauw, reproduced in Chapter 6. The same practice has been amply documented for the American South in Abrahams' wonderful Singing the master (1992).

More concrete information on the use of secret codes by slaves is provided by Teenstra (1835):

Unskilled as I am in the ordinary Negro-English, I am even less skilled in the so-called Vara, Cropina and Para; the first of these is the ordinary Negro-English, where $p a ́, p i$, poe, etc is added to each syllable (in order to be unclear to the Whites), for example: Ordinary Negro-English Massera, 'Master'; Tangi, 'Thank'; Dago, 'Dog', in the Vara language become: Mapásserapá, Tapangipi, Dapagoepoe. 
As for Cropina, Para, and other forms of speech, I am not sufficiently acquainted with them to be able to report anything. I believe that in Cropina they add $r a, r i$, roe, etc and in Para they add ga, gi, and goe, for example: Massera, Magasragá; Tangi, Tagangigi; Dago, Dagágoegoe.

(Teenstra 1835, Pt 2:209-210)

Of the three codes illustrated by Teenstra, at least two - Cropina and Vara - are still used today in certain Saramaka villages. Price (1976) describes no less than seven different play that were still used by Saramaka men (and only very rarely by women) in the 1970s and all of which are referred to generically as akoopina (< Coropina?) by their users. Most of these are (far) more complex than the ones described by Teenstra: some of them are based on a mixture of Saramaccan, Sranan and Ndyuka rather than just Saramaccan, or even on Guyanais (the French-based Creole of Guyana) while the linguistic manipulations involved are also more complicated. Play languages have been reported for Ndyuka, Aluku and Matawai (Price 1976:39).

Mous and Haabo (2002) report on the so-called 'P-language'. The procedure of turning Saramaka words into P-language words consists of doubling every syllable while replacing the initial consonant by /p/, yielding, for example, wapakapa for waka. This procedure for turning Saramaka into a secret language is exactly the same as the one described above by Teenstra for turning Sranan into Vara. Although the fact that P-language is mainly used by children suggests that its primarily a play language, this does not mean that it was not used as a serious secret language in the past. In fact, the history of slavery strongly suggests it was, as slaves had every reason to conceal some of their communication from whites.

Apart from these remarks concerning secret languages, there are a few additional observations regarding variation in ordinary Sranan which should be mentioned here. First of all, there are a number of remarks concerning variation in Schumann's (1783) dictionary, all of which were contributed not by Schumann himself but by his informant(s). ${ }^{61}$ The first case, presented without any further information as to which variety it belongs to, concerns the word mússunja - a synonym for sunja 'a certain type of grass' -, which is realized as mussungu in the speech of 'some Blacks' (Schumann 1783, s.v. mússunja). In the other two cases, the informant uses the phrase wi takki... 'we say...' to introduce the preferred alternative. ${ }^{62}$ Since the informants were native speakers, this may suggest that the variant preferred by the informant belonged to a more authentic, 'deeper' variety of the language. The first of these has to do with the selection of the preposition in the Sranan equivalent of the phrase 'full of'. After the sample sentence da glasi de fulu nanga wini lit. 'the glass is full with wine', the informant adds: datti wi takki

61. This is so because they are in Sranan rather than German.

62. I am grateful to Adrienne Bruyn for drawing my attention to these examples. 
morro hesi, leki: da glasi de fulu 'vo' wini; tog da bakkasanni no krukkutu'we prefer to say that over da glasi de fulu "vo"wini [lit. 'the glass is full of wine', JA]; still, the latter is not incorrect' (Schumann 1783, s.v. fulu). The second example, regarding the possibly African-derived idiom of 'being cool', may be the clearest of the three as regards the question of 'deep' Sranan. The sentence a no habi wan sari morro, a findi bro 'he doesn't have any worries anymore, he found peace and quiet' is followed by the remark: wi takki, hem hattifadomm, a koure lit. 'his heart has fallen, he is cold', i.e. 'his heart is at peace; everything is cool' (Schumann 1783, s.v. hatti).

A second source which contains interesting information regarding variation is Wullschlägel's (1856) dictionary; this case is more informative as it relates to a topic about which a considerable amount of information is available from other sources. Speaking about paragogic vowels, Wullschlägel writes that

the unstressed final vowel [in Sranan, JA] is often pronounced differently or is changed by the blacks. Thus they sometimes say zwaka, 'weak', sometimes zwake or $z$ waki. Especially $e$ and $i$, and $o$ and $u$ are used interchangeably.

(Wullschlägel 1856: viii)

While the existence of variation in the quality of paragogic vowels in Early Sranan has been known since Smith (1987a), the remarkable thing about this observation is not so much the remark itself as its relatively late date. While research based on earlier sources, such as Schumann and Van Dyk, suggests that the change from paragogic $<\mathrm{e}>$ to another vowel, such as $<\mathrm{i}\rangle$, had been completed by the end of the 18th century, Wullschlägel's remark shows this was not the case. One way to explain this discrepancy would be to assume that the Sranan contained in Wullschlägel's mid-19th-century dictionary is closer to the plantation variety than that presented in 18th-century sources such as Schumann (1783). This assumption would not be far-fetched because the Moravian missionaries hardly had any contact with the plantation variety in Schumann's time, while in Wullschlägel's days they had been active among plantation slaves for almost thirty years. Since plantation Sranan is a more archaic variety than (see Section 4.2.4 above), this might explain that this change, which appeared to be completed around 1800 in the latter, was still in process in the former fifty years later.

Finally, under the entry begi, 'beg' in Schumann (1783) an interesting example is given of stylistic variation with respect to the person addressed when making a request:

If blacks really request something from another black, they say: tangitangi, mi hatti-lobbi, mi bossi ju futu, du mi da plessiri! ('please, my dear beloved, I kiss your feet, do me that favour!', JA]; if blacks request something from a white, they say: grangtangi vo Masra, effi Masra plîs va gi mi datti! ('please, Master, would you please give me that!', JA] (Schumann's informant).

(Schumann 1783, s.v. begi) 
The fact that at this stage a class- or ethnicity-related difference in the linguistic encoding of politeness was expressed in Sranan, suggests that by the end of the 18 th century the language had developed beyond the purely 'referential mode' and had begun to acquire an expressive mode making it possible to introduce stylistic options. It also supports the suggestion made earlier that normative ideas with regard to the language were beginning to develop.

As far as 'religious Saramaccan' is concerned, Schuchardt (1914: xxviii) notes that the language used in Saramaccan Bible translations contains a significantly higher proportion of English-derived words than ordinary, secular Saramaccan. According to Schuchardt, the proportion is about $75 \%$ to $25 \%$, while in ordinary Saramaccan (according to Schumann's dictionary) the proportion is roughly fifty-fifty (the proportion refers to types; a token count would yield even larger differences). Apparently, the translators drew heavily on English (through Sranan, I suppose) to express Christian concepts, for which there was no word in Saramaccan. This is rather surprising in view of the fact that in their Sranan translations the Moravians borrowed Christian terminology largely from Dutch.

\subsubsection{Summary and conclusion}

Even when taking into account the limitations of our sources, it is remarkable that they do not contain a single reference to variation in syntax, whereas variation in pronunciation and lexicon is regularly reported. This lack of indirect evidence cannot possibly be due to the absence of such variation in 18th and 19th century Sranan, simply because we do have direct linguistic evidence of variation in syntax (e.g. in tense and aspect marking; see Chapter 4). More likely, it could be related to the fact that syntactic phenomena are not only less salient than lexical and phonological ones, but are also more problematic to describe and analyze, especially for lay linguists, even if they are relatively well qualified.

Turning to those types of variation for which we do have indirect evidence, let us now try to draw some conclusions by relating these findings to the three issues, mentioned in the introduction, concerning the importance of early variation in Creoles. Before discussing each of these issues in turn, it should be emphasized once again that since our findings are largely restricted to pronunciation and lexicon no wide-ranging conclusions can be drawn on the basis of these limited data.

First, with respect to the representativeness of early sources, the findings reported here may serve to make us aware of the fact that none of the early sources should be taken to represent the Sranan of a particular moment. This does not mean, however, that they are unreliable per se, only that they represent a particular variety of the language. The more we become aware of the different varieties that 
were used, the more we will we be able to judge the value of each source and the better we will be able to reconstruct the language situation that obtained during the early stages. But the fact remains, of course, that most early sources are written by whites, either Moravian missionaries, who used church Sranan, or by planters and colonial officers, who spoke bakra tongo. In both cases, what these authors represent are the urban, non-native varieties of a language that we should wish to study in its native and rural form. But to the extent that we can determine the degree and the direction of deviation of a particular variety from the 'real Sranan', we will be able to obtain some sort of measure of representativeness or reliability of individual sources. However crude such a measure may be, it will still help us forward in determining the value of older documents as sources for early Sranan.

Second, since synchronic variation often reflects diachronic change, a combination of findings from both the synchronic and the diachronic perspectives may help to clarify issues in both areas. An example of this approach - based on what we know about the diachrony of paragoge - the mid-19th century variation in paragogic vowels reported by Wullschlägel (1856) can be explained as a feature of the archaic character of Wullschlägel's Sranan. It is to be hoped that future research will yield more information on synchronic syntactic variation since that could then be put in relation to the mass of information that is available about diachronic syntactic change (cf., e.g. Arends 1989, Plag 1993, Bruyn 1995a, Van den Berg to appear, Braun 2005).

Third, if there is one thing that emerges from this chapter, it is the fact that variation was already present in the early stages of Sranan. In this respect, Sranan is not unique among creole languages: Lalla \& D'Costa (1990: 98), for example, in an in-depth study of Early Jamaican Creole, report that

(the corpus) does establish the existence, from the eighteenth century, of extensive variation (among speakers and within individual usage) in features of basilectal and acrolectal models of Jamaican speech.

(Lalla \& D'Costa 1990:98)

Unfortunately, since these authors did not find any evidence of intermediate mesolectal varieties of Jamaican Creole, their research does not allow us to decide whether a continuum situation existed in 18th-century Jamaica (cf. Alleyne 1971).

When trying to determine whether a continuum existed in 18th-century Suriname, we are confronted with other problems. Due to the replacement of English as a lexifier language by Dutch, the conditions for a Creole continuum situation to emerge were not fulfilled. Therefore, a straightforward conclusion with respect to the historical time-depth of the continuum in Suriname cannot be drawn. On the other hand, some of the variation reported above, e.g. with regard to the amount of Dutch-derived vocabulary, may be construed as relating to a continuum-like situation, i.e. between Sranan and its secondary lexifier, Dutch. 
Especially the fact that Dutch vocabulary shifted in the course of time from being an ethnic marker - serving to distinguish bakra tongo and negre tongo - to becoming a geographical and social marker - serving to distinguish low-status plantation Sranan from high-status urban Sranan - provides some evidence for the kind of social distribution of variation that is characteristic for Creole continua.

Finally, as to the question of the speed of Creole formation, the evidence reported here lends supports to gradualist views of creolization, which assume a step-by-step construction of creole languages (cf. Arends 1986, 1989, 1993a, 2002a). In such a scenario, variation would be precisely what one would expect in the early stages of Creole formation. However, since the evidence of variation reported here is largely restricted to lexical and phonological matters, it cannot serve as decisive evidence in favor of gradualism. For that to be the case, more evidence of early variation in other areas such as morphology and syntax would have to be found. ${ }^{63}$

\subsection{Language choice and attitudes}

Until now, the questions of language attitudes and language choice in the early stages of creole languages have not received much attention in the literature (but $c f$. Mühleisen 2002). While this may be explained to some extent by the fact that information on these issues is not easy to come by, a search of the historical literature regarding Suriname has shown that such evidence is by no means entirely lacking. The evidence reported here is derived from a large number of historical sources: primarily 18th and 19th-century histories, travel accounts, and 'descriptions' of Suriname, but also early dictionaries, grammars, and language manuals. None of these works was perused with the explicit goal of collecting information on language attitudes and choice. Rather, what I did when reading or consulting such works for more general purposes was to note down any relevant information on these specific topics I happened to come across. While I do not make any claim to completeness, I do believe that the information collected here on the basis of primary historical and archival sources yields a more complete picture on these issues than can be found in any other work on the Suriname Creoles, or any Creole, for that matter.

63. This should not be taken to imply, however, that these findings provide evidence in favor of instantaneist models of Creole formation, such as Bickerton's Bioprogram Hypothesis. In fact, this theory cannot in principle be falsified by this type of evidence. This is so because it claims that creolization is completed within the first generation of speakers whereas all the evidence presented here dates from later stages. 
Historical data on language attitudes and language choice are important as they may yield information regarding questions which are often taken for granted without any documented evidence. Some of these questions are: How did people really feel about Creole? Who actually spoke Creole? For how long did African languages remain in use? And, what other languages besides Creole were spoken in the colony? Since almost all the information presented here derives from European-authored sources, we should be careful in our interpretation of it. With only a few exceptions, if the Blacks' point of view is represented here at all, it is through the eyes of whites (or, in a few cases, coloureds). In other words, the voice of the black never reaches our ears directly, but only through a white filter. Furthermore, since virtually all the information I have been able to find is restricted to Sranan, the other Surinamese Creoles will be largely left out of the discussion. Finally, in most cases those quotations given below that contain information relevant to more than one subsection will only be presented once. After they have been given in full in a first instance, they will not be repeated but only referred to in subsequent subsections. We will by discussing the evidence regarding language attitudes. In Section 4.3.2, we will deal with questions of language choice.

\subsubsection{Attitudes towards Sranan}

Unfortunately, our sources are extremely poor in the amount of information they present on the attitudes of the Blacks towards Sranan. The only relevant comment I have found is the following remark made by Helmig van der Vegt in the Preface to his Sranan manual:

Everyone who has visited the colony knows that no Creole (native) ${ }^{64}$ can be found who does not possess a strong love for his native language, even to the extent that he speaks it with a pride as if he were a Frenchman.

(Helmig van der Vegt 1844:3)

This remark indicates that Sranan was not only the primary language among Suriname's locally-born, including blacks, but also that it was held in high esteem by them. Remarks explicitly concerning the attitudes of Europeans towards Sranan are more numerous. Although negative opinions predominate, a number of positive comments may be found as well. Listen, for example, to what Captain John Stedman has to say:

64. Helmig van der Vegt's addition in parentheses ('inboorling' in the Dutch original) suggests that the most likely interpretation of the word 'creole' as used here is that it refers to locally-born persons, either black, colored or white. In any case, blacks and coloreds are clearly implied. 
...this mixt speech...is so sweet, \& Sonorous that even Amongst the Genteelest European Companies, nothing Else is spoke in Surinam; it is also extremely Expressive and Sentimental....

(Stedman 1790:515-6)

Stedman also claims to be 'perfectly well acquainted with Sranan (p. 515), which suggests he found it easy to learn. This is also reflected in a comment made by Fermin (1769):

Je n'eus pas beaucoup de peine à comprendre ce langage; parce que je sçavois l'Anglois, \& qu'il y est beaucoup analogue.

(Fermin 1769, Pt 1:20)

Another author who viewed Sranan positively, at least in a number of respects, was A. F. Lammens, a white colonial official who was President of the Court of Civil Justice when he wrote his Contributions to the knowledge of the Suriname colony (published as Lammens 1982) around $1823 .{ }^{65}$ Since the passage on the language situation contain several interesting remarks, it is quoted here in full.

Since Suriname's population consists of people who have gathered there from all countries, such as Dutch, Germans, English, French, Italians, Portuguese and German Jews, in addition to those who were born in the colony and are called Creoles, one can understand that several languages are spoken there. Every group has retained its native language. When we add to this the different Negro languages as well as the Arabic, spoken by some Negroes, then there is no less differentiation than there is in the different religions adhered to by everyone. These languages are supplemented with a national language of their own, called NegroEnglish, which is a kind of general language spoken mainly with the slaves. It is a composition of several languages, of which English is the most important, then Dutch. This language is very poor and it is pronounced in an extremely sloppy fashion. At first hearing it is pleasant; it seems that the way it is spoken, the manifold vowels added at the end of most words give it a singing tone or melody as a result of which it sounds somewhat like Italian. ${ }^{66}$ The language is learned easily, the children prefer speaking it to the other languages they hear their parents speak. A very imperfect grammar ${ }^{67}$ of it has been published and some printed books, especially suited for the church service of the Moravian Brethren. The Herrnhutters have enriched the language with a number of words and compiled a dictionary of it, which has not been published.

65. This date is based on the fact that the manuscript was written between 1821 and 1824 (De Bruijne 1982: ix, xi).

66. Cf. Focke's (1855: viii) almost identical remark referring to Sranan's 'Italian-like euphony', which he claims is due to the tendency to end words with a vowel.

67. This probably refers either to Van Dyk (c1765) or Weygandt (1798). 
The indifferent use of the letters ' $\mathrm{l}$ ' and ' $\mathrm{r}$ ' is confusing for someone who is not sufficiently acquainted with the language. For example, for 'bottle' they say batla or batra; for 'pure', 'clean' they say krien or klien; for 'roll' they say lorre, etc. Whenever there is a strong sounding ' 1 ', they almost certainly replace it by 'r', as in the case of 'klein' and 'klont': krein, kront. ${ }^{68} \mathrm{~A}$ second feature showing the poverty of the language is the necessity to add an auxiliary noun to another noun in order to make it understandable, for example the word wieriwieri, whose general meaning is 'herbs of the field', becomes 'grass' when the word 'horse' haasi is added to it; it means 'hair' when the word 'head' hede is added to it, 'feathers' by adding the word 'bird' fowlu; kappewieri is 'wildshoots' ${ }^{69}$ It is the same with the word sanni: Teesanni is 'tea set', brikkisanni is 'breakfast', not to give any further examples. However, the language is fully adequate to express everything that is needed in daily life. Whenever a word is lacking, a Dutch or English word is used for it and it is understood. Also, there is no lack of proverbs or figurative expressions in the language. It would be important to make a whole of all this and the language is susceptible to much civilizing. The nature of this work does not allow to substantiate this with examples and most readers would be very indifferent to it. Still, I wish to note that I do not know of any swear words in the Negro-English language; when they curse, they use the appropriate words from English or Dutch, without making any changes to them.

(Lammens 1982 [c1823]: 119-20)

As regards the topic of this subsection, attitudes towards Sranan, the relevant though sometimes contradictory - features attributed to Sranan by Lammens are that

- it is a very poor language; this is shown in that

- it does not distinguish 'l' and ' $r$ ' properly

- it has to resort to compounding in order to refer to a wider range of concepts

- yet, it is completely adequate to express everything needed in daily life

- it is spoken in an extremely sloppy fashion

- yet, it is pleasant at first hearing

- it is easy to learn

- children prefer it to other languages

- it does not have any swear words

As we will see later on, the negative features mentioned by Lammens (poverty, sloppiness) were attributed to Sranan by a number of other observers as well. First, however, we will discuss two authors who have expressed themselves in an unusually positive tone about the language. It may not be accidental that both of

68. Note that the latter two examples are words from Dutch, not Sranan.

69. Note that the last example is not relevant here: the interpretation of kappewieri as kappe + wie$r i$ 'cut' + 'herbs' is based on a folk etymology. The correct etymology is Ptg. capoeira 'brushwood'. 
these were linguistically much more sophisticated than most of the other observers. The first is H. R. Wullschlägel, Moravian missionary and author of an excellent Sranan dictionary (1856) as well as a concise but good Sranan grammar (1854). In his only known article on the subject (partly identical to the Introduction to his dictionary), Wullschlägel (1855) has the following to say concerning the alleged poverty of the language.

The Negro-English language is usually considered to be very [italics in original, JA] poor; this, however, is not entirely indisputable, at least not to the extent that this is generally found. To be sure, for many concepts which are common to us the Negro does not have a fitting expression; but this is a result of the fact that he does not yet have that concept or it is foreign to him: if he had the concept he would soon find the correct expression for it, perhaps even without having to resort to new words. I cannot help believing that other languages, such as English, which originally was also a mixture of several languages, were not richer than Negro-English in the beginning, before the general civilization of the people had overcome those difficulties, introduced new words with new concepts and added figurative meanings they did not have before to those they already had. In daily life the Negroes know how to express themselves fluently and concisely, often with a surprising accuracy, sometimes even more concise and pithy than we Europeans do.

(Wullschlägel 1855:288-289) 70

Being among the linguistically most active Moravian missionaries, along with such talented and relatively unbiased people as Christian Ludwig Schumann and Wilhelm Treu, we would perhaps only expect Heinrich Wullschlägel to hold these enlightened opinions.

By far the most linguistically sophisticated remarks, however, were made not by a missionary stationed in Suriname, but by an extremely gifted English philologist (Reinecke 1987:23), who had never set foot in the colony: William Greenfield. Greenfield was employed as a superintendent of the editorial department of the British and Foreign Bible Society (BFBS), when in 1830 he published A defence of the Surinam Negro-English version of the New Testament (part of which was reprinted in JPCL 1(1) in 1986). In this 76-page pamphlet, Greenfield argued against an anonymous attack which had been leveled against the Sranan translation of the New Testament, published by the BFBS the year before (Anon. 1829). While the Defence would warrant a much fuller discussion than it can be accorded here (see Reinecke 1987 and Harris 1985 for further information), let us limit ourselves here to a discussion of the points most relevant to the issue at hand.

Since the essence of the attack on the Sranan version of the New Testament (written by someone who obviously did not know anything whatsoever about

70. These remarks are very similar to those made in Wullschlägel (1856: vi-vii). 
Sranan) was that Sranan was not a 'real language' but merely 'broken English', the Defence is aimed at showing that this is not true. Greenfield's main arguments (pp. 66-75), based on solid linguistic scholarship and showing a remarkably modern point of view, may, to the extent that they are relevant here, be summarized as follows ( $c f$. Harris 1985:218 for a fuller treatment). First, Sranan is a language in its own right, with a history of its own. This emerges, among other things, from the fact that it is clearly independent from English and from the fact that its lexicon contains several layers (English, Dutch, Portuguese) which it acquired in the course of time. Second, it is a complete, accurate and rule-governed language as Greenfield claims to have shown in his detailed analysis of its lexicon, grammar, and word structure. Third, Sranan is no more barbarous than any language is to those who are unacquainted with it. This is shown by a comparison of Sranan with other languages, such as English, that have particular traits such as a certain degree of 'corruption' and 'intermixture' in common with it. While English was often considered barbarous in the past, it is now regarded as one of the most civilized languages.

While there are many passages showing Greenfield's attitude towards Sranan, let me restrict myself to quoting the one remark which gives the best overall summary of his views.

The human mind is the same in every clime; and accordingly we find nearly the same process adopted in the formation of language in every country. The Negroes have been proved to be in no degree inferior to other nations in solidity of judgment, or fertility of imagination; and therefore it may fairly be presumed that they are capable of forming a language from the materials with which they are furnished qualified for expressing with accuracy and precision the ideas presented to their mind.

(Greenfield 1830:51)

Since the ultimate goal of the Defence was to show that Sranan was not unfit for a translation of the New Testament, it is only logical for him to stress the fact that Sranan, 'however rude and barbarous it may be deemed, is capable of expressing the great truths of Christianity with accuracy and precision' (Greenfield 1830:41). But the main importance of his work for the topic under discussion is that it shows that well before creolistics was established as an academic discipline there were Europeans who had a positive attitude towards Creoles, based on an unbiased and informed view of these languages. However, the fact that Greenfield was largely forgotten for the next 150 years shows that he was too far ahead of his time to have any real influence at the time. This is reflected by the fact that the number of authors expressing a negative opinion on Sranan exceeds that of those representing a positive attitude. 
Many of these negative authors either stress the alleged lack of grammatical rules or the idea that Sranan is not capable of expressing everything, something which many of these authors claim is due to the lack of words for abstract concepts. From this it is often concluded that the language is (very) 'poor'. Often, both alleged features are seen as a clear sign that the language is 'uncivilized'.

An example of the poverty claim is found in Van Dyk (c1765:3), who states that ' $[\mathrm{I}] \mathrm{t}$ is a language that is not capable of expressing everything.... Fermin (1769, Pt 1:22) describes it as a 'jargon, qui n'est qu'un Anglois fort corrompu, mêlé de quelques mots Hollandois.... A little further on he writes:

[I]ls'ont voulu apprendre la langue des Anglois, qui ont primitivement possédé cette Colonie; mais sans y pouvoir réussir; ce qui a fait qu'ils l'ont estropiée, en y mêlant divers mots de leur idiôme d'Afrique, par lesquels ils ont cru même la rendre plus élégante. Ensuite ils se sont vu contraints, pour se fair entendre, d'y insérer plusieurs mots Hollandois, depuis que cette Nation les a conquis...

(Fermin 1769, Pt 1:22-23)

Teenstra (1835, Pt 2:210) flatly claims that 'Negro-English is not a language', after having described it as a

hodge-podge of distorted English, Dutch, French, Spanish, Portuguese and Negro words, even Russian, such as Malenker ${ }^{71}$ for short, invalid Negroes; this jargon or patois can only be learned through daily contacts with lower classes.

(Teenstra 1835, Pt 2:209)

According to Helmig van der Vegt (1844:5), the number of nouns is very small due to 'the poverty of the language'; this renders it difficult to express one's thoughts in a single word, making it necessary to express oneself through paraphrase.

C. E. Lefroy, an English member of Suriname's Mixed Court against Slavery from 1819 until 1829 and the author of an anonymous, abolitionist novel entitled Outalissi set in Suriname (1826), calls it 'a barbarous jargon of Dutch and English'. In an 'Editorial epilogue', the 'editor' (i.e. Lefroy himself), says:

...their own jargon [i.e. Sranan, JA], which is so scanty as not to contain perhaps above five hundred words, and must, I think, be quite an inadequate vehicle to convey any comprehensive impression in all its foundations, parts, and purposes, of the sublime spiritual temple of Christianity.

(Lefroy 1826:289)

To this passage he adds a note in which he claims that

71. Although Teenstra is to be commended for his imagination, allowing for Russian influence in Sranan (!), we prefer to derive this word from French malingre 'sickly, infirm'. 
...the great truths of Christianity...certainly will not admit of definite explanation in the negro language at Surinam without the frequent introduction of English, Dutch, or German terms and idioms...

(Lefroy 1826:289)

In another note, he refers to

[t]he introduction of a barbarous jargon of Dutch and English amongst the negroes by way of a language...The whole vocabulary does not comprise above five hundred words, and those incapable of modification. How can any adequate idea of Christianity be conveyed in the mind by such a vehicle as this?

(Lefroy 1826: 310-311)

Finally, Prince Roland Napoléon Bonaparte (1884:193) refers to the fact that the Moravian missionaries 'had great difficulty to supplement words for abstract concepts which did not exist in the languages, such as 'grace', 'benediction', and 'eternity". The perceptive reader will have noticed, I assume, that the first two examples (to some extent, perhaps, also the third) given by Bonaparte concern Christian concepts for which Sranan would not be expected to have a word of its own, simply because Christianity was not part of the world view held by those who originated the language. A more enlightened view on this matter is espoused by Wullschlägel (1855), but then again, being the author of the first published Moravian Sranan dictionary, it was part of his job to come up with Sranan equivalents for Christian concepts.

[o]ne should not be led to believe that the Negro language is unfit for that [i.e. the expression of Christian ideas, JA]. To be sure, some ideas cannot be expressed in Negro-English as precisely as they can in German or Dutch, but that does not mean they should be abandoned. All one has to do is circumscribe them, being perhaps a little more verbose. At the same time, many things can be said more briefly and more concisely.

(Wullschlägel 1855:289-290)

Another type of linguistic 'poverty' is the alleged lack of grammar, referred to by, e.g. Nassy (1791), Beijer (1823), and Helmig van der Vegt (1844). Nassy (1791, Pt 1:18) claims that Sranan, 'a gibberish of the country, ... has neither order nor rules...', while Beijer (1823:88) is a little more explicit when says that it has 'no rules of grammar'. According to Helmig van der Vegt (1844:3), Sranan is '...a language without recognized and fixed basic rules'. Characteristically, none of these authors provides any examples to illustrate this alleged lack of grammar. Sometimes a more general complaint of incompleteness is expressed, even by such a competent lexicographer (and native speaker) as Hendrik Charles Focke, who refers to Sranan as 'an incomplete mixture of Portuguese, English and Dutch words' (Focke 1855: vii). 
This same author has also pointed to the alleged 'uncivilized' nature of Sranan (Focke 1855), along with others such as Beijer (1823), Van Breugel (1842), and Helmig van der Vegt (1844). According to Beijer (1823: 88), Sranan '....is so uncivilized as to be unfit for writing', while Van Breugel (1842:90) says Sranan is a dialect without grammatical rules and so uncivilized as to be unfit for writing. And while Helmig van der Vegt (1844:3) flatly claims that Sranan '...is an uncivilized language..., Focke (1855) seems to relate this to the fact that '.. . it is spoken by a people full of a lively imagery and strong passions'. Also in this category belongs Nassy (1791, Pt 2:18) who, while not using the word 'uncivilized' explicitly, manages to use the word 'gibberish' ('jargon' in the French original) no less than three times in one paragraph when speaking about Sranan.

Apart from these outright negative comments, there are a few others which contain a mixture of negative and positive judgments. Surprisingly, some of these were made by the same authors whose explicitly negative opinions were discussed above. An example of this is Beijer (1823: 88), who, after having said that Sranan is too uncivilized to be used in writing, adds:

This patois or common vernacular can only be learned by practice. The essentials are easily understood by everyone. But since the language of the Negro is rich in imagery and mysterious, there is much that remains incomprehensible for the European, even after many years' residence. Only those foreigners who, living on plantations for a long period of time, are in daily contact with many Negroes will learn the language to its full extent.

(Beijer 1823: 88)

By way of introducing the collection of 300 odos included in his book, Teenstra, whose outright negative opinions were quoted above, writes:

It is generally known that a language with a poor vocabulary has many imaginative, ambiguous and mysterious sayings, is naïve and symbolic, and has many folk sayings, and borrowed expressions.

Teenstra (1835, Pt 2:209)

Similarly, Van Breugel (1842), who thought Sranan an uncivilized, grammar-less language unfit for writing, also called it 'flowery and mysterious', easy enough to learn for daily purposes but requiring 'many years' residence to be able to express oneself well with a Negro and to understand him well' (Van Breugel 1842:90). In the same vein, Focke says:

Although the Negro-English language...is an incomplete mixture of Portuguese, English and Dutch words, which have been distorted and mutilated by an African pronunciation, it still has so many idiosyncrasies and is so pithy and picturesque in its expressions that often a foreigner who is not acquainted with the customs and uses of the Negroes would be at a loss if he would only make a literal translation of what was said because in that case he would still not understand the meaning.

(Focke 1855: vii) 
In his review of Focke (1855) and Wullschlägel (1856), Moes (1858) writes that Sranan is 'a defective language' (Moes 1858:300), yet it is not 'as defective as many make it out to be' (301). He also writes that '[a]ll everyday matters can be expressed in it with sufficient clarity and often with great power and conciseness' (Moes 1858: 301). Finally, W. Boekhoudt, who served as a protestant minister in Suriname from 1841 until 1846, felt that, while Sranan was poor in words, it was rich in proverbs (odos). More remarkably, he is the only author in my sample who sees Sranan as basically an African language:

The language of the Negroes, Negro-English (Ningretongo), is the language of the African tribes, on which the succeeding European planters with whom they came into contact, such as English, Portuguese and Dutch, yes even French and Germans, exerted an unmistakable influence.

(Boekhoudt 1874:91)

Thus, this linguistic dilettante put forward - albeit without any supporting evidence - the idea of Creoles as restructured African languages some ten years before it was elaborated by the linguist Lucien Adam (Adam 1883).

When surveying the opinions on Sranan expressed by early white or colored authors, one cannot escape the conclusion that negative attitudes predominate. This is not surprising, in view of what we know about how Europeans felt about creole languages more generally in those days. At the same time, however, we also see, in a number of authors at least, some striking contradictions in the opinions they express. People like Beijer, Van Breugel and Focke, while noting the uncivilized and/or grammarless nature of the language, also stress its 'flowery', 'picturesque' and even 'mysterious' qualities, noting that in order to fully understand it one has to be intimately acquainted with the culture of the blacks. Perhaps this curious mixture of condescension and respect is representative of how many people felt about Creole at the time.

\subsubsection{Linguistic repertoires}

Another topic worth looking at from a historical perspective is the question whoapart from the blacks - actually spoke Sranan and what other languages were in use, both among blacks and whites. It turns out that, in spite of the negative attitudes towards Sranan often found in early sources, it is often reported to be used quite frequently by Europeans. In this context, it may also be interesting to look at what the sources say concerning the use of Sranan by Maroons. Since most Europeans did not speak any of the Maroon Creoles - they had difficulties particularly with Saramaccan - communication between the two groups usually took place in Sranan. (This appears, among other things, from the documents 
concerning the negotiations which led to the 1760s peace treaties with the Ndyuka and the Saramaka, discussed elsewhere.)

By definition, language choice implies that more than one alternative is available. This was certainly true in Suriname, where, apart from the creole languages, a number of European languages were spoken as well. There is also considerable evidence that languages from the African continent remained in use, even well into the 19th century. Therefore, we will also discuss what our sources have to say concerning the use of Dutch, English, Portuguese, Spanish, French, and German, as well as African languages and Arabic. Finally, we will also take into account what information can be gleaned from these sources about the use of interpreters and about literacy both among whites and blacks, since this may help us get a better picture of the language situation in colonial Suriname.

\subsubsection{Sranan}

The earliest source showing that the use of Sranan was not entirely limited to blacks is the 1699-1701 Studienbuch (lit. 'study book', a kind of scholarly diary, published in Beer 1976) kept by the German/Dutch aquarellist and naturalist Maria Sibylla Merian. She visited Suriname from 1699 until 1701 and in this diary she mentions several Sranan words when describing Surinamese flora and fauna. Davis (1998: 179; Davis 1995) says that Merian used Sranan to communicate with the Amerindian slaves who assisted her in collecting and determining local flora and fauna, claiming that 'she...learned it as [she] had learned Dutch years before.... However, to what extent Merian actually used Sranan as an everyday language remains unclear.

For the remainder of the 18th century we found five comments. In 1726, one Claude Mourquis, requesting permission to act as a teacher in Suriname, announced that he 'would not tolerate any unsolicited speech from the pupils, especially not in Negro-English, which will be prohibited by punishment' (Benjamins \& Snelleman 1914-1917:518, quoted in Van Kempen 2003:236). The second is an anonymous source, dating from 1752 and commonly referred to as 'the Recueil' (Anon. 1752). Due to the nature of this work - a collection of documents concerning a conflict between the governor and a number of planters - it contains many (quasi-) verbatim extracts. According to historian Ruud Beeldsnijder (1994: 133, 298n39), who studied this text in detail, it contains evidence that 'some whites spoke Sranan so frequently that they even used it when expressing themselves emotionally'. In a personal communication, Beeldsnijder added that 18th-century archival documents, especially letters and reports concerning certain conflicts, frequently contain 'scoldings in which Sranan is not shunned' (Beeldsnijder, p.c. 3/1/95).

The third remark is from the manuscript commentary on Herlein (1718), written in the 1760 s by governor Jan Nepveu: 
Most whites learn the Negro-English language very easily; it being broken English, which has been retained since the English had their possessions there and which has now become mixed somewhat more with Dutch.

(Nepveu 1770: $\mathrm{f}^{\circ}$ )

Referring to the 1770s, Captain Stedman wrote that '...this mixt speech...is so sweet, \& Sonorous that even Amongst the Genteelest European Companies, nothing Else is spoke in Surinam...' (Stedman 1790: 515-516). Dating from roughly the same period is a remark by David Nassy, who talks about 'the women and young maidens continuously chattering in Negro-English' 1791, Pt 2:51). ${ }^{72}$ Finally, women's preference for Sranan is also mentioned by Bolingbroke (1807:400), who refers to 'the negro English, or talkee-talkee..., which is spoken by the Creole ladies in preference to any other dialect'.

Continuing with the 19th century, we have some more sources at our disposal. Von Sack (1810), referring to the years 1805-1807, writes:

But as all the new-comers from Europe were anxious to learn this language, in order to be understood by the Negroes, and as their children of course were attended by them, they learned from them, by which means it is now become the common language of the colony, so that frequently a long conversation is carried on by English and Dutch inhabitants in this common dialect [i.e. Sranan, JA], without the assistance of which they would not understand one another. The Moravians have made a grammar of this mixed language, but they were obliged to coin many new words, for the purpose of conveying to their hearers an idea of the Christian religion.

(Von Sack 1810: 117-118)

The role of children in the diffusion of Sranan across the white population is also highlighted by Lammens (1982 [c1823]: 119), when he says that 'the children' prefer Sranan to the other languages they hear their parents speak. ${ }^{73}$ White children are mentioned specifically by Benoit, when he writes that 'the white children adopt it easily, which may give difficulties later on' (Benoit 1980 [1839]: 40).

Finally, there are a number of authors who refer to the use of Sranan among the white population in more general terms. One of these is Helmig van der Vegt (1844:3), who claims that if you don't speak Sranan as a newcomer you 'will not be able to take part in conversations for months.... This is echoed by J. N. Helstone (1903: 117), a native speaker-cum-amateur linguist, who says that in Suriname the

72. From the context, it is not entirely clear whether this remark refers to women in general or more specifically to Jewish women, although the former interpretation seems the more likely one.

73. Although Lammens does not refer explicitly to white children, the context makes it very probably that it is them who he has in mind. 
Surinamese language [i.e. Sranan, JA] is spoken by everyone.. ${ }^{74}$ A similar remark, emphasizing the role of women is made by Moravian missionary Van Calker, who in a manuscript quoted by Lenders (1996) writes ( $c f$. Nassy's remark discussed above):

It is not only the language of slaves but also of free and coloreds. Women, or rather ladies, who are dressed in silk mantillas, speak Negro-English among each other.

(Van Calker 1860 MS, quoted in Lenders 1996:270)

This quotation is reminiscent of Nassy's remark quoted above where women are also particularly mentioned as being prone to using Sranan among each other.

While it is widely known that the Moravian missionaries made extensive use of Sranan in their missionary and educational activities, it seems that occasionally they used it in their daily life as well. Lenders, in a detailed historical study of the Moravian mission in Suriname, claims that '[a]mong each other the missionaries spoke German as well as occasionally Negro-English; with their personnel ${ }^{75}$ they spoke Negro-English' (Lenders 1996:294n7). The Herrnhutters, however, were not the only Christian mission to use Sranan. The Catholic church, which did not begin serious missionary work in Suriname until the early 1820s, did so too, and even the Jews resorted to it occasionally, as appears from a reference to a speech held in Sranan by rabbi Lewenstein in 1861 at the admittance of one Venus van Louise Johanissen ${ }^{76}$ to the Jewish congregation (De Bye 2002: 149).

Apart from the fact that Sranan was sometimes used by whites when speaking to other whites, in most cases it was the only language available when communicating with Maroons. This was especially so with the Saramaka, whose language - which is structurally more distant from Sranan than the Eastern Maroon Creoles are - appears to have presented many difficulties to them (due to its tonal system, perhaps). This appears from the manuscript diaries kept by the Moravian missionaries, where it is stated repeatedly that they were having trouble mastering the language. Brother Stoll, for example, did not feel sufficiently confident until four (!) years after his arrival in Saramaka to hold a sermon in it (Arends 1993a: 107; cf. also Price 1991). Not only missionaries, but colonial officials too sometimes had problems with the language, even if they knew they were up for a long-term stay in Saramaka, as in the case of officer Dörig, who, shortly after having arrived in Saramaka as a 'postholder' 77 in 1763, did not understand a thing

74. It should be added that in the next sentence Helstone modifies this claim somewhat by saying that Sranan is not as widespread in Suriname as Dutch and German are in Holland and Germany, respectively.

75. The word 'personnel' refers to the slaves owned by the Moravian missionaries.

76. Probably a former slave, judging by the name.

77. A 'postholder' was a colonial official who resided in Saramaka to ensure that the terms of the Peace Treaty were kept. 
when the Saramaka captains 'put their heads together' (De Beet \& Price 1982: 157). That he did not know the language had already become clear on his trip upriver when he saw an old woman on the river bank 'chattering in a language I could not understand' (De Beet \& Price 1982: 153).

Most of the evidence for the use of Sranan in communication between Maroons and whites is contained in documents concerning the peace negotiations with the Saramaka in $1749^{78}$ and $1761-1762$, and with the Ndyuka in 1760. The earliest piece of evidence is from the diary of Lieutenant Creutz, leader of the colonial delegation to the Saramaka in 1749 , who writes that the colonial officials 'made clear the conditions as well as possible and explained them in Negro-English' to granman Adoe (De Beet \& Price 1982:64). Creutz also notes that, of all the government officials, Louis Nepveu was best understood by the Saramaka (De Beet \& Price 1982: 66). This is not surprising as the latter led the successful negotiations of 1761-1762, which were also conducted in Sranan. (Cf. Nepveu's diary of the 1762 trip, published in De Beet \& Price 1982, esp. pp. 121-122).

In less peaceful encounters between Maroons and whites Sranan was also sometimes used, as appears, e.g. from an archival document relating to the Tempati rebellion of 1757 mentioned by Dragtenstein (2002). According to this document, these Maroons used Sranan when negotiating with government soldiers about the latter's retreat (Dragtenstein 2002: 168). When contacts between Maroons and the Sranan-speaking coastal area increased after the conclusion of the Peace Treaties, their knowledge of Sranan increased too, especially among males, who, due to the nature of their employment, were much more mobile than females. This appears, e.g. from Bonaparte (1884), who is referring both to Saramaka and Ndyuka Maroons, when he writes:

Due to their frequent contacts with the capital, the majority of the Maroons have learned Sranan, which they pronounce in a very particular manner.

(Bonaparte 1884: 148)

Finally, it should be realized that not all blacks whom one would expect to know Sranan actually did. A document discussed in De Beet \& Price (1982) says that many of the black soldiers who took part in a 1755 campaign against Maroons did not know Sranan (De Beet \& Price 1982: 83). When pondering the question which language(s) they did speak, the only realistic option - since normally speaking black soldiers were not speakers of any of the Maroon Creoles - would be to conclude that they were bozals who had not yet acquired Sranan sufficiently and who were still speaking their native African languages.

78. The 1749 negotiations failed. 


\subsubsection{European languages}

Although the theme of this book is the history of the Suriname Creoles, it is important to look at the use of other languages as well, in order to get as complete and representative a picture as possible of the language environment in which these Creoles developed. Almost from its very beginning as a plantation colony, Suriname was a multilingual society in which apart from English a number of other European languages were spoken, including Dutch, Portuguese, Spanish, French, German, and probably others, such as Scandinavian languages and Italian. The presence of these languages was a direct consequence of the demographic history of Suriname, which attracted colonists, government officials, soldiers and sailors from different language backgrounds. While colonists and officials were drawn from a number of European countries, this was even more so in the case of ships' crews and military forces. Especially in the Dutch colonial orbit, these were known to have been composed of people of very diverse origins.

While some of these, such as soldiers and sailors, did not always become permanent inhabitants of Suriname, they still played a role in the linguistic ecology of the colony, all the more so as they formed a significant portion of the overall white population. Also, at least some of these sailors and, especially, soldiers did become settlers, thereby contributing a more permanent linguistic influence. And even sailors who were in Suriname only temporarily often stayed there for considerable periods, up to several months or more. While part of the activities of the soldiers took place outside of Paramaribo, many of the sailors, contrary to what one would perhaps expect, made frequent trips to the plantations in order to trade (Pares 1956). This means that even temporary and semi-permanent groups had an opportunity to have a linguistic influence in Suriname.

The presence of several European languages did not only lead to multilingualism at a societal, but also at an individual level, not only among whites but among blacks as well. Oostindie (1997:220), for example, mentions the mid-19th century female slave J. C. Jonas, who spoke Dutch, English, French and German fluently. The Boni Maroon leader Baron is reported to have learned Dutch, French and English, when, prior to his escape, he was sent to Holland for his education in the late 18th century (Oostindie 1986: 18). But multilingualism in European languages was more widespread among whites, at least among the upper class, as appears from Benoit (1839), who claims that 'almost all wealthy citizens of Paramaribo know French, English, and Dutch' (Benoit 1989 [1839]: 40). In what follows, we will discuss the European languages that were spoken in Suriname in the order in which they entered the colony beginning with its permanent settlement by the English in 1651. 


\section{4·3.2.2.1 English}

Although part of the English colonists left Suriname after it had been taken over by the Dutch in 1667 , this by no means entails - in spite of frequent assumptions to the contrary - that English stopped being spoken there (cf. Chapter 3). The earliest post-1667 document that is relevant to this issue is a manuscript by one Jan Reeps (1693-1694), published in Van Alphen (1963). In his eye-witness account, based on a 7-month stay in 1693 and 1694, Reeps writes that 'the English have founded a colony here and that language is still spoken mostly by the slaves over there' (Van Alphen 1963:307). While recognizing the problems involved in the interpretation of this sentence ( $c f$. also Arends 1995c: 14), a literal reading implies that some version of English was widely spoken by blacks around the turn of the 18th century. Similarly, a literal reading of Herlein's (1718:121) remark that the blacks $^{79}$ 'have mostly learned their language [i.e. English, JA]' indicates that some form of English, albeit with 'Negro words in it', was widely used by blacks in the early 18th-century. However, since both authors refer specifically to blacks as the speakers of 'their/that language', a more likely interpretation would be that what they have in mind here is some restructured form of English (although, of course, the degree of this restructuring still remains unclear).

The only other piece of evidence is from Stedman (1790) in a passage where he describes his first encounter with a Creole-speaking female slave on the night of his arrival in Paramaribo:

I asked if her Master was at home - she spoke but I could not understand her I then mentioned him by his Name when she burst out into an immoderate fit of Laughter...[and she] explained in the best manner she was able by gesticulation and broken accents that her Massera with all the Family were gone to his plantation to stay a few Days upon business - \& that she was left behind to receive an English Captain whom she supposed to be me - I signified that I was Captain Stedman...I made shift to Enter with this black woman into a kind of Conversation, which nevertheless I was glad to end with my bottle - [italics in original, JA]. ${ }^{80}$

(Stedman 1790:43)

Although it is not entirely clear what to make of this passage, it suggests that the young woman was able to make herself understood, to some degree at least, to Stedman. However, since Stedman, who had been born and raised in the

79. The context strongly suggests that 'Blacks' only refers to slaves here, not to Maroons.

8o. Stedman does not add here that later that night he entered into a conversation of a different kind with her, as appears from his unpublished diary, where he describes the nightly encounter somewhat laconically as follows: 'go to sleep at Mr. Lolkens, who was in the countrij, I f-k one of his negro maids' (Price 1989:27; see p. 11 for a reproduction of the relevant diary entry; a qualitatively better reproduction can be found in Price \& Price 1988: xxviii). 
Netherlands, did not only speak English but Dutch as well, and since it was not unusual for domestic slaves to know (some) Dutch (see below), the conversation may have taken place in some form of Dutch rather than English.

While the evidence for the use of English among slaves is ambiguous at best, it is not much clearer regarding its use among Maroons. The only clear case concerns the Maroon leader Boston (aka Adjaka), who had been brought to Suriname from Jamaica. During the Tempati rebellion of the 1750s, Boston communicated with his colonial adversaries in letters written in a rudimentary form of English ( $c f$. Hoogbergen 1992: 44, 57; De Beet \& Price 1982:200n1; Van den Bouwhuijsen et al. 1988: 15, 22-27, 49, 97, 101-4). ${ }^{81}$ The other case, from Stedman's Narrative, is more problematic. Stedman claims that a Ndyuka Maroon understood him when he said to someone else in English to 'give him a Dram, and he would be gone' [Stedman 1988: 510; italics as in original, JA]. Taking into account the context - Stedman uttering this sentence to a companion in an effort to get rid of the Maroon - it seems that the latter's understanding of it may have been largely based on the three major content words - 'give', 'dram', and 'go' -, which are quite similar in Sranan (gi, dram, and go, respectively). ${ }^{82}$

As to the use of English by whites, the only remarks I found date from the 19th century. In a remark quoted above, Benoit mentions English among the languages spoken by 'almost all wealthy citizens of Paramaribo' (Benoit 1980 [1839]: 40). While it is not entirely clear whether Benoit's remark refers to actual, daily use of English - rather than merely academic knowledge of the language ( $c f$. his mentioning of French in the same context) - a less ambiguous statement is found in Beijer, who flatly claims that in the 1820s 'apart from Dutch, much English was spoken in Paramaribo' (Beijer 1823: 87). The position of English was especially strong in the western region of Nickerie, which attracted many English-speaking planters during the early 19th century, when the government of the colony was temporarily in the hands of the English (1799-1802; 1804-1816). This left a linguistic stamp on that part of the colony, as appears from Teenstra's remark that 'everybody [in Nickerie] except government officials and military speaks only English and Scottish' (Teenstra 1835, vol. 1:119). Although the proportion of English-speaking planters in the remainder of the colony must have been much lower, it was certainly more significant than is usually assumed. Wolbers (1861:677-678) notes that some 60 English 'owners of land and property' ('grond- en goedbezitters') paid tribute to Prince Hendrik (a son of King William II) during his visit to Suriname in

81. See De Beet \& Price (1982: 112) for a printed version of one of these letters.

82. Assuming that in direct discourse the sentence ran something like 'Give him a dram and he'll go (away)', i.e. containing the form 'go' rather than 'gone'. 
1835. Assuming that most of these were plantation owners, this means that there was a significant number of English planters present in Suriname at that time. This is confirmed by the fact that for some time after 1812 an English-language newspaper appeared in Suriname, while from 1804 onwards another newspaper was published in a bilingual (Dutch-English) edition (Van Kempen 2003: 329). An analysis of archival documents concerning Emancipation has shown that as late as 1863 there were still a dozen English plantation owners in Suriname, among whom one Hugh Wright, the biggest slave-owner in the colony (Ten Hove, Helstone \& Hoogbergen 2003: 55-68; cf. also Wolbers 1861:768). English plantation managers were also present, e.g. in the early 19th century on plantation Mon Bijou (Oostindie 1989:232). While the use of English in Nickerie seems to be related, although indirectly, to the English interregnum, this was probably less so in Paramaribo, since the role of the English there was largely restricted to administrative circles. It does not seem too far-fetched, therefore, to assume that English was spoken in Suriname during the 18thcentury as well.

\subsection{Portuguese and Spanish}

Since the majority of Suriname's Sephardic Jews had entered the colony in the years 1665-1667, i.e. just before it was taken over by the Dutch, it is no surprise to find that official documents in the post-1667 period were sometimes translated into Portuguese and/or Spanish. The earliest reference to such a case is from 1669, when one of the governor's decisions was translated into Spanish and Portuguese (De Bye 2002:328). While the use of Portuguese may be explained by the fact that many of these Jews came to Suriname from the Portuguese-speaking colony of Pernambuco (North-East Brazil), this is not the case for Spanish. One should realize, however, that although Spanish may not have been used very much in Brazil, it was the most important language of commerce in the rest of Central and Latin America at the time. Since the activities of the Jews in the New World were primarily focused on commerce, it is only to be expected that those who came to Suriname were well acquainted with it. In addition, it is important to know that part of the Sephardic Jews came to Suriname directly from Europe, from places like Amsterdam and Livorno, among whose Sephardic communities both Portuguese and Spanish were spoken at the time.

For some Sephardic Jews in Suriname, their primary language may even have been Spanish rather than Portuguese. This has been claimed, for example, for David Nassy, the author of the Essai historique (1788), mentioned in several places in this chapter. Based on the fact that the books of poetry owned by him were primarily in Spanish, Cohen (1991:114) concluded that this must have been his primary language. Nassy himself also mentions both languages when he writes that the 'usual language [of the Sephardic Jews in Suriname, JA] is the Portuguese 
and Spanish' (Nassy 1791, Pt 1:3; cf. also Pt 2:72). Note, incidentally, that Nassy's phrasing may also suggest that he perceived Spanish and Portuguese as (two varieties of) one language rather than two separate languages, a perception that was to some extent warranted by the historical reality.

Nevertheless, in the course of time Portuguese remained as the only important Iberian language in Suriname, with references to Spanish becoming less and less frequent. De Bye (2002: 109, 116), for example, mentions archival documents showing that court trials at Jews Savannah were conducted in Portuguese until as late as $1793 .{ }^{83} \mathrm{~A}$ document referred to by the same author indicates that in religious contexts Portuguese remained in use at least until 1837, when it was decided that the minutes of the Mahamad ${ }^{84}$ would be written in Dutch from then on (De Bye 2002:325; cf. also Oudschans Dentz 1927:26). Portuguese also remained in use in more secular activities at Jews Savannah, as appears from an 1828 document saying that 'the bidding for the sale of the Miswot will take place in Portuguese as usual' [De Bye 2002:322; italics mine, JA]. It can be no coincidence that all three references discussed here are to Jews Savannah, the semi-autonomous Jewish enclave along the Suriname River, where the conditions for the maintenance of Portuguese into the 19th century were better than in the rest of the colony. However, with the demise of Jews Savannah and the relocation of many Jewish planters to Paramaribo later that century Portuguese eventually went out of use.

\subsection{Dutch}

While it is usually assumed - although often tacitly - that very few blacks in Suriname knew any Dutch, it is not clear on which this assumption is based. This is not to say that knowledge of Dutch was widespread among blacks, but only to stress that this assumption is not based on historical evidence. The fact that Sranan was the primary language for blacks both among each other and in their communication with whites does not imply, of course, that it was their only language. In fact, it would be quite surprising to find that Dutch was not known at all among the black population, especially among those who would hear a fair amount of Dutch in their daily lives, e.g. domestic slaves, manumitted slaves, and mulattoes. Since all three categories of blacks lived predominantly in Paramaribo, they would hear (much) more Dutch than plantation slaves would. For many mulattoes there would be an additional opportunity for acquiring Dutch: since sexual unions between a

83. At that time, the Jewish community at Jews Savannah still had its own jurisdiction, independent from the courts in Paramaribo.

84. A Mahamad is the 'Church Council' of a Jewish Community. 
white woman and a black man were very rare, mulattoes would almost by definition have a white father. To the extent that these fathers kept in touch with their children - which was the case more often than is sometimes assumed - and to the extent that they were speakers of Dutch, many mulatto children would grow up speaking both Sranan and Dutch.

This is confirmed to some extent by our historical data, where all three categories of blacks are mentioned a number of times in relation to knowledge of Dutch.

The earliest source in this connection is Herlein (1718: 93-94), who mentions a black woman who not only became a Christian but also learned Dutch when she lived in Amsterdam accompanying her master. The question is how much of her Dutch persisted after coming back to Suriname as she quickly 'sought the company of her own people', dropping her newly-found religion in the process. Notarial documents dating from 1727 show that a mulatto called Charloo Jansz was able to read and write in Dutch, while his black half-sister, the free and wealthy Elisabeth Samson, left many letters written in Dutch (McLeod 1993: 25, 40, 96). Beeldsnijder (1994) mentions a 1738 document stating that some of the domestic slaves on plantation Ornamibo understood Dutch (Beeldsnijder 1994: 149). ${ }^{85}$ The same author mentions a slave called Cornelis van Maarssen, who in the years 1740-1741 wrote three letters in Dutch, requesting his freedom (and, ultimately, succeeding!) (Beeldsnijder 1991: 13-14). In the same work, a 1789 advertisement in a Surinamese newspaper offered for sale a slave named Jauw, with the following partly redundant - recommendation: 'typographer and printer, knows how to read and write' (Van Kempen 2003: 259). Finally, there is the case of the 'celebrated granman Quassie', who in 1777 sent a letter to the Prince of Orange to explain certain grievances (Dragtenstein 2004: 78). However, the extremely formal style of the letter (reproduced in Dragtenstein 2004: 101-102), makes it very unlikely that Quassie himself was the author. Nevertheless, we have to assume Quassie knew how to read and write: he is mentioned as the author of an account of an expedition to the Ndyuka Maroons led by him in 1762 (Dragtenstein 2004: 66); he is also known to have received letters addressed to him in his capacity as a widely-known herbalist (he discovered the medicinal power of 'Quassia Amara Linnaeus', known in Sranan as kwasi bita).

Apart from slaves, mulattoes and free blacks, there were also some Maroons who knew (some) Dutch. Dragtenstein (2002), for example, mentions a Maroon who in 1753 used Dutch in oral communication with whites (Dragtenstein 2002: 149-150), while Price (1990) presents a reproduction of a 1769 letter (mostly a list of goods) written in Dutch by Gemmis, a Saramaka boy who had been

85. According to this document, most of these domestic slaves were Creoles, some of them were mulattoes. 
taught reading and writing by the Moravian missionaries (Price 1990:95-96). Other Maroons reported to know Dutch were the Boni leader Baron, who had learned it before his escape, when he was in Holland in the late 18th-century, and the Ndyuka boy Johannes Kojo, one of the blacks who were 'displayed' at the World Exhibition in Amsterdam in 1883 (Oostindie 1986: 18, 23).

Just as it is not true that blacks did not know any Dutch, it is also not the case that all whites did know it. While the early sources frequently report that Dutch was the most frequently used language in Suriname ( $c f$. ., e.g. Nassy 1791, Pt 2:72; Beijer 1823: 87; Benoit 1980 [1839]: 40), this does not mean that all whites knew it. Nassy, for example says that a large part of the Jews ${ }^{86}$ did not understand Dutch sufficiently in order not to be disadvantaged in the courts (Nassy 1791, Pt 1:176). The same author reports that sometime in the past many of the French refugiés ${ }^{87}$ did not know Dutch well enough to understand sermons in that language, adding that this was no longer the case at the time of his writing (Nassy 1791, Pt 2:16-7). Other groups reported to have a limited competence in Dutch are the members of the Dutch Reformed Church, about whom Van Schaick (1856:26) says that many only knew a little Dutch while many of the women didn't know it at all, ${ }^{88}$ and the Moravian missionaries, who preferred their native German or Sranan (Lenders 1996: 294).

While all the remarks above refer to adult Europeans whose Dutch was defective, that does not mean children always learned the language fluently. Teenstra (1835), for example, points to the fact that the locally-born (white) children have 'a somewhat corrupted accent...confusing $r$ with $l$ and vice versa' (Teenstra 1835, Pt 2:208), ${ }^{89}$ an example of interference from Sranan, which does not distinguish /r/ and /1/ systematically. Kappler (1983 [1854]: 24) even goes so far as to claim that 'very few children know how to write Dutch without errors or speak it purely'. ${ }^{90}$ Although these are the only sources I have found to make this observation, it is important in that it ties in with what we know about the 'ecology of language

86. Here, as elsewhere in his book, Nassy uses the designation 'the Nation' to refer to the Jewish population of Suriname.

87. This refers to the French Huguenots, who had been coming to Suriname since the revocation of the Nantes Edict in 1685.

88. This is especially remarkable since this would refer to the majority of the Dutch people in Suriname.

89. It should be noted that, while the context suggests Teenstra is referring to Dutch here, the examples he gives further on in the same paragraph are from Sranan.

90. Although Kappler uses the word 'children' without any further qualification, it seems clear from the context that the reference is to white children in particular. 
acquisition' for white children in Suriname. Many of these children were taken care of by a so-called 'Creole mama', a - usually elderly - black woman who would be charged with the daily supervision of both black and white children. Since, as a result of that, white children would hear much more Sranan than Dutch, both from their primary caregiver and from their peers, they would be more inclined to use Sranan than Dutch. This important - though often neglected - fact has wide-ranging implications; in particular for the role white children may have played in serving as channels for superstrate interference in the formation of Creoles.

\subsection{French}

Although a number of French-speaking colonists had stayed in Suriname for a few years around 1670, they did not become a substantial and continuous part of the white population until the late 1680s and 1690s, when several hundred Huguenots came to Suriname - often via Holland - after the revocation of the Nantes Edict in 1685 (Abbenhuis 1943:131-132). ${ }^{91}$ The influence of these French colonists can be seen, among other things, in French plantation names, such as Ma Retraite, La Diligence, Mon Souci, and La Prospérité. The number of such names is relatively high: e.g. around $10 \%$ of the 303 plantation names listed in Focke (1855: 153-160) is French. That the French were not only successful as planters appears from the fact that at least six of Suriname's governors came from Huguenot families (Abbenhuis 1943: 132). The success of the French colonists both as planters and as administrators may, of course, have given the French language an importance beyond the sheer number of its speakers, an importance which may even have been strengthened by the fact that in Suriname, just as in Europe, French had the status of an elite language (see below).

Just like the Sephardic Jews, the Huguenots adhered to their native language for a long time after their arrival in Suriname. Stedman (1988:234) notes that in the 1770s services in the Protestant church in Paramaribo were still held in (Dutch and) French, apparently for the sake of the French who did not understand Dutch (cf. also Nassy 1791, Pt 2:16-17). This custom must have been abandoned shortly afterwards since Nassy, writing in 1788, says that at that time sermons were only held in Dutch (Nassy 1791, Pt 2: 17). ${ }^{92}$ Nevertheless, for some time during 1792 a French language bi-weekly was published in Paramaribo (Van Kempen 2003: 267).

The high social status of many of these French colonists probably contributed to the prestige enjoyed by their language in the colony, although the role of French

91. Their number is estimated at 500 around 1700 by Abbenhuis (1943: 132).

92. In the same sentence, however, Nassy also says that from time to time sermons are still being held in French. Although there may be several explanations for this contradiction, we will not go into these. 
as a prestige language in 18th-century Europe may also have played a role. This prestige function probably played a role in the custom of using French in writing the addresses on correspondence destined for the Netherlands. In a 'notification' by the Court of Police and Criminal Justice from 1759, the inhabitants of Suriname are asked 'at the request of some Dutch sea-faring skippers' to use Dutch instead of French for that purpose (De Smidt 1973, 1:655). Another indication of the importance of French can be found in Van Dyk's (c1765:38) Sranan manual, where a mother, inquiring after her daughter's progress in school, asks whether she is practicing her French everyday. More substantial evidence is provided by Nassy, who claims that many people in Suriname understand French (though not as many as in Europe) (Nassy 1791, Pt 2:72) and that some French is taught in the schools (Nassy 1791, Pt 2:68).

Quite remarkably, knowledge of French is also sometimes mentioned with reference to blacks, not only slaves but Maroons as well. The earliest reference (from 1730) is about a mulatto girl who could answer questions from the catechism in French (as well as Dutch) (Beeldsnijder 1994: 126). While this may refer to rote learning more than anything else, this does not seem to be the case with an escaped slave, about whom an advertisement in the Nieuwsvertelder of July 1792 claims that he 'speaks French' (Neus-Van der Putten 2003:44). One of the documents related to the 1762 Peace Treaty, collected in De Beet \& Price (1982), mentions a Saramaka Maroon who 'speaks French well and understands it even better' (De Beet \& Price 1982: 120,133). More than a century later, the Ndyuka boy Johannes Kojo, present at World Exhibition Amsterdam 1883, was claimed to speak 'a little French' (Oostindie 1986:23). These Maroons' knowledge of French may be explained by the fact that several Maroon groups, especially those living along the Marowijne River (the Ndyuka and the Boni) or traveling regularly to Guyane (the Saramaka), were in contact - to a greater or lesser degree - with French (or French Creole) from quite early on. In this context it is no surprise to find an 1839 document reporting knowledge of French Creole among Boni Maroons living in Guyane (Hoogbergen 1992:270).

\subsection{German}

Although the Moravian missionaries formed the most important group of German-speaking people in Suriname - both in terms of numbers and of influence - ever since they first arrived there in 1735 , this does not mean there were no other speakers of that language present in the colony. Already in the early 18th century, Herlein (1718:48) mentions Germans among the inhabitants of Paramaribo. Another group that probably had German in its linguistic repertoire (besides one or more Slavic languages and, perhaps, Yiddish) was the Ashkenazic Jews who started coming to Suriname from the late 17th century onwards. Unfortunately, 
however, I did not find any information in the historical sources regarding the linguistic practices of the latter groups. Around the middle of the 20th century a number of German-speaking colonists arrived, but their attempts at colonization were not very successful. Nevertheless, the following remark by Schumann shows that the German language was sufficiently known in Suriname to warrant the inclusion of the word Duits tongo 'German' in his (1783) dictionary:

the Dutch and the German language are both called Duits-tongo ${ }^{93}$ (source: Schumann).

(Schumann 1783, s.v. bakkra)

Although the Moravian missionaries are known for their extensive use of Sranan in their missionary work, they continued to use their native German (next to Sranan) for in-group communication (Lenders 1996:294n7). This means that, to some extent at least, German remained continuously present in Suriname, something which is further strengthened by the fact that for some time in 1792 a German language weekly newspaper was published in Suriname (Van Kempen 2003:267). This may explain why by the middle of the 19th century German and Dutch were no longer referred to by the same name, as they had been in Schumann's time. In Wullschlägel's dictionary, the Sranan word for 'German' is given as opo-duisi or hog-duisi (lit. 'up German, high German') while the word for 'Dutch' is hollands (the Dutch word for 'Dutch') (Wullschlägel 1856, s.v. 'Deutsch' and 'Holländisch', respectively). Whatever may be the case, it seems clear that German was spoken in Suriname for a considerable stretch of time by a small but influential group of people. Apart from the Moravian missionaries, however, there were other speakers of the language, as appears from the fact that German translators were employed by the courts in Paramaribo as late as the first quarter of the 19th century (Beijer 1823:87-88).

\subsubsection{The use of African languages and Arabic}

Several creolists have claimed that the native African languages of the slaves fell quickly out of use once they had arrived in the colony. One of these is Robert Chaudenson, who, concentrating on French-lexicon Creoles, has held this position for a long time, up to his most recent book (Chaudenson 2003: 91-97; but see also e.g. Chaudenson 2001:78-81). This position, however, is based on a number of assumptions derived from publications on the history of slavery which are not entirely up-to-date to say the least. Chief among these assumptions is that the number of African languages involved was simply too large for there to be any real chance for substantial numbers of speakers of the same language to end up on the same plantation. This assumption, in turn, is based on the idea that because very large number of languages was spoken in the slaves' catchment areas

93. Regarding the use of the word 'Duits' to refer both to German and Dutch, see note 7. 
in Africa similarly high numbers of languages must have been represented on the plantations. However, as shown in recent work on the history of slavery, especially Eltis et al. (1999), Eltis 2000), the degree of ethnic homogeneity in the colonies was much higher than was hitherto assumed. Therefore, the idea of a quick death for the slaves' native languages is no longer warranted.

Another creolist who holds this position is Derek Bickerton, who has not only defended it for Creoles in general but also for the Suriname Creoles in particular. Speaking about the Saramaka Maroons, for example, Bickerton (1994:70) has claimed that 'it is highly unlikely that subsequent generations [after ca 1700, JA] would have learned African languages'. This is based on the entirely unwarranted assumption that 'few if any speakers of those languages entered the community after 1712'. New runaways- among whom many African-born - continued to arrive in Saramaka well into the 18th century, even beyond the conclusion of the Peace Treaty in 1762 .

In view of these ill-founded ideas, it may be worthwhile to look at what the historical sources have to say about the use of African languages in Suriname. The picture that emerges from these sources shows that African languages remained in use well into the 19th century. Important evidence in this regard is provided by historians of plantation culture, such as Ruud Beeldsnijder, who on the basis of his wide knowledge of archival documents, says: 'Some court records show that slaves, such as the Cormantins, continued speaking their own language, especially when they were together as a group' (Beeldsnijder 1994: 132). This is not really surprising once it is realized that the slaves who continued to be brought to Suriname until around 1830 needed some time to get acquainted with Sranan, while some, especially the adults, may never have become fluent in it. (Cf. Section 4.2.5. above, where it was shown that slaves did not always find it easy to learn Sranan.) Also, the frequently made claim that slaves could not continue speaking their native tongue because there would be no fellow slaves speaking the same language, due to the alleged divide-and-rule policy, has been shown to be poorly founded. Since, to the contrary, the degree of ethnic homogeneity in Suriname was rather high, it is no surprise to find a number of references to the use of African languages, as well as, occasionally, Arabic, in the historical documents.

The earliest source that is relevant to this issue is Herlein (1718:121), who defends the inclusion of a Sranan specimen in his book with the argument that 'their own native language is incomprehensible', clearly implying that African languages were being used in his time (around 1700). Also relevant in this regard is a remark in the Preface, where Herlein says that 'the languages both of the Indians and of the Moors are very difficult to learn' (Herlein 1718, Preface, p. $4^{\mathrm{r}}$ ). Further support may be derived from the fact that Herlein actually makes a 'linguistic' comment on these languages, claiming that the Indians and the Blacks 
have 'strange designations in their languages, for they express one and the same thing by different words, not always using the same ones' (Herlein 1718, Preface, p. $4^{\mathrm{r}}$ ). Whatever the quality of this observation, it strongly suggests that African languages were spoken in Suriname around 1700.

References to the use of African languages are by no means restricted to this early stage, however, as appears from observations made in several 18th and even 19 th century-documents. It is remarkable to find that many of these sources, especially those from the 18th century, mention one language in particular, a language the authors refer to as 'Cormantin'. Assuming that this name refers to the language spoken in the area around the slave trading fort of the same name, located roughly half-way between the forts Elmina and Accra, and accepting Hair's (1967:260) well-founded claim that the location of languages in this area has not changed much since the 17th century, the most likely interpretation would be for it to refer to languages from the Akan cluster, especially Twi (a term covering both Asante and Akuapem), which is spoken in an area along the coast of South Ghana (cf. also Eersel 1998: 100). Although there are several other languages spoken around Cormantin, such as the Akan language Fante, the Guang languages Awutu and Efutu, and the Ga-Adangme language Gã, these are spoken in (much) smaller areas and by (much) smaller numbers of people. In addition to that, the identification of 'Cormantin' as Twi is supported both by historical-demographic evidence concerning the slave trade to Suriname and by linguistic evidence concerning substrate retentions in the Suriname Creoles.

The earliest occurrence of 'Cormantin' known to me is from a 1738 court record referring to a slave who was overheard talking to another slave 'in Cormantin' (Beeldsnijder 1994: 132, 298n34). Dragtenstein (2002: 193) mentions a 1760 archival document stating that Ndyukas spoke African languages among each other, among which was a language called 'Cormantin'. Referring to the 1770s, Hoogbergen $(1992: 48,210)$ refers to a document saying that Kormantin Kodjo, a Boni Maroon, never learned to speak Sranan and continued to speak 'Cormantin'. Stedman (1790:515) presents a two-sentence specimen of an African language 'Call'd Coromantyn [italics in original, JA]', crediting his 'Boy Qwaccoo, Who belong to that Nation' for the data.${ }^{94}$ It should be added, however, that Stedman does not say explicitly that this language was used in Suriname at the time.

94. It should be noted, however, that one of these sentences looks more like Portuguese Creole than like any African language. The sentence is given as Me Yeree, Nacomeda mee and glossed by the author as 'my Wife, I am Hungry' (Stedman 1790:515). This gloss becomes more plausible when the original sentence is written as mujeri, na come da me 'woman, ? food give me' (Matthias Perl, p.c.). The linguistic affiliation of the other sentence - Co fa ansyo na baramon bra 'Go to the River \& fetch me Some water' - is unclear. 
The fact that it is this particular language which is mentioned specifically by these early authors becomes less surprising if we realize that the same language is often mentioned as being used in song, especially in religious (winti) contexts. For example, Hoogbergen (1992: 138) mentions an archival document from the 1770s referring to Maroons singing a song in the 'Kormantin' language ( $c f$. also Von Sack 1821, Pt 1:101). Even to this day, 'Kromanti' is one of the main surviving ritual languages used in winti ceremonies ( $c f$. Voorhoeve 1971; Eersel 1998); it is also still used in oral history (Hoogbergen 1992: 164, 241,312n266; Hoogbergen 1996: 182). (For a brief sample of Kromanti, see Chapter 7.) Cormantin, however, was not the only African language reported as being used in Suriname. There are also a number of references to a language called 'Loango', as in a report from $1766^{95}$ about a confrontation between colonial military and a group of Maroons: '...furthermore a negro called out in the Loango language, which was understood by one of the commando negroes'. Since 'Loango' was the name for the slave recruitment area covering the coastal regions of the Congo and Angola, the most likely interpretation for 'Loango' as the name of a language would be for it to refer to a West-Bantu language, most likely either Kikongo or Kimbundu or both (cf. Chapter 3).

Some indirect, but not less powerful evidence supporting the use of African languages in Suriname is provided by a 1720 archival document mentioned by Dragtenstein (2002:79) which talks about two whites who knew 'the African languages of the slaves'. Even though this document does not refer to the use of African languages by blacks, it still constitutes strong evidence in favor of it: After all, why would white people in Suriname go through the trouble of learning African languages if these were not spoken there?

It is often assumed that, even if African languages continued to be used for some time, this could never have lasted very long, say more than a century after the beginning of colonization. Still, this is precisely what we find with regard to Suriname. Even in the 19th century African languages were still in use, as emerges, for example, from Lammens' (1982 [c1824]: 119) reference to '...the several Negro languages as well as Arabic, spoken by some Negroes...' Similarly, Hoogbergen (1996:54) mentions documentary evidence form 1829 about a runaway slave who spoke 'a kind of Loango [probably a West Bantu language, JA], mixed with Sranan'. This same language - Loango - was also mentioned some 100 years earlier, in a 1736 document mentioned by Beeldsnijder (1994:297n11), where it is said that Loango slaves had their own names for certain plants. Writing about the same period, Teenstra (1835) says:

95. CR 1.05.04.06, 331, f 429v ${ }^{\circ}$. 
Among the Pré-Negroes there are many good workers and in their language and pronunciation they are closest to the Abo and Gola Negroes, as a result of which these tribes understand each other in their native language.

(Teenstra 1835, Pt 2: 183)

Evidence of a different kind can be found in Wullschlägel's (1856) German-Sranan dictionary, more particularly in the section (pp. 301-40) which contains a large collection of odos (a kind of proverbs) This collection contains two 'Koromanti' odos (nos. 228 and 405) in their original form, accompanied by their equivalents in Sranan and German. Because of their importance, the two 'lemmas' are quoted here in full. (In order to distinguish the languages used in these quotations, different type faces are used: roman for English (German in the original), italics for Sranan, and bold for 'Koromanti'.)

228. Koromanti koti wan odo, taki: Aze minjami - alsani na Gado wani. The Koromanti Negroes have a proverb: Aze minjami - Everything according to God's will. - As God wants it.

(Wullschlägel 1856:313)

405. Koromanti koti wan odo, taki: Sodjapee: Vo joe, joe lobbi; vo tra soema, joe no lobbi. The Koromanti Negroes have a proverb: Sodjapee: what's yours, you like; what's someone else's, you don't like. You think also: Charity begins at home. Also: Everything that belongs to you, you like; what belongs to others, you find ugly.

(Wullschlägel 1856:323)

The fact that these proverbs are mentioned as late as 1856, more than 200 years after the first slaves arrived in Suriname, shows that African languages remained in use for a considerable time, even after fully-fledged creole languages had been available for a number of generations. Although it could be objected that the use of a few African proverbs does not necessarily mean that African languages were used in daily communication, the remarks by Lammens and Teenstra quoted above strongly suggest they were.

Still another type of evidence is formed by the fact that the Sranan lexicon contains a separate word - kondre tongo or simply kondre - to refer to 'native African language'. All three major Sranan dictionaries - Schumann (1783), Focke (1855), and Wullschlägel (1856) - report the use of this word with precisely this meaning. That the word kondre (tongo) has this specific meaning appears from a number of things. First of all, in Wullschlägel's dictionary the word kondre tongo is clearly distinguished from words meaning 'Sranan', such as ningre tongo, bakra tongo, and taki vo kondre (cf. Wullschlägel 1856, s.v. 'Landesart', 'Muttersprache', 'Sprache'; cf. also p. vi). Second, although one of the examples given by Wullschlägel (1856, s.v. 'Muttersprache') - a de taki hem kondre-tongo 'he speaks his native language' would in principle allow for kondre tongo to refer to 'Sranan', this is clearly not the case with the following sentences presented by Schumann and Focke: 
Mi vergeti mi kondre-tongo kaba 'I have forgotten my native language'

(Schumann 1783, s.v. kondre-tongo)

A de tâki hem kóndre tóngo 'He speaks the language of his country'

(Focke 1855, s.v. Tóngo)

In these examples, the word kondre tongo can only be plausibly construed to refer to 'native African language'. The fact that the concept of 'native African language' was lexicalized in Sranan before the late-18th century and remained in use until after the middle of the 19th century, constitutes another piece of evidence for the continuing use of these languages, even until after the importation of slaves had stopped around 1830 .

Finally, apart from the reference by Lammens (1982) [c1824] to the use of Arabic quoted above, there is at least one other source concerning the use of this language in Suriname. An article in a Moravian missionaries' magazine from 1837, based on an eye-witness account, mentions a Moslem slave in Paramaribo who had written down the essentials of the Islamic faith in Arabic (Klinkers 1997:32). While Arabic is often overlooked by creolists as one of the languages spoken by African slaves, this is clearly not justified because many slaves were taken from islamized areas such as Senegambia, where Arabic was used, if only in religious contexts. Although Senegambia was not among the major slave recruitment areas for Suriname, apparently enough Arabic-speaking blacks were brought to Suriname to be noticed by careful observers such as Lammens. At the same time, the presence of Arabic does not seem to have been strong enough to leave any traces in the Suriname Creoles, except, perhaps, in the naming system for the days of the week in Saramaccan (Martinus 1996).

\subsubsection{Some miscellaneous observations}

That Maroons had contacts with other Maroons from other tribes and with French Guyana also appear from the fact that the bas language for some of the Saramaka secret languages is a mixture of Sranan, Ndyuka and Saramaccan, or Guyanais (Price 1976).

Apart from the observations discussed in the preceding sections, which were directly concerned with language repertoires, there are a number of additional remarks to be found in the early sources which are relevant to this issue, even though they touch on it only indirectly. One topic that comes to mind in this connection is literacy. This is so because until the introduction of compulsory education in 1876 - when the creole languages were rarely used in writing - if blacks knew how to read and write, this almost certainly implied that they knew a European language, either Dutch or English. Apart from the cases from the 1740 s and 1750s where we know which language was used in writing - the slave 
Cornelis van Maarssen, who used Dutch, the Ndyuka Maroon Boston, who used English - (both discussed earlier), there are a few other places in the literature where reference is made to Blacks' literacy without the language in question being mentioned. One of these is Stedman's Narrative (1988:85n), where it is said that the Boni Maroon Baron was taught to read and write by his owner. Another case of literacy among Maroons is that of 'three mulattoes who could read and write in the so-called 'Criole-dorp' (Price 1983a: 93, referring to a 1747 document). Finally, there are the blacks present at the World Exhibition in Amsterdam in 1883, some of whom were also said to be able to read and write (Oostindie 1986: captions to illustrations on pp. 23,25). Since all these (semi)literate blacks are reported to know (some) Dutch, we may assume this was the language in which they wrote.

A second issue which has some relevance for the topic of language repertoires is the use of interpreters and translators in Suriname. The earliest reference to this practice comes from a 1739 document concerning a Jew who acted as an interpreter in court for slaves from Jewish plantations (Beeldsnijder 1994: 132). Since we know that in this period Sranan was used in court cases involving slaves (Van den Berg \& Arends 2004), this suggests that the Creole spoken on Jewish plantations was not mutually intelligible with Sranan. The use of translators became more formalized later on, as appears from Anon. (1757: 112) (De Hooge Regeering...), where it is said that sworn translators were employed at the courts of Paramaribo for French (1), English (1) and Portuguese/Spanish (3). According to Beijer (1823:87-88), this was still the case almost three quarter of a century later (with the addition of German). A document listed in De Bye (2002: 116) also mentions the use of a Hebrew interpreter in the Ashkenazic Jewish community in 1793. The 'Surinamese almanac' for 1818 even mentions the existence of no less than six interpreters for Sranan (Van Kempen 2003:377). Finally, translators for Amerindian languages were also occasionally employed, as in the case of the Carib translators who worked for the colonial government in the 1770s (Quandt 1807:282-283). The use of interpreters and translators for English, French, Spanish and Portuguese clearly suggests that these languages remained in active use until well into the 19 th century.

Finally, a few remarks will be discussed here which are directly about language but for which there was no place anywhere else in this chapter. First, as to the language spoken on the plantations, it may be interesting to note that according to Van den Bosch (1843:360), who in the 1820s visited both Suriname and the Dutch Antilles, there were two plantations on the Lower Suriname River - St. Barbara and 'a neighboring plantation' - where 'Curaçaoan' was spoken. Since Van den Bosch had visited Curaçao shortly before coming to Suriname and knew Papiamentu well, we assume 'Curaçaoan' to refer to Papiamentu. This assumption 
receives further support from the following remark made by Van den Bosch himself, which is quoted here in full, if only to satisfy the reader's curiosity:

[T] hey seem to be originally from that island [i.e. Curaçao, JA]. We spoke with some of them in Papiamentu; they answered our questions, to the extent they could, but they did not show any surprise about the fact that we could understand their language. However, we were not able to find out where they came from.

(Van den Bosch 1843:360)

Although Van den Bosch' supposition that these slaves came from Curaçao certainly makes sense, especially in view of the fact that he could communicate with them in Papiamentu, a few problems still remain. For example, the fact that 'they answered our questions, to the extent they could' suggests that the use of Papiamentu as a means of communication was not entirely successful. Also, the fact that he was 'not able to find out where they came from' shows that he did not get his supposition confirmed by the people themselves. For these reasons it seems better to leave open the possibility that they were not from Curaçao but from Suriname and that their language was not Papiamentu but a language mutually intelligible with it. This would, in principle at least, allow for the possibility that the language in question was Djutongo, the Portuguese-lexicon Creole once spoken on the Jewish plantations. This idea is not entirely unwarranted as St. Barbara was located within the Jewish plantation area and since Djutongo was still in existence by the time Van den Bosch had this encounter. If this supposition could be proved, this would be the latest attestation for the use of Djutongo that is available.

Finally, while the Amerindian languages are not often mentioned in connection with either whites or blacks, there are several historical sources which show that at least some whites and/or blacks were acquainted with Carib and/or Arawak. Thus, an archival document reports that the famous ex-slave Quassie knew both Carib and Arawak (Hoogbergen 1992: 59). Hoogbergen also presents evidence from 1839 showing that some of the Bonis in Guyane knew Carib (Hoogbergen 1992:270). Some whites were also interested in the Amerindian languages, as appears from an early 18th-century document about a Jewish planter named David Cohen Nassy (not to be confused with David de Izak Cohen Nassy, author of the Essai historique), who knew 'the language of the Indians' (De Bye 2002:53). 


\subsection{Appendices}

\subsubsection{Lexical items labeled 'bakratongo' in Schumann's (1783) Sranan dictionary}

The following items in Schumann's Sranan dictionary are marked as being typical of bakra tongo as opposed to nengre tongo. Although in some cases the label 'Dutch' rather than 'bakra tongo' is used by Schumann, it seems evident that these items belong to the bakra tongo variety. The commentary in the dictionary, which is either in German (by Schumann) or in Sranan (by Schumann's informant), is presented here in an English translation. These translations, as well as those of sample sentences and phrases, were made by the author.

Apart from the items listed below, there are an additional seventeen words in Schumann's dictionary which are marked with a sign meaning 'restricted usage/ regional variation'. Although in these cases no information is given as to whether these words are bakra tongo, it seems probable they are since most of these (fifteen) are derived from Dutch. These words are: düri (<Du. 'duur'), 'expensive', dwars (<Du. 'dwars'), 'cross', fanga (< Du. 'vangen'), 'catch', fou (< Du. 'vouw'), 'fold', he(e) le (<Du. 'heel'), 'very', krone (<Du. 'kroon'), 'crown', pardon (<Du. 'pardon'), 'sorry', rau (<Du. 'rauw'), 'raw', slave (<Du. 'slaaf'), 'slave', steiffi (<Du. 'stijf'), 'stiff', steki ( $<$ Du. 'steken'), 'stab', strafe ( $<$ Du. 'straffen'), 'punish', strepi ( $<$ Du. 'streep'), 'stripe', swampo (< En. 'swamp' or Du. 'zwamp'), 'swamp', verwondre ( $<$ Du. 'verwonderen'), 'wonder', wassi (< Du. 'wassen'), 'wash', warm (< En. 'warm' or Du. 'warm'), 'warm'.

Finally, there is one item in Schumann's dictionary - kibri 'cover' - which is labeled nengre tongo but for which no bakra tongo equivalent is mentioned. For that reason, it is not included in the list below.

adjossi (<Pt. 'adeus'), 'farewell'.

"That's Bakkratongo: blacks say kroboi but almost all blacks use adjossi too" (Schumann's informant).

Under the entry kroboi $i$ the following information is given:

" "farewell'. Approximately the same as adjossi; kroboi is the actual expression of the blacks, adjossi stems from the whites" (Schumann).

"The two words are the same, kroboi and adjossi; kroboi is our own, adjossi we took from the whites" (Schumann's informant).

agêhn (< En. 'again'), 'again'.

"Blacks would rather say bakka; ju de komm bakka agehn" (Schumann's informant).

aréde (<En. 'already'), 'already'.

"That's Bakkratongo: blacks say kaba; da dedde skin de tingi 'aréde', that's clear to us, who are used to Bakkra; da dedde skin de tingi ' $k a b a$ ', ${ }^{96}$ that's more clear, because all blacks understand that" (Schumann's informant).

bakka (<Du. 'bakken'), 'bake'.

"Whites say that: we blacks say: lossi" (Schumann's informant).

96. Both sentences mean: 'the corpse is already smelling'. 
beginn (< En. 'begin' or Du. 'beginnen'), 'begin'.

"That's Bakkra-tongo; we say setti” (Schumann's informant).

best (< En. 'best' or Du. 'best'), 'best'.

"Dutch, see morro betre” (Schumann).

betrou (< Du. 'betrouwen'), 'trust'.

Dutch, see bribi” (Schumann).

boutu (<Du. 'bout'), 'thigh'.

"Dutch, see biggi-futtu" (Schumann).

deki, dekki (<Du. 'dik'), 'fat'.

"It is Bakkra-tongo; blacks say: biggi” (Schumann's informant).

dondro (< En. 'thunder' or Du. 'donder'), 'thunder'.

"blacks say: tappo bari”97 (Schumann's informant).

dübri (< En. 'devil'), 'devil'.

“That's Bakkratongo; blacks say: didübri” (Schumann's informant).

duku (< Du. 'doek'), 'cloth'.

"Bakkratongo" (Schumann).

dumm (< En. 'dumb' or Du. 'dom'), 'stupid'.

"Bakkratongo, see tanfuru"98 (Schumann).

en (<Du. 'en'), 'and'.

"Bakkratongo, see kaba and nanga" (Schumann).

fesi (< En. 'face'), 'face, front'.

"mi de go fesi hem"9 ; whites say this; blacks say mi de go mitihem"100

(Schumann's informant).

flaute (<Du. 'flauwte'), 'swoon, faint'.

"Dutch" (Schumann).

geel (<Du. 'geel') 'yellow'.

“That's Bakkratongo; blacks say redi or ledi” (Schumann's informant),

"which means both 'yellow' and 'red"” (Schumann).

Gemeente (<Du. 'gemeente'), ${ }^{101}$ 'Community' [in the religious sense, JA].

"Dutch" (Schumann).

hüre (<Du. 'huren'), 'rent, let'.

"Dutch, see juru" (Schumann).

kalfe (< Du. '(af)kalven'), 'cave in'.

"Is used when the earth of the side of a trench or a dam collapses little by little,

da gotro sa kalfe 102 (Dutch)" (Schumann);

"that's Bakkra tongo; blacks say brokko, da gotro de go brokko"103 (Schumann's informant).

97. Lit. 'the sky is shouting. The implication that can be derived from other information under this entry is that whites say dondro bari, 'thunder cries', or dondro pikki, 'thunder answers'.

98. Lit. 'be foolish'.

99. Lit. 'I'm going towards him'.

10o. Lit. 'I'm going to meet him'.

101. Perhaps this word is better viewed primarily as 'church creole' rather than bakratongo.

102. Transl. 'The trench will cave in'.

103. Lit. 'the trench will break'. 
kamera (< Du. 'kamer'), 'room'.

"Bakkratongo, see hosso" (Schumann).

kappe (< Du. 'kappen'), 'cut'.

"Dutch, better kotti” (Schumann).

klagi (< Du. 'klagen'), 'complain'.

"Bakkratongo, see takki and tori" (Schumann).

laaste (<Du. 'laatste'), 'last'.

"Dutch, see bakkawan, bakkasanni"104 (Schumann).

leni (< Du. 'lenen'), 'lend, borrow'.

"Bakkratongo, see juru” (Schumann).

maniri (< Du. 'manier'), 'behavior, manners'.

"Whites say it; blacks say: fasi” (Schumann's informant).

mankeri (< Du. 'mankeren'), 'lack, be absent'.

"Dutch, see libi" (Schumann).

morse (<Du. 'morsen'), 'pollute, neglect, spoil'.

"That's Bakkra tongo; blacks say dotti and pori; da somma morse alla moni en gudu va

hem; ${ }^{105}$ we say: a pori a truehalla hem gudu; da pikin morse tumussi; ${ }^{106}$ we say: a dótti" 107

(Schumann's informant).

ondro (< En. 'under' or Du. 'onder'), 'under, below'.

"But that's Bakkratongo; blacks say: biló, na biló"108 (Schumann’s informant).

pili/piri (<En. 'peel'), 'peel, pluck'.

"Also 'pull someone's leg'. Bakkratongo" (Schumann).

printje (<Du. 'prentje'), 'picture'.

"Dutch (Schumann). blacks say: a jorka, or: a djersi" (Schumann's informant).

sibi (< En. 'sieve'), 'sweep'.

“Also 'sieve' (verb). Bakkratongo, see dorro. Also 'sieve' (noun), see manári and Bakkra-

kondremanári"109 (Schumann).

sneier (< Du. 'snijder'), 'tailor'.

"That's Bakkratongo; blacks say naiman"110 (Schumann's informant).

üre (<Du. 'uur'), 'hour, watch'.

"Dutch. See juru" (Schumann).

104. Lit. 'back-one, 'back-thing'.

105. Transl. '(s)he squanders everything (s)he's got'.

106. Transl. 'the child is very dirty'.

107. Transl. 'it's dirty'.

108. (na) bilo is the older expression, witness its occurrence in Herlein (1718). In Modern Sranan, however, the Dutch-derived phrase has won out as the general expression, the English-derived one being restricted to the meaning 'down stream'.

109. Lit. 'European sieve'.

110. Lit. 'sew-person'. 
vandu (<Du. 'van node') 'necessary, needful'.

"Bakkratongo" (Schumann).

"mi habi vandu vo datti. ${ }^{111}$ blacks say: mi habi worko nanga datti or vo datti112 (Schumann's informant).

weifi (< En. 'wife'), 'wife, spouse'.

"Bakkratongo. weifi can only be used in this sense; in all other cases one has to use uman.

And the blacks themselves use uman rather than weifi in this sense" (Schumann). winiboom (< Du. 'wijn' + 'boom', i.e. 'wine tree'), 'vine'.

"The blacks say droifi boom"113 (Schumann).

\subsubsection{Lexical items labeled Djutongo in Schumann's (1783) Sranan dictionary}

The following words are labeled Djutongo in Schumann's Sranan dictionary (source: Smith 1987: 125-6). As in the previous appendix, the commentary in the dictionary, which is either in German (by Schumann) or in Sranan (by Schumann's informant), is presented here in an English translation. These translations, as well as those of sample sentences and phrases, were made by the author.

adjabre (<Gbe 'àja' + 'bl ', i.e. 'conflict' + 'deceive'114), 'betray(al), treacherous'.

"adjabre is Djutongo; we blacks say: lei, meki lei, tori lei” (Schumann's informant).

affitùh (<Pt. 'aflito', i.e 'oppressed'? $\left.{ }^{115}\right)$, 'constipation'.

"That's Djutongo: mi habi affitù,${ }^{116}$ that means: mi belle tappa, belle tranga"117

(Schumann's informant).

bae (< Pt. 'baio' or < Pt. 'vermelho' or < Gbe 've'118), 'red/yellow' (s.v. geel 'yellow').

"It is Djutongo" (Schumann's informant).

bassia (<Pt. 'baixar'), 'bend'.

"bassia is Djutongo; still we use it too; but buku is better than bassia" (Schumann's informant).

bika (< En. 'because') 'because' (s.v. bikasi 'because').

"Jews say bika" (Schumann's informant).

111. Lit. 'I have need of that'.

112. Lit. 'I have work with/for that'.

113. < Du. 'druif' + 'boom', lit. 'grape tree'.

114. Proposed as a possible etymology by Smith (1987a: 127).

115. Proposed as a possible etymology by Ladhams (1999:235).

116. Lit. 'I have constipation'.

117. Lit. 'my belly is closed', 'belly is strong'.

118. Etymologies proposed by Schuchardt(1914:50), Ladhams (1999:235) and Smith (1987b), respectively. 
bringi (< En. 'bring'), 'give birth'.

"In Paramaribo they don't use that word very often; it's Djutongo: but quite a number of plantations use it. Still a real city Creole said: isredeh mi kau bringi wan mannpikin"119

(Schumann's informant).

bruija (< Pt. 'embrulhar') 'confuse'

"Approximately the same as bulja, 'mix up'; Djutongo" (Schumann).

"bruija and bulja is the same word; but we use bulja more often" 120 (Schumann's informant). buija (< Pt. 'bulhar'), 'cause trouble'.

"It is Djutongo; we say: kwari, trobbi" (Schumann's informant).

fikka (< Pt. 'ficar'), 'stay (behind)'.

"It's Djutongo; we say libi or tann; but still we use fikka too" (Schumann's informant).

frementu (<Pt. 'fermentar'), 'leaven'.

"Djutongo, see surdegi" 121 (Schumann).

fruta (<Pt. 'fruta'), 'fruit'.

"We don't have that word at all, it's Djutongo; we say: jamjam" (Schumann's informant). glua, grua (< Pt. 'crua'), 'green, raw'.

“That's Djutongo; we say grûn, ${ }^{122}$ or lala” (Schumann's informant).

krijà (< Pt. 'criar'), 'breed, raise'.

"Approximately the same as kweki"123 (Schumann).

"krijà is Djutongo; but still we use it rather frequently. Saramaka say kilja"

(Schumann's informant).

mai (< Pt. 'mai'), 'mother'.

"Djutongo" (Schumann).

paai/pai (< Pt. 'pai'), 'father, honorific term for old person'.

"Djutongo" (Schumann).

panja (< Pt. 'espalhar'), 'spread'.

"panja is Djutongo; in our language we say: platti ${ }^{124}$; but still we use panja too"

(Schumann's informant).

plattiri, plattérin (< Pt. 'parteira'), 'midwife'.

“That's Djutongo; other blacks say: helpiman” (Schumann's informant).

tanga (< En. 'tongs' or Du. 'tang'), 'pliers'.

"That's Djutongo; other blacks say: Kneiptang"125 (Schumann's informant).

faija tanga (< En. 'fire' + tanga), 'fire tongs'.

"Djutongo; other blacks say: issri va fassi krofaija"126 (Schumann's informant).

119. Transl. 'yesterday my cow had a bull calf'.

120. But compare the entry under bulja, where Schumann's consultant says "It is Djutongo".

121. < Du. 'zuurdeeg', i.e. 'leaven'.

122. < Du. 'groen', i.e. 'green'.

123. < Du. 'kweken', i.e. 'raise'.

124. < Pt. 'partir', i.e. 'distribute'

125. < Du. 'knijptang', i.e. 'pliers'.

126. Lit. 'iron for holding glowing coal'. 



\section{CHAPTER 5}

\section{Early developments (1667-c1800)}

Now that we have sketched the historical setting in which the formation of the Suriname creoles took place, it is time to take a look at some linguistic data. While more elaborate textual data will be discussed in more detail elsewhere, we will restrict ourselves here to a presentation of the earliest - i.e. pre-1800 - texts that have come down to us. Although it is difficult to decide precisely at which point in time Suriname Plantation Creole started to diverge into the separate (groups of) creoles, we have split up the discussion in separate sections dealing with Sranan (5.1), Saramaccan (5.2), and the other Creoles (5.3). Due to the large number of early sources for Sranan, Section 5.1 is further divided into five subsections: miscellaneous sources (1667-1763) (5.1.1), Herlein (1718) and Nepveu (1770) (5.1.2), Van Dyk (c1765) (5.1.3), and Stedman (1790) (5.1.5). Section 5.1.4 is devoted to an evaluation of the question of which features in the Herlein fragment may be interpreted as being characteristic of pidginization rather than creolization. The texts themselves, along with a number of other, post-1800 textual sources, are reproduced in Chapter 7.

\subsection{Sranan}

5.1.1 Miscellaneous early sources (1667-1763)

Part of the data that will be discussed in this section belong to the very oldest texts that are known for Sranan - or rather Suriname Plantation Creole (SPC), the more appropriate term for the earlier stages of Sranan. In some cases they do not really deserve the name 'text', as they consist mostly of isolated words and phrases. Nevertheless, because of the light the may shed on the earlier stages of creole formation, it seems worthwhile to discuss them in some detail. Unfortunately, some of the very earliest sources on Suriname, such as Van Berkel (1695), do not contain any information whatsoever to enlighten us on the situation with regard to SPC in the late 17th century. This is especially unfortunate in this case, as Van Berkel worked as a plantation overseer in Suriname for almost a decade (16801689). Another early source which is sorely missed here, is Andreas Mauricius' (c1740) Sranan translation of the Vraagjes van Borstius (a version of the Heidelberg 
Catechism). Despite considerable efforts, we have not been able to locate this item, which is mentioned in Voorhoeve \& Donicie's (1963) bibliography of Sranan and Saramaccan. If it could be found, this text - the earliest substantial source after Herlein - could enhance our knowledge of early Sranan considerably.

Warren 1667. George Warren, the author of An Impartial Description of Surinam (1667), claims to have spent three years in the colony (Van Donselaar 1993: 87). Although his work does not contain any words which can be regarded as true Suriname Plantation Creole, it is included here because some of the 17th-century English words used by Warren were incorporated later - in a restructured form in the Sranan lexicon.

\begin{tabular}{|c|c|c|}
\hline $\begin{array}{l}\text { Warren } 1667 \\
\text { vawes }\end{array}$ & $\begin{array}{l}\text { Modern Sranan } \\
\text { vasi }\end{array}$ & $\begin{array}{l}\text { Meaning } \\
\text { framboesia (a disease) }\end{array}$ \\
\hline muskeeta & maskita & mosquito \\
\hline quotto & kwata & spider monkey \\
\hline
\end{tabular}

Behn 1688. In her novel Oroonoko, or the royal slave (1688), set in early plantation Suriname, Aphra Behn uses a few words that may be construed as representing early SPC, even though they are found in a number of other creoles as well: ${ }^{1}$

\begin{tabular}{|c|c|c|}
\hline ) Behn 1688 & Modern Sranan & Meaning \\
\hline $\begin{array}{l}\text { backearary } \\
\text { pickaninnie }\end{array}$ & $\begin{array}{l}\text { bakra } \\
\text { pikin }\end{array}$ & $\begin{array}{l}\text { White (person) } \\
\text { child }\end{array}$ \\
\hline
\end{tabular}

Hermann 1689. In the Herbarium Hermann, which contains a number of names for Surinamese plants, we find one early SPC word (for further information, see Van Donselaar 1996):
(3)
Hermann 1689 Modern Sranan tasi
Meaning palm species

Merian 1699-1701. Unfortunately, Maria Sibylla Merian's splendid Metamorphosis Insectorum Surinamensium (1705) - her illustrated book on Suriname entomology and botany, based on her fieldwork in Suriname between 1699 and 1701 - contains no information at all on early SPC. That does not mean, however, that she did not make any observations on the language at all. During her stay in Suriname she continued making notes in her Studienbuch 'book of studies', which was published in 1976 under the title Schmetterlinge, Käfer und andere Insekten: Leningrader Studienbuch. On page 353, Merian writes of a particular worm which is roasted

1. The question whether or not Aphra Behn ever visited Suriname has not been definitively settled ( $c f$. Wekker 1991). 
and eaten by the slaves. She then says that a certain beetle is called 'the mother of this worm'. Although, unfortunately, she does not mention the SPC equivalent of this expression, this remark is interesting in that it suggests that the use of the word mama 'mother' in expressions such as mama ston 'big rock' lit. 'mother (of) stone' and mama alen 'heavy shower' lit. 'mother (of) rain' may go back to the very early stages of SPC.

Although the Studienbuch does not tell us anything about the structure of early SPC, it does contain a number of interesting words, especially relating to flora, which are relevant to the historical development of the lexicon of the Suriname creoles. Some of these are listed below.

\begin{tabular}{|c|c|c|}
\hline $\begin{array}{l}\text { Merian 1699-1701 } \\
\text { patates/batates }\end{array}$ & $\begin{array}{l}\text { Modern Sranan } \\
\text { patata }\end{array}$ & $\begin{array}{l}\text { Meaning } \\
\text { potato }\end{array}$ \\
\hline Annena $\beta$ & nanasi & pine-apple \\
\hline bacove & $b a k b a$ & banana \\
\hline babbande/bananne & bana & $\begin{array}{l}\text { cooking banana } \\
\text { (plantain) }\end{array}$ \\
\hline kasafa & kasaba & cassava \\
\hline bumbelmus/bambelmu $\beta$ & pompelmusu & grapefruit \\
\hline Cattun & katun & cotton \\
\hline Markes Jaas/Marquisjaas/Markessaas & markusa & passion flower \\
\hline blantagy & pranasi & plantation \\
\hline Banillie & baniri & vanilla \\
\hline Suer Sack/Suersack/Zürzack/ZuurZak & sunsaka & soursop \\
\hline
\end{tabular}

Some of these words, such as Annena $\beta$ and Suersack, should perhaps be seen as late-17th-century Dutch rather than early SPC, just as the words in Warren (1667) may be viewed as 17th-century English rather than SPC. Other words, however, such as blantagy and Banillie, show clear signs of the restructuring that led to their modern forms: pranasi and baniri. Although proper names have been excluded from this list, it may be interesting to note that Merian refers to Paramaribo as barimaribo or baliminiribo. ${ }^{2}$ Although the $\mathrm{p} \sim \mathrm{b}$ alternation in words such as batates (cf. Eng. potato), bumbelmus (cf. Du. pompelmoes), and blantagy (cf. Eng. plantation; Du. plantage) may be a relic of Merian's original Frankfurt dialect (Norval Smith, pers. comm.), it is also - though rarely - found in some other sources.

2. In the latter case, perhaps the plantation Palmeniribo rather than Paramaribo is meant (cf. the form Palmeribo used for the latter in a court record from 1707 (Van den Berg 2000: 98). 
Court records 1702-1725.

(5) a. W.: Mingo, joù no man

(CR 1.05.04.01, no 234, f272 vo; 1707)

b. M.: Mi man

c. W.: joù go dan

Morpheme gloss:

(6) a'. W.: Mingo, you NEG man

b'. M.: I man

$c^{\prime}$. W.: you go then

Free translation:

(7) a". W.: 'Mingo, you don't have the nerve' (i.e. to complain to the manager)

b". M.: 'I do'

c". W.: 'Then, go'

The other two sentences from 1707 are the following:

(8) nù wanti dat

(CR 1.05.04.01, no 234, f268 vo; 1707)

now want that

'I want it now'

(9) jou no meester ovoor mi

(CR 1.05.04.01, no 234, f268 vo ; 1707) you NEG master for me

'you are not my master'

The presence of early Sranan material in Court Records was first noticed by the historian Ruud Beeldsnijder (pers. comm.), who drew my attention to the following sentences:

(10) Mi no sabi hoe ple alle dem santi kom oppó. (PCZ no 798, I not know which place all the thing come from 5 May 1745) 'I don't know where all those things come from's

(11) Jae, Mie pothi hem na wan Sij caba. Yes I put him on one side already

(PCZ no 798, 13 May 1745)

'Yes, I put him on one side already'

(12) Santi dissi gro na boom tapo.

Things that grow on tree top

'Things that grow on trees'

3. All translations are mine unless indicated otherwise. 
(13) Mie Miesje kiele mie. (Minutes Hof van Politie no 411, 25 February 1747) My mistress kill me

'My mistress will kill me'

Even if the transcription may not always be $100 \%$ verbatim, there are clear indications that the data at least reflect natural speech as used by Blacks. For example, the word kaba rather than arede is used consistently to express the notion of 'already', as in (14):

\section{(14) mi doe langa hem caba \\ I do with him already \\ 'I'm finished with him already'}

(CR 1.05.10.02, 798, f-vo; 1745)

In his Sranan dictionary, Schumann (1783:50) comments on the use of arede with the remark da Bakkratongo 'that is "White Sranan"'; he then proceeds by adding: Ningre takki " $k a b a$ " 'Blacks say kaba'. Another indication of the authenticity of these records may be found in the repeated use of an insult word such as you mama pima 'your mama's cunt'. Finally, the occasional use of epenthetic vowels in words such as bakara 'white person' and masara 'master' - next to bakra and masra - may also be indicative of the authenticity of the language, since this type of epenthesis appears to have been typical of Blacks, especially plantation slaves (cf. Focke 1855: xii).

Overt marking of Tense (ben), Mood (zal, sal, sa, saa, zoe) and Aspect (de) does not occur in these records until 1745, while the first combination of TMA markers does not turn up until 1757. This is in agreement with Baker's (1995) finding that combinations of TMA particles appear relatively late in the development of creoles. The earliest combination of markers involves the - quite remarkable - sequence sa ben, which occurs in a sentence which is found in three slightly different versions (but invariably with the sa ben ordering):

(15) evie mi massra ben sendie mie go na Tampatie dan mie sa if my master PAST send me go to Tempati then I FUT
ben soria dem backara
PAST show the whites
(CR $1.05 .10 .02,942$, f $\left.260 \mathrm{v}^{\circ} ; 1757\right)$
'If my master had sent me to Tempati, then I would have shown the Whites (something)'

The presence of past tense ben in the main clause and the combination of past and future in the subordinate clause suggest that this sentence should be interpreted as a past counterfactual. However, the ordering of the past and future particles found here - sa ben rather than ben $s a$ - is at variance with the ordering ben sa which is the normal one in both early and contemporary Sranan. 
The absence of an overt copula in sentences (5a),(5b) and (9) above, all of which date from 1707 , is consistent with the fact that zero-copulas were not exceptional in early 18th-century Sranan nominal predicates (see Section 3.2 and Chapter 6). In both of other two nominal predicates from the Court Records, dating from 1761 and 1762 , the copula $d a$ is used:
(16) mi da bossiman
I am bushnegro
'I am a bushnegro'
(17) wie da ningre voor joe
we are slaves for you
'we are your slaves'

(CR 1.05.04.06, 313, f $\left.318 \mathrm{v}^{\circ} ; 1761\right)$

$\left(\mathrm{CR} 1.05 .10 .02,806, \mathrm{f}-\mathrm{v}^{\circ} ; 1762\right)$

The use of $d a$ in sentences (16) and (17) is in accordance with what we know about the development of the Sranan copula from other early sources, in particular Van Dyk (ca 1765), in which $d a$ and $\varnothing$ are the copulas used in nominal predicates. This lends further support to the idea that the split of the equative copula into two different forms - $d a$ for the expression of identity and de for the expression of attribution -, attested for the first time in Schumann (1783), does not go back earlier than the 1770s ( $c f$. Arends 1986, 1989).

The same copula form - $d a$ - is found in a presentative function in two sentences from 1759, one of which is given below:

(18) da him

(CR 1.05.10.02, 947, f-v ; 1759)

it-is him

'it's him'

Again, this is in agreement with the picture that emerges from other sources, which shows that $d a$ was used in this context in the 1760s. The presentative use of $d a$ in early stages as in (17) also lends further support to the claim that the development of $d a$ - originally a pronoun meaning 'that' - into a copula originated in presentative contexts such as this.

As far as adjectival predicates are concerned, only one example occurs in the court records. In accordance with the consistent treatment of predicative adjectives as verbs that is familiar from other sources, no overt copula is used:

(19) Argus, mie dede Argus I dead 'Argus, I'm going to die'

The reliability of this adjectival predicate pattern is confirmed by the occurrence of an almost identical sentence in Stedman's (1790) Narrative, which similarly does not contain an overt copula: 
(20) Massera, we Dede

(Stedman 1790:434)

master we dead

'master, we're going to die'

Finally, let us look at locative constructions. In all five cases found in the Court Records an overt copula - de/dee/die - is present, which, again, is in line with the more general picture of the development of the copula presented in Arends (1989):

(21) hoe sambre dee

(CR 1.05.10.02, 798, f-v ; 1745)

who is-there

'who's there?'

(22)

voevoereman de na hosse dappe
thief is LOC house top
'there's a thief on the roof'

$\left(\mathrm{CR} 1.05 .10 .02,808, \mathrm{f}-\mathrm{v}^{\circ} ; 1763\right)$

'there's a thief on the roof'

Further discussion of this and other material from the Court Records will be presented in Van den Berg (to appear).

\subsubsection{Herlein (1718) and Nepveu $(1770)^{4}$}

Apart from the five court record sentences from 1707 presented above, the Herlein fragment (1718:212-3), consisting of two dialogues plus some isolated words and phrases, contains the oldest known sentences in any of the Suriname creoles. Because of their special interest, we will discuss them in some detail here. Although the Herlein fragment is accessible in a number of places (e.g. Arends \& Perl 1995, where it is discussed in much more detail, along with Nepveu's corrections of it), it is reproduced in this book (see Chapter 6) because of its key importance for a proper understanding of creole formation in Suriname. Apart from the Sranan specimen, Herlein's book also contains some isolated Sranan words scattered through the text (see Van Donselaar 1996).

The author of the work containing the Sranan specimen, who is indicated only as 'J.D. Hl.' in the book itself, may - with a reasonable degree of certainty be identified as J.D. Herlein (Lichtveld 1966:28). In the Dedication of his book (p. $2 \mathrm{v}^{0}$ ), the author says that he was in Suriname 'during the administration of Governor Van der Veen'. Since Van der Veen’s governorship lasted from 1695 to 1707 , we assume Herlein was in the colony for some time during this period. On p. $4 \mathrm{r}^{0}$ Herlein says that, while he partly investigated and observed the customs he describes himself, he is also indebted to one Cornelis Pietersen Ederssen, a merchant in Paramaribo, and to one Adriaan van Zwol, a plantation manager. As

4. This section is largely based on Arends (1995c). 
to the Sranan represented in the fragment, there is reason to assume it represents Sranan as observed by a European (see below). This does not mean, however, that it should be discarded as unreliable; it only means we have to be careful in drawing conclusions from it.

The Sranan fragment is introduced by the author as follows:'Tot vermaak van de Lezer zullen we, tot besluit van dit Hooft-Deel, hier iets ter nederstellen aangaande de Spraak der Swarten, zo ze van haar op de Zurinaamsche Kust gesproken werd, dewijl haar eigen Moeder-taal niet te verstaan is. Maar om dat d'Engelschen deze Colonie lange tijd hebben bezeten, (gelijk voren gewag gemaakt is,) zo hebben ze dier zelver Spraak meest geleerd; dog om dat'er Negerze woorden onder lopen, zo werd het Neger-Engels genoemt; gelijk blijkt uit dit na-volgende.' (Herlein 1718:121-123).'To conclude this chapter and for the entertainment of the readers, we shall present something about the speech of the blacks, as it is spoken by them on the Suriname coast, ${ }^{5}$ because their own native language is incomprehensible. However, since the English owned this colony for a long time (as was mentioned), they have mostly learnt their language; but because there are Negro words in it, it is called Negro English; which appears from the following.'

Ironically, not a single 'Negro' - in the sense of African - word (with one exception perhaps: monbie) appears in the entire fragment.

The linguistically most interesting remark made by Herlein concerns the slaves' acquisition of English. His phrasing - 'they have learned their speech mostly' - seems to imply that the Blacks had some - perhaps even considerable - knowledge of English. A similar expression is used in a remark by one Jan Reeps, a shipwrecked sailor who ended up in Suriname and stayed in Paramaribo (with Governor Van Scharphuizen) for more than six months (July 1693-February 1694): 'The English have made a colony here and that language is still spoken mostly by the slaves' ('De Engelse hebben hier een colonie gemaeckt en wort die tael daer nog meest bij de slaven gesproken'; Van Alphen 1963:307). Although we have to be careful in interpreting these statements, both remarks seem to imply that, in the perception of these observers, Blacks in Suriname around the turn of the 18th century spoke some form of English. But as the Herlein fragment itself clearly shows, early 18th-century Sranan cannot easily be equated with any variety of Early Modern English, if only because of its pidgin-like features (see Section 3.1.5. Apparently, for these Dutch-speaking observers the language they heard the slaves speak was similar enough to whatever English they knew for them to state that the slaves spoke English. These statements indicate that the English element in Sranan

5. The phrase 'Suriname Coast' refers to the part of Suriname where plantations were located. 
was clearly recognized by these lay observers. This lends some support to the claim that the formation of Sranan was still in its early stages around 1700.

Of those who have commented on the Herlein fragment, both Schuchardt and Rens have expressed as their opinion that Herlein's Sranan is remarkably close to Modern Sranan. According to Schuchardt, apart from some English-derived words which have become obsolete, 'the similarity with the modern variety is very close, almost peculiar' ('Die Übereinstimmung der Sprache mit der heutigen ist sehr gross, fast befremdend'; Schuchardt 1914: xix). Rens, while noting a number of - particularly lexical - differences from Modern Sranan, thought that 'the most striking feature of the fragment... is the structure of its sentences. In this respect the NE [Negro English, JA] of 1700 is not different from the NE of our days' (Rens 1953:54). As we will show below, these judgments rest upon a rather superficial analysis of the fragment.

Voorhoeve \& Lichtveld, while not explicitly expressing an opinion on the issue of similarity, do seem to be aware that Early Sranan and Modern Sranan cannot be simply equated. This appears from the fact that their Modern Sranan equivalents of Herlein's sentences contain numerous structural as well as lexical differences when compared to the original. Apart from lexical and structural differences, they also point at a pragmatic difference, namely the fact that the author of the fragment was 'not aware of the subtle ways in which Surinamese Creoles show respect in their linguistic behavior' (Voorhoeve \& Lichtveld 1975:279). This appears from the fact that the dialogues do not obey the rules for the expression of honorifics, such as the avoidance of the 'second and third person singular pronouns to refer to people of higher social position or people with whom one is not on intimate terms'. That such honorific rules did indeed exist in 18th-century Sranan, appears from Schumann's 1783 dictionary: ${ }^{6}$

effi Ningre wanni begi Ningre tranga va tru, dem takki: tangitangi, mi hatti-lobbi, mi bossi ju futu, du mi da plessiri! effi Ningre begi bakkra, dem takki: grangtani vo Massra, effi Massra plìs va gi mi datti!

(Schumann 1783, s.v. begi)

If blacks really request something from another black, they say: tangitangi, mi hatti-lobbi, mi bossi ju futu, du mi da plessiri! ['thank you, thank you, my dear beloved, I kiss your feet, do me that favour!', JA]; if blacks request something from a white, they say: grangtangi vo Massra, effi Massra plîs va gi mi datti!' ['many thanks Master, would you please give me that! JA]

The existence of these politeness rules in 18th-century Sranan also appears clearly from several instances in Van Dyk's (c1765) reading drama.

6. In fact, the remark, which is in Sranan rather than in German, should be ascribed to his informant rather than to Schumann himself. 
While Schuchardt does not touch upon questions regarding the linguistic status of the fragment, such as its reliability and the language variety represented in it., both Rens and Voorhoeve \& Lichtveld do. Rens (1953:53) interprets the use of Dutch-derived words in cases where the English equivalent has remained current up to now as an indication that Herlein's fragment represents the white, probably Dutch, variety of the language. As shown elsewhere (Arends 1989: 123), however, most of the cases adduced by Rens are not necessarily Dutch-derived. To give just one example, the word agterdina 'afternoon' (from Du. achter 'back' and Eng. 'dinner'), considered by Rens to be an intrusion from Dutch (as opposed to the 'correct' bakadina), proves to be a perfectly accepTable 18th-century Sranan word: it occurs both in Van Dyk (c1765:90) - as aitre dinatim - and in Schumann's dictionary (1783: 84) - as àttara dina.

Voorhoeve \& Lichtveld feel that, due to the non-obeyance of the rules for polite usage referred to above, the fragment 'must have been constructed or elicited by a European, presumably the author himself...It gives the impression of a European speaking with total disregard for polite creole usage.' They add, however, that 'it is possible that the author elicited the text from a Creole speaker, but in that case he has put the text consciously or unconsciously in a European mouth. It is highly unlikely that a Creole would have used such forms in everyday language. The lack of good manners should rather be attributed to the European author' (Voorhoeve \& Lichtveld 1975: 279).

Both Rens (1953:54) and Voorhoeve and Lichtveld (1975:283) have noted the presence of quite a number of English-derived words and phrases, which became obsolete later, such as windels 'windows', à reddi 'already', bellewel 'very well', han (t)sum 'pretty', and wil 'will', which have been replaced by fensre, kaba, heri bun/bun fu tru, moy, and wani, respectively. As noted by Voorhoeve and Lichtveld, this may suggest that the fragment represents the language as it was spoken on the 'old' plantations, established by the English along the Commewina River. The idea that Herlein represents an 'English' variety of Sranan is supported by the spelling of some English-derived words, such as the following (in parentheses Nepveu's 1770 spelling is given): draei 'dry' (drei), gaeu 'go' (go), liewy 'live' (libi), love 'love' (lobi), bie laeu 'below' (bilo). In all these cases Herlein's spelling seems consistently closer to English pronunciation than Nepveu's. Some other cases of 'English' spelling of words in Herlein are the following (in parentheses the spelling in Schumann 1783 is given ${ }^{7}$ ): oudy 'hello' (odi), som bady 'person' (somma), kase 'call(s)' (kari). We should keep in mind, however, that an English pronunciation is not the only possible explanation for these features in Herlein's Sranan, since some of the differences between Herlein and Nepveu may have been caused by

7. These words do not occur in Nepveu (1770). 
internal phonological developments that took place in the fifty years separating both texts and that were independent from the fact that the influence of English pronunciation had diminished during this period.

Summarizing, it seems - notwithstanding Herlein's remark that the specimen represents the language of the Blacks - that the variety represented by Herlein is most likely the European - although not heavily Dutch-influenced - variety of Sranan; by the end of the 18th century this variety became known as bakra tongo 'Whites' Sranan'. This means that, although the fragment probably does not represent black speech and should therefore not be taken as representative of 'deep creole', it is perfectly suitable for the purpose of comparison with other texts which also represent bakra tongo, such as many of those discussed in this book. We will have to be very careful, however, not to project any findings with regard to this variety onto the nengre tongo variety, the language spoken by the Blacks.

Continuing now with Nepveu's (1770) manuscript, his Annotations form one long list of corrigenda et addenda to Herlein's (1718) book. As far as the Sranan fragment is concerned, Nepveu not only presents a number of (what he presents as) corrections to Herlein, but he also lists a number of additional words and phrases. While at least four versions of the manuscript are known to exist, the following is based on the fair copy from 1770, which is located at the Municipal Archives in Amsterdam. The entire manuscript is approximately 400 pages long. The Sranan material takes up nine pages, only one of which is taken up by corrections of Herlein, the other eight containing additional Sranan material. Although Nepveu probably knew Sranan quite well, we assume that the variety represented here is bakra tongo, the variety of Sranan spoken by Europeans.

Jan (or Jean) Nepveu (1719-1779), the son of Huguenot parents, came to Suriname at the age of fifteen (Encyclopedie 1977:424). He worked as a public servant, before he became (interim) governor of Suriname in 1768, a post he held until his death in 1779 (Wolbers 1861:826-827). Although he was not a native speaker of Sranan, he probably learned the language at a relatively early age. Since at the time of writing his Annotations he had been living in Suriname for more than thirty years, we may assume that by then he had acquired an adequate competence of the language. ${ }^{8}$ Nepveu's corrections of Herlein plus a selection of the additional Sranan material is repoduced in Chapter 6.

Since the Sranan sources provided by Herlein and by Nepveu are so closely related, we will take them together in our discussion of some of the linguistic features exhibited in these texts. The following (morpho)syntactic categories will be discussed: the article, the copula, serialization, complementation, and question words.

8. His brother Louis, who had a comparable career, knew Sranan quite well, as appears from the Sranan version of the 1762 Saramaka Peace Treaty (see Section 7.1). 
Articles. According to Bruyn (1993b: 10), the question whether an article occurs in 18th-century Sranan 'is often determined by semantic and pragmatic factors other than definiteness, but to some extent the choice between an overt determiner and a bare noun appears to be unpredictable'. This has to do with the history of both the indefinite article wan, which is derived from the numeral wan 'one', and of the definite article $d a$, which is derived from the demonstrative datti 'that'. Traces of these origins - in the form of an emphatic element in wan and a deictic element in $d a-$ are still present in the usage of both words as articles. In other words, rather than to conform to some formal distinction, such as that between specific and nonspecific (Bickerton 1981), or between individuated and nonindividuated (Mufwene 1986b), the use of articles in 18th-century Sranan is, at least partially, determined by the historical origin of the elements used to fulfill the article function, and by the fact that the process of grammaticalization was not yet completed. Further, Bruyn says, 'if there is an article present, its main function is to code indefiniteness or definiteness'. In the light of these observations we will now take a look at the use of overt articles in Herlein and Nepveu. In Herlein the only clear case of an overt article, in this case wan, is in (23): ${ }^{9}$

\section{(23) Kom bosse mie wantem ${ }^{10}$ come kiss me one-time 'Come kiss me then'}

The Dutch translation of wantem, namely reis 'once', suggests that wan in this expression is used as an article, not as a numeral, since in that case we would expect a translation like één reis 'one time'. On the other hand, wantem may be a fixed expression, which affects the status of wan in that its presence or absence may not be determined by any syntactic or semantic principle. The same seems to hold for the reduplicated expression wan tron wan tron lit. 'one time one time' in Nepveu, which is translated as nu en dan, enkelde malen 'now and then, a few times'.

Of the four cases of wan in Nepveu, three occur in the pattern ' $d a$ wan NP', as in (24); the fourth is an isolated NP - wan ollo Paaij 'an old man':

(24) da wan boen soma
that a good person
'he's a fine person'

9. For a discussion of the only other - unclear and possibly corrupted - case of wan in Herlein, namely en in No mie ben ben akase ta entre ples à reddi wen 'No, I have already asked somebody else if I could visit her', see Arends 1995c: 24.

10. For the three texts which are the focus of this section, sources are abbreviated as follows: $\mathrm{H}=$ Herlein 1718, $\mathrm{N}=$ Nepveu 1770, and VD = Van Dyk c1765. 
In (24) the sentence is introduced by $d a$, the deictic pronoun cum introductory copula which later gave rise to the development of the 'true' - linking - copula (Arends 1989:25ff). The usage of the article wan in this case may have been promoted by a wish to avoid the ambiguity that would result if it were absent: $d a$ boen soema could be interpreted as 'the/that good person'. Also, the article may function to signal singularity, since without it, when interpreted as a copular sentence, (24) could be construed as a plural: 'they are good people'.

As to the definite articles, $d a$ (sg.) and dem (pl.), these do not occur in Herlein at all. Although the latter neither occurs in Nepveu, it should be noted that no plural environments occur in Nepveu, as opposed to Herlein. Of the two cases of $d a$ in Nepveu, the one in (25) is a deictic element rather than an article; the example is mentioned here nevertheless, since there are good reasons to believe that the article function of $d a$ has, through a process of grammaticalization, developed out of a deictic function (Arends 1989:28). In (26) da occurs in the fixed phrase da tem, lit. 'the time', which in 18th-century Sranan is regularly used to express the conjunction 'when' ( $c f$. the many examples in Van Dyk):

(25) da tem jou plessie

the time you like

'Whenever you wish'

(26) datem

it=is-time/that-time

'it's time / that time'

In all other cases where $d a$ might be expected from the point of view of Modern Sranan, there is no article present.

As shown by Bruyn (1993b: 10), the absence of the article in 18th-century Sranan is not 'clearly related with either nonspecificity or nonindividuation'. The (non-)occurrence of an article is often determined by semantic and pragmatic factors, such as the fact that a noun may have a unique reference by itself, such as 'the sun', or the referring function may be performed by some other element, such as a modifying phrase or word, e.g. 'the name of your master', or knowledge of the world may imply definiteness, e.g. inalienably possessed nouns, such as body-part words. Other cases where zero-articles are preferred are certain fixed verb-noun combinations, mass nouns, and nouns that are neutral with respect to definiteness and number. As observed by Kramp (1983:38-41) with regard to Schumann's 1783 dictionary, an additional environment that favors zero-articles is when a noun follows the general preposition na. This pattern, which is still active today - albeit with vowel lengthening on the /a/ - can also be observed in both Herlein and Nepveu: in all five cases in Herlein and all nine cases in Nepveu there is no overt article present. Examples are (27) and (28): 
(27) Oe tem wie wil gaeu na Ø Riba? which time we will go $\mathrm{P} \varnothing$ river 'When will we go up the river?'

(28) ahakisi effi missie sa tan na $\varnothing$ Hosso she-asks if madam will be $\mathrm{P} \varnothing$ house 'She asks if you will stay at home'

If we assume that the same process was responsible in the 18th century as today, namely the merging of the preposition $n a$ and the article $d a / n a$ into $n a$, we have to conclude that either the vowel lengthening was not present in the 18th century or it was not recognized by Herlein nor Nepveu.

We will now give some examples for some of the categories distinguished here.

(29) -Unique reference:

$\varnothing$ Zon komotte

$\varnothing$ sun comes-out

'The sun rises'

(30) -Referent determined by modifier:

Oe fasse $\varnothing$ nam vor joe Mastre?

which fashion $\varnothing$ name of your master

'What's your master's name?'

(31) Inalienably possessed noun:

tappoe $\varnothing$ moffo

close $\varnothing$ mouth

'Be quiet'

(32) Fixed verb-noun combination:

ghi Ø pasi

give $\varnothing$ way

'Make some room'

Finally, while the basic parameter in the late-18th-century Sranan article system seems to be (in)definiteness, rather than (non-)specificity or (non-)individuation (Bruyn 1993b), there are some cases in the Herlein/Nepveu sample where the absence of the article seems to signal the nonspecificity or nonindividuation of the noun. According to Bickerton (1981:56), non-specific nouns, including those for which the specificity is unknown or irrelevant, in creoles receive no article. In Mufwene (1986b) it is (non-)individuation rather than (non-)specificity, which is held responsible for the absence or presence of the article: nonindividuated nouns receive no article. Although the categories of (non-)specificity and (non-)individuation are certainly not identical, they are collapsed here so as to include all NPs which belong to either category. Both Herlein and Nepveu 
categorically use zero-articles with NPs, both singular and plural, that are nonspecific and/or non-individuated. Some examples are given below:
(33) Tappe $\varnothing$ windels
close $\varnothing$ windows
'Close the windows'

Note that Nepveu similarly has a zero-article in his correction of (34), in which windels is replaced by fenstre $(<\mathrm{Du}$. venster):
(34) tappe $\varnothing$ fenstre
close $\varnothing$ windows
'Close the windows'

Summarizing, it seems that both Herlein and Nepveu tend to use what might be called a 'minimal' strategy in their use of articles, aimed at maximum reduction of redundancy. This strategy says: only use an article with a noun when it is absolutely necessary, either to determine the referent, its number or (in)definiteness, or to avoid ambiguity, and when this function is not performed by any other means. These other means may be either linguistic, such as in the case of modifiers, or non-linguistic, as in the case of uniquely referring nouns, where knowledge of the world determines reference.

Copulas. Our discussion of the copula is divided according to the type of predicate in which it occurs: presentative, adjectival, nominal, or locative. Looking at the overall Herlein/Nepveu sample and ignoring one or two unclear cases for the moment, we see the following pattern: Herlein has only zero-copulas; Nepveu has $d a$ as an introductory copula, $d e$ and $\varnothing$ as a copula for adjectival predicates, and de/dea for locative 'be'. Unfortunately, nominal predicates - the type which is perhaps most interesting from a diachronic point of view - do not occur in Nepveu, nor do existential and possessive sentences involving 'be'. Although this in itself diminishes the potential use of the Herlein/Nepveu sample for our understanding of the early- and mid-18th-century copula system, the copula still is a good choice for illustrativepurposes because the copula has been extensively studied from a diachronic point of view ( $c f$. Arends 1989). This makes it possible to interpret our findings from Herlein and Nepveu in the context of the overall development.

The label 'presentative' refers to the use of $d a$ as a sentence-introducing element, which could be interpreted either as a copula incorporating its subject - '(it) is' - or as a deictic element followed by a zero-copula - 'that/it (is)'. While ten cases of presentative da occur in Nepveu, as in (35) below, there are none in Herlein. This does not mean it did not exist in Herlein's time: there are simply no environments where presentative da could possibly occur in the Herlein fragment. 
(35) da wan biggi leij

that(=is) a big lie

'that's a big lie'

All adjectival predicates in Herlein have a zero-copula, ${ }^{11}$ even in cases where an overt copula is required in Modern Sranan, e.g. when the adjective is preceded by a modifier, such as belle 'very' or grande 'very' (or their modern equivalent:

$$
\begin{aligned}
& \text { My } \varnothing \text { belle wel } \\
& \text { I } \varnothing \text { very good } \\
& \text { 'I'm very well' }
\end{aligned}
$$

With one exception (to be discussed below), Nepveu has zero-copulas too, also when a past tense is expressed. This means that Nepveu's system of adjectival predication is identical to that of Modern Sranan.
aben
$\varnothing$ hansom
he/she-TNS $\varnothing$ beautiful
'he/she was pretty'

Predicates expressing a physical or mental state, which have zero-copulas in Herlein, are explicitly corrected by Nepveu, as in:

$$
\begin{aligned}
& \text { mi de boen } \\
& \text { I am good } \\
& \text { 'I am well' }
\end{aligned}
$$

Unfortunately, there is only a single case of a nominal predicate in the entire Herlein/Nepveu sample. In this sentence (41), which is from Herlein, no overt copula is used. ${ }^{12}$ The fact that Herlein's sentence is not corrected by Nepveu suggests that also in mid-18th-century Sranan it was not uncommon to have a zero-copulas in this context. This is in line with the earlier finding that zero-copula's in nominal predicates are not unusual in late 18th-century Sranan (Arends 1989:60):

11. The wording used here does not imply any preference with regard to the question whether predicative adjectives are verbs rather than adjectives ( $c f$. Sebba 1986; Seuren 1986). In other words, the terms 'copula' and 'zero-copula' refer simply to the presence and absence, respectively, of the element $d e$ in adjectival predicates.

12. Schuchardt (1914: xix), who excludes the possibility that som bady is from E. 'somebody', does recognize a copula here: interpreting $b a$ as 'brother' and $d y$ as $d e$, he analyzes the sentence as oe som ba de Mastre vor joe?, 'who, brother, is your master?' However, since it is clear that sma 'person' developed historically from 'somebody' (and (o) sma 'who' from 'which somebody'), this interpretation has to be rejected. Cf. also McWhorter (1997: 107) who also sees a copula in $d y$. 
'Who's your master?'

While no existential or possessive sentences occur in the Herlein/Nepveu sample, we find a number of locative sentences in Nepveu, all of them involving the locative verb de/dea. The form dea for de, which was demonstrated elsewhere (Arends 1989:37-38) to be a fusion of de hija 'be here', is also found in some other 18th-century sources, such as Weygandt (1798:94). ${ }^{13}$

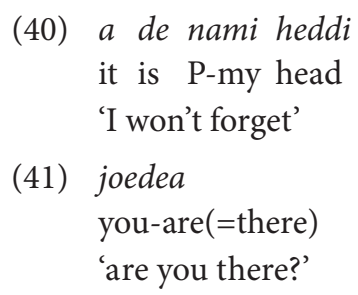

Summarizing, the copula system in Herlein, like his article system, can be described as 'minimalist', aimed at maximum reduction of redundancy. Although this may be a consequence of the fact that, at least to to some extent, Sranan was still a pidgin in the early 18th century, (see below; $c f$. also Arends 1989: 122ff), there are at least two other possibilities. First, it may be a symptom of the foreigner talk character of the English that was used by the Europeans in the early days ( $c f$. Ferguson 1971), or it may be a feature of the interlanguage variety of English, that was used by the blacks in the early days when the ethnic composition of the population still allowed some degree of successful second language acquisition. Of course, all three factors may have played their role.

Serialization. There are no clear cases of serial verb constructions (SVCs) in Herlein and the few unclear cases which could tentatively be interpreted as such all present too many difficulties to be of any real significance (cf. Arends 1995c:3637). In Nepveu, however, we do find a few instances of SVCs. Apart from the causative SVC in (42), the only other cases of SVC's in Nepveu are the directional in (43) and the completive in (44):

(42) no mi sendi hakisi, na tara plessi a redi

'No, I already had someone ask at someone else's place'

13. Note that, while Nepveu glosses adverbial dea as 'there', it is glossed as 'here' by Schumann (1783 s.v.dea); Nepveu's equivalent for 'here' is hia(so). For further details of the development of locative adverbs and verbs in Sranan, $c f$. Arends (1989:33-39). 


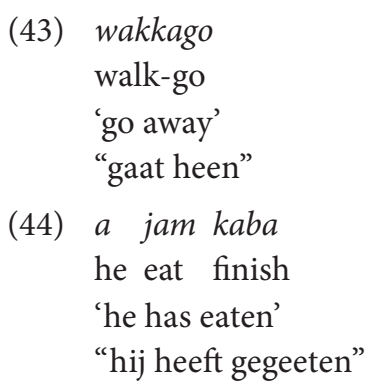

Interestingly, the $\mathrm{V}+g o$ and $\mathrm{V}+k a b a$ SVCs are among the five types of serialization that occur in Van Dyk (see below).

Complementation. Although $f u$ - the element used as a complementizer in later stages of Sranan - does occur as a preposition in both Herlein and Nepveu, it is never used as a complementizer in these sources. All of the cases where a complementizer could possibly have been used involve the matrix verbs wani 'want to' and sabi 'know how to'. In view of the fact that the use of a complementizer with these matrix verbs is optional in later stages (Focke 1855; Schumann 1783), the absence of $f u$ in Herlein and Nepveu is not surprising ( $c f$. Plag 1993).

Question words. Compared to the relatively undeveloped state of the features discussed until now, the development of the question word system in Herlein is surprisingly advanced. Apart from the word for 'why', all the question words that are found in Herlein have the bi-morphemic WH-Noun pattern (e.g. 'which place' for 'where') that is familiar from many creoles. Table 5.1 below lists all the question words that occur in Herlein and in Nepveu:

Table 5.1 Question words in Herlein 1718 and Nepveu 1770

\begin{tabular}{lll}
\hline & Herlein $\mathbf{1 7 1 8}$ & Nepveu $\mathbf{1 7 7 0}$ \\
\hline 'how' & oe fasse, oe fasje & hoefasi, hoe fasi, ou fasi, hoefisi \\
'where' & oe plasje, oe plesse & hoe plesi, hoe sey \\
'when' & oe tem & hoe tem, oe tem \\
'who' & oe som bady & - \\
'why' & ver wate & - \\
'how many' & - & oe meni \\
\hline
\end{tabular}

A few remarks may be in order with regard to this table. First, the absence of some question words, such as the equivalents of 'what', 'which', and 'how' (as a degree adverb) is best interpreted as a consequence of the small size of these text samples. Second, the occurrence of ver wate in Herlein is the only one ever found in a Sranan text; other 18th-century sources, such as Van Dyk, have variants of 
fu san ede 'for what reason' or (oe) fa 'what way', 'how' for 'why'. Third, oemeni in Nepveu has the literal meaning 'how many', i.e. it is not used as a degree adverb in combination with an adjective, as it is in some later sources, such as Schumann (1783). Fourth, only full forms occur: there are no cases where either the question particle is absent or the noun is phonetically reduced, or both. The latter type does occur in late-18th-century Sranan, e.g. in Schumann 1783, who has $h u f a$ for $h u$ fasi 'how', hu peh for hu plesi 'where', sanni for hu sanni 'what', and somma for hu somma 'who' (Bruyn 1993a).

\subsubsection{Van Dyk (c1765)}

Pieter van Dyk's language primer, containing word lists, some idiom, twelve dialogues and a 65-page 'reading drama' about life on a coffee plantation, is the oldest Sranan text of any substance (112 pages), predating Schumann by at least more than a decade. Although traditionally Magens' 1770 description of Negerhollands is held to be 'the first published grammar of any creole language' (Holm 1988: 18), it is predated by at least one year by Van Dyk's. While the book itself is undated, we know it must have been published in or before 1769 , since in that year it was noticed in a journal entitled Nieuwe Vaderlandsche Letter-Oefeningen (Van TrierGuicherit 1991:33). ${ }^{14}$ It may be interesting to know that Van Dyk's booklet was known to Stedman, who refers to '...this mixt speech/in Which I have even Seen a Printed Grammar' (Stedman 1790, in Price \& Price 1988: 515-16).

With regard to the author, Pieter van Dyk, very little is known. Van TrierGuicherit (1991:33), who has done archival research in order to obtain biographical information on Van Dyk, has found that in the 1747-1765 period at least three Pieters van Dyk lived in Suriname, but she adds that the information is too scant to be able to determine whether one of these is the author of the book. She also adds that the name may be a pseudonym. On the title page of the book itself it is said that the work was 'composed and published after many years of experience', which suggests that the author lived in the colony for a considerable number of years. If this is true, it would enhance the linguistic value of the text. Lichtveld and Voorhoeve (1980:243), based on the fact that the white overseer in the drama is depicted with much sympathy as a noble person, wonder whether Van Dyk may himself have worked as a blanke officier 'white overseer' on a plantation in

14. Note that this is twenty years earlier than Schuchardt's (1914:xxii) provisional post-1778 dating. 
Suriname. In view of the many historically correct sociocultural ${ }^{15}$ details in the text this could well be true, something which would enhance considerably the overall reliablity ${ }^{16}$ of the book as a source of early Sranan.

In addition to bibliological and historical evidence, some linguistic evidence has been put forward in order to locate Van Dyk chronologically vis-à-vis other 18th-century sources, such as Nepveu (1770) and Schumann (1783). Smith (1982: 100), discussing the development of nasal-stop clusters - as in wanti wandi 'want' -, has suggested that Van Dyk should be dated after Nepveu. This is based on the fact that Herlein contains only the form with /nt/ - wantje, wanto -, Nepveu both forms with /nt/ and with /nd/ - wanti, wandi -, and Van Dyk only the form with $/ \mathrm{nd} /{ }^{17}$ - wandi, wande. To this may be added that later sources, such as Schumann (1783) and Weygandt (1798), have a simple nasal instead of a nasal-stop cluster - wani or spelling variants thereof -, which suggests that Van Dyk is prior to Schumann 1783. It should be noted, however, that differences between sources may be due to dialectal variation as well. It has been suggested by Schuchardt (1914), for example, that Van Dyk represented the more conservative plantation language, while Weygandt reflected the less archaic city variety. ${ }^{18}$

15. Compare e.g. the rather detailed descriptions of a pre 'play', i.e. a slaves' party, on pages 106-9 and of contemporary funeral rituals on pages 111-2. Compare also scattered references to plantation customs, such as certain physical cruelties as the Spaansze Bok (p. 50), the custom to name a new born horse after the slave who first informs the owner of its birth (p. 55), the typically Afro-American way of committing suicide by swallowing the tongue (p. 75), precise indications of the amount of work which is reasonable to demand of a slave (p. 59,64), remarks concerning the specific character traits of slaves of certain tribal origin (p. 69), and rather detailed remarks concerning climate conditions (p. 80). The accuracy of these sociocultural observations adds to the overall, and thus to the linguistic, reliability of the work.

16. Van Dyk's book is considerd unreliable by Kramp (1983:6-7), because of its 'errors' and inconsistent spelling. It is certainly true that the spelling is inconsistent, but the question is whether that makes the text unreliable. Knowing that even the spelling of the author's native language - Dutch was not consistent, let alone standardized, at the time, we may cast some serious doubt on this assertion. As to the 'errors' contained in this text, these are unfortunately not illustrated by Kramp. Voorhoeve \& Donicie (1963:31) also doubt the reliability of the book, interpreting the archaic character of the language as a result of 'Netherlandicization' and attributing it to the imperfect competence of a city dweller. I believe these judgments are the result of a superficial examination of the text, treating forms that deviate from the standard variety as aberrant. It is one of the purposes of this introduction to show that only a thorough examination and comparison of this book with other early texts can tell us something about its value as a source for early 18 th-century Sranan.

17. Apart from wandi, Van Dyk also has the variant wan, which, being a monosyllabic word, is 'subject to other honological factors' (Smith 1982:99).

18. As we will see later, Donicie’s (1951: 158; $c f$. also Voorhoeve \& Donicie 1963:31) diametrically opposed claim that Van Dyk represents urban Sranan, based on the frequent use of reduced epithetic vowels (as in smoke instead of smoko 'smoke'), is not viable. 
Quite surprisingly, none of these authors mentions the possibility that the differences between Van Dyk and later 18th-century sources could be related to normal diachronic phonological developments. A cursory glance at the development of paragoge in 18th-century Sranan suggests that the distribution of paragogic vowels in Van Dyk fits perfectly in the pattern of change from only reduced vowels in Herlein (1718) via a mixed pattern in Nepveu (1770) to largely full vowels in Schumann (1783). In view of the brief time-interval between Van Dyk (c1765) and Schumann (1783), the most likely explanation for the relatively big difference between the two is that the former, as claimed by Schuchardt, represents the more conservative variety of the language, as it was spoken on distant plantations.

As to the aim and contents of Van Dyk's book, according to the subtitle and the 'Dedication', the book is aimed at merchants doing business with the colony, as well as at plantation owners, directors (owners' representatives at the plantations), carpenters, blacksmiths and others, in order to learn to understand the slaves and be understood by them. The book has a moral goal as well, which is to teach the reader how to become beloved and respected and not to commit inhumane cruelties. But here - something not unusual in Dutch society, especially in those days - merchant and minister walk hand in hand, as appears from the remark immediately following, that such cruelties can only turn good slaves into bad ones, which is to the disadvantage of 'all interested parties'.

The book contains 112 pages, including the title page and the dedication. The actual text consists of a fifteen-page vocabulary (15 pages), containing not only isolated words, but short phrases and some sentences as well, a three-page list of Gemeene Spreekwyzen 'Common Idiom', 24 pages of t'Zaamenspraaken 'Dialogues', and a 66-page 'reading drama' - a play meant to be read rather than performed. The drama is called Het leeven en bedryf van een Surinaamsze directeur, met de slaaven, op een koffi-plantagie 'The life and business of a Suriname plantation manager with his slaves on a coffee plantation'. The book is a language primer, rather than a grammar in the strict sense of the word: it does not give any rules, paradigms and so on; its emphasis is on providing useful words and phrases and on initiating the novice to the socio-cultural context of plantation society. Notwithstanding that, its value as a source of information on early Sranan, as we will see below, cannot easily be overestimated.

\subsubsection{Comparing Herlein, Nepveu, and Van Dyk}

\subsubsection{A second look at Herlein's Sranan}

Before going on to discuss Van Dyk's text, there is one other aspect of Herlein's text that merits some discussion. Although it would be rash to say that Herlein's Sranan represents a pidgin stage in the development of Sranan, there are some features 
in the fragment that could certainly be interpreted that way. At the same time, however, it should be recognized that the distinction between creole and pidgin is not as clear-cut as was once thought. In addition to that - and this is something that is often overlooked - we only have a very limited knowledge of which features are typical for pidgin languages. Nevertheless, we observed that Herlein's Sranan exhibits several features - the absence of copulas, TMA markers, articles, and serial verb constructions - that suggest that at the turn of the 18th-century Sranan still showed several traces of what may have been a pidgin past.

To begin with the copula, in all eight cases of a finite predicative adjective, Herlein does not have an overt copula, including in positions where this would be required in later stages of Sranan. Therefore, it is no coincidence that in some of these cases in Nepveu's corrections the copula de is added, as in the following example:

(45) Oe fasje jou tem? My bon

(Herlein 1718:280)

what fashion you are? I 0 good

'How are you? I'm fine'

(46) Oe fasi jou tan? Mi de boen

What fashion you are? I am good

(Nepveu 1765:280)

'How are you? I'm fine'

The use of a zero copula by Herlein agrees with Ferguson's observation (1971: 146147) that in simplified versions - such as pidgins - of languages that have an overt copula - such as English - this copula is often omitted.

Of the modern TMA particles ben (Tense), sa (Modality), go (Tense), and de (Aspect), only the first occurs in the Herlein fragment. There is only one attestation of it, in an obscure double form - ben ben - in what is an obscure passageanyway. If we leave this doubtful case out of consideration, there is not a single instance of TMA marking to be found in the entire fragment. The expression of future tense is either left implicit - as in (47) - or it is expressed by wil - as in (49). Only the former of these is corrected into $s a$ by Nepveu - as in (48):

(47) Akesi of joe tan an house?

(Herlein 1718:281)

he-asks if you stay LOC house

'She asks if you will stay at home'

(48) Ahakisi offi missie sa tan na Hosso

(Nepveu 1765:281) she-asks if Mrs. TNS stay LOC house

'She asks if you will stay at home'

(49) Oe tem wie wil gaeu na Riba?

(Herlein 1718:281)

what time we TNS go LOC river

"When shall we go to the river?" 
Although the aspect particle $(d) e$ is also absent from the fragment, it should be noted that there is only one sentence where it could have occurred (it is not corrected by Nepveu):

(50) Oe plesse jo liewy?

(Herlein 1718:281) what place you live 'Where do you live?'

On the basis of these limited data, it seems fair to conclude that in Herlein's days Sranan did not yet have a fully developed TMA system.

Another feature that is reminiscent of what is often found in pidgins is the absence of articles. There is not one article present in the entire fragment, while there are at least two cases where it would be obligatory in modern Sranan:

(51) Jo wantje smoke Pipe Tobakke?

(Herlein 1718:280)

you want smoke pipe tobacco

'Do you want to smoke a pipe?'

(52) Oe sombady Mastre vor joe?

(Herlein 171:281)

what person master of/for you

'Who is your master?'

Finally, there are two cases where Herlein does not use a serial construction - a feature that is not frequently found in pidgins - where this would be used in Modern Sranan. In one of these cases a serial construction is provided by way of correction by Nepveu: Herlein's use of the single verb akase 'ask' is changed by Nepveu into the serial sendi hakisi lit. 'send ask', i.e. 'have (somebody) ask'. Although the second case is not corrected by Nepveu, it certainly would be cast in the form of a serial construction in modern Sranan:

(53) Mie Misisi take joe oudy

(Herlein 1718:280)

My Mrs. says you hello

'My mistress sends you her greetings'

(54) Mi misi taygi ${ }^{19} \quad y u$ odi

My Mrs. sends say-give you hello

(Modern Sranan)

'My mistress sends you her greetings'

In spite of the presence of these pidgin-like features, it should not be forgotten that the Herlein fragment also contains several creole characteristics, such as the use of bimorphemic question words like oe fasse 'what fashion, how', oe plesse 'what place, where', and oe tem 'what time, when'. The most reasonable interpretation of

19. Note: taygi<taki gi lit 'say give, say to (someone)'. 
the facts, therefore, seems to be that Sranan around the turn of the 18th century was in transition from a pre-creole (pidgin?) to a creole stage.

\subsubsection{Van Dyk}

The following morphosyntactic categories found in Van Dyk's Sranan will be analyzed in this section: periphrastic constructions (circumlocutions), question words, articles, the copula, clefting, the comparative, and serial verbs. For all these categories the language represented in Van Dyk is compared both with Herlein and Nepveu and with some of the other 18th-century sources, such as Schumann 1783. Occasionally, Stedman $1790^{20}$ and Weygandt $1798^{21}$ will be referred to as well. Sometimes it is useful to take later stages of the language, as represented in Focke 1855, Wullschlägel 1856 and the Woordenlijst (Anon. 1980), into account too.

In most of these aspects, Van Dyk's booklet represents a variety of Sranan that on comparative grounds may be characterized as mid-18th-century Sranan, a variety intermediate between the early and late 18th-century varieties represented by Herlein and Schumann, respectively. Although this is not surprising in view of the dating of the book, there are several indications that Van Dyk represents a relatively early stage of Sranan in a deeper sense as well. In at least some respects, such as the use of periphrastic construction as opposed to lexicalised expressions in later sources, Van Dyk's language seems to be only partly creolized, thus constituting an intermediate developmental stage between the somewhat pidgin-like variety of Herlein and the more fully creolized variety of Schumann.

Periphrastic constructions. On pages 10, 11 and 16 of Van Dyk's book a number of references to persons (mostly in terms of their professional occupation) are given, most of which are not designated by simple or complex nouns, but by circumlocutions, as in (55):

$$
\begin{aligned}
& \text { wan zomma disi nay klossi } \\
& \text { a person who sews clothes } \\
& \text { 'tailor' }
\end{aligned}
$$

20. For Stedman's Sranan material the primary source is the edition by Price \& Price 1988, which is based on the original 1790 manuscript. For a more elaborate discussion of Stedman's Sranan, see Arends (1995d).

21. Since parts of Weygandt 1798 are plagiarized, though in not completely identical form, from Van Dyk (as was first noticed by Schuchardt 1914:XXII), it could be clarifying to make a detailed, point-by-point comparison of both works. (A preliminary study along these lines was made by Del Negro 1993.) Establishing the exact differences between identical structures in both sources may yield detailed insights into the development of Sranan in the second half of the 18th century. 
This type of circumlocution, not necessarily restricted to the names of professions, is typical for pidgins, not for creoles, as appears e.g. from Mühlhäusler (1979: 232), who gives examples like the following from Tok Pisin (from the pre-creolization stage):

(56) man bilong kamda

(Mühlhäusler 1979:233)

man belong carpenter

'carpenter'

The great majority (15/17) of the cases where Van Dyk uses a circumlocution are expressed by lexicalisations in Schumann (1783). The first of the two cases where Schumann optionally uses a circumlocution is 'blind man', which is paraphrased as anno habbe hay 'he/she does not have eyes' by Van Dyk (p. 11), and alternatively as blindeman 'blind man' or wan somma nanga hai tappa 'somebody with eyes closed' by Schumann (p. 64). The second case is da homan habi bile (Van Dyk, p. 10) 'the woman has belly', 'a pregnant woman', which is paraphrased as uman nanga belle 'woman with belly' by Schumann (p. 59). ${ }^{22}$

All the other cases of circumlocution in Van Dyk are expressed by nouns both in Schumann and Wullschlägel. Most of the circumlocutions in Van Dyk have the form of an NP containing a relative clause, either with - as in (55) - or without -as in (57) - overt relativizer:

(57) kalebassi no broke jeti calebash not broken yet

(VD: 16)

'virgin'

"Een Maagd"

The concept of 'virgin' is expressed as njuwendje/nju-nju-wendje 23 'young girl', 'very young girl' by Schumann (p. 300), and as njoe-wendje 'young girl' by Wullschlägel (p. 136).

The equivalents in the other sources are skrifiman 'write man' (Schumann, p. 249; Wullschlägel, p. 51) and klerki 'clerk' (Wullschlägel, ib.). Generally speaking,

22. It seems significant that both cases of periphrasis in Schumann do not have the form of a main sentence nor of an NP containing a relative clause, which is the 'canonical' form for circumlocutions in Melanesian Pidgin (Mühlhäusler 1979), but rather of an NP containing a PP. Thus, Schumann, who has phrasal periphrasis, forms an intermediate stage between Van Dyk, who has sentential periphrasis, and Wullschlägel, who has no periphrasis at all in these cases.

23. The difference between both forms appears to be a rather subtle one and refers to what the Moravians seem to have perceived as varying degrees of 'virginness': a njuwendje is a virgin in the technical sense, while a nju-nju-wendje is a girl who has never had anything to do with a man, whatsoever. 
both Schumann and Wullschlägel have a preference for compounding with man 'man' to refer to this type of concept. Cf.skrifiman 'write man' (Schumann, p. 249; Wullschlägel, p. 51). The fact that man is used to refer to females as well as to males (e.g. helpiman lit. 'help-man' for 'midwife', Schumann p. 128) is the result of a grammaticalization process, which made possible the use of man as a gender-neutral agentive suffix.

Apart from these circumlocutions there are five cases where Van Dyk uses a noun, either a simple noun, like dakteren 'doctor' or a compound, like koepa man 'cooper' (lit. 'cooper man'). All of these are also expressed by nouns in Schumann and Wullschlägel. It thus seems that the only productive way of making new nouns to refer to persons, namely by compounding (or suffixing) with man, is used only in a limited number of cases in Van Dyk.

[cf. Braun (2001), Braun \& Plag (2003), Van den Berg (2003)]

Question words. In a comparative study of question words in pidgin and creole languages, Muysken \& Smith (1990: 900) conclude that 'question words in eighteenth century Surinam creoles do not support the gradualist view of creolization'. This conclusion is based on their finding that 'from the early eighteenth century on a full-fledged transparent system [of question words, JA] had emerged in Sranan' (ib.). Although this observation is in agreement with our findings discussed above, it should be noted there are several omissions in Muysken \& Smith's (p. 898) listing of question words in the 18th-century sources they used (Herlein 1718, Van Dyk c1765, Nepveu 1765 and Schumann 1783), especially with regard to Schumann and Van Dyk. In addition to the forms cited, Schumann also contains husortu for adjectival 'which', hudissi for 'who', va husanni heddi (alongside va huheddi) for 'why', and humenni for 'how' as a degree adverb with adjectives. Other omissions include the use of $h u$ for adjectival 'which' in Van Dyk and Schumann, and of $h u$ for 'how' as a degree adverb with adjectives and hoe tem for 'when' in Van Dyk. ${ }^{24}$ In the next table, these additional data are taken into account as well.

If we take these additional data into account, a clear difference emerges between Van Dyk and Schumann: in several cases - 'where', 'who', 'which', 'how' the latter has two or even three alternatives where Van Dyk has only one. The non-occurrence in Van Dyk of these variants, as opposed to their occurrence in Schumann, may be related to the fact that Van Dyk represents an earlier stage in the development of the language, which, although adequate, did not yet have the possibilities for stylistic variation we find in Schumann (cf. Labov 1990).

24. Incidentally, there is also a singulary use of wat zan 'what thing' instead of hoe zan 'which thing' in Van Dyk (p. 21). 
Table 5.2 Question words in 18th-century Sranan

\begin{tabular}{lllll}
\hline & Herlein 1718 & Van Dyk c1765 & Nepveu 1770 & Schumann 1783 \\
\hline o sei 'where' & - & - & + & + \\
(o) sortu 'which' & - & - & - & + \\
odi 'who'/'which' & - & - & - & + \\
omeni 'how' & - & - & - & + \\
o 'which'/'how' & - & + & - & + \\
(fu) san ede 'why' & - & + & - & + \\
(o) san 'what' & - & + & - & + \\
(o) fa 'how' & + & + & + & + \\
(o) pe 'where' & + & + & + & + \\
oten 'when' & + & + & + & + \\
(o) sma 'who' & + & + & + & - \\
ver wate 'why' & + & - & $?$ & + \\
\hline
\end{tabular}

Notes. Because of their inconsistent spellings across and within different sources the question words are represented according to modern orthography. The meaning of 'how' for $o$ and omeni refers to their use as a degree adverb, i.e. in combination with an adjective.

Finally, the occurrence of the form ver wate in Herlein might be explained as a symptom of the more heavily English-influenced character of Herlein's Sranan, which is also present in several other respects (see above). It may be a syncretism of the form fu san ede lit. 'for what head' which is found from Van Dyk and English 'what for'. Reflexes of the latter meaning 'why' occur in other English-based creoles, such as St Kitts English Creole (Bruyn 1999) and Krio.

Articles. A provisional investigation of a small fragment of Van Dyk's booklet (pp. 20-26) suggests that articles are obligatorily absent in the environments noted by Kramp (1983:38-41) for Schumann (1783): inanimate subjects, inanimate objects and complements of the preposition na/nanga. Some examples are:

(58) nakki na $\varnothing$ dore

knock P Ø door

'knock on the door'

(59) kotti Ø kandele

cut $\varnothing$ candle

'put out the candle'

(60) $\varnothing$ Zon trange

$\varnothing$ sun strong

'the sun is hot' 
It should be noted, however, that many of these cases also fall in one of the environments for zero-articles that were distinguished above for Herlein and Nepveu. Needless to say, much more research is required in this area (see Bruyn 1995a: 80-92 for a fuller account).

The copula. As to the copula, again only the most salient characteristics of the Van Dyk text will be mentioned here. In order to put the Van Dyk data into perspective, they are complemented with our findings from Herlein and Schumann (1783) in the table below:

Table 5.3 The nominal copula in 18th-century Sranan

\begin{tabular}{llll}
\hline & $\varnothing$ & $d a$ & $d e$ \\
\hline Herlein 1718 & + & - & - \\
Van Dyk c1765 & + & + & - \\
Schumann 1783 & + & + & + \\
\hline
\end{tabular}

The preference for $\varnothing$, together with the infrequent use of $d a$ and the absence of $d e$, in nominal predicates in Van Dyk reflect the fact that this source is chronologically intermediate between Herlein - where the only case of nominal predication has a zero-copula - and Schumann - where we find a more differentiated system. In the latter source, identification ('John is the man with the hat') and attribution ('Mary is a linguist') are in most cases expressed by two distinct copula forms ( $d a$ and $d e$, respectively), while in a minority of cases $\varnothing$ is used. As to adjectival predication, we find that the Modern Sranan pattern of copula absence in declarative sentences with the adjective directly following the subject was already established at the beginning of the 18th century. However, with regard to the expression of the copula in adjectival predicates where the adjective is preceded by a modifier, such as nofo 'enough' or tumusi 'very', Van Dyk seems to be in line with the early-18thcentury system (as represented in Herlein), where no copula is expressed, rather than the middle- and late-18th century system (as represented by Schumann), where a copula $d e$ is obligatory in this environment.

(61) Mastra a $\varnothing$ noefe ogro
Master it $\varnothing$ enough bad
'Master, this is bad enough'
(62) ju no de so poti
you not are so poor
'you're not in such a bad situation' 
Summarizing, it seems that, although the general rule for copula-selection in adjectival predicates was already present in the early 18 th century, the more specific rule for preposed modifiers was in flux until the end of the 18th.

Clefting. With regard to clefting, we can distinguish several sub-types, according to the element being moved to the front of the sentence. Following this classification, we can reconstruct the development of the cleft-construction in the 18th century as presented in Table 5.4.

Table 5.4 The development of clefting in Sranan (1718-1798)

\begin{tabular}{lllllll}
\hline & Question wd & Clause & PP & Predicate & Adverbial & NP \\
\hline Herlein 1718 & - & - & - & - & - & - \\
Nepveu 1770 & - & - & - & - & - & - \\
Van Dyk c1765 & - & - & - & - & + & + \\
Schumann 1783 & - & - & - & + & + & + \\
Weygandt 1798 & - & - & + & - & + & + \\
\hline
\end{tabular}

The two subtypes of clefting that do occur in Van Dyk - with adverbials and NPs -, are only found in a very limited number: only two cases of each were attested in the entire text.

(63) da zo hede den no de worke noefe is so head they not ASP work enough 'that's why they don't work hard enough'

(64) No da $z i b i^{25}$ fom no is seven strike 'no, the clock strikes seven [not eight, JA]'

Of the other types of clefting represented in Table 5.4, none occurs in Van Dyk. Clefting of WH-elements does not occur at all (at least in clear cases) in any of the sources spanning the 1718-1950 period analyzed, while clefting of clauses is a late-19th-century development. PP clefting and predicate clefting emerge by the end of the 18th century, in Weygandt 1798 and Schumann 1783, respectively:

(65) Dafoe datie hédé joe no kan werie den soesoe (Weygandt 1798:115) is-for that head you not can wear these shoes

'that's why these shoes don't fit'

25. Although zebi 'seven' is a numeral, as the subject of this sentence it seems to function rather as an elliptical NP, i.e. 'seven strokes'. 
(66) da lei ju lei

is lie you lie

'that's a lie'

Summarizing, we observe a chronological development in clefting, such that the construction is restricted at first mainly to some fixed expressions (Van Dyk) and becomes more diversified and more productive in the course of the 18th and 19th centuries.

Comparatives. Restricting ourselves to the types of comparative found in Van Dyk (c1765) and Schumann (1783) - the Particle Comparative (with a particle comparable to English 'than', i.e. X more Adjective Particle Y) and the Exceed Comparative $^{26}$ (a serial construction containing a verb 'to exceed, to surpass', i.e. $\mathrm{X}$ Adjective exceed $\mathrm{Y}$ ) -, the expression of comparison is as represented below:

Table 5.5 The expression of comparison in Van Dyk (c1765) and Schumann (1783)

\begin{tabular}{llll}
\hline & Exceed Comparative & \multicolumn{2}{l}{ Particle Comparative } \\
\cline { 3 - 4 } & & leki & na \\
\hline Van Dyk c1765 & - & + & - \\
Schumann 1783 & + & + & + \\
\hline
\end{tabular}

The main types are illustrated below:

(67) ju langa morro mi (Schumann 1783:172) you tall exceed me 'you're taller than me'

(68) joe no de morre bon likki na disi manmatim you not are more good than $\mathrm{P}$ this morning 'Don't you feel better than you did this morning?'

(69) Adam móro lánga na mi Adam more tall than me (Focke 1855: 86) 'Adam's taller than me'

While in Van Dyk the expression of comparison is restricted to only one construction - the Particle Comparative -, we find a more differentiated system, with two different possibilities - the Exceed Comparative and the Particle Comparatives, the latter with either leki or na - in Schumann. Summarizing, it seems clear that in the options available for the expression of comparison Van Dyk represents a

26. The terminology is borrowed from Stassen 1985. 
stylistically more restricted language variety when compared to other 18th-century (and later) sources. Apparently, the Sranan of Van Dyk's days had not yet reached a stage of development where it was deemed necessary or functional to have several options for the expression of one and the same semantic content.

Serialization. The following verbs occur in serial verb construction in Van Dyk and Schumann:

Table 5.6 The development of serialization in Sranan (1750-now)

\begin{tabular}{lll}
\hline & Van Dyk c 1765 & Schumann 1783 \\
\hline seni $+\mathrm{V}$ & - & - \\
$\mathrm{V}+$ taki & - & + \\
$\mathrm{V}+$ moro & - & + \\
poti $+\mathrm{V}$ & - & + \\
sidon $+\mathrm{V}$ & - & + \\
teki $+\mathrm{V}$ & - & + \\
$\mathrm{V}+$ gi & + & + \\
$\mathrm{V}+$ kaba & + & + \\
$\mathrm{V}+$ kon & + & + \\
$\mathrm{V}+$ go & + & + \\
$\mathrm{V}+$ poti & + & \\
\hline
\end{tabular}

Notes. Because of inconsistencies in spelling, the modern orthography of the verbs in question is used.

The most remarkable aspect of this table is, of course, that Van Dyk is so much poorer in the variety of serial constructions than Schumann. Of the eleven subtypes of serialization which are mentioned for Modern Sranan, only five are attested in Van Dyk, as opposed to ten in Schumann. In addition, there is one sub-type, $\mathrm{V}+g i$, which is restricted in the selection of V in Van Dyk, since it is combined only with taki. As far as the differentiation of serialization is concerned, the variety represented in Schumann is almost identical to Modern Sranan, whereas in Van Dyk serialization is present as such, but its differentiation into several sub-types has proceeded only partially.

Two conclusions present themselves in relation to the foregoing. The first has to do with the value and reliability of older creole texts and is largely restricted to Van Dyk, since the Nepveu and, especially, Herlein texts are too small to judge their reliability in a well-founded manner; moreover, Herlein, being the oldest source and separated from the others by half a century, cannot be compared with other sources that precede or follow it with a more or less limited time interval. Now, the conclusion with respect to Van Dyk is that the variety of Sranan 
contained in it is more systematic than is sometimes assumed for this type of material. Although questions may be asked about exactly what variety of Sranan is represented in the book - whether it may be bakra tongo (whites' Sranan) rather than nengre tongo (blacks' Sranan) - the fact is that the variety that it represents fits in systematically, in practicaly all aspects that were investigated, between the varieties that surround it chronologically. This result would be extremely unlikely if Van Dyk's book were an unreliable and linguistically naive rendering of the language. In other words, strong opinions on the alleged unreliability of early creole sources, which are frequently expressed, usually without any empirical support (e.g. Bickerton (1988:281)), will have to be suspended, since they may be refuted by detailed comparisons with other contemporary texts.

Second, the - admittedly somewhat cursory - examination of several aspects of the language represented by Herlein, Nepveu and Van Dyk, shows that numerous developments have taken place during the second fifty years (roughly 1700-1750) after the beginning of slave importation into Suriname in the 1650s. What is especially striking is that in several of these cases, e.g. question words, comparatives, the developments concern the addition of new options for existing syntactic mechanisms rather than the introduction of new syntactic mechanisms per se. In other cases, such as serialization, the domain of a syntactic mechanism is expanded so as to include new subtypes. The development of Sranan during this period, then, was not restricted to purely linguistic expansion, but included the introduction of stylistic options as well. What this means for our understanding of creolization, e.g. the question of exactly which developments are part of the creolization process and which developments belong to normal language change, depends on the definition of the essential features of 'creole' and 'creolization'. If variation is not included in the definition, then some of these developments may pose no threat for instantaneous models of creolization. If, however, variation is viewed as an integral or even central element of language ( $c f$. Milroy 1992), then some of the developments described in this introduction may throw a new light on our understanding of creolization, in that variational expansion plays a prominent role in the early development of creole languages. 


\subsubsection{Stedman}

Although it has been claimed that the Sranan represented in Stedman's Narrative is not representative of the language as it was used by native speakers (Eersel $1984^{27}$ ), this claim was based - at least implicitly - on a comparison with modern Sranan. Our comparison with 18th-century Sranan will show that Stedman's Sranan is not as idiosyncratic, neither phonologically nor syntactically, as was suggested by Eersel. On the contrary, Stedman's variety may by and large be considered representative of 18th-century Sranan as we know it from sources such as Herlein (1718), Nepveu (1770), Van Dyk (c1765), Weygandt (1798), and Schumann (1783) dictionary.

This does not necessarily imply, however, that all these sources accurately reflect 18th-century Sranan as it was actually spoken by black native speakers, the so-called 'deep Sranan' or nengre tongo 'negro language' of the plantations. At least some of them are more likely to represent the variety known as bakra tongo 'white man's language', the Sranan spoken by the whites, some of whom spent more time in Paramaribo than on the plantations. On the other hand, at least one source Schumann's (1783) Sranan dictionary - is based on the information provided by one or more native speaker informants and it may therefore be considered a relatively reliable source for the nengre tongo variety.

With respect to the language variety reported by Stedman, we should note that most of the sentences he quotes are accompanied by an indication as to who actually uttered the sentence in question. Although I am aware that this in itself does not provide an absolute guarantee for the reliability of the material, it does indicate that what Stedman intended to represent was the language of the Blacks, not that of the Whites or some intermediate variety. Compare also, in this connection, Stedman's own remarks with regard to his competence in the language, which he himself considered to be very good.

27. Eersel does not say explicitly on which edition of the Narrative his paper is based, but from the fact that he gives 1796 as the year of publication and from the fact that the quotations are all in exactly the same spelling as in the 1796 edition (as edited by Rudolf van Lier (1972)), I conclude that it is based on Van Lier (1972). Since Eersel wrote his paper, a new edition, based on the original manuscript from 1790, has appeared (Price \& Price 1988). These authors found that, as a result of heavy editing by a ghost writer, the 1796 edition differs in significant respects from the 1790 manuscript version (see also Arends 1991). However, as far as linguistic information is concerned (apart from orthographic matters), differences are only slight, and will be noted where this is relevant. Therefore, quotations from Stedman in the present paper are all from the 1790/1988 edition, since this should be considered as the 'Urtext'. Apart from this, it should be emphasized that the Sranan material in the 1790 manuscript goes back to the period of Stedman's stay in Suriname (1773-1777), during

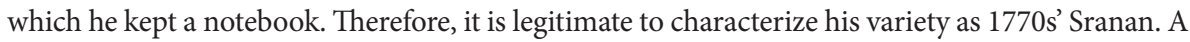
precise dating is important in order to be able to compare Stedman's Sranan with chronologically adjacent sources such as Nepveu (1765), Nepveu (1770) and Schumann (1783). 
With all the provisos we may want to make about the reliability of early 'European' Sranan documents as sources for the 18th-century language as it was actually spoken, we are still entitled to use them as points of reference to compare the Stedman material with. People like Herlein, Van Dyk, Nepveu, Schumann and Weygandt were, roughly speaking, in the same position as Stedman with respect both to the language they described and to its speakers. They were, as far as we know, all white. They all entered the colony as adults or, in the case of Nepveu, as an adolescent. As far as we know, none of them spoke the language natively. And they were all 'amateur linguists', although their linguistic abilities may have varied quite a bit. This means that, apart perhaps from Schumann's informant-based dictionary, there is no reason to assume that these sources differ significantly in the extent or direction of their deviations from the actual spoken language.

Below I will discuss the phonological and syntactic evidence presented by Eersel in support of his claim. Eersel notes three phonological features in Stedman's Sranan that strike him as somehow idiosyncratic.

The insertion of schwa in CC clusters. The insertion of schwa in a form like backera 'white person', where this is not present in modern Sranan (which has bakra), is certainly not restricted to Stedman: we find forms like backearary (Behn 1983/1688), Bakkerare (Herlein 1718) and bakkera (Van Dyk c1765) in other 18th-century sources as well (in Nepveu 1770 a full vowel is present: bakkara). Although the other example given by Eersel - masera 'master' - does not occur with schwa insertion in other early texts, it does fit regularly in the phonological development from mastre (Herlein 1718), through mastra (Van Dyk c1765) to massra (Nepveu 1770; Schumann 1783). Finally, a third form which has a vowel inbetween two consonants in Stedman, ${ }^{28}$ togeddere 'together' (not mentioned by Eersel), also has this in the Schumann dictionary (spelled tegédere).

In other words, the insertion of schwa in CC clusters, rather than being a 'Stedmanism', is a normal feature of mid-18th-century Sranan. It is especially frequent in Van Dyk's (c1765) Sranan primer, which dates from roughly the same the period from which Stedman's data are drawn. ${ }^{29}$ A quick search through Van Dyk yields more than a dozen forms with inserted schwa, where the modern va-

28. The term 'inserted vowel' is not appropriate here since it is present in the etymon ('together') from which the word is derived. Still, the example is relevant, because the issue is whether consonant clusters in Stedman are systematically broken up, regardless of their etymology. Also, there are many other words with schwa inbetween two consonants in the etymon, which are rendered with schwa in 18th-century texts (especially Van Dyk) but without it in modern Sranan.

29. In fact, Van Dyk's book is referred to by Stedman, although its exact title is not mentioned by him (see Arends 1991). 
riety has consonant clusters. Some examples are (the modern variant is given in parentheses): watera (watra), gottere (gotro), kondere (kondre), takkeri (takru), tigeri (tigri), kroekete (kruktu), abere (abra), middere (mindri), seribi (sribi), hameri (amra), dakteren (datra), kouwere (kowru), and ouwere (owru). Interestingly, most of the forms containing inserted vowels in Van Dyk have consonant clusters in Schumann (1783) (except krukkutu and kandera), which suggests a diachronic development, in which Stedman occupies a position intermediate between Van Dyk and Schumann.

In fact, some of the words containing inserted vowels in Van Dyk do occur in Stedman without schwa (e.g. tigri and kondre). More generally, if one takes a close look at the Stedman text, it appears that consonant clusters are not as rare as suggested by Eersel. The 1790 edition contains forms like Cramaca and prasella (Caramaca and parasalla in the 1796 edition ${ }^{30}$ ). This further undermines the suggestion that vowel insertion should be looked upon as something typical for Stedman.

Absence of vowel reduction and elision in reduplications. In contrast to Modern Sranan, reduplications in Stedman are always given in full, as in keesee-keesee 'monkey' and weeree weeree 'grass', as opposed to the reduced forms, keskesi and wiwiri (or, with gemination, w'wiri), found in Modern Sranan. Again, this feature cannot be claimed to be typically 'Stedmanian', because unreduced reduplications, like kesi kesi and wiri wiri, can also be found in other early sources like Van Dyk (c1765), Nepveu (1770), and Schumann (1783). The latter also has the alternative keeskees, showing the beginning of vowel reduction; the same phenomenon appears from the form fourfouro (in the special meaning of 'to live in concubinage with someone', not the usual meaning of 'to steal') in Nepveu (1770). Other reduplications found in Stedman, but not mentioned by Eersel, include wassy-wassy, tay-tay, mocco-mocco, monkee-monkee, and peeteeco-peeteeco. In so far as these forms are mentioned by Schumann, they are similarly given in their full form (e.g. wassiwassi, mokko mokko), with the exception of tetè (which also occurs in the spelling tetèh). Similarly, Nepveu (1770), apart from the reduced form fourfouro mentioned above, only contains full reduplications, such as fomfom, hafoe hafoe and queti queti. All in all, this suggests that generally speaking reduplications were only beginning to be reduced by the end of the 18th century and that full reduplications were the norm in Stedman's days. This means that, in this regard too, Stedman does not represent some idiosyncratic version of 18th-century Sranan.

30. The fact that some forms, like the ones above, contain an inserted vowel in the 1796 edition, where we find consonant clusters in the original 1790 manuscript, indicates how careful one should be in drawing conclusions from a few isolated words in one specific source. 
Meke instead of meki. While Eersel suspects Ndyuka influence in a form like meke ${ }^{31}$ 'make' (instead of meki), this is probably just a matter of spelling: Stedman sometimes uses $e$ to indicate /i/, as in $m e$ 'I, me'. Also, the sentence in question is given by Stedman as a quote from a Boni rebel in a story told by one of Stedman's fellow soldiers, which makes it extremely difficult to establish what variety of the language is exactly being reported here. ${ }^{32}$ The probability of Ndyuka influence is diminished further by the fact that Stedman has likee 33 'like', which has the form liki/ leki in 18th-century Sranan (Van Dyk and Schumann, respectively). If Stedman's Sranan were influenced by Ndyuka, we would expect to find a form like leke (the Ndyuka form is eke), since the latter has the same phonological pattern as meke.

As regards syntax, Eersel notes four features that strike him as characteristic of Stedman's variety of Sranan.

The form da instead of (n)a, for definite article, copula, and presentative. In Stedman we find the sentence sooto sooto da Bony Kiry da Dago? 'shoot, shoot, it's Boni (the Maroon leader), kill the dog', where $d a$ (instead of modern $n a$ ) is used both as a presentative and as a definite article. Although there are more examples with $d a$ in these two functions in Stedman, no examples can be found where it is used in a 'true' copular function, in spite of Eersel's assertion to the contrary. But even if this were the case, it would not support Eersel's hypothesis, because, as appeared above, $d a$ was the usual form for all of these three functions in 18th-century Sranan. The form $d e$ and the zero-copula are used only marginally in the 18th-century sources, while na does not appear until well into the 19th century. For instance, we can still find $d a$ in copular function in Focke's (1855) dictionary, which may be seen as one of the most reliable sources for 19th-century Sranan: soema bere da liba, lit. 'man's belly is a river' (Focke 1855: 10); da mi bere pikien, lit. 'it's my belly child' (Focke 1855: 10). The use of $d a$ as an article can be attested until the very end of the 19th century, for instance in Kraag's diary, e.g. da grankapten 'the great chief' (Kraag 1894-1896:34).

31. Modern Ndjuka has teke, meke, eke, where Modern Sranan has teki, meki, leki. Theoretically, the possibility of Ndjuka influence on the Sranan Stedman was confronted with, cannot be excluded since, as Eersel notes, 'the Dyuka are reported by Stedman to come and go as free men in and out Paramaribo' (p. 8). On the other hand, if there was Ndjuka influence on Sranan at the time, we would expect to find it in other 18th-century sources too. So far, there are no indications that would point to such influence (e.g. with regard to the forms mentioned above).

32. Eersel (1984:2) suggests that the Boni variety of Sranan cannot have developed that far from Sranan in the 1770s', since the tribe was formed after the peace treaties with the already existing maroon tribes had been signed in the 1760s.

33. Double $\leq e e>$ in Stedman's orthography stands for /i/. 
Zero copula - instead of na - in nominal predicates. Nominal predicates in Stedman receive no overt copula, as in you man?, 'are you a man?', and me man, 'I am a man'. Absence of copula in cases like these is not at all exceptional in 18th-century Sranan. In fact, one out of three predicate nominal sentences in our corpus has no overt copula. Compare e.g. the following sentence from Schumann's dictionary: djinja wan bune dresi, 'ginger is a good medicine' (Schumann 1783: 84). The absence of the copula in WH-questions, as in Stedman's who som ma datty, 'who is that?', has continued even longer, as appears from the following sentence from Wullschlägel's (1856) dictionary: soortoe maniri dati?, 'what kind of behavior is that?'

Aspect marker de - instead of e. In this respect Stedman's Sranan is completely in accordance with other pre-1900 sources in which de is exclusively used in this function. ${ }^{34}$ Compare e.g. a sentence like hangri de kili mi, lit. 'hunger is killing me' (Schumann 1783:120). There is one case that leads Eersel to suggest that $e$ was the form as it was actually spoken. He wonders whether me in so langa me leeby might be a contraction of $m i$ and $e$, which is a regular phonological process in Modern Sranan. But, as was mentioned earlier, me or mee in Stedman always stands for $m i$ (the latter is not attested in the book even once), as appears from environments where it cannot possibly have been contracted with $e$, as in me masera, 'my master', mee saloby you, 'I shall love you', and kebree me, 'cover me'.

Future marker sa - instead of alternation between sa and go. Eersel's claim that Stedman uses only $s a$, not go, is simply incorrect. Careful examination of the sample sentences also reveals a functional differentiation between $s a$ and $g o: s a$ seems to indicate irrealis modality, as in Gado Sa Blesse da Woma, 'God bless this woman', and in Mee Saloby you langa alla Mee Hatty so langa mee leeby, 'I shall love you with all my heart as long as I live', while the function of go seems to be restricted to the marking of immediate future tense, as in Son de go Sleeby caba, lit. 'the sun is already going to sleep', and in mee de go dede, 'I am going to die'. ${ }^{35} \mathrm{In}$

34. Incidently, in every instance in Stedman where the aspect marker de occurs, it marks the verb go, either as a main verb, as in me de go, 'I am leaving', or as a future auxiliary, as in son de go Sleeby, lit. 'the sun is going to sleep'. Although the small size of the sample does not allow any firm conclusions, this may suggest that aspect marking originated with the verb go, perhaps modelled on the English 'be going to' construction, and was extended later to other verbs.

35. As appears from Schumann (1783) dede can be both adjective ('dead') and verb ('die'). That go dede should be construed as FUT + Verb and not as FUT + Adj (in which case it could be related to Dutch doodgaan, lit. 'go dead', i.e. 'die'), appears from the fact that no overt copula appears inbetween the future marker and the verb: an overt copula is obligatory before adjectives in infinitive position, i.e. mi go de dede, 'I shall be dead'. 
the latter case, the context clearly reveals the immediacy of the predication, since the sentence is uttered by someone who is deadly wounded, whereas in the former immediacy is inherent in the utterance itself, since there is no point in uttering it unless the event is actually going to take place very soon.

This functional differentiation of $s a$ and $g o$ is fully in agreement with a general tendency that can be observed in the development of future marking in 18th-century Sranan. Starting from a situation where we have variation between wil and zero, in Herlein (1718), and passing through a stage with practically undifferentiated use of $s a$, in Van Dyk (c1765), we see a development towards a functional differentiation between $s a$ and $g o$ in Schumann and later sources, ${ }^{36}$ the former of which is used to indicate remote future or irrealis modality, while go is restricted to indicate near future. This differentiation still exists up to the present day ( $c f$. Wendelaar \& Koefoed 1988).

Summarizing, the Sranan as reported by Stedman does not in any significant way deviate from the language as it is known from other 18th-century sources. What from the perspective of the 20th-century variety appear to be idiosyncracies on Stedman's part, are in reality normal features of 18th-century Sranan as we know it from other sources.

\subsection{Saramaccan}

[Editor's note. Clearly, this section is incomplete. There were no indices as to its further content]

In this section we discuss the earliest data on what is presented in the sources as Saramaccan, even though it is not always clear whether what is actually given is Saramaccan, Sranan, or a combination of the two (some degree of bilingualism was not uncommon among Saramaka).

In the same collection of documents, we also find the phrase Gran Cassa, ${ }^{37}$ lit. 'big house', i.e. the house where a meeting of Whites and Maroons was held (Dörig 1763, in De Beet \& Price 1982:170).

36. Interestingly, the only two cases of sa/go in Nepveu (1770) seem to confirm the idea of a functional differentiation: $\underline{\mathrm{sa}}$ (in the form $\underline{\mathrm{sal}}$ ) is used in a (negative) promise, viz. mi no sal lobi him moro, 'I shall not love him anymore'; go is used to indicate immediate future, viz. a go a

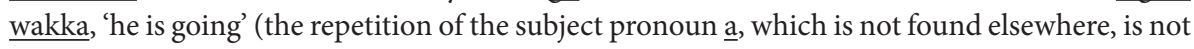
discussed here).

37. The phrase gran casa 'big house' and its equivalents (grand case etc) is widespread in the Caribbean. 


\subsection{The other Suriname creoles}

In contrast to Sranan and Saramaccan, the early history of Suriname's third major creole, Ndyuka, is almost completely undocumented. The earliest known manuscript, not available to the author, is an 18-page wordlist dating from the beginning of the 20th century (Voorhoeve \& Donicie 1963: 102). Apart from that, a few isolated sentences have been recorded from the period of the negotiations leading to the peace treaty of 1760 , a period when Ndyuka was closer to Sranan than it is now (see Chapter 7).

One sentence that might be construed as representing 1770s Boni (which at that time must have been even closer to Ndyuka than it is now) is given by Stedman (1790), who explicitly attributes it to a Boni Maroon. As the sentence shows, since the Boni Maroons had only recently begun to escape from the plantations, their language cannot have differed much from the plantation creole (ignoring Stedman's English-influenced orthography):

(70) Son de go Sleeby caba Mekewe liby den tara dago tay sun ASP go sleep already make-we leave the other dogs until

tamara.

(Stedman 1988 [1790]: 124)

tomorrow

'The sun is going down already; let's leave the other dogs until tomorrow.'

As far as the other Creoles (Paramaccan, Kwinti, Matawai) are concerned, no early data are available. That means that everything that will be said about the historical development of these languages is necessarily based on indirect evidence.

\subsection{Introducing early texts}

As far as the languages treated in this book are concerned, until now we have seen little more of them than isolated words, phrases and sentences, often analyzed in rather minute detail. In order to give an idea of what the Suriname creoles looked like in earlier stages, I have collected a number of early texts which are presented here together with their translation into English. The texts have been selected for various reasons: either because they represent a particular genre or language variety, or because of their special historical or documentary value, or because of their sheer beauty and power of expression. They have been divided into two categories: oral texts (Chapter 6) and written texts (Chapter 7). Because of the rather special character of religious texts, Chapter 7 has been subdivided into two separate sections: one on secular texts (7.1), the other on religious texts (7.2). Unless 
noted otherwise, the texts have been transcribed exactly as they are presented in the original, including inconsistent spellings and (apparent) typographical errors. In cases where words are not separated by spaces where this would be expected, such as daso for $d a$ so, the 'correct' alternative is added in parentheses. Punctuation has been adapted wherever that seemed necessary. While these texts are presented here without much linguistic analysis, it is to be hoped that future researchers will make use of them for that purpose. The diversity of the texts presented here - especially the oral texts, largely neglected until now - will certainly help to broaden the basis for the reconstruction of creole formation in Suriname. 


\section{CHAPTER 6}

\section{Oral texts}

While many of the Africans who were brought to Suriname came from oral cultures, this orality was continued in their new environment since literacy was strictly withheld from them. As a result, an extremely rich culture of oral literature developed both on the plantations and in the Maroon communities. While this literature is so encompassing as to deserve a book of its own, I have selected a number of texts to give the reader an impression of the importance of this part of Surinamese culture. ${ }^{1}$ Since folk-tales are well covered in the literature mentioned in note 1, I have included only two of those here, focussing instead on songs and odos (proverbs). The songs, odos, and stories are presented here without extensive introductions but clarifying notes are included where necessary. From the point of view of their linguistic use it is important to remember that oral texts, especially the more fixed genres such as songs and proverbs, often preserve features of earlier stages which have disappeared in the modern language. This makes them especially useful for purposes of linguistic reconstruction.

\subsection{Songs}

Most of the songs included here derive from the work of two authors, H. C. Focke (1858) and Th.A.C. Comvalius (1922, 1938, 1948-1949). Both were well-educated colored men. Focke, the author of the 1855 Sranan dictionary discussed elsewehere in this book, was a doctor of Law and President of the Court in Paramaribo; Comvalius was a teacher and a well-known folklorist. In all likelihood, they were both native speakers of Sranan. For a discussion of the different types of Surinamese songs, see Lichtveld \& Voorhoeve (1975:15-75), which also contains many examples. While many songs are very short, containing only a few lines of text, it should be remembered that repetition is a crucial element in Surinamese creole singing.

1. In fact, several books have been devoted to Surinamese oral literature, especially folk-tales: Herskovits \& Herskovits (1936), Voorhoeve \& Lichtveld (1975), and Price \& Price (1990). 
The very first song recorded in print is found in Stedman's (1790) Narrative. The text of the song is preceded by the following comment:

'Their Vocal Musick is like that of some birds, melodious but without Time; in Other respects it is not unlike that of some Clarks reading to the Congregation, One Person Pronouncing a Sentence Extemporary, which he next hums or Whistles, when all the others Repeat the Same in Chorus, another sentence is then Spoke and the Chorus is Renew'd a Second time \& So ad perpetuum. ${ }^{4}$ as a Specimen of it I will Try to Put the following Not[e]s to Musick Supposing a Soldier going to battle taking leave of his Mistress. ${ }^{5}$ (Stedman 1988 [1790]: 516)

One bus adiosi-o ${ }^{6}$

daso adiosso me dego

me loby fo fighty me man o

na inny da bossy amimba o

daso adiosso me dego

One kiss, farewell, oh,

So it is, farewell, I'm leaving.

I love to fight, I can hold my own, oh,

In the forest, Amimba, ${ }^{7}$ oh!

So it is, farewell, I'm leaving.

2. The songs are presented in a tentative chronological order, i.e. according to the date of their origin as far as that could be established. In cases where more than one source is given, it is always the one mentioned first which is the source of the transcription presented here.

3. This is the approximate date of 'recording' (as opposed to the date of publication), based on what we know about the dates of Stedman's stay in Suriname (1773-1777). Approximate dates of recording are also given in some of the other songs included here.

4. This refers unambiguously to the call-and-response structure of oral genres such as songs, which can be found all over Afro-America (as well as Africa, of course).

5. Note that Stedman, a soldier himself, had a black mistress, the 'beautiful Johanna'.

6. The - apparently meaningless - element $o$ is sometimes added at the end of a word or a line in Surinamese songs ( $c f$. songs nos. 3, 10, 16, 26, 33). A striking parallel can be found in some American folk-songs, such as 'Pretty Peggy-o'. Whether there is any connection in this respect between the black and white traditions, remains obscure.

7. The day-name of a female born on a Saturday. 


\section{Celebrating the Ndyuka Peace Treaty (c1760) (Focke 1858: 102; song no. $1^{8}$ )}

This song expresses the relief that the hostilities between the Maroons and the Whites had come to an end. The treaty with the Ndyuka Maroons was the first to be made (1760), being followed by treaties with the Saramaka and the Matawai a few years later (1762 and 1767, respectively). Although Sranan and Ndyuka were still very similar at this early stage, the content of the song makes it more likely to have been sung by Sranan speakers than by Ndyuka speakers.

Arabi na Pambo ben senni njoesoe,

Arabi na Pambo ben senni njoesoe.

Soesoetei! No broko hatti o:

alla joe kondre de na reti kabá.

Arabi and $\mathrm{Pambo}^{9}$ sent the news,

Arabi and Pambo sent the news.

Society! ${ }^{10}$ Don't worry:

Your entire country is back in order.

3. A BLACK OdysSeus (c1800)

(Focke 1858: 103; song no. 2)

This song is the lament of a slave who, having been forced to leave his woman for some time, upon his return finds his house intruded by others. As in so many of these songs, the force of the metaphor is striking.

Mienéri senni mi na koemando,

mi libi mi hoso gi oeman.

Mienéri senni mi na koemando,

mi libi mi hoso gi oeman.

Sikápoe de njaḿ na ini,

krabita de njaḿ na ini, kè!

Soema froedien da hoso,

meki a holi o!

da hoso, do hoso,

Soema froedien da hoso,

meki a holi o!

8. The songs from Focke (1858) are transcribed according to the text as it appears in the appendix to the article, where the texts are presented together with their musical notations. In some cases, these versions differ slightly from those given in the main text.

9. Arabi and Pambo were the main leaders of the Ndyuka Maroons.

10. Soesoetei 'Society' refers to the Societeit van Suriname 'Society of Suriname', the governing body of the colony at the time. 
Master sent me on 'commando'11

I left my house to my woman.

Master sent me on 'commando',

I left my house to my woman.

Sheep are eating ${ }^{12}$ in there,

Goats are eating in in there, ah!

Whoever deserves the house,

Let him have it!

The house, the house,

Whoever deserves the house,

Let him have it!

4. A CHILDREN'S SONG (c1800?)

(Comvalius 1938:293;

also in Comvalius 1948-9: 16-17

and Voorhoeve \& Lichtveld 1975: 65-66)

Although this song is known today as a children's song, sung in a particular game, it has been interpreted to refer to a specific historical event, in both cases concerning the arrival of an English fleet at the mouth of the Suriname River, either in 1667 (Ferrier 2001:135) or in 1799 (Comvalius 1938:293; Noordwijk 1991:38). For the time being, however, these interpretations present too many problems of linguistic analysis for them to be accepted. Due to the many incertainties presented by the text, the translation is rather tentative.

Sien, san de na mofo, sien de kom.

Peroen, Peroen, mi patron,

San wani kom, mek'a kom,

Ingrisiman sa tjari pranga go na jobo-pan.

Bakoeba, Bakoeba,

Kaseeri, kaseeri,

Nimo, nimo, Jaâsabo,

Bosro mapinka

Bosro maabo.

Alla dem griekie-bie din sab' na fien fien wroko,

O Codjo, Codjo fai dom,

joe dom so kita kita kai koi.

Basi doorsi, joe mofo langa toemoesi: poer' wan!

11. 'Commando' refers to certain tasks, such as maintaining fortifications and digging canals, which slaves were sometimes forced to do for the colonial authorities.

12. Note that njam/nyan has a much wider range of meanings than 'eat', including 'enjoy, celebrate' etc. 
The sign, ${ }^{13}$ which is there at the mouth of the river, the sign is coming.

Peroen, Peroen, my master,

What may come, let it come.

The Englishmen will carry the wood to the Whites, all of it. ${ }^{14}$

Bakuba, bakuba, ${ }^{15}$

Kaseri, kaseri,

Nimo, nimo, Jaâsabo,

Bosro mapinka

Bosro maabo.

All the grikibis ${ }^{16}$ know the very fine work.

Oh Codjo, Codjo, how dumb you are,

You're so dumb, la la la.

Boss Doorsi, ${ }^{17}$ your mouth is so long: pull one ${ }^{18}$ !

5. Praise for Governor Friderici (c1800)

(Comvalius 1938:292;

also in Comvalius 1922:41

and Comvalius 1948-9:15-16)

This song was sung by former Black Rangers - slave soldiers who were made free after completing their service - in praise of François de Friderici (Governor from 1790 until 1802), who had been their commanding officer during the Maroon campaigns. ${ }^{19}$ The black army corps was established in 1772 to fight the (unpacified) Boni Maroons. After the termination of their duty, Friderici had provided them with land on the outskirts of Paramaribo. This area, which has become part of modern Paramaribo, is still known today by its original name: Frimangron 'free

13. The arrival of a new ship would be signaled by a particular sign. The word sien is interpreted here as a creolization of Dutch sein 'sign', the word used in Suriname in this context (cf. Chapter 7, text no. 17).

14. Pan is an ideophone indicating fullness (Focke 1855, s.v. paḿ).

15. Since the words in the next few lines seem to be either nonsense words or words not used in their literal meaning they are left untranslated here. According to Noordwijk (1991:38), the lines in italics refer to the negotiations between the colonial government and the English invaders. For the sake of completeness: bakuba means 'banana'; kaseri means 'ritually clean'; jâasabo, when analyzed as ja, a sa bon, means 'yes, it will be good'; bosro literally means 'brush'; the first word in bosro mapinka, when analyzed as bosroma pinka, mean 'someone who brushes, brusher'; the meaning of pinka is unclear; bosro maabo, when analyzed as bosroma a bo, means 'brusher, it is good'.

16. A bird species.

17. Basi Dorisi also figures in song no. 20 below.

18. This refers to the part of the game where one of the players has to withdraw a leg.

19. According to Wolbers (1861:432note§), several songs concerning Friderici's role as commander were still known among former Black Rangers around 1860. 
men's land' ( $c f$. the use of the word friman to refer to a former Black Ranger in song no. 35 below).

Di mi teki mi howroe,

Di mi teki mi haksi,

Mi kotti da taja;

A ben langa a langa siksi foetoe,

Howroe srefi no man kap in;

A ben langa, a langa siksi foetoe,

Granman Fredrici wan boen Granman.

When I took my machete,

When I took my axe,

I cut the taja. ${ }^{20}$

It was long, six foot long,

Even the machete could not cut it.

It was long, six foot long,

Governor Friderici is a good Governor.

6. Mocking a CORRupt PUblic Servant (c1815²1) (Comvalius 1948-9:22)

(also in Comvalius 1922:47)

This song makes fun of a Mr Van Cogh, who was arrested on his wedding-day by order of the Attorney-General, Mr Gefken, on the accusation of malversation. The use of songs to mock fellow-citizens was a frequent phenomenon in Suriname.

Djin djin dee bari na pokoe dee preê,

Tide n'a dei die moi Jeanne go trow.

Djin djin dee bari na pokoe dee preê,

Dan Jeanne dee begi pardon gi van Cogh.

Jeanne dee begi pardon gi van Cogh,

Muller dee begi pardon gi van Cogh,

Papa dee begi pardon gi van Cogh,

Ma Gefken dee bari dim 'anga van Cogh.

The bells are ringing, the music is playing,

Today is the day pretty Jeanne is getting married.

The bells are ringing, the music is playing,

Jeanne asks forgiveness for Van Cogh,

Muller asks forgiveness for Van Cogh,

Papa asks forgiveness for Van Cogh,

But Gefken ignores them with regard to Van Cogh.

20. A tuber species.

21. Although the version in Comvalius (1922) is dated c1870, the contextual information presented in Comvalius (1948) suggests that the c1815 dating is probably more correct. 
7. MAKING FUn OF THE Governor's EATING HABIts (c1825) (Comvalius 1948-9: 18)

Before he came to Suriname, Governor De Veer, who relished pumpkin, had lived on Curaçao where this is a favorite food; Mr Lisman was his secretary (Comvalius 1948-9: 18-19). Below is one stanza from the song.

Lishman taki: na pampoen!

Granman tak': a no pampoen!

Fai kan stree nanga mi Granman?

Pampoen na kroesow njanjan!

Lisman says: 'It's a pumpkin!'

The Governor says: 'It's not a pumpkin!'

How can you disagree with me, Governor?

Pumpkin is a Curaçaoan food!

8. Prince Hendrik visits Suriname (1835)

(Comvalius 1922:25)

This song was addressed to Governor Van Heeckeren, who chose to show only the bright side of Suriname to Prince Hendrik, a son of King William II, when he visited the colony (Comvalius 1922:25).

Joe sorie hem da boen,

Joe moe sorie hem da orgie toe!

You show him the good things,

Show him the bad things too!

9. A SCEPTIC VIEW OF LOVE (pre-1850)

(Focke 1858: 103; song no. 3)

Tarawan sa de, opete bari, tarawan sa de!

Alla man da man, opete bari o, alla man da man. San mi ke?

There will be others, the vulture cries, there will be others!

All men are men, the vulture cries, all men are men. What do I care?

10. Love IS WAR (pre-1850)

(Focke 1858: 103; song no.4)

O! m' no frede, Sa Akoeba e! m'no frede, Ba, alwassi j'de lai toemofo-gon srefi o, m'no frede.

Ah! I'm not afraid, Sister Akoeba, hey! I'm not afraid, my friend.

Even if you'll load a two-barrel gun, ah, I'm not afraid!

11. Putting a curse on someone (pre-1850)

(Focke 1858: 104; song no. 5)

M'de gowe ti de, m'de gowe ti de

Gado Massra sa d'na joe bakka wan de, wan de

I'm leaving today; I'm leaving today.

The Lord God will pay you back one day, one day! 
$O$ a de na mongo, blakka wentje o, a de na mongo,

$O$ a de na mongo tjari-o, ho jo, a de na mongo

Oh, he's in the mountains, black girl, oh, he's in the mountains.

Oh, he's off in the mountains, ho jo, he's in the mountains

13. The END OF A LOVE AFFAIR (pre-1850)

(Focke 1858: 105; song no. 8)

Di Awai de passà, Sa Affi lob' no de di Awai de passà, Sa Affi lob' no de di Awai de passà, sa Affi lob' no de tan, joe srefi sa si, 'sa Affi, lob' no de.

When Awai passes by, Sister Affiba's ${ }^{23}$ love is not there;

When Awai passes by, Sister Affiba's love is not there;

When Awai passes by, Sister Affiba's love is not there;

Wait, you will see for yourself, Sister Affiba's love is not there.

14. Changing lovers (pre-1850)

(Focke 1858: 105; song no. 10)

Jo jo jo jo jo jo jo $\mathrm{Ba}$,

mi libi trawan, mi teki trawan

jo, jo, jo $\mathrm{Ba}$

mi libi trawan, mi teki trawan

jo, jo, jo

Jo, jo, jo, jo, jo, jo, my friend!

I left one, I took another.

Jo, jo, jo, my friend!

I left one, I took another.

Jo, jo, jo!

15. A ROWING SONG (pre-1850)

(Focke 1858: 104; song no. 7)

Focke (1858) contains two boto singi 'lit.: boat songs', i.e. rowing songs, both of which are reproduced below. The singing was accompanied by a movement known as to fumm watra 'lit.: beat the water', a custom already observed by Stedman (1790: 463): '...my Negroes had made Extraordinary Dispatch Fumming Watra all the time to Encourage each Other'. In a footnote, he adds: 'That is, one of the Rowers Beating the Watter with his Oar at every Stroke in Such a Manner, that it

22. Erroneously listed as no. 5 in Focke (1858: 104).

23. Affi is short for Affiba, the day-name of a female born on a Friday. 
Sounds Different from the Rest to Which the Others sing a Chorus'. As in song no. 1, Stedman obviously refers here to the call-and-response structure of these songs. While a major function of these boto singi - and of work songs in general - may have been to synchronize the movements of the work at hand, another function, as described by Van Breugel (1842:90), was for the rowers of one boat to be able to communicate with those of others : 'When one is traveling by boat, it is curious to hear how the Negroes understand each other; in song they tell the Negroes of another boat, at quite a distance, who they have on board, frequently by using nicknames known among them'. The reference to nicknames is, of course, another example of how the language used by blacks often contained two layers of meaning, one of which was only accessible to other blacks ( $c f$. the use of Kaperka in song no. 37).

O Dada, mi de go na Masari nomo, watra de dangra mi, O Jaja O Jaja ba, watra de dangra mi.

Oh Dada, I'm only going as far as Marshall's Creek.

The tide is against me. ${ }^{24}$

Oh Jaja, Oh Jaja, my friend, the tide is against me

16. ANOther ROWING SONG (pre-1850)

(Focke 1858: 105; song no.9)

Grewa, grewa de grewa, grewa de

Kwami (mati ${ }^{25}$ ) mi de go na mi dotti (kondre-, liba)-o,

grewa, grewa de

mi de go na mi dotti (kondre-, liba)

grewa, grewa de

Grewa, grewa de! ${ }^{26}$

$\mathrm{Kwami}^{27}$ (friend), I'm going to my piece of land (village, river).

Grewa, grewa de!

I'm going to my piece of land (village, river).

Grewa, grewa de!

24. In Suriname, the effect of the tides extends many miles upriver.

25. As noted by Focke (1858:105), the words in parentheses are sometimes used for the sake of variation.

26. The meaning of the word grewa is unclear.

27. Day-name for a male born on a Saturday. 
These songs were sung as part of a susa play, 'a play for adult men in which the players face each other. One person has to imitate the steps of the other...The songs often treat relations between men and women, just as in the banya, but from the male point of view' (Voorhoeve \& Lichtveld 1975:54).

Fransiman dede tide

Sabana weri njâ. ${ }^{28}$

Fransiman dede tide

Sabana weri njâ.

The Frenchman died today;

Sabana is wearing bright colored clothes.

The Frenchman died today;

Sabana is wearing bright colored clothes.

18. ANOTHER SUSA SONG (pre-1850)

(Focke 1858: 106; soesà song no. 2)

O soesa, majombe, nakki da boi, joe go, trawande (= trawan de).

O soesa, majombe, nakki da boi, joe go, trawande.

Oh play susa, Mayombe, ${ }^{29}$ leave the boy.

Go, there are others.

Oh play susa, Mayombe, leave the boy.

Go, there are others.

19. Love AND MONEY (pre-1850)

(Focke 1858: 106; street song no. 1)

This is one of the two 'street songs' ${ }^{30}$ included in Focke (1858); unfortunately, he does not provide any relevant information about these songs.

Alwassi da man no moi,

kaba a tjari moni kom, tek' hem,

a tjari moni kom, tek' hem.

Even if the man is not handsome,

If he brings in money, take him,

If he brings in money, take him.

28. njâ is an ideophone expressing brightness of color (Focke 1858: 106).

29. Mayombe is the name of 'a district in the old kingdom of Kongo' (Turner 1949: 130). Alternatively, it could be a misspelling for Wayombe, a place name in Suriname (check!!). I have interpreted it here as being a personal name.

30. This is the English equivalent of the term straatliedjes used by Focke. 
This is another 'street song':

Basi Dorisi, kitiko! Basi Dorisi, kitiko

joe libi joe ningroeman (= ningre oeman), kitiko,

joe teki wan bakroeman (= bakra oeman), kitiko!

Boss Dorisi, kitiko! Boss Dorisi, kitiko! ${ }^{31}$

You left your black woman, kitiko!

You took a white woman, kitiko!

21. A SONGE DANCE SONG (NDyUKa) (Anonymous c1850, in Focke 1858: 107, 111)

While all of the songs above are in Sranan, the following, apparently sung during a songe dance, is in Ndyuka. It was recorded by Focke himself in Kriki, a Ndyuka village at Sara Creek Although the je je je je je je sequence could be a repetition of the word jeje 'spirit', it is more probably simply a rhythmic 'lalala'-like sound. The same sound sequence is also found in another Ndyuka song (see song no. 30 below).

Je je je je je je
Da so wi de peré.
Je je je je je je
O sonjé.
Je je je je je je
O! Wi da wi.
Je je je je je je.
Je je je je je je
That's how we 'play.' ${ }^{32}$
Je je je je je je
Oh songe.
Je je je je je je
Oh, we are we.
Je je je je je je.

31. According to Focke, kitiko means something like 'lalala'.

32. The word peré/pee 'play' has a much wider meaning than just 'play': it refers to all kinds of celebrating through song, dance, music making etc.

33. Sonjé/songe is the name of a Ndyuka song-cum-dance. 
Although this song only became widely known after it had been published in Van Hoëvell's (1854) abolitionist book, it is included here in the section on oral literature since it clearly belongs to that tradition. It was sent from Suriname to Van Hoëvell, who claims it is based on an actual occurrence. Whether or not that is true, this heart-breaking song, simple as it may be, shows the consequences of slavery at their very worst. According to Van Hoëvell (1854, Pt 2:54), it had 'become generally known among the slaves. It is a folk-song, which can be heard almost daily in Paramaribo'. According to Lichtveld \& Voorhoeve (1980:302), the song is still known by some people in Suriname today. Although these authors present the song under the title Bastian fon! 'Basya, lash out!', it is untitled in Van Hoëvell's original rendition.

Meneri, meneri, da piekien, pardon,

Membrie wan tem, membri wan tron,

Fa yoe ben lobie mie so té,

En fa mie lobie yoe jette.

Bastian fon! bastian fon!

Da oeman mekie mie hatie bron!

Sir, Sir, the child, please,

Remember how one time

You loved me so much

And how I love you still.

Basya, lash out! Basya lash out!

The woman has made me furious!

Té na condré yoe kon fo srifiman, ${ }^{34}$

Mie no ben sabie san na wan man;

Fa yoe ben lobie mie so té...

En fa mie lobie yoe jette.

Bastian fon! bastian fon!

Da oeman mekie mie hatie bron!

When you came to this country as an overseer

I had never known a man.

You loved me so much

And how I love you still.

34. A typo for scrifiman/skrifiman 'lit. writer'; it was the usual designation for a white overseer-cum-clerk-cum-bookkeeper. 
Basya, ${ }^{35}$ lash out! Basya lash out!

The woman has made me furious!

Mie ben dékalli (= de kalli) yoe mooi scrifiman,

Yoe poeloe mie na mie nenne anan; ${ }^{36}$

Fa yoe ben lobie mie so té,

En fa mie lobie yoe jette.

Bastian fon! bastian fon!

Da oeman mekie mie hatie bron!

I called you 'handsome overseer',

You took me away from my mama, didn't you?

You loved me so much

And how I love you still.

Basya, lash out! Basya lash out!

The woman has made me furious!

Te yoe ben bossi joe Jaba

Mie ben takki: kaba! kaba!

Da falsie lobie, yoe no ké,

Ho fassi yoe doe so to dé.

Bastian fon! bastian fon!

Da oeman mekie mie hatie bron!

When you kissed your Jaba ${ }^{37}$

I said: 'Stop! Stop!'

It was a false love, you didn't care,

What are you doing now?

Basya, lash out! Basya lash out!

The woman has made me furious!

Pardon meneri! Pardon! pardon!

Yo ben lobi da skien wan tron;

Mie beggie yoe! mie beggi ké!

Meneri a no noffo jette?

Bastian fon! bastian fon!

Da oeman mekie mie hatie bron!

35. A basya is a black overseer; basyas were charged with executing punishments on fellow-slaves.

36. Anan/ana is a now archaic, sentence-final question particle (cf. Focke 1855, s.v. anáä).

37. Jaba is the name of the first-person narrator; it is the day-name for a female born on a Thursday. 
Forgiveness, Sir! Forgiveness! Forgiveness!

Once you loved this body.

I'm begging you, I'm begging, ah,

Sir, is it still not enough?

Basya, lash out! Basya lash out!

The woman has made me furious!

Meneri, meneri, membrie da piekien

Da sorri yoe me lobie krien

Mie beggi yoe, mie beggi ké!

Bastian a no noffo jette?

Bastian fon! bastian fon!

Da oeman mekie mie hatie bron!

Sir, Sir, think of the child,

It shows you my love clearly.

I'm begging you, I'm begging, ah,

Sir, is it still not enough?

Basya, lash out! Basya lash out!

The woman has made me furious!

Hoe fassi? mie takki fon!

Da oeman meekie mie hatie bon! ${ }^{38}$

Mie takki fon! fon hin so té,

Al wassi a fal don deddé.

Bastian fon! bastian fon!

Da oeman mekie mie hatie bron!

What? I said 'Lash out!'

The woman has made me furious!

I said 'Lash out! Lash her as much as you can,

Even if she drops down dead'.

Basya, lash out! Basya lash out!

The woman has made me furious!

22a. Wishing the Master a Happy New Year

(Bray c1860: 13)

In Suriname, as in other plantation societies (cf. e.g. Abrahams 1992; Genovese 1976), the Christmas season - when slaves received their annual 'gifts' of cloth, dried cod etc. - would be celebrated exuberantly, with song, dance and other festivities. On the morning of January 1, the slaves would greet the master, occasionally lifting him up in his chair and carrying him around. According to the Belgian artist Théodore Bray (1818-1887), who worked as a white overseer and

38. A typo for bron. 
plantation owner in Suriname from 1841 until 1868 and who made numerous drawings of plantation life including the New Year tradition, the slaves would cry out loud while doing this: ${ }^{39}$

Niov iari mastra eh

Niov iari mastra oh

Wi wens' wi mastra niov jar' oh

(source: Bray c1860: 13)

In order to make the text more accessible, I have transposed Bray's Frenchinfluenced orthography into normal modern Sranan spelling.

nyu yari masra eh

nyu yari masra oh

wi wens' wi masra nyu yari oh

Happy New Year, master, eh!

Happy New Year, master, oh!

We wish our master a Happy New Year, oh!

22b. A WORK SONG

(Bray c1860:314)

Apart from rowing songs (see nos 15 and 16 above), worksongs (wrokomansingi) are very scarce in earlier sources. One of the few references is found in Bartelink (1916:28), quoted in Van Kempen (2003: 166-167), who says that he heard songs being sung during the 'breaking' of the coffee beans, however without providing any text. The only text of song that was sung during the pounding of coffee I have found is given in a piece written by Théodore Bray, which contains several drawings of the scene. Since descriptions of work songs are so rare, it may be good to quote the entire passage describing the process of coffee pounding:

While the kwa kwa man pounds a rhythm on his stool, ${ }^{40}$ represented by the following words:

Koua katakoua katakoua katakoua katakoua, half of those who are pounding mutter:

Maka fissi boun maka fissi boun, etc, while the other half sings the octave, the fifth and the third on a single note. This orchestra, in which the pestles beat the rhythm, serves to accompany the women who sing while moving the part of the body on which one sits:

Mia ouan toutou na mi hoso (I have a trumpet in my house)

Di mi no bolio, pan (When I don't cook, pan!)

39. A photocopy of Bray's pieces in L'Illustration, containing nos 22a and 22b, was graciously made available to me by the late Monsieur Marcel Chatillon, for which I am very grateful.

40. This refers to the so-called kwa kwa bangi, a small wooden stool used as a drum; the kwa kwa bangi plays an important role in $d u$ and banya performances. 
Ouan enklé néti mi no bolio (A single night I not cook)

Toutou hé bolo pan, pan, patapan, panpan (Trumpet cries pan)

Toutou hé bolo pan, pan, patapan, panpan (Trumpet cries pan)

(This last line is the only one which is sung while the pestles are pounding).

I wouldn't know how to express how tarantulizing (I don't know which stronger word to use) are this note held by voices, some low, some high, the sound of the sticks on the stool, the regular movement of the pestles, the raucous singing of the women. To make you understand the sensation which all this makes my nervous system undergo, I'll say that I've heard the Juive, the Huguenots, Robert and all the rest without giving the delicious music of these operas anything but my utmost attention. However, as soon as my working gang gets going a power which I cannot control carries me away in the coffee barn; as soon as I arrive, my feet begin to move, my fingers beat the rhythm, and after a few minutes I not only sing along softly but if it were not for the respect which I owe myself I would look for a sounding object to play my part in this orchestra to get rid by this means of the musical electricity with which this african melody has charged me. Five minutes are enough to strip the coffee of its pellicles. The negroes are so much used to this work that they know instinctively at which moment they should stop in order not to break the beans. One of them, usually the one at the front, cries: Mahou!, with a heavy and lengthy leaning on the last syllable of this word. As soon as he stops, everyone puts their pestles down'. (Bray c1860:314)

As in my transcription of the previous text, I have transposed Bray's orthography into modern Sranan spelling. The first line, which is a purely sound symbolic representation on the part of Bray, is not included here. The second line is treated separately from the main text since it does not seem to be part of that.

Maka fisi bun maka fisi bun.

Makafisi ${ }^{41}$ is good, makafisi is good.

Mi a wan tutu na mi oso.

Di mi no boli o, pan.

Wan enkri neti mi no boli o.

Tutu e bolo 42 pan, pan, patapan, panpan,

Tutu e bolo pan, pan, patapan, panpan.

41. Maka fisi is a fish species which has a lot of bones (cf.maka 'prickle, thorn').

42. Probably a variant of blo/bro, which means 'to blow', as in bro toetóe 'to blow the horn' (Focke 1855, s.v. bro). 
I have a horn at home.

If I don't cook, ah, pan, ${ }^{43}$

If I don't cook one single night, ah,

The horn blows pan, pan, patapan, panpan, ${ }^{44}$

The horn blows pan, pan, patapan, panpan.

Although Bray realized that these words have a hidden meaning (cf. his note 2), his laborious paraphrase does not get to the core of the song, which, in my opnion, is a complaint about a man who overasks his woman sexually ( $c f$. e.g. the horn as a phallic symbol, the 'cooking' at night; the reference to the female sexual organ, and the fact that this part of the song is sung by women). This interpretation would fit in with the fact that there is a long tradition of hidden meaning, including sexual allusion, in African-American song, including, for example, the blues. ${ }^{45}$

\section{3. 'Puttin' on ole Massa' (1862)}

(Hoogbergen 1996: 84)

One of the uses to which songs were sometimes put was to make a fool of the master without him knowing it (a practice known in the American South as 'puttin' on ole massa'; $c f$. Abrahams 1992). For this effect to be obtained, the words used in the song had to be mysterious or ambiguous or in any other way not fully comprehensible to the white man. The song below is an example of that: it was sung during a party on the eve of a group escape from plantation Rac-à-Rac on September 14, 1862 (Hoogbergen 1996: 84). Although the text contains a clear allusion to the impending event ('tomorrow when you won't see me anymore'), apparently this was not enough for the master's to realize an esacape was about to

43. Pan is an ideophone expressing fullness.

44. Apart from being a repetition of the word pan, panpan also occurs as an independent word, meaning 'cunt'.

45. In some other songs, however, reference to sex is entirely explicit, as shown, for example in the following lobi singi, collected by Herskovits \& Herskovits (1936:30), who say that this type of song - understandably - was only sung in private. In my translation I have tried to retain the flavor of the original, e.g. translating bombina by 'vagina-lips' (following Herskovits and Herskovits) rather than 'labia'.

Tu bombina na lontu

Tu stonsiri na kontu,

Ala feif' yuru mamantem

$B$ skin de steifu.

Two vagina-lips around it,

Two balls against my ass,

Every morning at five o'clock

B's cock is hard. 
happen. He was fooled by the greeting kuneti 'goodnight' into thinking they were merely wishing him a good night's rest.

Gransmasra kunet-iii,

Granmisi kunet-ooo,

Bika tamara te you no si mi moro miauw.

Mi koti,

Odi di masra!

Mi wai,

Odi di masra!

Gransmasra kunet-iii, Granmisi kunet-ooo,

Bika tamara te you no si mi moro miauw.

Granmasra,${ }^{46}$ goodnight,

Granmisi ${ }^{47}$ goodnight,

Because tomorrow when you won't see me anymore: 'meow'.

I cut, ${ }^{48}$

Howdy Masra!

I weeded,

Howdy Masra!

Granmasra, goodnight, Granmisi, goodnight,

Because tomorrow when you won't see me anymore: 'meow'.

24. Slaves get PUnished, FREEMEN Do Not (pre-1863) (Comvalius 1948-9:20; also in Comvalius 1922:40)

This song was sung by free blacks and mulattoes, celebrating the fact that in contrast to slaves they did not run the risk of being punished, even if they were to do foolish things (Comvalius 1948-9: 18).

Stopoe dram na wan takroe dringie,

A mek' mi kos' mi granmama.

Stopoe dram na wan takroe dringie,

A mek mi kos' mi granmama.

Ef' na Jaw ef' na Kwasie

A ben sa go na Morgodam,

Ef' na Jaw ef' na Kwasie

A ben sa go na Morgodam.

Grantangi Masra, Grantangi misi,

Mi sa go na Morgodam!

46. Granmasra is the plantation owner.

47. Granmisi is the wife of the plantation owner.

48. This refers to the cutting of sugar-cane. 
A bottle of dramis an evil drink,

It made me curse my grandmother.

A bottle of dramis an evil drink,

It made me curse my grandmother.

If Jaw or Kwasi ${ }^{49}$ would do something like that,

They would go to Morgodam. ${ }^{50}$

If Jaw or Kwasi would do something like that,

They would go to Morgodam.

Thanks very much, Master! Thanks very much, Mistress ${ }^{51}$ !

I will go to Morgodam!

25. Celebrating Emancipation (1863)

(Bonaparte 1884: 190)

This song, of which only the first stanza is included here, was composed by the Moravian missionaries Bau and Van Calker (Klinkers 1997: 113). It belongs to the Moravian genre of aria-singi 'aria songs', usually set to well-known (often German) tunes, mostly with Sranan words. It is included here as a specimen of that genre, even though it is not as clearly part of the oral tradition as most other songs in this section are. Aria singi were published in many editions from 1853 onwards (Voorhoeve \& Donicie 1963:66-67). The song below was made to the occasion of the abolition of slavery on July 1, 1863. Ironically, it is set to the tune of 'Wien Neerlands Bloed', a national hymn of the time celebrating those 'through whose veins runs Dutch blood, free of foreign stains'.

Singi vo da 1. Juli 1863

Gi Konoe Willem bigi nem,

En tjari tangi kom!

Kom singi switi, prijzi hem,

A doe wan bigi boen;

A potti alla ningre fri,

A poeloe wi na sjem,

Da diri Konoe Willem dri,

O Gado, blessi hem.

Song for the First of July, 1863

Pay tribute to King William

And give him thanks.

49. Names of slaves: Jaw and Kwasi are the day-names for males born on a Thursday and a Sunday, respectively.

50. A place where slaves would be brought to be punished.

51. This is an allusion to the custom that slaves had to thank their masters for being punished. 
Come sing a sweet song and praise him,

He did a very good thing.

He made all blacks free,

He pulled us out of shame.

The beloved King Willem III,

Oh God, bless him.

\section{Poking fun at the nouveaux Riches (c1870)}

(Comvalius 1922:26-7)

This song belongs to a genre called banya, a kind of 'musical comedy...based on a simple story with fixed characters' (Voorhoeve \& Lichtveld 1975: 17). The song was meant to make fun of someone who rose to wealth after having come to Suriname from Curaçao, where he had been very poor. As happened more often with songs in which a white person was ridiculed, this song was composed and performed by a banya group on the order of another white. This tradition of whites' use of blacks to ridicule other whites is remarkable enough to receive more attention than it has thus far.

Wan Jobo, ee barie, oo,

Drie dee langa em no njam wan njanjam,

Wan kankie birie ben holie hem liebie.

A waka kom na Saranam,

Tidee a kom tron wan goedoeman:

Wakaliebie, na joe doe hem na boen!

A white man is crying out,

For three days he didn't have a thing to eat.

A little jug of beer kept him alive.

He came to Suriname.

Now he is well off:

Course of life, it's you who made him wealthy.

27. Mock-PRAISE FOr Governor VAn SyPesteyn (c1880) (Comvalius 1948-9: 19)

This song is clearly ironical: building a flower gardens for the ladies and benches for the gentlemen is not eactly what blacks would appreciate a Governor for. Irony was a widely used trope in (ex-)slave communities throughout Afro-America, where the ability to say one thing while intending another was an indispensable survival strategy (cf. Abrahams 1983, 1992; Gates 1988).

Graman Sypensteyn, mi teri joe, mi teri joe,

Graman Sypensteyn, mi teri joe vo troe.

Graman Sypensteyn, mi teri joe, mi teri joe,

Graman Sypensteyn, mi teer joe wan Graman. 
Joe meki blomki-djari gi dem missie,

Joe meki langa bangi gi dem masra;

Graman Sypensteyn, mi teri joe, mi teri joe,

Graman Sypensteyn, mi teer joe wan Graman.

Governor Van Sypesteyn, I regard you highly, I regard you highly,

Governor Van Sypesteyn, I regard you highly for sure.

Governor Van Sypesteyn, I regard you highly, I regard you highly,

Governor Van Sypesteyn, I regard you highly as Governor.

You made flower gardens for the ladies,

You made long benches for the gents.

Governor Van Sypesteyn, I regard you highly, I regard you highly,

Governor Van Sypesteyn, I regard you highly as Governor.

28. A CHILDREN's SONG (pre-1884)

(Bonaparte 1884: 190)

The only information provided by Bonaparte (1884:190) is that this is 'a tune sung by the black children passing through the streets of Paramaribo'.

Dat a no manirie

Fo so wan soerdatie

Fo libie da kartirie

Fo wakka na Combé.

What a strange thing

to do for a soldier.

To leave the barracks

And walk to Combé. ${ }^{52}$

29. Pride in the face of oppression (19th century?)

(Voorhoeve \& Lichtveld 1975:34)

This song belongs to a genre called laku, which is similar to the banya, but probably of more recent origin 'The laku has essentially the same pattern as the banya, but the drama is more elaborate and executed by many costumed actors, both men and women' (Voorhoeve \& Lichtveld 1975: 17). This song, with its repetition of the first line and its 'twelve beats to the bar' structure seems to foreshadow what at a later time - around the turn of the 20th century - and a different place - the Mississippi Delta - was to become 'the blues' (e.g. Lomax 1993). Although this is not meant to suggest any direct link between Surinamese song types and the American blues, it might be interesting to investigate the possible roots of the latter in similar types

52. At the time, a fairly new 'suburb' of Paramaribo. 
of song that may have existed in the American South. The song below is certainly not the only one to display a blues-like structure: e.g. songs nos. 13 and 31. As in some other songs, the force of the metaphor is striking.

Mi na kakfowru, kron de a mi ede

Mi na kakfowru, mi kron de a mi ede

Kaba wansi nefi de a mi neki,

Mi kron de a mi ede

I am a rooster, a crown is on my head,

I am a rooster, my crown is on my head.

Although the axe is at my neck,

My crown is on my head.

30. Two NDyuka DANCE SONGS

(Van Panhuys 1912:32)

Between 1893 and 1896, L.-C. Van Panhuys, Esq. recorded several songs sung by the Marowijne Ndyuka while dancing (Van Panhuys 1912:32). Two of these are reproduced below. Although most of the words in these songs seem to have no clear meaning, they are still included here as there are only very few earlier texts in Ndyuka.

30a. A BABOON SONG

Baboun ${ }^{53}$ yé yé yé

Baboun yé yé yé

Baboun yé yé yé ye gongolo gongolo gongolo

Baboon yé yé yé

Baboon yé yé yé

Baboon yé yé yé ye gongolo gongolo gongolo ${ }^{54}$

30b. The White-toothed Black

Da ningre nanga witi tana gi you o-di

The negro with white teeth says hello to you

yé yé yé yé yé yé yé yé ayemba

yé yé yé yé yé yé yé yé ayemba

53. Note that the use of ou to represent /u/ in baboun and you is influenced by French spelling conventions.

54. For what it's worth: Gongolo 'lit. millipede' is a personal name in Kikongo; it is also the name of a Dahomeyan king (Turner 1949:91). 
The lobi singi 'love song' is a female genre, which often - but not exclusively ( $c f$. song no. 32) - deals with lesbian relationships, especially a former lover. ${ }^{55}$ Although some lobi singi, just like some banya and laku songs, were used for public mockery, there are others which are entirely devoted to the celebration of love. For a brief introduction to the genre of lobi singi, see Voorhoeve \& Lichtveld (1975: 18-20); for a more elaborate treatment, see Herskovits \& Herskovits (1936:23-32).

Efoe wan lobbie ben lobbie mi, a no lobbie mi moro,

Efoe wan lobbie ben lobbie mi a no lobbie mi moro,

Mi no kan kirie mi srefie vo datie hede

Although a lover loved me, she doesn't love me any more,

Although a lover loved me, she doesn't love me any more,

I can't kill myself because of that.

32. An unfaithful husband (c1900)

(Comvalius 1948-9: 14; also in

Comvalius 1922: 39-40; Comvalius 1939:360;

Voorhoeve \& Lichtveld 1975:48)

This lobi singi is by Christiana Loloba, who accused her husband Sander publicly through song, after he had left her and her children for another woman. After some time, Sander started making inquiries to see whether he would go back to her; when he decided not to, Christiana added the last two odo-like lines (Comvalius 1922:40). While Sander saw everybody gradually turn their backs on him, Christiana, turning necessity into virtue, managed to earn a living by singing these songs on Sunday afternoons in the streets of Paramaribo (Comvalius 1948-9: 13).

Wan lage karaktre meki onderzoekoe,

pee mi de, fa mi tan,

pee mi de, fa mi tan.

A no jere mi nem, a no de si mi persoon,

O fa mi tan.

Nanga mi broko kotto en mi doti jakie,

so mi de, so mi tan,

so mi dee, so mi tan.

Mi no kom moro hei, mi no kom moro lage.

So mi dee, so mi tan

Masra Sander kom tron bigie toddo,

A no man takie watra foero hem moffo!

55. For more information on the phenomenon of so-called mati werk - the institutionalized system of lesbian relationships among black women in Suriname - see G. Wekker (1993). 


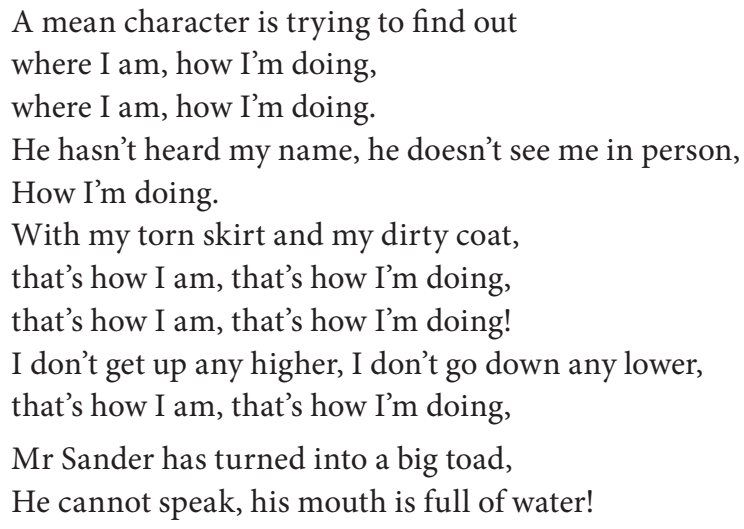

33. NobOdY KNOWS YOU WHEN YOU'RE DOWN AND OUT (c 1900)

(Comvalius 1922:28-29)

This is a banya song about a man who squandered his fortune on his friends. When he is broke, he turns to one of them asking for charity. Presented below is the first stanza of one of 'the four long poems' of which this song consists (Comvalius 1922: 27).

\author{
Wakaliebie gi ondervinding \\ Wan Jobo ee barie, oo, ${ }^{56}$ \\ Hem dee hopo na hem moni tapoe? \\ Na so em de waka na em goedoe tapoe. \\ Hem no ben denkie wan tem kan dee, \\ Vo so wan ogrie tesie kom nakie na hem doro. \\ Meebrie voe hoso'em no habie moro, \\ Kontantie monie 'em no habie moro, \\ Na now' em go doe bezoekoe \\ $\mathrm{Na}$ wan njoen goedoeman hoso. \\ So 'em dee nakie na fesi doro, \\ Dan goedoeman dee loekoe, na abra vensree \\ Dan joe tan jéré na antoewoortoe, \\ Die a dee taigi em: \\ "No pottie joe foetoe na inie mi hoso, \\ Voe joe kom dottie mi hoso gi mie, \\ Tan na mi doromoffo, \\ Efi mi a wan monie, mie sa iet em gi joe!" \\ Nanga ala vâa dee taki so, \\ Va mi eê breetie na mi hatti inie!
}

56. Note that this line is identical to the first line of song no. 26 . 
Waka liebie, voe a iet a moni gi mi!

Dan mi poeloe mi hattie, danki Gado.

Ma die meê drai gwee,

San fadon na mi hatti?

Watra ben ron na mi ai:

Bika mi srefi ben dee wan goedoeman,

Loekoe woortoe, die wan trawan ee taigi mi!

Life $^{57}$ brings experience

A white man is crying out, oh,

His money has lifted him up??

Just so his good fortune lets him walk??

He didn't think there could be a time

That such a bitter ordeal would come knocking on his door.

House furniture he doesn't have anymore,

Cash money he doesn't have anymore.

Now he's going to visit

The house of a nouveau riche.

So he's knocking on the front door,

The wealthy man is looking over the shutters.

Then you hear the reply,

When he's telling him:

"Don't put your feet inside my house,

Coming to dirty my house like that,

Stay at my doorstep.

If I have any change, I'll throw it to you!"

Although he spoke like that,

How happy was I inside my heart,

Life, that he threw me the money!

Then I took off my hat and thanked God.

But as I turned around,

What fell into my heart?

Tears were running down from my eyes:

Because I had been a wealthy man myself;

Such terrible things they are saying to me!

57. Since the word waka libi does not occur in any of the older dictionaries, it is difficult to present the correct equivalent here. In view of the context of the song, perhaps it means something like 'squander'. According to a recently published dictionary of Modern Sranan, its present meaning is 'promiscuity, living like a whore' (Blanker \& Dubbeldam 2005, s.v. waka libi). 
This song was obviously sung as part of a game; note the French-influenced spelling of tou (although toe occurs as well) for tu 'two'.

Wan tron draai

Nanga toe tron draai

Sinési sipi dé go wé

Nakki poti wan

Nakki poti tou

Nakki poti dri

Nakki poti fo

Tou tron draai

Nan drie tron draai

Sinési sipi dé go wé

Turn once

And turn twice

The Chinese boat ${ }^{58}$ is going away

Strike one

Strike two

Strike three

Strike four

Turn twice

And turn three times

The Chinese boat is going away

35. A lullaby (c1900)

(Van Panhuys 1912:35-36)

In this song, the word friman refers to a member of the black army corps. Slaves who joined this corps would become free upon their retirement (see notes to song no. 5). The song is categorised as a lullaby by Van Panhuys 1912:35).

Friman Taria kon njam, Koprou ${ }^{59}$ Kanon man tan déeeee

Free man, Taria, come eat; Copper Canon man, stay where you are

36. A COMICAL SONG (c1900)

(Van Panhuys 1912:38-39)

This is a bilingual (Sranan-Dutch) song; the Dutch is printed in bold. Although, unfortunately, Van Panhuys does not tell us what's so funny about this 'air railleur et comique' (p. 38), I suspect it has something to do with sex.

58. This may refer to the boats that brought Chinese contract laborers to Suriname, the first of which arrived in 1853.

59. Koprou Kanonman is the name of a feared Maroon; <ou $>$ represents /u/. 
Geloof mij vrij, geloof mij vrij, trouw koukou da ${ }^{60}$ bottrij.

Mi taki you, trouw koukou dena bottrij.

Mi taki you, trouw koukou déna bottrij.

Kon bribi mi, trouw koukou déna bottrij.

Geloof mij vrij, geloof mij vrij, trouw koukou déna bottrij.

Believe me truly, believe me truly, the wedding cake is in the pantry.

I'm telling you, the wedding cake is in the pantry.

I'm telling you, the wedding cake is in the pantry.

Come and believe me, the wedding cake is in the pantry.

Believe me truly, believe me truly, the wedding cake is in the pantry.

37. A SATIRICAL ROWING SONG (1900)

(Van Cappelle 1926:224-225)

The boto singi reproduced below provides a nice example of the innuendo used by blacks in their songs, which often went unrecognized by its victim. In this case, the target of the satire was Mr Van Cappelle, the man who published the song, without realizing, however, that the joke was on him. The clue is that the word Kaperka (in Kaperka kiri mi 'Kaperka is killing me') not only refers to the hill of that name, as assumed by Van Cappelle, but also to Van Cappelle himself, who the rowers felt asked too much of their physical strengths ( $c f$. the comment under song no. 15 regarding rowers' custom of using nicknames for the whites they had on board).

O, Nickérie! Mi lobi di, ${ }^{61}$

Ma dem bergi de hei so te.

Kaperka kiri mi,

tja' fracht na kilometer siksi.

Ma dem bergi de hei so te.

Wroko foe joe moni,

Wroko foe joe moni,

Te wi de na Fallawatra

da so wi de wroko wi moni.

Ah, Nickerie, ${ }^{62}$ I love you,

But the hills are so very high. ${ }^{63}$

Kaperka is killing me,

6o. dade na 'is in'.

61. Typo for $j i / y i$ 'you'?

62. Nickerie is the name of a river.

63. Due to the terraced structure of the Surinamese landscape, boats often had to be taken out of the water and carried overland past a sula 'waterfall', before a journey could be continued. 


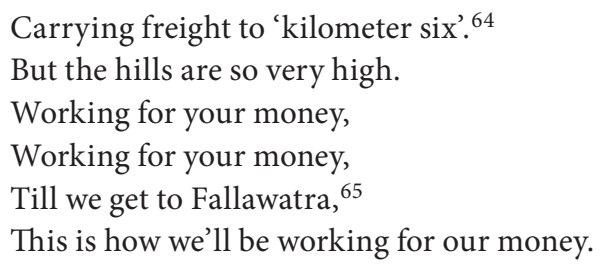

38. The TONGUE OF THE GODS

(Franssen Herderschee 1905: 125)

As was mentioned in Chapter 4, certain relics of African languages may still be heard in Suriname today, but their use seems to be largely restricted to religious (winti) ceremonies. One of these languages, called Kromanti and probably based on Twi, has been documented fairly well by Herskovits \& Herskovits, who included more than thirty Kromanti songs in their Suriname Folklore (1936:531-55). ${ }^{66}$ While these songs were collected among the Saramaka in 1929, I found a slightly older reference to Kromanti as used by a Ndyuka in an early-19th-century travel account (Franssen Herderschee 1905: 125). A Ndyuka member of the expedition, who is in lot of pain having been stung by a stingray, 'starts speaking in gadoe tongo[lit.: gods' language, JA] ... or Kromantie' (p. 125). His words are presented as follows:

héi, héi, héi, tangka, tangka, pioka, pioka, plawa, plawa, plawa, plawa, tangka, koto, koto, héi, héi, plasji, plasji, plasji, plasji, plasji, tloki, tloki, tloki, tloki, tloki, kille, kille, kille, kille, kille, plawa, pioka

Unfortunately, not enough is known about Kromanti at this moment for me to be able to provide a translation here.

39. The national anthem of Suriname (1959)

(Encyclopedie 1977: inside front cover)

Although the Sranan stanza of the national anthem was not composed until $1959^{67}$ and, therefore, strictly speaking falls outside the period covered here, it seems like the right text to conclude this section. While the original text of the anthem

64. The name of a place along the river.

65. A tributary of the Nickerie River.

66. Additional songs in other secret languages can be found elsewhere in the book: $c f$. Herskovits \& Herskovits (1936:556-578,629-685). This treasure of information on Suriname's secret languages, together with the sound recordings of these songs which are still available - be it in severely damaged form - is yet to be explored.

67. Suriname had become semi-autonomous in 1954. 
(composed in 1893) was in Dutch, the poet Trefossa ${ }^{68}$ was asked by the government to write an extra stanza in Sranan, the text of which is reproduced here.

Opo kondreman oen opo!

Sranan gron e kari oen.

Wans ope tata komopo,

Wi moe seti kondre boen.

Stré de f'stré wi no sa frede,

Gado de wi fesiman.

Eri libi te na dede,

Wi sa feti gi Sranan.

Up, fellowmen, get up!

The land of Suriname is calling you.

Wherever our ancestors came from,

We must build up this country well.

Struggles have to be fought, we will not be afraid,

God is our leader.

Our whole life until we die

We will fight for Suriname.

\section{2 $\operatorname{Odos}^{69}$}

This section is devoted to odos, the proverb-like sayings which play a prominent role in Surinamese creole culture. By way of introduction to this genre, let me quote Herskovits and Herskovits, who included well over 200 Sranan and Saramaccan odos in their (1936) Suriname folk-lore:

Among the Suriname Negroes of both town and bush, proverbs are employed in every kind of situation as they are in Africa. They are a prime factor in the education of the young, in pointing a lesson to a fellow adult, in passing a judgment on someone newly met...In the bush, proverbial sayings are woven into all conversation, and it is characteristic of an elder of a village, or a man who has standing in his group, that he is an adept at introducing these pithy sayings...Indeed, in the bush it may well be said that the skillful use of these proverbs marks the man who in our own civilisation would be regarded as scholarly. In the town, also,

68. For more information on Trefossa, one of the most gifted poets in Sranan, see Voorhoeve \& Lichtveld (1975: 195-215).

69. Unfortunately, I have not been able to find any early examples of Saramaka odos; $c f$., however, the two Djutongo proverbs disussed below. 20th-century examples of Saramaka odos can be found in Herskovits \& Herskovits (1936:473-81). 
it is the older people who introduce these proverbial asides and comments most frequently, but since...the culture is carried on chiefly by women, the proverbs in most frequent and most vigorous use are those that enter into disputes, either as threats, or with vituperative intent, or as expressions of indifference to threats... We find...that human ingratitude is remarked upon, and the faithlessness of women; that foolish show of courage is deplored, and boastfulness is ridiculed; that caution is recommended, and discretion, but not timidity; and the point is made that no one is so powerful or exalted that there is not someone to meet him on his own terms; greed is criticised, but reckless generosity is enjoined; the importance of wisdom is cited, and the role of necessity stated... Stylistically, the proverbs are given in a few instances as rhymed couplets, and all show a fixed rhythmic patterning.

(Herskovits \& Herskovits 1936: 135-136)

Since the purpose of this chapter is to present older texts, the odos in this section are all taken from 19th-century sources: Teenstra (1835), Focke (1855), and Wullschlägel (1856). These three works contain the by far largest collections of odos published before the 20th century: there are 300 of them in Teenstra (1835, vol 2:211-242), between 100 and 200 scattered throughout Focke's dictionary (1855, passim), and no less than 707 in Wullschlägel (1856:301-340). The examples presented below occur in all three collections, albeit in (slightly) different versions, including differences in spelling; they were selected specifically to enable comparison across the three sources. The odos taken from Teenstra and Wullschlägel are referred to by the numbers under which they appear in these works; those from Focke are identified by the dictionary entries under which they are quoted by him. Apart from the fourteen odos which occur in all three works, there are two, one of which is found only in Wullschlägel, the other in both Wullschlägel and Teenstra, which are in some form of Portuguese-based creole, possibly related to Djutongo.

Since proverbs are generally quite archaic both lexically and structurally, the odos presented here may well be representative of older stages in the development of Sranan (and, to a much lesser extent, Saramaccan). For the same reason, their modern equivalents are not very different from their 19th-century counterparts (apart from superficial aspects such as spelling). For a modern collection of some 1,000 (!) odos, see Schouten-Elsenhout (1974); for a brief introduction to the genre, see Herskovits \& Herskovits (1936: 5-7, and, especially, 135-136). 


\section{SRANAN ODOS}

1. a. Kakalakka no habi reti (of leiti) na fowlo moffo (Teenstra 1835, no. 14 ${ }^{70}$ )

b. Kakaráka no ha' réti na fówloe mófo (Focke 1855, s.v. mófo)

c. Kakraka no ha reti na fouwloe mofo (Wullschlägel 1856, no. 318) Cockroach has no rights in the mouth of a bird.

2. a. Saranam kondré na hasi terre, ti dé à waij so, tamárre á wai so (Teenstra 1835, no. 24)

b. Sranam ${ }^{71}$-kondre da hási-tére : tide a wai so, tamara a wai so (Focke 1855, s.v. Sranámí)

c. Sranàm-kondre da hasi-tere: tidèi a wai so, Tamara a wai so (Wullschlägel 1856, no. 597)

Suriname is a horse-tail: today it goes this way, tomorrow that way.

3. a. Ala piri tifi, a no lafoe (Teenstra 1835, no. 40)

b. Alla píri tífi a no láfoe (Focke 1855, s.v. tífi)

c. Ala pili Tifi a no lafoe (Wullschlägel 1856, no.625)

Not all showing of teeth is laughing.

4. a. Tangi foe Spansi boko, miki mi si beniforto (Teenstra 1835, no.67)

b. Tangi foe pansibóko, mi si Binnifóto (Focke 1855, s.v. tangi)

c. Tangi vo spansi boko mi si binfoto (foto) (Wullschlägel 1856, no. 622) Thanks to the Spanish buck ${ }^{72}$ I've seen the inside of the fort. ${ }^{73}$

5. a. Boesssi-Nengre sabi, ho pranassi á dé Brokko (Teenstra 1835, no. 91)

b. Bóesi-ningre sábi ho pranási a de bróko (Focke 1855, s.v. bróko)

c. Boesi-mingre ${ }^{74}$ sabi, hoe pranasi a de broko (Wullschlägel 1856, no. 107) The bush-negro know which plantations to plunder.

70. The use of italics in Teenstra (used to distinguish nouns from other parts of speech) has been discarded here.

71. Focke's $<\mathrm{m}+$ circonflexe $>$, used to represent its word-final realization as $/ \mathrm{\eta} /$, has been replaced by $<$ ḿ $>$ in my transcription.

72. The 'Spanish buck' was one of the most cruel ways of punishing slaves.

73. The 'fort' is Fort Zeelandia, the 17th-century fortification which formed the basis of the city of Paramaribo and where slaves were taken to be punished. The word 'fort' is the etymon of the Sranan word foto 'Paramaribo, town'.

74. A typo for ningre. 
6. a. Al wassi (= alwassi) fa Ingi droengoe, to koe (= tokoe) a saféni (= sa feni) hem amaka (Teenstra 1835, no. 101)

b. Alwássi fa Iéngi ${ }^{75}$ droéngoe, tókoe a sa sabi heḿ hamáka (Focke 1855, s.v. alwássi)

c. Alwasi fa Ingi droengoe, tokoe a sabi hem hámaka (Wullschlägel 1856, no. 299) No matter how drunk an Indian, he will still find his hammock.

7. a. A no soléki arén blakka, a no so a dé fadon (Teenstra 1835, no. 105)

b. A no so l'ki arén brákka, a no so a de fadón (Focke 1855, s.v. arén)

c. A no so leki Arèen blaka, a no so a de fadóm (Wullschlägel 1856, no. 36) The rain does not fall as black as it looks.

8. a. A no mi lafoe koni-koni meki a no habi terre (Teenstra 1835, no. 110)

b. A no mi lafoe koni-kóni, di a no ha tére (Focke 1855, s.v. láfoe)

c. A no mi lafoe koni koni, meki a no ha tere (Wullschlägel 1856, no. 385)

It's not me who laughed at the rabbit for having no tail.

9. a. A no ti dé a wiwiri fadon na watra, a no ti dé á pori (Teenstra 1835 , no. 149)

b. A no tid'ía wiwiri fadón na wátra, an tid'ía a póri (Focke 1855 s.v. ti)

c. A no tidèi Wiwiri fadóm na watra, a no tidei a de pori (Wullschlägel 1856, no. 693)

A leaf that falls into the water today is not going to rot today.

10. a. Je sa kibri ouroe mama, ma joe no sa kibri hem frikou toe (= frikoutoe) (Teenstra 1835 , no. 157)

b. Joe kan kíbri óuroe-mamà ma joe no kan kíbri heḿ froekóutoe (Focke 1855, s.v. kíbri)

c. Joe sa kibri ouroe mamà, ma joe no sa kibri hem verkoutoe (Wullschlägel 1856, no. 483)

You can hide your grandma but you can't hide her coughing.

11. a. Táki man, a no doe man (Teenstra 1835, no. 161)

b. Tákiman a no dóeman (Focke 1855, s.v. táki)

c. Takiman a no doeman (Wullschlägel 1856, no. 610)

Talking is not the same as doing.

12. a. A no foe hangri tem héde meki mi sa kali taya tatá (Teenstra 1835, no. 176)

b. A no foe hángri-tem héde, méki mi sa kali Tája "Tata (Focke 1855, s.v. tája)

c. A no vo hángritem hede, meki mi sa kali Taja tatà (Wullschlägel 1856, no. 606)

The fact that there's a famine is no reason for me to call taya ${ }^{76}$ 'Father'.

75. $<\mathrm{I}>$ corrected for $<\mathrm{J}>$, according to the Errata to Focke (1855) (taken from Focke's unpublished notes), published in Moens (1858:304).

76. A tuber species. 
13. a. Asau sabi fa hen lassi bradi, aswari (= a swari) kokronoto (Teenstra 1835, no. 192)

b. Azáu sâbi fa heḿ lási brâdi, a swâri kokronoto (Focke 1855, s.v. swâri)

c. Azáu sabi, fa hem lasi bradi, a swali kokronoto (Wullschlägel 1856, no. 42) The elephant swallows the coconut because he knows he has a fat ass (i.e. he knows he will be able to get rid of it).

Two early Ndyuka odos:

14. Te pikien boessi kiebrie joe boen, dan joe no moesoe falla biegie boessi te joe toeka naka ${ }^{77}$ hen (Coster 1866:23)

If a small bush covers you well, don't fell a big bush when you happen to come across it.

15. Na srefie avie ${ }^{78}$ die de falla pikien bon, de falla bigie wantoe (Coster 1866:23) The same ax that fells little trees fells big trees too.

16. a. Moetoe ${ }^{79}$ bira ji táki ${ }^{80}$ pari poeloe pondo (Teenstra 1835, no. 117)

b. Móendoe birà joe téki pári póeloe póndo (Focke 1855, s.v. pári; s.v. póeloe)

c. Moendoe bira: joe teki pari, poeloe pondo(Wullschlägel 1856, no. 440)

It's a world gone wrong: you row the pontoon with a paddle ${ }^{81}$ (i.e. you have to make do as best as you can).

17. a. [not found in Teenstra 1835]

b. [not found in Focke 1855]

c. Praga beroegoe no mata caballo(Wullschlägel 1856, no.488)

The curse of an ass does not kill a horse

Odo no. 16 is especially interesting as it appears to be a mixture of Saramaccan and Sranan: moendoe and bira are Saramaccan, pari and pondo are Sranan, while ji, teki and poeloe occur in both languages (cf. Schumann 1778 s.v. mundu, bilà, i, teki, pulu; Schumann 1783 s.v. ju, teki, pali, pulu; Focke 1855, s.v. póndo). While Focke (1855, s.v. pári; s.v. póeloe) states that the first two words are derived from Portuguese, Teenstra (1835:223) adds the additional information that it is a Jodenslavenspreuk'proverb of the Jews' slaves'. This suggests that the language of the proverb is (related to) a form of Djutongo, the Portuguese-based creole once

77. A typo for nanga?

78. A typo for akisi?

79. A typo for moendoe.

8o. A typo for teki.

81. A pondo is a big boat used for transportation of large quantities of goods; a pari is a paddle only fit for rowing smaller boats. 
spoken on Jewish plantations ( $c f$. Chapter 4). However, the fact that it is included both in Wullschlägel and Focke without this additional information suggests that it was also used by Sranan-speaking blacks. The presence of the Sranan words may suggest that the proverb as it is presented here is a partly relexified version of an older Djutongo proverb in which the Portuguese- rather than the Englishderived words for 'paddle' and 'pontoon' were used. The last odo (no. 17), tentatively identified as 'Negro-Portuguese' by Wullschlägel p. 328), consists almost entirely of unambiguously Portuguese-derived words (only the word no, which occurs both in Early Saramaccan and in Sranan, is derived from English). Somewhat surprisingly, however, most of these words (praga, mata, caballo) are not part of the Early Saramaccan lexicon, while another (beroegoe) differs somewhat from the form one would expect (buruku) (Smith 1987: 130). This means that this odo may not be taken to represent Early Saramaccan. With regard to Djutongo, however, the situation is a little different because we only have a very short list of Djutongo words at our disposal. The fact that these Portuguese-derived words are not in this list does not necessarily mean they were not part of the Djutongo lexicon. If the language represented is indeed Djutongo, it would be one of the very few attestations of this mysterious language. For the time being, however, it may be safest to follow Smith in identifying this proverb as 'Suriname Portuguese Creole' (without necessarily adopting the assumption that it was brought from Pernambuco; cf. Arends 1999; Smith 1999). As shown by Smith (1999: 138-139), the Suriname Portuguese Creole odo shows some striking parallels with proverbs in other creole (as well as certain European) languages. The first part of the odo is identical to, for example, the corresponding part of the Senegalese Portuguese Creole version: Prága di búru kataçiga na séu 'The curse of an ass does not reach heaven', while the second part is analogical to the Sranan version: Bari vo ouroe-koekoe no de kili hasi 'The screeching of an owl does not kill a horse' (Wullschlägel 1856:328). This suggests that the Suriname Portuguese Creole version may be a composite of a number of lexcally different but functionally equivalent proverbs, which would make it very difficult to determine its source and linguistic affiliation.

\subsection{Anansi stories}

The term Anansi tori refers to all kinds of folk-tales, not just those featuring the trickster-spider of that name. Some of them, for example, belong to the category of etiological stories, stories that explain the origin of something, like 'How come the giraffe has such a long neck?' The two stories reproduced below fall in a kind of mixed category. In both, the origin of an animal's feature (the spider's eight legs, the cross on its back; the woodpecker's digging into trees) is 'explained', but Anansi appears in both stories too, albeit in a very minor role in the second one. 
Although, unfortunately, I have not been able to find any early folk stories, I have still chosen to include two of them here, for the simple reason that a book about the creole languages of Suriname would not be complete if it does not contain at least one or two of these wonderful stories. The first one, in Sranan, was recorded in 1929 by Frances ${ }^{82}$ Herskovits (1936); the second one, in Saramaccan, was recorded in the early 1970s by Naomi Glock (Rountree \& Glock 1977). For a concise introduction to Sranan folk-tales, see Voorhoeve \& Lichtveld (1975: 76-79) which also contains several lengthy specimens; for a somewhat more elaborate treatment, see Herskovits \& Herskovits (1936: 138-146), which also contains some 150 stories; for an introduction to story-telling in Saramaka, see Price \& Price (1991: 1-37), which also contains an integral transcription of two evenings of story-telling.

41. A folktale in Sranan

(Herskovits \& Herskovits 1936: 162-163; ${ }^{83}$ told by Meli Abensitt in 1929)

This story was recorded by Frances and Melville Herskovits in Paramaribo. It is widely known throughout Afro-America, e.g. in the American South where it is known under the title 'Tar Baby'. The vitality and flexibility of these stories became clear to me when in a version I heard told to children a few years ago the tar had been replaced by chewing gum. The source from which this story was taken, Herskovits and Herskovits (1936), is a magnificent collection of Sranan folk-tales, riddles, proverbs (some of which are in Saramaccan), and dreams, told by native speakers in 1929 and recorded on phonocylinders. ${ }^{84}$ Although I agree with Voorhoeve \& Donicie (1963:91) that these texts should be used critically for linguistic purposes, their value still remains immeasurable.

\section{Tara Poptie}

Konim habi wan gron, a habi furu nanyam. Dan Ba Anansi ben 'e fufuru nanyam di Konim ben prani. Dan Konim no ben sabi suma 'e fufuru nanyam. Di a wani sani sabi suma 'e fufuru nanyam, a poti wan tara-poptie tenapu na ini gron. Dan Ba Anansi go si na potpie, dan a denki na wan suma dape. A taki, "Yu boi, san yu de du dape?" Na poptie no piki hem. A taki, "Efi yu no wani piki, mi de skop yu!" Dan a skopu hem. Dan en futu fasi. A taki, "Lus' mi, no so, mi de naki yu!" Dan hem hanu fasi tu. En taki, "Mi de skopu nanga na' tra futu!" A fasi, tu. A naki na tra hanu. A fasi tu. Dan Konim kom feni suma de na fufuruman. Konim fom en te...a kisi aiti futu nanga wan krois na baka.

82. See Price \& Price (2003).

83. The transcription has been slightly adapted.

84. Transmitted on CD, these recordings - though severely deteriorated - are still being preserved at Indiana University's Folklore Institute. 


\section{Tar Baby}

The King had a field, it held much food. Then $\mathrm{Ba}^{85}$ Anansi was stealing the food the King had planted. Then the King didn't know who was stealing the food. When he wanted to find out who was stealing the food, he put a tar-doll in the field. Then Ba Anansi saw the doll, then he thought there was a person there. He said, "You boy, what are you doing there?" The doll didn't answer him. He said, "If you won't answer, I'm going to kick you!" Then he kicked him. Then his foot got stuck. He said, "Let me loose, or I'll hit you!" Then his hand got stuck too. He said, "I'm going to kick you with my other foot!" It got stuck too. He hit with the other hand. It got stuck too. Then the King came to see who was the thief. The King beat him until...he had eight feet and a cross on his back.

\section{A Folk-tale in Saramaccan}

(Rountree \& Glock 1977: 177-81 ${ }^{86}$; told by Tiini Amoida in the early 1970s)

\section{Totomboti}

We da Gaangadu bi mbei lio. Fa a teki di sitonu, $-{ }^{87} \mathrm{fa}$ di lio de balala aki, so di sitonu tei go pii. I ta jei wata ta pasa a basu gililili. Sembe seei an de u bebe wata. De ta booko sitonu temmmmmmm sembe kaba. A ta kai dee peipei fou te dee fou kaba kiii. Dee woko, dee gbanini, fou seei an fika, dee tinde, - te a fika totomboti wanwan to fika. Hen totomboti taa we a o du luku tu. "Gaama, mi o go naki luku". Hen dee oto wan taki taa: "Ku un buka, i langa bakahedi ku di gaan taku fii de? Umfa a du ufo i sa booko en? U tuu we...luku di bigi de ku mi, woko". Gbanini taa: "We luku mi. Un totomboti?" Hen totomboti waka te ko dou. Hen a tjoko di sitonu kookookoo. Hen a waka go seeka taampu. Hen a tjoko: ko a domdomdom ko a domdomdom ma a moon fa a tjekede e ko a domdomdom buka na mi panjan. A puu wan sipandji go tuwe go $a$. Ha! a domdomdom ko a domdomdom ma a moon fa a tjekede e ko a domdomdom buka na mi panjan. A hiti go ala. Hon, a ko fika gaama de ta luku en diin, teeee: a domdomdom ko a domdomdom, ma a moon fa a tjekede e ko a domdomdom, buka na mi panjan, na mi a toto e. Hon! Hen totomboti djombo vuu ko a'. Hen Gaama taa a boo. Hen a boo te a kaba. Dee oto fou taa: "Andiwe mii o!" Anasi ko dou vaa. A taa: "We mi o go tu". De taa: "Legede! U tuu bi du puu. Totomboti wanwan to fika. Be totomboti ta du feen te a kaba". Ko a domdomdom ko a domdomdom ma a moon fa a tjekede e ko a domdomdom. Hen a ta naki teee eh-eh! De taa: "Huh, huh, di soni". A taa: "E a de tide seei fu tee-fu ndeti, Gaama, mi o si wan pisi feen". Gaama taa: "E aai". Ko a domdomdom ko a domdomdom ma a moon fa a tjekede e ko a domdomdom buka na mi panjan na mi a toto e. A puu di mbalu de guu tuwe go te

85. Ba means 'brother, friend, pal'. Cf. e.g. 'Brer Rabbit', whose role in Harris's Uncle Remus stories is similar to that of Anansi, i.e. that of a trickster.

86. The transcription has been slightly adapted.

87. ' - ' indicates a pause. 
kuma ala. Domdomdom ko a domdomdom ma a moon fa a tjekede e ko a domdomdom. A hopo wan mbalu tuwe go te a' gom. Ko a domdomdom ko a domdomdom ma a moon fa a tjekede e ko a domdomdom buka na mi panjan. A fuleen de buluum. De ta si wata ta pasa a' gililili. Di sembe aki katjakatjakatjakatja. A nan go. Gaama taa: "Un tan. E wan sembe tuusi maun go peka de, i o-dede". Oohn! Totomboti seeka zaaa go taampu a wan feen moon. Ko a domdomdom ko a domdomdom. A ko fika a ta waka ta naki. A ta waka a di sitonu liba ta naki en ta lontu nan go ta ko. Ko a domdomdom ko a domdomdom ma a moon fa a tjekede e ko a domdomdom. Dee sitonu saka holoo. A ta fika peipei sitonu de a kamiankamian. Di lio booko wajaa. Hen Gaama taa an saafa fa a du ku en. Hen a tei di be angisa, hen a tai hen hedi. Hen a fika a tja wata ko e. Hen a taa an sa disa soni u naki moon. Hen we a fika ta diki pau domdomdom. Ee saba seei a ta naki en pau. Di soni e, gaama taki deen tu taa, te mama feen dede, an musu bei en a goon. A musu bei en a liba. Hen we a ta diki pau. Fa a ta diki pau baaku de, noo baaku we a ta diki. Te hen mama dede, a tja ko ko bei. Totomboti.

(Rountree \& Glock 1977: 177-181)

Totomboti (Woodpecker)

Well, then, God had made the river. The way he took the rock, the way the river is flat here, that's how the rock went $p i i{ }^{88}$ You would hear the water passing underneath gililili. Nobody could drink the water there. They were trying to break the rock for a long time until they stopped. He [Gaama 'the chief', JA] was calling the different birds until the birds stopped kiii. The woko birds, the gbanini birds, even those birds gave up, the tinde birds, until only Totomboti [Woodpecker, JA] was left. Then Totomboti said that, well, he was going to try too. "Gaama, I am going to try". Then the others said: "With what beak, you long head-back, you who are so ugly? How are you going to break it? We all, well...look how big I, the woko bird, am". Gbanini said: "Well, look at me. Which woodpecker?" Then Totomboti walked until he arrived. Then he pecked at the rock kookookoo. Then he walked and got himself ready. Then he pecked. Ko a domdomdom ko a domdomdom ma a moon fa a tjekede e ko a domdomdom buka na mi panjan. He chipped off a piece of rock which went flying off. Ha! A domdomdom ko a domdomdom ma a moon fa a tjekede e ko a domdomdom buka na mi panjan. He chipped off another piece. Oh my, even the Gaama could only look at him diin. Until: a domdomdom ko a domdomdom, ma a moon fa a tjekede e ko a domdomdom, buka na mi panjan, na mi a toto e. Oh my, then Totomboti jumped here vuu. Gaama said he should rest. Then he rested until he was ready. The other birds said: "Great, child!" All of a sudden Anansi appeared. He said: "Well, I'm going to try too". They said: "Lies! We all had to give up. Totomboti is the only one left. Let Totomboti go on until he's finished". Ko a domdomdom ko a domdomdom ma a moon fa a tjekede e ko a domdomdom. Totomboti was pecking until eh-eh. They said: "Huh, huh, it's really something". He said: "Even if it is today until tonight, Gaama, I'm going to make some

88. Some of the ideophones in the story have been left untranslated. 
headway". Gaama said: "Oh, yes". Ko a domdomdom ko a domdomdom ma a moon fa a tjekede e ko a domdomdom buka na mi panjan na mi a toto e. He broke off a chip and tossed it away. Domdomdom ko a domdomdom ma a moon fa a tjekede e ko a domdomdom. He broke off another chip and tossed it away. Ko a domdomdom ko a domdomdom ma a moon fa a tjekede e ko a domdomdom buka na mi panjan. He split it there bulum! They saw the water passing there gililili. One person ran to it katjakatjakatjakatja. He was going towards it. Gaama said: "Wait. If someone puts his hand in there and gets stuck, he will die!" Totomboti got himself ready on another part of it again. Ko a domdomdom ko a domdomdom. He kept walking around pecking. He walked around on top of the rock pecking, going back and forth. Ko a domdomdom ko a domdomdom ma a moon fa a tjekede e ko a domdomdom. The rocks dropped down holoo. Now there are several rocks in several places. The river broke free wajaa. Then Gaama said he didn't know what to do with him. He took his red angisa [kerchief, JA] and tied it around his head. That's how he brought the water. Then he said he couldn't stop pecking at things anymore. That's why he's digging into trees all the time. Even on Sunday he's pecking at his tree. Another thing: Gaama said to him that, when his mother dies, he shouldn't bury her in the ground. He should bury her up high. That's why he's digging into trees. The way he's digging a hole in a tree there, he's digging a hole. When his mother dies, he will bring her there to be buried. Totomboti. 


\section{CHAPTER 7}

\section{Written texts}

Some of the texts reproduced below belong to the very oldest data known for the Suriname creoles. In some cases, especially the Sranan sources discussed at the beginning of this chapter, they do not really deserve the name 'text', as they consist mostly of isolated words and phrases. Nevertheless, I have chosen to reproduce them here because they may shed some additional light on the earlier stages of creole formation. Unfortunately, some of the very earliest sources on Suriname do not contain any linguistically relevant information with regard to Sranan. ${ }^{1}$ A case in point is Van Berkel's (1695) description of Berbice and Suriname, which is especially unfortunate as Van Berkel had first-hand knowledge of the language situation on the plantations: he worked as a plantation overseer in Suriname for almost a decade (1680-1689). However, apart from one correction to Warren (1667) (see no. 1 below), he does not present any relevant language data ( $c f$. Van Donselaar 1993).

One type of text which, unfortunately, is completely absent from this chapter are newspapers. Although weekly newspapers in Dutch, such as the Weekelijksche Woensdaagsche Surinaamsche Courant (1774-1805) and the Surinaamsche Nieuwsvertelder (1785-1793), started to appear in Suriname in the 1770s and 1780s, I have excluded them from my corpus of Early Sranan texts. The reason for that is that in all likelihood the amount of time that would have to be invested in perusing these newspapers would not be paid off by the amount of Sranan material (if any) to be found (Archie Sumter, p.c.; Michiel van Kempen, p.c). As to early newspapers in Sranan, I have found references to only two. Of the one - the Krioro koranti: Sranan njoensoe pampira 'Creole magazine: Surinamese newspaper' - only one issue appeared (in 1862; Voorhoeve \& Donicie 1963: 100), which, unfortunately, I have not been able to consult. The other - the Sranam Koranti 'Surinamese magazine' - was announced to appear in 1869 but it is unclear how long it existed (if it ever did) (Van Kempen 2003:378). In any case, no copies are known to exist.

In order to place these texts in their proper contexts, I will give some biographical information about their authors wherever such information is available. In

1. What little language data Van Berkel does present was copied from Warren (1667) (Van Donselaar 1993:90). 
doing so, I will, of course, focus on those biographical characteristics which have some linguistic relevance, such as: Was the author a native speaker or not? At what age did he ${ }^{2}$ learn the language? Was he black, white, or of mixed descent? Was he born in Suriname, in Africa, or in Europe? Did he belong to a particular group, such as the Moravian or Catholic missionaries, the colonial elite, the planters' class, the military? Answers to these questions may assist use in obtaining a proper appreciation of the nature of the language presented in these texts.

The texts are presented in chronological order; they have been divided into two sections, Section 7.1 (secular texts) and Section 7.2 (religious texts). Except where noted otherwise, the transcriptions are faithful to the original, including typographical errors, inconsistent spellings, etc. Punctuation, however, has been adapted wherever that seemed necessary.

\subsection{Secular texts}

\section{George Warren's Impartial description (1667)}

George Warren, the author of An Impartial Description of Surinam (1667), claims to have spent three years in Suriname (Van Donselaar 1993: 87). Since his work appeared in 1667, this must have taken place during the English period, i.e. before the colony was taken over by the Dutch in 1667. Although his work does not contain any words which are unambiguously Sranan (to the extent that we have any idea of what Sranan looked like at this early stage), there are some which should perhaps be regarded as 'pre-Sranan' in the sense that they were incorporated later - in a restructured form in the Sranan lexicon. These are listed here:

\begin{tabular}{|c|c|c|}
\hline Warren 1667 & Modern Sranan ${ }^{3}$ & Meaning \\
\hline muskeeta & maskita & mosquito \\
\hline quotto & kwata & spider monkey \\
\hline swanyes ${ }^{4}$ & swampu & (source: Warren 1667) \\
\hline
\end{tabular}

2. It should be noted that - with the exception of Behn's and Merian's works, which contain only a very limited amount of languaga data - the entire corpus of early Sranan and Saramaccan written sources does not contain a single female-authored text.

3. Modern Sranan equivalents in this as well as in other lists below are taken from the Woordenlijst (3rd ed., 1995).

4. This was corrected into swampen by Van Berkel (1695) (Van Donselaar 1993: 90). 


\section{Aphra Behn's Oroonoko (1688)}

In her novel Oroonoko, or the royal slave (1688), set in early plantation Suriname, Aphra Behn (1640-1689) uses a few words that may be construed as representing Early Sranan, even though they were quite widespread at the time (cf. their use in other English-lexicon creoles and in African American English of roughly the same period). To the extent that these words are indeed Sranan, they are the very first words in this language ever to appear in print.

$\begin{array}{lll}\text { Behn (1688) } & \text { Modern Sranan } & \text { Meaning } \\ \text { backearary } & \text { bakra } & \text { White (person) } \\ \text { pickaninnie } & \text { pikin } & \text { child }\end{array}$

\section{Hermann (1689)}

In the Herbarium Hermann, which contains a number of names for Surinamese plants, we find one Early Sranan word (for further information, see Van Donselaar 1996: 89):

$\begin{array}{lll}\text { Hermann (1689) } & \begin{array}{l}\text { Modern Sranan } \\ \text { tasi }\end{array} & \begin{array}{l}\text { Meaning } \\ \text { palm species }\end{array}\end{array}$

\section{Maria Sybilla Merian’s Studienbuch (1699)}

Maria Sibylla Merian (1647-1717) was born in Frankfurt am Main (Germany), where she was trained as an artist and became known for her water-colour painting of plants and insects. In 1685 she came to the Netherlands where she joined a religious sect, called the Labadists. In the years 1699-1700 she visited Suriname, where some Labadists had tried to set up a plantation and where she did the 'fieldwork' for her book Metamormphosis Insectorum Surinamensium (1705). Unfortunately, this marvellously illustrated book on Surinamese entomology and botany does not contain any remarks concerning language.

That does not mean, however, that she did not make any linguistic observations at all during her stay in Suriname. While she was there, she made some notes concerning language in her Studienbuch 'book of studies', which remained unpublished for almost three hundred years (Beer 1976). On page 353 of Beer's edition, Merian writes about a particular worm which is roasted and eaten by the slaves. She then says that they call a certain beetle 'the mother of this worm'. Since, unfortunately, she does not give the Sranan equivalent of this expression, we have to rely on reconstruction. Supposing that the name of the worm was ' $\mathrm{X}$ ', the name of the beetle might very well have been ' mama X'. If this is correct, this would be a very early use of the word mama to refer to something very big, as in mama ston 'big rock' lit. 'mother (of) stone' and mama alen 'heavy shower' lit. 'mother (of) rain'. Apart from this observation, the Studienbuch contains a number of words, mainly relating to flora, which are relevant for the historical development of the lexicon of the Suriname creoles. Some of these are listed below (source: Beer 1976). 


$\begin{array}{lll}\text { Merian 1699-1700 } & \text { Modern Sranan } & \text { Meaning } \\ \text { patates/batates } & \text { patata } & \text { potato } \\ \text { Annena } \beta & \text { nanasi } & \text { pine-apple } \\ \text { bacove } & \text { bakba } & \text { banana } \\ \text { babbande/bananne } & \text { bana } & \text { cooking banana (plantain) } \\ \text { Calelu } & \text { aguma } & \text { callaloo (type of vegetable) } \\ \text { kasafa } & \text { kasaba } & \text { cassava } \\ \text { bumbelmus/bambelmu } \beta & \text { pompelmusu } & \text { grapefruit } \\ \text { Coyabes } & \text { kabisi } & \text { palm cabbage } \\ \text { Cattun } & \text { katun } & \text { cotton } \\ \text { Markes Jaas/Marquisjaas/Markessaas } & \text { markusa } & \text { passion flower } \\ \text { blantagy } & \text { pranasi } & \text { plantation } \\ \text { Banillie } & \text { baniri } & \text { vanilla } \\ \text { Suer Sack/Suersack/Zürzack/ZuurZak } & \text { sunsaka } & \text { soursop }\end{array}$

Some of these words, such as Annenaßand Suersack, should perhaps be seen as late-17th-century Dutch rather than early Sranan ( $c f$. the remark made above with regard to Warren 1667). Others, however, such as blantagy and Banillie, show signs of the restructuring that later on led to their modern forms: pranasi and baniri. Although proper names have been excluded from this list, it may be interesting to note that Merian refers to Paramaribo as barimaribo and to a plantation called Palmeneribo as baliminiribo. The $\mathrm{p} \sim \mathrm{b}$ alternation in these names and in words such as batates (cf. Eng. 'potato'), bumbelmus (cf. Du. 'pompelmoes'), and blantagy (cf. Eng. 'plantation'; Du. 'plantage') may be a relic of Merian's original Frankfurt dialect (Norval Smith, pers. comm.).

\section{The voice of the Slaves (I) (1702-1711)}

An important source for early language data is formed by court records, which occasionally contain small fragments of testimonies in Sranan. These records are especially valuable for two reasons: first, they represent nengre tongo 'Blacks' Sranan'; second, being judicial testimonies, they were presumably recorded more or less verbatim. The presence of early Sranan in this type of document was first noticed by the historian Ruud Beeldsnijder, who encountered a few Sranan sentences in the records of the Hof van Politie en Criminele Justitie 'Court of Police and Criminal Justice', dating from the 1740s (see no. 8 below). On the basis of his findings, additional data, going back as far as 1702, were collected by my student, Margot van den Berg. Even though these testimonies were recorded by white clerks, we may assume that they represent the actual spoken language more closely than the 'European' sources do. In her study of early Suriname court records ranging over the 1667-1767 period, Van den Berg (2000) presents some two hundred early Sranan words (types), either as part of a sentence or as isolated words, as well as some fifty sentences. Since these findings are discussed 
extensively in Van den Berg (2000, to appear), I will only present a small selection here. As far as the 1702-1711 period is concerned, the data have been divided into two subsections: Section 5a (words) and Section 5.b (sentences). Since the order of presentation in this chapter is chronological, court record data from later years appear further below.

5a. Words (1702-1711)

\begin{tabular}{llll} 
Court records $^{5}$ & & Modern Sranan & Meaning \\
1702 & rokoe & ruku & roucou (plant sp.) \\
1704 & bananes & bana & cooking banana (plantain) \\
1707 & dat & dran & that (dem. pronoun) \\
& dram & go & dram (alcoholic beverage) \\
& $g(h) o$ & gu, & go \\
& jou & lansri & you (2sg) \\
& lancie & malássi & lance \\
& malassie & man & molasses \\
& man & mi & can, be able to \\
& mi(e) & no & I, me \\
& no & now, noya & not \\
& nu & dan & now \\
& tham & fu & then \\
& voor & wani & of, for \\
& wanti & mangro & want \\
& mangroe & mangrove \\
& \multicolumn{2}{c}{ (source: NA 1.05.01.02, 1137 (1702); NA 1.05.04.01, 231 (1704); NA 1.05.04.01, } \\
& & 234 (1707); NA 1.05.04.01, 239 (1711); see also Van den Berg 2000:97-8)
\end{tabular}

5b. Sentences (1707)

Apart from isolated words, the early Court Records also contain a number of sentences in Sranan, the very oldest of which date from 1707. These sentences form the very oldest textual Sranan material known until now, predating Herlein's (1718) dialogues by more than ten years. All five 1707 sentences presented here refer to a single incident, a slave uprising that took place on June 19, 1707, on a plantation named Palmeneribo, with its 148 slaves Suriname's biggest plantation at the time (the incident is discussed in detail in Dragtenstein 2004). Incidentally, this is the same plantation which set the scene for Dirk Valkenburg's well-known painting Slavendans 'Slave dance'. In fact, Valkenburg, who was employed both as a bookkeeper and a draughtsman at Palmeneribo, was

5. Repeated occurrences of the same word in different records have been omitted from this list.

6. The Woordenlijst does not contain this item; the form given here is the one found in Focke's (1855) dictionary (Van den Berg 2000:97). 
present when these events took place and even participated in them to some extent. This means that the people whose words are quoted below may in fact be represented on the painting. Although this may in itself not be a fact of enormous importance, it gains more relevance when it is realized that the voice of the black in the pre-Emancipation period, if it is heard at all, normally only reaches us in a complete vacuum, with no information whatsoever on who these people were and what they looked like.

Since these sentences are of special importance for the history of Sranan, it may be worthwhile to provide some context. ${ }^{7}$ The speakers in question are the slaves Waly and Mingo, two brothers who are referred to in the records as 'criole-negers', i.e. blacks born in Suriname, and belonging to the Congo ethnic group. When a new manager, Christiaan Westphaal, arrives at Palmeneribo in 1706, he is under orders to restore disiplin there and forbids both men to continue their relationships with their women on a neighboring plantation, without success. On June 18th, Westphaal and Valkenburg are in the front gallery of the planter's house when they see Mingo mooring his canoe and passing them by without greeting. Westphaal destroys Mingo's canoe with an axe. This brings Mingo into a frenzy in which he cries out nu wanti dat, you no meester voor mi. ${ }^{8} \mathrm{He}$ retreats to the slave huts and threatens to commit suicide. The next day, when a group of angry slaves has gathered in front of the planter's house, Valkenburg hits Waly, who says to his brother Mingo jou no man. After Mingo's reply mi man, Waly says jou go dan and Mingo and the other slaves retreat to their huts, 'roaring and raging' and threatening to run away from the plantation. Apparently, they did not execute this plan and Mingo, Waly, and three others were sentenced to be burnt alive, 'slowly' and 'while being pinched with red-hot tongs', as the verdict read. Although this extremely sadistic form of punishment was meant to set an example for other would-be rebels, it clearly did not reach its goal as is amply shown by the history of rebellion and marronage in Suriname.

While the court records often present several - slightly different - versions of the Sranan sentences they contain, I only give one transcription here. A fuller discussion of these and similar data may be found in Van den Berg (2000, 2001, to appear), and in Van den Berg \& Arends (2004). Since in a number of cases my transcriptions, based on photocopies of the original documents, differ from those presented by Van den Berg (2000), I only mention the original manuscripts under 'source'; this does not mean, of course, that Van den Berg's work was not of great help in arriving at these transcriptions. (This remark also applies to material from the court records included further below.)

7. This paragraph is based on Dragtenstein (2004) and Van den Berg (2000, 2001), which in their turn are based on consultation of the relevant archival documents. The latter represent the views of both the whites (letters by Westphaal and Valkenburg to the colonial government) and blacks (depositions by Waly, Mingo and others) involved in the dispute.

8. For translation, see below. 


\section{$18 / 6 / 1707$}

Mingo: nu wanti dat.

I want it now.

you no meester voor mi.

You're not my master.

$19 / 06 / 1707$

Waly: jou no man.

You don't have the nerve.

Mingo: mi man.

I do.

Waly: jou godan.

Go, then.

(source: NA 1.05.04.01, 234)

\section{Herlein's (1718) Dialogues}

The first Sranan specimen of any substance was published by one J.D. Herlein, who included two pages of dialogue plus some isolated words and phrases in his Beschrijvinge van de volksplantinge Zuriname 'Description of the colony of Suriname', published in 1718 (pp. 121-122). While almost nothing is known about the identity of the author, it has been established that he stayed in Suriname for several years in the early 18th century, most likely between 1707 and 1715 (but not necessarily that whole period). This suggests that Herlein's Sranan specimen is based on his personal observation, a point in favor of its reliability. This does not necessarily mean, however, that it represents nengre tongo 'Blacks' Sranan', even though it is presented as such by the author, who refers to '[...] de Spraak der Swarten, zo ze van haar op de Zurinaamsche Kust gesproken werd [...] 'the speech of the Blacks, as it is spoken by them along the coast of Suriname'. But even if the 'Herlein fragment' represents bakra tongo 'Whites' Sranan' rather than nengre tongo, the fact remains that Herlein provides us with an extremely valuable glimpse into an otherwise obscure period in the development of Sranan. (For more information, see Arends 1995).

First dialogue

Oudy.

Hello.

Oe fasje jou tem?

How are you?

9. In my transcription I have omitted the -like sign which is often placed above the letter $<\mathrm{u}>$ in this as well as in a number of other early manuscripts. I assume this sign has no special phonetic value, as it used not only in the Sranan but also in the Dutch portions of the text. (Perhaps it is used to distinguish $<\mathrm{u}>$ from $<\mathrm{v}>$ in writing?) 
My bon.

I'm allright.

Jou bon toe?

Are you allright too?

Ay.

Yes.

My belle wel.

I'm very well.

Jou wantje sie don pinkinine?

Would you like to sit down for a little while?

Jie no draei?

Aren't you thirsty?

Ay mie wanto drinkje.

Yes, I would like to have a drink.

Grande dankje no ver mie.

No thanks, not for me.

Jo wantje smoke Pipe Tobakke?

Would you like to smoke a tobacco pipe?

Jo wantje loeke mie jary?

Would you like to see my garden?

Loeke mie Druije se hansum?

See my grapes, how beautiful they are.

Mie jary no grandebon?

Isn't my garden very nice?

Ay hantsum fo trou.

Yes, it's very pretty.

Jo wantje gaeu wakke lange mie?

Would you like to take a walk with me?

Oe plasje joe wil gaeu?

Where would you like to go?

Mie wil gaeu na Watre-zy.

I would like to go to the waterside.

Oe tem wie wil gaeu na Riba?

When will we go up the river?

Oe plesje tem.

Whenever you wish.

\section{Second dialogue}

Mie Misisi take jou oudy.

My mistress sends you her greetings.

Akesi of joe tan an house?

She asks if you will stay at home.

à Wilkom loeke joe na agter dina tem.

She would like to visit you this afternoon. 
No mie ben benakese ta entre ples à reddi wen.

No, I have already asked somebody else if I could visit her.

As hem ples hem kom te maare.

If she wants, she can come tomorrow.

Oe som bady Mastre vor joe?

Who's your master?

Oe fasse nam vor joe Mastre?

What's your master's name?

Oe fasse kase joe Misisi?

What's your wife's name?

Oe plesse jo liewy?

Where do you live?

Klosse byna Forte.

Close to the fort.

Jie no love mie moore.

You don't love me anymore.

Je wantje sliepe lange mie?

Would you like to sleep with me?

No mie no wantje.

No, I wouldn't.

Jie no bon.

You're not nice.

Jie monbie toe moussie.

You're very unwilling.

Kom bosse mie wantem.

Come, kiss me then.

Some isolated words and phrases

Na tappe.

Upward.

Na bie laeu.

Downward.

Zon komotte.

The sun rises.

Zon gaeud on.

The sun sets.

Hause.

A house.

Tappe.

The roof.

Tappe windels.

Close the windows.

Ope windels.

Open the windows. 
Ver wate jie no ope windels?

Why don't you open the windows?

Santje.

A thing, and everything which is rare or for which there is no name.

Kaba.

Finished.

(source: Herlein 1718:121-122)

As noted by Van Donselaar (1996), a few other Sranan words occur in the remainder of Herlein's book. These are:

$\begin{array}{lll}\text { Herlein } 1718 & \text { Modern Sranan } & \text { Meaning } \\ \text { Bakkerare } & \text { bakra } & \text { White (person) } \\ \text { bobbe } \text { 10 }_{\text {Tom, Tom }}^{\text {bobi }} & \text { tonton } & \text { breast (female) } \\ \text { certain porridge }\end{array}$

\section{The voice of the Maroons (I) (1728/1733)}

The first two sentences reproduced here are from archival documents concerning the history of marronage which are discussed in Dragtenstein (2002). Although the language used in these sentences looks like ordinary 18th-century Sranan, the information about the people who uttered them suggests that they are perhaps better seen as reflections of early Ndyuka, the Maroon creole which began to split off from Sranan in the first half of the 18th century.

Kierie da bakara, die my mosse habie ${ }^{11}$ (1728)

Kill the white man; I have to get him

Bakra de ${ }^{12}$ (1733)

There are white people over there

(source: Dragtenstein 2002:81,111)

\section{The Voice of the Slaves (II) (1745-1762)}

All the sentences below were found by Margot van den Berg, although a few of them had been communicated to me by Ruud Beeldsnijder before. For further information, see the remarks made under 5 .

hoe sambre dee (1745)

Who is there?

mi no sal tron tongo (1745)

I will keep my word (lit. I will not turn my tongue).

10. The word bobbe only occurs in Herlein's book as part of a compound: bobbelap 'lit. 'breast cloth, a piece of cloth worn by women around the upper part of the body.

11. Said by a Maroon in the Para region when searching for a white man who had been chasing him.

12. Said by a Maroon woman in the Cottica region when discovering white soldiers. 
mi da hietie joe (1745)

I'm going to hit you.

mi doe langa hem caba (1745)

I finished him off already (lit. I'm done with him already).

mi no sabi hoe ple alle santi kom oppo (1745)

I don't know where everything came from.

mi potti hem na wan sij caba (1745)

I put him aside already.

(source: NA 1.05.10.02, 798)

mekka (= meki a) tan booy (1747)

Make him stay, boy.

(source: NA 1.05.10.02,929)

dankie dankie booy (1755)

Thanks vey much, boy.

(source: NA 1.05.04.06,296)

mie wisie mie daa na Tampatie, dan mie sa lerre Backaraman ( $x x x$ ) fom negre ${ }^{13}$ (1757)

I wish I was in Tempati, ${ }^{14}$ then I would teach the bakras to beat Negroes.

evie mi massra ben sendie mie go na Tampatie dan mie sa ben sorie dem Backara (1757)

If my master would send me to Tempatie, then I would show the bakras.

(source: NA 1.05.10.02,942)

na nekkie na hedi tappe en na bakkie lange na rassie (1759)

[wounds] in his neck, on his head, and on the back-side on his buttocks.

Argus mie dede (1759)

Argus, I'm dying.

hu santie tide, Picorna soetoe mi, da him, mie sie him, da no boesi neger (1759)

What's happening now? Picorna shot me, it's him, I saw him, it isn't a bush-negro. aaij booij tide mie kiesie joe (1759)

Yes, boy, now I got you.

massara Apolo takie (xxx) van Picorna soetoe him (1759)

Master, Apollo said (???) of/from Picorna shot him.

mie habi jou tide booij (1759)

I got you now, boy.

(source: NA 1.05.10.02,947)

dem no sa doe joe wan santie (1760)

They won't do anything to you.

(source: NA 1.05.04.06, 309)

13. This sentence, in different transcriptions, is also found in two other publications. It is transcribed as mi winsi mi de na Tempatie dan mi sa leri bakra voe fom negrein Dragtenstein (2002: 184), and as mie wisie dee no Tempati dan mie so seenie Bakra voeroe from negre in Van den Bouwhuijsen et al. (1988:21).

14. Tempati is the region where at that time a rebellion was taking place which contributed significantly to the expansion of the Ndyuka Maroon group. 
kontrie masseranegre mi da bossiman mi no zal doe jou okri (1761)

Fellow black countrymen, I'm a bush-negro, I won't do you any harm. tan boy of mi schoete jou (1761)

Stand still, boy, or I'll shoot you.

(source: NA 1.05.04.06,313)

danki massara wie da ningre voor joe (1762)

Please, master, we are your slaves.

(source: NA 1.05.10.02,806)

tanki tanki massera kom helpi mi, dem kili ningre (1762)

Please, master, come help me, they're killing slaves.

Massera mi no kan kom, somma voeloe rommotto mi, detappe (= de tappe) pasi (1762)

Master, I can't come, there are people all around me, blocking my way.

(source: NA 1.05.04.06,315)

\section{The voice of the Maroons (II) (1757-1759)}

The next three sentences were uttered by Ndyuka Maroons in the course of their encounters with the white soldiers who were sent out to fight them. The first sentence is by a man named Boston (a.k.a. Adjaka), who had lived in Jamaica before he was brought to Suriname. Although Boston had learned the essentials of reading and writing, his writing was very difficult to decipher. The sentence is from one of the notes he wrote to communicate with his white adversaries. ${ }^{15}$ It is addressed as To masra Dandulan ans po lambo, only the first three words of which seem to make any sense: 'to Mr Dandiran'. Boston's Sranan bears clear traces of Jamaican Creole: $c f$. to, sant, ne, litte, tabak, instead of Sranan $f u$, sendi, wan, pikien, tabaka. As regards the other two sentences, it is not entirely clear who uttered them, either Boston or his fellow Ndyuka Jacki.

Massa peelvi ${ }^{16}$ sant ne litte tabak (1757)

Sir, please send us a little tobacco

Gimmi han vossi (1759)

Give me your hand first

Audi maati, meki jou hatti koulou nofrede (= no frede) (1759)

Hello, friend, be calm, ${ }^{17}$ don't be afraid

(source: Van den Bouwhuijsen et al. 1988:49,109)

15. Incidentally, Boston's note was left at the gallery of the planter's house at plantation Palmeneribo, the location of the 1707 events which led to the recording of the very first Sranan sentences, discussed under no. 5 above (Dragtenstein 2004:233).

16. peelvi should probably read as plisi fu 'lit. please to', the usual way to express a request.

17. Lit. 'make your heart cool'. This is one of the earliest uses of the word kouroe 'cold, cool' to refer to the mental state of 'being calm, controlled'; $c f$. the use of the concept of 'cool' - which shows clear parallels with its use in a number of African languages - in several Caribbean Englishlexicon creoles as well as in African American English. 


\section{The Saramaka Peace Treaty in Sranan (1762) ${ }^{18}$}

The text presented below is the Sranan version of the Saramaka Peace Treaty, which was signed on September 19, 1762, at the junction of Sara Creek and the Suriname River, between the Saramaka Maroons on the one hand and the Dutch colonial government on the other. The text appears as an appendix to the minutes of the Court of Police, dated 27/12/1762. Together with the Sranan versions of the documents concerning the abolition of slavery (see no. 29 below), the Sranan version of the Saramaka Peace Treaty belongs to the core documents in the history of Suriname. It is for that reason that it is reproduced here in its entirety. While the Dutch text of the treaty has been accessible ever since it was published in Hartsinck (1770:802-9), the Sranan text as it was actually read to the Saramaka ${ }^{19}$ - most of whom did not know Dutch - remained unknown until it was published by Hoogbergen and Polimé (2000). ${ }^{20}$ Unfortunately, their edition is marred by a number of errors, concerning both transcription and interpretation. In collaboration with Margot van den Berg, I have prepared a new transcription, based, of course, on the same original manuscript text (see Arends \& Van den Berg 2004). ${ }^{21}$ As pointed out by Hoogbergen and Polimé (2000:226), the Dutch text of the treaty exists in two versions, one that does and one that does not contain the Saramaka's responses to the clauses of the treaty. The Sranan version corresponds to the former. ${ }^{22}$ My transcription of the Sranan text is accompanied by a translation into English, which - keeping in mind that the text is presented here primarily for creolists - has been kept as literal as possible, so as to enable readers who do not know Sranan to reconstruct the structure of the Sranan text from the translation.

The Sranan version of the text was written by Louis Nepveu, the leader of the colonial government's delegation to the negotiations that were held with the Saramaka in

18. The transcription that appears here is identical to that presented in Arends \& Van den Berg (2004). The introductory remarks are largely based on the introduction to that article.

19. It should be noted that the text as it appears in the manuscript does not necessarily represent a verbatim representation of what was actually said at the conclusion of the treaty. This becomes most clear in clause 15, where there is no direct connection between the words of the Whites and the Saramaka's response to them (see below).

20. Note that in the heading of Hoogbergen and Polimé's article, although not in the journal's table of contents, the name of Wim Hoogbergen erroneously appears as 'Okko ten Hove'.

21. Oud-Archief Suriname / Hof van Politie en Criminele Justitie, code 1.05.10.02, inventory number 66, ff. $177 \mathrm{v}^{\circ}-183 \mathrm{v}^{\circ}$ (appendix to the minutes of the Court of Police, 27/12/1762), National Archives, The Hague.

22. Apart from Hartsinck (1770), the Dutch version of the treaty can also be found in De Smidt (1973:757-762), De Beet \& Price (1980: 143-148), and Hoogbergen \& Polimé (2000:227-239). The latter also provide a translation into modern Dutch. An English translation of the Dutch text can be found in Price (1983b). See Hoogbergen \& Polimé (2000: 226-7) for further details on the manuscripts of both the Dutch and the Sranan versions of the text. 
March and April 1762. In the preamble of the treaty, Nepveu is more or less identified as such: $A$ [Louis Nepveu, JA] poti alle dissi santie deja na inni gi dem foe hakisi effi dem wandi holli dati alle 'He put all this in here for them, asking if they are willing to abide by it'. While this may not be completely unambiguous as to authorship, Nepveu's own statement is. In his report of the negotiations, he notes that, in explaining the terms of the treaty to the Saramaka, he 'translated the articles of the treaty word for word into Negro-English for them' (De Beet \& Price 1982: 121-2).

Louis Nepveu was a brother of Jan (or Jean) Nepveu, the author of the 'Annotations' to Herlein's 1718 book discussed below (see no. 14). Although we do not know whether Louis was born in Suriname, and if not, at what age he came to Suriname, we do know that by the time he wrote the Sranan text of the treaty in 1762 he had been living there long enough to have acquired a good knowledge of the language. He had been in Suriname at least since 1749, when he was involved in the first round of peace negotiations, and probably for quite some time before that. This is based on the fact that his brother Jan, after finishing school in Amsterdam, had come to live with his parents in Suriname in 1734 (Encyclopedie, p. 424). It would not be farfetched to assume that Louis followed more or less the same route.

As mentioned above, Nepveu had also been the government's spokesman in an earlier - failed - attempt to make peace with the Saramaka, in 1749. According to lieutenant Creutz's journal of that earlier expedition, among this delegation Nepveu was the one 'who was understood best by [the Saramaka]' (De Beet \& Price 1982:66). De Beet \& Price (1982: 197n2) also refer to Nepveu's 'extraordinary knowledge of Sranan and his ease in communicating with the Saramaka'. It should be noted, however, that Nepveu probably spoke bakra tongo, the variety of Sranan spoken by the Europeans, rather than nengre tongo. That there may have been some problems in the communication between Maroons and whites is suggested by a document concerning the visit of Quassie van Nieuw Timotibo to the Ndyuka in 1762. According to Quassie, the Ndyuka were very pleased to have him as a representative of the colonial government because 'the whites connot speak with us so clearly' (Dragtenstein 2004: 67). Whatever may be the case, apparently the Europeans were not sufficiently acquainted with Saramaccan to be able to negotiate in that language. As regards the Saramaka's part of the text - their responses to the clauses of the treaty - it seems clear that these are also presented in Nepveu's words ( $c f$. the use of the third rather than the first pronoun) rather than being verbatim recordings of what they actually said.

In the original manuscript the text is divided into two parts: the second part (ff. $180 v^{\circ}-183 v^{\circ}$ ) is formed by the actual clauses of the treaty while the first part (ff. $177 v^{\circ}-$ $\left.179 \mathrm{v}^{\circ}\right)$ consists of the Saramaka's responses to these. In the edition presented here I have merged the two parts into one (i.e. every clause is followed by the Saramaka's response) so as to achieve a more natural, integral text. Strictly speaking, there is a third part, namely that following the last clause (no. 15). In this part of the text the actual signing of the treaty is described, including the names of the captains (village 
headmen) who signed it. The only other emendations I have made in my transcription concern punctuation, including the use of ligatures, diacritics, and capitalization. The highly erratic punctuation of the original manuscript has been replaced by a more regular one, designed to enhance the overall readability of the text. Also, the occasional placement of the '-like sign above the letter $\langle\mathrm{u}\rangle$, as in, e.g. frigúittie 'forget', has been omitted in the transcription. Apart from that, however, the transcription presented here is faithful to the original text. Those few cases where I am uncertain about the reading and/or the interpretation of the manuscript have been indicated by ' $(\mathrm{xxx})$ ' and '(???)', respectively. Since this is not the place to go into the fascinating but highly complex historical context in which the conclusion of the treaty took place, I will only give some references to the most important literature on this topic. De Beet and Price (1982) is a collection of historical documents, preceded by an excellent summary of the events leading up to and surrounding the 1762 treaty. It also contains two maps indicating the location of several relevant spots, including the place where the treaty was signed. (An English translation of De Beet \& Price 1982 has appeared as Price 1983b.) The Saramaka's point of view, preserved in their oral history, is represented in Price (1983a, especially pp. 167-181). Dragtenstein (2002), the most extensive general history of marronage in Suriname to date, devotes an entire chapter (pp. 221-34) to the treaty. Finally, Hoogbergen \& Polimé (2000) provide some useful historical information.

\section{0a. The text of the treaty}

Fassie fou mekie frie nanga boussie nengre fou oppo Serameca nanga Saranam Riba. Granman langa coertoe sendie masara Louis Nepveu fou meki da fri. A poti alle dissi santi deja na inni gi dem foe hakisi dem effi dem wandi holli dati alle.

Peace Treaty (lit. 'way of making peace') with the Bush Negroes of the Upper Saramaka and Suriname Rivers. The Governor and the Court of Police have sent Mr Louis Nepveu to make peace. ${ }^{23} \mathrm{He}$ wrote all these things down for them in order to ask them if they are willing to stick to all these agreements.

1. Alla dem boussie nengre foe oppo Sarameca nanga oppo Saranam sa habie frie nanga alla bacara foe Saranam Condre, en bacara sa friguittie alla ogrie diesie dem ben doe. Mara nembre dem moessoe doe ogrie moro na bacara, mon gessie Jou, en nanga frie Ingien, effie na dem plantasie nanga goedoe.

All the Bush Negroes of the Upper Saramaka and the Upper Suriname (Rivers) will have peace with all the Whites of Suriname, and the Whites will forget all the bad things they ${ }^{24}$ have done. However, they should never again do any bad

23. Since the word frie covers both the meanings of 'peace' and 'treaty', it is translated by either one, depending on the context.

24. I.e. the Saramaka (!). 
things to the Whites, (???) Jews, nor to the Free Indians, nor to their plantations or their goods.

Dem peki: Dissi fri granboen; nembre no wan ogrie sa dé more fou dem langa bacra, monkisie judew langa vry Ingien diesi de boen langa bacra.

They replied: This peace is very good; never again will there be any problem between them and the Whites, (???) Jews, nor with the free Indians who live in peace with the Whites.

2. Dem sa moesoe sorie alle dem condre na bacara, en alla dem condre fou Ingien offoe nengre diessie conpé nanga dem, effie innie wan diessie dem sabie, dem sa moessoe sorie dem toe. En dem sa moessoe mekie bakara frie nanga dem en offoe dem no wandie mekie da frie nanga bakara, dem sa moessoe helpie bakara foe goo fettie nanga dem.

They should show all their villages to the Whites, and all the villages of the Indians or Blacks who are their allies, or any village they know, they should show them too. And they should force them to make peace with the Whites, and if they do not want to make peace with the Whites, they should help the Whites in fighting them.

Da reiti; so dem sa doe. No wan habi fou tan na baca.

They agree; they will do so. They will fully comply with this condition.

3. Dem sa moessoe tan libie de na da plessie dem habie dem condre dissi tem, ma datem dem wandie goo liebie na wan tara plesie, dem sa moessoe sendie takie na granman en dem sa moessoe tan tee dem kiessie moffo baca of dem sa can mequi condre na tara plessie.

They should continue to live right there where they have their villages now, but when they wish to go live at some other place, they should inform the Governor and they should not move until they have received a message back (informing them) whether they can make their village somewhere else.

Dem sa doe dati.

They will do so.

4. Dem sa moessoe callie neem foe alla den hedieman foe dem condre en datem wan com foe dede effie foe commoto, dem sa moessoe sendie takie na granman foe à can sabie offoe à boen.

They should mention the names of all the captains of their villages, and when one should die or step back, they should inform the Governor so he knows it is alright.

Dissi toe.

(They will do) this too. 
5. Dem sa moessoe gie bakka alla nengre diesie ben komoto of ronnewe na bacara, sensie dem nengre foe Ouwka ben com na dem nanga Willie. ${ }^{25}$ No wan fassie dem sa kan teekie foe hollie wan nengre foe bakara diessie dem sa kissie effie diesie sa ronnowe com na dem. Sensie da tem en so té dorro té goo nembre wantem dem sa holie wan. Fiscalla sa paij dem f 50: Sur: mon - da $f 42$ pissie vo serem - ma effie dem kisi dem na krosi bay, na wan plandasie, dem sa kisie tien piesie per Scr ${ }^{26}$ tee $f 42$, na fasie dem sa ben kisie dem farra weij, ofoe korosie bay foe fotto. En alla dem ronne wee nengre disie dem tarri backa, garan man effie couroetoe sa can doe innie sandie dem wandie nanga dem. En foe da hedde, al wassie dem nengre foe wie sa wandie foe takie datie dem ronnowe bikasie dem masara offoe bacara doe dem ogrie, dem boesie Saramaca sa moessoe gie dem bakka da tem dem com na dem han, bicassie granman nanga couroetoe nomo moessie loekoe na datie.

They should return all the Blacks who have escaped or run away from the Whites since the Auka Maroons came to them with Willie. In no way shall they be permitted to keep a Black belonging to the Whites, whom they shall capture or who shall run away to them. From that moment until forever they shall never keep one. The treasurer shall pay them fifty guilders in Surinamese money - that is forty-two pieces of four shilling ${ }^{27}$ - but if they capture them close-by, on a plantation, they shall get between ten and forty-two pieces of four shilling per slave (???), depending on whether they will have captured them far away or close to Paramaribo. And all the runaway Blacks they return, the Governor or the Court shall be permitted to do anything they like with them. And for that reason, even if our slaves may wish to say they ran away because their master or the Whites did them harm, the Bush Saramaka should return them when they come in their hands, because only the Governor and the Court should take care of that.

Dem swerie no wan negre fou bacra kom na dem sensie Willi kom taki fou dissi frie. Effi inniwan nengre kom na dem, dem no sa holli no wan nimbre; dem sa tiari dem na gran man. So aleki bakra poti da santi gi dem, a boen na dem; dem sa holi reiti.

25. dem nengre foe Ouwka refers to the Ndyuka (or Okanisi). While originally Ouwka was the name of the 'home' plantation of some of the Ndyuka, it was later used to refer to the area where they lived. Willie (or Wíi) was a Saramaka, who lived among the Ndyuka at the time when peace was made with the latter (in 1760) and who suggested the Saramaka make a similar peace with the colonial government.

26. This word is only partially present on the photocopy I consulted. My provisional interpretation is that $s c r$ stands for scrafu/skrafu 'slave'.

27. One piece of four shilling was equal to one 'Carolus guilder' (Van Dyk c1765:9), which in its turn equalled two and a half Dutch guilders. For further information on the - very complex history of Surinamese money and its relationship to Dutch currency, see Van Elmpt (2004) and Encyclopaedie (1914-1917:484-9). 
They swear not a single Black has come to them since Willi came to talk about this peace. If any Black comes to them, they will never keep any of them; they will bring them to the Governor. The way the Whites propose it to them, it is alright with them; they will stick to it.

6. Hoe fa dem sa wandie foe takie effie foe doe, dem no sa moessoe hollie nowan bacara nengre alwasie grandie of pikien na dem mindrie. En datem wan foe dem sa wandie datie effie wan so sandie diesie sa de foe boroko diesie frié, dan alla dem tarra wan sa moesoe gie hem na bakara han foe bakara kan doe nanga hem so allequi dem sa membre à sa boen. En effie wan heddeman na oenoe mindrie ${ }^{28}$ doe wan so sandie disie dem fredie foe kiesie hem, bicasie à habie bigie teij teij, dem sa moessoe sendie takie na ga granman, ${ }^{29}$ fou à kan sendie wan comando nanga soldatie foe goo fettie foe kiesie hem. En dan diesie tan hollie nanga bakara sa moesoe helpie foe kiesie dem ogrie wan foe bacara sa kan dewengie dem foe tan boen nanga bakara en fou holi diesie frie boen boen.

Whatever they ${ }^{30}$ may say or do, they should not keep any Black belonging to the Whites, whether big or small, in their midst. And when one of them should want (to do) that or anything that is bound to break this peace, then all the others should hand him over to the Whites so the Whites can do with him whatever they will think will be right. And if a captain in your midst does something like that and they are afraid to capture him because he has a powerful charm, they should inform the Governor so he can send a military command to go fight and capture him.

And then those who are friends with the Whites should help capture the evil ones so the Whites can force them to be friends with the Whites and to stick strictly to this peace.

Da reiti; so dem sa doe. Nembre wan sa habbi hatti kibri wan nengre foe bakra.

They agree; they will do so. Never shall anyone dare to hide a Black from the Whites.

7. Effie granman of koeroetoe sendie moffo gi na dem, takie ningre ron weij effie mekie troblie na plandasie en kalie dem foe kom helpie fou kisi dem, onoe sa moesoe goo foe kiesie dem, en tiarrie dem kom nà fotto; dan dem sa kissie dem paijman.

If the Governor or the Court sends them a message saying that Blacks ran away or caused trouble on the plantations and orders them to come help capture them,

28. Here, as in several other places in the text, the second plural pronoun is used where the third plural would be expected; this inconsistency has been preserved in the translation.

29. Probably a writing error for na granman.

30. I.e. runaway slaves coming to the Saramaka. 
you should go capture them and bring them to Paramaribo; then they will get their payment.

Da boen; dem sa kom innitem effi dem kisi jounsou fou granman.

They agree; they will come anytime they will receive a message from the Governor.

8. Effie fettie kom na condre foe tarra condre, bacara effoe tarra boesie nengre, innie wan effie innie plessie dem sa dé, dan onnoe Saramaca vrie man sa moesoe kom foe helpie bacara, foe Saranam Condre. En dem no sa moesoe mankerie foe sendie soo menni man nanga gon allekie grandiman nanga couroetoe sa haksie foe goo na da plessie grandman sa takie of sendie takie na dem, en fou harkie na dissie sama dissie granman sa pottie foe tirrie dem, foe helpie bacara inni fassie dem sa kan doe. Selfie effie dem bossie nengre na baka ouwka of mapana nengre disie frie arrede nanga bacara sa wandie foe mekie trobie offoe doe bacara ogrie, dan dem sa mossoe hilpie bacara foe goo fettie nanga dem en foe kissie dem effie foe mekie dem tan boen nanga bakara en holi da frie reijtie nomo.

If the colony should get in a war with another nation, whether they are Whites or other Maroons, whoever or wherever they may be, then you Saramaka Free Blacks should come help the Whites, for the sake of Suriname. And they should not fail to send as many armed men as the Governor and the Court will ask to the place the Governor will (have somebody) tell them, and to obey the person the Governor will appoint to lead them, to help the Whites any way they can. Even if the Bush Negroes behind Auka or the Mapana Blacks, ${ }^{31}$ who already made peace with the Whites, should wish to make trouble or do bad things to the Whites, then they should help the Whites to go fight them and capture them, or to make them become friends with the Whites and stick strictly to the peace.

Dissi toe, a boen; dem sa doe.

(They agree with) this too; they will do so.

9. Datem wan sandie sa fadom na dem mindrie datie dem sa moesoe sendie foe granman sabie, dan dem sa kan sendie vyffie of sieksie voe dem en da tem dem com na fotto dem sa moessoe go rettie na granman en dem no sa kan goo wan plessie effoe granman sa moessoe sabie. En datem sama foe onnoe sa tiarie ronnewe nengre of sama dissie dem sa kissie kom na fotto, dan dem sa kissi dem monie josno, en dem sa mossoe loekoe dem jamjam serefie sondro bacara sa hoefoe foe gie dem.

When anything should occur among them that they should report so the Governor will know, then they will be permitted to send five or six of them, and when they arrive in Paramaribo they should go to the Governor immediately and they will

31. Mapana nengre is how the Saramaka referred to the Ndyuka, who lived along the Mapana Creek for some time (De Beet \& Price 1982:202n7). 
not be permitted to go anywhere unless the Governor knows. And when your people will bring runaway Blacks or (other) people they captured to Paramaribo, then they should collect their money right-away, and they will have to take care of their food themselves without the Whites having to give them any.

Disie toe.

(They agree to) this too.

10. Dem sa kan kom alla jarrie 50 foe onnoe na Saramaka riba, thee na wannica criqui, effie na arwaticabo, effie na Saranam riba, thee na victoria, foe tiarrie alla sandie dissie dem sa habie foe serrie, allekie hamaka, katoen, hoedoe, fouwloe, coeriara, effoe innie sandie. Marra effoe dem sa wandie tiarrie dem sandie goo na fotto foe serrie, dan dem no sa kan sendie moro na tien sama. En soo allekie dem sa kom na fotto nanga dem sannie dissie dem sa wandie serie, dan dem sa mossoe mekie granman sabie bifossie, en datem dem sa dé na fotto, dan dem no sa moessoe wakka na sabatem passa aytie jourroe na passie foe somtem dem no sa kissie trobie nanga bacara, dissie sa membre dem na slaaf. Dem no sa waka na passie nanga gon, houwroe offoe langa neffie.

Every year fifty of you will be permitted to come to the Saramaka River, as far as Wanica Creek, or to Arwaticabo Creek, or to the Suriname River, as far as Victoria, to bring everything they will have to sell, such as hammocks, cotton, wood, fowl, dug-out canoes, or anything (else). But if they should wish to bring their things to Paramaribo in order to sell them, then they will not be permitted to send more than ten people. And when they will come to Paramaribo with the things they wish to sell, then they should inform the Governor in advance, and once they are in Paramaribo they will not be permitted to be out after eight o'clock at night, so that they will not perhaps get in trouble with Whites who may think they are slaves. They will not be permitted to go out with guns, machetes or knives.

A boen toe, mara dem no sa waka toemoessi na Saramaka sei. Dem hakisi fou wakka na sabatem, granman langa Courtoe plesi fou gidem wan marki fou weri.

This is alright too; they will not come to the Saramaka River area very often, though. They request the Governor and the Court to give them a sign they can wear when they are out (in Paramaribo) at night.

11. Dem sa moessoe loekoe boen dem no gie astrantie moffo of doe wan ogrie na bacara. Dem sa moessoe hollie dem serefie allekie dem frieman diesie wie mekie na wie miendrie. Somtem effoe dem kom foe kissie kwarrie nanga wan bacara effoe bacara kom foe doe dem ogrie dem sa moessoe goo takie gie granman en datem a sa fendie datie dissie sama sa habie rettie, a sa mekie a sa kiesie hem rettie. En onnoe sa moessoe doe so sreffie na onnoe ondro: dissie sa kom foe doe ogrie, onnoe sa moessoe fom hem, en serrefie killie hem, effoe da ogrie bigie, effoe gie hem abra na bacara. Moro nosso effoe wan foe dem doe of wandi doe wan sandie fou broko dissie frie effie wan 
foe dem doe ogrie na bacara, bakara sa kan kissie dem en straffe dem so allekie dem doe tarra friman.

They should take good care not to be impudent or to do any bad things to the Whites. They should behave like the Blacks among ourselves to whom we gave their freedom. ${ }^{32}$ Should they perhaps get into a quarrel with a White or should a White do them any harm, they should inform the Governor, and when he feels this person is right, he shall make sure justice will be done. And you should do likewise among yourselves: who shall do bad things, you should beat him, and even kill him, if it is a big evil, or hand him over to the Whites. Especially if one of them does or wishes to do something to break this peace or if one of them does bad things to the Whites, the Whites will be permitted to capture them and punish them just like they do with other Free Blacks.

Dissi boen; dem sa doe dati toe.

This is alright; they will do that too.

12. Nembre dem sa moessoe mekie wan conpé nanga no wan samma, no langa mapana of ouwca frieman toe, foe doe innie bacara ogrie effoe foe helpie dem na innie wan fasie, foe mekkie wan ogrie na bacara.

Never should they become allies with anybody, not with the Mapana Maroons or Auka Maroons, to do bad things to any White or to help them in any way to do bad things to the Whites.

Nembre dem sa doe so sandi.

Never will they do such a thing.

13. Foe mekie dissi frie tranga, onnoe sa kissie dem sandie dissie pottie na briffie disie mi habie hija na mie. Marra na onnoe sey onnoe sa moessoe gie - foe bacara sa kan bliebie onnoe toe - fo pikien foe onnoe. En dem fo pikien sa moessoe de pikien foe dem heddeman, en datem onnoe de foe takie sweerie, onnoe sa moessoe swerrie toe takie dem pikin dissie onnoe pottie na wie han, dem na reijtie piekien foe heddeman. Soo allekie oenoe sa gie dem nem dissie wie sa moessoe sabie, so foe tata langa mama. En alla heddeman dissie no sa ben kan kom foe swerie disie frie, moessoe sendie samma foe dem. Dem pottie da swerrie na dem han foe dem sama dissie dem sendie sa moessoe swerrie da frie foe dem. Onnoe sa moessoe swerrie toe dattie onnoe no habie no wan condre morro allekie disie onnoe kallie nem foe dem arrede gie na wie bacara. En alla dem disie no wandie foe mekie frie nanga bacara, onnoe no sa kibirie dem. Onnoe sa moesoe fettie foe mekie dem frie en offoe onnoe kissie dem na fettie, onnoe sa kan serie dem na bacara.

32. I.e the manumitted slaves or 'Free Blacks'. 
In order to make this peace strong, you will receive the things that were put in the letter I have here with me. ${ }^{33}$ But from your side you will have to give four of your children, so the Whites shall be able to trust you too. And these four children should be captains' children, and when you will take your oath, you should also swear that the children you will hand over to us are really the children of captains. Similarly, you should give their names, which we must know, both of their father and their mother. And all the captains who will not be able to come to take their oath on this peace, should send somebody in their place. They (should) hand over their oath to them so the people they will send will take their oath on the peace for them. You should swear also that you do not have any other villages than those whose names you have already mentioned to us Whites. And all those who do not wish to make peace with the Whites, you should not harbour them. You should force them to accept the peace and if you capture them in battle, you will be permitted to sell them to the Whites.

Dem gi 4 sama foe dem solanga dem hediman pikin no kom langa dem. Datem dem kom teki dem tara presenti goedoe, dem sa gie pikien foe heddeman, foe teki dem 4 diesi demgi baka.

They will give four of their people (as hostages) until the captains' children will have arrived there. When they will come to collect the other gifts, they will hand over the captains' children and they will take these four back.

14. Dem presentie disie sa libie foe gie onoe jette; onnoe sa moessoe kom foe teekie dem na Victoria disie den kalie Monima.

The presents that are still waiting to be given to you, ${ }^{34}$ you should come collect them at Victoria, called Monima by them.

Dem sa kom teki dem santi na Monima, mara effi granman langa coertoe plessi fou mekki a go pikien moro na oppo, da granboen.

They will collect the goods at Monima, but it would be very good if the Governor and the Court would have it brought a little more upstream.

15. Dem nengre dissi ben helpie foe killie dem bacara disie ben com foe mekie da fossie frie - Picolet nanga dem toe tarawan - dem sa moessoe gie dem na granman nanga couroutoe abara. En effoe onnoe no kan doe dattie, dan onnoe sa moessoe hollie dem allekie katibo na onnoe mindrie. En dem no sa moessoe kom nembre na wan plandassie offoe na fotto.

33. This refers to the 'gifts' (from the colonial perspective) or 'retributions' (from the Saramaka perspective) to be delivered to the Saramaka as part of the agreement.

34. These had to be shipped from the Netherlands. 
Those Blacks who helped killing the Whites who came to make the first peace Picolet and the other two ${ }^{35}$ - they should hand them over to the Governor and the Court. And if you cannot do that, then you should keep them as slaves in your midst. And they should never come to any plantation nor to Paramaribo.

Poudroe of kruiti betere fou dem bikassi kondre de na dem bakka jetti disi dem no sabi. ${ }^{36}$ Dem wandi fou hondi langa fou soutou gi dedi sama fou dem, no fou doe wan ogri, ma fou holi dissi fri quetti.

Gun powder or gun shot is better for them because there are still places in the interior they are not familiar with. They want to hunt and to fire in honor of their dead, ${ }^{37}$ not to do bad things, but to truly keep the peace.

Da so dem Saramaka Ningre teki da fri na fesi fou masara Dorich langa sergant Ritter. ${ }^{38}$ Masara Nepveu lesi gi dem. Alle taki, da reiti so; dem wan sweri da fri. Dem hediman selfi effi di samma dem sendi nem foe dem: ${ }^{39}$ Darie, hedeman voe alla; Abini, waca na hem baca; Coffi; Tanie, com na hem plesi; Lamotte; Jebooy, com na hem plesie; Aloetoe; Abram; Quamina, na hem plesi; Ettia (xxx); Kwakoe; Prima; Acapo na hem plesie. Maconde, foe Toefinga; Mafoengoe na hem plessie; Cabriatie \& Attama self; Jantie Acourie; Monima; Pianga na hem plessie; Moesinga; Jantie na hem plessie. Dem alla sweri gado langa gron na dem reiti fassie taki da so dem sa holi da fri, en dem sa mekki ibriwan holi so alleki wi ben poti, dede na libi.

This is how the Saramaka accepted the peace in the presence of Mr Dörig and Sergeant Van Rillertsz. Mr Nepveu read it to them. They all said it was good this way; they wanted to take an oath on the peace. The captains themselves or the people they sent in their names: Dabí, the paramount chief; Abini, his successor; Kofi, represented by Tani; Lamotte, represented by Jebooy; Alutu; Abram, represented by Quamina; Étja (also known as) Kwaku; Primo, represented by Akapo.

35. This refers to an event that took place during the first attempt at peace, in 1749, when three members of the colonial delegation were killed.

36. The fact that there does not seem to be any connection between this reply on the part of the Saramaka and the text of clause 15 is clarified by the Dutch text of the treaty, which contains a Nota Bene, saying that at this point the Whites tried to talk the Maroons into accepting an alternative gift instead of gun powder.

37. This is a well-known custom among the Saramaka.

38. These two military men are referred to in other documents as 'Dörig' and 'Van Rillertsz'.

39. Since at this time the colonial government was not yet very well aware of the political organization of the Saramaka (De Beet \& Price 1982:204n3), some inconsistencies may be present in this list. In my translation I have transcribed the names as they are known from other historical sources. Additional information on the captains and their villages is given by De Beet \& Price (1982:29, 200-201, notes 2 and 3). 
Makonde, of the Tufingas, represented by Afungu; Kabriati and Antamá (who were present) themselves; Jantie Akuri, ${ }^{40}$ represented by Monima and Pianga; Musinga, represented by Jantie. They all took an oath to God and to the land, entirely according to their custom, ${ }^{41}$ saying that this is how they will stick to the peace, and they will make everybody do so just like we wrote it down, until they die.

(source: NA 1.05.10.02,66)

\section{The voice of the Maroons (III) (1762)}

Although, as mentioned earlier, the 'true' voice of the Saramaka is not heard in the text of the treaty, a few quotations can be found in archival documents where they do express their view on certain issues regarding the treaty. The first quotation below is from the diary of Louis Nepveu, who, in the preparations for the negotiations with the Saramaka, had an encounter with the Ndyuka Granman Arabie (who had made peace with the Whites a few years earlier). In Nepveu's presence, Arabie made the following disparaging remark about the Whites to his fellow Maroon Joelie:

Caba Joelie bakra membre dem gran sandie (1762)

But, Joelie: Whites think they are very important (source: De Beet \& Price 1982:130)

After the treaty had been signed, a group of soldiers who were on their way to Saramaka encountered 'an old Negro who ..., shaking my hand, said...':

odie massara jou cossie mie, mie cossie jou bakka, dat soo da vrie wakka (1762)

Goodday, sir. If you are courteous to me, I am courteous to you, that's how this treaty works

(source: De Beet and Price 1982:154)

In contrast to the translation given by De Beet and Price (1982:205n4), the word $k o s i$ is translated here as 'to be courteous' rather than 'to curse'. As is clear from the quoatation given above, the latter is completely at odds with the context in which this utterance takes place. There are two homonyms kosi in Sranan: one from English 'curse', the other from English 'courtesy' (cf. Focke 1855, s.v. kósi).

\section{The voice of the Slaves (III) (1763-1767)}

Here are some more examples of slaves' speech, gleaned from the court records:

joe saa libe mistre worke, goo selle joe voule, joe noe sa go (1763) you shall abandon your masonry work; go sell your poultry; you shall go now

(source: NA 1.05.10.02,808)

40. The treaty also involved a small number of Akurio Indians, who lived among the Matawai Maroons (De Beet \& Price 1982:206n16).

41. For an interesting discussion of these 'customs', see Bilby (1997). 
Grand Gado soli wi, date wi no doe bon, maar mi no sabi, Massingo sabi, Mattuari negre doe ougrie, mi no sabi Grand Gado(1766)

the Great Lord showed us that we did not do the right things; but I don't know; Massingo knows; the Matawai Negroes did evil things; I don't know the Great Lord

(source: NA 1.05.04.06,330)

Jou Captein Dorig mama p----(1766)

Captain Dörig, fuck you! ${ }^{42}$

(source: NA 1.05.04.06, 331)

Aja, mie sabie jou(1767)

Yes, I know you

(source: NA 1.05.10.02,813)

\section{VAN Dyк (c1765)}

The sections reproduced below are taken from a language primer-cum-'country guide', containing word lists, some idioms, twelve dialogues and a sixty-five page 'reading drama' - a play meant to be read rather than performed - about life on a coffee plantation. It is the oldest substantial text in any Suriname creole (112 octavo pages), predating Schumann's (1778) Saramaccan dictionary by more than a decade. Although the work itself is undated, it has been established that it must have been published in 1769 at the latest, since a book notice about it appeared that year (Van Trier-Guicherit 1991: 33). ${ }^{43}$ This suggests that the book was published during one of the years preceding 1769. Based on this and a number of other considerations, the book was provisionally dated at c1765 (Arends 1995). This does not exclude, however, that it may have appeared a little earlier. One - admittedly slight - indication in that direction may be found in the fact that in the book, including the section on money (p. 9), no reference whatsoever is made to the so-called 'card money' (made out of playing cards), introduced to compensate for the chronic lack of cash in 1760 . Whether this is relevant or not, a pre-1765 dating would be in accordance with the generally archaic character of Van Dyk's Sranan (cf. Arends 1995 for further discussion).

42. $p$--- stand for pima 'cunt'; the phrase yu mama pima is reminiscent of the ritual insults containing sexual references to the opponent's mother, which are still used today in the African American verbal contest known as 'sounding' or 'playing the dozens' (e.g. Abrahams 1970[1963]; Labov 1972).

43. This book notice reads as follows: 'If the language, which we cannot judge, is represented adequately, this little work may serve to acquaint those who are in need of it rapidly with some words and idioms: however, the language appears to be an irregular hodge podge of several languages, which kind of language should be learned above all by practice. The author of this Instruction has complemented his brief colloquial dialogues with a lengthy dialogue, in which The life and business of a Surinamese plantation manager with the slaves on a coffee plantation is sketched: it is to be hoped he chose the very worst and that there are not many who resemble such a manager. The latter remark is an allusion to the extremely cruel behavior of the manager in the Life and business part of Van Dyk's book. 
Although no biographical information on the author is available (Van Trier-Guicherit 1991), I have found the name Van Dyk to occur in Suriname as early as 1712: Hartsinck (1770:709) mentions one Jan van Dyk as the owner of a plantation called Dykveld. Also, until today there is a Saramaka clan named Fandaaki ( $<$ Van Dyk). If Pieter van Dyk was a descendant of Jan van Dyk, this would lend further support to the idea, based primarily on the authentic quality of his Sranan, that he may very well have been a native speaker (for further discussion, see Arends 1995; for a discussion of the play from a literary point of view, see Laffrado 2001).

\section{3a. The burial scene from Van Dyk's Reading Drama}

The scene reproduced below, the final one of the play, describes the burial of a female slave. As is the case with other parts of the play, this section contains several accurately described features of plantation culture. Both the custom of covering the coffin with a cloth when it is lowered into the grave and the breaking of the deceased's plates and calabashes are confirmed by the description of these practices given by Hartsinck (1770:911-912). Also, the custom of making cuts in the cloth is still found in the Suriname interior today (Lichtveld \& Voorhoeve 1980:246). The fact that Van Dyk was so knowledgeable about plantation life adds to his reliability as a source of authentic 18th-century Sranan.

Zwarte Officier. Hoe ply oenne de da tem fo go beri potti klossi na kissi fo didde zomma den zomma wan zi da didde homan a moes kom hessi wi zey go tappe da kissi da tem da tem.

Black overseer. What's keeping you? It's time to bury the dead. Put the cloth on the coffin. Whoever wants to see the deceased woman must come quickly. We'll close the coffin. It's time, it's time.

Anna. $\quad$ a jusi konetti ziza wakke bon takki alle zomma odi myki joe wakke hessi na passe korbuy mi nem ziki gado za helpi joe.

Anna. Farewell, goodnight sister. Get home safely and say hello to everyone. Have a quick journey. Farewell, my 'namesake god'44 will help you.

Zwarte Officier. Tappe kissi myki wi go mastra negere oenno zikkesi zomma ope da homen hoe ply den human lange negere alle oenno wakke na hippi kry man moe wakke na fessi oenno no vergiti wan zanti kongo kongo.

Black overseer. Close the coffin. Let's go, master slaves. The six of you lift up the woman. Where are the women and the men? All of you walk closely together. The 'wailers' must walk in the front. Don't you forget a thing. Come, come, let's go.

44. A nem ziki (Modern Sranan nen seki; Saramaccan neseki) is that part of one's soul which leaves the body after death and, after the burial, serves as the 'supernatural genitor' in the conception of new children. The death of a person with whom one shares a nen seki places a person in grave danger until the 'second funeral' (Price 1990:309-10). 
Zangers.

Da zo wi jarri didde zomma go mi jan do, wi zarri fo joe alle da joe go lassi zo, na tra moen wi za troy watere moffe gi joe joe no dry trokke man lassi ô! mi jan do za alle tem.

Singers. $\quad$ This is how we carry our dead away. I rejoice. ${ }^{45}$ We're all sad because of you, that you died just like that. In a month we'll disperse saliva over you, so you won't be thirsty. Our trokiman ${ }^{46}$ has died, oh! I rejoice, etcetera.

Zwarte Officier. Potti na gron gimi klossi doe aber kissi kotti da klossi lange neffi krassi abere potti na ini gron potti dotti bon na tappe kaba kaba a bon zo.

Black overseer. Put it on the ground, give me the cloth and put it over the coffin. Make diagonal cuts in the cloth with your knives. Put it into the ground and put some earth on top of it. Stop it, stop it, it's enough.

Zillifa. $\quad$ Bassia wi no zy gi jam jam lange drinki na den didde zomma disi wi ben beri fo wikki passa alredi.

Zillifa. $\quad$ Overseer, shouldn't we give food and drink to the deceased whom we buried over four months ago?

Zwarte Officier. Ai wi za doe wan trom hoe ply jam jam lange drinki pletti lange kallebassi fo didde zomma.

Black overseer. Yes, we'll do it right away. Where are the plates with food and the calebashes with drink for the dead?

Zillifa. $\quad$ Bassia a de alle zanti.

Zillifa. $\quad$ It's all here, overseer.

Zwarte Officier. a Bon oenno go ziddom na tappe da didde zomma jam drinki billi foele pree toe troy piekien onno locke hoe fa mi doe ziza jam jam de drinki toe a bossi mi hatti lobbi a bossi fo alle zomma takki Diki odi lange Koridon lange Januari konetti konetti mi hatti lobbi konetti fo alle mastra negere wakke bon onno broke pletti lange kallebassi na hondere pisi kaba kaba mastra negere a noefe zo da tem fo trom go na hosse bakke.

Black overseer. Very well. Sit down on top of the dead. Eat and drink your fill and rejoice. Throw some on the grave. See how I do it. Sister, here's food and drink too. Cheers, sweetheart. Cheers to everybody. Say hello to Diki and to Koridon and to Januari. ${ }^{47}$ Goodnight, goodnight, sweetheart, goodnight to all fellow slaves, get home safely. Break the plates and the calebashes into a hundred pieces. Stop, stop, fellow slaves, it's enough. It's time to go back home.

(source: Van Dyk c1765: 110-2)

45. The 'rejoicing' (jando lit. 'have fun') refers to the custom of singing and dancing with the coffin (Lichtveld \& Voorhoeve 1980:246).

46. A trokiman is the lead-singer in Surinamese call-and-response singing.

47. These are slaves who had died earlier in the play (as a result of the manager's cruelty). 


\section{3b. Dialogue no. 2 From VAn Dyk's language Primer}

As noted above, Van Dyk's booklet contains a dozen dialogues, which are meant to instruct the reader in culturally appropriate conversation in Sranan. I have selected dialogue no. 2 since this allows a comparison with one of the dialogues included in Weygandt (1798). Although the latter claims complete originality for his Sranan primer, an earlier study of the two works has shown this claim to be false (Arends 1995). This can be seen, for example, from a comparison of Van Dyk's dialogue no. 2 with Weygandt's dialogue no. 1 (see no.20). Although in the original every sentence starts on a new line, I have grouped together sentences which seem to form one unit, either because they constitute one conversational turn or one because they are presented as alternative ways of saying the same thing. For the reader's convenience I have added abbreviations to indicate who is the speaker in the different passages $(\mathrm{M}=$ master; $\mathrm{S}=$ slave; $\mathrm{V}=$ visitor $)$

S: $\quad$ Myn Heer wan zomma hakkeze na joe. Wan man de na dore. Wan zomma kom fo takki lange joe.

Sir, somebody's asking for you. There's a man at the door. Somebody came to see you.

M: Hoe man dat joe zabi hem. Hoe neffi hem.

Who is it, do you know him? What's his name?

S: $\quad$ Mino zabbi. Mino zi hem wantem.

I don't know. I never saw him before.

M: Hoe klossi a weri.

What kind of clothes does he wear?

S: $\quad$ Riddi jakti.

A red coat.

M: Joe takki hem mide na Hosse. Joe myke a kom na ine hosse.

Did you tell him I'm home? Did you let him in?

S: $\quad$ Ai de na fessi hosse.

Yes, he's in the front-room.

M: Tak hem a watti pikien. Mi za go takki lange hem. Mi za zie hoe zomma dati.

Tell him to wait a moment. I'll talk to him. I'll see who it is.

M: $\quad$ Ki da joe myn heer. Mi bleytie foe troe. Hoe fa santi wakki lange joe.

Oh, it's you, Sir. I'm very pleased. How's your business?

V: Zanti fo mi wakki bon.

My business is fine.

S: $\quad$ Zomma de kom. Dri zomma hakkesi na joe.

Some people are coming. Three gentlemen are asking for you.

M: a Hatti mi. Mi ben hangeri fo takke lange joe.

I'm sorry. I would have liked to talk to you.

V: Wi za doe na wan tarre tem. Te betere tem de kom. Hoe tem mi za kom bakke.

We'll do that another time. When there's a better opportunity. When shall I come back? 
M: Da tem joe wandi. Na bakke dinatim joe gona dore.

Whenever you like. Will you go out in the afternoon?

V: $\quad$ Ai miza go na fyfi ure mi za kom na hosse bakke.

Yes, I will, but I'll be back at five.

M: Offe joe kom mi za tan watti joe.

If you come, I'll be waiting for you.

$\mathrm{V}$ : Da bon tanna den zomma disi de na joe zey. Joe doe te moesi worki na mi.

Very well, stay with your company. You needn't bother.

M: $\quad$ Mi zi go na dore moffe lange joe. Locke bon voete no missi.

I'll see you to the door. Watch out so you don't fall. （source: Van Dyk c1765:24-26)

\section{Fermin (1769)}

Philip Fermin (1730-1813) worked as a medical doctor in Suriname from 1754 until 1762 (Encyclopaedie 1914-1917: 296; Van Kempen 2003:238). In one of his books about Suriname (all of which were written in French), he presents a few sentences and some isolated words in Sranan. Fermin was born in the southern town of Maastricht, where French was a much used language at the time. Influence of French spelling conventions appears from his use of <ou > for / $\mathrm{u}$ / in hou, although he uses Dutch-influenced <oe> in goede. (The same phenomenon is found in the spelling of Sranan used by two other French-oriented authors, Prince Roland Bonaparte and L.C. van Panhuys, Esq.; see Chapter 7.)

audi massera, hou fassi you tan, welkom na dissi ccontri

Hello, Sir, how are you? Welcome to this country.

goede Godi

good God!

Give mi da hedi

Give me my hat.

Forki

Fork

Pleti

Plate

Bredi

Bread

Boy

Boy

(source: Fermin 1769, Pt 1:20,22)

\section{Nepveu (1770)}

In his voluminous 'Annotations' to Herlein's 1718 book, Jan (or Jean) Nepveu (17191779) included a number of observations on Sranan, some of which are meant as corrections of what he perceived to be errors in Herlein's dialogues while also including a fair number of additional words, phrases, and short sentences. Jan Nepveu, a brother of Louis (the author of the Sranan version of the Saramaka Peace Treaty; see no. 10 
above) was a son of Huguenot parents; he was born in Amsterdam and moved to live with his parents in Suriname in 1734. Gradually he moved up through the colonial government's hierarchy, ultimately fulfilling the post of Governor from 1770 until 1779. The text was written during a stay in the Netherlands between 1763 and 1765, while revisions and additions were added later. The manuscript of the 'Annotations' exists in several versions, all dating from between 1765 and 1770; I have used the fair copy from 1770, stored in the Municipal Archives of Amsterdam. For more information, see Arends (1995b).

\section{5a. Nepveu's Corrections to Herlein 1718 (1770)}

As to Nepveu's corrections to Herlein's Sranan specimen, it should be noted that by the time he made these some 50 years had elapsed since the publication of Herlein's book. Even though this is a fairly short period, the language may have undergone significant changes, especially as it was still in its initial stages of development at that time. Since Nepveu's corrections to Herlein's Sranan specimen have been reproduced in their entirety elsewhere (Arends \& Perl 1995; see also Voorhoeve \& Lichtveld 1975), I have only included the most important ones here. ${ }^{48}$

Herlein (1718)

tem $(\mathrm{V})$

my bon

my belle wel

mie jarij no grande bon?

Oe plesje tem

Akesi of joe tan an house?

à Wilkom loeke joe...

No mie ben benakese ta entre ples à reddi wen

as

na bileau

tappe windels
Nepveu (1770)

$\tan (\mathrm{V})$

mi de boen

mi de bellewel ${ }^{48}$ or: mi de boen

mi jarie no mooij?

da tem jou plessie.

ahakisi effi missie sa tan na Hosso

a sa kom loeke jou...

no mi sendi hakisi, na tara plessi a

reddi or: no mi de go na doro

effi

na grom

tappe fenstre or: oppo fenstre.

\section{5b. Nepveu's additions to Herlein 1718 (1770)}

As to the additional Sranan material presented by Nepveu, I have omitted those sentences and phrases that are structurally (more or less) identical to others included in his manuscript; for a complete list, see Arends \& Perl (1995).

48. Although Nepveu correctly adds that 'bellewel is more English; now, many English words have been replaced by Dutch words', it should be realized that the alternative - boen - is derived from Portuguese, not Dutch. 
da troe?

is it true?

da no so

that is not so

a taki leij

s/he is telling lies ${ }^{49}$

da wan boen soma

it is a good person

a leij for troe

$\mathrm{s} /$ he is truly lying

da wan biggi leij

that is a big lie

a sabi leij

s/he knows how to lie

a hansom for troe

it is very pretty

aben (= a ben) hansom

s/he was pretty

a nomooij (= no mooij) moro

$\mathrm{s} /$ he is not pretty anymore

mino (= mi no) wanti joe

I do not want you

a go boen of belwel

I am fine, or: (I am) very well

a takoeroe

s/he is ugly

mi ben lobi him

I loved him/her

mino (= mi no) sal lobi him moro

I will not love him/her anymore

jou lobi mi?

do you love me?

hoefasi jou tan

how are you?

a pekien toe moussi

it is too small

49. With regard to tense and aspect, I follow Nepveu in my translation even though occasionally this is at odds with what one would expect from the point of view of Modern Sranan. In the case at hand, for example, one would expect a taki leij to be translated as 'he was telling lies', while the present tense would be rendered as a de taki leij. Apart from the fact that TMA, especially tense, is very difficult to interpret without context, it may also be the case that changes in the TMA system that have taken place since Nepveu's time play a role here. 
da him reeti man

that is her lawfully wedded husband

dat him Souta

that is her/his concubine

a de wakka langa him

s/he has an affair with him/her

a fourfouro langa him

s/he lives with him/her in concubinage

jou wanti mi

do you want me?

a kom hia allatem

$\mathrm{s} /$ he always comes here

adea (= a dea) na tappoe

she/he/it is upstairs

wakkago $(=$ wakka go $)$

go away

$\operatorname{akom}$ (= a kom), adekom (= a de kom)

$\mathrm{s} /$ he is coming

meki migo $(=$ mi go)

let me go

$\operatorname{abin}(=a \mathrm{bin}) \mathrm{kom}$

s/he has come

oemeni de?

how many are there?

kon hiaso

come right here

$\operatorname{abin}(=a$ bin) go

$\mathrm{s} /$ he is gone

a no pleij langa him

s/he does not play with it

giem $(=$ gi $(h) e m)$

give it

gie $m i$

give me

gie hem

give him/her

meki atan (= a tan)

let it be

a kaba

it's finished

tappoe moffo

shut up

no taki notti

don't say a thing 


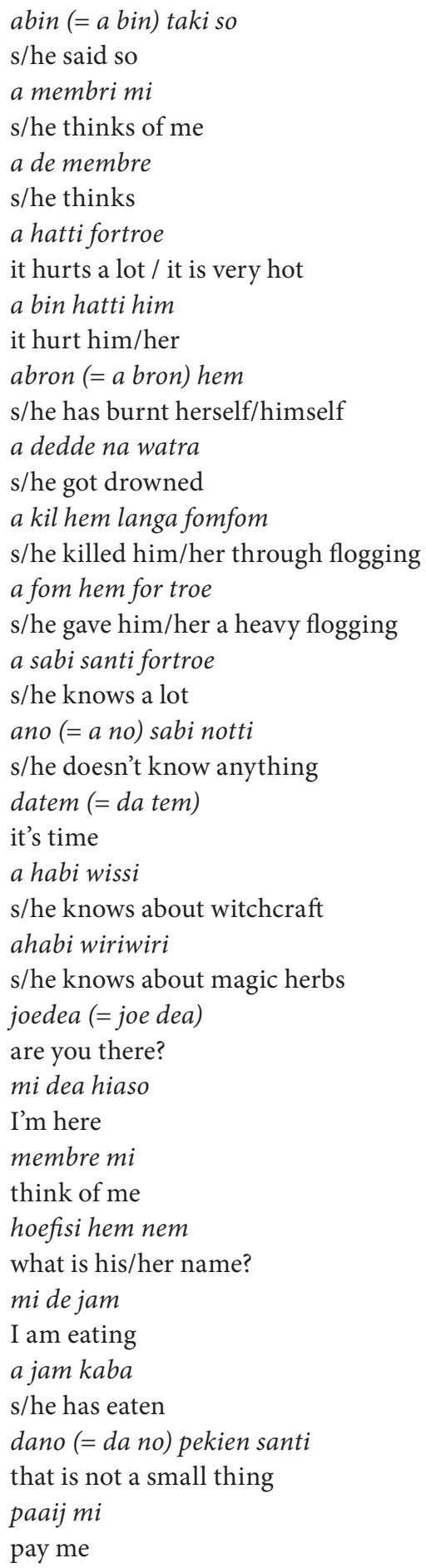




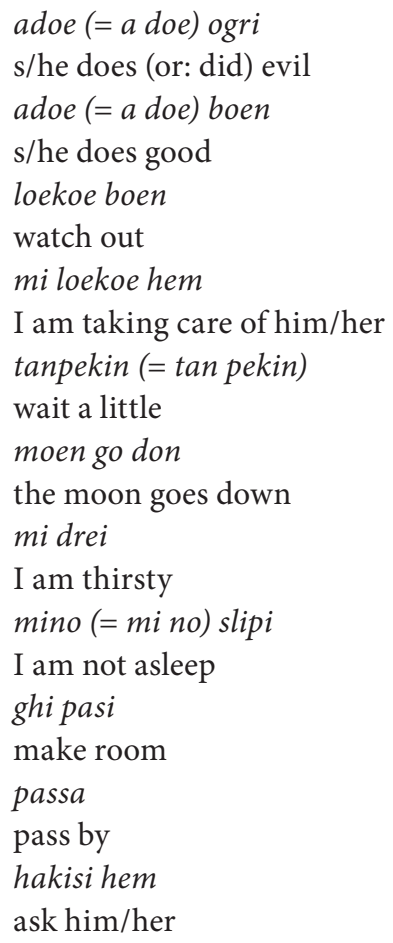

(source: GA 231, inv. no. 298)

16. Hartsinck (1770)

Although he never actually visited Suriname, Jan Jacob Hartsinck, author of a two-volume Description of Guyana, was well-informed about Suriname, especially because he had access to the documents of the Societeit van Suriname, the governing body of the colony. Unfortunately, he has very little to say about the language of the Blacks, especially in terms of concrete language data. The only information of any substance he provides has to do with burial ceremonies. At the end of these ceremonies, Hartsinck tells us, the Blacks use the expression '...Winje mooy, that is Farewell, you went to a happy place; remain still; others went before you, whom you will find there...' (Hartsinck 1770, vol 2:911). The exact meaning of this expression is unclear: while mooij ( $<\mathrm{Du}$. 'mooi') is a normal Sranan word meaning 'pretty, beautiful', the winje part remains obscure; is it perhaps a word of African origin? Because of the presence of mooij and in view of Hartsick's translation, I provisionally assume the expression as a whole means something like 'have a good journey', but this remains speculation. 


\section{Schumann (1778) ANd (1783)}

Without any doubt, Schumann's manuscript dictionaries of Saramaccan (1778) and Sranan (1783) are the pièces de résistance of early Suriname Creole lexicography, and, with the possible exception of Oldendorp's 1767-1768 dictionary of Negerhollands, of Creole lexicography tout court. Schumann was not a native speaker but made extensive use of informants (one of them being Saramaka convert Johannes Alabi - see Section 7.2 ), which enhances the reliability of his data considerably. An edited and annotated version of the Saramaccan dictionary was published by Schuchardt (1914), while an edition of the Sranan dictionary appears in Kramp (1983). In spite of these publications, Voorhoeve's desideratum to have 'two historical lexicological studies ... based upon the old dictionaries of Schumann' (Voorhoeve 1961: 106) still remains unfulfilled. Apart from his lexicographical work, Schumann was very active in translating religious material both into Sranan and into Saramaccan. Examples are his translation of the Gospel Harmony ${ }^{50}$ (1781) into Sranan and of a number of religious hymns into Saramaccan (1779).

Christian Ludwig Schumann (1749-1794) was the son of a Moravian Brother, Theophile Schumann, who - rather unusual for a Moravian missionary - had received an academic training and who is the author of both an Arawak dictionary and an Arawak grammar. Christian Ludwig was born at the Moravian mission post of Pilgerhut, in Berbice, ${ }^{51}$ and was sent to Europe for his education, where he probably attended the theological seminary in Barby (Lenders 1996: 81). Since we know from Stähelin (1913-16, vol II, 2:191-9) that Schumann père made a trip to Saramaka in 1755 , there is an - admittedly slight - chance that Saramaccan was not something completely unknown to Schumann fils when he arrived in Saramaka as a missionary in 1777 . Whatever may be the case, the fact is that during his short stay there (May 1777-August 1778), he managed, despite many problems including various illnesses, not only to learn Saramaccan but also to compile an excellent Saramaccan-German dictionary (Schumann 1778). During the next two years he worked among the Arawak Indians, while from August 1780 onwards he lived in Paramaribo for three consecutive years. It was during this period that he compiled his equally invaluable SrananGerman dictionary. Since he did not have very much (if any) personal experience with life on the plantations, we must assume that his own knowledge of Sranan was primarily based on the language of Paramaribo while the information he provides on the language of the plantations must have been largely based on what his informant(s) told him. In August 1783, just after finishing the Sranan dictionary, he was made to

50. A Gospel Harmony is a compilation of the four gospels into one text.

51. This raises the question whether Schumann fils might have known Berbice Dutch, and, if yes, whether he, or his father perhaps, might have left any recordings of that language, which is not recorded at all in its early stages of development. 
leave the colony, leider wegen ein Vergehen dazu genötigt 'unfortunately forced to do so due to an offence' (perhaps related to the fact that he had returned from his post among the Arawak unauthorized by his superiors). He was first sent back to Herrnhut and from there to the Moravian mission post in Trankebar (India), where he died in 1794. Unfortunately, nothing is known about that period in his life (Stähelin 1913-19, vol. III, part 2, p. 58).

Apart from Sranan and Saramaccan, Schumann also spoke Carib and Arawak, which he may have learned either as a child growing up among the Indians or as an adult when he was stationed at some of the Indian missionary posts in between his assignments in Saramaka and Paramaribo. His knowledge of Arawak enabled him to finish his father's Arawak dictionary, which was later published by Crevaux, Sagot \& Adam (1892). Since nothing more is said about C. L. Schumann in Stähelin's (1913-19, vol III, part 1, p. 402) otherwise very detailed history of the Moravian mission in Berbice and Suriname (due to his Vergehen perhaps?), this is all we know about this remarkable man, who compiled two superb creole dictionaries in a time when hardly anyone thought these languages worthy of recording. Although for a full appreciation of their quality the reader will have to consult these dictionaries themselves, a first impression can be had from the lemmas presented below. They show that apart from being a good linguist Schumann was also an acute and relatively unprejudiced observer of black culture.

For his edition of Schumann's (1778) manuscript dictionary of Saramaccan, Hugo Schuchardt worked from a copy which was made for him especially for that purpose (Schuchardt 1914:44). As noted by Schuchardt (p. 44), his edition is not completely identical to the copy made available to him: he corrected the German, redundant word definitions were cut down, and homonyms were distinguished as separate entries. In other cases, additions, e.g. regarding etymology, were inserted between square brackets. The original from which the copy used by Schuchardt was made is located in the EBG archives in Paramaribo (EBGP H. III A 12(11)). Apart from this, at least two other versions, neither of them completely identical to the Paramaribo manuscript, are known to exist, both of which are stored in the EBG Archives in Herrnhut (EBGH NB VII R3, 8b and EBGH NB VII R3, 9g, respectively). The latter of these is the anonymous (c1780) dictionary hitherto ascribed to Johann Andreas Riemer ( $c f$. Perl 1995), which overlaps to a large extent with Schumann (1778) but which contains interesting differences and additions as well (for further discussion, see no. 18 below). While it would be extremely interesting to compare these three versions of Schumann's Saramaccan dictionary with each other as well as with Schuchardt's edition of the Paramaribo manuscript, such a study cannot be undertaken here. With regard to the sample lemmas from Schumann's Sranan and Saramaccan dictionaries presented below, these have been selected as far as possible to enable comparison between them as well as with the Sranan dictionaries compiled by Focke and Wullschlägel (see nos 28 and 29). 


\section{7a. Sample lemmas From Schumann's Saramaccan dictionary}

$b i$, perfective marker, subjunctive marker, optative marker. Indicates that something is already past or did already happen: mi bi de ko hem, I was with him; mi bi libi $a l a$, I lived there. Often it means wäre [German, i.e.'would, would have', JA]: $a b i$ bun, effi a bi wakka, it would be good if he would have gone; effi a bi jeri, a bi sa $k o m m,{ }^{52}$ if he had heard about it, he would have come; $a$ bi so, it may be that way; a bi ju lau, you must be crazy.

obia, medicine; medicinal herbs; superstitious hocus-pocus; oracular deceit; the things they use for that. Obiaman, someone who performs this.

(sources: Schuchardt 1914; EBGP H. III A 12(11))

ben, had, is, was (auxiliary verb); never stands alone, is put in front of other words (verbs) to express something that is long past, like German 'hat' and 'ist'. Also, subjunctive marker, 'hätte', 'würde', 'wäre', to express something that is uncertain. mi de takki, I say; mi takki; I said; mi ben takki, I have said; also, I had said; ju ben komm, you have or had come; a ben go, he has or had gone; a de go, he is going; $a$ go, he went; wi de teki, we take; wi teki, we took; wi ben teki, we have taken, we had taken; une ben ronneweh, you ran away, you would have run away, you have been away running; dem ben slibi, they have or had slept; a ben habi, he has or had had it; $a$ de, he is; a ben de, he was there, he has been there; mi bribi, a sa ben komm, I think he will have come; a sa ben go kaba, it will have gone; effi mi no ben takki gi $j u$, ju no ben sa sabi, if I hadn't told you, you wouldn't know or have known; effi a ben jeri, a ben sa komm, if he would have heard, he would have come; effi ju ben $d u$ datti grandeweh, a ben bun, if you had done that a long time ago, it would be good or it would have been good.

óbia, idolatrous medicine; witchcraft; especially the things the Negroes use for their alleged witchcraft and to which they ascribe magical powers. meki obia gi mi, make obia for me; obia tetei, a simple string of twine or grass or straw or something else, which they tie around their neck or their body etc. and to which they ascribe magical powers.

dem, they, these (when you talk about many) those, them, one (impers. pron.), their. Also definite and indefinite plural article, i.e. when dem is put in front of a word it means more things of the kind (without the word itself undergoing any change). dem somma, the people...However, when dem is stressed, then it means 'these' (it is the plural of $d a$ and datti). dem somma, these people...gi dem datti, give this to them...datti de vo dem, that belongs to them...dem hosso, their house; hosso va dem, their house...dem no wanni sabi dem famili morro, they don't want to know their kinfolk anymore; dem takki so, it is said... For many verbs, the passive voice can only be expressed with dem. For example, dem ben meki mi na Bakkrakondre,

52. Note that the equivalent of this sentence occurs both in Schumann 1778 and in Schumann 1783 (see lemma ben below). 
I was born in Europe...Gado de so grandi, dem no kann takki da grandi va hem, God is so great, his greatness cannot be pronounced.

tongo, the tongue; the voice, language, the tone, resonance, sound; also, a single word. Tongo tjarri hem Massra na bun, a tjarri hem na dedde tu, The tongue kan make a man happy or unhappy [lit. the tongue carries its master to good things, it carries him to death too, JA]. Ningre tongo no has so menni trobbi va leri, the Negro languages is not very difficult to learn. A de singi biggi tongo, he sings in a deep voice, (he sings) bass. Ju tongo pikki tranga tumussi, your voice is too loud.

hem...Furthermore, there is a distinction between hem and $a$, just as in Latin between se and eum; hem is analogous to Latin se and $a$ to Latin eum; i.e., when I quote someone else's words and the quoted words refer to that person, then I use hem; when the quoted words refer to a third party, I use $a$. For example: A takki, hem no komm (Latin: dicit se non venturum), he says - about himself - that he won't come. A takki, a no komm jette (Latin: eum nondum venisse), he says that he someone else - hasn't arrived yet...da uman takki, hem no wanni, the woman says that she (i.e. she herself) doesn't want to. da uman takki, a no wanni, the woman says that she or he (but someone else than the one who says this) doesn't want to. a membre, hem de wan biggisanni, he thinks of himself that he is great. a membre, a de wan biggisanni, he thinks of another person that he (the other one) is great.

(sources: Kramp 1983; EBGU H. III A 12(1))

\section{Anon. [SChumann] (c1780)}

As was noted above (see no. 17), the anonymous (c1780) Saramaccan dictionary ascribed to Riemer by Perl (1995) is probably more correctly seen as another version of Schumann's (1778) dictionary. Although the name of the Moravian missionary Joh[ann] And[reas] Riemer is on the cover, there are serious doubts whether Riemer should be considered as the author of this manuscript. First of all, as is recognized by Perl (p. 247), Riemer, who was a weaver by profession, did not have the educational background to perform such a work. Second, he stayed in Suriname for only ten months (August 1779-June 1780), less than half of which he spent in Saramaka (September-November 1779 and January-March 1780), which seems like an awfully short period to get acquainted with a new language so thoroughly. Third, the title of the work - 'Dictionary for learning the Saramaka Negro language' - may suggest that Riemer used it as a tool in learning Saramaccan (although, of course, this may also refer to its general purpose as such). Fourth, and most importantly, the high degree of similarity between the 'Riemer manuscript' and Schumann's (1778) dictionary strongly suggests that the former was based on the latter rather than being an original work. This would be entirely in accordance with the Moravian practice of making handwritten copies of Sranan and Saramaccan texts, often modifying them in the process. For all these reasons, the so-called 'Riemer dictionary' is better seen as a version of Schumann's dictionary. 
The following scenario could be imagined. While acclimatizing in Paramaribo after his arrival in August, Riemer, who was to leave for Saramaka in September 1779, received instruction in Saramaccan from Schumann, who had returned there from Saramaka a year earlier. Having just finished his Saramaccan dictionary, Schumann was, of course, an ideal teacher for Riemer. He would have been one of the very few speakers of Saramaccan available anyway. In this connection, I should add, though, that in Saramaka, Riemer received instruction in Saramaccan from Johannes Alabi, the Saramaka convert who also assisted Schumann in compiling his Saramaccan dictionary (Stähelin 1913-1919, vol 3, part 1:217). In any case, to proceed with our scenario, Riemer, while making a copy of Schumann's manuscript for personal use made additional notes, based on Schumann's explanations. As far as practical circumstances are concerned, there are no problems with this scenario: both men were staying in Paramaribo during the same periods of time (November 1779-January 1780 and March 1780-August 1780).

An important addition in the c1780 dictionary, when compared to the 1778 one, is the inclusion of an appendix which contains a 'mini-grammar' of Saramaccan (less than 10 pages), written in German. Together with Oldendorp's more extensive manuscript grammar of Negerhollands, written some ten years earlier, this mini-grammar of Saramaccan is one of the very first serious grammatical descriptions of any creole language known to exist. The main part of it is taken up by a discussion of the verbal system, which is reproduced below (translated into English).

\section{8a. The verbal system of Early Saramaccan}

With verbs, the first type of change [i.e. conjugation for person and number, JA] does not occur at all; the person is just put in front of it and the verb is left unchanged. For example: go, 'go', mi go, 'I go', ju go, 'you go', a go, 'he goes, she goes, it goes', wi go, 'we go', une go, 'you (pl.) go', dem go, 'they go'.

Regarding the second type of change [i.e. the expression of tense, JA] one should note the following: to express the present tense, tann is put in front of the verb. For example: mi tann go, 'I'm going right now', mi tann worko 'I'm busy working'; however, when the tense is not really important, tann is left out, as a result of which $m i$ go may also mean 'I go', mi worko, 'I work'. To express the simple past, the verb is put on its own, without any addition, as in: mi go, 'I went'; mi worko, 'I worked'. This also serves the function of perfect, although this is often expressed by bi, as in: mi bi go, "I have gone'; mi bi worko, 'I have worked'. The real function of $b i$, however, is to express pluperfect. For example: mi bi go, 'I had gone', mi bi worko, 'I had worked'. The future is expressed by tanngo. For example, mi tanngo, 'I will go'; mi tann go worko, 'I will work'. Sometimes $s a$ is used instead of tanngo. For example, mi sa go, mi sa worko; in this usage, however, $s a$ is actually 'town language' [i.e. Sranan rather than Saramaccan, JA] because in Saramaccan it means only 'should'. 
Regarding the third type of change [i.e. the expression of mood, JA], the only thing worth noting is that the optative or conjunctive mood is expressed by bi or bi sa. For example: a bi so, 'it could be like that'; mi bi go, 'I would have gone'; effi mi bi jeri, mi bi sa kom, 'If I would have heard about it, I would have come'; mi bi sa takki, 'I would have said it'.

(source: Perl 1995:370-371)

\section{Schouten (1783)}

Hendrik Schouten came to Suriname when he was twenty-three and married a colored woman a few years later. A civil servant, he published several pieces of poetry, including the handsomely crafted one reproduced here, entitled Een huishoudelyke twist 'A domestic quarrel'. In this bilingual text the man, who is white, speaks Dutch while his woman, who is black, speaks Sranan. This kind of 'bi-monolingual' conversation may not have been uncommon in 18th-century Suriname, especially in conversations between a white male and a black female. According to Voorhoeve and Lichtveld (1975:7), it is 'the first Creole poem ever seen in print'; whether that is true or not, it is certainly the oldest Sranan poem ever published.

Een huishoudelyke twist

A domestic quarrel

Kind lief, laat voort de Coffij geeven!

Tan Baija, jusno a sa kom.

Dear child, let them bring the coffee!

Wait now, it'll be there in a moment.

Maak met de Slaaven dog geen leeven!

Den booijs den de toe moessie dom!

Don't make such a racket with the slaves!

These guys are so dumb!

Spreek zagtjes! waarom zoo te schreeuwen?

Te mie no balie, den no doe.

Speak softly! Why shout so loud?

If I don't shout, they don't do anything.

'T Was best jou bek maar toe te breeuwen!

Mekkie den tappou vo jou toe.

It was best to shut your mouth!

Let them shut yours too.

Kan een Creoole smoel wel zwijgen?

Da ogrie te mie pikki dan?

Can a creole mouth be silent?

Is it wrong for me to answer, then?

Moet men dan altoos woorden krijgen?

Mie sabie, haksie tarawan.

Do we always have to quarrel?

I know, ask someone else. 
Wat middel om die kop te breeken?

Jou no kan nak em langa ston.

How to break that head?

You can't hit it with a stone.

Waar moet ik dan het vuilnis steeken?

Mie swerie Gado loekoe bon!

Where do I leave the mess? ${ }^{53}$

I swear, Lord, watch out!

Wat zullen wij van middag eeten?

Na dienatem jou no sa sie?

What will we have for dinner?

You won't see that at dinnertime?

Ik zeg, ik wel het aanstonds weeten!

Mie takkie jou no balie mie.

I tell you, I want to know now!

I tell you, don't shout at me.

Wat schielijk, en niet lang te draalen!

Jou memmere mie fredde dan?

Hurry up, don't take so long!

You think I'm afraid?

Moet ik de Bullepees ook haalen?

Fom mie, effe jou da wan man!

Should I get the cat of nine tails?

Hit me if you dare!

Zie daar...wijl gij mij dwingt te straffen!

De Diebrie moese nakkie jou!

Here then...since you force me to punish you!

May the devil hit you too!

Wilt nu maar Neeger-Engelsch blaffen!

Jou da wan schurke, dattie trou!

Bark your Negro-English now!

You're a rogue for sure

Moet ik dan hier de Baas niet weezen?

Nou mie no wannie gie jam jam.

Am I not the master here?

Now I don't want to serve you food.

De Slagter heeft meer Bullepeezen!

Eff jou goo Baij, jou moesse lam!

The butcher has more whips!

If you go buy one, may you become lame!

53. The meaning of this line in this context is not entirely clear to me. 
Hoor eens dat schelden! is 't geen schanden?

Jou memmere mie sa kaba?

Hear that cursing! Isn't it a shame?

You think I'm finished?

Pas op! 'k heb 't stuur nog in mijn handen!

Kaka vo so wan Bakkera!

Watch out! I'm still in charge!

I shit on you, white man!

Wat schepzel zal dat wijf bedwingen?

Doe san jou wannie, mie no kee!

Who could ever control that shrew?

Do as you please, I don't care!'

Men breekt wel eerder staale klingen!

Jou no sa brokke mie ti dee.

It's easier to break steel swords!

You won't break me today.

't Hart is door haat reeds ingenoomen!

Jou takkie reijtie, da no kij.

The heart is already filled with hate!

You say a true thing.

Zij zal nog Hel nog Duivel schroomen!

Da vo da hede wie sa scheij.

She'll fear hell nor devil!

That's why we'll separate.

(source: Voorhoeve \& Lichtveld 1975:287-288)

\section{Stedman (1790)}

Captain John Gabriel Stedman (1744-1797), born in the Netherlands of a Scottish father and a Dutch mother, was a member of the 'Scots Brigade' of the States-General army and served in Suriname (1773-1777) in the colonial army fighting the Boni Maroons. During this period, he had a relationship with a mulatto slave, Johanna, with whom he must have communicated in Sranan. He knew Jan Nepveu, the author of the 'Annotations' to Herlein's book (see no. 15 above), who was Governor at the time (Van der Meiden 1987:66). After moving to England in 1783, Stedman wrote an extremely lively book about his experiences in Suriname, entitled Narrative of a five years expedition against the revolted negroes of Surinam (1796), which quickly became very popular. Since the 1796 version was heavily edited by the publisher, I have used the new edition, based on original manuscript, that was published by Price \& Price (1988). It is unfortunate that this voluminous work only contains a relatively small amount of language material in Sranan, especially because Stedman shows himself to be a very keen and relatively unprejudiced observer. Because of their value, all the creole sentences found in Stedman's book are reproduced here, including those which might, 
perhaps, better be regarded as Ndyuka or Boni rather than Sranan. On the other hand, since these language varieties (especially Boni) had only started to split off from Sranan shortly before Stedman was in Suriname, this does not present too much of a problem.

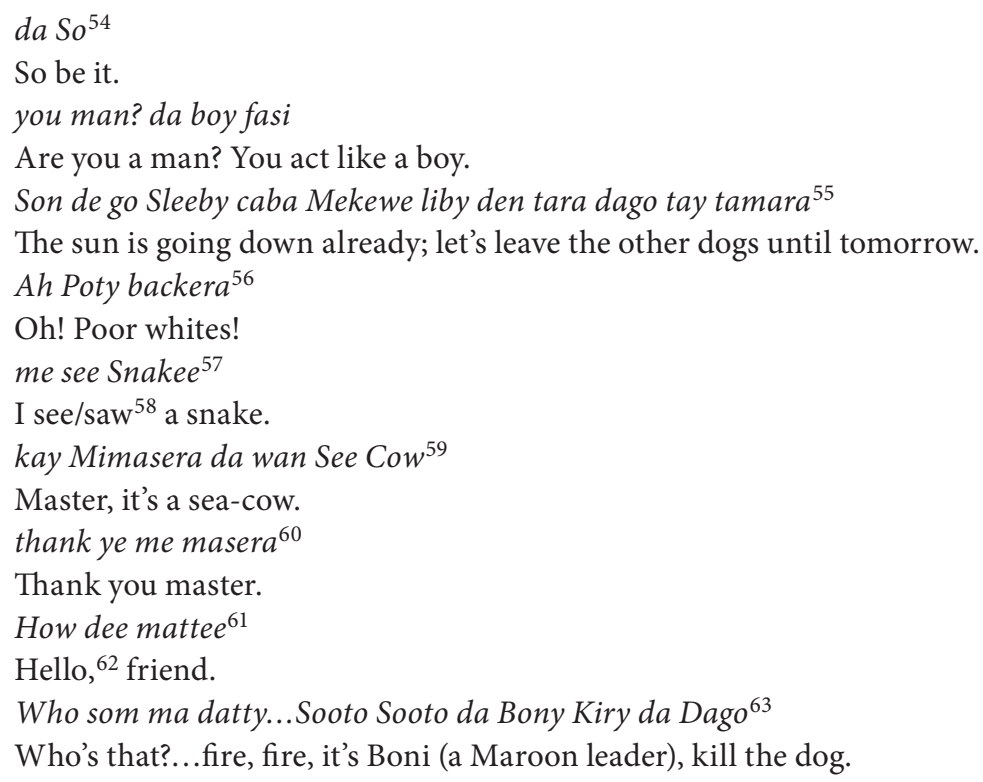

54. This formula was used when the 1760 Ndyuka Peace Treaty was signed (e.g. Hartsinck 1770:); it is grammatical both as a Ndyuka and as a Sranan sentence.

55. Said by a Boni maroon.

56. Said by the Blacks in Stedman's regiment.

57. Said by a Black in Stedman's regiment.

58. Since in the narrative context both readings are possible, and since marking of non-statives in the present tense with de was not obligatory in 18th-century Sranan, no choice with regard to tense can be made in the translation of this sentence.

59. Said by a Black in Stedman's regiment.

6o. Said by a Boni maroon.

61. This sentence occurs in a footnote which provides some valuable information about greeting practices among 18th-century Blacks. It runs as follows: 'the Negroes Generally Salute each other by Shaking hands, When they meet the tops of the Middle Fingers Snap them 3 times and make a bow Saying how dee Matee, how are you Friend'.

62. Contrary to Stedman, I interpret how dee as a representation of modern Sranan odi 'hello' rather than (u) fa yu de 'how are you?'.

63. Said by an unidentified Black. 


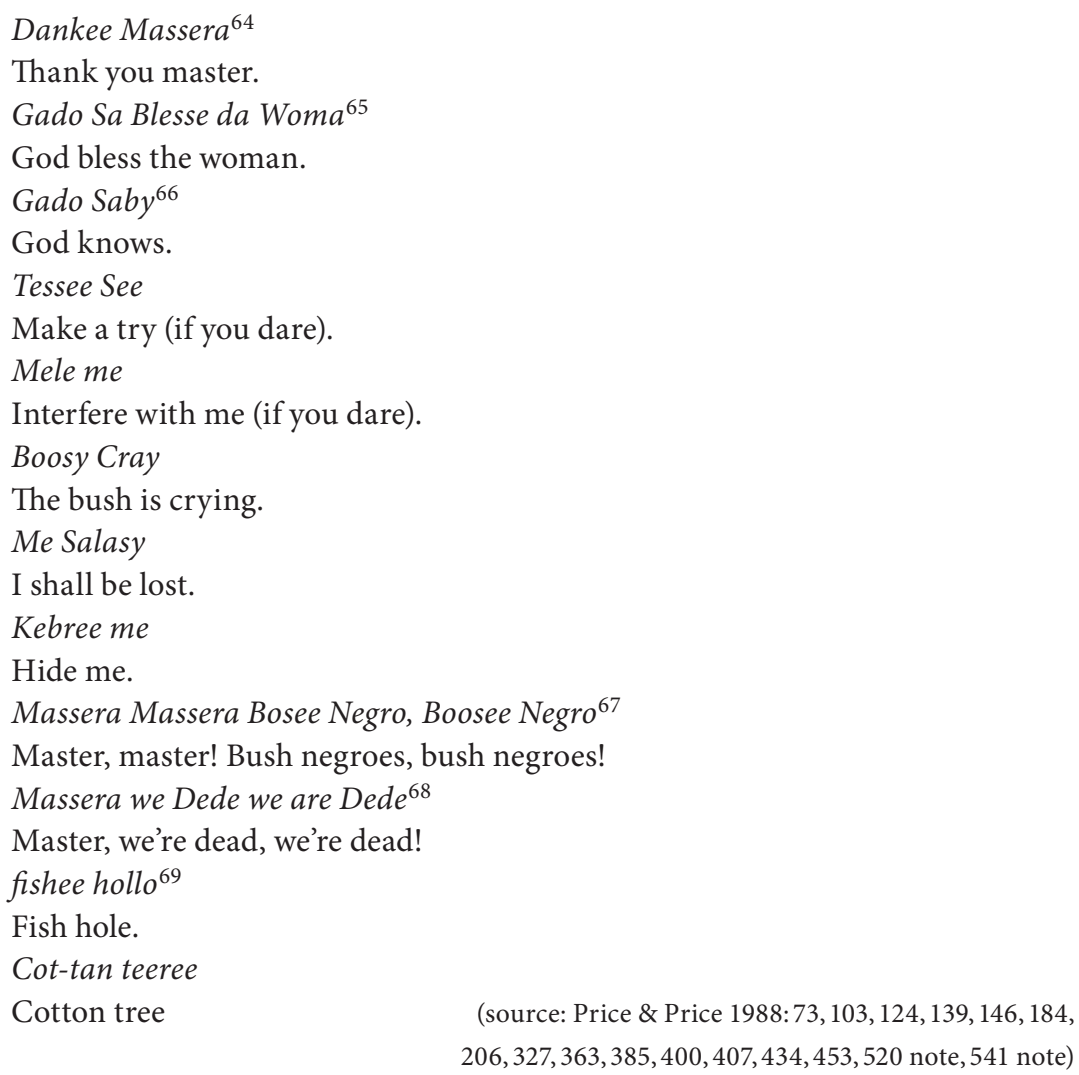

\section{Weygandt (1798)}

In 1798, C. G. Weygandt published a language primer very similar to Van Dyk's (see no. 13), containing a word list, some idioms, some grammar, and twelve dialogues. Five of these dialogues (numbers 1, 2, 3, 5 and 9) were largely plagiarized from Van Dyk's dialogues numbers $2,3,5,7$ and 11, respectively (cf. Schuchardt 1914:xxiii). ${ }^{70}$

64. This was a fixed expression slaves were obliged to use after having been flogged.

65. Said by Stedman's misi, Johanna.

66. The following six examples all refer to names of Boni Maroon settlements; they were mentioned by a Black in Stedman's regiment, referred to as 'Captain Hannibal'.

67. Said by Stedman's black boy-servant Qwacco.

68. Said by Stedman's black boy-servant Qwacco.

69. The name of a Boni Maroon setttlement near the sea, mentioned by a captive Boni woman.

7o. Weygandt, in his turn, was heavily plagiarized by Helmig van der Vegt (1844) (cf. his lesson no. 11 with Weygandt's dialogue no. 1 , reproduced here). 
According to the Voorbericht 'Preface', Weygandt's booklet represents the Paramaribo dialect, whereas Van Dyk probably represents the language as it was spoken on the plantations ( $c f$. Schuchardt 1914: xxiii). Voorhoeve \& Donicie's (1963:31) interpretation of the archaic features in Van Dyk as symptoms of the imperfect competence of a city-dweller is probably incorrect. No biographical information on the author is available. In order to enable comparison between Weygandt and Van Dyk, Weygandt's dialogue no. 1, which is clearly based on Van Dyk's dialogue no. 2 (see no. 13 above), is reproduced below. As in the case of Van Dyk's dialogue above, I have grouped together sentences which seem to form one unit ( $\mathrm{S}=$ slave; $\mathrm{M}=$ master; $\mathrm{V}=$ visitor).

Dialogue no. 1 from Weygandt's language primer

S: $\quad$ Masra soema dé aksie na joe. ${ }^{71}$ Wan Masra dee na dore. Wan soema dee foe takie nanga joe. Da wan Masra diesie dé aksie na joe.

Sir, somebody's asking for you. There's a man at the door. There's someone who wants to talk to you. There's a gentleman who's asking for you.

M: Da oe Masra datie. Joe sabie em? Oe fa a nem?

Who is it? Do you know him? What's his name?

S: $\quad$ Mie no sabie em. Mie no sabie fa a nem. Mie no sabie o sama da em. Mie no ben sie em nemree deja.

I don't know him. I don't know his name. I don't know who he is. I've never seen him.

$\mathrm{M}$ : O klosie a werie?

What kind of clothes does he wear?

S: $\quad$ A werie wan blau lake jaktie.

He's wearing a blue cloth coat. ${ }^{72}$

M: Joe ben takie gie em datie mie dee na hoso. Joe mekie a kom na ienie?

Did you tell him I'm home? Did you let him in?

S: A dee na foorhoso.

He's in the front-room.

M: Takie gie em mekie a tam piekien. Mie sa go takie nanga em. Mie sa go loekoe oe soema datie.

Tell him to wait a moment. I'll talk to him. I'll see who it is.

M: A! da joe Masra! A boen na mie foetroe datie mie sie joe. Oe fa joe tam?

Ah, it's you, Sir. I'm very pleased to see you. How are you?

V: Heelie boen Gado tangie. Mie no sa dee na joe pasie? Mie sa kom wan tratrom baka. Very well, thank God. I'm not disturbing you? I'll come back some other time.

M: San hédee datie? Mie begie joe tam. Mie no abie notie foe doe. Joe no dee na mie pasie. Why? I beg you to stay. I don't have anything to do. You're not disturbing.

71. In my transcription I do not follow Weygandt's habit of ending declarative sentences with a comma, replacing them by full stops instead.

72. Notice Weygandt's - vain! - attempt to avoid the impression of plagiarism by changing Van Dyk's red coat into a blue one. 
S: $\quad$ Soema dé kom. Soema dée diesie dee aksie na joe.

Someone is coming. There's someone who's asking for you.

M: Datie hatie mie foetroe. Mie ben hangrie foe takie nanga joe.

I'm very sorry. I was anxious to talk to you.

V: Datie sa tam foe wan tratrom. Mie sa kom bamba baka.

That will wait for some other time. I'll come back soon.

M: Joe sa doe mie pliesierie foetroe. A sa boen na mie foetroe. Joe sa wanie doe datie.

That will be a great pleasure for me. That will please me very much. Would you be so kind to do that?

V: $\quad$ San hédee no.

Why not?

M: $\quad$ No fergietie datie doe. ${ }^{73}$

Don't forget to do that.

$\mathrm{V}: \quad$ Mie pramiesie joe. Oe tem joe pliesie datie mie kom baka. Oe tem mie moe kom baka? I promise. What time would you like me to come back? What time should I come back?

M: Da tem joe pliesie.

Whenever you please.

$\mathrm{V}$ : Joe dee go baka dina na doro?

Are you going out this afternoon?

M: $\quad$ Mie sa dee tee fyfie joeroe na hoso.

I'll be home until five.

$\mathrm{V}$ : Joe sa abie mie na drie joeroe deeja.

You'll see me here at three.

M: Doe da sanie joe takie. Mie sa tam loekoe joe. Joe no sa kom foe soso.

Do as you say. I'll be waiting for you. You won't come in vain.

$\mathrm{V}$ : Tam na dem soema diesie dee na joe. Joe dé mekie toemoesie wroko. No goo moro fara dan.

Stay with your company. You needn't bother. Don't go any further.

M: Mie sa go tee na doro. Loekoe boen. Da stoepoe glatie foe troe. No fadon. Té bamba. I'll see you to the door. Watch out. The steps are really slippery. Don't fall. Until soon.

(source: Weygandt 1798:91-93)

\section{Riemer (1801)}

Some twenty years after he returned from his 9-month stay in Suriname, J. A. Riemer (1801) published Missions-Reise nach Suriname und Barbice 'Missionary journey to Suriname and Berbice'. Apart from the Saramaccan version of the Lord's Prayer (see Section 7.2), this book includes a few pictures whose captions contain some Saramaccan. The one reproduced here, the caption to plate no. 7, describes a scene where some Saramaka man tell the culturally ignorant missionary that the bird he has just shot and is holding up proudly is, in fact, sacred:

73. Apparently, the words datie and doe were interchanged by the printer. 
Massra $^{74}$ bi dedde $e^{75}$ wan Gado!

Sir, you killed a god!

(Riemer 1801: in Price 1990: 187)

(source: Price 1990:187)

\section{BolingBRoKe (1807)}

The Englishman, Henry Bolingbroke, worked as an auctioneer in Paramaribo during the second English interregnum (1804-1816). Since he only arrived in Suriname in early 1807 , he cannot have had much experience with Sranan by the time he wrote his book, which was published that same year. However, he may have been familiar with creole languages in general as he had lived in Stabroek (Guyana) from 1799 until 1806 (Bolingbroke 1807: title page; unnumbered page preceding p. 1; pages 1, 3). On the final page of his book he presents the following '[s]pecimen of the negro English, or talkee-talkee' (the English translations are Bolingbroke's):

Da wan tieri somma 'That is a free person'

No mekie bawli bawli 'Don't make any noise'

Den de mekie too mooso bawli bawli 'They make too much noise'

Mekie hesie 'Make haste'

Loeke boen 'Take care, or look good'

Tantiere 'Stand still'

Loeke deeja 'Look here'

Piekienmoro 'A little more'

Onofo 'Enough'

Oe soma die da pree?'Who's there?'

Matie 'A friend'

Da mie 'It's me'

Da massa 'It's a gentleman'

Da misse 'It's a lady'

(source: Bolingbroke 1807:400)

\section{3a. A Dialogue Between A NeWly ARRIVEd bakra} AND A FREE MULATTO GIRL (1829)

The author, who served for several years (1828-1831) as a lieutenant in Suriname, included the following dialogue in his book to show his proficiency in Sranan to his readers. He explicitly adds that he writes Sranan 'as it is spoken, i.e. not according to the spelling of English, even though most of the words are derived from that language' (Nagel 1840:79-80).

74. Note that here (as in several other items in this chapter, e.g. nos 6, 27), in accordance with Sranan politeness rules, the the third person is used to address someone considered to be superior.

75. Assuming my translation is correct, this is a very rare case of dedde 'dead, die' used as a transitive verb. 
O die, ${ }^{76}$ miessie, oe fa joe tan?

Mi die boen, masra; fa masra tan?

So so, haffe haffe, mie dee won nioe kommer ${ }^{77}$ na diessie kondree.

Masra dee wan Duitsieman?

Ai, miessie, joe fatta $^{78}$ wan Duitsieman toe?

No no, masra, a wan Englisman.

Uppei ${ }^{79}$ a dee now?

Ago wei na em kondree; a baai mi nenni, an gi mi fri. Adeddi kaba.

San joe wroko alla dei?

Mi wassie kroossie; if masra wannie, sa ${ }^{80}$ wassie den fo masra toe.

A boen; joe kan kom takie ${ }^{81}$ dem, na ienie foto ta marra momentie. ${ }^{82}$

Tanji, masra; wi abie wan pokim ${ }^{83}$ boy so ${ }^{84}$ sturie, if masra pliesie.

Ibri wan, fassi ${ }^{85}$ boen na mie, alie ${ }^{86}$ sa gie em; no forget. Adjossie, miessie.

Djossie, masra.

Howdy, miss, how are you?

I'm alright; how are you?

Quite alright; I'm a newcomer to this country.

Are you Dutch?

Yes, miss; is your father Dutch too?

No, Sir; he's English.

Where is he now?

He went back to his country; he bought my mother and gave me freedom. He's dead.

What's your everyday job?

I wash laundry; if you wish, I'll wash yours too.

76. I.e. odie 'hello'.

77. The word nioe kommer 'newcomer', which I have not encountered in any other text, strikes me as an intrusion from English; $c f$. also the spelling take for teki and the English sounding no forget.

78. A typo for tata 'father'.

79. I.e. hupe 'where'.

80. The word mie ' $\mathrm{I}$ ' is missing before $s a$.

81. A typo for tekie 'take'.

82. Here the word mamantem 'morning' is intended.

83. A typo for pikin 'small, little'.

84. A typo for fo 'to'.

85. I.e. ibriwan fasi 'whichever way'.

86. A typo for $m i$ 'I'. 
Very well; you can collect them at the inner fort ${ }^{87}$ tomorrow morning. Thank you, Sir; I have a little boy that I can send, if that's alright with you. Any way you want is alright with me, I'll give it to him; don't forget. Goodbye, miss.

Bye, Sir. ${ }^{88}$

(source: Nagel 1840:80-81)

\section{Benoit (1830)}

Pierre Jacques Benoit was a Belgian artist, who visited Suriname in or around 1830. In 1839, he published his Voyage à Surinam, which included one hundred hand-colored lithographs depicting life in the colony. The book also includes a few samples of Sranan.

Poor man abi no pikin moni to bai njoen krosi

poor man, who doesn't have money to buy new clothes ${ }^{89}$

Mi no sabi

I don't know

Tata, Tata, lepi mi

God, help me

Danki, Masra

Thank you, master

Loekoe, wan bigi boesnengre

Look, an important bush negro

(source: Benoit 1980 [1839]: 35, 38; 39,71)

\section{AnON. (c1836)}

In 1843, the Dutch literary journal Braga published an anonymous song/poem in Sranan, entitled Njoe-jaari-singi voe Cesaari'Cesaari's New Year song'. Cesaari was probably not the author, only the distributor of the song. Cesaari was a deaf black man who walked with a limp ( $c f$. the first stanza below) and who made his living distributing so-called 'signal notes' ${ }^{\prime}$ ( $c f$. the fifth stanza below) as well a selling songs and poems on the streets. ${ }^{91}$ Although the text was first published in 1843, Lichtveld \& Voorhoeve (1980:290-292) claim it goes back at least to 1836 or 1837. Based on the style of the piece, they feel it may have been written by a European or by by a Creole who was heavily influenced by European culture. In Voorhoeve \& Lichtveld (1975:7)

87. I.e. Fort Zeelandia.

88. Here the Dutch translation adds '(neiging)', referring to the blacks' custom of making a curtsy.

89. This expression is presented as a way of describing someone who wears repaired clothes. Note the English elements in this sentence: poor (instead of Sranan poti), and to (instead of $f u$ ).

90. The note indicating the type, name, and origin of a newly arrived ship.

91. The custom of selling pieces of literature on the streets of Paramaribo was continued well into the 20th century. 
they suggest, based on 'the clever use of Creole proverbs' (used as a finishing line in some stanzas; $c f$. also Section 2 of Chapter 6), that the author may have been H.C. Focke, the man who compiled the 1855 Sranan dictionary ( $c f$. no. 29 below). At the same time, they feel that even though the text was not written by a slave, it shows 'how people knew how to write a very subtle poetry based on and heavily influenced by folk-culture', while also alluding to the genre of the $d u$ (cf. Chapter 6) (Lichtveld \& Voorhoeve 1980:292).

Njoe-jaari-singi voe Cesaari

Soema de jompo janna so?

Mi bribi na Cesaari, ${ }^{92}$

Pooti, a no man voe go,

Moffina fa a haari!

Wan soro no hati toe soema, loekkoe fa a mangrie,

Daggoe habi foeloe masra, a slibi nanga hangrie.

Cesaari's New Year song

Who is going there with that limp?

I think it's Cesaari.

Poor man, he can't walk,

Poor thing, how he's dragging his leg!

One sore does not hurt two people. Look how thin he is.

A dog who has many masters sleeps with an empty stomach.

Tangie Masra! Tangie Missie!

Ti dée mi de njan jaari;

San joe gi mi, joe sa kissie

Dobbroe na tra jaari!

Wan sreng sa tron toe sreng, effi Masra Gado prissie,

Da sanie joe lassie na vaja, joe sa venni na inni assissie.

Thank you, Master! Thank you, Madam!

Today I'm celebrating the New Year.

Whatever you'll give me, you'll get it back

Double next year!

One shilling will become two shillings, if it pleases God.

Whatever you lose in the fire, you'll find it back in the ashes.

Da ouloe jaari go agéen,

Da njoe wan dée na doro;

Effi a tjari son, ef' a tjari a réen

Gaddo sabie; o soema moro!

A fitti mi voe takki joe houdi, na alla mi klanti mi go, Bonjo no de soekkoe daggoe, daggoe de soekkoe bonjo.

92. Small capitals in original version. 
The old year has gone again,

The new one is waiting at the door.

Whether it will bring sun or whether it will bring rain,

God knows, who else?

I must say good-bye, to all my clients I must go.

The bone does not seek the dog, the dog seeks the bone.

Effi a tjari wi geluk effi no,

Datti wi sa venni na bakka;

Mi no de baari jette: Ho!

Soema baai poess-poessi na sakka?

njoe jaari bissi mi? voe monni na inni sweeti mi ron,

Respekki voe switti braffoe mi njan soewa ton-ton.

Whether it will bring us fortune or not,

That we'll find out afterwards.

I'm not shouting 'Ho!' yet,

Who buys a pig in a poke?

What do I care about the New Year? I'm running myself into a sweat for money.

To get the sweet brafu I'll eat the sour tonton ${ }^{93}$

Tokkoe té wan sippi kon

Fa mi de wakka wakka;

Nanga briefie mi de ron

Na alla soema bakka;

Shjah! na troe san bijblie takki, na troe san Domine leesie,

Wi njan wi switti-moffo nanga sweeti voe wi veesie.

Still, when a ship arrives

I have to run like hell.

With the 'signal note'

I'm running after everyone.

Ugh! It's true what the Bible says, it's true what the Preacher reads,

We eat our meat and fish in the sweat of our face.

Na bakkra-kondre wan njoe sanie

Bakkraa ben prakkiseeri;

Mi mamma dissie meeki mi!

Wan toori joe moesso jeeri!

Sippi na inni winti lijki vriegrie dé go vlij

Bakkraa de go haari den, en gi den teitij.

In Europe the white people

Invented something new.

My mother who bore me!

93. Brafu is a tasty broth which is eaten by dipping tonton, balls of banana dough, in it. 
You should hear this story!

Ships flying in the wind like kites,

Whites hauling them in and easing them off. ${ }^{94}$

Derappée sippi na wi tappo de vlij

Lampoe sondro olie de bron;

Sjeesi sondro haasi de rij,

Na tappoe iesri paasi den ron;

Ai ba! kondre draai, poess-poessi jan slaa,

Adjoosi vlagra-tikki, boda kabaa!

Ships flying above us over there,

Lamps burning without oil,

Carriages riding without horses,

On iron roads they run.

Yes, man! Everything is upside down.

Good-bye flag-pole, the party's over! ${ }^{95}$

Ma, awassi wi no de konniman,

Wi no habi trobbie;

Wie Koning nanga wi Granman,

Wie Kondre wi lobbie;

Wi no leeti vaja nanga gaasi, wie no sabie boekkoe,

Wi de wrokko na Pranaasi na dati gi den koekkoe!

But even if we are no learned men

We have no troubles.

Our King and our Governor

And our country we love.

We don't use gas to burn our lights, we don't know many books.

We work on the plantations, that's what gives them a profit.

Mi wensi geluk na ibrie wan,

Na inni da jaari dissie;

Alla oeman sa venni man,

Den jonkman sa venni missie;

Joe sa maala soekkroe ibrie dée, koffi sa repi na bon,

Katoen-pranaasi sa meeki so tée, a no sa kissi woron.

I wish good luck to everyone

In this coming year.

May all the ladies find a man,

May all the young men find a girl.

94. This probably refers to ballooning, a fairly new phenomenon at the time.

95. This refers to the pole Ceaasri would use to hoist the Dutch flag upon arrival of a new ship. If ballooning is going to take over, he is bound to lose this source of income. 
May you grind sugar every day, may the coffee ripen on the trees,

May the cotton plantation thrive so they will not be plagued by worms.

Ma mi teeki Gaddo beggi joe,

No forgitti Cesaari!

Awassi mi pooti, tokkoe na troe,

Mi habi mi libbi voe tjaari;

Mi no habi foeloe voe wensi, mi no habi foeloe vo fredde,

Mi no habi noffo foe libbi, ma mi habi toe moessie vo dedde.

I beg you by God,

Don't forget Cesaari!

I may be poor but still it's true,

I have to take care of myself.

There isn't much I desire, there isn't much I fear.

I don't have enough to live but I've got too much to die.

(source: Lichtveld \& Voorhoeve 1980:292-299)

\section{Them Belly full (But We hUngry) (1835)}

Apart from 300 odos, some of which can be found in Chapter 6, Teenstra (1835) also contains the following Sranan sentence, which is presented as the general way in which Blacks in Suriname express their hunger:

Massera! Fiele (of loeke) mi belle, hangri di kili mi!

Sir! Feel (or: look at) my belly; I’m starving! ～(source: Teenstra 1835, vol 2:187)

\section{Winkels (1840)}

Willem Winkels arrived in Suriname in 1839, where he worked as a white overseer for some time. The text fragments reproduced below are taken from the captions to a series of unpublished watercolors satirizing plantation life, in particular the vicissitudes of a newly arrived white overseer. Since they were made only a year after Winkels' arrival in the colony, some proviso should be made with regard to the reliability of the Sranan used in these dialogues. What is especially interesting is the fact that the dialogues exhibit a fair amount of code-switching, as can be seen in some of the following examples (the Sranan is in italics, the Dutch is in roman typeface). Also note that the Dutch put in the mouth of blacks is somewhat pidginized: ${ }^{96} c f$. e.g. the lack

96. A similar tendency to represent black speech as a slightly pidginized form of - in this case English is in the English-written novel Outalissi, where blacks are quoted as saying e.g. 'Yes, me, Massa!' in response to the accusation 'thou art the thief, thou rascal' (Lefroy 1826:114) or, when asked 'Is she ill then?' as replying 'No, massa, not ill, but sick in heart a little' (131). Elsewhere, an Amerindian says 'No! massa! Me no Christian' (136). At the same time, the hero Outalissi, a former African prince, speaks an impeccable, not to say literay, English, occasionally even using such words as soi-disant (164). I should add, however, that this stylistic feature was introduced 
of V2 as well as the use of the verb stem instead of the infinitive form in 'anders ik zal loop hard weg' (instead of 'anders zal ik hard weglopen') and the omission of the adverb 'er' in 'ik zal zeker zijn' instead of 'ik zal er zeker zijn'. (Both features are still present today in Surinamese Dutch: $c f$. De Kleine 2002.) (The number following each fragment refers to the number of the original watercolor to which the caption belongs; the full text can be found in Medendorp 1994.)

O no no vala kaba! maar massa no sabi ningre jété, water is niet meer om voortgaan (no. 3)

Oh, no, no, the ebb-tide is finished! But you don't know Blacks yet, the water is not fit to continue rowing anymore.

O no no vala kaba! maar massa no sabi ningre jété, water is niet meer om voortgaan (no. 3)

Oh, no, no, the ebb-tide is finished! But you don't know Blacks yet, the water is not fit to continue rowing anymore.

booi go sori schriviman da kamera, opé a moesoe libie. (no.4)

Boy, show the overseer his room, where he is going to stay.

Loekoe no so wan bakra va a don; mi denki Bakra sabi alla sanni, en disi no sabi voe krin na inni wan hamakka srefi voe slibi: Ha! ha! ha! datti na wan bigie kau. (no.7)

Look at that bakra, how stupid he is; I thought bakras knew everything, and this one doesn't even know how to climb into a hammock in order to sleep: $\mathrm{Ha}$ ! Ha! He is a big cow.

Hu! bakra sabi alla sanie, en a no kan zwem, mi mama! dat een Indiaan zelf kan doen. (no. 12)

Ha! The bakra knows everything but he can't swim, mama mia! Even an Indian knows how to do that.

Ja, ik lobi massra toemoessi, maar ik vrees direkteur al te veel. (no. 13)

Yes, I love you very much, but I fear the manager a lot.

Troe? massra zal kom? maar massra moet mij geen kwaad doen, want anders ik zal loop hard weg. (no. 13)

Really? You will come? But you should not do me any harm or else I'll run away fast.

O nee massra, ik zal zeker zijn, mi lobi wan swietie tori. (no. 13)

Oh, no, master, I'll be there for certain, I like to hear sweet things.

(source: Medendorp 1994)

explicitly by the author to 'convey what appears to me the force of his impressions with more clearness (97 footnote). 


\section{Greeting the master (c1840)}

August Kappler (1815-1887) was a German, who - with a brief intermission - worked in Suriname, first as a soldier and then as an entrepreneur, from 1836 until 1879. In 1854 he published a book about his first six years (1836-1842) in the colony. The sentence below is presented by him as an example of the 'nonsense' plantation managers have their slaves tell them 'as if they were parrots'. It is part of the ceremony that took place every morning when the slaves were made to gather in front of the 'big house' and wish their master a pleasant day. In this case, it is not the adult slaves but the little children, who 'at a sign given by the Creole Mama all put their hands in the air and shout':

Odi Masra, odi Missi, fai ${ }^{97}$ Masra dan, fai Missi dan!

Goodday Sir, goodday Madam; how are you, Sir? How are you, Madam?

(source: Kappler 1983[1854]: 28)

\section{Focke (1855)}

Hendrik Focke (1802-1856), a colored man who was born in Paramaribo, studied law in the Netherlands and returned to Suriname in 1834, where ultimately he became president of the Court. He was one of the founders of the journal West-Indië, in which he published a seminal article about the music of the Blacks (Focke 1858; cf. Section 1 of Chapter 6). Focke, who in all likelihood was a native speaker of Sranan, was highly regarded among his contemporaries for his knowledge of the language. His fellow lexicographer, H. R. Wullschlägel, for example, refers to Focke as 'the astute language researcher...Focke', whom he singles out in his acknowledgments for having checked his dictionary with him word-by-word and for providing him with valuable remarks (Wullschlägel 1856: iv). Another Moravian missionary, the prolific translator Wilhelm Treu, regularly consulted Focke, which suggests he regarded the latter's knowledge of Sranan highly (Lenders 1996: 173). ${ }^{98}$ Finally, the reverend Boekhoudt, who knew Sranan well enough to be able to hold sermons in it, notes that Focke was 'unsurpassed as a conoisseur of Sranan' (Boekhoudt 1874:97-98).

Focke's 150-page Sranan-Dutch dictionary is not the largest but undoubtedly the best published Sranan dictionary to date. ${ }^{99}$ It contains a short introduction to the language, and some 100-200 odos are scattered throughout the text. A review of the work by Moes (1858), published in West-Indië, contains a list of errata and addenda, which are based on handwritten notes by Focke himself. Though published in 1855,

97. $f a i=f a y u(d) e$ 'how are you?'

98. In his turn, Focke bestowed the highest praise on Treu (Focke 1855: viii).

99. Not included in this evaluation is the new Sranan dictionary (Blanker \& Dubbeldam 2005), which was published, incidentally, on the very same day I wrote this. 
the work was conceived several years earlier: a preliminary version is dated March 1846 (Voorhoeve \& Donicie 1967). The lemmas reproduced below refer to some of the same words and grammatical phenomena as those taken from Schumann's and Wullschlägel's dictionaries (see nos 17 and 30, respectively).

\section{9a. Sample lemmas from Focke's (1855) SRAnan dictionary}

Ben, auxiliary verb used to express the past tense (from Dutch ${ }^{100}$ ). Mí ben táki joe, I had told you; Wan Mamà ben de, once there was an old lady; mi ben sa koḿ, I would have come.

Obia, noun, magical charm which the Negroes in their superstition bury in the ground or put somewhere in order to harm an enemy or keep off a misfortune. (2) sometimes also cicatricizations in the skin, to which certain magical powers are ascribed. Óbia-man, magician, witch; someone who makes Obias or deals with them or makes use of them; Óbia-tetéi, magic string or thread, charm, amulet. Óbia boen, ji sa si na kóti (proverb). The meaning is: You know a tree from its fruits [lit. You can see from the cut whether the obia is good, JA]

Herm, pronoun, he, she, him, her. (Herm is used in the nominative case to transmit what someone else said, as in the first example below.) (2) possessive pronoun, his, her (from Dutch) A táki: heŕ no kan doe, he (she) says that he (she) cannot do it.

Tóngo, noun, tongue in all its meanings; (2) language; (3) voice (from Dutch). Sákka joe tongo, lower your voice. Pikíen tóngo, the uvula. Mi sâbi hem tóngo, I know his voice. A de tâki heŕn kóndre tóngo, he speaks the language of his country.

(source: Focke 1855)

\section{WullsChlägel (1854) AND (1856)}

Heinrich Rudolph Wullschlägel, a Moravian Brother who was educated as a theologist and botanist, stayed at mission posts in Antigua (1844-1847) and Jamaica (1847-1849) before coming to Suriname, where he served as praeses 'president' of the Moravian community from 1849 until 1855 . He is the author of a brief, anonymous grammar of Sranan ${ }^{101}$ (Wullschlägel 1854), which was reviewed, interestingly, by his 'colleague' H. C. Focke. Apart from one point of detail, Focke's only criticism is concerned with orthographical matters, in particular the inconsistency and arbitrariness of the Moravian missionaries' (Dutch-based) spelling system. As far as the book qua

10o. The etymology proposed by Focke is incorrect: ben is based on English 'been'; it has nothing to do with Dutch ben nor (dialectal) benne, present tense forms of the verb zijn 'to be'.

101. Although this is disputed by Voorhoeve \& Donicie (1963:20), who see parallels with Wilhelm Treu\#x2019;s 1850 manuscript grammar (itself part of the Moravian grammar writing tradition which started around 1830), it is unambiguously clear from Focke (1855: ix) that Wullschlägel is the author. 
grammar is concerned, however, he is unequivocally positive. Focke is especially happy with the quality of the sample sentences: 'His truly Sranan sentences are so surprising to us that we have the impression that the author has listened to the conversations among the Negroes with an accurate ear and in an untiring effort' (Focke 1855b:297).

Apart from his grammar, Wullschlägel also compiled a 300-page GermanSranan dictionary (Wullschlägel 1856). With the possible exception of the newly published dictionary mentioned in note 82 , this is the most extensive printed Sranan dictionary in existence. It is the culmination of a 75-year long tradition of Moravian Sranan lexicography, which began with Schumann's (1783) manuscript dictionary and continued with the many revised and expanded versions based on it that were made during the first half of the 19th century. Being part of that tradition, it contains the typically Moravian neologisms needed for Bible translations, which are absent, for example, from Focke's dictionary. The dictionary concludes with a 40-page listing of some 700 odos with their translations (cf. Chapter 6 for some examples). As to its use as a resource for linguists, Voorhoeve \& Donicie (1963:29) feel that, due to the archaic and typically 'church creole' character of the language, it should be consulted with prudence. Below, a small section from Wullschlägel's grammar on logophoric pronouns is reproduced. His dictionary is represented by the lemma on 'language'. For comparison, see the parallel lemmas from Schumann $(1778,1783)$ and Focke (1855) above.

\section{0a. WULLSCHLÄGEL (1854) ON LOGOPHORIC PRONOUNS}

When the words of a third party, who is not present, are quoted, 'he', 'she', 'it', may not be expressed by $a$, but it should be expressed by hem. Da soema taki, hem no kan kom, hem de siki, the man says he cannot come, he is sick. A de siki would be the words of the speaker of the entire sentence, not those of the sick person himself. ${ }^{102}$

(source: Wullschlägel 1854: 18)

\section{0b. SAmple Lemma From Wullschlägel's SRANAN Dictionary}

Sprache 'language, speech'

Language, tongo; taki; in our language, na wi tongo; it is neither a language nor a tongue, no wan taki de en no wan tongo de; I don't understand the language very well yet, mi no sabi da tongo so krin jete; to know a language, sabi da tongo; to talk about something, taki vo dati; Negro language, ningretongo; (however, the African Negroes call the language spoken here bakra as well).

(Wullschlägel 1856, s.v. Sprache 'language, speech’)

102. Although the entry Er 'he' in Wullschlägel's dictionary does not say anything on logophoricity, it does contain an example illustrating the phenomenon: 'He, $a$, hem...he says he doesn't want to come, a taki, hem no wani kom' (Wullschlägel 1856, s.v. Er 'he'). 


\section{Documents Concerning Emancipation (1862-1873)}

When slavery was finally abolished in Suriname (on July 1, 1863), it was followed by a ten-year period of Staatstoezicht 'State supervision', comparable to the 'Apprenticeship' period in the British colonies. During this period, the ex-slaves, though formally free, were subject to a large number of rules and regulations (see nos 31d and 31e below). But the event of Emancipation itself too was accompanied by the publication of a number of official documents, written in Dutch. In order to inform the slaves about the abolition of slavery, part of these texts, in particular those concerning them directly, were translated into Sranan, so that they could either read them themselves or have them read to them. ${ }^{103}$ The translators of the texts are A. J. Comvalius Az. ${ }^{104}$ (31a, 31b, 31c) and J.P.W. van Eijck (31d, 31e, 31f). While Comvalius accompanies his translations with the information that he is a 'sworn translator for Sranan', Van Eijck adds a more general statement explaining the official status of his translation. Unfortunately, I have not been able to find any biographical information about these men, except the fact that the Comvalius family were free coloreds who were employed by the government as clerks and sworn translators from early on (Brana-Shute 1985:315).

In all six cases, the Dutch text of the original was published in the Gouvernementsblad Suriname, the official newspaper of the colonial government (see Table 7.2 below). However, as far as I have been able to establish, only one of the Sranan texts (no. 31c) was published there. Two others (nos 31a and 31b) were distributed in the form of a plakati 'placard', which was a normal way of making public announcements in those days. Despite serious efforts, I have not been able to locate the original version of the three remaining texts (nos 31d, 31e, 31f). For the transcription of these I have had to rely on those presented in Helstone and Vernooij (2000).

Although one or two of the shorter texts had been republished before (e.g. 31c, in Encyclopedie 1977:564), it was not until Helstone and Vernooij (2000) that a more extensive selection of these texts became available (31b, 31c (partly), 31d, 31e, 31f). Unfortunately, however, this publication is not easily accessible, especially for an international readership. In addition to that, there is at least one text (31a) which is not included in Helstone and Vernooij (2000); that is the Sranan version of the Emancipation Act, of which they only present the Dutch original. Since they concern one of the most important, if not the most important, events in the history of Suriname and since they are written in Sranan, these texts are of paramount importance for the historiography both of the country and its national language. For that reason, they are reproduced here in full. Since some of the texts are quite extensive, they have been numbered separately (and in chronological order; see Table 7.1). Unfortunately, I have only been able to locate the original versions of some of these texts (31a, 31b, 31c); my transcriptions of them

103. Reading instruction of slaves was officially allowed in 1844 (writing in 1856).

104. 'Az' means something like 'son of A', a designation sometimes used in Dutch names to distinguish oneself from others bearing the same name. 
are based on the original documents. For the remaining texts (31d, 31e, 31f) I have had to rely on the transcriptions provided by Helstone and Vernooij (2000). In Table 7.2 I provide the sources for both the Sranan and the Dutch versions of these texts.

Table 7.1 Sranan translations of texts concerning Emancipation

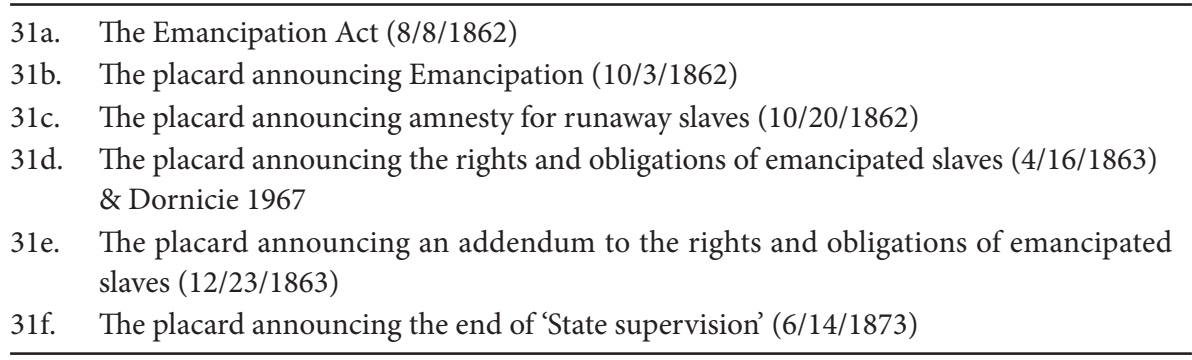

Table 7.2 Sources for Dutch and Sranan versions of texts concerning Emancipation

\begin{tabular}{lll}
\hline$\#$ & Dutch version & Sranan version \\
\hline 31a. & GB 1862(6) (also in H\&V: 37-43) & Plakatti 1862 \\
31b. & GB 1862(7) (also in H\&V: 53) & Plakatti 1862 \\
31c. & GB 1862(8) (also - partly - in H\&V: 54) & GB 1862(8) \\
31d. & GB 1863(9) & GB 1863(9) \\
31e. & GB 1863(29) & GB 1863(29) \\
31f. & GB 1873(19) & GB 1873(19) \\
\hline
\end{tabular}

Notes. GB = Gouvernementsblad Suriname; H\&V = Helstone \& Vernooij 2000

\section{1a. The Emancipation Act (1862)}

Before Emancipation could be effected, a number of legal measures had to be taken, in particular the passing of the Emancipation Act in Dutch Parliament. This Act consists of 39 articles, not all of which were included in the Sranan version. As is said in the Dutch version of the Proclamation of Emancipation, the texts was translated 'as far as it is of any concern to you [i.e. slaves, JA]'. This meant that articles nos 2, 4-9, 11-17, and articles nos 37-39 were left out. The former are all concerned with the financial compensation owners were entitled to for each slave (300 guilders), while the latter relate to certain formal, juridical matters affecting the Governor and the Minister of Colonies. The preamble, which among other things contains a fixed introductory formula, was also left untranslated. As to the articles that are included in the Sranan version, the translation is often seriously incomplete (e.g. Art. 18). The text reproduced below was taken from a version published as a broadsheet in 1862 and kept in the Royal Library in The Hague ${ }^{105}$ (Plakatti 1862). Apart from the text of the Emancipation Act,

105. It is not clear to me whether the 1862 Plakatti is identical to the text published the same year by one A. L. G. de Randamie (cf. Van Kempen 2003:378). 
this broadsheet also includes the Sranan version of the Proclamation of Emancipation (see no.31b).

Art. 1. Sieksi moen na bakka jari, na da fosi dei voe da moen di de meki seibi, da katibofassi sa kaba na Sranan kondre.

Six months after New Year, on the first day of the seventh month, slavery will stop in Suriname.

Art. 3. Kondre sa potti soema di de na hei kondre wrokko, voe potti en hori hai na tapoe den njoen friman; ma datti sa de voe no morro langa leki tein jari.

The state will appoint high public servants to supervise the new freemen; but this will only be for ten years.

Art. 10. Alla sanni die den njoen friman ben habi na da ten die den ben de katibo jette, so leki den krosi, den kweki, den sanni die de na den hosso, alla tra sanni die kondre gi passi, datti wan katibo kan habi, den alla de, en de tan voe den srefi.

All the possessions owned by the new freemen when they were still slaves, such as their clothes, their livestock and poultry, their movable properties, and all the other things the state allows a slave to have, all these things are and remain theirs.

Art. 18. Den soema die Kondre potti voe potti en hori hai na den tapoe, Kondre sa meki bakaten bekenti, voe ibriwan soema kan sabi san den moe doe en en da makti di den sa habi.

As to the persons appointed by the state to supervise them, the state will make an announcement about that later, so that everyone knows what their tasks and their authorities are.

Art. 19. (xxx); di kondre potti soema na tapoe den njoen Friman, datti de nomo, voe den kan habi? soema, di kan de voe den; voe sorgoe datti no wan soema kori den; voe kaferi gie den te den habi reti. Voe leri den voe den liebi nanga den famili, so leki a fieti voe den liebi makandra. Voe liebie na tra soema miendri na kondre da wan boen, safr?i en sakka fassi, so leki a fieti alla boen soema voe liebi makandra. Voe sorgoe, datti den no sa tan sondro doe wrokko, voe wakka soso, na wan jajo en lasra fassi; ma datti ibriwan voe den sa habi den vasti wrokko voe doe. Voe sorgoe datti den sa leri na skollo voe den sabi boekoe, en voe leri sabi Gado, en da wanni voe Gado. Voe sorgoe datti den helpi den potiwan en den di fieti voe kisi helpi, en voe meki den sikiman kisi boen loekoe, En voe sorgoe datti alla sanni voe den sa wakka nanga boen, en wan boen fassi.

(???); the only reason for the state to appoint people to supervise the new freemen is that they will have someone who is there for them; to make sure nobody will cheat them; to represent them when they are right. To teach them how to live with a family as well as to live in society.

To live among other people of the land in a good, meek and humble manner, just as it befits all good people to live together. To make sure they will not remain without work, walk around idly, like tramps and vagabonds; and that they will all have a 
steady job. To make sure they learn in school how to read and write, and to get to know God and God's will. To make sure that the poor and those who are entitled to help will get help and that the sick will get proper care. And to make sure everything will proceed well and in a proper way.

Art. 20. Granman voe Sranan Kondre habi da makti, effi den njoen friman holi den srefi so leki a fieti, de wrokko, en sori datti den kan vertrouw den, voe a poeloe den na ondro den soema di den potti gi den; voe meki den tron en de na da srefi fassi leki ibriwan tra fri soema na kondre.

The Governor of Suriname is authorized, if the new freemen behave like they should, if they work, and show that they can be trusted, to discharge them from State Supervision; to make them become and be exactly like every other free person in the colony.

Art. 21. Den katibo di de go tron friman noja so, den moe teki wan famili nen, di den moe doe so meni leki den kan, voe ibriwan famili habi da srefi nen, dan den de teki da nen voe den, nanga di voe den famili skrifi na ini den boekoe di de voe datti na kantoro. Te den potti den nen na ini boekoe kaba, den sa gi den wan bewijsi di habi da nomroe voe da presi di den nen de, den famili en den fesi nen en da dei di den meki den, - di no sabi hoe ten den meki hen, den sa potti wan jari gi hen so leki den denki a kan habi. Granman voe Sranan Kondre sa sorgoe datti da skrifi voe den nen sa de bifo da dei di da katibo fassi sa kaba.

The slaves who are going to be free men now, they should get a family name, which, as far as possible, should be the same for all members of one family, then they will take care that their names and their family names will be written in the book that is in the office for that purpose. When thay have put their names in the book, they will be given a proof with the registration number, their family name and their first name and their date of birth, - those who do not know their date of birth, they will put the year that they think they were born. The Governor of Suriname will take care that the registration of names will be finished before the day slavery will stop.

Art. 22. Alla den reti disi wan Borgroe habbi en alla strafoe di wet potti gi den te den doe ogri, sa de da srefi toe voe den njoen friman, boiti den verandri di da plakatti disi meki voe so langa leki kondre potti soema vo hori hai na den tapoe.

All the rights a citizen has and all the punishments the law imposes on them if they do evil, will be the same for the new freemen, except for the changes stated in this placard for the duration of the State Supervision.

Art. 23. Den njoen friman sa de leki ibriwan tra soema na kondre, ma voe den kisi den reti leki wan Borgroe voe kondre, datti sa de te den no de moro na soema ondro, ma dan den moe doe den plekti toe di kondre potti voe wan borgroe moe doe.

The new freemen will be considered like everyone else in the colony; but they will not obtain the rights of a colony citizen until the period of State Supervision is over, but then they must also do the duties imposed by the state to a citizen 
Art. 24. Den njoen friman moe habbi den vasti wrokko de doe, en den moe doe den wrokko alla dei, boiti Sondei nanga Biddakki, leki da plakatti disi taki.

The new freemen must have a steady job and they must do their work everyday except Sunday and Prayer Day, as stated by this placard.

A. Voe den di de liebi na pranasi, effi di de da presi de wrokko.

For those who live on a plantation or work at some other place.

$\$ 1$. den alla di ouwroe tien na veifi, te na den sieksi tenti jari, sa moesoe voe meki wan panpira (kontraki) voe wrokko na pranasi, nanga den eiginari, granmasra, driektoro voe pranasi effi tra soema di de doe pranasi wrokko, so leki den hatti wanni.

All those who are between fifteen and sixty years old must make a paper (contract) to work at the plantation, with the owners, plantation managers or anyone else in the plantation business, as they desire.

$\$ 2$. Da panpira effi kontraki die den sa meki, moe meki na fesi voe den Soema di den potti na den tapoe, en a moe meki na da fassi so leki Kondre sa potti fa a moe de - ma voe no morro mindri dan wan jari, en no morro voeloe dan drie jari.

That paper or contract which they will make, must be made in the presence of the people in charge of the Supervision and in such a way as will be established by the state - but for not less than one year and not more than three years.

\$3. Granman voe Sranan Kondre habi da makti, effi a feni datti a sa de voe wan boen, voe meki den fosi toe jari na baka da dei di da katibofassi kaba, datti den no sa meki den kontraki, (panpira voe den joeroe den srefi) voe go wrokko na wan tra presi leki na ini da divisi da presi den ben de wrokko da dei di fri kon.

The Governor of Suriname is authorized, if he thinks this is for the best, to enforce that during the first two years after the day slavery has stopped no contracts (papers for hiring themselves out) will be made for any other place except within the district where the place was located where they worked on the day freedom came.

$\$ 4$. Den disi di no sa meki kontraki (panpira voe den joeroe den srefi voe wrokko) drie moen na bakka da dei den tron friman, Kondre sa sorgoe voe potti den voe wrokko na wan lanti pranasi, effi na wan tra wrokko di sa de boen voe Kondre.

As to those who will not make a contract (papers for hiring themselves out for work) within three months after the day they became freemen, the state will make sure they will be put to work at a government plantation or at some other work of general benefit. 
\$5. Den disi di ouwroe moro leki sieksitenti jari, sa tan nanga den soema effi famili voe den; den pikien di moro jongoe leki tien na veifi jari sa go en tan da presi den mama de.

Those who are above sixty years, shall stay with their folks or families; the children below fifteen years, shall go and stay where their mamas are.

\$6. Den disi di ouwroe moro leki sieksitenti jari, en di moro jongoe leki tien na vijfi jari, den sa tan wrokko toe gi den soema, di da gransoema voe den famili effi den mama meki kontraki (effi panpira voe joeroe den srefi voe wrokko.) da wrokko di den ouwroe soema, nanga den jongoe wan moe doe, moe de so leki den man en tranga voe doe; voe datti hede toe, da paiman di den sa kisi, sa de fieti da wrokko di den de doe.

Those who are above sixty and those who are below fifteen, they shall work for the people with whom the head of the family or their mother has made a contract (or paper for hiring themselves out for work). The work the old people and the young people must do, must be such as they are able and strong enough to do; therefore, the payment they will get will be in proportion to the work they do.

B. Voe den disi no ben liebi effi wrokko na pranasi.

For those who do not live on a plantation or work at some other place.

$\$ 1$. Den alla di de telli tien na vijf te nanga sieksi tenti jari, sa moesoe voe meki wan kontraki effi panpira voe joeroe den srefi foe wrokko na wan soema di den hatti sa wanni.

All those who are between fifteen and sixty shall have to make a contract or or paper for hiring themselves out for work with someone of their choice.

$\$ 2$. Da kontraki effi panpira di den sa meki, moe meki na fesi voe da soema di den potti na den tapoe, ma no voe moro mindri leki drie moen, en no moro langa leki wan jari, voe den wrokko na fotto; - ma effi den meki panpira vo go wrokko na pranasi dan a sa moe de voe da srefi langa ten leki a de voe den disi di de liebi en wrokko na pranasi en dan, da srefi sanni di da plakkatti disi potti voe pranasi soema di moro ouwroe leki sieksi tenti jari, en den di moro jongoe leki tien na vijfi jari, sa de toe voe den fotto soema di joeroe den srefi voe wrokko na pranasi.

The contract or paper they will make, should be made in the presence of the people in charge of the Supervision, but not for less than three months and not for more than one year, to work in town; - but if they make a paper for working at a plantation, then it will have to be for the same length of time as it is for those who live and work on a plantation and then the same things stated in the placard about plantation people who are above sixty and below fifteen will also go for the town's people who hire themselves out to work at a plantation. 
\$3. Den disi kan gi da soema di kondre potti na den tapoe, wan bewijzi datti den sabi wan wrokko voe doe di den kan verdien noffo voe sorgoe voe den srefi nanga den famili, dan den sa kisi passi voe de na den srefi, sondro voe meki kontraki effi panpira nanga ini wan soema voe doe wan wrokko, ma den sa moesoe voe bai wan patenti na kantoro, so leki Kondre Wet potti, voe ibri wan soema di de doe srefi wrokko. Voe a kan habi makti voe doe datti, a de kisi wan bewijsi voe da soema di Kondre potti voe hori hai na den tapoe, en alla jari a sa go kinki da bewijzi voe teki wan njoenwan.

Those who can give some proof to those charged with their supervision that they know a trade by which they can earn enough money to support themselves and their families, will get a pass to live independently, without making a contract or paper with anyone to do some work, but they will have to buy a patent right at the office, as the law of the colony requires from anyone who does that kind of trade. In order to be authorized to do so, he will get a proof from the person charged with their supervision, and every year he shall go and change the proof for a new one.

$\$ 4$. Den di, dri moen na bakka da katibofassi kaba, no meki kontraki voe wrokko, en den di kisi passi voe voe de na den srefi, kaba den no de doe wan wrokko, Kondre sa potti den na wan lanti pranasi na wrokko, effi, na wan tra wrokko voe boen voe kondre, di den sa man en sabi voe doe.

As to those who have not made a work-contract within three months after slavery has stopped and those who have received a pass to live independently but are not working in a trade, the state will put them to work on a state plantation or at some other work of general benefit, which they will know and are able to do.

\$5. Den di ouwroe moro leki siksi tenti jari, en pikien di ouwroe twaarfu te tien na vijfi jari, den sa doe likti wrokko, so leki den kan en man voe doe.

Those who are above sixty and children who are between twelve and fifteen shall do light work, just as they can do and know how to do.

\$6. Pikien di ouwroe twaarfoe jari no sa prati nanga den mama, ma pikien di ouwroe moro leki twaarfoe te tien na vijf jari den datti sa kan wrokko na wan tra presi leki den mama.

Children who are (below) twelve shall not be separated from their mothers, and children who are between twelve and fifteen, they may work at a different place from their mothers.

Art. 25. Voe leri Gado tori en voe leri sabi boekoe, Kondre de sorgoe voe datti, en so meni leki a kan, voe helpi den, gi den tranga en plisiri voe doe datti.

The state will take care that they will learn about God and how to read and write and to help them, give them strength and pleasure to that as much as it can.

Art. 26. Den njoen friman en den fri wrokkoman di den sa tjari kon na Sranan no mak voe habi voe den srefi, effi de tjari wakka gon, pistoor, ponjarti, en den soortoe speri sanni moro, sondro den kisi passi voe datti. 
The new freemen and the free workers that will be brought to Suriname are not allowed to have for themselves or carry along guns, pistols or machetes and other similar things, if they do not have a pass for it.

Art. 27. Boiti den di moe wrokko strafwrokko voe wan ogri di den doe, alla tra wrokko na lanti pranasi, en alla tra lanti wrokko den sa kisi paiman voe datti. Da paiman en da marki voe da wrokko Kondre sa meki bekenti voe ibriwan soema kan sabi; en datti sa de voe alla tra pranasi so srefi toe, effi den wrokkoman no ben kroederi wan tra fassi di den ben de meki kontraki. Wan wrokko dei sa de aiti joeroe langa, effi den wrokko na fieri, en tien joeroe langa, effi den wrokko na hosso effi sei hosso, en wan jari sa habi drie hondro wrokkodei.

With the exception of work that has been imposed for an evil they have done, all other work on state plantations and all other work for the government will be paid. The state will announce the pay and the amount of work, for everyone to know; the same will be the case for all other plantations if the workers have not agreed by any other means when they made a contract.

A working day will be eight hours long, if they work in the field, and ten hours, if they work in or near the house, and in one year there will be three hundred working days.

Art. 28. Effi Kondre wanni voe joeroe soema voe tjari sroedatti go wan presi, effi voe doe wan wrokko di de boen voe kondre, kaba a no kan kisi soema di wanni go, kondre habi makti voe teki so meni voe den njoen friman di no moro jongoe leki tien na vijfi en no moro ouwroe leki sieksi tenti jari, effi noso tra fri pranasi wrokkoman di a sa habi van nodoe voe do da wrokko.

If the state wishes to hire people to bring soldiers to some place or to perform some work for the general benefit and they cannot get people who are willing to go, the state is authorized to take as many new freemen between fifteen and sixty or, if necessary, other free plantation workers as it will need to do the job.

Art. 29. En di lesi, de wakka passa den ten sondro wrokko, no habi wan vasti tanpresi, de wakka na wan jajo fassi, lasra den srefi, den sa kisi strafoe voe datti so leki wet takki. As to those who are lazy, pass the time without working, do not have a permanent residence, roam like vagabonds, or neglect themselves, they shall be punished for it according to the law.

Art. 30. Den Eiginari effi soema di ben habbi kattibo die kon fri, sa de verplikti voe wan heli drie moen langa, effi den no habi wan presi voe den tan, voe sorgoe den datti; ma effi den wanni den kan poeroe datti na den tapoe, effi den pai gi den voe den libie wan tra presi so langa da drie moen no tapoe, ma nanga wanni voe da soema di de voe loekoe den. Ma di datti moe passa toe, den slavoe di kon fri sa moesoe voe wrokko ibri wan wieki no morro mindri leiki fô dei, gi da soema di gi den presi voe liebi.

Owners or (other) persons who had slaves who have become free, will be obliged during three months, if they do not have a place to stay, to provide one; but if they wish, they can be released from that obligation if they pay for them to live at some 
other place as long as the three months are not over, but with the permission of the person charged with their supervision. But when that happens, the slaves who have become free shall have to work not less than four days every week for the person who gives them a place to live.

Art. 31. Ibri wan soema di sa meki den njoen friman wrokko gi den, eff gi den wan presi voe den liebi, sondro a meki kontraki nanga den, so leki datti moe de, a sa kiesi strafoe voe datti, voe pai wan boetoe, en effi a no pai datti, den sa potti hen na benifotto, so leki den sa potti bakaten fa datti moe de.

Everyone who will make the new freemen work for them or give them a place to live without making a contract with them as they should, will be punished for it by paying a fine, and if he does not pay it, he will be put benifotto [inside the fort, JA] as it will be established later how it should be.

Art. 32. Voe den, di den potti soema voe loekoe den, Kondre sa sorgoe, voe den kisi datra, nanga dresi en boen loekoe te den sieki. Voe den di de wrokko na pranasi, kondre sa potti san da soema di joeroe den sa moesoe voe doe, voe sorgoe wan boen presi voe siekiman tan, voe den kiesi datra nanga dressi en boen loekoe, en na alla tra presi kondre sa meki hatti hoso so meni leki datti sa de van nodoe. Den disi di voe ogri sieki hede den poeroe den na tra soema miendri, so leki kondre wet de takki, Kondre de tan sorgoe datti den de loekoe den na da presi di den meki voe den tan.

For those who are put under state supervision, the state will take care for them to get doctors and medicine and good care when they are sick. For those who work on a plantation the state will establish what the person who has hired them shall have to do, to provide a good place for the sick to stay, for them to get a doctor and medicine and good care, and everywhere else the state shall have built as many hospitals as will be needed. As to those who have been isolated from society because of a contagious disease, as prescribed by law, the state will take care they will be looked after at the place they prepared for them to stay.

Art. 33. Den soema di sa joeroe den njoen friman sa habi da verplekti na den tapoe di den moesoe voe doe voe sorgoe den wan boen hosso, voe den nanga den famili liebi, en voe gi den wan piesi gron so langa leki den de na den joeroe, di den habi van nodoe voe den kan prani den njanjan, so leki kondre sa potti fa datti moe de.

Those who will hire the new freemen shall be obliged to provide a good house for them and their family to live in and to give them a piece of land as long as they hire them, which they need to grow their crops as the state will establish how it should be done.

Art. 34. Den njoen friman di no wrokko na pranasi, den moe sorgoe voe den srefi nanga den famili, so voe presi voe den libi, leki alla sanni di den habi van nodoe na sieki joeroe, effi den no kroederi wan trafassi, di den meki den kontraki voe wrokko. 
As to those new freemen who do not work on a plantation, they should provide for themselves and their families both a place to live and everything they will need when they get sick, unless they agreed otherwise when they made their work-contract.

Art. 35. Kondre sa teki na hen tapoe voe doe so leki a kan de, voe sorgoe den pikien di no habi tata nanga mama, voe notti moe mankeri den; - so srefi toe voe den tra poti wan, di habi helpi van nodoe. Voe helpi Kondre nanga alla den someni sanni di de voe doe, di moe kostoe so voeloe voeloe moni, meki voe datti hede a sa de na tapoe alla den njoen friman di sa meki kontraki effi panpira voe joeroe den srefi voe doe fieri effi pranasi wrokko, di de wrokko na fotto, so toe den disi kisi passa? voe bai patenti, den alla sa pai ibri jari na lanti: Man Soema, sieksi banknotoe. Oeman, drie banknotoe; Da paiman disi, sa de voe pai, na bigin voe alla jari na lanti kantoro, den soema di sa joeroe den voe wrokko, sa pai, en poeloe san den pai bakka na ini den joeroe moni, na ini da srefi jari; - den di de pai patenti, en den trawan di no de toe na ondro soema, da san di den moe pai, den sa pai ibri jari na da soema di de na den tapoe, te den go teki, effi kenki da bewijsi di den kisi datti den no de na ondro voe soema, di alla jari den moe kisi effi teki wan njoen wan.

The state will do all it can to look after the children who do not have a father and a mother, that they will want nothing; - the same with regard to other poor people who need help.

To help the state with all the many things that need to be done, which cost an awful lot of money, for that reason all the new freemen who will make a contract or paper to rent themselves out to do field work or plantation work, or who work in town, and similarly those who have got a pass to buy a patent right, all of them shall pay to the state every year: Men, three guilders. Women, one-and-a-half guilders; This tax will have to be paid at the beginning of every year at the government office; the people who shall hire them shall have to pay it and shall subtract what they paid from the wages in the same year; - those who bought a patent right and the others who do not work for someone else, they shall pay what they have to pay to the person charged with their supervision when they go to pick up or change the proof they received that they do not work for someone else, which they have to get or change every year.

Art. 36. Da strafoe voe den di no doe so leki da kontraki effi panpira di den joeroe den fri wrokkoman voe wrokko - takki sa de so: Voe da soema di joeroe den, Sa pai wan boetoe; te a no pai da boetoe, den sa kisi hen potti na benifotto, en da kontraki sa kan brokko toe, en effi da kontraki brokko, kaba dati fiti voe de, da wrokkoman sa kisi paiman voe da san a de lassi voe dati hede. Voe den wrokkoman, wan boetoe toe; te a no pai da boetoe, voe kotti datti na joeroe moni di a moe kisi. strafoe wrokko voe wrokko gi kondre. Alla so leki baka ten, da wet voe datti sa meki fa alla sanni moe wakka, hoe soema sa de voe kotti kroetoe en fa da fassi sa de voe soekoe reti. 
The punishment for those who do not as the contract or paper when they hire the free workers to work - is as follows: For the person that hires them, They shall pay a fine; when they do not pay the fine, they will be put in benifotto and the contract may be destroyed too, and if the contract was destroyed and it was right to do so, the worker will receive payment for what he lost because of that. For the workers, also a fine; when he does not pay the fine, to subtract it from his wages. Forced labour for the state. Everything according to how the law later shall establish everything should be done, how the judicial system shall be organized and how justice shall be performed.

Da Plakatti disi, da mi tjari hen abra na nengre tongo, A. J. Comvalius Az., Sweriman na nengre tongo.

This placard was translated into Sranan by me, A. J. Comvalius Az., Sworn translator for Sranan.

(source: Plakatti 1862)

\section{1b. The placard announcing Emancipation (1862)}

Although the original Dutch text of the Proclamation of Emancipation (Gouvernementsblad 1862(7)) says that the Negro-English translation is 'attached to this document', it does not appear in that issue nor anywhere else in the 1862 volume. The text reproduced below was taken from the same broadsheet used for text no. 31a above.

Plakatti voe Granman, gi alla Katibo na ini Sranan Kondre!

Wi Konoe pliesi voe poti da dei, di da Katibofassi di oen de, sa kaba voe alla ten na Sranan kondre.

Sieksi moen na bakka jari, na da fosi dei voe da moen de meki seibi, Oen alla Fri! Ma di datti sa passa, Konoe wensi oen alla, di a de na oen tapoe leki wan Tata, voe si oen alla na wan boen fassi; datti hede a wanni datti da boen njoensoe moe go na oen alla jessi nojaso kaba, voe oen hatti kan njam pre, habi plisiri na hatti en de tevredefassi, voe wakti so wan bigi ten di de kon. Nanga mi heli hatti toe mi flisiteri oen, en wensi oen alla sanni di de voe boen, so leki mi flisiteri en wensi mi srefi toe, di mi de na oen mindri na presi voe Konoe, en di da mi moe habi da boenhede voe tjari so wan switi njoensoe gi oen. Mi hopoe datti da vertrouw di mi potti na oen tapoe no sa kori mi, ma datti mi sa si na oen alla da plisiri di de na oen hatti sa de toe voe si na den wrokko di den gi oen voe wrokko; holi oen srefi so leki a moe de; meki notti moe de voe takki na oen tapoe; harki nanga sakkafassi da wanni voe oen masra; so wan fassi sa meki oen sori datti oen waarti voe kisi da boen hatti di passa nanga oen, en di de wakti voe passa jette nanga oen na da fosi dei vo da seibi moen na bakka jari. Mo no morro mindri mi de verwakti voe oen toe, te da joeroe sa fon di oen sa takki da katibofassi voe oen adjosi, oen tron friman, oen sa holi oen srefi toe leki a fiti alla boen soema, voe liebi na wan sakkafassi, voe sabi datti kondre de na oen tapoe; doe san oen moe doe, leki an frisoema; holi oen wrokko dorro, voe oen verdien oen moni, di oen kan habi voe loekoe oen srefi nanga oen soema, en voe doe san oen hatti sa wanni voe doe nanga hen. Effi datti passa so, dan oen no sa gi mi trobi, ma nanga alla boenfassi oen sa meki mi doe alla den boen sanni, di Konoe wanni moe passa nanga oen. 
Voe oen srefi jessi kan jere morro betre da san oen moe sabi voe doe te da ten kisi, mi meki den potti disi, nanga da Plakatti, na nengre tongo voe oen kan jere en oen kan sabi. Paramaribo, da 3 Octobroe 1862.

(a ben tekien) Van Lansberge .

Nanga ordroe voe Granman, Da Ambtinari di de doe da wrokko voe Secretaris voe Granman, (a ben tekien) J. E. Wesenhagen.

Da Plakatti disi da mi tjari hen abra na nengre tongo, A. J. Comvalius Az. Sweriman na negre tongo.

(source: Plakatti 1862)

Placard of the Governor for all the slaves of Suriname!

It has pleased our King to fix the day when the system of slavery in which you live will be finished forever in Suriname. Six months after the beginning of the new year, on the first day of the seventh month, you will all be free! But now that this will take place, the King, who is above you like a father, wants to see all of you happy; therefore, he wants this good news to be given to your ears already now, so that you can rejoice, be happy and content to await this important moment to come. With all my heart I congratulate you, and wish you all the best, just as I congratulate and wish myself, that I am among you in place of the King, and that I am so fortunate as to bring you such sweet tidings. I hope that I will not be deceived in the confidence I put in you but that the pleasure that is in your hearts will also be seen in the work that you will be given to do; behave yourselves like you should; make sure that nothing can be said against you; listen humbly to your master's wishes; through such behavior you will show that you deserve the fortune that has happened to you and that is still waiting to happen to you on the first day of the seventh month of the new year. But no less do I expect from you too, when the hour will come when you will say goodbye to your days of slavery, when you are free men, that you will behave as befits all good people, to live humbly, to know that the government is above you; do what you have to do, like a free man; work steadily, to earn your money, which you can use to look after yourself and your loved ones, and to do what your heart shall wish to do with it.

If things will go this way, you will not give me any trouble, but with all your good behaviour you will make it possible for me to do all the good things the King wants to happen to you. In order for your ears to better understand the things you should know how to do when the time comes, I have had a translation into Sranan made of this [i.e. the Emancipation Act, reproduced above under 31a, JA] and of this placard, so that you can hear and you can know.

Paramaribo, 3 October 1862.

(was signed) Van Lansberge.

On order of the Governor, The public servant who is acting as secretary of the Governor (was signed) J.E. Wesenhagen.

I translated this placard into Sranan, A. J. Comvalius Az. Sworn translator for Sranan. 


\section{1c. The placard announcing AmNesty For RUNAWAy SLAVes (1862)}

The Proclamation of Emancipation was followed by a placard of October 20, 1862, granting amnesty to those runaway slaves who had escaped after the peace treaties of the 1760s had been signed. Although this text was published at least twice before (Encyclopedie 1977:564; Helstone \& Vernooij 2000:54), in both cases only the text of the actual article was included (i.e. from $\mathrm{Na}$ da enkri pisi disi onwards), not the preamble.

Plakatti.

Na nen voe Konoe! Granman voe Sranan Kondre, Wensi boen gi alla soema di sa si, effi jere den lesi da Plakatti disi, a sa meki den sabi: Di wi prakseri na alla fassi, datti a kan de nanga noffo voe den katibo, di dorro nomo de ronwe voe den Masra effi Pranasi di den de, datti notti leki frede voe kisi strafoe di den ronwe, de tappoe den voe den drai kon bakka; datti so srefi a kan de toe nanga den krioro voe boesi, di sonten de hangri voe go we libi den kampoe, voe kon na soema miendrie, effi na den presi di soema de liebi na kondre; Wi jere na da Hei Kroetoe voe Kondre; En feni voe boen: Voe do so leki da makti di wi kisi voe Konoe de takki voe potti:

Na da enkri pisi disi.

Datti alla den katibo di ben ronwe granoewe kaba, nanga den di go we bakkaten, effi den di ronwe na da kriboi ten nojaso - effi den srefi drai kon bakka, Wi de pramisi den, en da pramisi de voe troe troe, datti voe da ronwe, di den ronwe, den no sa kisi strafoe voe datti. So srefi toe den krioro voe boesi, no ha voe frede toe, den kan kon bakka na den masra effi na da pranasi di den denki den mama, effi Granmama ben de liebi. Voe alla soema kan sabi en jere san da plakatti disi takki, den sa doe so leki den njoensoe voe doe alla ten voe meki hen bikenti, en potti hen nanga di den tjari abra na mengre ${ }^{106}$ tongo, na koranti voe kondre.

Paramaribo, da 20 October 1862.

(a ben tekien) Van Lansberge.

Da Ambtinari di de doe da wrokko voe Secretaris voe Granman, (a ben tekien) J.E. Wesenhagen.

Da Plakatti disi da mi tjari hen abra na nengre tongo, A. J. Comvalius Az. Sweriman na nengre tongo.

(source: Gouvernementsblad 1862 (8), 10/20/1862)

Placard.

In the name of the King! The Governor of Suriname, Greets all those who will see or who will have read to them this placard, he lets them know: As we thoroughly believe that it is possible that many slaves who ran away from their masters or form the plantations they lived on are held back from returning by fear of being punished

106. A typo for nengre. 
for having run away; and that the same thing goes for the 'bush creoles', ${ }^{107}$ who may be anxious to leave their 'camps', 108 to come among the people and the places where the people live; Having heard the 'High Council', ${ }^{109}$ we see fit to decide, as the power conferred to us by the King says:

This is the only article.

We promise to all slaves who ran away a long time ago as well as those who did so later and those who did so recently, if they come back voluntarily - and it is a true promise - they will not be punished for running away. Similarly, those who were born as Maroons should not be afraid; they may return to their master or to the plantation where they think their mother or grandmother lived. In order for everyone to be able to know and understand what this placard says, the same thing will be done as is always done, namely to make it known and publish it, together with a translation into Sranan, in the government newspaper.

Paramaribo, October 20, 1862.

(was signed) Van Lansberge.

The public servant who does the job of the Governor's secretary (was signed) J.E. Wesenhagen.

I, A. J. Comvalius Az., sworn translator for Sranan, translated this placard into Sranan.

31d. The Placard AnNouncing the Rights And Obligations OF EMANCIPATED SLAVES $(4 / 16 / 1863)$

Since the slaves were put under State supervision for ten years following Emancipation, the colonial government published a text in which their rights and obligations were clearly stated. Since I have not been able to locate the original version of the Sranan version of this placard the transcription presented here is taken from Helstone and Vernooij (2000:44-50).

\section{PLAKKATI}

Disi meki alla njoen friman disi de na ondro lanti, en dem soema disi joeroe dem, sabi san na dem reti en san da dem plikti toe.

(Gouvermentsblad 1863 No 9) PLACARD,

Which makes known to all the new freedmen who belong to this country and to those who hire them what their rights are and also what their duties are.

(Gouvermentsblad 1863 No 9)

107. Maroons who were born 'in the bush'.

108. This was the usual word used by the colonial government to refer to Maroon villages.

109. The Colonial Council, a representative body of the elite among Suriname's population of the time. 


\section{NA NEM FOE KONOE!}

Granman foe Sranam Kondré Si dati a de fannodoe, foe meki wan plakkati, disi meki alla njoen friman dsi de na lanti ondro, en dem soema disi joeroe dem, sabi san na dem reti, en san na dem plikti toe; En disi Granman jere san da heikroetoe disi de helpémeki plakkati taki; A finni boen foe poti, so leki da Plakkati disi de taki:

\section{IN THE NAME OF THE KING!}

The Governor of Suriname, Seeing that it is necessary to make a proclamation to make sure all the new freedmen who fall under the jurisdiction of the government and the people who hire them know their rights and their obligations, the Governor, having heard the High Court that helped make this proclamation, thinks it is right to proclaim, as is proclaimed in this proclamation:

Foe alla njoen friman disi de na lanti ondro, so na Foto leki na Pranasi.

Concerning all the new freedmen who fall under the jurisdiction of the government, both in Paramaribo and on the plantations.

Supervisorsi foe ibri riba en disi foe foto sa meki wan boekoe, so leki Granman sa sori hem.

The supervisors of every river and those of Paramaribo shall keep a book like the Governor will show them.

2. Na ini da boekoe Supervisorsi sa skrifi alla dem njoen friman nomroe, dem nem, ho tem dem meki dem, iffi ho meni jari a denki dem habi, soortoe wroko da friman de doe; so srefi dem nem, jari en da wroko foe hem mama, nanga di foe dem tra famili, en iffi da mama trou kaba, dan a sa skrifi da tata nem toe. Boiti na ini dem boekoe pé kondré meki dem skrifi alla soema nem disi tron, disi meki pikien, nanga disi dede, Supervisorsi sa skrifi toe na ini da boekoe, pé dem njoen friman nem de, dem njoen friman disi tron, disi meki, iffi disi dede. Ibri friman disi ouroe 15 jari kaba, de kom aparti na boekoe.

In the book the supervisors shall write the numbers of all the new freedmen, their names, when they were born or how old they think they are, what kind of work the freedman does; similarly the names, years and work of their mother and of the rest of their family, and if the mother is married he shall write the name of the father too. Apart from the book in which the government has them write the names of everybody who got married, who had a baby and who died, the supervisors shall write in the book containing the names of the new freedmen the new freedmen who got married, who had a baby, or who died. Every freedman who has reached the age of fifteen shall be entered separately in the book.

3. Iffi wan soema komopo foe wan riba go na trawan, Supervisorsi foe pé a komopo sa poeloe hem na hem boekoe, en da Supervisorsi foe da riba pé a go, sa potti hem na hem boekoe.

If someone leaves one river to go to another one, the supervisor of his place of origin shall remove him from his book and the supervisor of the river he is going to shall enter him in his book. 
4. Dem friman disi sa kisi in wan tem primisi foe Granman foe komopo na lanti ondro, Supervisorsi sa poeloe dem nem na ini da boekoe.

Whenever freedmen shall get permission from the Governor to be dismissed from the jurisdiction of the government, the supervisor shall remove their names from the book.

5. Ibri wan njoen friman foe 15 té 60 jari, so srefi dem, disi, alwassi dem habi moro leki 60 jari, tokoe kroederi foe wroko, nanga dem disi kisi primisi foe doe wan ambakti iffi wan tra wroko na dem srefi, de kisi foe Supervisorsi wan pikien boekoe; a moesoe pai 25 sensi foe segri; - da soema disi joeroe hem sa pai da segri-moni na fesi, en a sa poeloe dati bakatem na ini hem joeroe-moni. Dem disi kisi primisi foe wroko na dem srefi, moesoe pai da segri-moni so hesi leki dem kisi da pikien boekoe.

Every new freedman of fifteen to sixty years old and those who have agreed to work even though they are over sixty as well as those who have permission to ply a trade or to work independently shall get a little book from the supervisor. $\mathrm{He}$ must pay 25 cents for the seal. The person who hires him shall pay the money for the seal in advance and shall subtract it later from his wages. Those who have permission to work independently shall pay the money for the seal as soon as they receive the little book.

6. Te da pikien boekoe foeloe, da friman de kisi wan trawan foe soso, mara iffi a lasi, kaba Supervisorsi ondroesoekoe en a finni dati da soema no lasi iffi trowé hem foe espresi, dan a kan kisi wan tra pikien boekoe, mara a moesoe pai agèn 25 sensi foe segri. Iffi a kom na krien dati wan friman priti, trowé iffi pori da pikien boekoe foe espresi, a sa pai, boiti da segri-moni, wan boekoe foe 2 té 5 banknotoe. Wan friman disi farsi hem pikien boekoe, iffi meki gebruiki foe wan farsi wan, iffi foe wan trasoema pikien boekoe, Supervisorsi sa strafoe hem foe a wroko na strati, njoen foto, iffi lanti pranasi, foe wan moen te dri moen langa. Soema disi joeroe njoen riman en alla tra soema, iffi dem farsi wan pikien boekoe, iffi helpi foe farsi wan pikien boekoe, dem sa kisi strafoe, so leki plakkati foe kondré poti.

When the little book is full the freedman will get another one for free, but if he loses it and the supervisor finds he didn't lose it or threw it away deliberately, he can get another one but again he should pay 25 cents for the seal. If it turns out that a freedman destroyed or threw away or damaged the little book deliberately, he shall pay, apart from the money for the seal, a fine of two to five banknotes. A freedman who makes a counterfeit book or makes use of a counterfeit book or of someone else's book, the supervisor shall punish him with having to work on the streets, in the new part of Paramaribo or on the government's plantations for one to three months. Persons who hire new freedman and everybody else, if they make a counterfeit book or help make a counterfeit book, they will be punished according to the laws of the country. 
7. Na ini da pikien boekoe dem nomroe, dem nem en jari foe da friman de kom, so srefi da kroederi, disi a meki, Supervisorsi sa teeken hem nem na da fosi en da kriboi sei foe da boekoe en a sa marki dem tra blad nanga dem fosi letter foe hem nem.

In the little book will be the number, the name and the age of the freedman, as well as the working agreement he makes; the supervisor will sign it at the front and at the back and on the other pages he will put his initials.

8. So langa dem njoen friman de na lanti ondro, dem de verplikti foe kroederi foe wroko doro, na wan reti fasi, na wan pé; foe dati hede dem moesoe meki wan kontraki (dati wani taki wan pampira, pé Supervisorsi skrifi alla sani disi dem kroederi.). Alla kroederi foe wan jari en moro langa moesoe de na tapoe wan segri foe 25 sensi, en foe moro sjatoe tem leki wan jari, 10 sensi. Moro leki wan soema kan kroederi na tappoe wan segri.

As long as the new freedmen are under the jurisdiction of the government they are required to agree to work in a correct way at one place. Therefore, they should make a contract (that is a piece of paper on which the supervisor writes down everything they have agreed upon). All agreements for one year and more will be done on a seal of 25 cents, those for shorter periods, 10 cents. More than one person can make an agreement on one seal.

9. Dem pikien foe dem njoen friman disi de na lanti ondro, alwassi dem tata nanga mama habi foe taki na dem, tappoe so langa dem no ouroe 23 jari, tokoe, iffi den habi 18 jari, dem kan meki kontraki sondro primisi foe dem tata iffi mama. Iffi dem, disi na tapoe 18 jari, no kan kisi primisi foe dem tata iffi mama, foe meki kontraki, den Supervisorsi sa koti da trobi.

The children of the new freedmen who are under the jurisdiction of the government, even though they fall under their parents' authority until they are twenty-three, if they are eighteen they can make an agreement without their parents' permission. If those who are eighteen cannot get permission from their parents to make an agreement, the supervisor will decide.

10. So hesi a kom na krien, dati dem tata iffi mama, iffi dem soema disi teki da sorgoe na dem tappoe, foe pikien disi no habi 18 jari jette, de teki da moni disi dem pikien de wroko sondro foe gi dem san dem habi fannodoe, Supervisorsi sa bemoei na ini en a sa meki dati da san dem pikien verdieni tan foe dem.

As soon as it turns out that parents or caretakers of children below eighteen take the money their children earn without giving them what they need, the supervisor will interfere and he will make sure that what the children earn remains theirs.

11. Alla kroederi foe wroko moesoe meki na fesi foe Supervisorsi en a moesoe teeken da pampira foe dati toe. A sa skrifi da kroederi na ini da pikien boekoe; te da tem foe da kroederi kaba en dem srefi soema kroederi so srefi agèn, Supervisorsi sa poti dati na tappoe da kontraki en na ini da pikien boekoe; so toe iffi dem srefi soema no meki njoen kontraki, Supervisorsi sa poti na ini dem boekoe foe san hede dem no doe dati. 
All agreements should be made in the presence of the supervisor and he should sign the paper too. He shall write the agreement in the little book. When the agreement runs out and the same people hold on to it, the supervisor will put it in the contract and in the book. Similarly, if the same people do not renew their agreement, the supervisor will write in the book why that is.

12. Iffi wan friman di de na lanti ondro wani joeroe hem srefi na wan tra riba, a moesoe meki da Supervisorsi foe hem riba sabi dati, dan iffi Supervisorsi si na ini da pikien boekoe dati da soema kontraki kaba, a sa gi hem wan bewijsi foe sori da Supervisorsi foe da tra riba. So hesi leki so wan soema meki da njoen kontraki, da wan Supervisorsi sa meki da trawan kisi foe sabi, foe kan poeloe da friman na hem boekoe.

If a freedman who is under the jurisdiction of the government wants to get hired on another river, he should notify the supervisor of his river; then, if the supervisor sees in the little book that that person's contract has expired, he will give him a proof to show to the supervisor of the other river. As soon as such a person makes a new contract, the one supervisor shall notify the other one so he can remove the freedman from his little book.

13. Ibriwan soema kan joeroe hem srefi foe someni moni leki a kan kisi; mara iffi no wan tra kroederi de, dan da pai sa de foe pranasi wroko, so leki da plakkati disi sori lanti marki poti kaba, iff tra plakkati sa poti bakkatem. Dem, disi dri moen na bakka dem fri, no ben kan meki kontraki, so dati lanti moesoe poti dem na wroko, habi allatem passi foe kroederi en meki kontraki nanga tra soema.

Every person can let himself be hired for as much money as he can get. But if there is no other agreement, payment shall be that for plantation work, just like it was already established in the proclamation that showed the government's tasks or will be established by other proclamations in the future. Those who, three months after emancipation, have not been able to make an agreement, so that the government has had to employ them, maintain the right to make an agreement with someone else.

14. Dem njoen friman disi de na Lanti ondro, iffi dem foefoeroe wan pikien sani, iffi dem feti nanga makandra; iffi dem sori kaprisi nanga mofo, iffi ibri wan tra asrantifasi, gi da soema disi joeroe dem, iffi driktoro, iffi dem kosi, nakki, dreigi foe nakki, iffi pramisi trawan, iffi dem droengoe, lesi, mankeri wroko foe espresi, iffi dem no doe dem plikti so leki a fiti en dem kontraki taki, iffi meki oproeroe na pranasi, sondro dati moro bigi ogri kon na tappoe, Supervisorsi sa strafoe dem nanga wan boetoe disi no sa de moro foeloe leki 5 banknotoe; iffi nanga doengroe hoso foe dri dei te dri moen langa; iffi nanga strafoe wroko na Lanti, srefi na ini ketien-boei foe aiti dei te dri moen langa. Di soema meki - foe ogri hatti hede, iffi bikasi a no loekoe da sani boen - wrokosani, sani foe mierihoso, iffi foe bakrahoso, iffi ini wan tra sani foe da soema disi joeroe hem, iffi disi foe driktoro, lasi, broko iffi kisi mankeri, Supervisorsi kan meki da soema disi sani pori, poeloe san da sani waarti na ini da joeroe moni foe da friman, boiti da strafoe disi a sa kisi. 
The new freedmen who fall under the jurisdiction of the government, if they steal something small, if they fight with each other, if they use foul language or show any other kind of impudent behavior towards the person who hires them, if they curse, hit, or threaten to hit, or threaten others, if they are drunk, lazy, do not perform their duties deliberately, if they do not fulfill their obligations like they should and like the contract says, if they cause a riot on the plantation, without any other serious offences in addition to that, the supervisor shall punish them with a fine that will not exceed five banknotes, or with imprisonment from three days to three months, or with forced labor for the government, even in chains for eight days to three months. If someone, out of spite or carelessness, causes equipment, things belonging to the mill or to the owner's house or anything else belonging to the person who hires him or to the manager, to get lost or broken or be missing, the supervisor may allow the person whose things have been damaged to subtract the value of those things from the freedman's wages, apart from the punishment he will get.

15. Dem njoen friman disi de na lanti ondro habi réti te wan soema joeroe dem, kaba a no pai dem da joeroe-moni, foe soekoe dem réti na kroetoe, sondro pai onkostoe foe dati. Dem disi de na foto anga den disi de na pranasi kan doe dati na Pikienkroetoe na foto, en dem disi foe Nickerie en Coronie, na da kroetoe disi de na dem plesi dati. The new freedmen who are under the jurisdiction of the government have the right, if someone hires them but does not pay them their wages, to seek justice at the Court without incurring any costs. Those who are in Paramaribo or on the plantations can do so at the Small Court in Paramaribo, and those in Nickerie and Coronie can do so at the Courts in those places.

16. Alla klagi disi dem njoen friman habi, den kan doe dati na Supervisorsi.

All complaints the new freedman may have should be directed to the supervisor.

17. Iffi Supervisorsi kisi foe sabi dati wan soema disi joeroe njoen friman, iffi wan driktoro no doe so leki a kroederi en hem kontraki de taki,-so srefi iffi a no doe dem plikti disi plakkati foe kondre poti, - Supervisorsi sa meki Fiskari kisi dati foe sabi; Te Fiskari finni dati fitti so, a sa tjari, dem disi doe so na kroetoe fesi. Te kroetoe finni dati dem soema disi joeroe dem njoen friman, iffi den driktoro no habi réti, a sa strafoe dem nanga wan boetoe foe 50 banknotoe te wan doesoen banknotoe; en srefi kroetoe kan broko da kontraki, en meki dem pai da friman alla san a lasi foe dati héde.

If the supervisor finds out that a person who hires new freedmen or a manager does not act according to the agreement and the contract, similarly if he does not fulfill the obligations mentioned in the law of the country, he shall notify the fiskari. If the fiskari finds this confirmed, he will bring those who do so to justice. If the Court feels that the persons who hire the new freedmen or the managers are wrong, it will punish them with a fine of fifty to one thousand banknotes. The 
Court may even break the contract and have them pay the freedmen every damage they incurred because of it.

18. Iffi kroetoe broko da kontraki, dan Supervisorsi sa helpi da friman foe meki wan njoen kontraki nanga wan tra soema; te a no finni wan joeroe hesi, Lanti sa poti hem na wroko, mara allatem a habi passi, alwassi a de na Lanti, foe kroederi en meki kontraki nanga tra soema.

If the Court breaks the contract, the supervisor will help the freedman make a new contract with someone else. If he does not find employment quickly, the government will employ him, but he always maintains the right, even though he works for the government, to make an agreement and a contract with someone else.

19. Iffi kroetoe strafoe wan soema disi joeroe wan njoen friman, iffi wan driktoro morotron bikasi a no noli hem na dem kontraki, iffi bikasi a no de libi nanga dem soema disi de na hem ondro so leki a fiti, Fiskari kan tjari hem baka na kroetoe fesi, foe tapoe hem foe joeroe wrokoman iff foe kommanderi dem.

If the Court has punished someone who hires new freedmen or a manager several times because he does not adhere to the contract or because he does not treat his employees the way he should, the fiskari can bring him to Court again in order to keep him from hiring workers or being in charge of them.

20. Granman kan gi dem njoen friman disi de na Lanti ondro, primisi foe habi hoso, gron, pranasi, foe dem srefi; mara Granman habi da reti toe foe tapoe dem foe libi na dem gron iffi pranasi, te dem no doe alla plikti disi wet poti na dem tappoe do langa dem de na ondro Lanti. So srefi iffi dem wani joeroe wan gron, Granman moe gi primisi fosi, en iffi dem no doe dem plikti, dem so sa kan habi pasi foe libi pé dem joeroe, iffi prani da gron.

The Governor may give the new freedmen who are under the jurisdiction of the government permission to have a house, land, and a farm for themselves. But the Governor has the right too to keep them from living on their land or farm if they won't fulfill all the obligations the law imposes on them as long as they are under the jurisdiction of the government. Similarly, if they want to rent a piece of land, the Governor must give permission first, and if they do not fulfill their obligations they will not be permitted to live where they rent or cultivate the land.

21. Lanti sa sorgoe so meni leki a kan, meki dem pikien foe dem njoen friman disi de na Lanti ondro, go na skólo en foe dem leri sabi Gado. Na dem presi, pé skólo de, dem pikien foe 7 te 15 jari moesoe go na skólo; ma dem disi habi 12 té 15 jari de go ibri dei toe joeroe nomo na skólo. Tata, mama en alla tra soema disi teki pikien foe loekoe, moesoe sorgoe foe dem pikien go na skólo, iffi no so, dem sa pai wan boetoe foe 5 banknotoe. Dem soema disi joeroe dem njoen friman, iffi dem driktoro disi sa tapoe dem pikien foe go na skólo iffi na leri, sa pai 50 té 200 banknotoe boetoe. 
The government will take care, as much as it can, that the children of the new freedmen who are under the jurisdiction of the government will attend school and learn about God. At the places where there is a school, the children of seven to fifteen should go to school, but those from twelve to fifteen shall attend only for two hours a day. Fathers, mothers, and caretakers should make sure the children go to school; if not, they will pay a fine of five banknotes. The persons who hire the new freedmen or the managers who keep the children from going to school or from learning will pay a fine of 50 to 200 banknotes.

22. Alla boetoe disi da plakkati disi poti de foe lanti. Dem boetoe, disi dem njoen friman moesoe pai, de komopo na ini dem joeroe-moni, iffi dem no pai hem wantem.

All fines mentioned in this proclamation belong to the government. The fines to be paid by the new freedmen will be subtracted from their wages unless they pay them immediately.

23. Alla njoen friman disi de na Lanti ondro, disi no sabi foe skrifi, kaba dem moesoe teeken kontraki iffi iri wan tra pampira, Supervisorsi iffi hem Sekretarsi sa meki dem meki wan kroismarki na plesi foe den nem.

All new freedmen who are under the jurisdiction of the government and who cannot write, if they are required to sign a contract or any other paper, the supervisor or his secretary shall have them make a cross instead of their name.

24. Foe helpi pikienso nanga dem bigi onkostoe disi a habi foe boekoe dem pikien disi no habi tata iffi mama, en dem ouroe en malingri njoen friman disi no kan wroko moro, alla njoen friman disi de na Lanti ondro en disi moesoe meki kontraki foe wroko, en alla dem disi kisi primisi foe wroko na dem srefi, moesoe pai Lanti kantoro ibri jari, dem manwan 6 banknotoe en dem oemanwan 3 banknotoe ibri soema, boiti da patent-moni foe da ambakti disi dem de doe. Na bigien foe ibri jari dem soema, disi joeroe dem njoen friman, moesoe pai Lanti-kantoro gi dem, en na ini da jari dem sa poeloe dati baka na ini dem joeroe-moni; - dem njoen friman disi de wroko na dem srefi, moesoe pai kantoro-moni da srefi dei di dem kisi da bewijsi foe Supervisorsi, dati dem kan wroko na dem srefi.

To assist a little in the big costs the government makes to support the orphans and the sick and elderly new freedmen who are no longer able to work, all new freedmen who are under the jurisdiction of the government and who must make an employment contract, and all those who have permission to work independently, every one of them must pay to the government's office every year six banknotes per man and three banknotes per woman, apart from the 'patent money' for the trade they ply. At the beginning of every year the people who hire the new freedmen must pay the government's office on their behalf, and during the year they will subtract it from their wages. The new freedmen who work independently must pay the 'office money' the same day they get the official permission from the supervisor to work independently. 
B. Foe dem njoen friman na Lanti ondro, disi ben de libi, iffi ben de wroko na pranasi. Concerning all the new freedmen under the government's jurisdiction, who used to live or work on a plantation

25. Dem njoen friman disi ben de libi allatem na pranasi, iffi ben njoensoe foe wroko na pranasi en disi ouroe 15 té 60 jari, de verplikti foe meki kontraki, foe dem srefi nanga dem famili, foe tan wroko na pranasi na ondro ibriwansoema disi dem srefi wani en disi plakkati gi makti foe joeroe. Da kontraki moesoe de foe moro sjatoe tem leki wan jari en no moro langa leki dri jari.

The new freedmen who always used to live on a plantation or used to work on a plantation and who are between fifteen and sixty years of age, are obliged to make a contract for themselves and their families to continue working on a plantation for anyone they want to who is permitted by this proclamation to hire people. The contract should be for at least one year and at most three years.

26. Dem disi ouroe moro leki 60 jari de tan nanga dem famili; pikien disi no habi 15 jari jete, moesoe go pé dem mama de. Ma dem ouroe soema en dem pikien, so meni leki dem kan, dem moesoe wroko gi da soema disi joeroe da famili iffi da mama, en da soema sa pai dem so meni leki dem wroko waarti.

Those who are above sixty stay with their families. Children below fifteen must go with their mothers. But the elderly and the children must work, to the extent they can, for the person who hires the family or the mother and the person shall pay them what their labor is worth.

27. Foe wan oeman disi trou, dem no mak soekoe moro wroko leki toe poorsi na ini wan marki; (dati wani taki, dem sa prati da marki na dri poorsi, en toe poorsi (2/3) foe dati a sa moesoe wroko). Foe oeman, disi habi 5 moen béré dem no mak soekoe moro wroko leki háfoe marki, té da bere ouroe 7 moen; -abra 7 moen, da soema disi joeroe hem no kan soekoe wroko moro na hem. Iffi wan oeman meki wan dédé pikien, dan fotenti dei na baka a moesoe go na wroko, mara iffi da pikien dé na libi, dan té a ouroe dri moen fosi.- Dem heeli dri fosi moen, disi a de na wroko, a no de go na fili, ma a de wroko na seihoso té 6 moen tapoe; dan a de go na háfoe marki so langa da pikien no ouroe wan jari. Bifosi háfoe aiti joeroe na mamantem, en na baka sieksi joeroe sapatem, no wan soema kan soekoe wroko na dem mama disi habi pkien na bobbi, so langa da pikien no ouroe wan jari. So langa dem béréman en mekiman no de wroko heeli marki, dem no kisi moro paiman, leki da wroko waarti disi dem doe. Iffi dem srefi finni dati dem kan doe moro wroko leki da soema disi joeroe dem mak soekoe na dem, dan dem sa kisi paiman foe da wroko disi dem doe na tappoe.

A married woman may not be given a job of more than two thirds of a full task. (That means they will have to divide the task into three parts and she shall do two parts of that.) A woman who is five months into her pregnancy may not be given a job of more than half of a full task, until she gets into her seventh month. Past her seventh month, the person who hires her may not employ her anymore. If a 
woman gives birth to a still-born baby, she should go back to work after 40 days, but if the baby lives only after three months. The entire first three months when she is back at work, she shall not go to the field but she shall work in the house until the end of the sixth month. Then she will return to half-task until the baby is one year old. Before half past seven in the morning and after six o'clock at night, nobody may require work from the mothers who are suckling their babies until the baby is one year old. As long as the pregnant women and the women who gave birth recently do not perform a full task, they will not get more payment than the work they do is worth. If they themselves feel they can do more work than the person who hires them is allowed to require from them, they will get payment for the extra work they do.

28. Iffi dem njoen friman no meki wan tra kroederi, dan dem moesoe doe ibriwan wroko disi dem gi dem foe doe en disi dem kan doe, boiti da fasti wroko disi dem joeroe dem srefi na kontraki, foe doe na pranasi. Foe dati hédé dem no mak weigri foe holi wakti na sloisi, iffi na ini njanjam gron, na dei, iffi na neti; so srefi toe, dem sa moesoe doe alla soortoe wroko, disi joeroeman mak soekoe na dem, na Sondei en Feestti dei, so leki ro boto iffi pondo, doe hoso wroko, loekoe kweki en alla so soortoe wroko. Na dem pranasi pé watra-miri de, kaba a de tem foe mala, dem moesoe wroko na Sondei toe, foe koti en tjari ken; -na ini miri en boli-hoso en foe meki soekroe; so srefi toe na kofi-, kakau-nanga katoen pranasi, te dem de piki iffi wroko kofi, kakau iffi katoen, dem wrokoman no mak weigri foe wroko na Sondei, iffi a dé fanodoe; mara dan dem moesoe kisi bakatem so meni dei foe bloo, leki so meni Sondei disi dem lasi.

If the new freedmen do not want to make an agreement, they must do any kind of work that they are given and that they can do, apart from the steady work they hired themselves to do on the plantation by contract. For that reason they may not refuse to hold watch over sluices or provision grounds, day or night. Similarly, they will have to do all kinds of work their employer may require from them, on Sundays or holidays, such as rowing boats or ferries, do domestic work, look after children and all that kind of work. At the plantations where there is a water-mill, when it is time to grind, they must work on Sundays too, cut and carry the sugar-cane into the mill and the boiling-house and make sugar. Similarly, at coffee, cocoa, and cotton plantations, when they pick or process coffee, cocoa or cotton, the workers may not refuse to work on Sundays if it is necessary. But they should get as many resting days in return as the number of Sundays they lost.

29. Ibri joeroeman nanga wrokoman no kroederi trafasi, dan dem wrokoman moesoe wroko aiti joeroe ibri dei na fili, en ten joeroe na sei hoso; - wan jari habi drie hondro wrokodei. Dem soema disi wroko na neti, habi reti da tra dei foe kisi so meni joeroe baka foe bloo, leki dem ben lasi na neti; dem sa kisi foe da dei dati so meni paiman leki da wroko disi dem doe waarti. Dem soema disi de wroko na fili moesoe go seebien joeroe mamantem na wroko, en dem disi de wroko na miri iffi na sei hoso, sieksi joeroe; boiti iffi dem kroederi trafasi. 
Unless employer and employee agree otherwise, the employer must work eight hours in the field and ten hours in the house a day. A year has three hundred working days. The people who work at night have the right to be given as many hours of rest the next day as they lost during the night. They shall get for that day as much payment as the work they did is worth. The people who work in the fields should go to work at seven in the morning and those who work at the mill or in the house at six, unless they agreed otherwise.

30. No wan soema habi makti foe komopo na da gron iffi pranasi pé a joeroe hem srefi foe wroko, go na wan tra plesi, sondro a habi wan passabrifi foe hem driktoro. Foe wan soso sanni hédé hédé hédé dem driktoro no mak weigri wan soema wan passa-brifi, - en nooiti, iffi a aksi dai foe go gi klagi na Supervisorsi, mara no moro leki dri soema kan kisi passi makandra foe go na Supervisorsi. Iffi wan driktoro weigri brifi foe wan soso sanni hédé, iffi no wani gi brifi foe go klagi na Supervisorsi, a sa pai wan boetoe foe twinti banknotoe té toehondro banknotoe.

No-one is allowed to leave the land or the plantation where he got himself hired to work, to go somewhere else without permission from his manager. The manager may not refuse permission for some petty reason and he may never do so when asked for permission to bring a complaint before the supervisor. But no more than three people may get permission to go to the supervisor at the same time. If a manager refuses to give permission for a petty reason or does not want to give permission to bring a complaint before the supervisor, he shall pay a fine of twenty to two hundred banknotes.

31. Iffi dem kisi wan njoen frman sondro passa-brifi foe hem driktoro, dan a moesoe pai wan boetoe foe 5 banknotoe, iffi a moesoe doe srafoe wroko 8 dei té wan moen, so leki Supervisorsi sa finni foe boen; biti iffi da friman kan bewijsi dati a ben aksi wan passa-brifi foe go klagi na Supervisorsi en hem driktoro no ben wani gi hem.

If a new freedman is caught without permission from his manager, he must pay a fine of five banknotes, or he must do a slave's work for eight days to one month, just as the supervisor thinks is right, unless the freedman can prove that he had asked for permission to bring a complaint before the supervisor and his manager refused to give it to him.

32. Ibri soema disi joeroe njoen friman, moesoe pai dem da joeroe-moni alla wiki; a moesoe gi dem, nanga dem famili, wan boen hoso foe libi; a moesoe gi ibriwan foe da famili disi ouroe moro leki 15 jari, wan pisi gron disi bigi wan kétien na langa en wan ketien na bradi, na ini poldroe en so dati dem gotro kan poeloe den watra. Da pisi gron sa dé foe dem prani dem njanjam; ma foe prani baâna, dem moesoe habi aparti rimisi foe driktoro; a moesoe gi dem nanga dem famili datra nanga dressi en san sikiman habi fanodoe, en a moesoe sorgoe foe boen siki-hoso.

Everyone who hires new freedmen must pay them their wages every week. He must give them and their families a good house to live in. He must give every member of the family who is over fifteen a piece of land of one ketting wide and one 
ketting long, in the polder so the water can be drained by gutters. That piece of land will be for them to grow food. But to grow bananas they need special permission from the manager. He must give them and their families a doctor and medicine and whatever sick people need, and he must make sure there is a good hospital.

33. Iffi wan soema siki en driktoro sénni hem na siki-hoso, a dé verplikti foe go, en a moesoe doe alla san driktoro taki, so foe a kon bétré hési, leki foe a tan krien. Dem soema srefi, ibriwan foe hem poorsi, moesoe krien da plasi rontoe foe dem hoso. Da soema, disi joeroe dem, moesoe sorgoe foe ondrohou da hoso nanga dem gotro.

If a person is sick and the manager sends him to the hospital, he is obliged to go and he must do everything the manager says in order to get well quickly, as is clear. The people must clean the space around their house, everyone their own part. The person who hires them must take care of the maintenance of the house and the gutters.

34. So langa da dri moen no passa, disi dem njoen friman no meki kontraki jete en dem de san dem ouroe masra plesi, dern moesoe wroko fo dei na ini wan wiki gi da masra; foe dati a moesoe gi dem datra, en a moesoe pai dem toe poorsi foe da moni, disi plakkati potti foe lanti-marki (186, No. 1,) (dati wani taki, dem sa prati da joeroe moni disi lanti potti foe dem marki wroko na dri poorsi, en toe poorsi (2/3) sa de da paiman).- Foe dem ouroe en malingri soema en foe dem pikien disi no kan wroko, en foe dem pikien disi no habi soema foe loekoe dem, Lanti sa sorgoe, ma dem ouroe masra moesoe gi dem plesi foe tan da dri moen dóro. Dem massra disi no wanni joeroe dem soema disi ben dé dem katibo, alwassi dem moesoe gi dem plesi foe libi dri moen langa, sa meki Granman sabi dati so hesi leki dem kan, foe Lanti kan potti dem njoen friman so langa na wroko té dem meki kontraki nanga tra soema. Iffi wan massra no wanni hem ouroe katibo tan libi da dri moen na hem pranasi, a kan joeroe wan tra plesi gi dem.

During the first three months, if the new freedmen have not made a contract yet and they are at their old plantation, they must work four days a week for their master. For that he must give them a doctor and he must pay them two thirds of the money required by the law of the country $(186$, no. 1$)$ (that means, they shall divide the wage fixed by the government for a full task into three parts, and two parts of that will be their payment). The government will take care of the elderly and sick people and of the children who have no-one to look after them, but their former master must give them a place to stay for three months. The masters who do not want to hire the people who used to be their slaves, even though they are obliged to give them a place to stay for three months, shall notify the Governor as soon as they can, so that the Government may put them to work for the time being until they make a contract with someone else. If a person does not want his former slave to stay on his plantation for three months, he may rent another place for him. 
C. Foe dem njoen friman na Lanti ondro, disi no ben de libi iffi no ben de wroko na pranasi.

Concerning the new freedmen under the government's jurisdiction who did not use to live or work on a plantation.

35. Dem njoen friman disi de na Lanti ondro, foe 15 jari té 60 jari, en disi no ben de libi iffi no ben dé wroko na pranasi, dé verplikti foe meki kontraki foe wroko na soema ondro disi dem srefi wanni. Wan heeli famili makandra, iffi ibri soema aparti kan meki kontraki, mara foe no moro mindri tem leki dri moen en no moro langa leki wan jari: iffi dem joeroe dem srefi foe wroko na foto. Pikien, disi no moro ouroe leki 12 jari, no kan prati nanga dem mama.

The new freedmen who are under the government's jurisdiction, between fifteen and sixty, and who did not use to live or work on a plantation, are obliged to make a contract to work for someone of their own choice. An entire family may make a contract or each person separately, but not for less than three months nor for more than one year, if they hire themselves out in Paramaribo. Children below the age of twelve may not be separated from their mothers.

36. Dem disi passa 60 jari, en pikien foe 12 té15 jari moesoe doe wroko disi no hebi foe dem jari.

Those who are over sixty and children between twelve and fifteen should do work that is not too heavy for their age.

37. Dem njoen friman, disi kan bewijsi Supervisorsi, dati dem sabi wan ambakti iffi wan wroko boenboen, en dati dem kan verdini nanga dem wroko someni moni dati dem kan ondrohou dem srefi en dem famili, Supervisorsi kan gi dem primisi foe wroko na dem srefi, en dan dem no habi fanodoe foe meki kontraki. Alla jari Supervisorsi sa skrifi na ini dem pikien boekoe, dati a gi dem passi foe wroko na dem srefi. Iffi Supervisorsi si dati dem no meki wan boen gebruiki foe da primisi disi a gi dem, dan a sa poeloe dati baka, en dan dem sa moesoe joeroe dem srefi na kontraki.

The new freedmen who can prove to the supervisor that they know a trade or a type of work very well and that they can earn enough money through their work to support themselves and their families, the supervisor may give them permission to work for themselves and they do not need to make a contract. Every year, the supervisor will write in their little book that he gave them permission to work for themselves. If the supervisor sees that they do not make the right use of the permission he gave them, he will withdraw it and they will have to hire themselves out by contract.

38. Dem njoen friman disi joeroe den srefi foe doe wan fasti wroko na soema ondro, so leki foetoe-boi, bakra-hoso-oeman, djariman, ambaktiman, sjouman na soema disi de holi winkri, koki, wassiman en alla so soortoe wroko, no mak weigri, iffi a de fanodoe, foe doe wan tra wroko gi da soema disi joeroe dem, alwassi dati no de na dem kontraki. En dem de verplikti foe harki en foe doe alla san disi moesoe de foe holi boen ondroe na wrokoplesi en na ini hoso. 
The new freedmen who hire themselves to do a steady job for someone, such as personal servant, domestic servant, gardener, skilled worker, porter for someone who runs a shop, cook, laundry woman and all kinds of jobs, are not allowed, if it is necessary, to refuse to do another kind of work for the person who hires them, even though that is not in their contract. And they are obliged to obey and to do everything that must be done to keep everything in order in the workshop and in the house.

39. Iffi toe wiki bifosi da kontraki kaba dem soema disi ben meki hem no bedanki dem srefi, dan da joeroe de go doro foe dri moen agèn.

If two weeks before the contract expires, the persons who made the contract have not terminated it, the hire will continue for another three months.

40. Wan soema disi joeroe wan njoen friman, habi reti foe bedanki hem té a wanni, sondro foe taki san hédé, ma dan a moesoe pai da friman, boiti san a wroko kaba, jete sieksi wiki joeroemoni, en a sa meki Supervisorsi sabi dati da soema no de na hem joeroe moro. Iffi da joeroe no libi sieksi wiki moro foe kaba, dan da njoen friman habi reti na tappoe da joeroe-moni foe alla dem tem disi mankeri jete.

A person who hires a new freedman has the right to terminate the employment whenever he wishes, without giving a reason, but he must pay the freedman, apart from his wages, an extra six weeks and he shall notify the supervisor that he does not hire that person anymore. If the contract period left is less than six weeks, the freedman is entitled, in addition to his wages, to the money for the remaining period.

41. Na soema disi joeroe ambaktiman, kaba a no habi wroko, iffi noffo wroko, foe gi dem, a kan gi da joeroe abra na tra soema, iffi da ambaktiman tefredi nanga da soema; ma foe da srefi moni leki a ben joeroe hem, en a sa meki Supervisorsi sabi bifosi.

The person who hires skilled workers but does not have employment or not enough employment for them, may transfer the hire to someone else, if the skilled worker is agreed with that. But for the same wages he hired him for and he shall notify the supervisor.

42. Na wroko-joeroe dem njoen friman no mak libi da wroko-plesi, winkri iffi hoso pé dem joeroe dem srefi, sondro primisi foe da soema disi joeroe dem.

During working hours the new freedmen are not allowed to leave the work place, shop or house where they are hired without permission from the person who hires them.

43. Iffi dem no meki wan tra kroederi, dan dem soema disi joeroe dem njoen friman moesoe pai dem alla wiki dem joeroe-moni.

Unless they have made a different arrangement, the persons who hire the new freedmen should pay them their wages every week. 
44. No wan soema de verplikti iffi a joeroe wan njoen friman foe wroko na foto, foe gi hem hoso foe libi foe soso, iffi datra nanga dressi té a siki; boiti iffi dem kroederi na fesi en dem potti na dem kontraki toe. Pé wan mama habi fri hoso foe libi, dem pikien foe hem, so langa dem no ouroe 12 jari, kan libi nanga da mama toe.

No-one is obliged, when he hires a new freedman to work in Paramaribo, to give him free housing or a doctor or medicine when he is sick, unless they agreed otherwise in advance and put it in the contract. When a mother has free housing, her children may live with their mother as long as they are under twelve.

45. Alla sanni da plakkati disi taki foe dem njoen friman na pranasi, de toe foe dem fotowan, iffi dem joeroe dem srefi foe wroko na pranasi.

Everything this proclamation says about the new freedmen at the plantations goes for those in Paramaribo as well when they hire themselves to work on a plantation.

46. Nanga da dei foe fri (1 Julij 1863), da plakkati disi de bigien. En so leki dem njoensoe foe meki alla plakkati kom bekenti, so srefi dem sa doe nanga disi toe, en dem sa potti hem na ini plakkati-boekoe.

This proclamation is valid from the day of emancipation (1 July, 1863). This proclamation will be announced the same way all proclamations are usually announced, and it will be put it in the book of proclamations.

Paramaribo, 16 April 1863

(A ben teeken) VAN LANSBERGE

Nanga ordroe foe Granman,

Da Sekretarsi foe Granman, (A ben teeken) E. A. van EMDEN

Foe meki dem njoen friman sabi boenboen, ho san da plakkati disi de taki, Granman meki dem potti hem na ningre-tongo.

Paramaribo, 16 April 1863

(It was signed) Van Lansberge

By order of the Governor,

The Governor's secretary,

(It was signed) E. A. van Emden

To make sure the new freedmen know very well what this proclamation says, the Governor had it translated into Sranan.

Paramaribo, 1 October 1863

Da Sekretarsi foe Granman

(A ben teeken) E. A. van Emden

Nanga ordroe foe Granman, mi potti da plakkati disi na ningre-tongo.

Paramaribo, 1 October 1863

The Governor's secretary

(it was signed) E. A. van Emden

By the order of the Governor I have translated this proclamation into Sranan. 
Paramaribo, 1 October 1863

J. P. W. van Eijck.

(A drokoe na drokoerij foe J. C. Muller Az.)

(Gouvernementsblad 1863 No 9)

Paramaribo, 1 October 1863

J.P. W. van Eijck

(Printed at J. C. Muller Az.'s printing shop)

(Gouvernementsblad 1863 no. 9)

(source: Helstone \& Vernooij 2000:44-50)

31e. The PlacARd ANNOUNCING AN ADDENDUM TO THE RightS

AND OBLIGATIONS OF EMANCIPATED SLAVES (1863)

A few months after the previous document had appeared, an addendum to article no. 28 was published concerning the rights for freedmen to have four (unpaid) holidays during the New Year season. The addition of this clause may be a reflection of a belated awareness on the part of the colonial government of the great importance attached by slaves to the festivities surrounding New Year. The transcription is taken from Helstone and Vernooij (2000:56).

\section{Plakkati}

Disi potti sani moro na ini da plakkati, disi meki alla njoen friman disi de na ondro Lanti, en dem soema disi joeroe dem, sabi san na dem reti en san na dem plikti. Na nem foe konoe! Granman foe Sranam Kondré Wanni datti alla soema disi lesi iffi jere dem lesi na plakkati disi, sa sabi: Datti a de fannodoe foe potti wan sani moro na ini da plakkati, disi meki alla njoen friman disi de na ndro Lanti, en dem soema disi joeroe dem, sabi san na dem reti en san na dem plikti toe; foe datti hede, disi Granman jere san da heikroetoe disi de helpi meki plakkati taki; a finni boen foe potti, so leki da njoen plakkati disi de taki:Da san da plakkati disi meki alla njoen friman disi de na ondro Lanti, en dem soema disi joeroe dem, sabi san na dem reti en san na dem plikti toe, potti datti dem njoen friman disi joeroe dem srefi foe wroko na pranasi no mak weigri foe holi wakti na sloisi, iffi na ini njanjamgron, na dei iffi neti, so srefi toe dem moesoe doe alla soortoe wroko disi joeroeman mak soekoe na dem, na Sondei en Feesti-dei, so leki ro boto iffi pondo, doe hoso wroko, loekoe kweki en alla so soortoe wroko; na datti de tan so; mara tokoe alla njoen-jari dem njoen friman disi meki kontraki foe wroko na pranasi, iffi dem wani, dem kan kisi dri dei foe njam jari en wan dei foe bloo dem skien, mara da soema disi joeroe dem no habi fannodoe foe pai joeroe-moni foe dem fo dei datti. Dem, disi teki nanga dem wanni srefi moro leki fo dei foe njam njoen-jari en foe bloo, Supervisorsi sa strafoe dem nanga boetoe, iffi doengroe-hoso, iffi strafoe-wroko na Lanti, srefi na ini wan likti kétien-boei; ibri strafoe Supervisorsi sa potti so fara leki plakkati gi hem makti foe doe. So leki dem njoensoe foe meki alla plakkati kom bekenti, so srefi dem sa doe nanga disi toe, en dem sa potti hem na ini plakkati-boekoe.

Paramaribo, 22 December 1863.

(A ben teeken\} Van Lansberge.

Nanga ordroe foe Granman.
Paramaribo, 23 December 1863.

Da Sekretarsi foe Granman,

(a ben teeken) E. A. van Emden. 
Da Sekretarsi foe Granman, (A ben teeken\} E. A. van Emden.

Paramaribo, 23 December 1863.

Foe meki dem njoen friman sabi

boen-boen, ho san da plakkati disi

de taki, Granman meki dem potti

hem na ningre-tongo.
Nanga ordroe foe Granman, mi potti da plakkati disi na ningre-tongo.

P. W. van Eijck.

(a drokoe na drokoerei foe J. C. Muller Az.)

(source: Helstone \& Vernooij 2000:56)

Placard.

This contains additional statements to the proclamation that informed all new freedmen who are under the government's jurisdiction as well as those who hire them what their rights and obligations are. In the name of the King! The Governor of Suriname wants everybody who reads this proclamation or hears it read to them to know: That it is necessary to add another clause to the proclamation that informed all new freedmen who are under the government's jurisdiction as well as those who hire them what their rights are as well as their obligations. Therefore, the Governor, having heard the 'High Council'110 that helped make this proclamation, thinks it is right to proclaim, as is proclaimed in this new proclamation: The stipulation made in the proclamation that informed all new freedmen who are under the government's jurisdiction as well as those who hire them about what their rights and obligations are, said, namely that the new freedmen who hire themselves to work on a plantation may not refuse to keep watch at sluices or at provision grounds, day or night, and that they must similarly do all kinds of work that their employer may require from them, on Sundays and holidays, such as rowing a boat or a ferry, doing domestic work, look after children and all kinds of work, that stipulation remains as it was. But still, every New Year the new freedmen who made a contract to work on a plantation, if they want, they may take three days off to celebrate New Year and one day to rest, but the person who hires them is not obliged to pay for those four days. Those who, on their own account, take more than four days off to celebrate New Year and to rest will be punished by the supervisor with a fine or imprisonment or forced labor for the Government, in chains even. The supervisor will push every punishment as far as the proclamation allows him to. This proclamation will be announced the same way as all others are usually done and it will be put in the book of proclamations.

Paramaribo, 22 December 1863

(It was signed) Van Lansberge

By order of the Governor

The Governor's secretary,

(It was signed) E. A. van Emden

Paramaribo, 23 December 1863

To make sure the new freedmen know very well what this proclamation says, the Governor had it translated into Sranan.
Paramaribo, 23 December 1863

The Governor's secretary,

(It was signed) E. A. van Emden

By order of the Governor I translated

this proclamation into Sranan

P.W. van Eijck

(Printed in J.C. Muller Az's printingshop)

110. The Colonial Council. 


\section{1f. The placard announcing the end of 'State supervision' (6/14/1873)}

When the State supervision period was nearing its end, the Colonial government felt it opportune to publish another placard telling the freedmen to 'stay humble' and to 'do what the Whites tell you to do'. The transcription is taken from Helstone and Vernooij (2000:57).

Plakkati

Granman foe Sranam Kondré. Na alla dem friman, disi de jéte na Lanti ondro. Di na ini da jari 1863 da katibo-fassi foe oen ben kaba en Konoe ben gi oen fri, A ben potti oen na Lanti ondro foe oen boen srefi. Wan pikien tem jéte, ja nanga da fosi dei foe da moen Juli foe disi jari, oen sa komopo na Lanti ondro en oen sa kisi so srefi réti leki alla tra borgroe foe disi kondré habi. Boen-hede foe oen nanga da sanni disi sa passa da dei datti! Ma' Mi wensi oen alla sa sori no wawan datti oen waarti so wan bigi boen, ma' datti oen sa doe oen plikti toe so leki a fiti ibri wan boen borgroe, na ini kondré, bikasi datti oen de tron nojaso. En oen kan sori oen de datti troe-troe, iffi oen tjari en tiri oen srefi na alla saka en respeki fassi; iffi oen doe san Weti potti; iffi oen sorgoe foe loekoe oen famili na alla boen fassi en foe lobi oen pikien en sori da lobi nanga datti, te oen meki dem teki leri, disi dem kan kisi na kerki en na skolo; iffi oen no gi oen srefi abra na lési; iffi jajo en lasra-libi, ma' holi wroko leki a fiti en leri en kweki oen pikien na ini wroko. Da moro bétre fassi disi oen kan passa oen tem, me de:iffi nanga wroko na tra soema ondro foe moni, so leki da wroko waarti; iffi foe holi dem ambakti disi oen ben leri; iffi foe wroko da pisi gron disi oen srefi habi, so leki a fiti. Foe oen boen srefi en foe boen foe oen pikien toe, nojaso en foe bakatem, mi de rai oen, iffi oen de joeroe oen srefi, meki wan kontraki foe wroko fasti na wan prési. No dénki taki da kontraki sa potti na ini katibo-fassi baka, kwéti-kwéti, ma' a de boen so srefi foe oen, leki foe da soema disi meki hem nanga oen, bikasi so wan fassi hem sabi datti a habi, wrokoman foe hem moni en oen sabi oen habi wan fasti wrokoprési,- ma' boiti datti, hoso foe libi, wan pisi gron foe prani oen njanjam, en, iffi oen siki, datra nanga dréssi foe soso, troe, alla datti de sani disi waarti foeloe. Sori toe nanga lobi foe wi Konoe en foe hem Kondré, dati oen sabi en oen hatti fili da bigi boen disi Konoe doe na oen.

Paramaribo, 14Juni 1873

(A ben teken\} Van Idsinga

So leki Granman skrifi da Plakkati na Dóisi, mi tjari hem abra na Ningré-tongo.

J.P. W. van Eijck

(source: Helstone \& Vernooij 2000:57)

\section{Placard}

The Governor of Suriname. To all freedmen who are under the government's jurisdiction. When in the year 1863 your enslavement was terminated and the king granted you freedom, he put you under the government's jurisdiction for your own good. Not long from now, yes on the first day of July of this year, you shall leave the government's jurisdiction and you shall acquire the same rights like every other citizen of 
this country. Congratulations to you on the event that will happen on that day! But I wish all of you will show not only that you deserve such a great good thing, but also that you will do your duty just like every good citizen in the country, because that is what you are now. And you can show you really are good citizens if you behave yourself in a humble and respectful manner, if you do what the Whites tell you to, if you take good care of your family and love your children and show your love by having them take lessons, go to church and attend school, if you do not indulge in laziness, or behave like vagabonds or hoodlums, but hold on to your work like you should and teach your children how to work. The best way for you to pass the time is either to work for someone for money, whatever your labour is worth, or to ply the trade they taught you, or to work the piece of land that you have, whatever is fitting. For your own good and for that of your children too, now and in the future, I advise you, if you hire yourself, to make a contract for a steady job in one place. Don't think the contract will put you back in enslavement, not at all, but it is good both for you and for the person who makes the contract with you, because that way he knows that he has workers for his money and you know you have a steady job, but apart from that, a house to live in, a piece of land to grow your food, and, if you are sick, a doctor and medicine for free, all things that are worth a lot. Also show with love for our king and for his country that you know and that your hearts feel what a good thing the king has done for you.

Paramaribo, 14 June 1873

(It was signed) Van Idsinga

Just like the Governor wrote the Proclamation in Dutch, I translated it into Sranan. J.P.W. van Eijck

\section{BLACKS TALKING BACK}

Although the voice of the blacks is hardly ever heard in connection with Emancipation, in spite of the enormous importance this event had for them, there are a few rare cases where, however briefly, we hear them speak. In both cases, ex-slaves remind their former master that the time of slavery is over.

No no masra, fonfon kaba noja (1863)

No, no, master, the time of beating is over now

A no mi wan friman leki joe? (shortly after 1863)

Am I not free just like you?

(source: Klinkers 1997: 106, 154)

\section{Ndyuka-Trio Pidgin: Crevaux (1883)}

When in the first half of the 18th century the Ndyuka began to settle in the south-eastern part of Suriname, they came into contact with Amerindian groups, especially the Trio, with whom they established trade relations. Out of the contact between Ndyuka (an English-lexicon creole) and Trio (a member of the Cariban language family) a new trade language emerged, called Ndyuka-Trio Pidgin. Although this pidgin may 
have been in use from before 1800 , the earliest substantial documentation dates from the early 20th century (De Goeje 1908:204-16; see no. 35 below). While many words (especially pronouns, adverbs, and verbs) are derived from Ndyuka, the grammatical structure is largely based on Trio. Apart from the fact that the basic word order is OV, there are also a number of Trio grammatical elements, such as the negative suffix -wa and the facsimile suffix - me; the preverbal element so is probably derived from the Trio desiderative marker -se (Carlin 2002:25). Since the pidgin is no longer known among younger people, it will probably not survive very long. The very earliest data are from Crevaux (1883), who reports what a Trio woman said to him when he was traveling in southern Suriname. (For more information on Ndyuka-Trio Pidgin, see Huttar \& Velantie 1997; this paper also gives some information on another creole-based pidgin, used between Boni Maroons and Wayana Indians.)

Panakiri ouani oua...A la pikininialele...Nono poti...Echimeu ouaca...Cassava mia oua

Whites not wanted... all children dead...(they have been) put in (this) hole... quickly leave...no cassava to eat

(source: Crevaux 1883:276, as quoted in Huttar \& Velantie 1997:120n7)

\section{A Sranan grammar in Sranan: Helstone (1903)}

J. N. Helstone (1853-1927), the author of the first (and, until now, only) grammar of Sranan written entirely in Sranan, was a black musician, director and composer and a native speaker of Sranan. He studied in Leipzig (Germany) for two years (1880-1881; 1893-1894), obtaining a doctoral degree in music in 1894. Ironically, the aim of his Sranan grammar was not to promote Sranan but to facilitate its replacement by Dutch (p. viii). In order to encourage the learning of Dutch by the local Creoles, the author thought it necessary to impose rules on Sranan bringing it in line with Dutch as much as possible. Because of the 'Netherlandicized' flavour of his Sranan, the book should only be consulted with much care.

The fragment reproduced below, however, is very different from the rest of the book. Here Helstone discusses different styles of speaking, making a plea for a more natural pronunciation of colloquial Sranan, especially when speaking to strangers. His observations regarding the differences in pronunciation between 'ordinary style' and 'elevated style' are among the very earliest of this phenomenon known to exist. What is also interesting is that to illustrate unnatural (i.e. spelling) pronunciation, Helstone refers to the Sranan as it was used in church. While others, such as Moravian missionary Heinrich Wullschlägel, felt that it was the blacks who used the wrong pronunciation (!), Helstone makes it very clear that it is the whites who do not know how to pronounce some words correctly (cf. Chapter 4 for a discussion of 'church Sranan'). 


\section{Da fasi vo taki}

Net so leki na hollandsch en foeloe tra tongo, da alladei fasi vo taki, en da taki b.v. vo wan rede - wan toespraak, wan preeki ofoe wan begi-habi wan bigi onderscheid, net so a dee na da tongo disi. Na dem moreo foeloe vreemdesoema a dee wan trobi sani vo verstaan ofoe vo volge wan taki boen, te toe sranamsoema de taki nanga makandra. Da foutoe disi no komopo na dem vremde soema, ma dem kondreman vo mi habi hem. Sodra wan sranamsoema de taki nanga wan vreemde soema, wantem a de bigin vo taki woord vo woord so duidelijk leki a kan, vo meki da vreemde soema kan versta hem boen, en da so da fasi vo taki nanga vreemde soema dee wan heeli trawan dan te toe sranamsoema de taki nanga makandra (dem na dem). Ma moro etee. Da moro takroe gewenti vo dem sranam soema dee, dati alwasi da nooiti dem sa helpi da soema, vo taki gi hem fa a moe taki da woord reti; ja, na pleesi vo dati, so hesi da sranamsoema jeeri da verkeerti fasi toe, nomo di somtem a de meene, dati efi hem taki da woord reti, dan da trawan no de go versta hem. Da takroe gewegti disi a geersi na mi leki a dee wan vo dem gewenti ofoe frede di da slavoetem ben habi. A kan dee toe dati na ini da onwetende fasi vo datem, dem soema ben de denki dati da vreemde soema moese sabi da taki moro boen leki dem sreefi. En so dem vreemde soema de tan allatem na ini da sreefi verdwale. Tee tidei joe kan sidom na kerki en alladi dem woortoe ibri leisi de taki nanga so verkeeryi accent, jete no wan lafoe, ja no na dem skoloboi sreefi joe de si wan lafoe na dem feesi. Alladi wan rede, begi ofoe preeki de haksi dati dem woortoe moe dee taki net so leki dem dee skrifi, da alladei fasi vo taki de haksi heli trafasi. Dia nofo letters en lettergrepen sreefi dee djompo. Dia wan toe voorbeeld dee:

De wijze van spreken

Gewone stijl

M'kal' en mia no kon.

$\mathrm{Na}$ tap'sei n'ina kedre.

F'a d'ang'is'sa.

M'taag'ien mia no kee.

A g'adoro mia nee go tan langa.

Fosfos'a ben ee kon dia.

W'im go loek'en.

Mem'ri mien'o jag'en.

D'a n'ee pik'i'idenk a no sabi?

\section{Deftige stijl}

Mi kali hem ma a no kom. ${ }^{111}$

Na tapo sei na ini da kedre.

$\mathrm{Fa}$ a dee nanga joe sisa.

Mi taki gi hem ma a no kee.

A go na doro ma no de go tan langa.

Fosifosi a ben de kom dia.

We joe moe go loekoe hem.

Membre joe ben de go jagi hem.

Di a no de piki joe, joe denki a no sabi?

Dem weinigi voorbeeld disi kan soori krin dati a moese trobi pikinso vo verstaan allasani, te dem soema vo da tongo de taki dem na dem, ma mi hopoe da boekoe disi sa tjaari nofo sani kom na krin, gi dem kondeman vo mi net so boen leki gi dem vreemde soema.

(source: Helstone 1903:110-112)

111. In the transcription I have omitted the Dutch equivalents of these sample sentences given by Helstone. 


\section{Ways of speaking}

Just like in Dutch and many other languages there is a big difference between everyday speech and the language used in oratory - a speech, a sermon, or a prayer -, it is the same in this language [i.e. Sranan, JA]. Most strangers have trouble understanding or following a conversation when two Surinamese are talking to one another. This error is not on the part of the strangers, it's the fault of my fellow countrymen. As soon as a Surinamese is talking to a stranger, immediately he will start to pronounce every word as clearly as he can in order for the stranger to be able to understand him well, and that is how the way of speaking to a stranger is completely different from the way two Surinamese talk to one another (tête-à-tête). But there is more. The worst habit of Surinamese people is that, even when a stranger pronounces a word incorrectly, they will never help that person, telling him how he should pronounce the word correctly; yes, instead of that, as soon as a Surinamese hears the incorrect word from the stranger, immediately he will pronounce that word incorrectly too, only because he may think that if he pronounces the word correctly the other will not understand him. To me this bad habit looks like one of those habits or fears which existed during slavery. It may also be that in the ignorance of those days the people thought that the stranger necessarily knew the language better than they did themselves. And this way, the stranger will always continue making the same errors. To this very day you can sit down in a church and even though every time the words are pronounced with a completely wrong accent, yet no one laughs, yes, you won't even see a smile on the faces of the schoolboys. Even if a speech, a sermon or a prayer requires the words to be pronounced just as they are written, everyday speech requires something completely different. Here many letters and syllables are deleted. Here are a few examples:

Speech styles: Ordinary style vs elevated style

I called him but he did not come.

On top in the basement.

How is your sister?

I told him but he does not care.

He went out but he will not be away for long.

He used to come by here in the past.

Well, you should look him up.

Remember you were going to chase him away?

Since he does not answer you, do you think he does not know?

These few examples may show clearly that it must be a little problematic to understand everything when native speakers are talking among each other, but I hope this book will shed light on a number of things, both for my fellow countrymen and for strangers. 


\section{Ndyuka-Trio Pidgin: De Goeje (1908)}

Twenty-five years after Crevaux (1883; see no. 33 above), De Goeje (1908) presented a 10-page wordlist of Ndyuka-Trio Pidgin plus a short discussion of its structure and a very short conversation he had with a Trio captain. 'We shook hands, and immediately he asked: mooimee kong? krasji-wa? 'do you come in peace? not to fight?', to which I replied: mooimee kong, matimee wanni 'we come in peace and want your friendship' [italics mine, JA] (De Goeje 1908: 117). He also included a more elaborate piece of text, which is reproduced below. It is, in De Goeje's words, 'the story as it was told to the Trio by the [Ndyuka] Maroons in order to put them at ease' (p. 214). The Ndyuka, who were part of De Goeje's expedition, tell the Trio not to worry about the white men 'making papers'. This refers to the activities of the technicians, such as a land surveyor and an engineer, who were part of De Goeje's expedition (cf. De Goeje 1908: 139). In order to preserve as much of the structure of the original as possible, I have remained close to De Goeje's original, pidgin-like Dutch translation in my translation into English.

\section{A Ndyuka-Trio pidgin text}

Panakiri so kong, pai, mooimee kong, krásji-wa, oli wanni-wa, pikinini wanni-wa; tíngenee passi so wakka, pampila meki; sabana so moenoe loekoe wanni, Sipaliwini wanni, hésimee pampila potti, tlonbaka; akabá, tlawan kong-wa, passi so atapoe. Panakiri tíngenee so kong, no no, móoimee wa, aalla Tlio pelele, hésimee boesi kibri, sonten allele, no no, takroemé pai! Mékolo akoloni kong, Tlio pelele-wa. Mékoloso grandwei Tlio akoloni broedoe miáng, panakiri, granwee matti-wa, tidéi jenoeloe loekoe. Panakiri mooimee, sósomee passi wakka, pampila meki. Tlio akoloni, Mékolo akoloni kassaba miáng, napěkèmiáng, asikaloe miáng. Kaikoesi wanni-wa.

(source: De Goeje 1908:214)

Whites come, friend, in nice way they come, not fight, women not want, children not want; only walk path, make papers; want see savanna so big, want Sipaliwini ${ }^{112}$ quickly put on paper, turn back; finished, others come not, path closed. Whites only come, no no, not nice, all Trio afraid, quickly hide in bush, perhaps die, no no, bad friend! Negroes come, Trio not afraid. Long ago Negroes and Trio drink blood, long ago whites not friends, now first see. Whites nice, only walk path, make papers. Eat cassave with Trio and with Negroes, eat napi, ${ }^{113}$ eat sweet potatoes, eat sugar cane. Dogs not want.

112. A river in southern Suriname.

113. A tuber species. 


\section{Saying 'Hello' in Ndyuka: De Goeje (1908)}

Apart from his observations on Ndyuka-Trio Pidgin, De Goeje (p. 58) also included a few remarks about Ndyuka, in particular about greeting ceremonies, which he says 'are performed with great care', something which is still the case among Surinamese Maroons today. He notes the following greetings:

Morning:

neti kabá 'the night has passed'

Or: dei bloko baka 'the day has broken again'

Daytime:

bala (sisa, da, ma) odió, how fa joe de ba? 'brother (sister, father, mother), hello, how are you?'

Upon meeting someone again:

wi mitibaka 'we met again'

\section{Koenders (1946)}

Julius G. A. 'Papa' Koenders (1886-1957), born in a lower-class black family, worked as a school-teacher until 1936; after his retirement he became the founder and editor of Foetoe-boi 'Errand boy', a weekly 'one-man' magazine written in Sranan (and Dutch). It appeared between 1946 and 1956 and it was aimed at promoting cultural awareness among Suriname's Creole population. Being Suriname's first true cultural nationalist, Koenders may be considered a predecessor of Wi Eygi Sani 'Our Own Things', an emancipatory movement of the 1950s that tried to promote Suriname's culture and languages among young Surinamese. A native speaker of Sranan, he was one of the first teachers to propagate its use in education at a time when many still considered it improper to use it at all. The text reproduced below is one of many in which he addresses the more general issue of the status of Sranan, urging its speakers to take pride in their native tongue. To me it seems precisely the right piece to end this section with.

\section{Wie tongo}

Datie a no san din de karie 'neger-engelsch' ofoe 'negre-tongo'. Neger-engelsch datie na da broko broko Engelsch, san wan nengre de takie: 'mie no no' na presie foe 'I don't know'. Nengre tongo na da tongo foe ala nengre en datie wie tongo no de toe, bieka die na Sranan kaba, din abra soeal nengre habie din eegie tongo. Wie tongo na Sranan 'nengre tongo', datie na da tongo foe na moro biegie hiepie Sranan nengre. Net so lekie na ienie ala tra tongo joe habie wörtoe, die din ben tekie foe trawan, so na wie tongo toe, ma broko broko foe wan tra tongo a no de; a habie in eegie fasie, a de mekie wörtoe na in eegie fasie. Wan piepel, die liebie ofoe lassie in tongo ofoe a frontoe in foe wan tra tongo hede, awansie sört'wan, na piepel datie don moro din afo fow wie; bieka din bin kotie na odo kaba takie: 'joe kan kibrie granmama, ma joe na kan tapoe koso koso'. Efie foe joe brede ofoe priesierie joe moe lerie wan freemde tongo, lerie in boen, ma a no foe datie 
hede joe moe feraktie joe eegie tongo en trowe in. Wan dee mie bin de takie nanga wan jonkoeman, die bin finie ala tra kondre (die noitie a bin sie) ala sanie moro boen lekie Sranan en na Sranan. Sranan tongo a takie na foe te na Branspin. We, datie na troe, ma fa a de nanga Hollandsch tongo, Japaneesie tongo nanga foeroe trawan moro? Na herie grontapoe de takie din? Trawan, die kisie piekienso lerie takie, 'er is geen literatuur in die taal'. We mekie mie mie aksie din söroe soema datie: Sörtoe piekien de opo waka wantin, fa a fadon na gron? Na literatuur foe Hollander, Doisrie en trawan, soema bin mekie in gie din? Na joe, na mie, ofioe na den srefie? Takie san die joe wanie, Soema sanie a no joe sanie, ${ }^{114}$ Soema pe a no joe pe, Sör' mie pe die f' joe de!

(source: Foetoe-boi 1 (1): 1-2) (1946)

Our language

That [i.e. Sranan, JA] is not what they call 'Negroes' English' or 'Negroes' language'. 'Negroes' English' is the broken English spoken by a Negro: 'me no no' instead of 'I don't know'. 'Negroes' language' is the language of all Negroes, and that is not what our language is either, because here in Suriname alone the Negroes in the interior have their own language. Our language is 'Surinamese Negroes' language, i.e. the language of the majority of the Surinamese Negroes. Just as in other languages you find words that were borrowed from other languages, so it is in our language too. But it is not a broken version of some other language; it has its own principles, it makes words in its own way. A people that abandons or loses its language or looks down on it for the sake of another language, whichever that is, that people is more stupid than our ancestors; because they made up the odo: yu kan kibri granmama, ma yu no kan tapu koso koso 'You can hide your grandmother but you can't keep her from coughing. When you must learn a foreign language, either for business or for pleasure, learn it well. But this is no reason for despising or rejecting your own language. One day I was talking to a young man, who felt that all other countries (which he had never seen) were better than Suriname and that everything was better than it is in Suriname. Sranan is only spoken as far as Braamspunt. ${ }^{115}$ Well, that's true, but how are things with regard to Dutch, Japanese, and many other languages? Are they spoken by the whole world? Others, who have had a little education, say: 'There is no literature in that language'. Well, let me ask those kind of people: What child gets up and walks right away, how does it fall to the ground? As to the literature of the Dutch, the Germans, and others: Who made it for them? Was it you, was it me, or was it themselves? Say whatever you want, The things of others are not your things, The places of others are not your places, Show me where yours are!

114. This line is reminiscent of the name of the Wi Eygi Sani movement, whose founders were very much inspired by Koenders' writings.

115. The most western point of the Commewijne district coast, symbolic for 'the end of Suriname'. 


\subsection{Religious texts}

Apart from the secular texts discussed in the previous section, a large number of early religious texts have been preserved, often in manuscript form. This is largely due to the work of the Moravian Brethren, who produced an enormous amount of religious writing in Saramaccan and, especially, Sranan. While their Sranan texts cover the entire period from the 1770s onwards, their Saramaccan work is limited to a fairly short period, roughly $1780-1810$. This has to do with the fact that the Moravian missionaries' activities among the Saramaka were severely reduced in the early 19th century. In these thirty years they produced, apart from descriptive works such as Schumann's Saramaccan dictionary, some 2,000 pages of texts - Bible translations, hymns and other religious works ( $c f$. Arends 1995 for further information). Unfortunately, however, until now only a few of these documents have been made available for linguistic research. The most important among these are Wietz's (partial) translation of the Acts of the Apostles, published by Schuchardt (1914), and a selection of the Saramaka Maroon Letters, published in Arends \& Perl (1995) (cf. nos 40 and 42 below).

As to the amount of Moravian missionaries' religious writings in Sranan, this is much and much larger. The total number of manuscript pages, preserved in the archives in Paramaribo, Herrnhut, and Utrecht, should be estimated at least several tens of thousands, if not well over a hundred thousand. If one knows that the total corpus of Suriname-related material (written in German, Dutch, Sranan, Saramaccan and other languages) stored in the Moravian archives in Herrnhut, Paramaribo, and Utrecht, amounts to at least 50 running meters of archival records, one will understand that it is not possible to make a more precise estimate of the total amount of material written in Sranan and Saramaccan. Although creolists have only recently begun to scratch the surface of this goldmine of early language material, a good impression of its contents can be had by consulting works such as Voorhoeve \& Donicie's (1963) invaluable Bibliographies du négro-anglais du Surinam, which despite its title includes both Sranan and Saramaccan texts. Other bibliographical surveys were published by Arends $(1992,1995)$ and Stein \& Perl (1995) (and much earlier by Wullschlägel 1856).

As mentioned earlier, the Moravian Brethren have a reputation as knowledgeable and acute observers of the Suriname creoles, although a normative and Europeanizing influence in their use of these languages cannot be denied. This tendency, however, is largely confined to orthography, phonetics and lexis, affecting syntax to a much lesser degree (Voorhoeve 1971). A similar tendency is present in the writings of those who were taught reading and writing by the Moravian missionaries, such as Johannes Alabi, Christian Grego, and Johannes King, whose writings are represented below. Apart from the Moravian Church, the Catholic 
mission has also left us some texts in Sranan, including a catechism from 1822 and a papal bull from 1878 ( $c f$. nos 43 and 46 below).

Before presenting the sample texts below, a few words will have to be said about a manuscript which, despite serious efforts, I have not been able to locate. If it exists, it is the earliest substantial text in Sranan (with the possible exception of Herlein's Sranan specimen, of course, depending on whether that may be considered 'substantial'). The author, Andreas Mauricius, was the son of Jan Jacob Mauricius, governor of Suriname from 1742 until 1751. Interestingly, his Sranan teacher was the 'celebrated Quassie van Nieuw Timotibo', a Surinameborn black ${ }^{116}$ who gained a reputation as a connoisseur of indigenous medicine and as a negotiator between the colonial government and the maroons (see Price 1983a: 155-159; Dragtenstein 2004). Shortly after his arrival in Suriname, Andreas' father had conceived the idea of having a number of christian texts translated into Sranan and distributed in Suriname in order for the slaves to be taught from them (Wolbers 1861: 198). Among these texts was a work known at the time as 'Borstius' queries. ${ }^{117}$ These translations had to be made in such a way as to be fit for teaching the essentials of christianity to the slaves 'in a simple and concise manner' and 'in accordance with their limited powers of understanding' (J. J. Mauricius, quoted in Wolbers 1861:198). In a document written around 1750, Mauricius père writes:

...shortly after my arrival [in 1742, JA] I made a proposal to the Court ${ }^{118}$ to make only a small beginning by translating Borstius' queries and other principles of the faith into Negro-English, which translation, made by my son, was already finished, but from the reply of the Court one can judge the general sentiments of the general public.

(Recueil 1752, vol. 4:4 $4^{119}$ )

Although Encyclopaedie (1914-1918:505) claims that the translation by Mauricius fils of this Catechism was published around 1750, Voorhoeve and Donicie (1963:57) strongly deny it ever was: 'Elle n'a sans doute pas été imprimée'. Even if the work was never published, that does not mean it may not exist in manuscript form. For the time being, however, we will have to do without it and contend ourselves with the texts collected here.

116. In contrast to what has been generally assumed until now, Quassie was not born in Africa but in Suriname, as is demonstrated on the basis of archival documents by Vrij (2005: 193).

117. This work, a version of the Heidelberg Catechism, was known in the Netherlands as De vraagjes van Borstius 'Borstius' queries'.

118. Either the Court of Police and Criminal Justice or the Court of Civil Justice, the two main governing bodies of the time.

119. Note that vol. 4 of Recueil contains two instances of 'p. 4'; the Mauricius quote can be found at the end of the book, where, for some reason, pagination starts anew. 


\title{
38. SKIPIO (1768): ASKING FOR HELP WITH A SORE FOOT
}

One of the earliest specimens of native writing was recorded in 1768 by a Moravian missionary, Brother Stoll, who noted in his diary that his Saramaka pupil, David Skipio, who had a sore on his foot, had written the following mini-prayer on his writing tablet:

Jesus meki mi foette kom boen

Jesus make my foot get well

(source: Price 1990:97)

As in other cases of early Saramaka writing, such as the Saramaka Maroon Letters (see no. 40 below), we cannot exclude the possibility that Skipio's Saramaccan was influenced by the Sranan of the missionaries who taught him how to write. In this case, however, it is impossible to establish with certainty since all the words used occur both in Saramaccan and in Sranan.

\section{Schumann (1779) And Anon. (1803): 'Oh Head so full of bruises' In SARAMACCAN AND SRANAN}

Sometime after he returned to Paramaribo from his 15-month stay in Saramaka, Schumann finished a manuscript containing Saramaccan translations of a number of texts used during service, including the Easter Litany and several religious hymns. Among the latter is the well-known 'Oh Head so full of bruises, ${ }^{120}$ the first and last stanza of which are reproduced below. (For biographical information on Schumann, see no. 16 above.)

\author{
O heddi ko brudu en Wonden \\ na liba Kruis ala, \\ o heddi, hufa dem tai ju \\ ko Krone va makka! \\ O heddi, bevo so hansem \\ na Tabor-kunnunu, \\ jusnu ju de va dedde: \\ wi takki ju grang hodi \\ Oh head with blood and wounds \\ On the cross there \\ Oh head, how they tied you \\ With a crown of thorns! \\ Oh head, so beautiful before
}

120. This hymn is typical of the religious outlook of the Moravian missionaries, which was very much focused on the physical aspects of the sufferings of Christ (Price 1990: 60). In fact, this particular hymn seems to have been a favorite of Count Zinzendorf, the founder of the Moravian community (Price 1990:294n7). Many readers will be familiar with it from Bach's Matthäus Passion ('O Haupt voll Blut und Wunden...'). 
On Tabor mountain,

Now you are about to die:

We salute you.

Mi takki ju grang tangi,

hatti lobbi Jesu,

va tule penna en hati

teh dedde bi killi ju.

Tru tru didè mi sabi,

ju no sa dissa mi:

wan bunne Massra mi habi,

a lobbi tumussi

I say thanks to you,

Dearly beloved Jesus,

For all your suffering and pain

Until death killed you.

This I truly know:

You will not leave me.

A good Lord I have,

He is loved very much.

(source: EBGH NB VII R 38 1(= Schumann 1779: 8, 10))

For the sake of comparison, I also include the Sranan version of the first stanza, dating from 1803.

O heddi nanga wonden

en brud na kruis janda;

O heddi hufa dem tai ju

nang krone va makka.

$\mathrm{Na}$ fossitem dem fredde

va lukku ju Glori;

Jusnu wi si joe dedde.

Wi takki joe grangodi.

(source: Price 1990:60)

40. Christian Grego and Johannes Alabi (1790-1791):

The Saramaka Maroon LetTers

Apart from Skipio's one-line prayer quoted above ( $c f$. no. 38) and Boston's short notes written in a mixture of Jamaican Creole and Ndyuka ( $c f$. no. 9 above; $c f$. also Chapter 4), the ten Saramaccan letters written by Christian Grego (c1755-1824) and Johannes Alabi (1743-1820) between 1790 and 1818 are the first true native texts written by Blacks in any Suriname creole. ${ }^{121}$ Alabi and Grego were the very first Saramaka

121. Apart from the Negerhollands 'Slave Letters', dating from the mid-18th century (Van Rossem \& Van der Voort 1996), they are probably among the earliest native texts in any creole. 
to be converted to Christianity ('Johannes' and 'Christian' are their christian names; Grego sometimes also uses the surname '(Van) Aliedja'). Their letters were part of the correspondence network that was established by the Moravian missionaries in order to foster communication between converts and missionaries as well as among converts themselves, who lived in different parts of the world. (In order to enable understanding between, say, converts in Saramaka and Greenland, Saramaccan letters were translated twice: from Saramaccan to German and from German to Inuktitut; for letters from Greenland, of course, the same procedure was followed in the opposite direction.)

Due to the Moravian missionaries' habit of recording in their diaria 'diaries' even the most minute details of their activities, quite a lot is known about these men as well as about the circumstances of their lives (see Price 1990). Alabi, Saramaka granman 'chief' from 1783 until his death in 1820, was the very first Saramaka convert. Grego, who was also among the first Saramaka to be baptized, lived in the missionaries' household (Lenders 1996:127) and he was one of the first pupils the Moravian missionaries taught how to read and write. Presumably, Alabi never mastered the skill very well and dictated his letters to Grego. This assumption is based on the fact that the handwriting of Alabi's and Grego's letters is very similar.

The story of the conversion of Alabi, Grego, and a few others to christianity and its impact on Saramaka society is magnificently told in Richard Price's Alabi's world (1990), from which most of the extralinguistic information below was taken. ${ }^{122}$ Alabi was baptized on January 6, 1771. He was the principal consultant for Schumann's (1778) Saramaccan dictionary and he was also helpful in teaching Saramaccan to other missionaries, such as Brother Riemer (Stähelin 1913-1919, vol. 3,1:217). He is said to have had an excellent memory, especially for the concepts and terminology of the Christian faith. Christian Grego was still a boy when he got into contact with the missionaries in 1768; he was baptized in 1775 (Wolbers 1861:794). Although, according to one of the missionaries, Grego did 'not show much talent for [reading and writing]' (Price 1990:95), he eventually mastered the skill rather well, as appears from these letters.

In fact, it was the acquisition of reading and writing skills by young Saramaka rather than a desire for religious instruction which was the primary motive for their parents to bring them into contact with the missionaries. Alabi and Grego were among the very few converts among the Saramaka who showed an authentic interest in the Christian faith and who remained christians throughout their lives. They even served as leriman 'teachers, missionaries' among their fellow Saramaka. In 1813, when the

122. Additional information was obtained from Wolbers (1861:791-799). The primary reference, however, which alsoprovided most of the information on the Moravian part of the story for Price, is Stähelin (1913-1919), a detailed three-volume account of the Moravians' missionary activities in Suriname and Berbice, based on the diaries, letters and other records written by the missionaries during their stay in these colonies. 
last Moravian missionary left Saramaka, the missionary task was left entirely to Alabi and his few fellow Saramaka converts.

With regard to Alabi and Grego's language situation a few things may be important to note. Alabi was a matu kreôl (lit. 'bush creole', i.e. a Saramaka who had been born in the bush, not on a plantation or in Africa). In fact, as can be inferred from Price (1990:3-9), he belonged to the third or fourth generation of native Saramaka. Although we have no such specific information about Grego, we may assume that he was also born in Saramaka and that, therefore, he was a native speaker of Saramaccan. ${ }^{123}$ Both men visited Paramaribo several times (Wolbers 1861:796), occasionally for prolonged periods of time: Alabi's visit to Paramaribo in 1768, for example, lasted as long as six months (Price 1990: 101). Inevitably, these stays involved speaking Sranan, since the explicit purpose of Alabi's stay was to trade and very few people in town knew Saramaccan. Apart from visiting Paramaribo, they also made several missionary journeys upstream the Suriname River in their function of leriman, trying - rather unsuccessfully - to convert their fellow Saramaka. One such journey is referred to in one of the letters below (see also Price 1990).

As a result of their contacts with the missionaries, their language may have undergone serious influence from Sranan (see below). This is so because in the early days of the Moravian mission in Saramaka (which began in 1765), religious teaching must have been almost entirely in Sranan, simply because the missionaries did not know Saramaccan well enough. (Stähelin 1913-1919, vol. 3, 1 contains numerous references to the problems many missionaries had in mastering the language.) This influence turned out to be a long-lasting one, as appears from the fact that even today christian Saramaka 'often speak a Srananized version of Saramaccan' (Price 1990:277).

As to the addressee of the letters included here, Brother Liebisch was a Moravian bishop who visited Paramaribo from November 1790 to May 1791; he never actually served there. Apparently, he never visited the Saramaka missionary post: no such visit is mentioned in the otherwise very detailed description of Liebisch's stay in Stähelin (1913-1919, vol. 3, 2: 152-170). It is very unlikely he knew either Saramaccan or Sranan, so the letters were probably translated into German for him.

To conclude, I will say a few words about the language used in these letters. Being sister languages, Sranan and Saramaccan have a great deal of vocabulary in common. While nowadays these shared lexical items often differ in their phonetic shapes, due to phonological changes of the last two centuries, this was not the case when these letters were written. This means that in order to determine to what extent the language used here is Saramaccan or Sranan or a mixture of both, one has to look at non-shared vocabulary only. If we do this, we find that one third of these words (types) are Sranan,

123. Grego was still a boy when he got into contact with the missionaries in 1768 (Price 1990: 95). This was only six years after the 1762 Peace Treaty, which had made it more difficult for runaways to join the Saramaka community. 
while two thirds are Saramaccan. ${ }^{124}$ This means that, lexically speaking, the language is not 'pure' Saramaccan, as we know it from other contemporary sources, such as Schumann's Saramaccan dictionary. In other words, we are dealing here with letters written in a Saramaccan which has borrowed heavily from Sranan.

Apart from forms that are used only in either the Saramaccan or the Sranan variant, there is also a number of words that are used in free variation. Some of the most frequent examples are the following pairs: bi/ben (tense marker), di/da (determiner), and da/gi ('give', dative marker) (the Saramaccan variant is mentioned first in all cases). In some cases, the members of these pairs are used interchangeably within one and the same letter. Surprisingly, in almost half of the cases, the items concerned are function words rather than content words. Although this is remarkable at first sight, since in language contact situations in general function words are much less likely candidates for borrowing than content words, it may be explained by the fact that the languages in question are closely related varieties of each other ( $c f$. cases of koineization).

Although the addressee of the letters included here did not know Sranan nor Saramaccan, a motivation for the use of Sranan words in the Saramaka Maroon Letters as a whole may have been a desire on the part of the authors to accommodate linguistically towards the group they perceived as their primary audience, the Moravian missionaries. Oral communication between missionaries and Saramaka probably took place in some form of mixed Sranan/Saramaccan, using mainly shared vocabulary. As mentioned earlier, many missionaries had great difficulty in learning Saramaccan (due to it being a tone language, perhaps?). But even if they did master the language, their knowledge was often only short-lived due to the extremely high mortality among them. It does not seem too far-fetched to assume that in such a situation some sort of compromise language developed which was accessible to both parties involved.

The selection of the letters reproduced below is based on the fact that as yet the other letters pose too many problems of transcription and interpretation to be included here. Although the first two letters - written on the same date, in the same hand, and directed to the same addressee - are treated as one in the Herrnhut Archive, they are better seen as two separate letters: it appears that the first letter, which ends with a greeting from Grego in the first person, was both conceived and written by Grego, while the second, which ends with a greeting from Alabi in the third person, may have been dictated to Grego by Alabi. Finally, the third letter seems to have been conceived and written by Grego.

124. The criterion used to determine whether a word belongs to shared vocabulary or not, is its occurrence in Schumann 1778, in Schumann 1783, or in both. Although, obviously, such a criterion is not watertight, it provides - in the absence of other criteria - a heuristic tool for the preliminary analysis presented here. 


\section{Grego to bishop Liebisch, December 5, 1790}

mi hangri va takki na Joe lobbi Brara va Joe sabbi, mi ha sanni va takki na Joe en Joe no sabbi da Moeffe va mi bieka Joe kan Jerri gweette gweet

Nuwe Bambey den 5 December 1790

Mi biegin va Schriffi wan Briffi na Fotto va dem lobbi Brara sabbi, va hoefa mi ben go na lieba, va loekke mi Tatta, ala mi bi findi dem Sombreh ala, dem hangri va Jerri di boene tori va Massra Jesus Christus; en Mi ben takki gi dem hoefa hem ben Dedde va dem heddi, so a boen va oene sabbi hoefa Helpiman ben kom na di Grond tappéva lobbi heddi hem ben kom na Contri, va loesse wi sombreh na Mouw Dubri, so a dé na ieniwan Sombreh dem ha va beggi na mi Lobbi Massr Jesus Christus na hem Ala somma kan findi boene liebi va teh go, mi zih hoefa dem somma bribi wan retti faassi, mi no sih wan korri faassi na dem, mi takki dem hoefa Massra Gado ben lehri mi na hatti, so mi no minga va takki, da dem, bieka di oto va Gado a dé va toelle Sombreh musse Jerri di oto, A no va kubri hem na baassoe manda, ma hoppo na lieba va ienewan Jessi kan Jreri, mi bribi na Gado nanga mi Helli hatti, en mi hangri va kissi ienetem morre lobbi va Massra di dé Jamjam va mi Schee mi tan bribi ienidaga va hem musse gi mi tranga va lobbi hem morre morre, mi beggi o Massra kom na mi poti hatti va limba hem va no wan Soengoe fieka na hem, va a musse kom retti limbo Hosse va Massra, en hem musse kom va liebi na Hosse, di dé mi hangri va kissi di de Mi De Christian Grego van Aliedija (source: EBGH R 15 Lb 32b)

I am anxious to speak with you, beloved brother, so you'll know the things I have to tell you. And you don't know my language because you can't understand it at all.

New Bambey, December 5, 1790

I start writing a letter so my beloved brothers in Paramaribo will know how I went upstream to visit my father. There I found all the people, anxious to hear the good story of our Lord Jesus Christ. And I told them how He died for their sake, and that it is good that you know how our Saviour came to the world and to Saramaka out of love, to release us people from the hands of the devil. And everybody should pray to my beloved Lord Jesus Christ. In Him everybody can find eternal life. I saw how these people believed in a true manner, I didn't see any deceit among them. I told them how our Lord God instructed my heart, so I couldn't help but tell them, because the story of God is for all people to hear. It should not be kept at the bottom of the basket, but lifted up so everyone's ears can hear it. I believe in God with all my heart and I am anxious to receive more love from the Lord all the time. It is food for my soul. Every day I believe He will give me strength to love Him more. I pray: Oh Lord, come to my poor heart to make it clean, so no uncleanness will be left in it. And it will become a truly clean house for my Lord and He will come and live in it. This I long for very much. I am Christian Grego van Aliedija. 
Alabi/Grego to bishop Liebisch, March 24, 1791

Nuwe Bambey den 24 Mart 1791

mi lobbi Grang Brara Liebisch va Bakkara Contri diessi mi bi sieh na Paramaribo, na Massra Liebiessi, na hem mi tan sindi di briffi gi hem va a sabbi hoefa wi liebi na Contri Nuwe Bambey, en wi tan kreh na Helpiman va a da wi Potti tranga na hatti va lobbi hem morre, so mi wenschi va jam da boen na Helpiman Jesus Christus; va da mi di Santa Jeje na mi, va tieri mi Potti soma va tan na iene da lobbi va Helpiman so mi hatti jam wan swutti Peh na di Dedde va Jesus; na hem mi findi liebi va teh go bieka na di Mondoe mi no sih wan boen va hem, va da heddi mi da mi na han va Helpiman, en mi ha wan sanni va takki na oene Grang Brara va Bakkara Contri, Grang Massra Gado ben sindi di lehriman na wi, en hem bi doe toeloe sanni so lekki Helpiman ben gi hem. A takki da wi na Kerki limbo limbo ote va Jesus Christus da wi so dem blakka brara toelloe lobbi di brara J. L. Wietz toemoeschi kaba a meekki sarri kissi wi toele va di hem tan hoppo va kom loekkoe oene, na Hatti wi ha Preh ma oye a meeki sarri, en dem brara va wi takki grang oudi gi oene, en mi beggi oene va oene membre wi na di beggi va oene toe na bakkara kondre, en di lobbi grang brara Johanus takki grang oudi oene

(source: EBGH R 15 Lb 32b)

New Bambey, March 24, 1791

My beloved great brother Liebisch from Europe, who I have seen in Paramaribo, to master Liebiessi, to him I send this letter so he knows how we live in the village of New Bambey, and how we are crying out to our Saviour to give us poor people strength in our hearts to love Him more. So much do I wish to experience the goodness from our Saviour Jesus Christ, that He give me the Holy Ghost in me, that He steer me, poor person, to stay in the love of the Saviour. Thus my heart shall enjoy a sweet place in the death of Jesus. In Him I found eternal life, because in the world I do not see any of His good things. Therefore I am in the hands of the Saviour. And I have something to tell you, great brothers in Europe. God, our Great Lord, sent us the missionary, and he did everything just like our Saviour gave it to him. He told us the story of Jesus Christ very clearly in our church. So all the black brothers loved brother J. L. Wietz very much, but he made us all sad, because he left to visit you. In our hearts we had joy, but our eyes he made sad. And our brothers say goodbye to you, and I beg you to remember us also in your prayers in Europe. And the beloved great brother Johanus [Alabi, JA] says goodbye to you.

Grego to bishop Liebisch, March 24, 1791

mi dé brara Christian di Potti wan en mi takki hoe biegie sanni Gado ben du na mi a dangra mi en mi no kan kissi hem ko Konni, ma Gado hem musse da mi di tranga morre, va wakka na Paazi, so langa mi liebi na da Potti moendoe, va mi beggi na Helpiman ko wan retti Hatti, hem sa da mi ondi mi beggi na hem Nem Jussnu a tam helpi mi, so mi beggi na Helpiman va a Loekoe di brara Wietz ko wyffie na di Grang Watra lieba, va no wan sanni sa doe dem, teh mi Jerri dem dorre boene a Swutti na wi toeloe, mi ko brara 
Wietz ben go morre na dem Contrieman va mi; na lieba, va takki gi da, tori va Helpiman We dem sombreh bi kom hiera va harka di boene ote va mi lobbi helpiman en di sanni bi kom swutti na mi va troe va da heddi mi sindi boeka na oene Grang brara va Bakkar Contri, hoefa mi bi findi dem Contriman va mi na lieba, dem hangri va tron liebi en mi hangri effi oene sa Pris va sindi da lehriman va wi Bakka gi wi dide sa boene toemoeschi. mi takki grangoudi na oene mi Lobbi Brara va Bakka Co. Mi De Christian Gr. Aliedja

(source: EBGH R 15 Lb 32b)

I am brother Christian, the poor one, and I say what big things God has given me. $\mathrm{He}$ was obscure to me and I could not grasp Him with my intellect, but God's word gave me the extra strength to walk the path, as long as I live in this poor world, and to beg the Saviour with an honest heart, that $\mathrm{He}$ shall give me what I ask for in His name. $\mathrm{He}$ has been helping me just now. I begged the Saviour to take care of brother Wietz and his wife on the Atlantic Ocean, so nothing would hurt them. When I heard they had arrived safely, it was sweet for all of us. Further, I and brother Wietz went to my fellow Saramaccans upstream to tell the story of the Saviour. Well, the people came in great numbers to hear the good story of my beloved Saviour. And it was truly sweet to me. Therefore I sent you a message, great brothers in Europe, to tell you in what situation I found my fellow Saramaccans upstream. ${ }^{125}$ They are anxious to convert and I am anxious to know whether you will be so kind as to send our missionary back to us. This would be very good. I say goodbye to you, my beloved brothers in Europe. I am Christian Grego Aliedja.

\section{The Lord's Prayer in Saramaccan and Sranan $(1779,1801,1829,1884)$}

A text one would certainly expect to have been translated into the Suriname creoles by the Moravian missionaries is The Lord's Prayer. In fact, several versions exist both of the Sranan and of the Saramaccan translation. As to the latter, I found two translations dating from the late 18th century, one in Schumann's Verse in die SaramackaNeger-Sprache (1779), the other in Riemer's (1801) account of his 10-month visit to Suriname in $1779-1780 .{ }^{126}$ It is not entirely clear to what extent Riemer's version is of his own making rather than being based on an existing translation, e.g. Schumann's, to which it is largely identical, at least structurally ( $c f$. the remarks made above in connection with the anonymous (c1780) Saramaccan dictionary; see no. 18). The oldest Sranan translation I found is the text as it appears in the 1829 translation of the New Testament (partly republished in Anon. 1966). I have also included a later Moravian translation which I found in Bonaparte (1884).

125. This probably refers to the letter above.

126. Riemer's version was also included in Adelung \& Vater's Mithridates (1807-1817), a collection of versions of The Lord's Prayer (plus some other language data) in several hundreds of languages. 


\section{1a. LAte-18Th-CENTURy SARAmacCAN Version I: SCHUmAnn (1779)}

Massra Gado, Tatta va wi na liba, ju santa nemm komm santa na wi tu; kontri va ju komm na wi; kumma dem du wandi vo ju na liba, so srepi a musse kai na mundu tu; da wi jamjam inidagga; iniwan missi, wi missi, takki na hatti vo wi dasnotti, kumma wi du na sombre dem missi na wi; no tesi wi va kai na wan pikkado, ma lussu wi va tule ougri! Bika tule kontri de na ju, tranga ko grandi nemm, nanga tule hansem va ju no go kaba. Amen!

(source: EBGH NB VII R 38 1 (= Schumann 1779:1))

\section{1b. Late-18Th-Century Saramaccan version II: Riemer (1801)}

Masra Gado Tatta va wi na Liba, ju santa nem kom santa na wi tu. Kondre va ju kom na wi, kumma dem du wanni va ju na Liba, so srefi a mussu koi na mundu tu, da wi jamjam iniwan Dagga, iniwan missi wi missi, takki na hatti va wi dasnotti, kumma wi da dasnotti na sombre dissi missi na wi, notjarri wi na dindru tesi, ma lussi wi va tulu ougri. Bika tulu Kondre de na ju, Tranga, ko grang nem ko tulu hansem va ju no go kaba. Amen.

(source: Riemer 1801:249-50)

\section{1c. EArly 19Th-Century Sranan version: Anon. (1829)}

Wi Tata na hemel, joe nem moe de santa! Joe kondre moe kom! Joe wani moe go doro na grontapo leki na hemel! Gi wi tidei da njanjam vo wi! Gi wi pardon vo dem zondoe vo wi, so leki wi toe de gi pardon na dem soema, disi doe wi ogri! No meki wi kom na ini tesi! Ma poeloe wi na da ogriwan!

(source: Anon. 1966:70,72)

\section{1d. Late 19th-Century Sranan Version: Bonaparte (1884)}

Wi Tata, die de na hemel. Joe neem moe dee santa! Joe kondré moe kom. Joe wanni wi moe doe na grontapoe, so leki dem doe na hemel. Gi wi tidei da njamjam va wie. Gi wi pardon vo dem ogri di wi doe, so leki wi toe de gi pardon na dem soema disi doe wi ogri! No meki wi kom na ini tesi, Ma poelse wi na da ogriwan; Bikassi alla kondré da vo Joe, alla tranga nanga glorie, da vo Joe tego. Amen.

(source: Bonaparte 1884: 193)

Our Father, who art in heaven, hallowed be thy name. Thy kingdom come. Thy will be done, on earth as it is in heaven. Give us this day our daily bread. And forgive us our trespasses, as we forgive those who trespass against us. And lead us not into temptation, but deliver us from evil. For thine is the kingdom, and the power, and the glory, for ever and ever. Amen.

\section{The Acts of the Apostles in Saramaccan and Sranan (1805 [1793], 1829)}

As mentioned earlier, most of the Moravian missionaries' translation activities were directed at the Bible. Among the first Biblical texts to be translated, both in Saramaccan and Sranan, were the Acts of the Apostles. The Saramaccan translation (covering only the first half of the text) was made by Brother I. L. Wietz, who worked 
in Saramaka for many years from 1779 onwards. Although Wietz himself said that in the beginning he had problems learning Saramaccan, his Saramaka pupil, Christian Grego, later wrote that he spoke it well. As a translator he was very prolific: apart from Acts, an extract of which is reproduced below, he also made an integral translation of a 600-page work entitled Idea Fidei Fratrum lit. 'Summary of the Faith of the Brethren', the religious doctrine of the Moravian Church. In addition to that, he is probably also responsible for some anonymous translations ( $c f$. Voorhoeve \& Donicie 1963: 106-9).

The copy of Acts, dating from 1805, which was used for this book is based on Wietz's original translation made in 1793, which is probably lost (Voorhoeve \& Donicie 1963: 108). The edition published by Schuchardt (1914) is based on another copy which was made for him especially for that purpose (Schuchardt 1914: 44); this edition does not include verses 13:34-52 and 14:1-28, which are part of a different manuscript (Voorhoeve \& Donicie 1963: 108). In contrast to Schuchardt's (1914) edition, the fragment presented here is based on the original 1805 manuscript; as a result, my transcription differs from Schuchardt's here and there.

The Sranan translation of Acts used here is part of the first printed integral Sranan translation of the New Testament, which was published in 1829. Parts of it were republished in Anon. (1966), which is the source used for the fragment reproduced below. In a sense, the 1829 translation represents a culmination point in a tradition of New Testament translations begun around 1770 (Voorhoeve \& Donicie 1963:49). Being a collective work, it cannot be attributed to a specific (group of) author(s). Therefore, no biographical information is provided here.

\section{2a. ACts 1: 1-10 in Saramaccan: Wietz (1805[1793])}

Di fossu takki da mi bi takki, mi lobbi Theophili va tulu di sondi dissi Jesus bi begin va du, en va leri, teh na di dagga teh a hoppo subi go na liba, so srefi a bi da bukka na dem apostel dissi a bi kuje nanga Santa Jeje. Kaba teh a bi jam di penna en dedde, kaba dem bi si hem na so menni faasi a bi tan votentin dagga na dem mindrie, a takki oto nanga dem va Gado Kondre. Kaba teh a bi sunta dem, a takki da dem, dem no mussu komotto na Jerusalem; ma dem mussu lukku di pramüssi va Tatta so leki unu bi jeri va mi. Kaba a takki; Johannes bi da doop ko watra; ma unu sa kissi doop ko Santa Jeje, no langa va tideh. Dem sombre dissi kom sunta, dem haksi hem, dem takki: Massra ju sa hoppo kondre va Israel djusnu? Kaba Jesus pikki a takki da dem, a no füti unu va sabi di tem effi üre, bika mi Tatta bi kibré dide vo hem srefi. Ma unu sa kissi di tranga va Santa Jeje, hem sa kom na unu liba, kaba unu sa kom takkiman va mi na Jerusalem, na Judea, en na Samaria, teh na baka va mundu. Teh a takki dide kaba; A hoppo na dem feesi, kaba wan ahu va liba teki hem, pulu hem na dem ojo. Kaba teh dem lukku so na hem bakka, lukku, dem si tu omi va liba tan na dem sei, dem bisi weti klossi. 


\section{2b. ACts 1:1-10 in Sranan: Anon. (1829)}

Da fosi tori mi ben skrivi kaba, mi lobbi Teofilus, vo ala demsani, disi Jezus ben begin vo doe en vo leri, Tee na da dei, disi a ben hopo go na hemel, na baka di a ben gi dem Apostel ordre nanga santa Jeje, dem, disi a ben verkizi, En disi a ben sori hem srefi toe gi dem liebi liebi na baka da pina vo hem, a gi dem foeloe krin marki; fotentien dei a ben meki dem si hem na dem mindri, en a taki nanga dem vo Gadokondre. En di a ben de nanga dem makandra, a taki gi dem taki, dem no moese komoto na Jerusalem, ma dem moese tan wakti da pramisi vo Tata, disi oen ben jeri na mi - so hem taki-Bikasi Johannes ben doopoe nanga watra, ma oenoe sa kisi doopoe nanga santa Jeje, en dati no sa tan langa. Ma dem, disi ben kom makandra dapee, haksi hem taki: Masra! Joe sa hopo da koningkondre vo Israel baka noja? Hem taki gi dem taki: Oenoe no ha vo sabi da tem ofoe da joeroe; dati mi Tata wani, a moe tan vo hem tranga wawan. Ma oenoe sa kisi da kragti vo santa Jeje, disi sa kom na oen tapo; oen sa de mi getuige na Jerusalem, na heeli Judea nanga Samaria en tee na dem moro farawei kondre na grontapo. Di a taki dati, nomo a hopo na dem fesi, en wan wolkoe teki poeloe hem na dem hai. We, di dem tanapoe so, loekoe na hemel, fa a hopo gowei, loekoe! Toe mansoema nanga weti klosi kom tanapoe na dem sei.

(source: Anon. 1829, reprinted in Anon. 1966)

The first story I wrote, my beloved Theophilus, about all the things that Jesus began to do and to teach, until the day he went up to heaven, after he had given directions through the Holy Spirit to the Apostles he had chosen. To them he also showed himself alive after his sufferings of which he gave them many clear proofs. He appeared to them during forty days and he spoke with them about the kingdom of God. And when he was together with them, he told them they should not leave Jerusalem but they should wait for the promise of the Father, which you heard from me - so he said. Because John baptized with water, but you shall be baptized with the Holy Spirit, and it will not be long from now. But they, when they had gathered there, asked him, saying: Lord! Are you going to restore the kingdom of Israel now? He told them, saying: It is not up to you to know the time or the hour; my Father keeps those things to himself. But you shall receive the power from the Holy Spirit, which will come upon you; you shall be my witness in Jerusalem and in all of Judea and Samaria and to the most faraway countries on earth. When he said that, right then he went up before their faces, and a cloud took him out of their eyes. And while they were standing there, looking at the sky, how he went up, behold! two men in white clothes were standing by them.

\section{The Apostles' Creed in Sranan: A Catholic and a Moravian TRANSLATION $(1822$, c1830)}

Although the great majority of the translations of religious texts into Sranan were made by Moravian missionaries, the Catholic Church also took its share. While the Moravian missionaries were active among Suriname's black population from 1765 onwards, the Catholic mission - ignoring a false start in the late 17th century - did 
not get involved in missionary work until the early 19th century. The text reproduced below, for which both a Catholic and a Moravian translation are available, is known as 'The Apostles' Creed'. The former is taken from a printed catechism published in 1822 , the latter from an anonymous manuscript catechism dating from around 1830. Apart from differences in spelling and vocabulary, the two versions differ in other respects as well, for example in their use of the aspect particle de: while it is present with sidden 'sit' and absent with bribi 'believe' in the Catholic translation, it is precisely the reverse in the Moravian version.

\section{3a. The Catholic version (1822)}

Mi bribi na Gado, Tattà almagtig, disi ben meki va noti Hemeli nanga Gron. E na Jesus Christus, da wawan pikien va hem Masra va wi. Disi da njoe wenke Maria ben kissi va Santa Jeje, è ben meki hem. A ben pinà ondro Pontius Pilatus, den ben spikri hem na kruisi: a ben dede, è den ben beri hem. A ben go na hel na ondro gron: a ben oppo na dede na ini drie dey. A ben go na tappo na Hemel: a dee sidden na reti han va Gado hem Tattà almagtig. Na dapree a sa komotto foe doe reti na den libiwan è den dedewan. Mi bribi na Santa Jeje.

Da Santa Catholyke Kerki: na makandra kompee va den Santawan. Da pardon va zonde. Da oppo va skien.

E da libi va teego. Amen.

(source: Wennekers 1822:6)

\section{3b. The Moravian version (c1830)}

Mi de briebi na Gado Tatta, dissi ben meki Hemel en Grontappo nanga da Gadotranga va hem. Mi de briebi na Jesus Christus da wan, Pikien va Gado, Massra va wi. Hem ben kom somma nanga worko va Santa Jeje, da njoe Wendje Maria ben geboore hem. Hem ben pinna na Kroettoe va Pontius Pilatus, dem ben hengi hem na Kruis, a ben dedde, dem ben beri hem. Hem ben sakka go na ondro, na hell; drie deh na bakka a ben hoppo na dedde. Hem ben hoppo go na inni Hemel, siddom na reti han va Gado Tatta, dissi habi alla tranga. Hem sa kom bakka vo Hemel, va holi da Grangkroettoe va dem Liebiwan nanga dem Deddewan. Mi de briebi na Santa Jeje. Wan santa Christenkerki, da Gemeenschap va dem Santawan. Da pardon en dasnotti va pikado. Da hoppo va dedde. Da Liebi va tehgo.

(source: EBGU H. III A 7(2), pp. 10-12)

I believe in God, the Father almighty, creator of heaven and earth. I believe in Jesus Christ, God's only Son, our Lord. He was conceived by the Holy Spirit, born of the Virgin Mary. He suffered under Pontius Pilate, was crucified, died, and was buried. He descended to the dead; on the third day he rose again. He ascended into heaven, he is seated at the right hand of the Father.

He will come again to judge the living and the dead. I believe in the Holy Spirit. The holy catholic/christian church, the communion of saints. The forgiveness of sins. The resurrection of the body. The life everlasting. Amen. 


\section{Jonas Adam: A Sranan letter Written by a Slave (1835)}

Apart from the Saramaccan letters, some of which were discussed above (see no. 40), there is a much larger collection of letters in Sranan, many of which were written by slaves (cf. e.g. Voorhoeve \& Donicie 1963:4). Like many of these letters, the one reproduced below is part of the Moravians' correspondence network meant to enhance communication between converts and missionaries all over the world (cf. no. 40 above).

Paramaribo den 23 Augustus 1835

na mi boenne leerman Wetting mi Jonas Adam dissi joe sreffi ben tjari na inni da bigie lobi vo Massra Jesus christus senni takki joe bigie odie, mi de hoop alla deh vo genade en frie vo wie boenne tatta en Massra Jesus christus moesse de nanga joe mie boenne leerman en mie de senni grang odi na dem twalf grang somma, dissi wi boenne Massra ben potti da boene filie na dem member vo den ben seni gi wi potti blendi nenger da switi torie vo wi boenne Massra Jesus christus en mi senni bigie odie na da heel gemeente, noffe trom mi de jerie hoefa dem senni odi gie wi, en hoefa dem de doe da switti wani vo wi boenne Massra, kaba datti de gi na mi wan retie filie vo mi moe kom loekoe dem ma dissi da bigi zout water platti wi na midrie vo da hedde a no de mogelijk vo mi kan kom na dem, maar mi de hoop alla deh vo wi alla sa romboto da glorie stuloe vo wi boenne helpiman Jesus christus na baka vo dissi liebie. En mi senni taki joe grang tangi vo den boek dissi joe ben senni gi na wi sens da tem dem boek ben kom na da sreffi tem mi ben kissi da amt vo dienaar, dem lidmaat vo joe noffe de jette na libi en noffe go slibi kaba, en da bigi deh vo Massra dissi joe ben si Engel kaba joe ben kali da heel gemeent vo wi ben kan kom toe vo geniete da Santa Avondmaal, mi no vergiti jette bikassi mi ben sikkisi hem na mi hatti. En mi de wensche alla deh vo da heel gemeent sa holi da reti saka fassi na onder kruis vo wi boenne Massra Jesus christus, en vo wi sa harkie na dem leerman, en vo wi sa hoppo da grang neem vo wi Massra Jesus christus dissi de da winniman, Hallelujah Amen. Jonas Adam.

(source: EBGH R15 Lb 32 b 15)

Paramaribo, August 23, 1835

To my good teacher Wetting, I, Jonas Adam, whom you yourself brought to the great love of our Lord Jesus Christ, sends you his greetings. Every day I hope that the grace and peace of our good Father and Lord Jesus Christ may be with you, my good teacher. And I send my greetings to the twelve great men in whose minds our good Lord put the good feeling in order to send us poor blind negroes the sweet story of our good Lord Jesus Christ. And I send my greetings to the whole community. I often hear how they have sent us their greetings and how they do the sweet will of our good Lord, and that gives me the right feeling that I should visit them but the big ocean separates us. That's why it's impossible for me to come to them, but I hope every day that we shall be around the glorious throne of our good Saviour Jesus Christ after this life. And I send you my thanks for the books you sent us. When the books arrived, since that time I have held the office of servant. Of the members of your church many are still alive 
and many have passed away. And the big day of our Lord, when you saw an angel and you called the whole community to have Holy Supper, I didn't forget it because I have sealed it in my heart. And I wish every day that the whole congregation will keep its humble ways below the cross of our good Lord Jesus Christ and that we shall listen to the teachers and that we shall raise the big name of our Lord Jesus Christ, who is the victor. Hallelujah Amen. Jonas Adam

\section{5. 'Little White MAN TALKING SWEet': W. BoekHOUdT'S SERMON} IN SRANAN (1846)

W. Boekhoudt was a minister for the Reformed Church, who stayed in Suriname from 1845 until 1849 (Van Kempen 2003:378). A quarter century after his return to the Netherlands he published his memories of the time he had spent in Suriname (Boekhoudt 1874). During his residence there he gave several sermons in Sranan, one of which (delivered in 1846) is included in its entirety in his book (pp. 145-56); the first paragraphs of it are reproduced below. Boekhoudt's Sranan sermons were well received, as appears from the praise of a black woman, who expressed her approval as follows: fa da pikien bakkra takki switi! 'How sweet the little white man speaks!' (p. 37). Nevertheless, the language used in the sermon clearly bears a bakratongo stamp. (Perhaps that was precisely what the woman appreciated in it!) The somewhat stilted style may also be a result of the fact that Boekhoudt had not had much exposure to everyday spoken Sranan when he gave this sermon: he had arrived in Suriname only the year before. Boekhoudt's example of preaching in Sranan was followed a few years later by another minister of the Reformed Church (Wolbers 1861:772).

Soleki wi no kan sabi wan soema boen-boen sondro sabi 'fa a ben libi en san a ben doe, so wi no kan sabi reti-reti wi lobi Masra Jesus Kristus té wi no sabi san a ben taki en doe disi a libi na grontapoe. Den fo Evangelist nanga wantoedri foe dem Apostel ben taki wi foeloe foe alla den woortoe, disi Hem ben taki en foe dem foeloe wroko, disi Hem ben doe, alwassi den no ben skrifi na ini Gadoboekoe alla wroko, disi Hem ben doe, bikassi - soleki da Apopstel Johannes taki - iffoe den ben skrifi alla sanni di Jesus ben doe, da heeli grontapoe no ben sa kan kibri wan so bigi boekoe. Ma alwassi wi no sabi dan alla sanni di wi Masra Jesus Kristus ben wroko, disi a wakka na mindri den soema, tokkoe wi sabi nofo foe si na ini Hem wan soema, disi Masra Gado srefi ben senni, wan bigi profeet, da Pikien foe Masra Gado. Datti wi dé si krien, iffoe wi lezi 'fa Hem ben wakka go na kroeboi foe Hem libi na Jerusalem, da bigi foto foe da kondre Judea, foe njam na Djoefassi Paaska. Na datti wi wanni memre na ini disi joeroe. Gado srefi bresi wi! Hem jerepi mi na da wroko en opo oen hatti foe oen teki Gado woortoe! Den woortoe foe disioen sa jeri mi taki, oen kan finni na ini da Evangelium foe Johannes, kapittel tiennatoe, verstiennatoe té tiennanegi, offoe da Evangelium foe Lukas, kapittel tiennanegi, versi toetentien nanegi té fotentiennafo. 
Just as we cannot know somebody really well without knowing how he lived and what he did, we cannot truly love our Lord Jesus Christ as long as we don't know what he said and did while he lived on earth. The four Evangelists and several Apostles have told us a lot about all the words he said and about the many deeds he did, even though they didn't write up all the deeds he did in the Bible, because - as the Apostle John says - if they would write up all the things Jesus did, the whole world would not be able to contain such a large book. But although we don't know all the things our Lord Jesus Christ did while he walked among the people, still we know enough to see in Him a person who was sent by our Lord God himself, a great prophet, the child of the Lord God. That we see clearly when we read how He went up to the end of His life in Jerusalem, the capital of Judea, to celebrate Jewish Passover. It is that we wish to remember at this moment. God himself blessed us! He helped me in my work and he lifted up your hearts so that you would accept God's word! You can find the words about which you will hear me speak in the Gospel according to John, chapter twelve, verses twelve until nineteen, or in the Gospel according to Luke, chapter nineteen, verses twenty-nine until forty-four.

\section{A papal bull in Sranan (1878)}

One of the most curious texts in Sranan is the translation of a papal bull known as the Bulla "Ineffabilis". This bull, in which the doctrine of the 'immaculate conception' ${ }^{27}$ is formulated, was issued by Pope Pius IX in $1854 .{ }^{128}$ In 1878, a translation was published in no less than fifteen dialects of Dutch and in Frisian, supplemented with translations into four languages spoken in the colonial empire: Malay, Javanese, 'Negro-Spanish' (i.e. Papiamentu), and Sranan (Berns 1997:3-4). The Sranan translation was made by Monsignor S. Meurkens, with the assistance of Father J. P. A. van Mens (Berns 1997:4). I have no biographical information about these men, except that Meurkens had done several translations before, including a catechism (Voorhoeve \& Donicie 1963:59, 74).

Foe datti hede, di wi teki hem Pikien presenteri wi srefi begi nanga den begi foe Kerki makandra gi Gado da Tata kaba na sakkafasi nanga vasti, foe A sa teki da tranga foe santa Jeje prisi tiri wi gi wi krakti - di wi begi alla Gado kondresoema kaba, meki den assisteri wi, di wi senni wi soktoe gi santa Jeje, disi de foe helpi, begi helpi kaba, - di Hem poti datti so na wi hatti kaba; wi poti sani na krien, taki leti opo, poti fasti foe gi da santa Driwanfasi grani, foe gi mooifasi nanga krienfasi na da santa krienjoenwenke, da Mama foe Gado, foe opo da Katoliki bribi meki da christen bribi kom moro foeloe,

127. Contrary to what many people seem to think, the doctrine of the immaculate conception states that the virgin Mary conceived without bearing the burden of the original sin, not that the conception of Christ took place in some 'immaculate' fashion.

128. I am grateful to Hein Eersel for making this text available to me. 
bicasi wi Masra Jesus Christus ben taki so, den Apostel Petrus nanga Paulus nanga wisrefi leri so, taki da tori de troe, disi leri, taki na Gado srefi ben meki wi sabi datti, na so alla bribi-soema doro den moesoe bribi tranga toe, taki da santa krienjoenwenke Maria ben de wantem sondro flakka foe da sondoe foe wi fossi tata Adam da srefi joeroe di a kom na hem mamaskien, - da Almakti Gado nanga bigi genade nanga bigi boen foe hem wawan ben meki datti kom so foe da verdini foe Jesus Christus da helpiman foe alla soema hede. - Datti hede, di soema de somtem, kaba Gado moe kibri den foe datti, disi habi hati foe bribi trafasi na ini den hati, leki fa wi ben poti datti, den moesoe sabi, den moe memre doro, taki nanga da prakseri foe den srefi den poti densrefi na kroektoe pasi meki da sipi foe da bribi foe den go broko, poeloe densrefi na ini kerki; so toe nanga densrefi foutoe den meki da strafoe, disi de foe datti, fadon wantem na den tapoe, sosrefi den soema, disi memre so na ini den hati, taki so nanga moffo efi srifi so efi meki wan marki foe sori datti na wanfasi na dorosei.

For that reason, after having presented our own prayers as well the prayers of the Church to God the Father, through His Son, in humiliation and fasting, so that $\mathrm{He}$ would guide and strengthen us through the power of the Holy Ghost, having asked everybody in God's Kingdom to help us and having sent our sighs to the Holy Ghost, who is there to help, asking for his help and He having thus put it in our hearts: we declare and pronounce and establish, to give honor to the Holy Trinity, to give lustre and splendour to the Holy Virgin, the Mother of God, to uplift the Catholic faith so that the Christian faith will be expanded, because our Lord Jesus Christ said so, because the Apostles Peter and Paul and we ourselves taught so, that the doctrine is true which says that God Himself has made it known to us, and all faithful people must believe this firmly, that the Holy Virgin Mary was without the stains of the sin of our first father Adam from the very moment she was born - the Almighty God has done this, in a great grace and a great privilege of Him alone, for the merit of Jesus Christ, the Saviour of all people - Therefore, if there are people who, but may God prevent them from it, dare to believe in their hearts otherwise than we have determined, they should know and they should remember from now on that with their own judgment they have put themselves on the wrong path so that the ship of their faith is wrecked and that they have placed themselves outside the church. Similarly, with these same errors they make the punishment which is appropriate for this fall upon them immediately, as well as those who think this way in their hearts and say it with their mouth or write it or make it known in any outward way. ${ }^{129}$

129. Due to the idiosyncracies in the language used in this text, I based my translation both on the Sranan text and on the Dutch translation of the Latin original presented in Berns (1997: 16). 


\section{7. 'The Writing in the Sky': Visions from Johannes King's Skrekibuku (1882-1888)}

Johannes King, occasionally referred to as the 'bushland prophet', was a Matawai Maroon and may be regarded as the first true native author in Sranan. ${ }^{130}$ With a Ndyuka father and a Matawai mother - herself the daughter of a granman - , King (c1830-1899) was a Matawai according to the Maroon system of matrilineal descent. However, due to suspicions related to wisi 'witchcraft' his mother was not accepted by the Matawai community and she and her family led a roving life in the region between the Para and the lower Saramacca Rivers. This area was inhabited by Whites and their slaves as well as Saramaka and Ndyuka maroons, all of whom worked the many timber estates in that region. During this period, King may have learned to speak Sranan in addition to his native Matawai as well as, perhaps, some Saramaccan and/or Ndyuka. In 1852 the family found a more permanent residence in Maripaston, a small village along the lower Saramacca river (about 20 miles southwest of Paramaribo). Later on in his life, King made several missionary journeys to maroon communities in different parts of Suriname.

In late 1857, King reported himself in Paramaribo with Brother Van Calker, head of the Moravian Community in Surinam. He told Van Calker that having recovered from a serious illness he had been seeing visions urging him to adopt and propagate christianity. When he left Paramaribo, he was given a copy of an $A B C$-boekoe, a reading method-cum-catechism developed by the Moravian missionaries and used in their educational activities among the Blacks. Upon his return to Paramaribo in 1860, he had not only taught himself to read but he had also begun missionary work among his fellow Maroons, even though he was not baptized until a year later. Within a few years he must have lear-ned to write as well, since his earliest writings date from 1864 . This marked the beginning of a continuous flow of texts written between 1864 and 1895, covering a total of some 1,000 manuscript pages, all written in Sranan. This figure does not include the Dresiboekoe 'Book of medicine', a text that contains information on how to counteract the effects of wisi. Due to its secret character, King's descendants are reluctant to have outsiders see this item (but $c f$. Zamuel 1994, where some portions of it have been published).

Apart from the Dresiboekoe, King's work, still largely unpublished, includes diaries, confessions, travel accounts, and an exposition of indigenous Maroon religion for the Moravian missionaries. Some of his work has been made available in printed form (De Ziel 1973; De Beet 1981, 1995; Zamuel 1994). Among these is the Skrekibuku 'Book of terrors', from which the excerpt below was taken. We should not be surprised that King wrote in Sranan rather than in his native Matawai. He had learned how to read and write from a reading method for Sranan, the only Surinamese creole used in writing at the time. Although he probably did not write with the aim of getting published, we may assume that he addressed his writings to the Moravian missionaries,

130. Most of the information below is based on De Beet (1995:9-34). 
most of whom did not know any of the other creole languages. This may also explain the 'church Sranan' features in his language, although at the same it also shows many characteristics of an oral style (Voorhoeve \& Lichtveld 1975: 118). Johannes King is a most intriguing figure, who stood with one foot in the Christian world of the Moravian missionaries while the other was still firmly planted in the Maroon world of his kinfolk. In this respect he may be compared to Johannes Alabi, the first Saramaccan convert, whose 'cultural schizophrenia' has been evoked vividly in Price (1990). (For more biographical information on King, see 'De Ziel' 1973:2-8.)

Besides King's descriptions of his dreams and visions, the Skrekibuku contains episodes from the history of his family and of maroon society in general. It also features an account of King's conflict with his half-brother, Noah Adrai, who was one of King's religious followers at first but later turned into one of his most bitter enemies. The quarrel had to do with the fact that Noah Adrai was appointed granman of the Matawai while later on it also took on religious and moral aspects. ${ }^{131}$ Some visions are supplemented by King's drawings representing the scenes he saw. Interestingly, some of his visual images are inspired by the world of plantation slavery: one drawing shows people wearing chains on their feet, their hands, and even their tongues, while in some of his visions of hell people are burned in sugar kettles.

Several of King's visions reveal his preoccupation with writing, such as those reproduced below. In the vision described in the first text fragment, he sees the whole firmament covered with letters and numbers, such as the sequence 'hkkh 5. C.' Their meaning remains hidden from him since 'God did not say what they meant.' In another vision, God writes letters up in the sky, but takes them away just when King tries to read them. In the third vision, God gives him a pen and has him write 'on the side of the firmament, just like people write on a slate'. While the latter example suggests that King saw his writing as inspired by God, the other cases suggest that the domain of writing and literacy was full of mystery for him. ${ }^{132}$

The dating of King's writings is a notoriously difficult affair. When describing events that took place in a particular year, he would put that date above the entry, even if the actual writing took place decades later. In the case of the Skrekibuku, De Beet claims that the manuscript was probably written between 1882 and 1888, even though many of the visions took place in the 1860s and 1870s. The excerpts below are taken from De Beet's edition (1995), which is based on Ms EBGH H. R 15Lb N 35 $20 \mathrm{f} 6-8 .{ }^{133}$

131. Noah Adrai was granman from 1870 until 1893 . When King was finally given the post in 1895 , he abandoned it after several weeks.

132. The mystery presented by books (and writing in general) to illiterate African-Americans is well-known from other parts of Afro-America: cf., for example, Gates (1988, ch. 4) on the 'magic of writing' experienced by Blacks in the Plantation South.

133. Note that in De Beet's transcription spelling and punctuation of the original manuscript were adapted. 
Den 22 december 1865, mi geest libi mi skin. Masra sori mi wan moi sani en wan verwondroe sani toe. Da heeli hemel tenti na tapoe foeloe nanga skrifi retre en nomroe. Da skrifi ben foeloe toemoesi-toemoesi, en wan vo den retre ben skrifi so: hkkh 5.C. Ma Masra no taki gi mi san dem retre nanga dem nomroe wani taki, Masra hooli dati vo hem srefi. A sori mi vo skrifi nomo.

(source: De Beet 1995: 175)

On the 22nd of December 1865 my spirit left my body. The Lord showed me something beautiful and wondrous too. The whole firmament of heaven above was full of letters and numbers. The writing was all over the place and one of the letters was written as follows: hkkh 5.C. But the Lord did not tell me what the letters and the numbers meant. The Lord kept it to himself. He only showed it to me to write it down.

[January 9, 1866, JA] Wi tapoe na ondro wan deiki nanga wan sribi krosi. En da krosi wai pikinso komoto na mi tapoe, nomo mi si Masra skrifi letre na da hemel tenti na tapoe, an (wan?) hafoe lo. En di mi wani vo lesi da skrifi, nomo Masra poeroe da skrifi baka, en wan toe stari hoopo krin na tapoe.

(source: De Beet 1995:228)

We were covered with a blanket and a sleeping cloth. And the cloth was blown a little away from me; right then I saw that the Lord had written letters in the firmament of heaven above, half a row. And when I wanted to read the writing, right then the Lord pulled the writing away.

Den 25 augustus 1867, Masra sori mi wan verwondroe sani. En aladi mi geest liebi mi skin. Masra meki da jeje vo hem tjari mi go tee na sei da hemel tenti na tapoe. Masra gi mi wan skrifi pen na mi leti hanoe, en Masra gi mi krin verstand so leki mi de nanga liebi-liebi hai dia. En dan Masra meki mi de skrifi letre na sei da hemel tenti so leki soema de skrifi na tapoe wan pan lei. Masra meki mi Johannes King hanoe srefi skrifi, ma Masra no wani mi sabi san da skrifi de taki.

(source: De Beet 1995:208)

On the 25th of August 1867 the Lord showed me something wondrous. And while my spirit was leaving my body, the Lord made his spirit bring me to the side of the firmament. The Lord gave me a writing pen in my right hand and the Lord gave me a clear sense, just as I have living eyes here. And then the Lord made me write letters at the side of the firmament just like people write on a slate. The Lord made my own hand, that of Johannes King, write but the Lord did not want me to know what the writing said.

\section{Food for Christian souls: the MAKZien foe Kristen-SOEMA Zieli (1902)}

After the Moravian mission acquired a printing press (in 1831), it took another twenty years before their Makzien foe Kristen-soema zieli 'Magazine for the souls of Christians' saw its first issue in print. This monthly magazine, written entirely in Sranan, was published from 1852 until 1932 (with an intermission from December 1879 until January 1889). It contained edifying stories, songs, missionary news, and some political information (Voorhoeve \& Donicie 1963: 100). The items reproduced below are from the 'Community news' section of the magazine. 


\section{Som njoesoe vo gemeente.}

Na da 31 December 1901 wan njoe leriman, masra Fabricius, ben kom. We, wi de wensi en begi taki, Masra moe blesi hem nanga da wroko vo hem, disi a sa go doe na ini wi gemeente.

Na da 2 Januari 1902 Masra Gado ben finni vo boen, vo kali wan vo dem pikin masra na ini winkri, Max Moritz Otto John, komopo na disi liebi kom na hem. A ben de wan soema, disi no ben bekenti da bribi vo hem nanga mofo wawan, ma disi ben zoekoe doronomo vo doe ${ }^{134}$ Masra wani toe, en alwasi da wroko vo hem na ini winkri ben de wan dorosei-wroko nomo, tog a ben doe da wroko dati leki wan disciple vo Kristus. Vo dati hede ala soema, disi ben habi wroko nanga hem, ben lobbi hem, en wi fili sari reti reti, di wi lasi so wan boen en vertrouw wrokoman. Ma moro foeloe wi fili sari nanga hem tata nanga mama, disi ben lasi nanga hem da wan enkli manpikien vo dem. A ben ouroe 23 jari, en a ben wroko dia wan sebi moen nomo, ma vergiti, wi no sa vergiti hem so hesi.

(source: Makzien foe Kristen-soema zieli 1902 (1), p. 8)

Some news from the community

On December 31, 1901, a new missionary, Mr Fabricius, arrived. We wish and pray that the Lord will bless him and his work he will be doing in our community.

On January 2, 1902, the Lord God decided to call one of the junior assistants in the shop, Max Moritz Otto John, away from this life onto him. He was someone who not only confessed his faith in words but who was constantly looking to do God's will as well. And even though his work in the shop was only 'external' work, he nevertheless did that work like a disciple of Christ. For that reason, everyone who had any dealings with him loved him, and we're truly sorry to have lost such a good and reliable worker. But we're even more sorry for his father and his mother who with him lost their only son. He was 23 years old and he had been working here for only seven months, but we will certainly not forget him that quickly.

\section{An indigenous Syllabic SCRipt for Ndyuka: Afaka (1917)}

Somewhere around 1908, an illiterate Ndyuka man named Afaka started to develop a syllabic script for his native language. ${ }^{135}$ A syllabic script is very well suited for Ndyuka because its syllable structure is overwhelmingly CV, as a result of which the total number of different syllables is relatively low. Afaka's script consists of only 56 characters, which is sufficient for the basic purposes for which it was designed. While it bears some striking similarities to a syllabary used for writing Vai, a Mande language spoken in Liberia and Sierra Leone, it is not at all clear how these similarities should be explained. Although Vai is spoken in a region that was a major recruitment area

134. Bold represents italics in the original.

135. These introductory remarks are based on Dubelaar \& Pakosie (1999:7-39). 
for Surinamese slaves (see Chapter 3), it is hard to imagine how Afaka's script could have been invented on the basis of the Vai syllabary it being almost one hundred years after the end of slave importation. One cannot, of course, exclude the possibility that it was introduced to Suriname earlier, in the time when many Africans from Liberia and Sierra Leone were brought to Suriname (1750-1800), and that it was preserved secretly for more than a century. Whatever may be the case, the result is that Ndyuka is the only creole language known to exist that has its own script. Although Afaka's syllabary met with some success at first, it never became very wide-spread among the Ndyuka; recently, however, efforts have begun to be made to breathe some new life into it. The most comprehensive publication about the script, containing many texts both in Afaka and in alphabetic script plus their translations into Dutch, is Dubelaar, Pakosie and Hoogbergen (1999). Discussions in English can be found in Dubelaar (1995), Dubelaar \& Pakosie (1988, 1993), Gonggryp (1960), and Huttar $(1987,1992)$. The text below is excerpted from a letter written by Afaka, in which he explains how the script was given to him by God in a dream. It is interesting to see how for him, as for Johannes King, the use of writing is connected with the supernatural ( $c f$. no. 47 above).

(source: Dubelaar \& Pakosie 1999: 50-56)

...Wi konde wi kali Afilika. Da Gadu ben du so aga en wani, aga en koni, aga en ligeli: a ben puu afu den Afilika na ini a konde fu den Afilika tyali kon na Salana. Te a ten di a wani, a ben puu afu na ini Salana baka tyali go poti na busi. A kali den Ndyuka. A taki: Na ya un mu tan. A gi den libi. Da a tan wan bun pisi langa. Da a kali den pilisitisi. Den piki. A taki: Den Afilika di de na busi, den mu kon santa na ini a bilibi di yu abi. Aga pamisi fu Masa Gadu yu mu gi den leli aga lafu aga nyan aga diligi aga losutu....Da Masa Gadu lafu. A sede wan yeye go na de Afilika, en nen Usa. A meke a siibi dipi. A go, a kali en: Usa! A piki. A taki: Mi sa gi yu wan ebi fi yu tyali. Te yu go na Gadukonde, yu sa fede yu paima na Gadu Konde. A teke wan pisi papila, a gi Usa, sonde eki, sonde tiki. Usa taki: Mi Masa, fa fu mi du aga a papila. A yeye kon, a taki: I sa fede ala sa di de fanoudu. Da a opo wan sitali aga faya. Masa Gadu soli wan maliki. A taki: Ai sa si, yesi sa yee. Da a gi Okanisi nenge papila. A opo wan bigi feti. Na a mun fu a sitali a papila opo...A sabi taki a mu gi lowenenge papila fu wi libi. A bun gi lowenenge...Okanisi kisi papila. Den sa kisi leli. Den sa kisi koni. Den sa kisi sabi. Wi sa libi na sata libi. Na kilifasi sa kon. Te na leti dei sa kon, wi ala sa de na a wan pasi e go na a leti konde, aga lafu, aga singi, aga pilisili. Na so amakiti Tata taki. Wi mu libi aga leli....

(source: Dubelaar \& Pakosie 1999:51-57)

Our land is called Africa. Then God did thus with his will, with his wisdom, with his guidance: he brought half of the Africans from the land of the Africans to Suriname. The moment he wanted to, he took half of them from Suriname again and put them in the bush. He called them 'Ndyuka'. He said: here you must stay. He gave them life. Then he waited for quite some time. Then he called the priests. They answered. He said: The Africans who are in the bush, they must become holy in the faith that you have. With 
the permission of God you must teach them, with laughter, with food, with drink and with rest...Then the Lord God laughed. He sent a spirit to the African, called Usa. ${ }^{136}$ He put him in a deep sleep. He went and called him: Usa! He answered. He said: I will give you a load for you to carry. If you go to the land of God, you will find your reward in the land of God. He took a piece of paper, he gave it to Usa, without ink, without a pen. Usa said: My Lord, what should I do with the paper? The spirit came, saying: You will find everything that is needed. Then he put up a star with fire. ${ }^{137}$ The Lord God showed a sign. He said: Eyes will see, ears will hear. Then he gave the paper to the Okanisi Negroes. He started a big fight. The paper appeared in the month of the star... He knew he had to give us the paper in order to live. It is good for the Maroons...The Okanisi ${ }^{138}$ got the paper. They will get teaching. They will get wisdom. They will get knowledge. We will live the holy life. The enlightenment will come. When the right day will come, we will all be on the one road, going to the right land, with laughter, with song, with pleasure. Thus spoke the Father Almighty. We must live with teaching.

136. 'Usa' is Afaka's 'book name', the alternative name adopted by so-called buku man 'book men', i.e. people who use the Afaka script.

137. This refers to the appearance of Halley's comet in 1910, which formed the impetus for Afaka to make his script more widely known.

138. Okanisi 'people from Auka' (cf. Chapter 2) is an alternative name for the Ndyuka Maroons. 



\section{References}

Abbenhuis, M. F. 1943. Volksplanting. Paramaribo: Eben Haezer.

Abrahams, Roger D. 1970-1964. Deep Down in the Jungle, rev. edn. Chicago IL: Aldine.

Abrahams, Roger D. 1983. The Man-fo-words in the West Indies Performance and the Emergence of Creole Culture [P. imprenta No. 398.0922 A2.] Baltimore MD: The Johns Hopkins University. Abrahams, Roger D. 1992. Singing the Master: The Emergence of African American Culture in the Plantation South. New York NY: Pantheon.

Aceto, Michael. 1996. Early Saramaccan syllable structure: An analysis of complex onsets from Schumann's 1778 manuscript. Journal of Pidgin and Creole Languages 11: 23-44.

Aceto, Michael. 1997. Saramaccan Creole origins. Portugese-derived lexical correspondences and the relexification hypothesis. In: A. K. Spears and D. Winford (eds). The structure and status of pidgins and creoles, 219-239. Amsterdam: John Benjamins.

Adam, Lucien. 1883. Les idiomes négro-aryen et maléo-aryen. Paris: Maisonneuve.

Adamson, Lilian \& Smith, Norval. 1995. Sranan. In Arends, Muysken \& Smith (eds), 219-232.

Adamson, Lilian. 2001. Sranan. In Babylon aan de Noordzee: Nieuwe talen in Nederland, Guus Extra \& Jan Jaap de Ruiter (eds), 287-305. Amsterdam: Bulaaq.

Alber, Birgit \& Plag, Ingo. 2001. Epenthesis, deletion and the emergence of the optimal syllable in creole: The case of Sranan. Lingua 111(11): 811-840. doi: 10.1016/Soo24-3841(00)ooo51-6

Alleyne, Mervyn. 1971. Acculturation and the cultural matrix of creolization. In Pidginization and Creolization of Languages, Dell Hymes (ed.). Cambridge: CUP.

Alleyne, Mervyn. 1980. Comparative Afro-American. An Historical-comparative Study of Englishbased Afro-American Dialects of the New World. Ann Arbor MI: Karoma.

Anon. n.d. [1740]. Ontwerp tot een beschryving van Surinaamen. Typed copy of a lost manuscript from the Colonial Library in Paramaribo, Catalogue 1911 Nr. C17, Central Library of the Royal Tropical Institute in Amsterdam.

Anon. 1829. Da njoe testament va wi masra en helpiman Jesus Christus. London: British and Foreign Bible Society.

Anon. 1829. Tori vo dem Apostel. In Anon. 1966, Den toe boekoe di Lukas skrifi. N.p.: Bijbelgenootschap.

Arbell, Mordechai. 1995. The Jewish settlement in Pomeroon/Pauroma (Guyana) 1657-1666. Revue des Études Juives 154: 343-361. doi:10.2143/REJ.154.3.519416

Arends, Jacques. 1986. Genesis and development of the equative copula in Sranan. In Substrata versus Universals in Creole Genesis [Creole Language Library 1], Pieter Muysken \& Norval Smith (eds), 103-127. Amsterdam: John Benjamins. doi:10.1075/cll.1.07are

Arends, Jacques. 1987. De historische ontwikkeling van de comparatief in het Sranan als 'post-creolisering'. OSO: Tijdschrift voor Surinaamse Taalkunde, Letterkunde, Cultuur en Geschiedenis 6: 201-217.

Arends, Jacques. 1989. Syntactic Developments in Sranan. Creolization as a Gradual Process. PhD dissertation, Radboud University Nijmegen. 
Arends, Jacques. 1991. Review of Narrative of a five years' expedition against the revolted negroes of Surinam by John Gabriel Stedman, edited by Richard Price \& Sally Price. Journal of Pidgin and Creole Languages 6: 326-332. doi:10.1075/jpcl.6.2.18are

Arends, Jacques. 1992. Variation in Early Suriname Creole. Paper, Conference of the Society for caribbean Linguistics. Barbedos.

Arends, Jacques. 1993a. Towards a gradualist model of creolization. In Atlantic Meets Pacific: A Global View of Pidginization and Creolization [Creole Language Library 11], Frank Byrne \& John Holm (eds), 371-380. Amsterdam: John Benjamins. doi:10.1075/cll.11.36are

Arends, Jacques. 1993b. Alabi's taal: Over taal en taalgebruik in 'Alabi's world' (Alabi's language: On language and language use in 'Alabi's world'). OSO: Tijdschrift voor Surinaamse Taalkunde, Letterkunde, Cultuur en Geschiedenis 12: 104-109.

Arends, Jacques. 1994. The African-born slave child and creolization (a postscript to the Bickerton-Singler debate on nativization). Journal of Pidgin and Creole Languages 9: 115-119. doi:10.1075/jpcl.9.1.14jac

Arends, Jacques. 1995a. Demographic factors in the formation of Sranan. In The Early Stages of Creolization [Creole Language Library 13], Jacques Arends (ed.), 233-285. Amsterdam: John Benjamins. doi:10.1075/cll.13.11are

Arends, Jacques. 1995b. An inventory of Sranan and Saramaccan material in the Moravian archives in Utrecht. Amsterdam Creole Studies 12: 73-86.

Arends, Jacques. 1995c. Introduction to Part I: The Sranan texts. In Early Suriname Creole Texts: A Collection of 18th-century Sranan and Saramaccan Documents, Jacques Arends \& Matthias Perl (eds), 11-71. Frankfurt: Vervuert.

Arends, Jacques. 1995d. Stedman's 'Narrative' and 18th-century Sranan. Amsterdam Creole Studies 12: 33-48.

Arends, Jacques. 1998. The development of complementation in Saramaccan. In Proceedings of the XIth International Congress of Linguists, Bernard Caron (ed.). Oxford: Pergamon (CD-Rom). Arends, Jacques. 1999. The origin of the Portuguese element in the Surinam creoles. In Spreading the Word: The Issue of Diffusion among the Atlantic Creoles, Magnus Huber \& Mikael Parkvall (eds), 195-208. London: University of Westminster Press.

Arends, Jacques. 2001. Social stratification and network relations in the formation of Sranan. In Creolization and Contact [Creole Language Library 23], Norval Smith \& Tonjes Veenstra (eds), 291-307. Amsterdam: John Benjamins. doi:10.1075/cll.23.13are

Arends, Jacques. 2002a. The historical study of creoles and the future of creole studies. In Pidgin and Creole Linguistics in the 21st Century, Glenn G. Gilbert (ed.), 49-68. Bern: Peter Lang.

Arends, Jacques. 2002b. Young languages, old texts: Early documents in the Surinamese creoles. In Atlas of the Languages of Suriname, Eithne B. Carlin \& Jacques Arends (eds), 183-205. Leiden \& Kingston: KITLV Press \& Ian Randle Publishers.

Arends, Jacques. 2008. A demographic perspective on creole formation. In Silvia Kouwenberg \& John Victor Singler (eds), Handbook of Pidgin and Creole Studies, 307-331. Oxford: Wiley-Blackwell.

Arends, Jacques, Muysken, Pieter \& Smith, Norval (eds). 1995. Pidgins and Creoles: An Introduction [Creole Language Library 15]. Amsterdam: John Benjamins. doi:10.1075/cll.15

Arends, Jacques \& Perl, Matthias. 1995. Early Suriname Creole Texts. A Collection of 18th-century Sranan and Saramaccan Documents. Frankfurt: Vervuert.

Arends, Jacques \& van den Berg, Margot. 2004. The Saramaka Peace Treaty in Sranan: An edition of the 1762 text (including a copy of the original text). Creolica, Revue du Groupe Européen de Recherches en Langues Créoles, 16 March 2004. <www.creolica.net> 
Artur, J.-F. 1770. Mémoires. Bibliothèque Nationale de France, MSS n.a.fr. 2571-82.

Baker, Philip. 1982a. On the origins of the first Mauritians and of the creole language of their descendants. A refutation of Chaudenson's “Bourbonnais” theory. In Isle de France Creole, Affinities and Origins, Philip Baker \& Chris Corne (eds), 131-257. Ann Arbor MI: Karoma.

Baker, Philip. 1982b. The Contribution of Non-Francophone Immigrants to the Lexicon of Mauritian Creole. PhD dissertation, University of London.

Baker, Philip. 1990. Off target? Journal of Pidgin and Creole Languages 5: 107-119. doi:10.1075/jpcl.5.1.07bak

Baker, Philip. 1995. Some developmental inferences from the historical studies of pidgins and creoles. In The Early Stages of Creolization, Jacques Arends (ed.), 1-24. Amsterdam: John Benjamins.

Baker, Philip. 2000. Theories of creolization and the degree and nature of restructuring. In Degrees of Restructuring in Creole Languages [Creole Language Library 22], Ingrid NeumannHolzschuh \& Edgar Schneider (eds), 41-63. Amsterdam: John Benjamins.

doi: 10.1075/cll.22.05bak

Baker, Philip \& Bruyn, Adrienne (eds). 1999. St. Kitts and the Atlantic Creoles: The Texts of Samuel Augustus Mathews in Perspective. London: University of Westminster Press.

Bakker, Peter, Smith, Norval \& Veenstra, Tonjes. 1995. Saramaccan. In Arends, Muysken \& Smith (eds), 165-178.

Barbot, J. 1732. A Description of the Coasts of North and South Guinea; and of Ethiopia Inferior, Vulgarly Angola. London: A. \& J. Churchill.

Bartelink, E. 1914. Hoe de tijden veranderen. Paramaribo: Van Ommeren.

Beckles, Hilary. 1990. A History of Barbados: From Amerindian Settlement to Nation-state. Cambridge: CUP.

Beckles, Hilary. 2000. A riotous and unruly lot: Irish indentured servants and freemen in the English West Indies, 1644-1713. In Caribbean Slavery in the Atlantic World: A Student Reader, Verene Shepherd \& Hilary Beckles (eds), 226-238. Kingston: Ian Randle.

Beeldsnijder, Ruud. 1991. Op de onderste trede. Over vrije negers en arme blanken in Suriname, 1730-1750. OSO, Tijdschrift voor Surinaamse Taalkunde, Letterkunde, Cultuur en Geschiedenis 10.

Beeldsnijder, Ruud. 1994. 'Om werk van jullie te hebben': Plantageslaven in Suriname, 17301750 [Bronnen voor de Studie van Afro-Suriname 16]. Utrecht: Department of Cultural Anthropology, Utrecht University.

Beer, Wolf-Dietrich. 1976. Maria Sibylla Merian. Schmetterlinge, Käfer und andere Insekten; Leningrader Studienbuch. Luzern: Reich Verlag.

Behn, Aphra. 1983[1688]. Oroenoko, of De koninklijke slaaf. Translation and epilogue by Albert Helman. Amsterdam: Arbeiderspers. (Originally published as Oroonoko, or The royal Slave. London: Dent, 1688).

Beijer, E. 1823. Suriname in deszelfs tegenwoordigen toestand. Amsterdam: Sulpke.

Benjamins, H. D. \& Snelleman, J. F. (eds). 1914-1917. Encyclopaedie van Nederlandsch West-Indië. Hague \& Leiden: Nijhoff \& Brill. (Reprinted 1981, Amsterdam).

Benoit, Pierre Jacques. 1980[1839]. Reis door Suriname. Zutphen: Walburg Pers. (Originally published as Voyage à Surinam. Bruxelles: Société des Beaux-Arts, 1839).

Berns, J. B. 1997. Een merkwaardig taalmonument: De Bulla "Ineffabilis". Taal en Tongval 49: $1-15$.

Bickerton, Derek. 1981. On the supposed 'gradualness' of creole development. Journal of Pidgin and Creole Languages 6: 25-58. doi:10.1075/jpcl.6.1.03bic 
Bickerton, Derek. 1984. The Language Bioprogram Hypothesis. The Behavioral and Brain Sciences 7: 173-88. doi:10.1017/S0140525Xooo44149

Bickerton, Derek. 1988. Creole languages and the bioprogram. In Linguistics: The Cambridge Survey, Vol. II, Frederick Newmeyer (ed.). Cambridge: CUP.

Bickerton, Derek. 1992. The sociohistorical matrix of creolization. Journal of Pidgin and Creole Languages 7: 307-318. doi:10.1075/jpcl.7.2.05bic

Bickerton, Derek. 1994. The Origins of Saramaccan syntax: A reply to John McWhorter's “Substratal influence in Saramaccan serial verb constructions". Journal of Pidgin and Creole Languages 9: 65-78.

Biet, Antoine. 1664. Voyage de la France equinoxiale en l'isle de Cayenne entrepris par les François en l'année 1652. Paris: François Clouzier.

Bilby, Kenneth. 1983. How the 'older heads' talk. A Jamaican Maroon spirit possession language and its relationship to the creoles of Suriname and Sierra Leone. New West Indian Guide 57: 37-88. doi: 10.1163/13822373-90002097

Bilby, Kenneth. 1997. Swearing by the past, swearing to the future: Sacred oaths, alliances, and treaties among the Guianese and Jamaican Maroons. Ethnohistory 44: 655-689. doi: $10.2307 / 482884$

Blanker, J. C. M. \& Dubbeldam, Jaap. 2005. Prisma woordenboek Sranantongo: SranantongoNederlands, Nederlands-Sranantongo. Utrecht: Het Spectrum.

Bloom, Herbert I. 1931. The Dutch archives, with special reference to American Jewish history. Publications of the American Jewish Historical Society 32: 7-21.

Bloom, Herbert I. 1934. A study of Brazilian Jewish history 1623-1654, based chiefly upon the findings of the late Samuel Oppenheim. Publications of the American Jewish Historical Society 33: 43-125.

Bloom, Herbert I. 1969[1937]. The Cconomic Activities of the Jews of Amsterdam in the Seventeenth and Eighteenth Centuries, repr. of the 1937 edn. Port Washington NY: Kennikat Press.

Boekhoudt, W. 1874. Uit mijn verleden. Winschoten: Van der Ven.

Böhm, Günter. 1992. Los sefardíes en los dominios holandeses de América del Sur y del Caribe, 1630-1750. Frankfurt: Vervuert.

Bolingbroke, H. 1807. A Voyage to the Demerary. London : Stevenson and Marchett.

Bonaparte, R. 1884. Les habitants de Suriname. Paris: Quantin.

Boretzky, Norbert. 1983. Kreolsprachen, Substrate und Sprachwandel. Wiesbaden: Harrassowitz.

Bosman, Willem. 1704. Nauwkeurige beschryving van de Guinese Goud-, Tand-en Slavenkust. Utrecht: Anthony Schouten.

Bouton, Jacques. 1640. Relation de l'établissement des françois depuis l'an 1635 en l'isle de la Martinique l'une des Antilles de l'Amérique. Paris: S. Cramoisy.

Brana-Shute, R. 1985. The manumission of slaves in Suriname, 1760-1828. Doctoral dissertation, University of Florida.

Brana-Shute, Gary (ed.). 1990. Resistance and Rebellion in Suriname: Old and New [Studies in Third World Societies 43]. Williamburg VA: College of William and Mary.

Brana-Shute, Rosemary. 1989. Approaching freedom: The manumission of slaves in Suriname, 1760-1828. Slavery and Abolition 10: 40-63. doi:10.1080/01440398908574991

Brana-Shute, Rosemary. 1990. Legal resistance to slavery in eighteenth century Suriname. In Brana-Shute (ed.), 119-136.

Braun, Maria. 2001. Complex words in Early Sranan: An investigation into Creole Morphology. MA thesis, University of Siegen. 
Braun, Maria. 2005. Word-formation and Creolisation: The Case of Early Sranan. PhD dissertation, University of Siegen.

Braun, Maria \& Plag, Ingo. 2003. How transparent is creole morphology? A study of early Sranan word-formation. In Yearbook of Morphology 2002, Geert Booij \& Jaap van Marle (eds), 81-104. Dordrecht: Springer. doi:10.1007/0-306-48223-1_4

Breton, Raymond. 1665. Dictionaire caraibe-francois. Auxerre.

Breton, Raymond. 1666. Dictionnaire Francois-Caraibe. Auxerre.

Bridenbaugh, Carl, and Roberta Bridenbaugh. 1972. No peace beyond the line: The English in the Caribbean, 1624-90. Oxford University Press.

Bruyn, Adrienne. 1993a. Question words in 18th-century and 20th-century Sranan. In Historical Linguistics 1991. Papers from the 10th International Conference on Historical Linguistics [Current Issues in Linguistic Theory 107], Jaap van Marle (ed.), 31-47. Amsterdam: John Benjamins. doi:10.1075/cilt.107.05bru

Bruyn, Adrienne. 1993b. The determiner system in 18th-century Sranan. Paper presented at Annual meeting of the Society for Pidgin and Creole Linguistics, Los Angeles, 7-10 January.

Bruyn, Adrienne. 1995a. Grammaticalization in Creoles: The Development of Determiners and Relative Clauses in Sranan. Amsterdam: IFOTT.

Bruyn, Adrienne. 1995b. Relative clauses in early Sranan. In The Early Stages of Creolization [Creole Language Library 13], Jacques Arends (ed.), 149-202. Amsterdam: John Benjamins. doi:10.1075/cll.13.09bru

Bruyn, Adrienne. 1996. On identifying instances of grammaticalization in creole languages. In Changing Meanings, Changing Functions: Papers Related to Grammaticalization in Contact Languages, Philip Baker \& Anand Syea (eds), 29-46. London: University of Westminster Press.

Bruyn, Adrienne. 1997. Grammaticalisatie in creooltalen: implicaties van historisch onderzoek van het Sranan. Gramma/TTT 6: 91-105.

Bruyn, Adrienne. 1999. Early forms of question words and relativizers in Atlantic English Creoles. In St Kitts and the Atlantic Creoles: The Texts of Samuel Augustus Mathews in Perspective, Philip Baker \& Adrienne Bruyn (eds), 289-314. London: University of Westminster Press.

Bruyn, Adrienne. 2002. The structure of the Surinamese creoles. In Atlas of the Languages of Suriname, Eithne B. Carlin \& Jacques Arends (eds), 153-182. Leiden \& Kingston: KITLV Press \& Ian Randle Publishers.

Buddingh', Hans. 1995. Geschiedenis van Suriname. Utrecht: Het Spectrum.

Buve, Raymond T. J. 1962. De Positie van de Indianen in de Surinaamse Plantagekolonie Gedurende de $17^{\mathrm{e}}$ en de $18^{\mathrm{e}}$ Eeuw. PhD dissertation, Leiden University.

Buve, R. 1966. Gouverneur Johannes Heinsius: de rol van van Aerssen's voorganger in de Surinaamse Indianenoorlog, 1678-1680. Nieuwe West-Indische Gids/New West Indian Guide 45: $1,14-26$.

Byam, William. 1665. An exact relation of the most Execrable Attempts, Committed on the Person of His Excellency Francis, Lord Willoughby of Parham. (See Williamson (1923: 150)).

Byam, William. 1667. An Exact Narrative of ye State of Guyana and of ye English Colony in Surynam in ye Beginning ofye Warre with ye Dutch, and of its Actions During the Warre, And the Taking Thereof by a Fleet from Zealand. Feb. 1667. Ms, Ashmolean Mss 842, ff. 109-122 (Bodleian Library). In Harlow 1925.

Byam, William. c1662. A Narrative of the Late Troubles in Surinam. (See Williamson (1923: 150)). Byam, William. c1667. A Journall of Guiana from 1665 to 1667. Ms, Sloan Mss, 3662, ff. 27-37 (British Museum). (See Williamson (1923: 150)). 
Byrne, Francis. 1987. Grammatical Relations in a Radical Creole. Verb Complementation in Saramaccan [Creole Language Library 3]. Amsterdam: John Benjamins. doi:10.1075/cll.3

Carlin, Eithne B. 2001. Of riches and rhetoric: Language in Suriname. In Hoefte \& Meel (eds), 220-243.

Carlin, Eithne B. \& Arends, Jacques (eds). 2002. Atlas of the Languages of Suriname. Leiden \& Kingston: KITLV Press \& Ian Randle Publishers.

Chander, R. 1988. Slavenhandel in de periode 1789 tot 1826 . Suriname op de grens van twee eeuwen. MA thesis, Leiden University.

Chaudenson, Robert. 1979. Les créoles français. Évreux: Fernand Nathan.

Chaudenson, Robert. 1981. Textes créoles anciens (La Réunion et Île Maurice): Comparaison et essai d'analyse. Hamburg: Helmut Buske.

Chaudenson, Robert. 1992. Des îles, des hommes, des langues. Paris: L'Harmattan.

Cohen, Robert (Ed.) 1982. The Jewish Nation in Surinam: Historical Essays. Amsterdam: S. Emmering

Cohen, Robert. 1991. Jews in Another Environment. Surinam in the Second Half of the Eighteenth Century. Leiden: Brill.

Comvalius, Theod. A. C. 1922. Iets over het Surinaamsch lied: een bijdrage tot de kennis van de folklore van de kolonie Suriname. Paramaribo: Heyde.

Comvalius, Theod. A. C. 1938. Twee historische liederen in Suriname. De West-Indische Gids 20: 291-295. doi:10.1163/22134360-90000749

Comvalius, Theod. A.C. 1939. Een der vormen van het Surinaamsche lied na 1863. De WestIndische Gids 21: 355-360. doi:10.1163/22134360-90000692

Comvalius, Theod. A. C. 1948. Krioro: Een bijdrage tot de kennis van het lied, de dans en de folklore van Suriname. De West.

Coster, A. M. 1866. De Boschnegers in de kolonie Suriname. Hun leven, zeden en gewoonten. Bijdragen tot de Taal-, Land-en Volkenkunde 13: 1-36. doi:10.1163/22134379-90000898

Crevaux, Jules. 1883. Voyages dans l'Amérique du Sud. Paris: Hachette.

Cultru, P. 1913. Premier voyage du Sieur de la Courbe fait à la coste d'Afrique en 1685: publié avec une carte de Delisle et une introduction. Champion, Larose, Libraries de la Société de l'Histoire des Colonies Françaises.

Cundall, Frank. 1919. The migration from Surinam to Jamaica. Timehri, Journal of the Royal Agricultural and Commercial Society of British Guiana 6(3rd series): 145-172.

Curtin, Philip. 1969. The Atlantic Slave Trade. A Census. Madison WI: The University of Wisconsin Press.

Daeleman, Jan. 1972. Kongo elements in Saramacca Tongo. Journal of African Languages 11: 1-44.

Dapper, O. 1668. Naukeurige beschrijvinge der Afrikaensche gewesten .... Amsterdam: Jacob van Meurs.

Davis, Natalie Zemon. 1995. Women on the Margins: Three Seventeenth-century Lives. Cambridge MA: Harvard University Press.

Davis, Natalie Zemon. 1998. Metamorfosen: Maria Sibylla Merian. In Maria Sibylla Merian: 1647-1717: Kunstenares en Natuuronderzoekster, Kurt Wettengl (ed.), 176-201. Haarlem: Becht \& Teylers Museum.

de Beet, Chris (ed.). 1981. Berichten uit het bosland (1864-1870), by Johannes King, Bronnen voor de Studie van Bosnegersamenlevingen 7. Utrecht: Centrum voor Caraïbische Studies.

de Beet, Chris (ed.). 1995. Skrekiboekoe/Boek der verschrikkingen: Visioenen en historische overleveringen van Johannes King [Bronnen voor de Studie van Afro-Suriname 17]. Utrecht University. 
de Beet, Chris \& Sterman, Miriam. 1981. People in Between: The Matawai Maroons of Suriname. $\mathrm{PhD}$ dissertation, Utrecht University.

de Beet, Chris \& Price, Richard. 1982. De Saramakaanse vrede van 1762: Geselecteerde documenten. Utrecht: CLACS \& IBS.

de Bye, John H. 2002. Historische schetsen uit het Surinaamse jodendom. Schoorl: Conserve.

de Bruijne, Ad. 2001. A city and a nation: Demographic trends and socioeconomic development in urbanizing Suriname. In Hoefte \& Meel (eds), 23-47.

de Goeje, C.H. 1908. Verslag der Toemoekhoemak-expeditie. Leiden: Brill.

de Granda, Germán. 1974. El repertorio lingüístico de los sefarditas de Curaçao durante los siglos XVII y XVIII y el problema del origen del papiamento. Romance Philology 28: 1-16. de Granda, Germán. 1976. A socio-historical approach to the problem of Portuguese creole in West Africa. International Journal for the Sociology of Language 7: 11-22.

de Groot, A. 1984. Tweedelig Woordregister Auka-Nederlands, Nederlands-Auka. Paramaribo: Artex.

de Laet, J. 1625. Nieuwe Wereldt ofte Beschrijvinghe van West-lndien.

del Negro, Rosanna. 1993. 18th-century Creole English of Surinam: A Linguistic Comparison of Van Dyk and Weygandt. Tesi di laurea, University of Bologna.

de Naxera, José. 1672. Espejo mystico en que el Hombre interior se mira. Madrid.

de Rochefort, César. 1658. Histoire naturelle et morale des Iles Antilles de l'Amérique. Rot[t]erdam:

Arnould Leers.

de Smidt, Johannes Th. (ed.). 1973. West Indisch plakaatboek: Plakaten, ordonnantiën en andere wetten, uitgevaardigd in Suriname, 1667-1816. Amsterdam: S. Emmering.

de Vries, D. P. 1655. From the "korte hisotriael ende journaels aenteyckeninge," by David Pietersz.

De Vries, 1633-1643. Original Narratives of Early American History 12, 181-234.

Devonish, Hubert. 2001. On the Sierra Leone-Caribbean connection: Hot on the trail of the 'tone-shifted' items in Anglo-West African. In Due Respect: Essays on English and Englishrelated Creoles in the Caribbean in Honour of Professor Robert Le Page, Pauline Christie (ed.), 184-205. Kingston: University of the West Indies Press.

de Ziel, H.F (ed.). 1973. Life at Maripaston, by Johannes King. The Hague: Nijhoff.

Do Couto, H. H. 1994. O crioulo português da Guiné-Bissau. Helmut Buske Verlag.

Donicie, Antoon. 1954. De creolentaal van Suriname. Spraakkunst. Paramaribo: Radhakishun.

Dörig, J. C. 1763. Journaal gehouden bij J. C. Dorigh. Alg. Rijksarchief, Sociëteit van Suriname 155, 20/IV/1763. In de Beet \& Price 1982: 149-195.

Dragtenstein, Frank. 2002. De ondraaglijke stoutheid der wegloopers: Marronage en koloniaal beleid in Suriname 1667-1768 [Bronnen voor de Studie van Suriname 22]. Utrecht: CLACS \& IBS.

Dragtenstein, Frank. 2004. Trouw aan de blanken: Quassie van Nieuw Timotibo, twist en strijd in de 18de eeuw in Suriname. Amsterdam: KIT.

Dubelaar, C. N. 1995. The petroglyphs of the Lesser Antilles, the Virgin Island and Trinidad, with 689 text illustrations, Societas investigatrix hitoriae naturalis regionis Caribenis. Publications for Scientific research in the Caribbean Region 135: 414-424.

Dubelaar, C. N., \& Pakosie, A. 1988. Seven notes in Afaka script. Nieuwe West-Indische Gids/New West Indian Guide 62(3/4): 146-164.

Dubelaar, C. N., \& Pakosie, A. 1993. Kago Buku: Notes by Captain Kago from Tabiki, Tapanahoni River, Suriname, written in Afaka script. New West Indian Guide/Nieuwe West-Indische Gids 67(3/4): 239-279. 
Dubelaar, C. N., Pakosie, André R. M. \& Hoogbergen, Wim. 1999. Het Afakaschrift van de Tapanahoni in Suriname. Amsterdam: Thela Thesis.

du Tertre, Jean-Baptiste. 1654. Histoire générale des Isles de Saint-Christophe, de la Guadeloupe, de la Martinique et autres de l'Amérique. Paris: Jacques Langlois et Emmanuel Langlois.

du Tertre, Jean-Baptiste. 1667-1671. Histoire générale des Antilles habitées par les François. Paris: Thomas Jully.

Echteld, Jan. 1961. The English Words in Sranan. Groningen: Wolters.

Edmundson, George. 1901. The Dutch in Western Guiana. The English Historical Review 16(64): 640-675. doi:10.1093/ehr/XVI.LXIV.640

Eersel, C.H. 1998. The use of language in Winti, an African-American religion. Caribnet. Journal of the Caribbean Studies international network 1: 95-101.

Encyclopedie. 1977. Encyclopedie van Suriname. Amsterdam: Elsevier.

Eltis, David. 2000. The Rise of African Slavery in the Americas. Cambridge: CUP.

Eltis, David. 2001. The volume and structure of the transatlantic slave trade: A reassessment. William and Mary Quarterly 58(3rd Series): 17-46. doi:10.2307/2674417

Eltis, David \& Richardson, David. 1997. The "numbers game" and routes to slavery. In Routes to Slavery: Direction, Ethnicity and Mortality in the Transatlantic Slave Trade, David Eltis \& David Richardson (eds), 1-15. London: Frank Cass. (Special issue of Slavery \& Abolition $18(1))$.

Eltis, David, Behrendt, Stephen D., Richardson, David \& Klein, Herbert S. 1999. The Transatlantic Slave Trade, 1562-1867: A Database on CD-ROM. Cambridge: CUP.

Essed, Hugo A. M. 1984. De Binnenlandse Oorlog in Suriname, 1613-1793. Paramaribo: Anton de Kom Universiteit van Suriname.

Everaert, Huub A. M. 1999. Een zoektocht naar de aard van man-vrouw relaties onder Surinaamse slaven: de suikerplantages Fairfield, Breukelerwaard, Cannewapibo en La Jalousie in de periode voorafgaande aan de emancipatie. PhD dissertation, University of Amsterdam.

Ferguson, Charles A. 1971. Absence of copula and the notion of simplicity: A study of normal speech, baby talk, foreigner talk, and pidgins. In Pidginization and Creolization of Languages, Dell Hymes (ed.), 141-150. Cambridge: CUP.

Fermin, P. 1769. Description générale, géographique et physique de la colonie de Surinam. Amsterdam: Van Harrevelt.

Ferraz, Luis. 1979. The Creole of São Tomé. Johannesburg: Witwatersrand University Press.

Ferrier, Deryck J. H. 2001. Surinames oudste liedje. In Jan Bongers et al., Tussen droom en werkelijkheid: een keuze uit de literaire pagina van de Ware Tijd, 134-138. Paramaribo: Okopipi.

Fields, Linda. 1995. Early Bajan: Creole or non-creole? In The Early Stages of Creolization [Creole Language Library 13], Jacques Arends (ed.), 89-111. Amsterdam: John Benjamins. doi:10.1075/cll.13.07fie

Fleischmann, Ulrich. 1984. Communication et langues de communication pendant l'esclavage aux Antilles: Contribution aux problèmes de la genèse des langues créoles. Etudes Créoles 6: $29-46$.

Focke, H. C. 1855. Neger-Engelsch woordenboek. Leiden: Van den Heuvell.

Focke, H. C. 1855b. Boekaankondiging. Kurzgefasste Neger-Englische Grammatik. In H. C. Focke et al. (eds.), West-Indië. Bijdragen tot de bevordering van de kennis der Nederlandsch WestIndische koloniën, vol. 1, 296-299. Haarlem: Kruseman.

Focke, H. C. 1858. De Surinaamsche negermuzijk. In H. C. Focke et al. (eds.), West-Indië. Bijdragen tot de bevordering van de kennis der Nederlandsch West-Indische koloniën, vol. 2, 93-107. Haarlem: Kruseman. 
Franssen Herderschee, Alphons. 1905. Verslag der Tapanahoni-Expeditie. Leiden: E. J. Brill.

(Originally in Tijdschrift van het Koninklijk Nederlandsch Aardrijkskundig Genootschap, 1905: 847-1032).

Gates Jr., Henry Louis. 1988. The Signifying Monkey: A Theory of Afro-American Literary Criticism. Oxford: OUP.

Genovese, Eugene D. 1976. Roll, Jordan, Roll: The World the Slaves Made. New York NY: Vintage. Gonggryp, J. W. 1960. The evolution of a Djuka-script in Surinam. New West Indian Guide 40: 63-72. doi:10.1163/22134360-90002363

Goodman, Morris. 1987. The Portuguese element in the American creoles. In Pidgin and Creole Languages. Essays in Memory of John E. Reinecke, Glenn Gilbert (ed.), 361-405. Honolulu HI: University of Hawaii Press.

Greenfield, W. 1830. A Defence of the Surinam Negro-English Version of the New Testament. Londen: Bagster.

Grimes, B. F. 1996. Ethnologue Language Name Index. Summer Institute of Linguistics.

Harcourt, Robert. 1613. A Relation of a Voyage to Guiana. Hakluyt society [1928].

Hair, Paul Edward Hedley. 1967. Ethnolinguistic continuity on the Guinea Coast. Journal of African History 8: 247-268. doi:10.1017/So021853700007040

Hair, Jones Adam \& Law, Robert. 1992. Barbot on Guinea. The Writings of Jean Barbot in West Africa 1678-1712. London: The Hakluyt Society.

Hall, Robert Anderson. 1966. Pidgin and Creole Languages, Vol. 7. Ithaca NY: Cornell University Press.

Hancock, Ian. 1986. The domestic hypothesis, diffusion and componentiality. An account of Atlantic Anglophone creole origins. In Substrata versus Universals in Creole Genesis [Creole Language Library 1], Pieter Muysken \& Norval Smith (eds), 71-102. Amsterdam: John Benjamins. doi:10.1075/cll.1.06han

Harlow, Vincent T. (ed.). 1925. Colonising Expeditions to the West Indies and Guiana, 1623-1667. London: Hakluyt Society.

Harris, John W. 1985. The 1830 defence of Sranan: William Greenfield's gift to the creole-speaking world. OSO, Tijdschrift voor Surinaamse Taalkunde, Letterkunde, Cultuur en Geschiedenis 4: $213-220$.

Hartsinck, J. J. 1770. Beschrijving van Guiana. Amsterdam: Tielenburg.

Hazaël-Massieux, Guy. 1994. Les plus anciens textes de créole français de la Caraïbe. Apport et fiabilité. In Actas do XIX Congreso Internacional de Lingüística e Filoloxía Románicas, Santiago de Compostela, 1989: Seccion X. Historia da Linguistica e da filoxia romanicas, Ramón Lorenzo (ed.).

Hazaël-Massieux, Guy. 1996. Les créoles: Problèmes de genèse et de description. Aix-en-Provence: Publications de l'Université de Provence. (posthumous collection).

Hein, Jeanne. 1993. Portuguese communication with Africans on the searoute to India. Terrae Incognitae 25: 41-51. doi:10.1179/tin.1993.25.1.41

Helman, Albert. 1982. Avonturen aan de wilde kust. De geschiedenis van Suriname met zijn buurlanden. Alphen aan den Rijn: Sijthoff.

Helmig van der Vegt, A. 1844. Proeve eener handleiding om het Neger-Engelsch. Amsterdam: Van Kampen.

Helstone, J. N. 1903. Wan Spraakkunst vo taki en skrifi da tongo vo Sranan, een grammatica van de Surinaamse taal. Paramaribo: Heyde.

Helstone, Heinrich \& Vernooij, Joop. 2000. Documentatie afschaffing van de slavernij in Suriname. Paramaribo [s.n.]. 
Herlein, J. D. 1718. Beschrijvinge van de volksplantinge Zuriname. Leeuwarden: Injema. Hermann, Paul. 1689. Horti academici Lugduno-Batavi catalogus. doi:10.5962/bhl.title.98142 Herskovits, Melville J. \& Herskovits, Frances S. 1936. Suriname Folklore. New York NY: Columbia University Press. (Reprinted 1969, New York NY: AMS Press).

Hira, Sandew. 1982. Van Priary tot en met De Kom: De geschiedenis van het verzet in Suriname, 1630-1940. Rotterdam: Futile.

Hoefte, Rosemarijn. 1996. Free blacks and coloureds in plantation Suriname: The struggle to rise. In Against the Odds: Free Blacks in the Slave Societies of the Americas, Jane G. Landers (ed.), 102-129. London: Frank Cass. (Also published in: Slavery \& Abolition 17(1): 102-129).

Hoefte, Rosemarijn. 2001. Development of a multiethnic plantation economy: An introduction to the history of Suriname from circa 1650 to 1900. In Hoefte \& Meel (eds), 1-22.

Hoefte, Rosemarijn \& Meel, Peter (eds). 2001. Twentieth-century Suriname: Continuities and Discontinuities in a New World Society. Kingston \& Leiden: Ian Randle Publishers \& KITLV Press.

Hoeree, Joris. 1983. De Saramakaanse wereld: Formatie, stabilisatie, akkulturatie. PhD dissertation, Rijksuniversiteit Gent.

Holm, John. 1988. Pidgins and Creoles, Vol 2. Cambridge: CUP.

Hostmann, F. W. 1850. Over de beschaving van negers in Amerika, door kolonisatie met Europeanen. Amsterdam: J. C. A. Sulpke.

Hoogbergen, Wim. 1990. The history of the Suriname Maroons. In Brana-Shute (ed.), 65-102.

Hoogbergen, Wim. 1992. De Bosnegers zijn gekomen! Slavernij en rebellie in Suriname. Amsterdam: Prometheus.

Hoogbergen, Wim. 1996. De kunu van Ta Agosto. OSO, Tijdschrift voor Surinaamse Taalkunde, Letterkunde, Cultuur en Geschiedenis 15(2): 181-190.

Hoogbergen, Wim \& de Theye, Marjo. 1986. Surinaamse vrouwen in de slavernij. Vrouwen in de Nederlandse koloniën. In Zevende jaarboek voor vrouwengeschiedenis, Jeske Reijs Els Kloek, Ulla Jansz, Annemarie de Wildt, Suzanne van Norden \& Mirjam de Baar (eds), 126-151. Nijmegen: Sun.

Hoogbergen, Wim \& Polimé, Thomas. 2000. De Saramakaanse vrede in het Sranantongo. OSO, Tijdschrift voor Surinaamse Taalkunde, Letterkunde, Cultuur en Geschiedenis 19: 221-240.

Huber, Magnus. 1999. Atlantic English creoles and the lower Guinea coast: A case against Afrogenesis. In Spreading the Word: The Issue of Diffusion among the Atlantic Creoles, Magnus Huber \& Mikael Parkvall (eds), 81-110. London: University of Westminster Press.

Huttar, George L. 1975. Sources of creole semantic structures. Language 51: 684-695. doi: $10.2307 / 412893$

Huttar, George L. 1981. Some Kwa-like features of Djuka syntax. Studies in African Linguistics 12: 291-323.

Huttar, George L. 1985. Sources of Ndjuka African vocabulary. New West Indian Guide 59: 45-71. doi: $10.1163 / 13822373-90002077$

Huttar, G. L. 1987. Afaka and his Creole Syllabary. In: Annual Meeting of the Linguistic Association of the South West, October.

Huttar, George L. 1989. The Portuguese contribution to the Ndjuka lexicon. In Estudios sobre Español de América y lingüística Afroamericana: Ponencias presentadas en el 45 Congreso Internacional de Americanistas (Bogotá, julio de 1985), 263-279. Instituto Caro y Cuervo.

Huttar, G. L. 1992. Afaka and his Creole syllabary: The social context of a writing system. In: Shin Ja J. Hwang and William R. Merrifield (eds). Language in context: Essays for Robert E. Longacre, 593-604. 
Huttar, George L. \& Huttar, Mary L. 1994. Ndyuka. London: Routledge.

Huttar, George L. \& Velantie, Frank J. 1997. Ndyuka-Trio Pidgin. In Contact Languages: A Wider Perspective [Creole Language Library 17], Sarah Grey Thomason (ed.), 99-124. Amsterdam: John Benjamins. doi:10.1075/cll.17.07hut

Israel, Jonathan. 1995. De Republiek der Verenigde Nederlanden tot omstreeks 1750: Demografie en economische activiteit. In De geschiedenis van de joden in Nederland, Hans Blom, Rena Fuks-Marsfeld \& Ivo Schöffer (eds), 97-126. Amsterdam: Balans.

Israel, Jonathan. 1992. The Sephardi contribution to economic life and colonization in Europe and the New World (16th-18th centuries). In Moreshet Sepharad: The Sephardi lecagy, Vol. 2, Haim Beinart (ed.), 365-398. Jerusalem: Magness Press.

Janssen, René, ten Hove, Okke \& van der Aa, A. J. 1993. Historisch-geografisch Woordenboek van Suriname. Utrecht: Vakgroep Culturele Antropologie, Utrecht University.

Jennings, William. 1995. The first generations of a Creole society: Cayenne 1660-1700. In From Contact to Creole and Beyond, Philip Baker (ed.), 21-40. London: University of Westminster Press.

Jones, Adam. 1985. Brandenburg Sources for West African History 1680-1700. Stuttgart: Steiner. Kappler, August. 1983[1854]. Zes jaren in Suriname. Zutphen: Walburg Pers.

Keller, Saskia. 1982. De slavenplantage: Een totale institutie? Antropologische Verkenningen 1: $1-45$.

Klein, Herbert. 1986. African Slavery in Latin America and the Caribbean. Oxford: OUP.

Klinkers, Elle. 1997. Op hoop van vrijheid: van slavensamenleving naar Creoolse gemeenschap in Suriname, 1830-1880. Utrecht: Vakgroep Culturele Antropologie, Utrecht University.

Koefoed, Geert \& Tarenskeen, Jacqueline. 1996. The making of a language from a lexical point of view. In Wekker, H. (ed.) Creole languges and language acquisition. Berlin: Mouton de Gruyter.

Koenders, Julius Gustaaf Arnout (ed.). 1946-1956. Various issues of the periodical Foetoeboi.

Kraag, Christiaan. 1980[1894-1896]. Copenkrisi, 1894-1896. In Aantekeningen over de geschiedenis van de Kwinti en het dagboek van Kraag (1894-1896), Chris de Beet \& Miriam Sterman (eds), 34-46. Utrecht: Centrum voor Caraibische Studies.

Kramp, André. (1983). Early Creole Lexicography. A study of C. L. Schumann's manuscript dictionary of Sranan. PhD dissertation, Leiden University.

Kropp Dakubu, Mary Esther. 1997. Korle Meets the Sea: A Sociolinguistic History of Accra. Oxford: OUP.

Labat, Jean Baptiste. 1722. Nouveau voyage aux Isles de l'Amérique. Paris: J. B. Delespine.

Labat, Jean Baptiste. 1730. Voyage du Chevalier des Marchais en Guinée, isles voisines et à Cayenne. Paris: G. Saugrain.

Labov, William. 1972. Rules for ritual insults. In Language in the Inner City. Studies in the Black English Vernacular, William Labov (ed.). Philadelphia PA: University of Pennsylvania Press.

Labov, William. 1990. On the adequacy of natural languages, I: The development of tense. In Pidgin and Creole Tense-mood-aspect Systems [Creole Language Library 6], John V. Singler (ed.), 1-58. Amsterdam: John Benjamins. doi:10.1075/cll.6.02lab

La Courbe, M. J. D. 1688. Premier voyage fait à la coste d'Afrique en 1685. Ed. Prosper Cultru. Paris: Societe d'Histoire des Colonies Françaises. 1913.

Ladhams, J. 1996. The Portuguese creole spoken in Guinea-Bissau-French-HonoriodoCouto, H.

Ladhams, John. 1999. The Pernambuco connection? An examination of the nature and origin of the Portuguese elements in Surinam creoles. In Spreading the Word: The Issue of Diffusion among the Atlantic Creoles, Magnus Huber \& Mikael Parkvall (eds), 209-248. London: University of Westminster Press. 
Ladhams, John. 2006. In search of West African Pidgin Portuguese. Revista Internacional de Lingüística Iberoamericana 7: 87-105.

Laffrado, Laura. 2001. Constructing the subaltern: white creole culture and raced captivity in eighteenth-century Dutch Suriname. Studies in Eighteenth-Century Culture 30: 31-48. doi: $10.1353 /$ sec.2010.0361

Lalla, Barbara \& D'Costa, Jean. 1990. Language in Exile. Tuscaloosa AL: The University of Alabama Press.

Lammens, A. 1982[1816-1822]. Bijdragen tot de Kennis van de Kolonie Suriname. Amsterdam: Geografisch en Planologisch Instituut VU.

Lamur, Humphrey. 1985. De kerstening van de slaven van de Surinaamse plantage Vossenburg, 1847-1878. Amsterdam: Department of Anthropology, University of Amsterdam.

Lamur, Humphrey. 1987. The production of sugar and the reproduction of slaves at Vossenburg, Suriname 1705-1863. Amsterdam: Centre for Caribbean Studies.

Lamur, Humphrey. 1990. Slave religion on the plantation Vossenburg (Suriname) and missionaries' reaction. In Brana-Shute (ed.), 103-117.

Lefebvre, Claire. 1998. Creole Acquisition and the Origin of Grammar. Cambridge: CUP.

[Lefroy, C. E.] 1826. Outalissi: A tale of Dutch Guiana. Londen: Hatchard.

Lenders, Maria. 1996. Strijders voor het lam. Leven en werk van Herrnhutter-broeders en -zusters in Suriname, 1735-1900. Leiden: KITLV Press.

le Page, Robert. 1960. Jamaican Creole. An Historical Introduction to Jamaican Creole. London: Macmillan.

Lichtveld, U. M. 1966. De onbekende Herlein. Nieuwe West-Indische Gids/New West Indian Guide 45(1): 27-31.

Lichtveld, Ursy \& Voorhoeve, Jan. 1980[1958]. Suriname: Spiegel der vaderlandse kooplieden. Den Haag: Nijhoff.

Lomax, Alan. 1993. The Land Where the Blues Began. New York NY: Pantheon Books \& London: Methuen.

Loor, A.H. 1973. De kartografie in dienst van de landbouw. In Links With the Past. The History of the Cartography of Suriname, 1500-1971, Cornelis Koeman (ed.), 36-73. Amsterdam: Theatrum Orbis Terrarum.

Lorimer, Joyce. 1989. English and Irish Settlement on the River Amazon, 1550-1646. London: Hakluyt Society.

Lucassen, Jan \& Penninx, Rinus. 1994. Nieuwkomers, nakomelingen, Nederlanders: Immigranten in Nederland 1550-1993. Amsterdam: Het Spinhuis.

Manning, Patrick. 1990. Slavery and African life. Occidental, Oriental, and African Slave Trades. Cambridge: CUP.

Marcus, Jacob R. 1970. The Colonial American Jew, 1492-1776, 3 Vols. Detroit MI: Wayne State University Press.

Martinus, Efraim Frank. 1996. The Kiss of a Slave: Papiamentus West-African Connections. PhD dissertation, University of Amsterdam.

McLeod-Ferrier, Cynthia. 1993. Elisabeth Samson: Een vrije, zwarte vrouw in het achttiende-eeuwse Suriname [Bronnen voor de Studie van Afro-Suriname 15]. Utrecht: Department of Cultural Anthropology, Utrecht University.

McWhorter, John. 1992. Substratal influence in Saramaccan serial verb constructions. Journal of Pidgin and Creole Languages 7: 1-53. doi:10.1075/jpcl.7.1.02mcw

McWhorter, John H. 1996. The diachrony of predicate negation in Saramaccan Creole: Synchronic and typological implications. Studies in Language 20: 275-301. doi:10.1075/sl.20.2.03mcw 
McWhorter, John H. 1997. Towards a New Model of Creole Genesis. New York NY: Peter Lang. Medendorp, Clazien. 1994. Licht en luimen, of W.E. H. Winkels, tekenaar in Suriname in de 19e eeuw. Mededelingen van het Surinaams Museum 53: 3-13.

de Mello, José Antônio Gonsalves. 1989. Gente da Naçao. Recife: Fundaçâo Joaquim Nabuco and Editora Massangana.

Merian, Maria Sibylla. 1699. Studienbuch. (See Beer (1976)).

Merian, Maria Sibylla. 1705. Metamorphosis insectorum Surinamensium ofte Verandering der Surinaamsche insecten. Amsterdam: Gerard Valck.

Migge, Bettina M. 1998. Substrate influences in the formation of the Surinamese Plantation Creole: A consideration of the sociohistorical data and linguistic data from Ndyuka and Gbe. PhD dissertation, Ohio State University.

Migge, Bettina M. 1999. The origin of prepositional phrases in the Surinamese Plantation Creole. Presented at the 9th International Colloquium on Creole Studies. Université de Aix-enProvince, Aix-en-Province, France.

Migge, Bettina M. 2003. Creole Formation as Language Contact: The Case of the Suriname Creoles [Creole Language Library 25]. Amsterdam: John Benjamins. doi:10.1075/cll.25

Milroy, Leslie. 1980. Language and Social Networks. Oxford: Blackwell.

Milroy, James. 1992. Linguistic Variation and Change. Oxford: Blackwell.

Mintz, Sidney W. 1959. The plantation as a socio-cultural type. In Plantation systems of the New

World: papers and discussion summaries of the seminar held in San Juan, Puerto Rico, Vera Rubin, . (eds), 42-50. Washington DC: Pan American Union.

Mintz, Sidney W. 1987. Suiker \& macht: De rol van suiker in de geschiedenis. Utrecht: Veen.

Moes, C. M. 1858. Boekaankondiging: H. C. Focke, Neger-Engelsch woordenboek; H. R. Wullschlägel, Deutsch-Negerenglisches Wörterbuch. West-Indië 2: 300-316.

Morgan, Philip D. 1997. The cultural implications of the Atlantic slave trade: African regional origins, American destinations and New World developments. In Routes to Slavery: Direction, Ethnicity and Mortality in the Transatlantic Slave Trade, David Eltis \& David Richardson (eds), 122-145. London: Frank Cass. (Special issue of Slavery \& Abolition 18(1)).

Mous, Maarten \& Haabo, Vinije. 2002. P-language. In Atlas of the Languages of Suriname, Eithne B. Carlin \& Jacques Arends (eds), 163. Leiden \& Kingston: KITLV Press \& Ian Randle Publishers.

Mufwene, Salikoko S. 1986a. Les langues créoles peuvent-elles être définies sans allusions à leurs histoires? Études Créoles 9: 135-150.

Mufwene, Salikoko S. 1986b. Number delimitation in Gullah. American Speech 61: 33-60. doi: $10.2307 / 454708$

Mufwene, Salikoko S. 2001. The Ecology of Language Evolution. Cambridge: CUP. doi: $10.1017 / C B O 9780511612862$

Mühleisen, Susanne. 2002. Creole Discourse: Exploring Prestige Formation and Change across Caribbean English-lexicon Creoles [Creole Language Library 24]. Amsterdam: John Benjamins. doi: 10.1075/cll.24

Mühlhäusler, Peter. 1979. Growth and Structure of the Lexicon of New Guinea Pidgin [Pacific Linguistics, C-52]. Canberra: Australian National University.

Mulert, F. E. 1917. De bewoners van Suriname in 1675. De Navorscher 26.

Müller, Wilhelm J. 1968[1676]. Die africanische auf der guineischen Gold-Cust gelegene Landschafft Fetu. Graz: Akademische Druck- und Verlagsanstalt. 
Muyrers, Sabine. 1993. Het netwerk van de slaaf: Een onderzoek naar contacten van Surinaamse plantageslaven in de achttiende en negentiende eeuw. MA thesis, Erasmus University Rotterdam.

Muysken, Pieter \& Smith, Norval. 1990. Question words in pidgin and creole languages. Linguistics 28: 883-903. doi:10.1515/ling.1990.28.4.883

Nagel, J.H. 1840. Suriname in losse tafereelen en schetsen. Rotterdam: Locke en Zoon.

Naro, Anthony J. 1978. A study on the origins of pidginization. Language 54: 314-347. doi: $10.2307 / 412950$

Nassy, David I. C. 1788. Essai historique sur la colonie de Surinam. English translation: Historical essay on the colony of Surinam. Reprinted in 1974.

Nassy, David I. C. 1791. Geschiedenis van Suriname. Amsterdam: S. Emmering. Reprinted in 1974. Nepveu, Jan. 1765. Klad-Aantekeningen op Herlein's Beschrijvinge van Zuriname. Ms. State Archives, The Hague, Nepveu collection nr. 19. In Voorhoeve \& Lichtveld (1975).

Nepveu, Jan. 1770. Annotatien op de Surinaamsche Beschrijvinge van A0 1718. MS. Municipal Archives, Amsterdam, Marquette-archive, nr. 231, inv. nr. 298. In Arends \& Perl 1995.

Netscher, Pieter Marinus. 1888. Geschiedenis van de koloniën Essequebo, Demerary en Berbice, van de vestiging der Nederlanders aldaar tot op onze tijd. The Hague: Martinus Nijhoff.

Neumann-Holzschuh, Ingrid. 1987. Textes anciens en créole louisianais: avec introduction, notes, remarques sur la langue et glossaire. Hamburg: Helmut Buske.

Neus-Van der Putten, Hilde. 2003. Susanna du Plessis. Portret van een slavenmeesteres. Amsterdam: Koninklijk Instituut voor de Tropen.

Noordwijk, Mavis. 1991. Alonki: Een verzameling Surinaamse volksliedjes, 3rd edn. Paramaribo: Bolivar.

Oomens, Marja. 1986. Veelwijverij en andere losbandige praktijken. In Bevolkingspolitiek tegenover Surinaamse plantageslavinnen in de 19de eeuw, Jeske Reijs Els Kloek, Ulla Jansz, Annemarie de Wildt, Suzanne van Norden \& Mirjam de Baar (eds). Nijmegen: Sun.

Oostindie, Gert. 1986. Kondreman in Bakrakondre: Surinamers in Nederland 1667-1954. In In het land van de overheerser II: Antillianen en Surinamers in Nederland 1634/1667-1954, Gert Oostindie \& Emy Maduro (eds), 1-131. Dordrecht: Foris.

Oostindie, Gert. 1987. Historiography on the Dutch Caribbean (-1985): Catching up? Journal of Caribbean History 21: 1-18.

Oostindie, Gert. 1989. Roosenburg en Mon Bijou: Twee Surinaamse plantages, 1720-1870. Dordrecht: Foris.

Oostindie, Gert. 1990. Preludes to the exodus: Surinamers in the Netherlands, 1667-1960s. In Brana-Shute (ed.), 231-258.

Oostindie, Gert. 1993. Voltaire, Stedman and Suriname slavery. Slavery and Abolition 14: 1-3. doi: $10.1080 / 01440399308575095$

Oostindie, Gert. 1997. Het paradijs overzee. De 'Nederlandse' Caraïben en Nederland. Amsterdam: Bert Bakker.

Oppenheim, Samuel. 1907. An early Jewish colony in Western Guiana, 1658-1666: And its relation to the Jews in Surinam, Cayenne and Tobago. Publications of the American Jewish Historical Society 16: 95-186.

Oppenheim, Samuel. 1909. An early Jewish colony in Western Guiana: Supplemental data. Publications of the American Jewish Historical Society 17: 53-70.

Oudschans Dentz, Frederik. 1918. Suriname vóór de verovering door Abraham Crynssen. Bijdragen en Mededeelingen van het Historisch Genootschap 39: 173-213, 411-412. 
Oudschans Dentz, Frederik. 1975[1927]. De kolonisatie van de Portugeesch Joodsche natie in Suriname en de geschiedenis van de Joden Savanna. Amsterdam: S. Emmering.

Oxenbridge, John. c1667. A Seasonable Proposition of Propagating the Gospel by Christian Colonies in the Continent of Guiana. London.

Parkvall, Mikael. 2000. Out of Africa: African Influences in Atlantic Creoles. London: Battlebridge. Pares, Richard. 1956. Yankees and Creoles: The Trade between North America and the West Indies before the American Revolution. Cambridge MA: Harvard University Press.

Perl, Matthias. 1990. A reevaluation of the importance of early Pidgin/Creole Portuguese. Journal of Pidgin and Creole Languages 5: 125-130. doi:10.1075/jpcl.5.1.10mat

Perl, Matthias. 1995. Part II: Saramaccan. In Early Suriname Creole Texts: A Collection of 18th-century Sranan and Saramaccan Documents, Jacques Arends \& Matthias Perl (eds), 243-374. Frankfurt: Vervuert.

Pistorius, T. 1763. Korte en zakelijke beschrijving van de kolonie van Zuriname. Amsterdam: Crayenschot.

Plag, Ingo. 1993. Sentential Complementation in Sranan. Tübingen: Max Niemeyer.

Plag, Ingo. 1995. The emergence of taki as a complementizer in Sranan: On substrate influence, universals, and gradual creolization. In The Early Stages of Creolization [Creole Language Library 13], Jacques Arends (ed.), 113-148. Amsterdam: John Benjamins.

doi:10.1075/cll.13.08pla

Plag, Ingo \& Uffmann, Christian. 2000. Phonological restructuring in creole: The development of paragoge in Sranan. In Degrees of Restructuring in Creole Languages [Creole Language Library 22], Ingrid Neumann-Holzschuh \& Edgar Werner Schneider (eds), 309-336. Amsterdam: John Benjamins. doi:10.1075/cll.22.16pla

Postma, Johannes. 1970. The Dutch Participation in the African Slave Trade. Slaving on the Guinea Coast, 1675-1795. PhD dissertation, Michigan State University.

Postma, Johannes. 1990. The Dutch in the Atlantic Slave Trade, 1600-1815. Cambridge: CUP. doi:10.1017/CBO9780511528958

Postma, Johannes. 1998. Breaching the mercantile barriers of the Dutch colonial empire: North American trade with Surinam during the eighteenth century. In Olaf Uwe Janzen (ed.), Merchant organization and maritime trade in the North Atlantic, 1660-1815, Research in Maritime History 15, 107-131, St. John's, Newfoundland: International Maritime Economic History Association.

Postma, Johannes. 2003. Suriname and its Atlantic connections, 1667-1795. In Johannes Postma \& Victor Enthoven (eds), Riches from Atlantic Commerce. Dutch transatlantic trade and shipping, 1585-1817, 287-322, Leiden Brill.

Price, Richard. 1976. The Guiana Maroons. A Historical and Bibliographical Introduction. Baltimore MD: Johns Hopkins University Press.

Price, Richard. 1983a. First Time: The Historical Vision of an Afro-American People. Baltimore MD: Johns Hopkins University Press.

Price, Richard. 1983b. To slay the hydra: Dutch colonial perspectives on the Saramaka wars. Karoma Pub.

Price, Richard. 1990. Alabi's world. Baltimore MD: Johns Hopkins University Press.

Price, Richard \& Price, Sally. 1980. Afro-American Arts of the Suriname Rain Forest. Berkeley CA: University of California Press.

Price, Richard, \& Price Sally (eds). 1988. Narrative of a Five Years Expedition against the Revolted Negroes of Surinam. Baltimore MD: Johns Hopkins University Press. 
Price, Richard \& Price, Sally. 1991. Two Evenings in Saramaka. Chicago IL: The University of Chicago Press.

Price, Richard \& Price, Sally. 2003. The Root of Roots: Or, How Afro-American Anthropology Got its Start. Chicago IL: Prickly Paradigm Press.

Prudent, Lambert-Felix. 1993. Pratiques langagières martiniquaises: Genèse et fonctionnement d'un système créole. PhD dissertation, Université de Rouen Haute Normandie.

Quandt, C. 1968[1807]. Nachricht von Suriname und seine Einwohnern. Amsterdam: S. Emmering. Randt, A. 1779. Oto va oure fri Gado bi meki ko sombre. Ms 621. Moravian Archives Utrecht.

Reinecke, John E. 1987. William Greenfield, a neglected pioneer creolist. In Pidgin and Creole Languages: Essays in Memory of John E. Reinecke, Glenn G. Gilbert (ed.), 23-34. Honolulu HI: University of Hawaii Press. ([Originally published in Lawrence D. Carrington (ed.), Studies in Caribbean language, 1-12. St. Augustine, Trinidad: Society for Caribbean Linguistics, 1983).

Rens, Lucien. 1953. The Historical and Social Background of Surinam's Negro-English. Amsterdam: North-Holland.

Rens, Lucien. 1982[1954]. Analysis of annals relating to early Jewish settlement in Surinam. In The Jewish Nation in Surinam: Historical Essays, Robert Cohen (ed.), 29-46. Amsterdam: S. Emmering. (Originally published in Vox Guyanae 1:19-38).

Rickford, John R. 1986. Social contact and linguistic diffusion: Hiberno-English and New World Black English. Language, 245-289.

Rickford, John R. 1987. Dimensions of a Creole Continuum: History, Texts, \& Linguistic Analysis of Guyanese Creole. Stanford CA: Stanford University Press.

Rickford, John R. \& Handler, Jerome S. 1994. Textual evidence on the nature of early Barbadian speech, 1676-1835. Journal of Pidgin and Creole Languages 9: 221-255.

doi:10.1075/jpcl.9.2.02ric

Riemer, A. 1801. Missions-Reise nach Surinam und Barbice. Zittau.

Rodway, James. 1912. Guiana: British, Dutch and French. New York: Fisher Unwin.

Roth, Cecil. 1930. Notes sur les Marranes de Livourne. Revue des Etudes Juives 91: 1-27.

Roth, Cecil. 1974[1932]. A History of the Marranos. New York NY: Schocken Books.

Rountree, S. Catherine \& Glock, Naomi. 1977. Saramaccan for Beginners: A Pedagogical Grammar of the Saramaccan Language. Paramaribo: Instituut voor Taalwetenschap \& Summer Institute of Linguistics.

Sanford, Robert. 1662. Surinam Justice. London.

Schaafsma, M. D. 1966. Suriname: Militair geschiedkundig overzicht (tot 1683). Jaarboek van de Koninklijke Landmacht 1966: 336-352.

Schaafsma, M. D. 1967. Suriname. Militair-geschiedkundig overzicht (tweede deel) van 1683 tot 1795. Jaarboek van de Koninklijke Landmacht 1967.

Schilder, Günter. 1973. Een historisch overzicht van de ontdekking van Suriname tot 1667. In Links with the past. The history of the cartography of Suriname, 1500-1971, Cornelis Koeman (ed.), 1-35. Amsterdam: Theatrum Orbis Terrarum.

Schiltkamp, Jacob A. \& de Smit, T. 1973. West Indisch Plakaatboek. I Suriname: Plakaten, ordonnantien en andere wetten, uitgevaardigd in Suriname, 1667-1816. Amsterdam: S. Emmering.

Schouten, Hendrik. 1783. Een huishoudelijke twist. In: Voorhoeve \& Lichtveld (1975).

Schouten-Elsenhout, Johanna. 1974. Sranan pangi. 1057 Sranan odo di Johanna SchoutenElsenhout piki makandra. Paramaribo: Bureau Volkslektuur.

Schuchardt, Hugo. 1909. Die Lingua Franca. Zeitschrift für Romanische Philologie 33: 441-61. 
Schuchardt, Hugo. 1914. Die Sprache der Saramakkaneger in Surinam. Amsterdam: Johannes Müller.

Schumann, Christian Ludwig. 1778. Saramaccanisch-Deutsches Wörterbuch. In Die Sprache der Saramakkaneger in Surinam, Hugo Schuchardt (ed.), 1914, 44-120. Amsterdam: Johannes Müller.

Schumann, Christian Ludwig. 1781. Die Geschichte unseres Herrn und Heilands Jesu Christi. Moravian Archives Utrecht 12/617.

Schumann, Christian Ludwig. 1783. Deutsch-Negerenglisches Wörterbuch. In Early Creole Lexicography, A. Kramp (ed.), 1983: 44-305. PhD dissertation, Leiden University.

Sebba, Mark. 1986. Adjectives and copulas in Sranan Tongo. Journal of Pidgin and Creole Languages 1: 109-121. doi:10.1075/jpcl.1.1.07seb

Sebba, Mark. 1987. The Syntax of Serial Verbs [Creole Language Library 2]. Amsterdam: John Benjamins. doi: $10.1075 / \mathrm{cll} .2$

Seuren, Pieter \& Wekker, Herman. 1986. Semantic transparency as a factor in creole genesis. In Substrata versus Universals in Creole Genesis [Creole Language Library 1], Pieter Muysken \& Norval Smith (eds), 57-70. Amsterdam: John Benjamins. doi:10.1075/cll.1.05seu

Sheridan, Richard. 1985. Doctors and Slaves. A Medical and Demographic History of Slavery in the British West Indies, 1680-1834. Cambridge: CUP. doi:10.1017/CBO9780511759864

Siegel, Jeff. 1997. Mixing, levelling and pidgin/creole development. In The Structure and Status of Pidgins and Creoles [Creole Language Library 19], Arthur K. Spears \& Donald Winford (eds), 111-149. Amsterdam: John Benjamins. doi:10.1075/cll.19.09sie

da Silva Neto, Serafim. 1957. História da língua portuguesa. Rio de Janeiro.

Singler, John. 1986. Short note. Journal of Pidgin and Creole Languages 1: 141-5.

doi:10.1075/jpcl.1.1.12joh

Singler, John. 1988. The homogeneity of the substrate as a factor in pidgin/creole genesis. Language 64: 27-51. doi: 10.2307/414784

Singler, John. 1990. On the use of sociohistorical criteria in the comparison of creoles. In Issues in Creole Linguistics, Pieter Seuren \& Salikoko Mufwene (eds), 645-659. Linguistics 28(4).

Singler, John. 1992a. Nativization and pidgin/creole genesis. A reply to Bickerton. Journal of Pidgin and Creole Languages 7: 319-333. doi:10.1075/jpcl.7.2.07sin

Singler, John. 1992b. The sources of substratal input into French-lexifier creole in the Caribbean in the seventeenth century: Some demographic evidence. Paper presented at the Ninth Biennial Conference of the Society for Caribbean Linguistics, University of the West Indies, Cave Hill, Barbados, August 28.

Singler, John. 1993a. African influence upon Afro-American language varieties: A consideration of sociohistorical factors. In Africanisms in Afro-American Language Varieties, Salikoko Mufwene (ed.), 235-253. Athens GA: University of Georgia Press.

Singler, John. 1993b. The cultural matrix of creolization: Evidence from Goupy des Marets' description of a 1690 sugar plantation in French Guyana. In Singler 1993d, 187-224.

Singler, John. 1993c. The setting for creole genesis in France's Caribbean colonies: Evidence from seventeenth-century Marie-Galante. In Singler 1993d, 225-236.

Singler, John. 1993d. The African Presence in Caribbean French Colonies in the Seventeenth Century: Documentary Evidence [Travaux de Recherche sur le Créole Haïtien 16-17]. Montréal: UQAM, Groupe de recherche sur le créole haïtien.

Singler, John. 1995. The demographics of creole genesis in the Caribbean: A comparison of Martinique and Haiti. In The Early Stages of Creolization [Creole Language Library 13], Jacques Arends (ed.), 203-232. Amsterdam: John Benjamins. doi:10.1075/cll.13.10sin 
Smith, Abbot E. 1947. Colonists in Bondage: White Servitude and Convict Labor in America, 1607-1776. Chapel Hill NC: The University of North Carolina Press.

Smith, Norval S. H. 1982. The development of nasal-stop clusters in the Surinam creoles. Amsterdam Creole Studies 4: 90-103.

Smith, Norval S. H. 1983. Vroege invloeden op het Sranan van Berbice Nederlands: Enkele mogelijkheden. Gramma /TTT 7: 97-99.

Smith, Norval S. H. 1984. An early source for English in Surinam. Oso, Tijdschrift voor Surinaamse Taalkunde, Letterkunde, Cultuur en Geschiedenis 3: 31-33.

Smith, Norval S.H. 1987. The Genesis of the Creole Languages of Surinam. PhD dissertation, University of Amsterdam.

Smith, Norval S. H. 1996. We-focus in Saramaccan: Substrate feature or grammaticalization? In Changing Meanings, Changing Functions: Papers Relating to Grammaticalization in Contact Languages, Philip Baker \& Anand Syea (eds), 113-128. London: University of Westminster Press.

Smith, Norval S. H. 1999. Pernambuco to Surinam 1654-1665? The Jewish slave controversy. In Spreading the Word: The Issue of Diffusion among the Atlantic Creoles, Magnus Huber \& Michael Parkvall (eds), 251-298. London: University of Westminster Press.

Smith, Norval S. H. 2002. The history of the Surinamese creoles II: Origin and differentiation. In Atlas of the Languages of Suriname, Eithne B. Carlin \& Jacques Arends (eds), 131-151. Leiden \& Kingston: KITLV Press \& Ian Randle Publishers.

Smith, Norval S. H. 2003. New evidence from the past: To epenthesize or not to epenthesize? That is the question. In Phonology and Morphology of Creole Languages, Ingo Plag (ed.), 91-107. Tübingen: Niemeyer.

Smith, Norval, Robertson, Ian E. \& Williamson, Kay. 1987. The Ijo element in Berbice Dutch. Language in Society 16: 49-90. doi:10.1017/Soo47404500012124

Stassen, Leon. 1985. Comparison and Universal Grammar. PhD dissertation, Katholieke Universiteit Nijmegen.

Speedy, Karin. 1995. Mississippi and Tèche Creole: Two separate starting points for Creole in Louisiana. In From Contact to Creole and Beyond, Philip Baker (ed.). London: University of Westminster Press.

Stähelin, F. 1913-1919. Die Mission der Brüdergemeinde in Surinam und Berbice im achtzehnten Jahrhundert, 3 Vols. Herrnhut: Vereins für Brüdergeschichte in Kommission der Unitätsbuchhandlung in Gnadau.

Stedman, John Gabriel. 1790. Narrative of a Five Years Expedition against the Revolted Negroes of Surinam. Original manuscript version, Richard \& Sally Price (eds.), (1988). Baltimore MD: Johns Hopkins University Press.

Stedman, John Gabriel. 1796. Narrative of a Five Years' Expedition, against the Revolted Negroes of Surinam, first printed version, R. A. J. van Lier (ed.), 1972. Amherst MA: University of Massachusetts Press.

Steger, Hanns-Albert. 1973. Der karibische Raum. In Lateinamerika, Gerhard Sandner \& HannsAlbert Steger (eds), 181-213. Frankfurt: Fischer.

Stein, Peter \& Perl, Matthias. 1995. The Sranan and Saramaccan documents in the Unitäts-Archiv (Archives of the Moravian Brethren) at Herrnhut: A commented bibliography. Amsterdam Creole Studies 12: 49-72.

Teenstra, Maarten Douwes. 1835. De landbouw in de kolonie Suriname. Groningen: H. Eekhoff, $\mathrm{Hz}$. 
ten Hove, Okke, Helstone, Heinrich \& Hoogbergen, Wim S. M. 2003. Surinaamse emancipatie 1863: familienamen en plantages. Amsterdam: Rozenberg.

Thoden van Velzen, Hendrik U. E. 2003. Een koloniaal drama. De grote staking van de vrachtvaarders, 1921. Amsterdam \& Utrecht: Rozenberg \& CLACS \& IBS.

Thomason, Sarah G. 2001. Contact-induced typological change.

Thomason, Sarah, and T. Kaufman. 1988. Language contact, creolization, and genetic linguistics. Berkely: University of Califorinia Press.

Toaff, Renzo. 1990. La nazione ebreica a Livorno e a Pisa (1591-1700). Florence: Leo S. Olschki. Turner, Lorenzo Dow. 1949. Africanisms in the Gullah dialect. Chicago IL: University of Chicago. van Alphen, G. 1963. Suriname in een onbekend journaal van 1693. New West Indian Guide 42: 303-313. doi:10.1163/22134360-90002329

van Berkel, Adriaan. 1695. Amerikaansche voyagien. Behelzende een Reis na Rio de Berbice, Mitsgaders een andere na de Colonie van Suriname. Amsterdam: Johan ten Hoom.

van Breugel, G. 1842. Dagverhaal van een reis naar Paramaribo. Amsterdam: Sulpke.

van Cappelle, H. 1926. Mythen en sagen uit West-Indië. Zutphen: Thieme.

van den Berg, Margot. 2000. "Mi no sal tron tongo". Early Sranan in Court Records, 1667-1767. MA thesis, University of Nijmegen.

van den Berg, Margot. 2001. De reconstructie van het 18e eeuwse Sranantongo. Paper presented at the ACLC Junioren-Overleg, 10 December 2001, Amsterdam.

van den Berg, Margot. 2003. Early 18th Century Sranan '-man'. In Phonology and Morphology of Creole Languages, Ingo Plag (ed.), 231-251. Tübingen: Niemeyer.

van den Berg, Margot. 2007. A Grammar of Early Sranan. PhD dissertation, University of Amsterdam.

van den Berg, Margot \& Arends, Jacques. 2004. Court records as a source of authentic early Sranan. In Creoles, Contact and Language Change: Linguistic and Social Implications [Creole Language Library 27], Geneviève Escure \& Armin Schwegler (eds), 21-34. Amsterdam: John Benjamins. doi: 10.1075/cll.27.03ber

van den Boogaart, E. \& Emmer, P. C. (1979). The Dutch participation in the Atlantic slave trade, 1596-1650. In The Uncommon Market: Essays in the Economic History of the Atlantic Slave Trade, Henry A. Gemery \& Jan S. Hogendorn (eds), 353-375. New York NY: Academic Press. van den Bosch, G.-B. (1843). Reizen in West-Indië. Utrecht: Bosch.

van den Bouwhuijsen, Harry, de Bruin, Ron \& Horeweg, Georg. 1988. Opstand in Tempati, 17571760 [Bronnen voor de Studie van Afro-Suriname 12]. Utrecht: Department of Cultural Anthropology, Utrecht University.

van der Linde, J. 1956. Het visioen van Herrnhut en het apostolaat der Moravische Broeders in Suriname (1735-1863). PhD dissertation, Utrecht University.

van der Linde, J. M. 1966. Surinaamse suikerheren en hun kerk. Plantagekolonie en handelskerk ten tijde van Johannes Basseliers, predikant en planter in Suriname, 1667-1689. Wageningen: H. Veenman en Zonen NV.

van der Meiden, G. 1987. Betwist bestuur. Een eeuw strijd om de macht in Suriname, 1651-1753. Amsterdam: De Bataafsche Leeuw.

van der Sijs, Nicoline. 2004. Taal als mensenwerk: Het ontstaan van het ABN. Den Haag: Sdu.

van Deursen, A. 1975. De Surinaamse negerslaaf in de negentiende eeuw. Tijdschrift voor Geschiedenis 88: 210-223.

van Donselaar J. 1993. De boeken van Warren (1667, 1669), Van Berkel (1695) en Herlein (1718) en hun onderlinge betrekkingen. OSO, Tijdschrift voor Surinaamse Taalkunde, Letterkunde, Cultuur en Geschiedenis 12: 87-93. 
van Donselaar, J. 1996. Vroege vondsten van woorden uit Surinaamse creooltalen tot 1764. OSO, OSO, Tijdschrift voor Surinaamse Taalkunde, Letterkunde, Cultuur en Geschiedenis 15: 87-98. van Dyk, Pieter. ca 1765. Nieuwe en nooit bevoorens geziene onderwijzinge in het Bastert Engels, of Neeger Engels. Amsterdam: Jacobus van Egmont.

van Eyck, J. W.S. 1830. Beschouwing van den tegenwoordigen staat, zeden en gewoonten van de Saramaccaner bevredigde Boschnegers, in deze kolonie. Surinaamsche Almanak voor het Jaar 1830, 260-275.

van Eyck-Benjamins, Nelly. 1927. Suriname van 1651 tot 1668. New West Indian Guide 8. van Hoëvell, Wolter Robert. 1854. Slaven en vrijen onder de Nederlandschen wet.

van Hogendorp, Dirk. 1801. Stukken rakende de tegenwoordigen toestand der Bataafse bezittingen in Oost-Indië. Den Haag: J. C. Leeuwestijn.

van Kanten, Frank. 1992. A República dos Palmares. OSO, Tijdschrift voor Surinaamse Taalkunde, Letterkunde, Cultuur en Geschiedenis 11: 156-73.

van Kempen, Michiel (ed.). 1995. Spiegel van de Surinaamse poëzie: Van de oude liedkunst tot de jongste dichters. Amsterdam: Meulenhoff.

van Kempen, Michiel. (2003). Een geschiedenis van de Surinaamse literatuur. Breda: De Geus. van Lier, Rudolf. 1977[1949]. Samenleving in een grensgebi(ed.) Een sociaal-historische studie van Suriname, 3rd edn. Amsterdam: S. Emmering.

van Panhuys, L. C. 1912 Development of ornament amongst the bush-negroes in Suriname. Actes du XVIII Congrès International des Américanistes. London.

van Renselaar, Herman Cornelis. 1966. Oude kaarten van Suriname. New West Indian Guide 45(1): 2-13. doi:10.1163/22134360-90002270

van Rossem, Cefas \& van der Voort, Hein (eds). 1996. Die Creol Taal: 250 years of Negerhollands Texts. Amsterdam: Amsterdam University Press. doi: 10.5117/9789053561348

van Schaick, C. 1856. Proeve van of bijdrage tot de geschiedenis vooral der Hervormde Kerk in Suriname. West-Indie 1: 5-41, 81-88.

van Sijpesteijn, C. 1854. Beschrijving van Suriname. Den Haag: n.p.

van Stipriaan, Alex. 1993. Surinaams contrast: Roofbouw en overleven in een Caraïbische plantagekolonie 1750-1863. Leiden: KITLV Uitgeverij.

van Trier-Guicherit, Ingrid. 1991. De eerste taalgids Sranan-Nederlands. OSO, Tijdschrift voor Surinaamse Taalkunde, Letterkunde, Cultuur en Geschiedenis 10: 31-47.

Veenstra, Tonjes. 1996. Serial verbs in saramaccan. The Hague: Holland Academic Graphics.

von der Groeben, O. F. 1694. Guineische Reisebeschreibung, nebst einen Anhang der Expedition in Morea. (Partially translated into English in Jones 1(985) as Document 6. 1682-83. Otto Friedrich von der Groeben's Account of his Voyage).

von Sack, Albert. 1810. A Narrative of a Voyage to Surinam. London: G. \& W. Nicol. von Sack, A. 1821. Beschreibung einer Reise nach Surinam. Berlin.

Voorhoeve, Jan. 1961. Linguistic experiments in syntactic analysis. In Creole Language Studies No. II, Proceedings of the Conference on Creole Language Studies. Le Page, ed., 37-60. London, Macmillan \& Co., Ltd.

Voorhoeve, Jan. 1964. Creole languages and communication. In Symposium on multilingualism, 233-242).

Voorhoeve, Jan. 1970. The regularity of sound correspondences in a creole language (Sranan). Journal of African Languages 9: 51-69.

Voorhoeve, Jan. 1971. Church creole and pagan cult languages. In Pidginization and Creolization of Languages, Dell Hymes (ed.). Cambridge: CUP. 
Voorhoeve, Jan. 1973. Historical and linguistic evidence in favour of the relexification theory in the formation of creoles. Language in Society 2: 133-145. doi:10.1017/So047404500000099

Voorhoeve, Jan \& Donicie, Antoon. 1963. Bibliographie du négroanglais du Surinam. The Hague: Martinus Nijhoff.

Voorhoeve, Jan \& Lichtveld, Ursy (eds). 1975. Creole Drum. An Anthology of Creole Literature in Surinam. New Haven CT: Yale University Press.

Voorhoeve, Jan \& Kramp, André. 1982. Syntactic developments in Sranan. Paper presented at the 4th Biennial Conference of the Society for Caribbean Linguistics, Paramaribo.

Vrij, Jean Jacques. 2005. Review of Frank Dragtenstein, 'Trouw aan de blanken'. Quassie van Nieuw Timotibo, twist en strijd in de 18de eeuw in Suriname. OSO, Tijdschrift voor Surinamistiek 24: $190-194$.

Warren, George. 1667. An Impartial Description of Surinam on the Continent of Guiana in America. London: William Godbird.

Wätjen, Hermann. 1921. Das Holländische Kolonialreich in Brasilien. Gotha: Verlag Friedrich Andreas Perthes. doi:10.1007/978-94-011-8930-9

Wekker, Gloria. 1993. Mati-ism and Black lesbianism: Two idealtypical expressions of female homosexuality in Black communities of the Diaspora. Journal of Homosexuality 24: 145-158. doi:10.1300/Jo82V24no3_11

Wekker, Just. 1991. Surinaams plantagewezen: Een kwestie van aantallen. OSO, Tijdschrift voor Surinaamse Taalkunde, Letterkunde en Geschiedenis 10: 71-85.

Wendelaar, Wendela \& Koefoed, Geert. 1988. "Sa" en "o" in het Sranan. OSO, Tijdschrift voor Surinaamse Taalkunde, Letterkunde en Geschiedenis 7: 63-75.

Wennekers, P. A. 1822. Rooms-Catholyke catechismus, of kort begrip der christelijke leering, in de Neger-Engelsche taal, voor de colonie Suriname. Amsterdam.

Weygandt, G. C. 1798. Gemeenzame leerwijze, om het basterd of Neger-Engelsch op een gemakkelyke wyze te leeren verstaan en spreeken. Paramaribo: W. W. Beeldsnyder.

Whinnom, Keith. 1965. The origin of the European-based creoles and pidgins. Orbis 14: 509-527.

Whinnom, Keith. 1977. Lingua Franca: Historical problems. In Pidgin and Creole Linguistics, Albert Valdman (ed.), 295-310. Bloomington IN: Indiana University Press.

Wietz, I. L. 1805[1793]. Die Apostel Geschichte in die Saramaka Negersprache übersetzt durch Br. Wietz. Revidirt und abgeschrieben 1805. Part 1: Moravian Archives, Utrecht MS. 632. Part 2: Moravian Archives, Paramaribo; MS H. III A 13(16).

Williamson, J.A. 1923. English Colonies in Guyana and on the Amazon: 1604-1668. Oxford: Clarendon Press.

Willoughby, Francis. c1656. Reasons offered by the Lord Willoughbie why Hee ought not to bee confined in his settlement upon Serranam. [Egerton Mss 2395, ff. 279-282.] In Harlow 1925: 177-183.

Winer, Lise. 1993. Trinidad and Tobago [Varieties of English around the World T6]. Amsterdam: John Benjamins. doi:10.1075/veaw.t6

Winford, Donald. 1998. On the origins of African American Vernacular English: A creolist perspective. Part II: The linguistic features. Diachronica 15: 99-154. doi:10.1075/dia.15.1.05win

Winford, Donald. 2000. Tense and aspect in Sranan and the creole prototype. In Language Change and Language Contact in Pidgins and Creoles [Creole Language Library 21], John McWhorter (ed.), 383-442. Amsterdam: John Benjamins. doi:10.1075/cll.21.14win

Winford, Donald. 2006. The restructuring of tense/aspect systems in creole formation. In Structure and Variation in Language Contact [Creole Language Library 29], Ana Deumert \& Stephanie Durrleman-Tame (eds), 85-110. Amsterdam: John Benjamins. doi:10.1075/cll.29.06win 
Wiznitzer, Arnold. 1954. The exodus from Brazil and arrival in New Amsterdam of the Jewish Pilgrim Fathers, 1654. Publications of the American Jewish Historical Society 44: 80-97.

Wiznitzer, Arnold. 1956. The Jews in the sugar industry of colonial Brazil. Jewish Social Studies 18: 189-198.

Wiznitzer, Arnold. 1960. Jews in Colonial Brazil. New York NY: Columbia University Press.

Wolbers, J. 1853. De slavernij in Suriname of dezelfde gruwelen der slavernij, die in de 'Negerhut' geschetst zijn, bestaan ook in onze West-Indische koloniën! Amsterdam: H. de Hoogh.

Wolbers, J. 1861. Geschiedenis van Suriname, unchanged reprint. Amsterdam: H. de Hoogh.

Wong, E. 1938. Hoofdenverkiezing, stamverdeeling en stamverspreiding der Boschnegers van Suriname in de 18e en 19e eeuw. Bijdragen tot de Taal-, Land-en Volkenkunde van Nederlandsch-Indië 97: 295-362. doi:10.1163/22134379-90001338

Wooding, Charles J. 1981. Evolving Culture: A Cross-cultural Study of Suriname, West Africa, and the Caribbean. Lanham MD: University Press of America.

Wullschlägel, H. R. 1855. Iets over de Neger-Engelsche taal en de bijdragen tot hare ontwikkeling en literatuur, door de zendelingen der Evangelische Broedergemeente geleverd. West-Indië 1: 286-295.

Wullschlägel, H. R. 1965[1854]. Kurzgefasste Neger-Englische Grammatik. Amsterdam. S. Emmering. Wullschlägel, H. R. 1965[1856]. Deutsch-Negerenglisches Wörterbuch. Amsterdam: S. Emmering. Zamuel, Hesdie S. 1994. Johannes King: Profeet en apostel van het Surinaamse Bosland. Zoetermeer: Boekencentrum. 


\section{Index}

A

abolition of slavery $\quad 121,295$, 372

abolition of the slave trade 2, 5

Abron 133-134

Adam, Jonas 424-425

adjectival predication 14,20 , $242,251-252,258,264-265$

Afaka 24, 431-433

Afaka script 24, 431-433

African American English 317,326

African languages $11,13-14$, 18-20, 24-25, 30, 33-34, 131, $154,158,165-166,168-169,183$, 194, 209-210, 213, 223-228, 304, 326

(lexicon) derived from 19, 24, 167-168, 178, 197

African origins 19, 75, 123-125, 135-136

African-born 109, 112-113, $123,138,140,143,151-152,154$, $156-161,169,192-193,224$

Africans 7, 36-38, 44-45, 55, 59, 61-62, 75, 88, 108-109, 122-124, 131-132, 136, 141, 143 , $148,151,172,277,432$

age distribution 122-124, 138-140, 154-157

Akan 11-13, 19, 30, 113, 130, $133-135,225$

Akuapem 133-134, 225

Akuriyo 6

Akuriyo Indians 338

Alabi, Johannes $\quad 4-5,7,28-29$, $121,167,187,349,353,410$, $413-416,418,429$

Aluku $\quad 8-10,17,23,196$ see also Boni

Amerindian languages $6,11,13$, $24,39,88,229-230$ (lexicon) derived from 24
Amerindian slaves $35,44,48$, $60-62,74,84-86,88,120$, $144-145,148,156,210$

Amerindian War 3, 46, 55, 71-73, 76, 86-88, 94, 99

Amerindians 2, 4, 11, 40, 44, $50,55,61,71,73,75-76,83,86$, $88,94,116,119-120,165,175$, 224, 230, 330, 338, 349-350, 403-404

Anansi tori 15, 310-314

Anyi-Baule 134

apprenticeship 6,116,372

Arabic 202, 210, 223-224, 226, 228

Arawak 11, 120, 230, 349-350

Arawak(s) 2, 62, 86, 88, 349-350

Arawakan 6

article 248-251, 253, 258-260, 263-264

definite $13,248-249,272$

indefinite $13,248-249$

plural 13, 249, 351

zero-, absence of 248-251, $258-259,263-264$

Asante 133-134, 225

Asian languages 6

aspect 14, 20, 175, 198, 241, 273, 345

marker 175, 258-259, 273, 423

Atlantic 113, 134, 161

Auka 10, 22, 331, 333, 335, 433 see also Ndyuka, Okanisi

Awutu 225

\section{B}

bakra tongo $165-173,179$, 199-200, 227, 231-234, 241, 247, 268-269, 321, 328, 371, 425

Bantu 11, 19, 113, 131, 134-137, 193, 226 banya $104,193,286,291,296-$ 297, 299-300

baragouin $\quad 39-42$

Barbados 3, 27, 44-45, 52, 54, $56-57,59-61,63,65,71,73$, 81-84, 124-127, 141

Barbot, Jean $\quad 37-38,42$

basic vocabulary $12,18-19$, 6o, 64

Behn, Aphra $\quad 42,238,270,316-317$

Beijer, E. 207-209, 216, 220, 223, 229

Benoit, Pierre J. 211, 214, 216, 220, 363

Berbice 47-52, 81, 349-350, 36o, 414

Berbice Dutch 81,349

Berbice River 48-51

Biet, Antoine $\quad 42,57,59,62$, 70,145

bilingual(ism) 217, 274, 302, 354

Bioprogram 30, 101, 148, 200

black soldiers 4, 116, 213

black(s) see free, manumitted, overseers

black-to-white ratio $\quad 148-149$

Boekhoudt, W. 209, 369, 425

Bolingbroke, Henry 211, 361

Bonaparte, Prince Roland Napoléon 207, 213, 288, 295, 297, 343, 419-420

Boni (language) 272, 275, 357 see also Aluku

Boni (Maroons) 4-5, 10, 17, 23-24, 116, 145, 222, 230, 275, 281, 356, 358, 404

Boni Maroon Wars 4, 5, 24

Bouton, Jacques $39-40$

bozals 152, 154, 157-158, 192-193, 213

Bray, Théodore 290-293

Brazil 1, 3, 36, 39, 47-48, 52-53, $63-71,126,138,150,185,217$ 
Breton, R. $\quad 40-41$

Byam, William 55, 58-60, $80-83,146$

C

Calabary $75-76,126$

Carib 11, 40, 120, 229-230, 350

Cariban 6, 403

Caribbean creoles $42-43,164$, 326

Caribs 2, 40, 62, 74-75, 86-88

Cassewine 90, 92-93, 96

Cassewinica 90, 92-93, 96

Catholic mission 212, 410-411, 422

Cayenne $47-48,53,64-70$, 113,185

Cayenne River 50-53

Chinese 2, 5-6, 11, 302

circumlocution 260-262

clefting 14, 29, 260, 265-266

Coesewijne 92-93

coffee 4, 62, 112, 114, 291-292,

$354,367,394$

plantation 154, 255, 257, 339

coloured authors $\quad 209,277,369$

coloured slaves 110

coloureds 102, 114, 122, 201, 212

free $113-114,172,372$

Commewijne 23, 44-45, $47-48,52,54,63,74,86-87$,

92, 174, 246, 409

comparative 14, 29, 260, 266, 268

complementation 14, 29-30,

247,254

complementizer 20,254

compound 25, 29, 262, 324

compounding 13, 30, 203, 262

Comvalius, Th.A.C. $277,280-$

283, 294, 296, 299-300

consonant cluster $24,177,256$, 270-271

continuum $122,164,181$, 199-200

contract labourers $\quad 5-6,60,302$

conversion 13, 25

Coppename 3, 10, 45, 47, 54, $76,86-88,92-94$

Coppename Maroons $\quad 4,87$

Coppename Nenge $\quad 76,87-88$ copula $14,29,177,242-243,247$,

249, 251-253, 258, 264-265,

272-273

Corantijn $3,47-49,51,53$, 86,96

Cormantin 93, 225-226

Cormantins 113, 135, 224

Cottica 10, 23, 74, 86-87, 174, $179,191,324$

court records $7,28-29,181,224$, 239-240, 242-243, 318-320, 338

creole formation XXIII-XXIV, $1,30-36,46,58,101-102,112$, $122,157,161,200,221,237,276$

creole genesis xxIV, 1, 30-32, $34,87,89,103,131$

creole-to-bozal ratio 154, 157-158

Creoles (persons) 2, 108-109, 158, 192-194, 202, 219, 404 creolization $\mathrm{xxIV}-\mathrm{xxV}, 18$, $30-35,42-43,101,103,123$, $138,164,178,193-194,200$, 237, 262, 268

Crijnssen, Abraham 3, 81

Curaçao 65, 229-230, 283, 296

D

dative $14,189,416$

de Goeje, C. H. $\quad$ 404, 407-408 de Laet, J. 48

definite see article

definiteness 248-251

Demerara 47-48

diphthong 181, 189-190

Djutongo $9,29,165,173,177$, 179, 182-188, 194, 230, 234235, 305-306, 309-310

Duits-tongo 166, 223

Dutch (language) 2, 6, 7, 10-12, 23, 37, 40, 81, 87, 96, 112, 142, 150-151, 165-167, 169-170, 178-180, 189, 191, 198-212, 214-223, 228-229, 231-233, 239, 244, 246-248, 256, 273 , $281,302,305,315-316,321$, $327,337,343-344,349,354$, 369-370, 372-373, 403-410, 426,432 see also Surinamese Dutch -derived (lexicon)

11-12, 166-173, 175-177,

189-190, 199, 231, 233, 246

Dutch Brazil 65-67,69

Dutch Guyana see Guyana

Dutch settlements $3,44,48$, 50-53

Dutch(men) 2, 3, 12, 39, 45, $48-55,59,67,72,74,79-81$, $86,128-129,138,142,146,149$, 150, 151, 211, 220, 222

planters $39,59-60,81$ slavers $\quad 75,125-127,138-139$

E

Eastern Maroon Creoles 8-10, $18,23-24,212$

education $\quad 6,10-11,191,212$, 228, 408

Efutu 225

elision 189,271

Elmina 129-130, 225

emancipation $6,154,163,217$, 295, 372-374, 382, 385, 389, 399, 403

Emancipation Act $\quad 372-373,383$ English (language) 13, 18-19,

24, 33, 37, 40, 55, 60-62, 81-82, $87,117,149,180,185,199,205$, 210, 214-217, 228-229, 239,

$244,247,253,367,409$ as second language $\quad 61-62$, $80,141,253$ -derived (lexicon) 12-13, 18-20, 42, 60, 82, 166-172, 174-179, 181, 198, 203, 233, $238,245-246,263,310,317$, $338,344,361,370$

English(-lexicon) creole 9, 11, $19,27,86,99,178,263,317$ Caribbean (CEC) 43, 164, 326

English planters $71,73,80$, 85-87, 180, 216-217

English settlements 3,45 , $48-53,56,94$

English settlers $3,54,56-57,59$, $77,82-84,125$

English(-owned) plantations 62, 150, 179 'old' $165,174,180,188,246$

Enys, Renatus $\quad 57,63,78$ 
Essequibo $47-49,51-52,63,66$, $68-70,81$

Ewe 24, 130, 135

\section{F}

Fante 133-135, 225

Fermin, Philip 202, 206, 343 first language acquisition XxIV, $32,34,101,138,154,158$, 16o-161

Focke, Hendrik C. 5, 26, 29-30, $132,177-178,184-185,193$, 202, 207-209, 221, 227-228, 241, 254, 260, 266, 272, 277, 279, 281, 283-287, 289, 292, 306-310, 319, 338, 350, 364, 369-371

Fon 130, 135

foto tongo 173,183

Franssen Herderschee, A. 304 free blacks $87,105,107,113-114$, 116, 118-120, 219, 294, 333, 335

French Guiana see Guyana

French (language) 37,39-41, $73,87,150,167,182,188,210$, 214, 216, 221-223, 229, 291, 298, 302, 343

French settlements $3,44,46$, 48-53

French(-lexicon) creole 27, 222

French-owned plantations $73,150,182,188,221$

French(men) 12, 22, 40, 48-50, 70, 72-73, 94, 98, 149, 202, 209, 220-221

Friderici, François de 281 future marking $\quad 241,258,273-274$

\section{G}

Gã 134, 225

Ga-Adangme 225

Gaelic 141

Gbe 11-13, 19, 24-25, 30, 62, 75, $113,130-131,133-135,137,161,234$

German (language) $5,27,87$, $141,166-168,178,187,189,196$, 210, 212, 214, 220, 222-223, 227, 229, 231, 234, 295, 349$351,353,371,410,414-415$

Low- 141-142

German-owned plantations 150
Germans 12, 73, 149, 202, 209, 222-223, 409

Ghana 11, 75, 128, 225

Gold Coast 125, 127-130, 133-136, 140, 161

Gospel Harmony $\quad 28,349$

gradualist model 30, 200, 262

Grain Coast 127-130, 133-134, 136-137, 140, 161

grammaticalization 13,30 , 248-249, 262

Greenfield, William 5, 204-205 Grego, Christian 5, 7, 28-29, $121,410,413-419,421$

\section{Guang 225}

Guiana see Guyana

Guinea 33, 39, 42, 129-130, 140

Guinea Coast 129-130, 140

Guyana 1, 3, 27, 35-36, 42, $44-48,56,66,126,196$

British 42, 46-47

Dutch 47,48

French 5, 10-11, 35, 47-48, $113,121,185,228$

Greater 47,48

Spanish 42

Guyanais 196, 228

Guyane 1, 46-48, 54, 81, 121, 222, 230

\section{$\mathrm{H}$}

Hakka 6

Hartsinck, J. J. 81, 88, 93-94, $98,135,184,327,340,348,357$

Helmig van der Vegt, A. 201, 206-208, 211, 358

Helstone, J. N. 6, 26, 211-212, 404-405

Herbarium Hermann $\quad 238,317$ Herlein, J. D. 4, 22, 28-29, 98, $106,116,118,175-176,181,195$, 210, 215, 219, 222, 224-225, 233, 238, 243-254, 256-260, 262-265, 267-270, 274, 319, $321,324,328,343-344,356,411$

Herlein fragment 175,181 , 243-247, 251, 258-259, 321

Herrnhutters 202, 212

Herskovits, Melville J. \& Herskovits, Frances S. 7, 15, 20, 26, 277, 293, 299, 304-306, 311
Hindi 6

Hindustani 6

Hindustani(s) 2, 5-6, 11

homestead society 54,63

Huguenots 4, 72-73, 220-221,

247,292

\section{I}

Iberian languages $\quad$ 182, 218

Iberian-derived lexicon 41, 43,182

Iberian-lexicon creole $\quad 182$

Ibibio 126, 134

ideophone $13,281,286,293,313$

Igbo 134

indefinite see article

indentured

$$
\begin{aligned}
& \text { labour } 61,72,142 \\
& \text { labourers } 2,60-61,141-142, \\
& \quad 172 \\
& \text { servants } 57-58,60-61,80, \\
& \quad 86,125,132
\end{aligned}
$$

Indian(s) see Amerindian(s)

interpreters $37-38,182,210,229$

Irish (language) 61

Irish(men) 57-58, 60-61, 86, 125,141

irrealis $258,273-274$

Ivory Coast $\quad 11,128-129$

J

Jamaica $3,65,73,79,81,83-85$, $101,199,216,326,370$

Jamaican Creole $199,326,413$ Javanese 2, 6, 11 Javanese (language) 2, 6, 426 Jewish $63,65-68,83,184-185$, 211, 212, 218, 220, 229 -owned plantations 87,105 , $108,177,182-185,229-230$, 310

planters $39,41,55-56$, $64-65,67,69,74,87,108$, $150,182,184,218$ settlements 53,92

Jews $45,53,57-58,63-71,87,93$, $114,148,150,165,182,212,217$, 220, 234, 309, 330

Ashkenazic $72,114,141,149$, 222, 229

German 202 
Portuguese(-speaking)

$11-12,18,39,49,64,70,72$,

141, 146, 150, 185, 202, 217

Sephardic $2-3,9,18,23$,

$41,53,55-56,60,63-65$,

67-70, 72, 87, 114, 124, 141,

149-150, 182, 217, 221

Spanish-speaking 64,72 ,

$141,150,217$

Jews' Savannah 63, 87, 92-93, 150,218

Joden Savanne see Jews' Savannah

K

Kabugru, Karboegers $\quad 87-88$, 110

Kappler, August $\quad 220,369$

Kari'na 6, 13, 24, 87

Kejia 6

Kikongo 11-13, 19, 24, 30, 75, 130-131, 133-134, 137, 161, 226, 298

Kimbundu 134, 226

King, Johannes $5,7,26,410$, 428-430, 432

Koenders, Julius G. A. 'Papa' 6, 26, 408-409

Kraag, Christiaan $\quad 26,272$

Krio 43, 263

Kromanti 226-227, 304

Kru 134, 161

Kwa 11, 19, 113, 131, 133-134, 137,161

Kwinti (language) $\quad 8-10,24,275$

Kwinti (Maroons) 17, 23-24

L

La Courbe, M. J.D. $\quad 37-38$

Labadists 4, 73, 317

Labat, Jean B. $\quad 38-39,41$

language acquisition $\quad 55,148$, $152,158,167,220-221,244$ see also first, second language acquisition

Lefroy, C. E. $\quad 206-207,367$ lexical semantics $\quad 12,137,190$ lexical-semantic $174,179,188$ lexifier $\quad 9,18-19,117,199$

Liberia $\quad 128-129,431-432$

Lingua Franca $37-38,42-43$

Livorno $63-64,67-69,217$
Loango (area) 38, 75-76, 125 , 127-129, 133-134, 136, 140, 161, 193, 226

Loango (languages) 75, 137, 193, 226

Loango(s) 113, 132, 134-136, 193, 226

locally-born $105,109,123,143$, $148,154,160$

children $138,140,148,154$, 156-157

locative predication $\quad 251,253$

logophoric pronoun 371

Lokono 6, 13, 24

\section{M}

Machado, Immanuel 90-91, 95, 97

Machado escape 91-92

Machado theory $\quad 92,94,96-97$

Makzien foe Kristen-soema zieli 5, 430-431

Mande 113, 134, 161, 431

Mandingo 135

manumission 113

manumitted

blacks 170

slaves 114, 117, 144-145, 172, 218, 335

Mapana (Maroons) 333, 335

Marechal's Creek 90, 96

Maroon authors 7

Maroon communities 17, 33, $102,111,119,277,428$

Maroon creole (language) 8-10, 17-18, 23-24, 33, 71, 88-89, $121,209,212-213,324$

Maroon groups $3,10,23-24$, 94, 98, 119-121, 132, 159, 222

Maroon population $\quad 2,144$, 158-159

marronage 22, 33, 46, 55, 63 , $69,71,76,87,89,94,99,119$, $320,324,329$

Marshall theory 92, 94, 96

Marshall's Creek 90, 95-96, 285

Marshall's settlements 44-46, 49-50, 52, 77, 92, 94-96

Matawai (language) $8-10,23$, $196,275,428$
Matawai (Maroons) 4, 17, 279, $338-339,428-429$

Matjáu clan $\quad 45,91,94-96$

Matjáu Creek 90-91, 94-95

Mauricius, Andreas 237, 411

Mauricius, Jan J. 159, 411

Merian, Maria Sibylla 4, 210, 238-239, 316-318

Moes 209, 340, 369

Mon Bijou 154, 217

Montserrat $\quad 58-59,61,125,141$

$\operatorname{mood} 14,241,354$

Moravian (Brethren) 4-6, 12, 19, $26,120,163,165,167,183,188-$ 191, 197-198, 202, 204, 207, 211212, 220, 223, 261, 295, 370, 410, $412,414,416,421,424,428-429$

Moravian mission 4-5, 212, 349-350, 415, 430

morphology 13-14, 20, 25, 30-31, 137, 200

mulattoes $38,105,107-110$, $118-119,122,170,218-219,222$, 229, 294, 356, 361

multifunctionality 13,25 multilingual(ism) 2, 73, 150, 179,214

Muraato 87

\section{$\mathrm{N}$}

Nagel, J.H. 361

Nantes Edict $\quad 4,73,220-221$

nasal 13, 189, 193, 256 see also stop

Nassy, David 67-68

Nassy, David C. 230

Nassy, David I. C. 90-93, 96-97, 207-208, 211-212, 217-218, 220-222

nativization $143,151,153-154$, $157,160-161,194$

Ndyuka (language) 1, 8-10, 20, 22-25, 120, 178, 196, 228, 272, 275, 279, 287, 298, 309, 324, $357,403-404,407-408,413$, 428, 431-432

Ndyuka (Maroons) 4, 17, 2224, 120-121, 158-159, 213, 219, 222, 225, 279, 287, 298, 304, $325-326,328,331,333,338,357$, $403,407,428,432-433$ 
Ndyuka-Trio Pidgin 120, 403-404, 407-408

Negerhollands 27, 72, 255, 349, 353,413

Nengre (tongo) 10-11, 165-173, $179,192,194,231,247,268-269$, $307,318,321,328,382-384,408$

Nepveu, Jan 4, 28-29, 210-211, $243,246-260,262-265,267-$ $271,274,328,343-345,356$

Nepveu, Louis $\quad 213,247,327-$ $329,343,337-338$

Nevis $\quad 58-59,61,125,141$

Nickerie $\quad 216-217,390$

nominal predication 14,242 , 251-252, 264, 273

North Americans 117

\section{$\mathrm{O}$}

odo 7,208-209, 227, 277, 305-307, 309-311, 367, 369, 371, 408-409

Okanisi 10, 22, 331, 432-433 see also Auka, Ndyuka oral history $45,90-92,94-95$, $97,226,329$

oral literature $7,15,277,288$ overseers

black 103, 105-113, 289, 340-341

white $81,106-108,111,142$, $255,288,290,367$

Oxenbridge, John $\quad 50,53,55,78$ Oyapock 50-52

\section{P}

P-language 196

Papiamentu 229-230, 426

Para 3, 74, 76, 86, 93, 188, 324, 428

Paramaccan $8-10,17,23,275$

Paramaka 17, 23-24

peace treaty $4,27,29,62,73-74$ $76,86,88,99,111,116,120$, $173,185,210,212-213,222,224$, $272,275,279,327,329,343,357$, 384,415

periphrastic construction $179,260-261$

Pernambuco $39,49,53,63-64$, $67-70,124,126,141,217,310$ pidgin $33,35,36-39,41,45,50$, $54,181,195,244,253,258-262$, 403-404, 407

stage 33,257

pidginization 237

pidginized 367

plantation

see also slaves

agriculture $36,54-55,62,67$, $69,72,80$

colony $46,55,72,77,214$

creole $8,17-18,23,33,50,86$, $172,237-238,275$

culture 224,340

society $10,54,63,81$, 103-104, 106, 257, 290

Pomeroon $47-48,50,53,66$, $68-70,81$

Portuguese (language) 3, 9, 11, $18-19,23,33,37-39,63-65$, $70-72,87,93,141,150,165,167$, $172,177,180,182-187,210,214$, 217-218, 229

see also Jews

-derived (lexicon) 11, 13, 18-20, 23, 41, 39, 64, 91, $167-168,171-172,176-177$, $183,205,231,234-235$, 309-310, 344

Portuguese(-lexicon) creole $9,37,39,64-66,165,177,182-$ $183,225,230,306,309-310$

Portuguese planters $\quad 69,177$ Portuguese-owned plantations $150,165,179,182$

preposition $14,25,29,189,196$, 249-250, 254, 263

presentative $242,251,272$

pronoun 13, 242, 245, 249, 274, $319,328,332,370-371,404$ proverb see odo

Q

question word 29, 247, 254, 259-260, 262-263, 268

R

Randt, A. 29

Recueil 147, 210, 411

reduplication $13-14,20,25,271$ Reeps, Jan $181,215,244$
Riemer, Johann A. $\quad 28,350$, $352-353,360-361,414,419-420$

Roosenburg 153-154, 156 runaway(s) 18-19, 22-23, 86, 93, 95, 97-98, 116, 118, 120, $158-159,166,224,226,331-$ $332,334,373,384,415$

Saamáka see Saramaccan

Samson, Elisabeth 119, 219

Saramacca River $10,17,47$, $49-50,52-53,86,92-97,185$, $329,334,428$

Saramaccan 1, 5, 7-10, 17-21, $23-30,60,64-65,72,89,92$, 95-97, 99, 160, 163-166, 171173, 185-188, 196, 198, 209, 228, 274, 305-306, 309-312, $316,328,349-353,360,410$, $412-416,419-421$

Saramaccans $17,186-187,191$, 419

Saramaka (Maroons) 4-5, 17-19, 23, 45, 88-99, 117, 119-121, 132, 158, 160, 165, 173, $182,184-186,188,196,212-213$, $219,222,224,228,235,274,279$, 304-305, 311, 327-329, 331-333, $336-338,340,349,352-353$, $360,410,412-416,421,428$

Saramaka Maroon Letters $26,410,412-413,416$

Saramaka Peace Treaty 4, 27, $29,111,120,247,327,343$

Sarnami 2, 6

school 114, 189, 191, 222, 375 , 392, 403

Schouten, Hendrik 354

Schuchardt, Hugo 27-28, $42,167,176,186,198,234$, 245-246, 252, 255-257, 260, $349-351,358-359,410,421$

Schumann, Christian L. $\quad 4-5,26-$ 30, 95, 163-164, 166-175, 180, 183-187, 189-194, 196-198, 204, 223, 227-228, 231-235, 241-242, 245-246, 249, 253-257, 260-267, 269-274, 309, 349-353, 370-371, $412-414,416,419-420$

Scots $58,60-61,125$ 
Scott, John $\quad 46,48-53,55-56$, $58,66,96$

Scottish 57, 216

second language acquisition

$32,34,61-62,101,154,160-$ 161,253

secret language $\quad 195-196,228$, 304

semantic 13-14, 34, 190-191, 248-249, 267

see also lexical-semantic

serial verb $14,189,253,258-$ 260, 266-267

serialization $\quad 253-254,266-268$ sex distribution $58,78,85$, 123-124, 139, 141, 154-157

Sierra Leone $\quad 43,128-129,431-432$ Skipio, David 412-413

Slave Coast $\quad 38-39,62,75,113$, $125,127-128,133-137,140,161$ slave trade $2,5,62,75,123-125$, 128-129, 131, 137, 225

slaves see also Amerindian, coloured, manumitted domestic $105,108,110,112$, $157,170,172,216,218-219$ field 105,108 plantation $5,114,119,154$, $165,170,177,197,218,241$ skilled 108-110, 115-116, 170, 172

Societeit van Suriname $4-5$, $72-73,88,151,279,348$ Spanish (language) 39-41, 63-64, 70, 72, 87, 141, 150, 182, 210, 214, 217-218, 229 see also Jews

Spanish settlements 48,50 Sranan

church $165,169,188-192$, 199, 232, 371, 404, 429 rural vs. urban $33,165-166$, 170, 173-179, 199-200 as lingua franca $7,11,150$ as second language 11,121 , 166, 192, 194 pronunciation 163,165 , 178, 188-190, 192-195, 198, 246-247, 404

St Christophe(r) 52, 65
St Kitts $\quad 58-59,61,65,125,141$ St Kitts English Creole 263 Staatstoezicht see apprenticeship Stähelin, F. $166,173,183,188$, 349-350, 353, 414-415

Stapleton, William 83,85

stative, non-stative 14,357

Stedman, John G. 4-5, 29, 109-110, 135, 166-167, 174-175, 180, 201-202, 211, 215-216, 221, $225,229,242-243,255,260$, 269-275, 278, 284-285, 356-358 Stoll, Brother $\quad 182-183,212,412$ stop complex 19-20, 24 nasal 19-20, 24, 256 substrate (languages) 33, 123, $131,134,137,161$

substrate influence $33-34,101$, $132,136-137,161,167,194,225$ suffix 404

agentive $13,20,262$

suffixation 13,262

sugar $3,44,46,54,62-63,71,73$, $80-81,89,105,109,112,114,117$, $122,125,294,367,394,407,429$ plantation $44,54,62,68-69$, $74,107,113-114,117,149$, $153-154,156$

superstrate $33-34,180,221$ Surinaams 7,10 Surinaams Nederlands 7 Suriname Plantation Creole (SPC) $8,18,23,50,86,237-239$

Suriname River $3-4,10,17-18$, $22-23,45,47-54,59,63,68$, $71,74-76,79,86-87,92-97$, $119,121,165,179,183-185,187$, 195, 218, 229, 280, 327, 329, 334,415

Surinamese Dutch 2, 7, 142, 151,368

syllable $13,20,195-196,292,406$ structure 13,431

T

Tapanahony 10

Teenstra M. D. 7, 135, 155, 193, 195-196, 206, 208, 216, 220, 226-227, 306-309, 367
Tempati rebellion $\quad 4,22,118$, $213,216,241,325$

tense $14,20,198,241,252,258$, $273,345,353,357,370$ marker $174,258,416$ tense-mood-aspect (TMA) $14,20,241,258-259,345$ tone $19-20,24,202,416$

Torarica 59,87

Touvingas, Tufingas 184,338 translators $198,223,229,372$

Treaty of Breda 3,73

Treu, Wilhelm 204,369-370

Trio (language) 6, 120, 403-404

Trio (people) 120, 403-404, 407

Twi 130, 133-134, 137, 161, 225, 304

U

Universal Grammar 34 universals 30

\section{V}

Valkenburg, Dirk 118, 319-320 van Berkel, Adriaan 82, 237, 315-316

van Breugel, G. 208-209, 285 Van Calker, Brother $\quad 212,295$, 428

van Cappelle, H. 303

van den Bosch, G. B. 229-230 van Dyk, Pieter 4, 27-29,

112, 176-177, 197, 202, 206,

222, 242, 245-246, 248-249,

254-257, 260-272, 274, 331,

339-343, 358-359

van Eijck, J.P.W. 372, 400-403 van Eyck, J.W.S. 111, 120 van Hoëvell, W. R. 288 van Panhuys, L. C. 298, 302, 343

van Sommelsdyk, C. $\quad 4,72-74$, $88,146,148$

variation $112,163-166,168$, 173-175, 177, 179, 195-200, 231, $256,262,268,274,285,416$

Venezuela 42, 47-48 von Sack, Albert 211, 226 


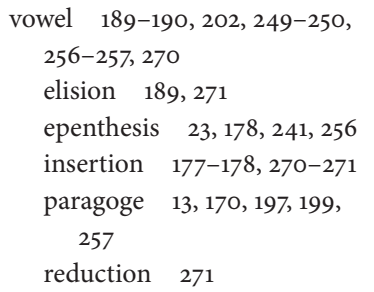

W

Warren, George $55,60,63,74$, $238-239,315-316,318$

Wayana 6, 404

West African Portuguese Pidgin $37-38$
West India Company (WIC) 3-5, 67, 72, 124, 129, 138

Western Maroon Creoles 8-10, 18

Weygandt, G.C. $\quad 5,27,29$, 176-177, 202, 253, 256, 260, $265,269-270,342,358-360$

white see overseers

Wi Eygi Sani 6, 408-409

Wietz, I. L 28-29, 410, 418-421

Wild Coast $\quad 47,52$

Willoughby, Francis 3, 45-46, $49-50,54,56-60,81-83$

Willoughby, Henry $\quad 83-84$

Willoughby Land $45,49,54,82$
Windward Coast $\quad 125,129$

Winkels, Willem 367

word order 25, 404

Wullschlägel, H. R. $5,7,26,30$, 163-164, 166, 168-170, 177$178,184-185,189-190,192,197$, 199, 204, 207, 209, 223, 227, 260-262, 273, 306-310, 350, 369-371, 404, 410

Y

Yiddish 141, 222

Yoruba 113 
This posthumous work by Jacques Arends offers new insights into the emergence of the creole languages of Suriname including Sranantongo or Suriname Plantation Creole, Ndyuka, and Saramaccan, and the sociohistorical context in which they developed. Drawing on a wealth of sources including little known historical texts, the author points out the relevance of European settlements prior to colonization by the English in 1651 and concludes that the formation of the Surinamese creoles goes back further than generally assumed. He provides an all-encompassing sociolinguistic overview of the colony up to the mid-19th century and shows how ethnicity, language attitude, religion and location had an effect on which languages were spoken by whom. The author discusses creole data gleaned from the earliest sources and interprets the attested variation. The book is completed by annotated textual data, both oral and written and representing different genres and stages of the Surinamese creoles. It will be of interest to linguists, historians, anthropologists, literary scholars and anyone interested in Suriname.

\begin{abstract}
"With meticulous scholarship and in his characteristically clear prose, Jacques Arends presents a linguistic and social history of early Suriname that is remarkable in what it achieves. Arends, in considering the factors that bear upon the emergence of Surinamese creoles (and creoles more generally), displays an unmatched breadth. Moreover, he effectively challenges key elements of the received narrative on which linguists have built their theories of creole genesis in Suriname."
\end{abstract}

John Singler, New York University

"The rich account of Jacques Arends' insights into the complex history of the Surinamese creoles provides an invaluable contribution to this exciting field."

Pieter Muysken, Radboud University, Nijmegen

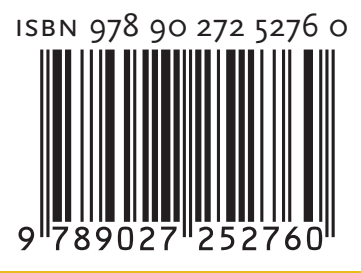

